\title{
NOVEL MODIFIED QAC ANTIMICROBIAL COATINGS: APPLICATION, EVALUATION AND FUNCTIONAL DETERMINATION
}

by

\author{
Alexander Gabriel Caschera \\ Bachelor of Science (Chemistry Major / Biology Minor) \\ Ryerson University, Toronto, Ontario, Canada, 2015
}

A thesis presented to Ryerson University in partial fulfillment of the requirements for the degree of Master of Science in the program of Molecular Science

Toronto, Ontario, Canada, 2018

(C) Alexander Gabriel Caschera 2018 


\section{AUTHOR'S DECLARATION FOR ELECTRONIC SUBMISSION OF A THESIS}

I hereby declare that I am the sole author of this thesis. This is a true copy of the thesis, including any required final revisions, as accepted by my examiners.

I authorize Ryerson University to lend this thesis to other institutions or individuals for the purpose of scholarly research.

I further authorize Ryerson University to reproduce this thesis by photocopying or by other means, in total or in part, at the request of other institutions or individuals for the purpose of scholarly research. I understand that my thesis may be made electronically available to the public. 


\title{
NOVEL MODIFIED QAC ANTIMICROBIAL COATINGS: APPLICATION, EVALUATION AND FUNCTIONAL DETERMINATION
}

M.Sc., Alexander Gabriel Caschera, Molecular Science, Ryerson University 2018

\begin{abstract}
A series of novel quaternary ammonium compounds (QACs) previously synthesized by the Foucher Research Group containing the core motif $\mathrm{R}^{1}-\left(\mathrm{CH}_{2}\right)_{3}-\mathrm{N}^{+}\left(\mathrm{CH}_{3}\right)_{2}-\left(\mathrm{CH}_{2}\right)_{3}-\mathrm{R}^{2}$, where $\mathrm{R}^{1}$ represents functional groups responsible for anchoring the compound to various substrates and $\mathrm{R}^{2}$ represents moieties responsible for altering the activity and surface properties of coated materials are described. $\mathrm{R}^{1}$ groups include benzophenone $\left(-\mathrm{O}-\mathrm{C}_{6} \mathrm{H}_{4}-\mathrm{C}(\mathrm{O})-\mathrm{C}_{6} \mathrm{H}_{5}\right)$ 1a-11a for anchoring to polymer surfaces, and organosilane $\left(-\mathrm{Si}\left(\mathrm{OCH}_{3}\right) \mathbf{3 b}-\mathbf{1 0 b}\right.$ for anchoring to textiles and fabrics, while $\mathrm{R}^{2}$ groups include linear alkyl chains $\left(-\left(\mathrm{CH}_{2}\right)_{\mathrm{n}}-\mathrm{CH}_{3} ; \mathrm{n}=11,17\right) \mathbf{1 - 2}$ and aryl or alkyl sulfonamide containing moieties (-NH-SO $\left.{ }_{2}-\mathrm{C}_{\mathrm{X}} \mathrm{H}_{\mathrm{Y}}, \mathrm{X}=2-10 ; \mathrm{y}=5-11\right)$ 3-11.
\end{abstract}

These compounds were tested for antimicrobial activity at solid/air interfaces (LDI) and were found highly effective against representative Gram-positive and Gram-negative bacteria (except 7a-8a, 11a). Selective solid/liquid antimicrobial testing (LRI) was performed on 1a, 5a and only 5a was found to be highly effective against Gram-positive bacteria. 


\section{ACKNOWLEDGEMENTS}

Many of the acknowledgements I would like to give would be to the members of Faculty of Science at Ryerson University. Dr. Daniel Foucher has been an inspirational supervisor who has provided guidance, assistance, tools and equipment necessary to do an excellent job and become a better scientist. Dr. Otini Kroukamp and Dr. Robert Gossage have been wonderful committee members who have always aided whenever there were any gaps in understanding and have supported broadening my horizons. Dr. Gideon Wolfaardt for providing a welcoming place to perform my studies. Dr. Martina Hausner has also provided new opportunities to expand my knowledge relating to my research. Also, to the vast number of number of professors and administrative staff that have been there along the way, I promise to thank you all individually whenever given the chance.

I would also like to thank my colleagues in the Foucher, Gossage and Wolfaardt research groups. I've had the joy of learning from my upperclassmen Dr. Lukasz Porosa, Evan Ronan and Kamlesh Mistry. These individuals are responsible providing a starting point for this research and have given much of their lives during their periods of study. I would also like to thank my lab mates (Jeffery, Kathy, Julie, Desiree, Rachel, Gloria, Kristy, Baviena, Tristan, Patrick, Farhan, Amir) and classmates for their collective community and companionship. Specifically, I would like to thank Joseph Bedard for the herculean effort of pulling together much of the previous research performed by his mentors and greatly assisting with the chemistry required of this project, and Moiz Ali for assisting with the insurmountable amount of microbiology required of this project.

Finally, thank you mom and dad (Heather and Claudio), grandparents (Libby and Vince, Patricia and Cecil), and my little sister (Meagan) for giving me a welcoming place to return to whenever the day is done. You've done more for me than I could have ever asked for. 


\section{TABLE OF CONTENTS}

AUTHOR'S DECLARATION FOR ELECTRONIC SUBMISSION OF A THESIS ........... ii

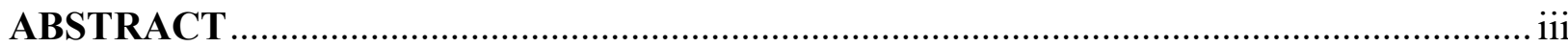

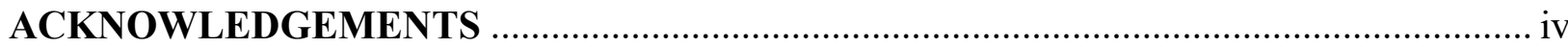

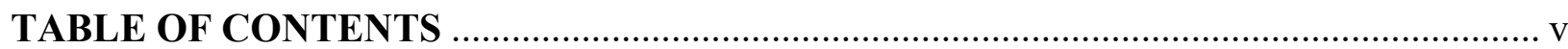

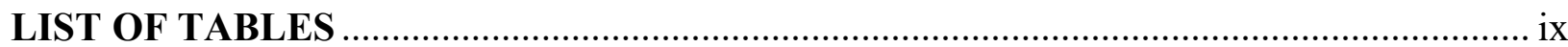

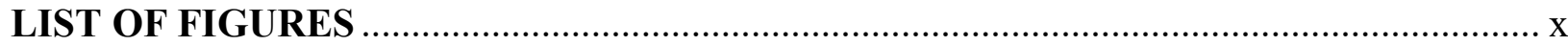

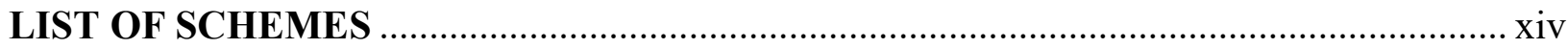

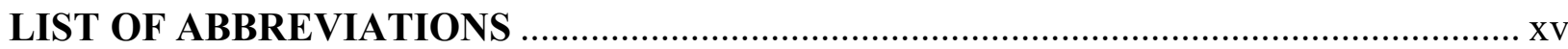

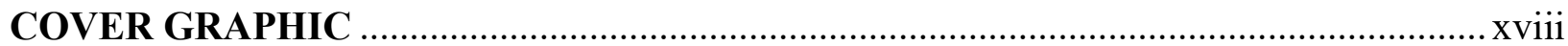

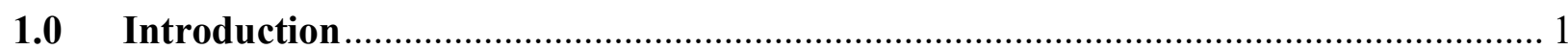

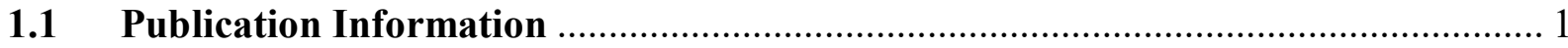

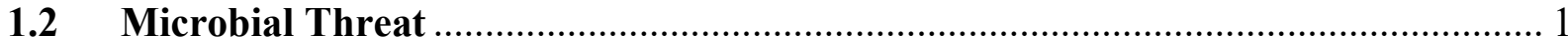

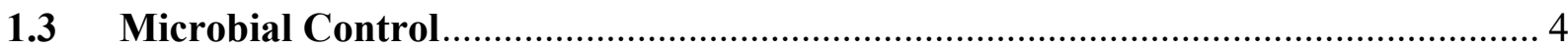

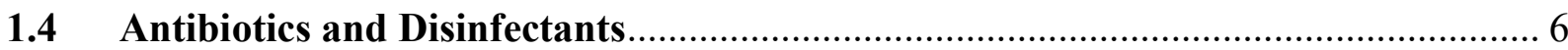

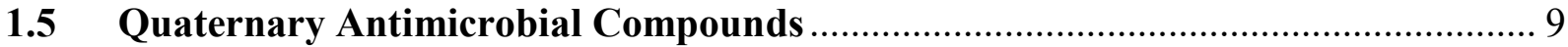

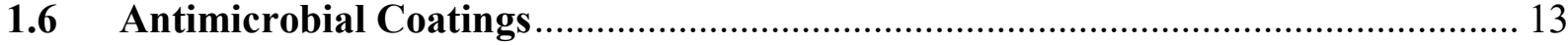

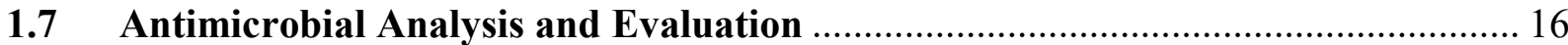

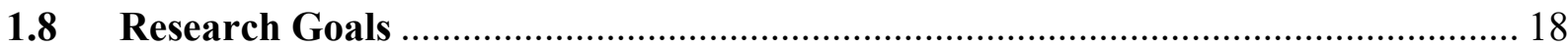

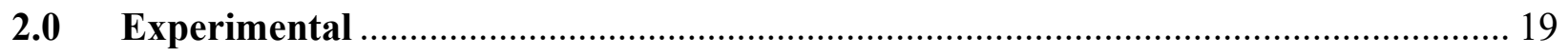


2.1 Materials and Active Antimicrobials

2.2 Antimicrobial Compound Characterization ....................................................... 20

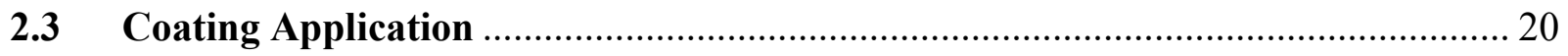

2.4 QAC Visualization via Anionic Dye Staining ................................................. 21

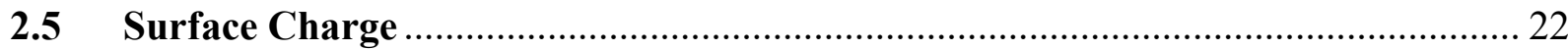

2.6 Characterization of Antimicrobial Treated Surfaces ....................................... 23

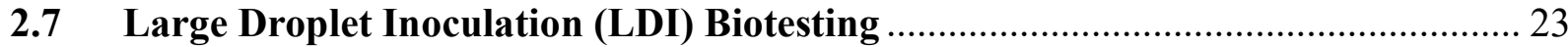

2.8 Liquid Reservoir Inoculum (LRI) Biotesting ................................................ 24

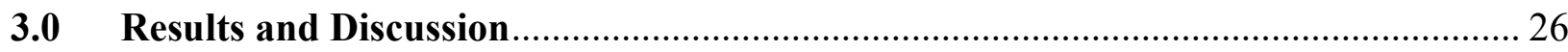

3.1 Synthesis of Alkyl QAC Compounds........................................................... 26

3.2 Synthesis of Sulfa QAC Compounds .............................................................. 28

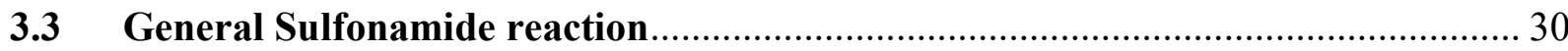

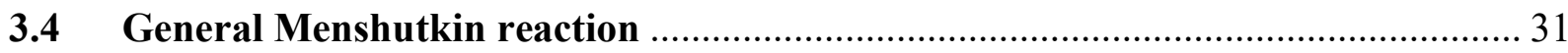

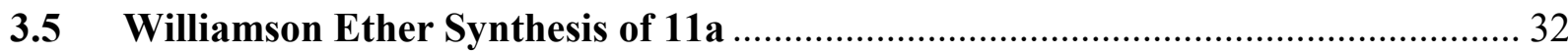

3.6 Coating and Curing of Test Samples ................................................................ 33

3.7 Antimicrobial Coating Visualization via Anionic Dye Staining ......................... 35

3.8 Surface Wettability, Plasma Pre-treatment, and Coating Adhesion ..................... 37

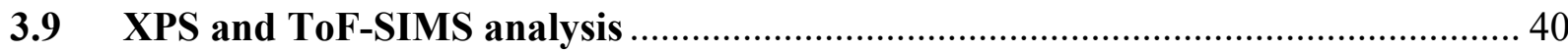

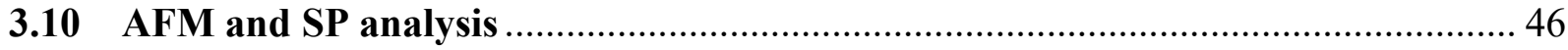

3.11 Antimicrobial Treatment Biotesting at Solid/Air Interfaces (LDI method) .......... 51 
3.12 Antimicrobial Treatment Biotesting at Solid/Liquid Interfaces (LRI method) ..... 65

3.13 Evidence Towards Antimicrobial Mechanism 68

4.0 Conclusion and Future Studies 71

APPENDICIES 72

(A) "UV-Curable Contact Active Benzophenone Terminated Quaternary Ammonium Antimicrobials for Applications in Polymer Plastics and Related Devices" Supplementary Information 72

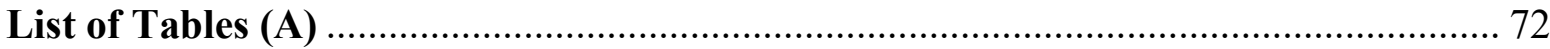

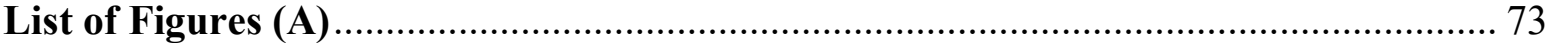

X-ray Photoelectric Spectroscopy and ToF-SIMS Data ........................................... 75

Atomic Force Microscopy and Surface Profilometry Data ...................................... 87

Epifluorescence Compound Imaging ................................................................... 91

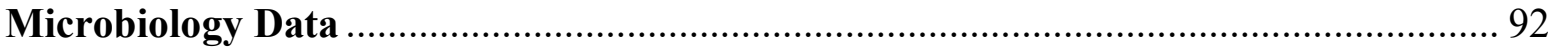

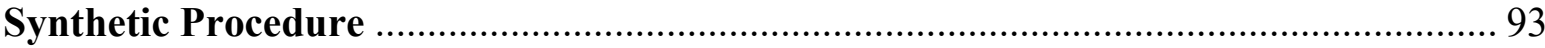

NMR and HRMS Spectra of Synthesized Compounds ............................................ 96

(B) “ Killing at a Solid/Liquid Interface: Surface-Attached Sulfonamide Containing Quaternary Ammonium Antimicrobials for Textiles and Plastics" Supplementary

Information 106

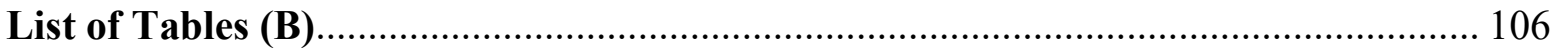

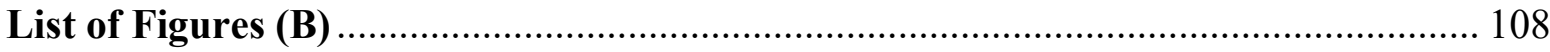

X-ray Photoelectric Spectroscopy and ToF-SIMS Data ....................................... 115 
Atomic Force Microscopy and Surface Profilometry Data

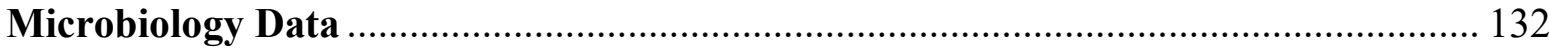

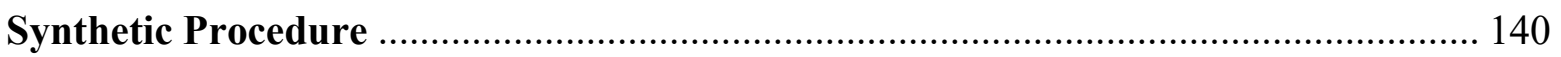

NMR Spectra of Synthesized Compounds ...................................................... 158

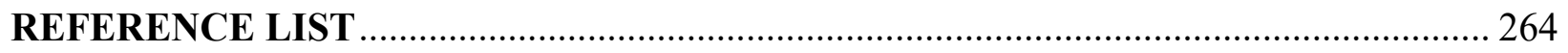




\section{LIST OF TABLES}

Table 1 - Current (2011) CDC estimates of Hospital Acquired Infections. Data collected from 11282 patients across 183 hospitals, where 452 patients had one or more healthcare associated infections. Table adapted from www.cdc.gov and Magill et al. ${ }^{4}$ 4

Table 2 - Partial list of important antibiotic classes. Table adapted from Powers (2004). ${ }^{22}$ 7

Table 3 - (C) Selected studies involving silver nanoparticle antimicrobial activity. Note that all microorganisms are bacterial species unless otherwise noted. ${ }^{16,28}$ (a) refers to citrate-capped nanoparticles; (b) refers to silver-coated polyvinyl pyrrolidone; (c) refers to silver nanoparticle size incorporated into a Zeolite A composite. 8

Table 4 - (B) Advancing contact angle and surface charge measurements of sample materials. 38

Table 5 - (A) Properties of surface attached benzophenone antimicrobials. 40

Table 6 - (A) Select XPS survey data for control and UV-coated CPVC samples of 1a. 41

Table 7 - (B) Select XPS survey data for control and 5a treated CPVC samples. 44

Table 8 - Thickness Measurements of Surface Attached Benzophenone Antimicrobials. ${ }^{1,2}$ 50 


\section{LIST OF FIGURES}

Figure 1 - Differences between the phospholipid cellular membrane (green) and peptidoglycan cell wall (blue) of Gram-negative (left) and Gram-positive (right) bacteria. 11

Figure 2 - Visual example of the polymeric spacer (top) and phospholipid sponge (bottom) mechanisms

Figure 3 - Benzophenone grafting mechanism through ketyl radicalization. Adapted from reference ${ }^{68}$. 15

Figure 4 - (B) Schematic representation of surface grafted branching of a sulfa QAC (left) and a alkyl QAC (right). 15

Figure 5-(A) ORTEP representation of 2a found in the unit cell and selected bond lengths $(\AA)$ and bond angles $\left({ }^{\circ}\right)$ : O(1)-C(3) 1.442(2), O(2)-C(10) 1.221(2), N(1)-C(1) 1.514(2), N(1)-C(19) 1.508(2), C(4)-O(1)C(3) 119.06 (15), C(19)-N(1)-C(1) 113.21 (14), C(7)-C(10)-C(11) 119.98 (17), C(30)-C(29)-C(28) 113.5 (2). Crystal discovered by Alexander Caschera, Joseph Bedard and Lukasz Porosa. 27

Figure 6 - (B) ORTEP representation of 11a found in the unit cell and selected bond lengths $(\AA)$ and bond angles $\left(^{\circ}\right)$ : S(1)-O(1) 1.4325(10), S(1)-O(2) 1.4348(9), S(1)-N(1) 1.6203(11), S(1)C(4) 1.7861(13), N(1)-C(3) 1.4701(17), O(3)-C(1) 1.4337(16), O(3)-C(13) 1.3619(16), O(4)C(19) 1.2235(18), O(1)-S(1)-O(2) 118.04(6), N(1)-S(1)-C(4) 106.79(6), C(3)-N(1)-S(1) 119.53(9), C(13)-O(3)-C(1)117.60(10). Crystal discovered by Alexander Caschera. 29

Figure $7-($ B $)$ ORTEP representation of 10a found in the unit cell and selected bond lengths $(\AA)$ and bond angles $\left(^{\circ}\right)$ : S(1)-O(3) 1.431(2), S(1)-O(4) 1.433(2), N(1)-C(1) 1.469(4), N(2)-C(3) 1.514(3), N(2)-C(4) 1.514(3), N(2)-C(20) 1.499(4), N(2)-C(21) 1.504(4), O(1)-S(1)-O(2), 119.91(13), N(1)-S(1)-C(22) 107.40(13), C(1)-N(1)-S(1) 118.8(2), C(3)-N(2)-C(4) 112.5 (2). Crystal discovered by Joseph Bedard. 
Figure 8 - Advancing contact angle images of control polystyrene before(left) and after (right) plasma pre-treatment. Test was performed using $5 \mu \mathrm{m}$ distilled water droplets. 35

Figure 9 - (A) Treated and untreated surfaces stained with bromophenol blue dye. .................. 36

Figure 10 - (A) XPS data corresponding to the nitrogen content for the control (left) and 1a coated (right) PS samples.

Figure 11 - (B) XPS data corresponding to the nitrogen content (top) and sulfur content (bottom) for control (left) and 5a treated (right) CPVC samples.

Figure 12 - (A) Composite negative ion ToF-SIMS image of $500.0 \times 500.0 \mu \mathrm{m}$ section of control and $\mathbf{1}$ treated samples. Intensity is a function of fragment quantity during analysis. Images correspond to negative ionic fragmentation products of chlorine $\left(\mathrm{Cl}^{-}\right)$, bromine $\left(\mathrm{Br}^{-}\right)$, ethane $\left(\mathrm{C}_{2} \mathrm{H}^{-}\right)$, tetracarbonyl ammonium $\left(\mathrm{C}_{4} \mathrm{~N}^{-}\right)$, and hydroxybenzophenone $\left(\mathrm{C}_{13} \mathrm{H}_{9} \mathrm{O}_{2}{ }^{-}\right)$. 45 Figure 13 - (B) Composite negative ion ToF-SIMS image of $500.0 \times 500.0 \mu \mathrm{m}$ section of control and 5a treated samples. Intensity is a function of fragment quantity during analysis. Images correspond to negative ionic fragmentation products of chlorine $\left(\mathrm{Cl}^{-}\right)$, bromine $\left(\mathrm{Br}^{-}\right)$, ethane $\left(\mathrm{C}_{2} \mathrm{H}^{-}\right)$, tetracarbonyl ammonium $\left(\mathrm{C}_{4} \mathrm{~N}^{-}\right)$, and hydroxybenzophenone $\left(\mathrm{C}_{13} \mathrm{H}_{9} \mathrm{O}_{2}{ }^{-}\right) \ldots \ldots \ldots . . .46$ Figure 14 - (A) AFM images of PS control (left) and $\times 2$ Coating of $\mathbf{5 b}$ on PS (right).............. 48 Figure 15 - (A) AFM images of PC control (left) and 5a treated PC (right)........................... 49 Figure 16 - (B) AFM images of PC control (left) and 10a treated PC (right)............................ 49

Figure 17 - (B) Visual representation of the large droplet inoculum (LDI) procedure................ 51 Figure 18 - (A) Survivability of Arthrobacter sp. when inoculated onto a variety of 1a treated and control sample materials. The measurement at $0 \mathrm{~h}(\log 7 \mathrm{CFU})$ indicated the initial number of bacterial cells being inoculated onto the surface material and was determined concurrently to

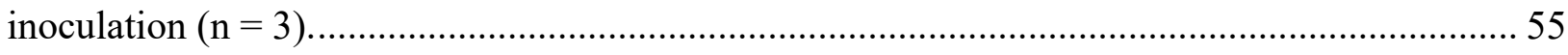


Figure 19 - (A) Survivability of L. monocytogenes, P. aeruginosa and Arthrobacter sp., when

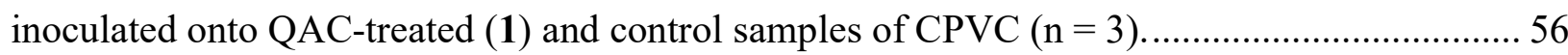

Figure 20 - (B) Survivability of Arthrobacter sp. when inoculated onto a variety of 1a and 2a

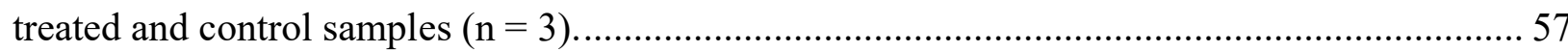

Figure 21 - (B) Survivability of Arthrobacter sp. when inoculated onto plastic coupons treated with compounds 1a-4a, compared against untreated controls $(\mathrm{n}=3) \ldots \ldots \ldots \ldots \ldots \ldots \ldots \ldots \ldots \ldots \ldots \ldots \ldots \ldots . . . .58$

Figure 22 - (B) Survivability of Arthrobacter sp. when inoculated onto cotton samples treated

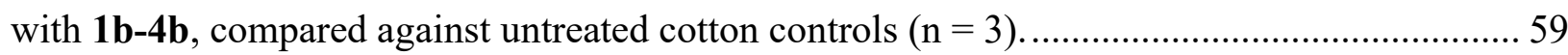

Figure 23 - (B) Survivability of Arthrobacter sp. when inoculated onto plastic coupons treated with compounds 7a-10a, compared against untreated controls $(n=3)$.

Figure 24 - (B) Survivability of Escherichia coli when inoculated onto plastic coupons treated with compounds 3a-6a, compared against untreated controls $(\mathrm{n}=3)$.

Figure 25 - (B) Survivability of Escherichia coli when inoculated onto cotton fabric treated with compounds $\mathbf{3 b} \mathbf{b} \mathbf{6} \mathbf{b}$, compared against untreated controls $(\mathrm{n}=3)$.

Figure 26 - (B) Survivability of various microorganisms when inoculated onto plastic samples treated with compound 5a, compared against untreated plastic controls. The measurement at $0 \mathrm{~h}$ ( $>10^{7} \mathrm{CFU}$ for Arthrobacter sp. and Escherichia. coli, $>10^{5} \mathrm{CFU}$ for Staphylococcus. aureus) indicated the initial number of bacterial cells inoculated onto sample material and was determined concurrently to inoculation $(\mathrm{n}=3)$. 62

Figure 27 - (B) Survivability of Arthrobacter sp. when inoculated onto PS samples treated with compounds 5a and 11a, compared against untreated PS controls $(n=3)$. 63 
Figure 28 - Survivability of Arthrobacter sp. when repeatedly inoculated onto PS samples treated with compounds $\mathbf{1 a}$ and $\mathbf{5 a}$ without rinsing, compared against untreated PS controls $(\mathrm{n}=$

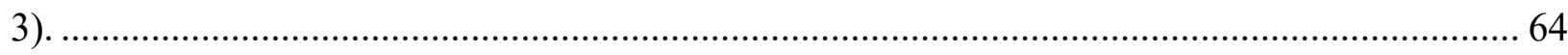

Figure 29 - (B) Visual representation of the liquid reservoir inoculum (LRI) procedure.......... 65 Figure 30 - (B) Survivability of Arthrobacter sp. and Escherichia coli when inoculated into LDPE vials treated with compound 1a, compared against untreated LDPE controls. $(n=3) \ldots . .67$ Figure 31 - (B) Survivability of Arthrobacter sp. and Escherichia coli when inoculated into LDPE vials treated with compound 5a (Mesityl sulfa QAC), compared against untreated LDPE controls. $(n=3)$ 68 


\section{LIST OF SCHEMES}

Scheme 1 - General sulfonamide reaction ................................................................ 31

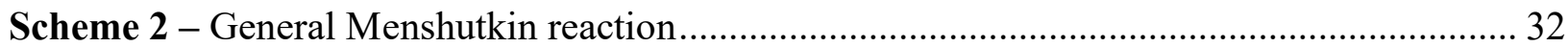

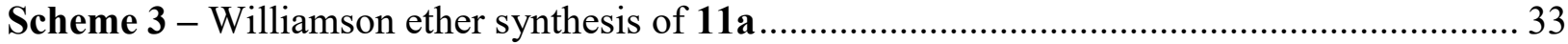




$\begin{array}{ll}\text { LIST OF ABBREVIATIONS } \\ \text { QAC } & \text { Quaternary ammonium compound } \\ \text { LDI } & \text { Large droplet inoculum } \\ \text { LRI } & \text { Liquid reservoir inoculum } \\ \text { MRSA } & \text { Methicillin-resistant Staphylococcus aureus } \\ \text { VRE } & \text { Vancomycin-resistant Enterococci } \\ \text { MDR } & \text { Multi-drug resistant } \\ \text { WHO } & \text { World Health Organization } \\ \text { CDC } & \text { Centre for Disease Control } \\ \text { PS } & \text { Polystyrene } \\ \text { CPVC } & \text { Clear polyvinyl chloride } \\ \text { PMR } & \text { Nuclear magnetic resonance } \\ \text { LDPE } & \text { Low-density polyethylene } \\ \text { PVC } & \text { Polyvinyl chloride } \\ \text { PEEK } & \text { Polyether ether ketone } \\ \text { HDPE } & \text { High-density polyethylene } \\ \text { Polypropylene } \\ \text { POIycarbonate }\end{array}$


$\mathrm{CDCl}_{3} \quad$ Deuterated chloroform

$\mathrm{CHCl}_{3}$ Chloroform

$\mathbf{C F C l}_{3}$ Trichloromonofluoromethane

TMS Tetramethylsilane

COSY Correlated spectroscopy

HSQC Heteronuclear single quantum coherence

HRMS High-resolution mass spectrometry

ESI-ToF Electrospray ionization time-of-flight

CCDC Cambridge Crystallographic Data Centre

XPS X-ray photoelectron spectroscopy

ToF-SIMS Time-of-flight secondary ion mass spectrometry

AFM Atomic force microscopy

SP $\quad$ Surface profilometry

CFU Colony forming units

$\operatorname{MeCN} \quad$ Acetonitrile

EtOH Ethanol

ORTEP Oak Ridge thermal ellipsoid plot

i-PrOH Isopropanol 


\begin{tabular}{|c|c|}
\hline DCM & Dichloromethane \\
\hline $\mathbf{N E t}_{3}$ & Triethylamine \\
\hline RT & Room temperature \\
\hline $\mathrm{K}_{2} \mathrm{CO}_{3}$ & Potassium carbonate \\
\hline TBAB & Tetrabutylammonium bromide \\
\hline CTAB & Cetyltrimethylammonium bromide \\
\hline RMS & Root mean square \\
\hline SEM & Scanning electron microscope \\
\hline ASTM & American Society for Testing and Materials \\
\hline ISO & International Organization for Standardization \\
\hline JIS & Japan Industrial Standards \\
\hline $\mathbf{h}$ & Hours \\
\hline d & Days \\
\hline
\end{tabular}




\section{COVER GRAPHIC}

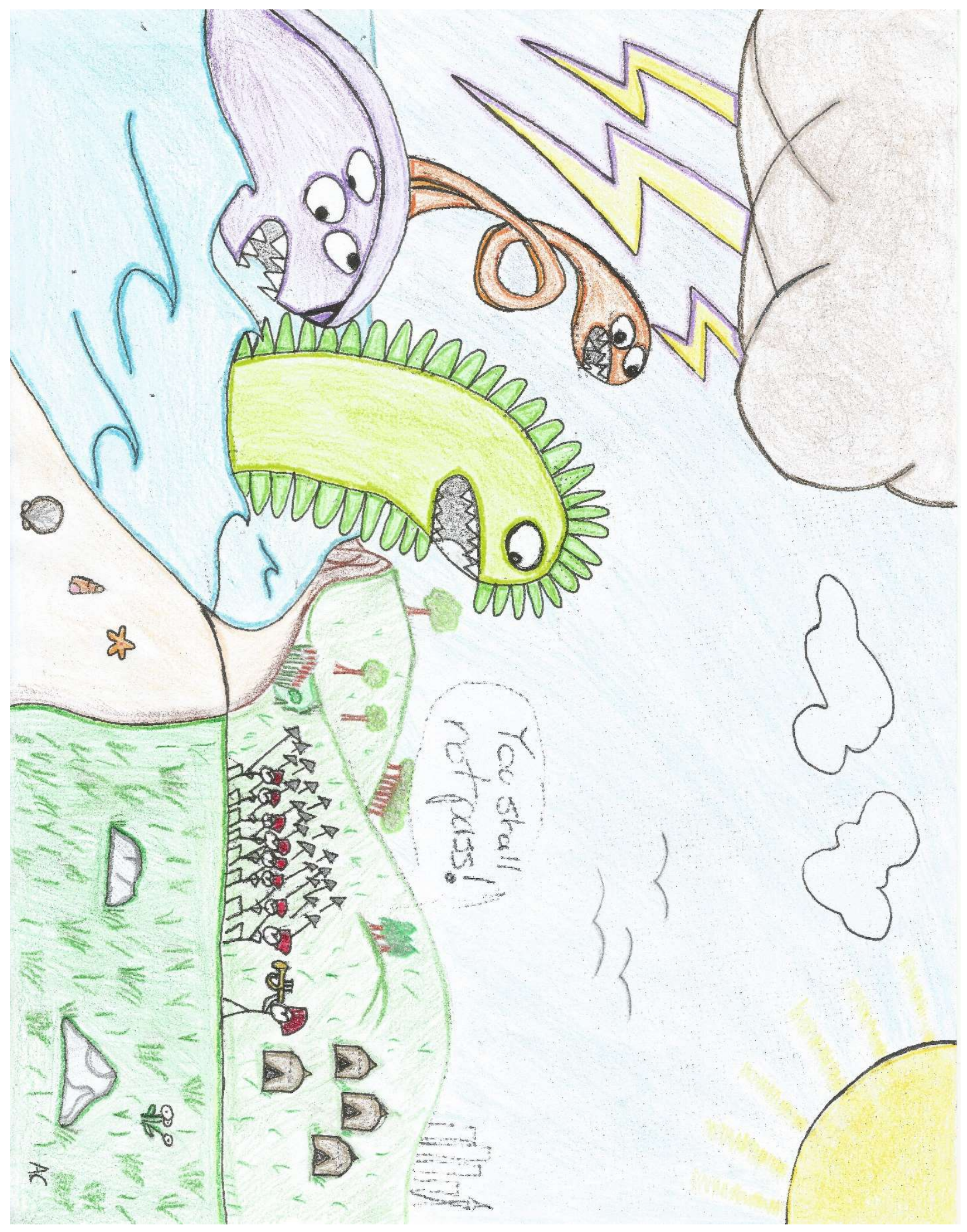




\subsection{Introduction}

\subsection{Publication Information}

A significant amount of work contained herein has been previously expressed within prior publications "UV-Curable Contact Active Benzophenone Terminated Quaternary Ammonium Antimicrobials for Applications in Polymer Plastics and Related Devices" (referenced directly as “(A)") and "Killing at a Solid/Liquid Interface: Surface-Attached Sulfonamide Containing Quaternary Ammonium Antimicrobials for Textiles and Plastics"2 (referenced directly as “(B)”), as well as a directed studies report titled "Silver Nanoparticles - Societal and Environmental Effects" (referenced directly as "(C)"). In summary, (A) investigated the application of benzophenone-anchored quaternary ammonium antimicrobials onto a variety of commonly used plastic surfaces, the results of which found broad-spectrum antimicrobial activity at commonly encountered solid/air contact points. (B) tested several sulfonamide-containing quaternary ammonium antimicrobials and found similar antimicrobial activity to those compounds in the first publication, but also had the capability of imparting an antimicrobial effect at solid/liquid interfaces. Both are part of a series of articles designed to illuminate the question behind the mechanism of kill for quaternary ammonium compounds. (C) explored the usefulness and future consequences of overusing nanoparticles comprised of silver and found that their effectiveness as antimicrobials are tempered by their expensive, ephemeral qualities and can accumulate negatively in the natural environment.

\subsection{Microbial Threat}

It is considered common knowledge that infections caused by pathogenic organisms pose a serious risk to human health. ${ }^{4}$ Based on that understanding, a significant portion of the modern 
healthcare system is dedicated to combating the proliferation of harmful organisms through a wide regiment of sterilization and disinfection techniques. Antibiotic treatment options alone currently receive over $\$ 40$ billion dollars worldwide in $\mathrm{R} \& \mathrm{D}$ and associated costs. ${ }^{5}$ There are also intense efforts into other medical research fields to deal with preventing the spread of microorganisms before they can cause infections to potential hosts, and includes the use of vaccines, sterilization of equipment and surfaces through chemical or physical means, and physical isolation and potentially destruction of infectious sources and materials. With that in mind, finding solutions relating to preventing illnesses caused by infection can be both a rewarding and lucrative endeavour.

One factor unique to the microbial threat is how difficult they can be to remove/eradicate once they establish a biofilm on a contaminated surface. These biofilms are produced from extracellular polymeric substances that are secreted and inhabited by microorganisms, and act as both a form of habitation and as a defensive mechanism to protect against various forms of physical and chemical stress. ${ }^{6}$ Biofilms can also offer a desirable microecological niche that can support a community of microorganisms, including pathogenic variants, independent of the host organisms.

Another important factor that needs to be considered regarding the spread of pathogenic organisms is the emergent threat of antimicrobial resistance. Through evolutionary influence, pathogens can develop resistance to antibiotic drugs through their improper use and overprescription. ${ }^{7,8}$ Once acquired, antimicrobial resistance genes can make infections caused by resistance strains into life-threatening ordeals. Common examples that are frequently encountered within a healthcare setting include methicillin-resistant Staphylococcus aureus (MRSA), ${ }^{9,10}$ vancomycin-resistant Enterococci (VRE), ${ }^{9,11}$ and many other multi-drug resistant (MDR) bacterial strains. ${ }^{12}$ 
With the rise of antimicrobial resistance, the costs and scope associated with treating infected patients has become a significant ordeal. On a global scale, the World Health Organization (WHO) estimates that $7 \%$ of patients admitted to healthcare facilities in developed countries will contract an infection. That percentage increases to $10 \%$ when considering patients in developing countries, according to most recent reports. ${ }^{13}$ The Centre for Disease Control (CDC) estimates that there is a $4 \%$ chance of contracting a healthcare associated infection in North America, of which the mortality rate is $10 \% .{ }^{4}$ From a financial perspective, it has been estimated that diseases acquired from healthcare associated infections currently costs around $\$ 8$ billion dollars in Europe and $\$ 6.5$ billion dollars in North America according to information provided by the WHO and CDC institutions. ${ }^{13,14}$

There are numerous routes available for antimicrobial resistant infections to spread within a healthcare setting. From medical tools, surgical equipment and protective devices for healthcare workers, the majority can be transmitted through the suspension and dispersion of contaminated droplets and liquids. ${ }^{15}$ These devices pose a risk towards the individual being treated with the contaminated equipment which is further magnified if the infected individual has a compromised immune system, as found during surgery and with regards to certain age groups ${ }^{16}$ (Table 1). 
Table 1 - Current (2011) CDC estimates of Hospital Acquired Infections. Data collected from 11 282 patients across 183 hospitals, where 452 patients had one or more healthcare associated infections. Table adapted from www.cdc.gov and Magill et al. ${ }^{4}$

\section{Infection Site}

Survey patient

Infections

Pneumonia
Inpatient Surgical Site Infections
Gastrointestinal Illness
Urinary Tract Infections
Primary Bloodstream Infections
Other Sources of Infection
Total Hospital Acquired Infections

\begin{tabular}{|lc}
\hline 110 & $50800-281400$ \\
\hline 110 & $50800-281400$ \\
86 & $28100-176700$ \\
65 & $20700-140200$ \\
\hline 50 & $25900-306200$ \\
\hline $\mathbf{5 0 4}$ & $\mathbf{2 1 4 7 0 0 - 1 4 1 1 0 0 0}$ \\
\hline
\end{tabular}

\section{Estimated infections}

(95\% confidence) 
compliance by doctors and patients, represents the controlled use of these prescriptions and reduces resistance development by lessening the chance of exposing bacterial cells to sub-lethal drug concentrations. ${ }^{8,21}$ This can also take the form of antibiotic rotation regimens, which regularly swap classes of antibiotics before specific resistance genes can develop within a given microbial population. ${ }^{7}$ Infection control programs at hospitals and clinics are used to check the spread of disease between patients and also require strict compliance by patients, visitors and hospital staff. 9,22 These programs focus on hygienic practices and sterilization techniques to reduce the transfer of viruses and bacteria on contaminated surfaces and individuals, however, adherence to these protocols have yet to prove their efficacy in preventing the proliferation of healthcare associated infectious disease. ${ }^{9,23}$

To avoid the complications involved with treating established infections, there has been an increased effort to discover effective preventative measures. In most commercial and institutional settings, this involves strict cleaning and disposal of potentially contaminated objects to prevent the spread of disease to susceptible individuals. Advancing from this approach, many areas and objects have been designed to be easier to clean or dispose of after use, including newer institutional facilities. ${ }^{16,21,24}$ Some of the issues associated with this approach largely stem from compliance to proper procedure, where improper cleaning, sterilization and disposal can lead to biohazardous exposure from objects believed to be safe for handling. Another concern is the costs associated with increased waste produced through using single-use disposable equipment. 


\subsection{Antibiotics and Disinfectants}

Throughout human history, various chemical compounds have been used to clean, sterilize and disinfect surfaces and individuals. ${ }^{6,25}$ Disinfectants are a class of such compounds that can kill and neutralize infectious microbial species, and examples include commercially available alcohols (ethanol, iso-propanol), peroxides (hydrogen peroxide, benzoyl peroxide), bleaching agents (sodium hypochlorite, calcium hypochlorite) and metal-based solutions (titanium dioxide, silver nanoparticles). Antibiotics represent a class of drugs developed to treat individuals suffering from a bacterial infection, and work by inhibiting specific microbial functions that are required for the activity and proliferation of bacterial cells within an infected host (Table 2). Since their initial discovery multiple classes of antibiotics have been identified for treating infections, however there has been a recent slowdown regarding the discovery of new compounds due to current costs and stringent regulation requirements. ${ }^{25}$ 
Table 2 - Partial list of years when important antibiotic classes were introduced to society, including modern examples. Table adapted from Powers (2004). ${ }^{25}$

\begin{tabular}{l|cc}
\multicolumn{1}{c}{ Year } & Drug Class & Example Drug \\
\hline 1935 & Sulfonamides & Prontosil \\
1941 & $\beta$-lactams & Benzylpenicillin \\
1944 & Aminoglycosides & Gentamicin \\
1950 & Tetracyclines & Tetracycline \\
1952 & Macrolides & Erythromycin \\
1956 & Glycopeptides & Vancomycin \\
1962 & Quinolones & Ciprofloxacin \\
2000 & Oxazolidinones & Linezolid \\
2003 & Lipopeptides & Daptomycin
\end{tabular}

More recently, there has been an increased interest in silver nanoparticles and nanoparticles in general, for use as antimicrobial agents. (C) Currently, there are already a vast number of nanomaterials being used as antimicrobial agents for environmental and in vivo applications. These materials predominately include, but are not limited to, copper, silver, gold, titanium, iron, carbon, and silicon. ${ }^{8,26-30}$ Antimicrobial activity of these nanoparticle materials can be further augmented by changing the physical characteristics of the nanoparticle shape, size, and composition. One example is to encapsulate a core nanoparticle substrate with a distinctly different coating material, in order to control the distribution and activity of the composite nanomaterial compound. ${ }^{31,32}$ In one recent example, silver nanoparticles were incorporated into aluminosilicate zeolite materials for the production of antimicrobial filler material for food packaging and other plastics. ${ }^{33}$ 
(C) Antimicrobial activity of silver nanoparticles related to size has been a prominent topic of interest in numerous silver nanoparticle reviews, and is currently considered a hot topic of study. ${ }^{8,27,31,34-37}$ Continuing research on silver nanoparticles has demonstrated that their ability to act as an antimicrobial agent against different strains and species of microorganisms can be affected by physical characteristics, including size and various other modifications (Table 3). ${ }^{8,31,37}$ To this effect, silver nanoparticles prepared with sizes ranging between 1-100 nm have been shown to be effective against many different microorganisms, including Pseudomonas aeruginosa, ${ }^{38}$ Escherichia coli, ${ }^{36,39}$ and Salmonella enteritidis. ${ }^{40}$

Table 3 - (C) Selected studies involving silver nanoparticle antimicrobial activity. Note that all microorganisms are bacterial species unless otherwise noted. ${ }^{8,31}$ (a) refers to citrate-capped nanoparticles; (b) refers to silver-coated polyvinyl pyrrolidone; (c) refers to silver nanoparticle size incorporated into a Zeolite A composite.

\section{Diameter (nm)}

$50 \mathrm{~nm}$

$16 \sim 19 \mathrm{~nm}$

$12.6 \mathrm{~nm}$
Affected Microorganism

P. aeruginosa, S. epidermidis

S. enteritidis, S. hader, S. senftenberg

Mycobacterium spp.

\section{Reference}

38

40

41

36

42

Hepatitis B (virus)

P. aeruginosa

S. pneumoniae

S. aureus, E. coli
43

44

33

$4 \sim 32 \mathrm{~nm}^{\mathrm{c}}$ 


\subsection{Quaternary Antimicrobial Compounds}

Quaternary ammonium compounds (QACs) represent an effective framework for producing novel antimicrobial agents through peripheral modification of the cationic ammonium core. Initially, these compounds were used in commercial and medical disinfectants including Lysol ${ }^{\circledR}$ for sterilizing food equipment, and Bactine ${ }^{\circledR}$ for disinfecting cuts and scrapes. ${ }^{45}$ Since then, there has been an interest in functionalizing QAC compounds with polymeric anchors to produce antimicrobial surfaces.

(B) To address the rising concerns regarding infection control and contamination from material surfaces, researchers have investigated the application of surface attached antimicrobials to glass, ${ }^{34,46,47}$ plastic, ${ }^{1,48,49}$ textiles $^{48-50}$ and metals. ${ }^{48,51}$ While the attachment chemistry differs with each surface, the common functional active site design relies on the presence of a long chain $\left(\mathrm{C}_{12}-\mathrm{C}_{24}\right)$ alkyl quaternary ammonium salt which is proposed to impart an adsorbent "phospholipid sponge" effect on cellular membranes through measurable surface charge, thereby damaging cell function and integrity (Figure 2). ${ }^{52-54}$ Evidence of this phospholipid sponge effect has been studied through the comparison of available surface charge to antimicrobial efficacy of the coated material. This was usually accomplished through complexing an anionic dye with the coating surface before removing and measuring the amount of adherent dye in previous studies. Through these tests, evidence has been discovered that indicates towards a minimal amount of surface charge required to impart antimicrobial activity, although there are potential issues with the ability of certain dye molecules to complex to these coated surfaces. ${ }^{55}$

(A) Another potential mechanism that exists to explain the antimicrobial activity of QACs

is called the "polymeric spacer" effect (Figure 2). This mechanistic theory ultimately operates by damaging cell function and integrity by directly piercing the cellular membrane via a long polymer 
tail consisting of repeating QAC subunits. ${ }^{56}$ One recent discovery that lends additional support towards this mechanism involves the study into the antimicrobial properties of dragonfly wings. Through the combination of electron microscopy and microbiology techniques, it was found that the wing surface was covered in irregularly-sized non-charged nanopilli which would cause the exposed bacterial cells to lyse when in contact. ${ }^{57}$ (B) Long chain QAC materials demonstrate promise as effective microbial resistant coatings when in contact with Gram-positive and Gramnegative bacteria at a solid/air interface, ${ }^{1,46,58}$ and could provide a viable platform for producing self-sterilizing surfaces. ${ }^{1}$

Considering the sheer quantity of variations in structure and morphology between the numerous microbial species that exists, there are a few factors that may impact the effectiveness of the previously proposed QAC mechanisms. One of the most relevant factors depends on the presence of a thick exterior cell wall comprised of peptidoglycan, ranging between 30-100 nm in thickness (Figure 1). ${ }^{59}$ Bacterial cells that exhibit this structure are considered Gram-positive, since this peptidoglycan layer can be stained purple using crystal violet dye ${ }^{60}$ These bacteria include the Arthrobacter, Listeria, and Staphylococcus genera. Conversely, bacterial cells that are not stained by crystal violet are consider Gram-negative, since a secondary cellular membrane covers a significantly thinner peptidoglycan layer. ${ }^{60}$ These bacteria include the Pseudomonas and Escherichia genera. Since QAC compounds are proposed to interact with the phospholipid membrane microorganisms, the thick cell wall of Gram-positive cell poses a challenge for ultrathin QAC coatings that would rely on the polymeric spacer effect but would not discourage the polymeric sponge mechanism. Likewise, the double phospholipid membranes may pose difficulty for the phospholipid sponge effect via saturation without impacting the polymeric spacer effect. 
As an additional point towards the phospholipid sponge mechanism though, there is evidence that disrupting the outer membrane of Gram-negative cells can lead to biodegradation. ${ }^{61}$
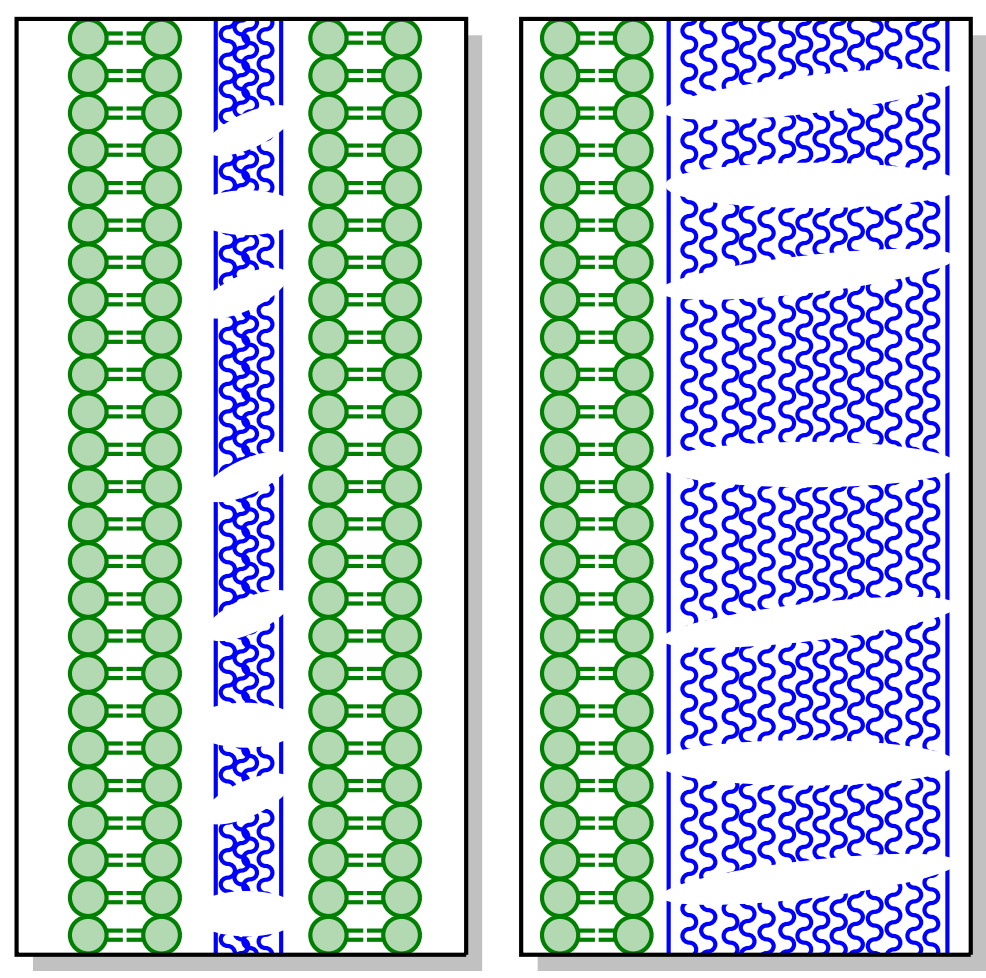

Figure 1 - Differences between the phospholipid cellular membrane (green) and peptidoglycan cell wall (blue) of Gram-negative (left) and Gram-positive (right) bacteria. 


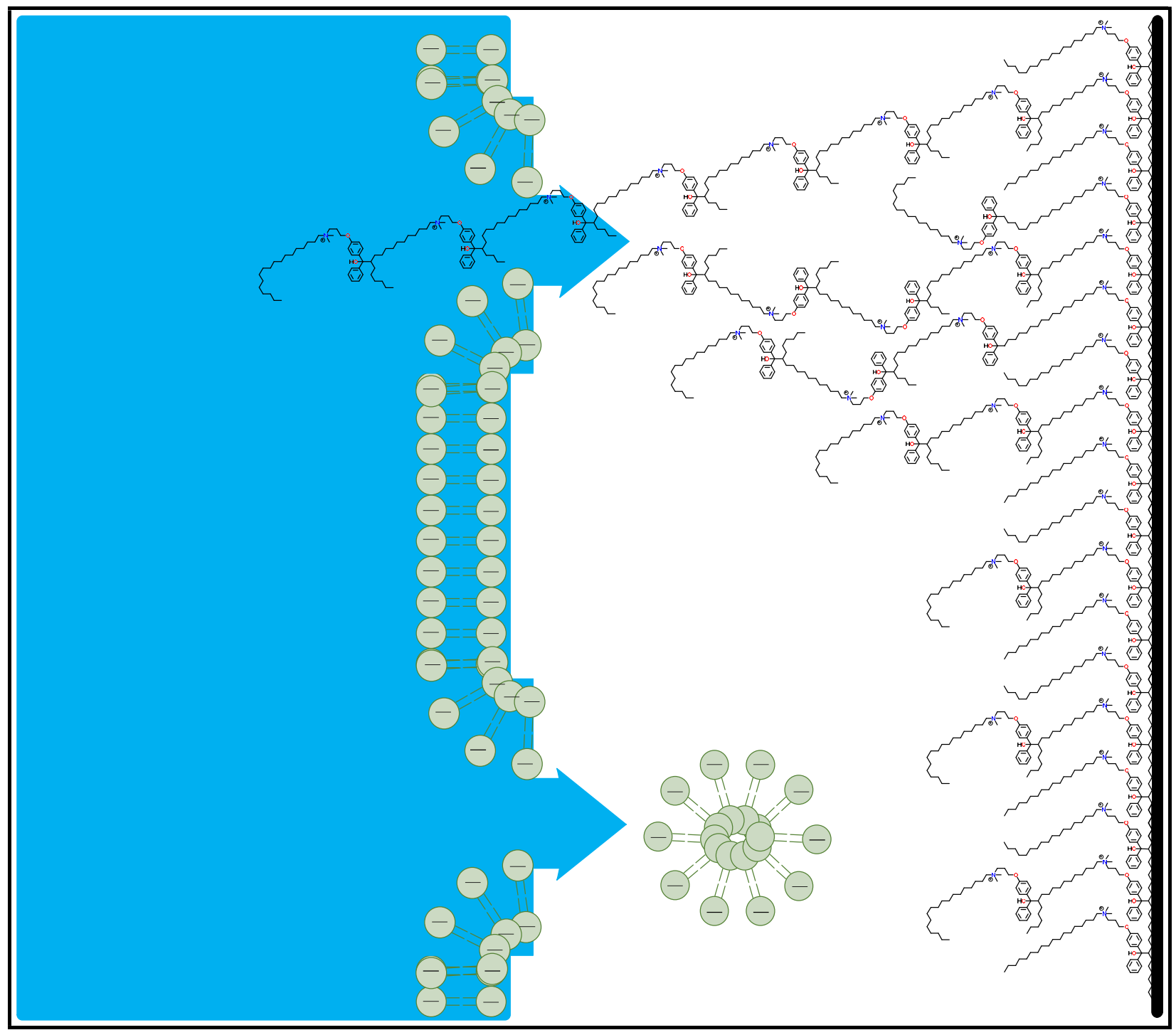

Figure 2 - Visual example of the polymeric spacer (top) and phospholipid sponge (bottom) mechanisms.

(B) To avoid biofilm formation on solid materials under diverse conditions, modifications to QACs through the addition of potent functional moieties have been investigated herein. Dating back to their discovery in 1935 , sulfonamide-based antimicrobial drugs represent the initial stages of antibiotic treatment in modern medicine. These compounds evolved into the premier treatment method for infectious disease, such as blood-borne and gastrointestinal infections, but have limitations based on potential toxicity and allergic reaction. ${ }^{62}$ However, these potent antibiotics 
may serve effectively as attached sulfa-containing QAC antimicrobials. Even today, new sulfonamide compounds have been developed as sulfa drugs and have shown promising antibacterial properties against various bacterial and fungal strains. ${ }^{63,64}$

Along with modifying QACs to contain sulfonamide functionality, there has also been investigations into modifying compounds to increase hydrophobicity. Recently, Tiller et al. ${ }^{65}$ investigated combining silane-anchored QACs with silicon nanoparticles to produce a coating that exhibits the hydrophobic lotus-leaf effect, while still exhibiting antimicrobial characteristics. This concept was performed by functionalizing silicon nanospheres with QAC compounds before depositing the nanoparticles onto a silica-coated sample. This produced a rough nanostructure that helped to repel water from the material surface and exhibited antimicrobial properties against Gram-positive Staphylococcus aureus. ${ }^{65}$

\subsection{Antimicrobial Coatings}

One of the significant benefits of tailoring QAC-containing antimicrobials is the ability to graft to different substrate surfaces. ${ }^{1}$ This further distinguishes them from current disinfectants which rely on residual activity, where the compound is slowly released into the environment over time. ${ }^{66,67}$ This may benefit situations where the goal is to sterilize an isolated biohazardous

medium, however, the loss of disinfectant over time greatly diminishes the capacity of a disinfected surface to remain antimicrobial over extended periods. Another issue caused by residual antimicrobials is the potential to contaminate the natural environment with the compound, potentially leading to antibiotic resistance through sub-lethal microbial exposure and toxic exposure through bioaccumulation and biomagnification of persistent compounds. 
The discovery of silane-anchored QACs represents a significant breakthrough in the development of surface-attached antimicrobial coatings. Previously discovered and developed at Dow Corning in the 60 's and 70 's,${ }^{68}$ these compounds were found to adhere to porous fabrics such as cotton and polyester via condensation reactions with available hydroxyl groups present on the target substrate material to form silyl ester linkages or the formation of Si-O-Si bonds from reaction of nearby silane-anchors. These coatings have been found to exhibit excellent antimicrobial properties and have since been used in many medical, industrial and commercial applications..$^{24,69-71}$

Although silane-anchored QAC antimicrobials are effective at establishing a non-leaching coating on porous substrates, they are generally more difficult to adhere to smooth surfaces commonly associated with plastic materials with an absence of hydroxyl sites. Benzophenoneanchored QACs are a more recently developed alternative that allows for the preferential grafting of QAC antimicrobials to hydrocarbon-based substrates. These photoactive materials can adhere to plastic surfaces through a UV-initiated radical grafting mechanism, where the benzophenone moiety forms a ketyl radical species from UVA exposure. This radical can then proceed to extract a hydrogen atom from a nearby hydrocarbon substrate, before forming a carbon-carbon bond between the compound and substrate materials (Figure 3). ${ }^{72-74}$ Since this reaction occurs if radicalized benzophenone groups are present, it is then possible for multiple layers of benzophenone-anchored QACs to attach to the material surface (Figure 4). 


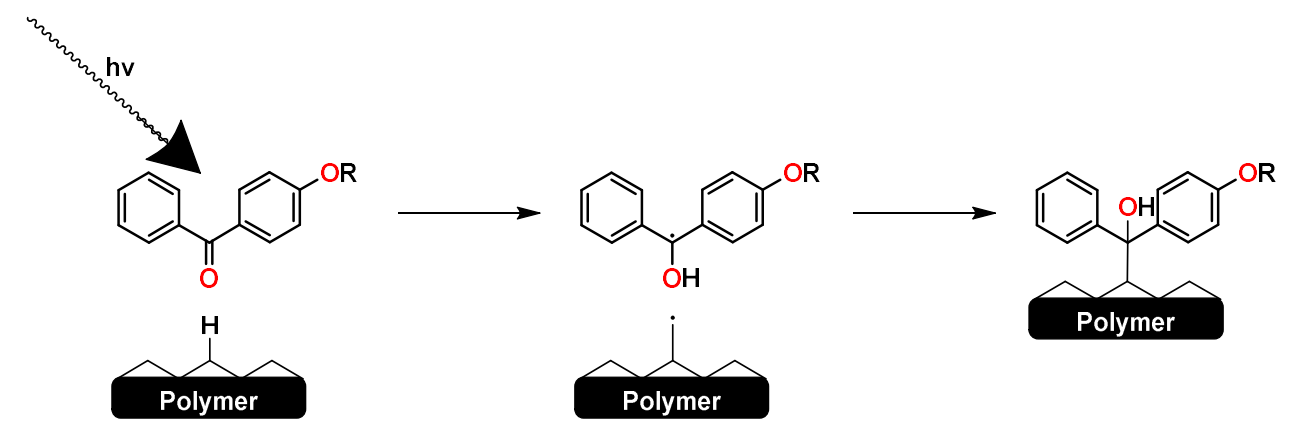

Figure 3 - Benzophenone grafting mechanism through ketyl radicalization. Adapted from Ma et al. $(2000){ }^{74}$
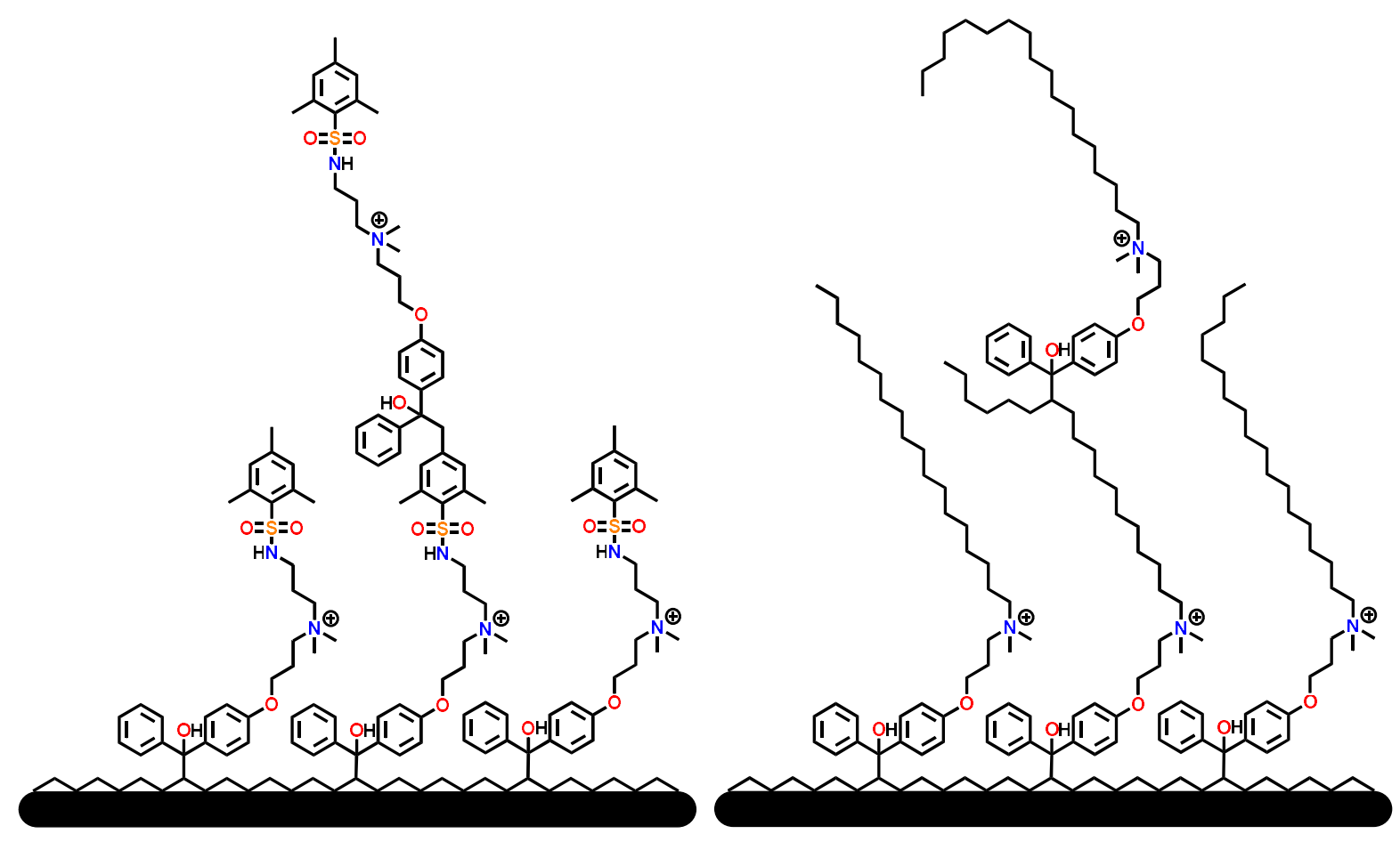

Figure 4 - (B) Schematic representation of surface grafted branching of a sulfa QAC (left) and an alkyl QAC (right).

One way to increase the adhesion and coating quality of antimicrobial treatments is to expose the coating substrate to a plasma pre-treatment. This exposes the surface material to a bombardment of ionized gases which can remove surface contamination and deposit charged 
radicals onto the substrate material. Plasma pre-treatments using atmospheric plasma have been found to promote surface adhesion characteristics and increase surface wettability on a variety of plastics, which is beneficial when trying to evenly coat a solution-dissolved antimicrobial compound. ${ }^{75}$

\subsection{Antimicrobial Analysis and Evaluation}

(B) While there has been significant research effort into preparing non-leaching contact active antimicrobial coatings, there are a limited number of techniques used to assess antimicrobial activity via immersive inoculation. More often, the primary goal of biotesting surface-immobilized antimicrobials is to demonstrate that coated materials can prevent microbial proliferation through direct inoculation methods. ${ }^{58,76}$ To assist in determining the antimicrobial effectiveness of QAC materials, the large droplet inoculum (LDI) method developed by Wolfaardt et al. to examine microbial survivability on dry surfaces was employed. This technique involves placing a single droplet containing a known quantity of microbial cells onto a test surface and allowing the droplet to dry before removing and enumerating any surviving cells. A key advantage to this technique it is reproducibility and the similarity to real-world conditions.

(B) When immersive solid/liquid interface testing is performed on treated surfaces, it is usually accomplished using the ASTM E2149 shake flask method which simulates submerging an antimicrobial-treated object into an aqueous body of contaminated liquid. ${ }^{58,77}$ Another method that is used to test for microbial activity at solid/liquid interfaces utilizes a flow cell system, where a nutrient medium is continuously passed through an inoculated flow channel. ${ }^{78}$ This type of test 
represents a more dynamic, high shear solid/liquid system where the nutrient medium is replenished during the course of the test and simulates environments similar to catheter tubing or general plumbing. Limits of this test involve the potential for bacterial species to migrate upstream and establish a biofilm colony in an untreated section of channel, as well as the difficulty of completely treating a full flow system from influent to effluent ports. ${ }^{79}$

(B) Although there is significant concern with the proliferation of pathogenic microorganisms on dry solid/air surfaces, solid/liquid contact surfaces are also present in many high-risk environments and often provide safe breeding grounds for pathogenic microbes. These surfaces include sinks and drains in hospitals ${ }^{16}$ and air cooling towers, ${ }^{15,79}$ where there is an aqueous medium in constant contact with a solid container. These microbial niches are areas of concern when disturbed by mechanical forces, which can lead to the continuous distribution of microorganisms into new environments, ${ }^{11,16}$ as well as a continuous release of cells as a proliferation mechanism described by Bester et al. ${ }^{80}$ In certain cases, mature biofilms can develop within $24 \mathrm{~h}$ and start to release $10^{6}$ cells per mL. ${ }^{80,81}$ The Liquid Reservoir Inoculum (LRI) method was devised to replicate microbial interactions between solid/liquid interfaces conducted under static, low shear conditions in a controlled environment, as well as provide accurate information regarding antimicrobial activity of constantly wet surfaces. ${ }^{82,83}$ In this work, we describe our efforts to prepare and evaluate a series of new shorter chain sulfonamide quaternary antimicrobials that operate at solid/air interfaces and explore how well these antimicrobial treatments suppress microbial proliferation at solid/liquid surfaces. 


\subsection{Research Goals}

The goal of this project was to develop strategies to treat useful materials with QAC antimicrobials, discover how to evaluate the surface characteristics of these coated materials, and to determine the antimicrobial activity of these treated samples. Coating strategies were developed using electrospray and plasma pre-treatment methods. Surface characteristics were evaluated using simple counterionic staining procedures, followed by advance microscopy techniques. Antimicrobial activity of samples treated with these materials was determined using the LDI and LRI methods, which were adapted and developed for the testing of surface-attached antimicrobial coatings. Throughout this work, surface-attached QACs were investigated as a method of microbial control on treated materials, the results of which were used to answer whether these compounds are effective and can be consistently examined. 


\subsection{Experimental}

\subsection{Materials and Active Antimicrobials}

All reagents and solvents were obtained from commercial sources and used as received unless indicated otherwise. Stock cotton fabric was sourced from Gildan (cat. G2000-W). Stock plastic polystyrene (PS) (cat. 89106-754) and clear polyvinyl chloride (CPVC) (cat. 82027-788) was sourced from VWR International, Nalgene-brand $5 \mathrm{~mL}$ low-density polyethylene (LDPE) vials (cat. 6250-0005) were sourced from ThermoFischer Scientific Inc., polyvinyl chloride (PVC) sourced from Bow Plastics (cat. 650598), polyether ether ketone (PEEK) sourced from Drake plastics (cat. KT820NT), high density polyethylene (HDPE) sourced from ePlastics (cat. HDPENAT0.125SR24X48), and polypropylene (PP) sourced from Special Coatings USA, LLC., and LEXAN-brand polycarbonate (PC) was sourced from Sabic. The trimethoxysilane propyl halide precursor was prepared as previously described by Isquith et al. ${ }^{68}$ The benzophenone propyl halide precursor, 1a and 2a were prepared as previously described by Saettone et al. ${ }^{84}$

Many of the compounds used in this work were synthesized by members of the Foucher Group. 1a was subsequently synthesized and characterized by Alexander Caschera and Joseph Bedard, while 2a was synthesized and characterized by Lukasz Porosa and Joseph Bedard. 3-8, 3a-8a and 3b-8b were originally synthesized and characterized by Kamlesh Mistry, Alexander Caschera and Aman Khan, and subsequently synthesized by Joseph Bedard. 9-10 and 9a-10a were synthesized and characterized by Joseph Bedard. 11 and 11a was synthesized and characterized by Alexander Caschera. All other experimental details are included in the supplementary section. 


\subsection{Antimicrobial Compound Characterization}

Nuclear magnetic resonance (NMR) experiments were carried out with a $400 \mathrm{MHz}$ Bruker Avance II Spectrometer using deuterated chloroform $\left(\mathrm{CDCl}_{3}\right)$ unless otherwise noted. ${ }^{1} \mathrm{H}$ spectra were referenced to the residual chloroform peak $\left(\mathrm{CHCl}_{3}, 7.26 \mathrm{ppm}\right),{ }^{13} \mathrm{C}$ spectra were referenced to the $\mathrm{CDCl}_{3}$ solvent peak $(77.0 \mathrm{ppm})$, and ${ }^{19} \mathrm{~F}$ resonance was referenced against the internal standard $\mathrm{CFCl}_{3 .}{ }^{29} \mathrm{Si} \mathrm{NMR}$ was referenced against the internal standard tetramethylsilane (TMS).

Peak assignments in the ${ }^{1} \mathrm{H}$ NMR spectra are given in $\delta(\mathrm{ppm})$ and were made with the assistance of 2D COSY spectra, while assignments in the ${ }^{13} \mathrm{C}$ NMR spectra (proton-decoupled) were made with the assistance of 2D HSQC spectra. High resolution mass spectrometry (HRMS) was carried out using electrospray ionization time of flight (ESI-ToF). Melting points were measured in open air using a Fisher Scientific melting point apparatus. A Bruker-Nonius Kappa-CCD diffractometer was used to obtain the X-ray information of the crystal structures of two precursor materials 9 (CCDC 1842645) and $\mathbf{1 1}$ (CCDC 1842536) and three active antimicrobials, 2a (CCDC 1546440), 9a (CCDC 1842528), and 11a (CCDC 1842659) have been deposited with the Cambridge Crystallographic Data Centre.

\subsection{Coating Application}

Coating of plastic test samples $\left(6.25 \mathrm{~cm}^{2} \pm 1 \mathrm{~cm}^{2}\right.$ coupons) was performed via an ESS AD - LG electrospray apparatus (S/N 20073037, Athens, Georgia) set to spray a 1\% (w/v) antimicrobial coating solutions of 1a-11a at $150 \mathrm{kPa}$. Consistent coating uniformity was achieved by spraying test surfaces for $\sim 3 \mathrm{~s}$ at an average distance of $45 \mathrm{~cm}$ from the spray nozzle. UV curing of benzophenone-anchored QAC 1a-11a coated plastics was performed using a Novacure spot curing system with a mercury-arc discharge lamp at a peak intensity of $10 \mathrm{~W}, 7 \mathrm{~cm}$ from the light 
guide source. A peak intensity of $0.075 \mathrm{~W} \mathrm{~cm}^{-2}$ monitored over a $60 \mathrm{~s}$ curing period, delivered $\sim 5$ $\mathrm{J} \mathrm{cm}^{-2}$ total dose UVA, as measured using an EIT UV Power Puck 2. Coating solutions of sulfonamide QACs 3b-6b were created by dissolving 1\% (w/v) of the desired antimicrobial in an EtOH: $\mathrm{H}_{2} \mathrm{O}$ solvent, with the ratio varying between $30: 70$ to $90: 10$ based on the solubility of the test antimicrobial compound. Coating of fabric test samples, $\left(6.25 \mathrm{~cm}^{2} \pm 1 \mathrm{~cm}^{2}\right.$ swatches of cotton), was performed by dip coating the samples into a coating solution before allowing them to dry at room temperature. In certain cases where low surface-energy materials were being tested, samples were pre-treated by passing samples five times at $1.5 \mathrm{~cm}$ away from the nozzle of a Dyne-a-Mite HP (Enercon Industries) atmospheric plasma to increase surface wettability and coating adhesion.

\subsection{QAC Visualization via Anionic Dye Staining}

Treated samples were tested for coating quality by submerging samples into aqueous solutions containing $1000 \mathrm{ppm}$ of anionic dye. Different dye solutions used during staining include bromophenol blue, fluorescein, and dichlorofluorscein. A positive test for the presence of QAC would result in a colour change caused by the formation of a dye-QAC complex and would manifest as a change from purple to blue for bromophenol blue, from green to orange for fluorescein, and from yellow to pink for dichlorofluorscein. Bromophenol blue dye was also used to check if QACs were present in solution after rinsing or after biotesting had been performed by adding enough dye to make the resultant solution contain 4 ppm bromophenol blue. 


\subsection{Surface Charge}

Accessible surface charge density $\left(\mathrm{N}^{+} \mathrm{cm}^{-2}\right)$ of treated coated polystyrene samples was determined based on a fluorescein staining-destaining protocol as previously described. ${ }^{85}$ The relation between fluorescein molecules and QAC molecules is 1:1 during this test. ${ }^{55}$ Triplicate control and treated samples $\left(4 \mathrm{~cm}^{2}\right)$ were submerged in $1 \%(\mathrm{w} / \mathrm{v})$ aqueous fluorescein disodium salt solution and placed on an orbital shaker for $24 \mathrm{~h}$ at $150 \mathrm{rpm}$. Samples were exhaustively rinsed with distilled water to remove unbound fluorescein molecules, as indicated by the visual absence of fluorescein dye within the rinse fluid. Samples were sonicated for 15 minutes in $9 \mathrm{~mL}$ of cetyltrimethylammonium chloride and $1 \mathrm{~mL}$ of $0.1 \mathrm{M}$ phosphate buffered saline to liberate bound fluorescein into solution. UV-Vis was performed using quartz cuvettes (path length; L= $1 \mathrm{~cm}$ ) on collected sonicated solutions, and absorbance was recorded at $501 \mathrm{~nm}$. Concentration (C) and surface charge were calculated using the Beer-Lambert law, with the extinction coefficient value $\left(\varepsilon_{501}\right)$ of $77000 \mathrm{M}^{-1} \mathrm{~cm}^{-1}$.

$$
C_{\text {fluorescein }}\left(\mathrm{mol} \mathrm{L}^{-1}\right)=A_{501} / \varepsilon_{501}\left(M^{-1} \mathrm{~cm}^{-1}\right) \times L(\mathrm{~cm})
$$

Accessible QAC surface charge density to fluorescein was calculated

per centimeter square using the following equation:

$$
\left[N^{+}\right]=\frac{C_{\text {fluorescein }}\left(\mathrm{mol} \mathrm{L}^{-1}\right) \times V(L) \times N}{A\left(\mathrm{~cm}^{2}\right)}
$$

where V represents the volume of collected sonicated solution, N represents Avogrado's number $\left(6.023 \times 10^{23}\right)$, and A represents the surface area of a coated sample. 


\subsection{Characterization of Antimicrobial Treated Surfaces}

Contact angle images of treated and untreated surfaces were taken using a Teli CCD camera equipped with a macro lens attached perpendicularly to the sample surface. Contact angle measurements were performed using OCA15 contact angle software by Data Physics Corporation. X-ray photoelectron spectroscopy (XPS) was performed using a ThermoFisher Scientific KAlpha, and time-of-flight secondary ion mass spectrometry (ToF-SIMS) was performed using an IonTOF ToF-SIMS IV at the Ontario Centre for the Characterisation of Advanced Materials (OCCAM), located at the University of Toronto. Atomic force microscopy (AFM) using an Anasys nanoIR2 equipped with Contact Mode NIR2 Probes (Resonance frequency $13 \pm 4 \mathrm{kHz}$, Spring constant $0.07-0.4 \mathrm{~N} \mathrm{~m}^{-1}$ ), and surface profilometry using a KLA-Tencor P16+ Surface Profilometer were also performed at OCCAM. AFM data was processed using Gwyddion 2.50 software. $^{86}$

\subsection{Large Droplet Inoculation (LDI) Biotesting}

Several clinically relevant bacterial stock cultures were used in these tests. Bacterial test species were grown overnight in $10 \mathrm{~mL}$ of $3 \mathrm{~g} \mathrm{~L}^{-1}$ tryptic soy broth (EMD Millipore) at $30{ }^{\circ} \mathrm{C}$ within a shaking incubator, and cultures were washed twice via centrifugation at $9000 \times g$ to replace the growth media with sterile water. Arthrobacter sp. (IAI-3), a Gram-positive bacterium originally isolated from indoor laboratory air was inoculated onto all treated and control test surfaces as the model organism for bacterial survival on solid surfaces. ${ }^{83}$ Lab strains of Gram-negative Escherichia coli (DH5a), Pseudomonas aeruginosa (PAO1) and Gram-positive Staphylococcus aureus (Ryerson University), Gram-positive Listeria monocytogenes (Scott A) were also tested on treated materials. These strains were chosen since they are well characterized and are present in 
biofilms found within high-risk environments. The large drop inoculum (LDI) method (Figure 17) was used to assess the antimicrobial efficacy of the antimicrobial treatment at a solid/air interface and is a modification of the ISO 22196/JIS Z 2801 standard procedure. ${ }^{87,88}$ Triplicate treated samples were inoculated with $100 \mu \mathrm{L}$ bacterial aliquots of subsequently determined concentration, and survival on the sample was determined by spot plating, described as following. The inoculated droplets were naturally air-dried within a class II, type A2 biosafety cabinet (Model 3440009, Labconco Corp.) to avoid contamination, and surviving cells were enumerated upon drying, typically $3 \mathrm{~h}$ after inoculation. Note that the final drying time depends on the evaporation of the inoculum liquid and can be hard to determine on fabric samples due to droplet wicking. Enumeration was performed by rehydrating and vortexing samples in $5 \mathrm{~mL}$ of a $0.9 \%$ saline retrieval solution, which was then serially diluted and spot-plated onto $3 \mathrm{~g} \mathrm{~L}^{-1}$ tryptic soy agar. Plates were then incubated at $25^{\circ} \mathrm{C}$ for a period of 5-7 d which allowed for visualization of colony forming units (CFU). At each time point, bacterial survival on the treated samples was compared to survival on triplicate untreated control surfaces of the same material.

\subsection{Liquid Reservoir Inoculum (LRI) Biotesting}

Arthrobacter sp. and E. coli were grown overnight in $3 \mathrm{~g} \mathrm{~L}^{-1}$ tryptic soy broth at $30^{\circ} \mathrm{C}$ within a shaking incubator, and cultures were washed twice via centrifugation at $9000 \times g$ to replace the growth media with sterile water. The LRI method (Figure 29) was used to assess the efficacy of the antimicrobial treatment at a solid/liquid interface and is a modification of the ASTM E2149 standard procedure. ${ }^{77}$ Triplicate treated $5 \mathrm{~mL}$ LDPE tubes containing $2.7 \mathrm{~mL}$ of $0.9 \%$ sterile saline were inoculated with $300 \mu \mathrm{L}$ bacterial aliquots of subsequently determined concentration. These tubes were capped and placed onto a VWR orbital shaker (cat. 57018-754) set to 150 RPM for 48 
$\mathrm{h}$ to prevent sedimentation. At $24 \mathrm{~h}$ and $48 \mathrm{~h}, 100 \mu \mathrm{L}$ aliquots were removed from the sample, serially diluted and spot-plated onto $3 \mathrm{~g} \mathrm{~L}^{-1}$ tryptic soy agar to enumerate the survival of planktonic cells suspended within the liquid reservoir. After $48 \mathrm{~h}$, sample shaking was suspended, the remaining liquid was replaced with $5 \mathrm{~mL}$ sterile saline, and the samples were gently inverted 10 times to rinse any loosely-adhered cells from the tube walls. With the rinse solution discarded, the LDPE tubes were then filled with $1 \mathrm{~mL}$ of sterile saline and vortexed for 1 min to dislodge any biofilm formed on the tube surface. One $100 \mu \mathrm{L}$ aliquot was then removed from each tube, serially diluted and spot-plated to enumerate the survival of biofilm cells attached to the walls of the sample tube. Agar plates were incubated at $25^{\circ} \mathrm{C}$ for a period of 5-7 d, which allowed for visualization of CFUs. At each time point, bacterial survival on the treated samples was compared to survival on triplicate untreated control surfaces of the same material. 


\subsection{Results and Discussion}

\subsection{Synthesis of Alkyl QAC Compounds}

Initial research into QAC materials stems from investigations into propyl-dimethyl (benzoylphenoxy)octadecylammonium bromide, 1a and propyl-dimethyl (benzoylphenoxy)dodecylammonium bromide, 2a. Discovered by Saettone et al. in 1988, 1a and 2a were synthesized for inclusion into sunscreens to increase the duration of UV protection and were found to have the additional benefit of acting as an antimicrobial agent. ${ }^{84}$ Since then, these compounds have been further investigated by Foucher et al. in 2017 for use in surface-grafted antimicrobial coatings. ${ }^{89}$

(A) In the present research, $N, N$-dimethyldecylamine or $N, N$-dimethyloctadecylamine was quaternized using ( $n$-haloalkoxy)benzophenone in $\mathrm{MeCN}$ solution by heating to $100^{\circ} \mathrm{C}$ overnight (Scheme 2). This yielded compounds 1a and 2a as off-white colored powders in good yields. These compounds were further purified by recrystallization from $\mathrm{EtOH}$ or $\mathrm{EtOH} / \mathrm{H}_{2} \mathrm{O}$ mixtures. NMR $\left({ }^{1} \mathrm{H}\right.$ and $\left.{ }^{13} \mathrm{C}\right)$ spectroscopy of both compounds, along with HRMS analysis, support their structural identity. Compound 2a was also characterized by single crystal X-ray diffraction. An Oak Ridge thermal ellipsoid plot (ORTEP) representation of one of the unique molecules of $2 \mathbf{a}$ found in the unit cell is displayed in Figure 5. Interestingly, the cationic component of the salt appears folded over on itself, with visible twisting of one of the benzophenone rings to accommodate the presence of the carbonyl oxygen. 


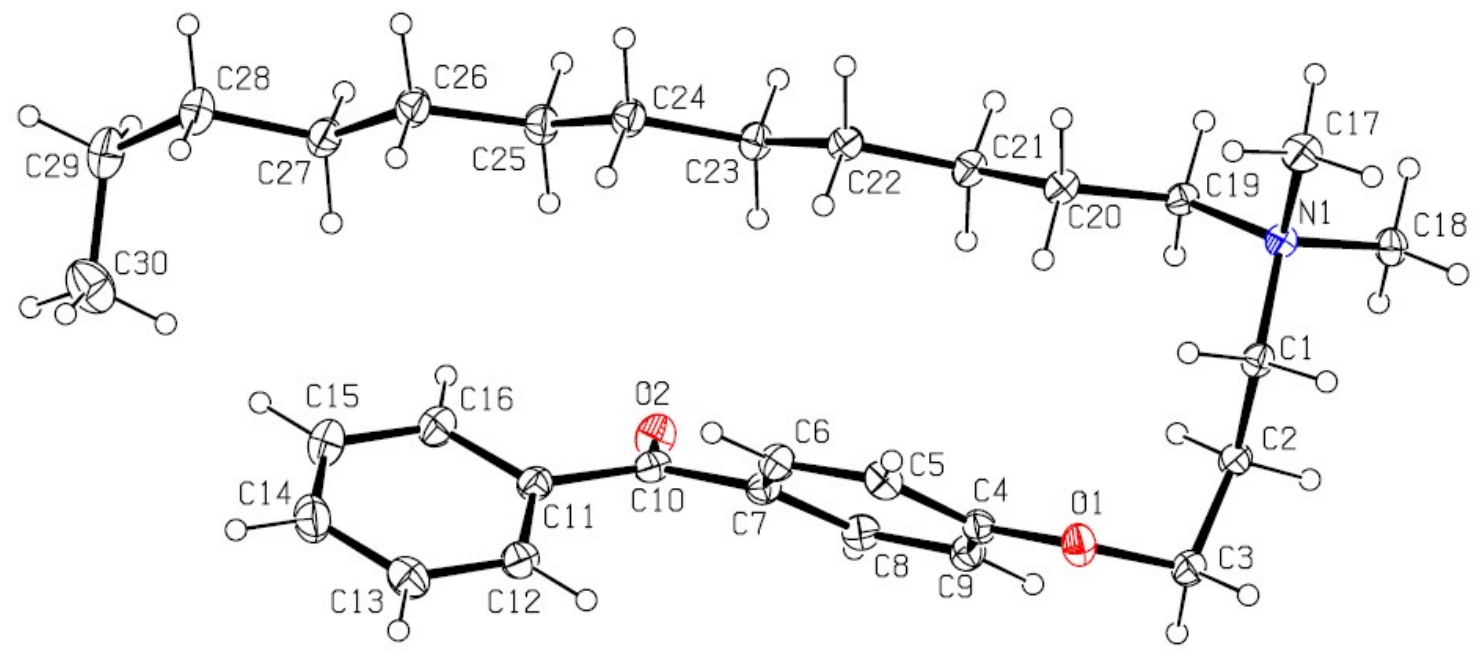

Figure 5 - (A) ORTEP representation of $\mathbf{2 a}$ found in the unit cell and selected bond lengths $(\AA)$ and bond angles ( ${ }^{\circ}$ ): O(1)-C(3) 1.442(2), O(2)-C(10) 1.221(2), N(1)-C(1) 1.514(2), N(1)-C(19) 1.508(2), C(4)-O(1)C(3) 119.06 (15), C(19)-N(1)-C(1) 113.21 (14), C(7)-C(10)-C(11) 119.98 (17), C(30)-C(29)-C(28) 113.5 (2). Crystal discovered by Alexander Caschera, Joseph Bedard and Lukasz Porosa.

(A) For the purpose of producing coating solutions for electrospray application, 1a is only partially soluble in water and fully miscible at $1 \%(\mathrm{w} / \mathrm{v})$ in $70: 30 \mathrm{EtOH}: \mathrm{H}_{2} \mathrm{O}$ or $i-\mathrm{PrOH}: \mathrm{H}_{2} \mathrm{O}$ solutions. In contrast, 2a was found to be fully soluble in $\mathrm{H}_{2} \mathrm{O}$ at the same concentration. The relative solubility of these materials in $\mathrm{H}_{2} \mathrm{O}$ or EtOH: $\mathrm{H}_{2} \mathrm{O}$ mixtures is in contrast to the closely related alkylated benzophenone quaternary ammonium salts and the hydroxybenzophenone copolymers prepared by Locklin et al. These materials required formulation in DCM and acetone, respectively, for coating purposes. ${ }^{49,90,91}$ 


\subsection{Synthesis of Sulfa QAC Compounds}

(B) The addition of 3-(dimethylamino)propylamine to the appropriate sulfonyl chloride in $\mathrm{CH}_{2} \mathrm{Cl}_{2}$ with $\mathrm{NEt}_{3}$ for $3 \mathrm{~h}$ at room temperature followed by a workup in distilled water produced sulfonamide precursors 3-6 and 9-10 in high yields (Scheme 1). Alkyl sulfonamide precursors 7 and $\mathbf{8}$ were successfully synthesized in moderate to high yields in the absence of $\mathrm{NEt}_{3}$ to avoid salt formation, while varying the order of addition, with the sulfonyl chloride added to a solution of 3(dimethylamino)propylamine in DCM. The non-quaternary ammonium sulfonamide 11a was prepared from the reaction of sulfonamide precursor 11 with 4-hydroxybenzophenone (Scheme 1) using the classic Williamson ether synthesis reaction and was isolated as a yellow crystalline solid. Compound 11a was additionally characterized by single crystal X-ray diffraction and an ORTEP representation of the molecule found in the unit cell is displayed in Figure $6 . \mathrm{NMR}\left({ }^{1} \mathrm{H}\right.$ and $\left.{ }^{13} \mathrm{C}\right)$ spectroscopy of all sulfonamide containing compounds, along with HRMS analysis, support their structural identity (Appendix B). 


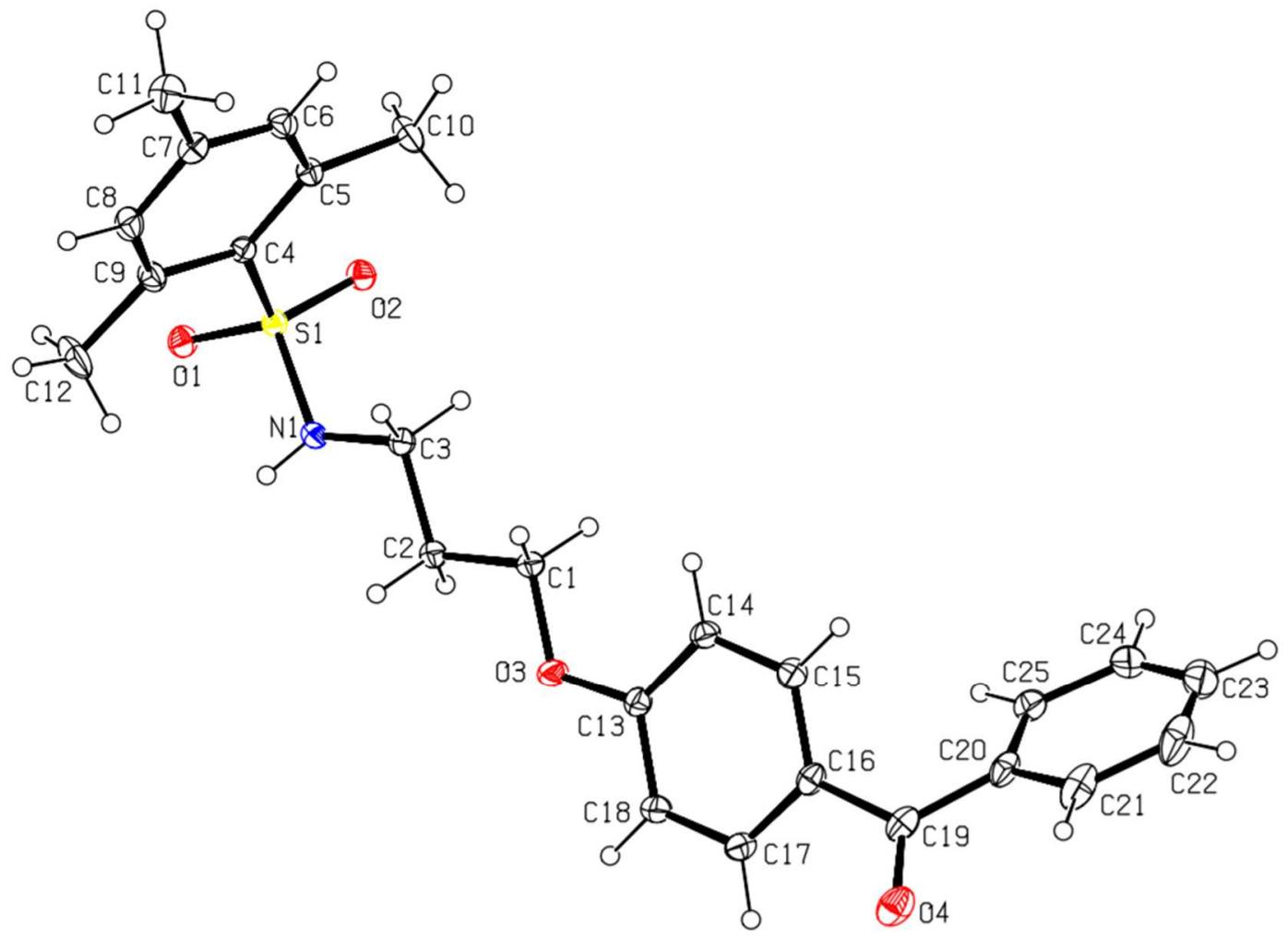

Figure 6 - (B) ORTEP representation of 11a found in the unit cell and selected bond lengths $(\AA)$ and bond angles ( ${ }^{\circ}$ ): S(1)-O(1) 1.4325(10), S(1)-O(2) 1.4348(9), S(1)-N(1) 1.6203(11), S(1)-C(4) 1.7861(13), N(1)-C(3) 1.4701(17), O(3)-C(1) 1.4337(16), O(3)-C(13) 1.3619(16), O(4)-C(19) 1.2235(18), O(1)-S(1)-O(2) 118.04(6), N(1)-S(1)-C(4) 106.79(6), C(3)-N(1)-S(1) 119.53(9), C(13)-O(3)-C(1)117.60(10). Crystal discovered by Alexander Caschera.

(B) Further conversion of the sulfonamide precursors to quaternary ammonium salts was achieved using conventional Menshutkin quaternization procedures, which involves heating a mixture of 3-10 and the appropriate haloalkyl silane or benzophenone attachment functionality to reflux in $\mathrm{MeCN}$ for extended periods (Scheme 2). Compounds 3a-10a were recovered as whitecoloured crystalline solids, while $\mathbf{3 b}$-6b were isolated as clear or golden brown-coloured oily 
gums. These compounds were further purified with successive washes of the crude product with $\mathrm{Et}_{2} \mathrm{O}(10 \mathrm{~mL} \times 3) \cdot{ }^{92}$ Compound 10a was additionally characterized by single crystal X-ray diffraction and an ORTEP representation of the molecule found in the unit cell as displayed in Figure 7.

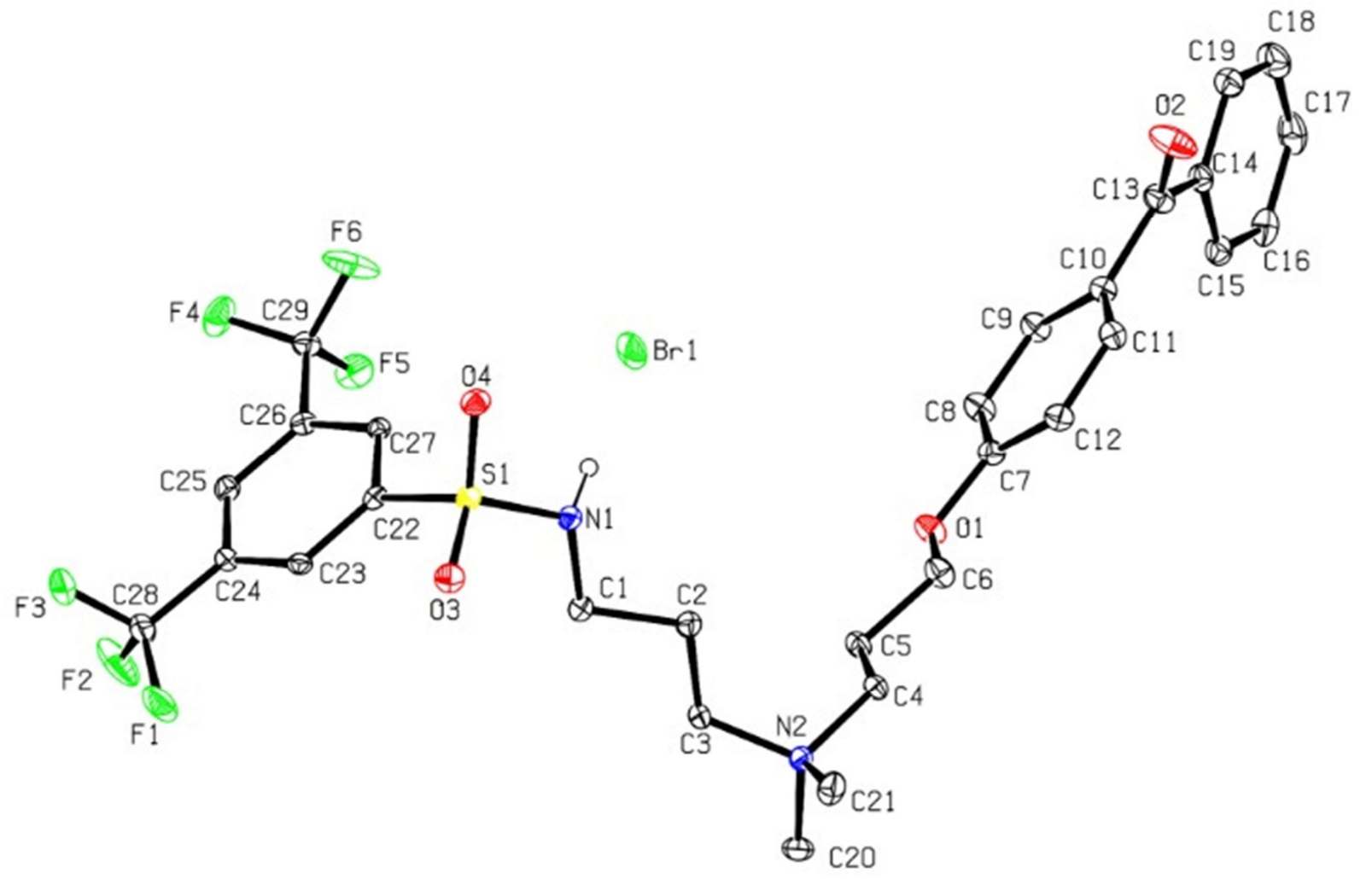

Figure 7 - (B) ORTEP representation of 10a found in the unit cell and selected bond lengths $(\AA)$ and bond angles $\left({ }^{\circ}\right)$ : S(1)-O(3) 1.431(2), S(1)-O(4) 1.433(2), N(1)-C(1) 1.469(4), N(2)-C(3) 1.514(3), N(2)-C(4) 1.514(3), N(2)-C(20) 1.499(4), N(2)-C(21) 1.504(4), O(1)-S(1)-O(2), 119.91(13), N(1)-S(1)-C(22) 107.40(13), C(1)-N(1)-S(1) 118.8(2), C(3)-N(2)-C(4) 112.5 (2). Crystal discovered by Joseph Bedard.

\subsection{General Sulfonamide reaction}

To a flame dried, round bottom flask in an ice bath equipped with a stir bar containing an appropriate amount of anhydrous DCM, an adequate amount of respective sulfonyl chloride 
(Scheme 1) was added, followed by an equimolar amount of $\mathrm{NEt}_{3}$ (omitted for $\mathbf{7}$ and $\mathbf{8}$ ) and dropwise addition of a stoichiometric quantity of 3-(dimethylamino)propylamine (Note: 3bromopropylamine hydrobromide was used for 11). After $30 \mathrm{~min}$. the reaction mixture was removed from the ice bath and allowed to stir at room temperature for the indicated time. The reaction was then transferred to a separatory funnel and extracted with an appropriate amount of distilled water. Volatiles and/or solvent were removed from the organic phase using a rotary evaporator followed by drying under high vacuum.

Scheme 1 - General sulfonamide reaction

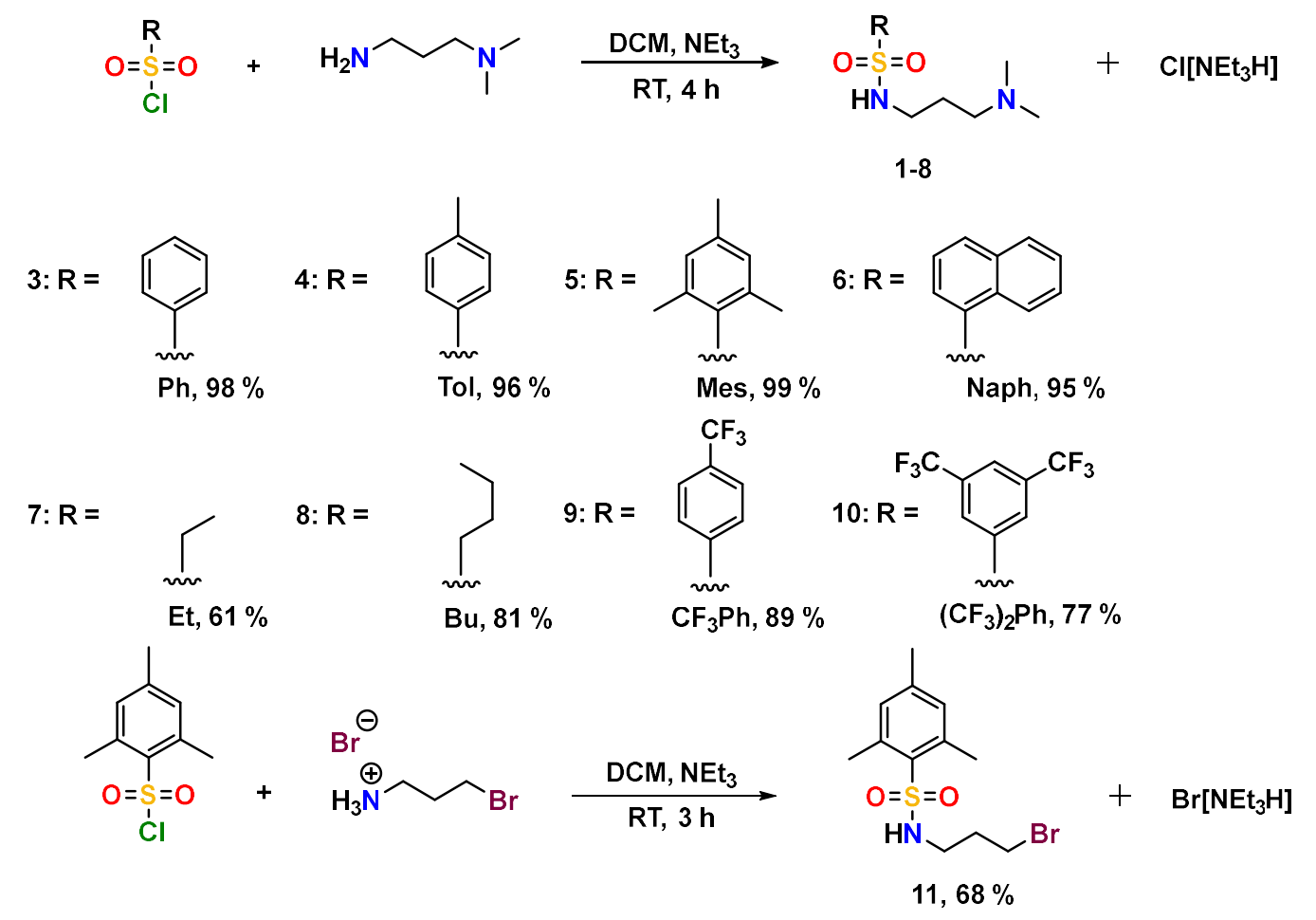

\subsection{General Menshutkin reaction}

In an appropriately sized round bottom flask or scintillation/microwave vial, an appropriate amount of a tertiary amine-terminated sulfonamide and a chloroalkyl trimethoxy silane or 
benzophenone alkyl halide starting material was dissolved in acetonitrile (Scheme 2). The reaction mixture was stirred at $110^{\circ} \mathrm{C}$ for the indicated time. The crude material was purified by addition of $\mathrm{Et}_{2} \mathrm{O}$ directly into the reaction mixture followed by decanting $\left(\mathrm{Et}_{2} \mathrm{O}\right.$ wash $\left.\times 3\right)$ and dried in vacuo.

Scheme 2 - General Menshutkin reaction

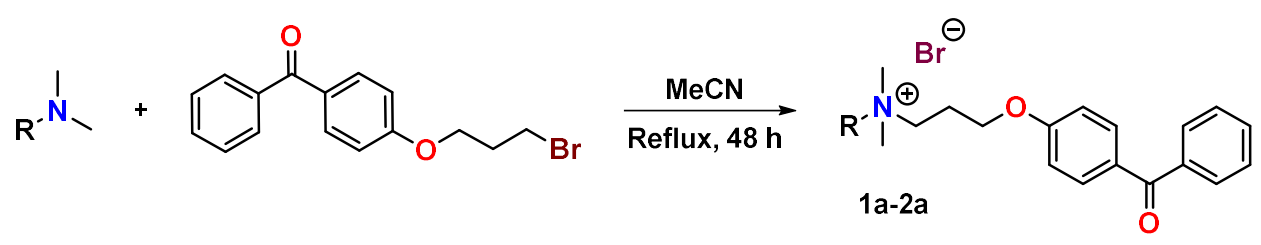

1: $\mathrm{R}=\mathrm{C}_{18} \mathrm{H}_{37}(\mathrm{a}: 97 \%)$

2: $R=\mathrm{C}_{12} \mathrm{H}_{25}(\mathrm{a}: 93 \%)$<smiles>[R]S(=O)(=O)NCCCN(C)C</smiles>

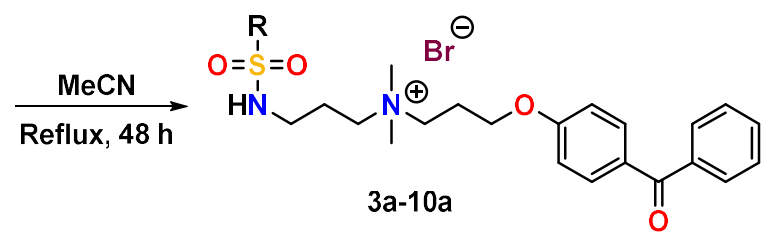<smiles>[R]S(=O)(=O)NCCCN(C)C</smiles>

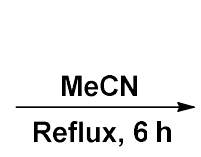<smiles>[R]S(=O)(=O)NCCC[N+](C)(C)CCC[Si](OC)(OC)OC</smiles>

3: $\mathrm{R}=\mathrm{Ph}(\mathrm{a}: 82 \%, \mathrm{~b}: 82 \%)$

4: $R=$ Tol (a: $80 \%, b: 97 \%)$

5: $R=\operatorname{Mes}(a: 67 \%, b: 93 \%)$

6: $R=\operatorname{Naph}(a: 82 \%, b: 80 \%)$

7: R = Et (a: $77 \%, b: 86 \%)$

8: $R=B u(a: 73 \%, b: 60 \%)$

9: $\mathrm{R}=\mathrm{CF}_{3} \mathrm{Ph}(\mathrm{a}: 86 \%)$

10: $\mathrm{R}=\left(\mathrm{CF}_{3}\right)_{2} \mathrm{Ph}(\mathrm{a}: 89 \%)$

\subsection{Williamson Ether Synthesis of 11a}

A round bottom flask was charged with 1,3-dibromopropane, $\mathrm{K}_{2} \mathrm{CO}_{3}$ and $\mathrm{MeCN}$. A solution of 4-hydroxybenzophenone in $\mathrm{MeCN}$ was prepared and added dropwise to the previous mixture under reflux (Scheme 3). The resultant yellow mixture was heated at reflux until a colourless solution was obtained or until thin layer chromatography showed the disappearance of 
starting material 4-hydroxybenzophenone. Excess salt was filtered through diatomaceous earth and washed with acetone. The solution was evaporated under reduced pressure to give the crude product, which was packed onto silica and purified by dry column chromatography, first by preeluting with $5 \%$ ethyl acetate/hexanes then eluting acetone to retrieve the purified product. The resulting yellow oil was recrystallized from $20 \%$ ethyl acetate/hexanes to yield translucent yellow crystals.

Scheme 3 - Williamson ether synthesis of 11a

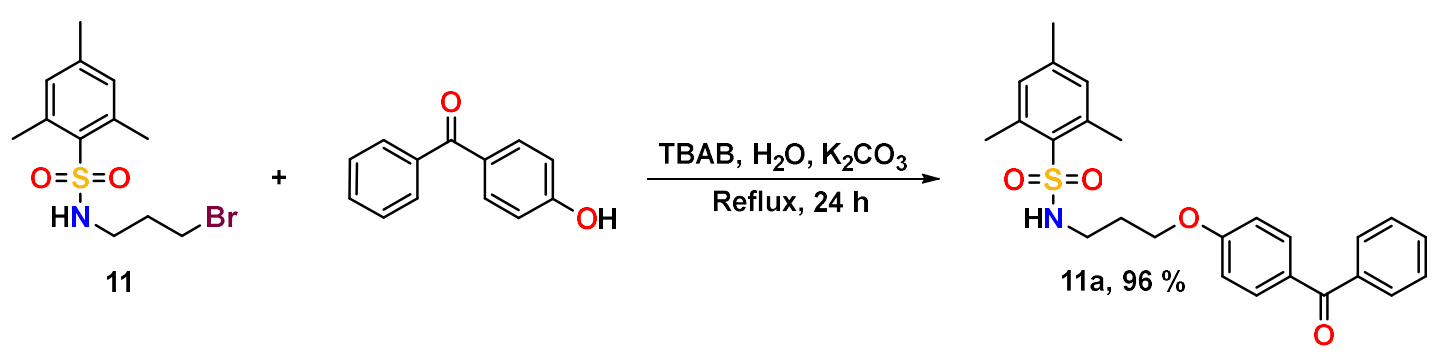

\subsection{Coating and Curing of Test Samples}

(B) Plastic coupons were twice treated with $1 \%(\mathrm{w} / \mathrm{v})$ ethanolic solutions of the active benzophenone-anchored antimicrobial to ensure complete coverage. After treatment, samples were rinsed with distilled water and the rinse solution tested for residual antimicrobial leachate with bromophenol blue stain or by UV-Vis spectroscopy. Once the rinse solution was clear of unadhered antimicrobial, additional samples from each batch were sacrificed for bromophenol blue dye staining to visualize coating quality across the material surface. Commonly, only one rinse step was required to remove excess QAC deposited during the coating process. Coating uniformity was also visualized by submerging test samples in a $400 \mathrm{ppm}$ bromophenol blue dye solution, where treated samples stained blue while leaving uncoated samples unchanged. ${ }^{1}$ The 
remaining samples were then used for microbiological evaluation using the LDI procedure with triplicate treated samples compared against controls for antimicrobial activity.

(B) Silane-anchored QAC coatings bearing long chain alkyl substituents have been used extensively on porous surfaces to protect against pathogenic infections and to control against odors caused by bacterial metabolites. The rationale behind these efforts is to effectively kill bacterial species before the establishment of a microbial biofilm, thereby preventing the possibility of exposure to contaminated materials. Some of the products treated using these compounds include sporting goods, medical curtains and fabrics, common clothing and protective gear for infection control and odor prevention. ${ }^{93}$ Fabric samples were treated with $1 \%(\mathrm{w} / \mathrm{v})$ of the active silaneanchored antimicrobial by submerging and agitating cotton swatches within a desired antimicrobial solution for $\sim 5$ minutes, followed by a $24 \mathrm{~h}$ curing period at room temperature. After treatment, samples were exhaustively rinsed with $10 \mathrm{~mL}$ aliquots of distilled water and the rinse solution was monitored for antimicrobial leachate with bromophenol blue stain. Once the rinse solution was clear of any unattached antimicrobial, the samples were tested in triplicate under the same conditions as the plastic samples.

In some circumstances, a plasma pre-treatment was used to increase the wettability of the treated sample surfaces and improve the coating quality of hydrophobic materials. Using the HP Dyne-a-Mite atmospheric plasma treater, surfaces that were subjected to pre-treatment were found to exhibit a greatly decreased advancing contact angle, which changes from $91.7^{\circ} \pm 1.5^{\circ}$ to $22.6^{\circ}$ $\pm 3.5^{\circ}$ were seen for polystyrene (Figure 8 ) and $80.8^{\circ} \pm 5.0^{\circ}$ to $15.8^{\circ} \pm 5.2^{\circ}$ were seen for omniphobic glass. 


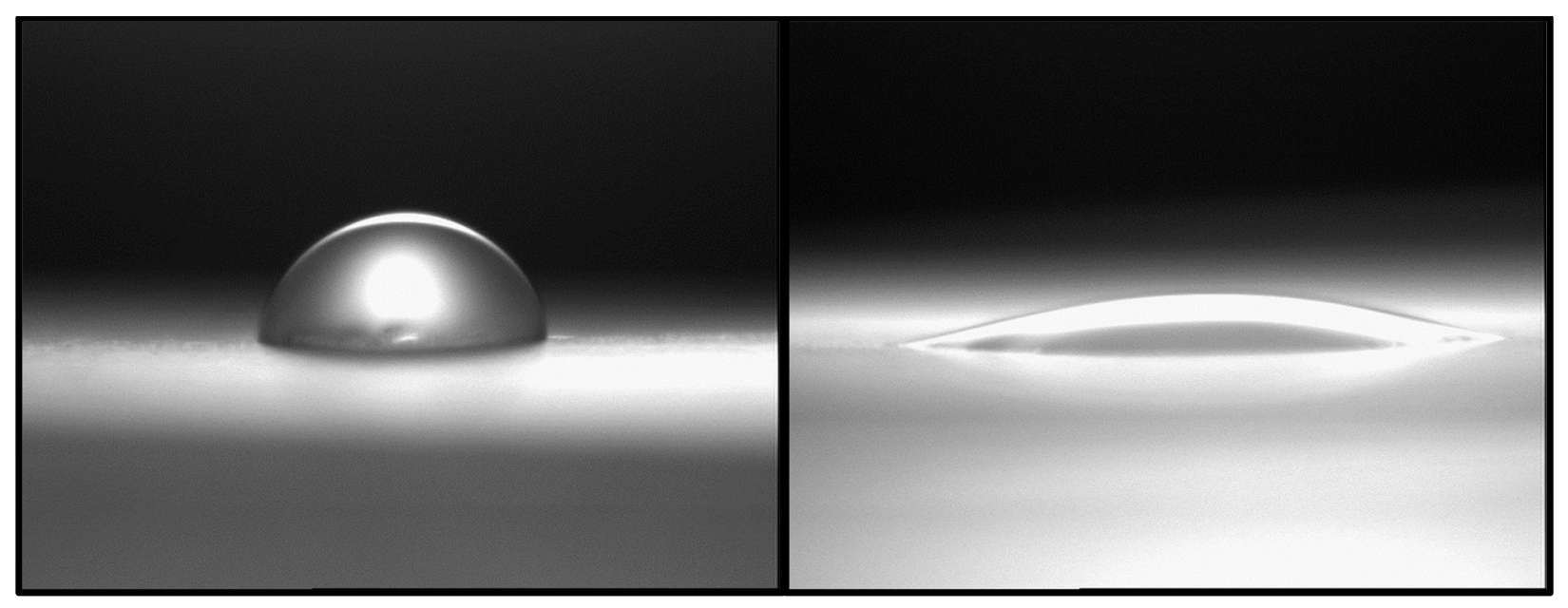

Figure 8 - Advancing contact angle images of control polystyrene before(left) and after (right) plasma pre-treatment. Test was performed using $5 \mu \mathrm{m}$ distilled water droplets.

The main benefit of increasing the contact angle prior to coating would be to prevent the coalescence of the coating solution into large droplets scattered across the material surface. This would impart a more uniform coating across the treated material during each coat/cure step performed. Plasma pre-treatment was also seen as a necessary step to ensure consistent treatment with super hydrophobic or omniphobic materials, since these materials would repel any coating solution prior to curing.

\subsection{Antimicrobial Coating Visualization via Anionic Dye Staining}

(A) Following application of the compound to the test surface, the presence and uniformity of the coating was confirmed prior to any subsequent antimicrobial efficacy testing. Visualization of the coating was carried out using a water-soluble bromophenol blue stain, which forms an ionic pair with the quaternary ammonium cation present at the surface (Figure 9). One consideration is that this interaction between anionic dye and cationic QAC coating is not exclusive to 
bromophenol blue. For surface charge analysis, fluorescein dye is used instead of bromophenol blue dye and is found to dye the sample surface orange. Likewise, dichlorofluorescein has also been successfully used and was found to stain the sample pink.

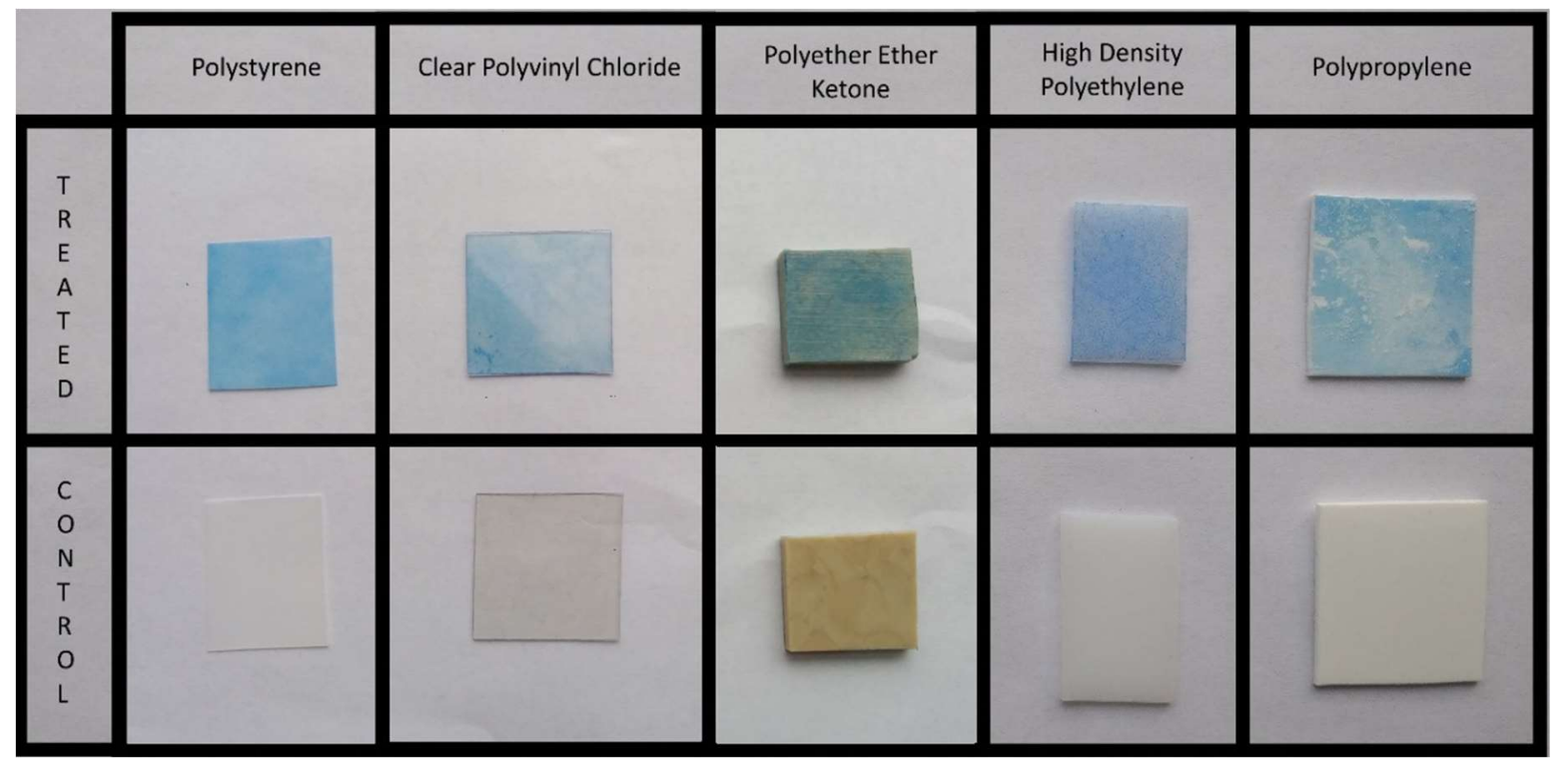

Figure 9 - (A) Treated and untreated surfaces stained with bromophenol blue dye.

(A) The robustness of the immobilized coating 1a to withstand routine chemical disinfection and mechanical washing was then evaluated. Bromophenol blue stained samples were vigorously washed or vortexed in a detergent solution of cetyltrimethyl ammonium bromide (CTAB). While the cationic surfactant did remove the staining agent, re-staining with bromophenol blue after the CTAB wash confirmed that the coating was still present. This test was also performed using a saturated salt solution dissolved into isopropanol and found similar destaining/restaining results. Using a polypropylene fabric sample, the antimicrobial solution was supplemented with a trace $(\sim 0.01 \% \mathrm{w} / \mathrm{v})$ amount of the dansyl fluorophore 12a prior to electrospraying, was employed to help visualize the antimicrobial coating via epifluorescent 
microscopy (Figure (A) 18). Successive water rinses failed to remove the fluorophore from the coated surface, indicating that the compound has been successfully immobilized upon UV curing.

\subsection{Surface Wettability, Plasma Pre-treatment, and Coating Adhesion}

(B) Several tests were performed to confirm the qualities and characteristics of each antimicrobial coated sample, including dye stain exposure, contact angle, and surface charge measurements. Antimicrobial coated surface quality on polystyrene samples was investigated by advancing contact angle measurements to determine surface wettability (Table 4). Sulfa QAC treated materials 3a-6a displayed an advancing contact angle between $47.6^{\circ}$ and $61.0^{\circ}$ after application of two coats, which is significantly lower than untreated polystyrene $\left(91^{\circ}\right)$, but similar to the long chain QAC 1a $\left(56.7^{\circ}\right) .{ }^{1}$ For the partially-fluorinated sulfa QAC treated materials 9a10a, the advancing contact angle was notably higher $\left(73.9^{\circ}\right.$ and $\left.66.7^{\circ}\right)$ than non-fluorine containing sulfonamide QACs, but in a similar range to the value reported for the attached benzophenone antimicrobial on glass developed by Locklin et al. ${ }^{54}$ The presence of the quaternary ammonia moiety within the sulfa QACs increase the wettability of these surfaces, while being partially offset by the relative hydrophobicity of the tail moiety. 
Table 4 - (B) Advancing contact angle and surface charge measurements of sample materials.

\begin{tabular}{|c|c|c|c|}
\hline Sample & $\begin{array}{c}\text { Advancing contact angle } \\
\left({ }^{\circ}\right)\end{array}$ & $\begin{array}{l}\text { Charge density } \\
\qquad\left(\left[\mathrm{N}^{+}\right] \mathrm{nm}^{-2}\right)\end{array}$ & Reference \\
\hline Control PS & $91.7 \pm 1.0$ & N/A & 1 \\
\hline 1a on PS (2 coats) & $56.7 \pm 1.9$ & $120 \pm 18$ & 1 \\
\hline 3a on PS & $60.4 \pm 4.9$ & $7.3 \pm 0.9$ & 2 \\
\hline 4a on PS & $51.1 \pm 6.5$ & $22 \pm 6.6$ & 2 \\
\hline $5 \mathbf{a}$ on PS & $61.0 \pm 1.6$ & $24 \pm 0.7$ & 2 \\
\hline 6a on PS & $47.6 \pm 0.6$ & $3.5 \pm 1.0$ & 2 \\
\hline 9a on PS & $73.9 \pm 2.1$ & $19 \pm 3.7$ & 2 \\
\hline 10a on PS & $66.7 \pm 4.2$ & $15 \pm 6.8$ & 2 \\
\hline $\mathrm{Br}^{\ominus}$ & 69 & 35.7 & 49 \\
\hline on glass & & & \\
\hline
\end{tabular}

(B) To compliment the contact angle data, the charge densities of the sulfa QAC antimicrobials were determined indirectly using UV-Vis spectroscopy (Table 4). As outlined by Kugler et al. ${ }^{94}$ this technique involves complexing an anionic dye with the quaternary ammonium cation present on the surface of antimicrobial coatings. After saturating the coating surface in a fluorescein dye solution over a $24 \mathrm{~h}$ period and rinsing with distilled water, the bound dye 
molecules were detached by washing the stained samples in a $\mathrm{pH}-$ balanced cationic solution. The solution can then be analysed using a spectrometer to determine dye concentration, which correlates to the number of exposed charges present on a coated sample. Comparing the surface charge and contact angle data values, there appears to be no correlation between the two factors. This could be due to the restricted accessibility of bulky anionic dye molecules to the cationic charges contained within the coated material, or to types of grafted surface structures formed through the coating and curing process. This could also explain the relatively low surface charges of sulfa QACs compared to those found in our previous studies, ${ }^{1}$ as well as those reported by Locklin $^{49}$ and Murata. ${ }^{55}$ Therefore, the significance of meeting a certain threshold of surface charge as established in previous studies may not be as significant with sulfa QACs, since microbiological testing performed with these materials exhibit similar antimicrobial properties.

(A) Advancing water contact angles of surfaces that were repeatedly coated and cured with 1a were also compared. These tests show that the initial UV-cured coating had a notable effect on the contact angle, changing from an average of $91.7^{\circ}$ for the control polystyrene sample to $63.4^{\circ}$ for a single coat. For the subsequent coating layer, the change in contact angle is less dramatic, dropping an additional $8^{\circ}$ and then remains essentially unchanged with the addition of a third layer (Table 5). Surface charge density measurements of polystyrene samples indicated a high charge value associated with coated materials. Charge density increased as further coating and curing steps are performed corresponding to an increase in the quantity of $\mathbf{1 a}$ applied to the plastic substrate. 
Table 5 - (A) Properties of surface attached benzophenone antimicrobials.

\begin{tabular}{l|ccc} 
Sample & $\begin{array}{c}\text { Advancing contact angle } \\
\left({ }^{\circ}\right)\end{array}$ & $\begin{array}{c}\text { Charge density } \\
\left(\left[\mathrm{N}^{+}\right] \mathrm{nm}^{-2}\right)\end{array}$ \\
\hline Control PS & $91.7 \pm 1.0$ & $\mathrm{~N} / \mathrm{A}$ & 1 \\
\hline 1a on PS (1 coat) & $63.4 \pm 2.5$ & $67 \pm 6.0$ & 1 \\
\hline 1a on PS (2 coats) & $56.7 \pm 1.0$ & $120 \pm 18$ & 1 \\
\hline 1a on PS (3 coats) & $57.8 \pm 1.5$ & $200 \pm 42$ &
\end{tabular}

*All reported values measured in triplicate

\subsection{XPS and ToF-SIMS analysis}

(A) To further quantify alkyl QAC coating quality and composition, XPS analysis (Table 6) was performed on CPVC samples UV-coated with compound 1. For comparative analysis of the binding energy peaks relating to the carbon content of the sample (Figs $\mathrm{S}+-\mathrm{S}+$ ), a larger $\mathrm{C} 1 \mathrm{~s}$ A $(286.6 \mathrm{eV})$ peak $^{95}$ was detected for the treated sample compared to the untreated control. This is likely a result of an increase in the quantity of carbon-oxygen bonds found present at the coating survey site. For the XPS peak analysis relating to nitrogen content of the treated and control samples, two peaks relating to N1s $(402.5 \mathrm{eV})$ and N1s A $(400.0 \mathrm{eV})$ exhibit large increases (Figure 10) over the control sample. ${ }^{96}$ The larger N1s A peak corresponds to an increase in carbonnitrogen bonding, while the N1s peak corresponds to an increase in cationic nitrogen present within the sample. ${ }^{97}$ When comparing elemental analysis data obtained via XPS, there is a $46 \%$ increase in atomic concentration at the sample surface. This was a significant increase in nitrogen at the material surface, considering 1a would consist of $2.27 \%$ nitrogen as determined from the empirical formula. Although a pure polystyrene sample would be devoid of nitrogen content, the initial appearance of 0.35 atomic concentration of nitrogen on the control sample was regarded as 
contamination of the PS sample, either by adsorption of atmospheric nitrogen during its lifespan or by its inclusion during plastic fabrication.

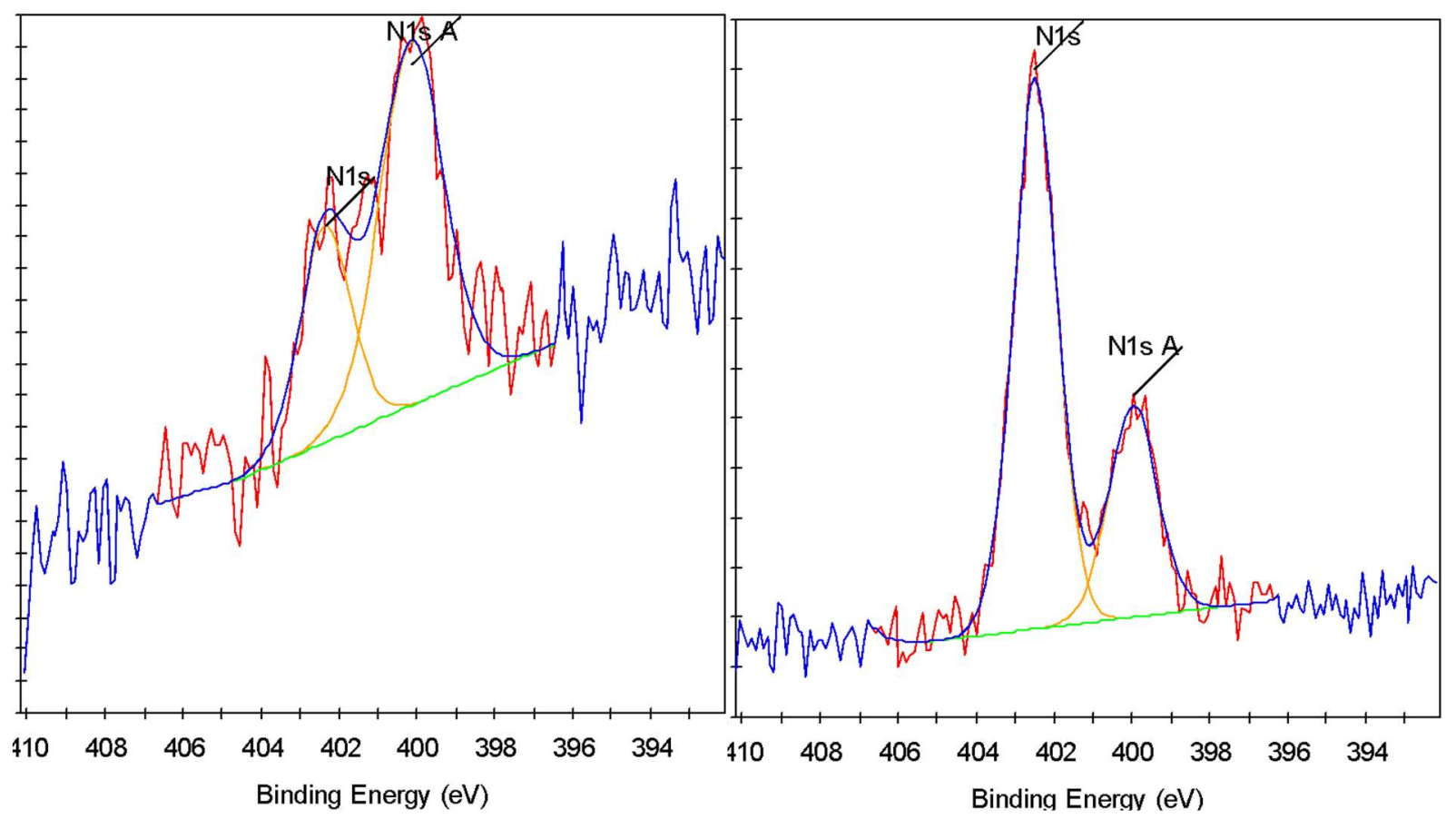

Figure 10 - (A) XPS data corresponding to the nitrogen content for the control (left) and 1a coated (right) PS samples.

Table 6 - (A) Select XPS survey data for control and UV-coated CPVC samples of 1a.

\begin{tabular}{l|ccc} 
Sample & Element & Atomic Concentration & Sensitivity Factor \\
\hline Control CPVC & C1s & 77.16 & 1.000 \\
Control CPVC & N1s & 0.35 & 1.800 \\
CPVC Treated with 1a & C1s & 84.24 & 1.000 \\
CPVC Treated with 1a & N1s & 1.46 & 1.800
\end{tabular}


(B) Similarly, XPS was also performed to determine the quality and composition of sulfa QAC-treated CPVC sample compared to an untreated control (Table 7). A comparative XPS analysis between the 5a coated sample and the untreated control showed that that there were three significant variations in binding energy peak intensities relating to the carbon, nitrogen and sulfur content (Figure 11). With relation to the carbon content, there is a significant decrease (3.99\%) in carbon present on the coated sample surface compared to the control material, which corresponds to a proportional increase of other elements located within the coating material. There is also an increase in the size of the $\mathrm{C} 1 \mathrm{~s} \mathrm{~A}(286.6 \mathrm{eV})$ peak, which indicates the presence of carbon-oxygen ether bond of the benzophenone moiety of $\mathbf{5 a} \cdot{ }^{95}$ Comparisons of the nitrogen content between the two samples showed a notable increase of $0.91 \%$ on the treated samples. This increase is seen through the rise of the N1s $(402.5 \mathrm{eV})$ and N1s A $(399.9 \mathrm{eV})$ peaks, which correspond to the presence of cationic nitrogen and carbon-nitrogen bonding within the sample coating. ${ }^{96}$ There is also a $0.31 \%$ increase in sulfur content found upon the coated samples, similar in significance and scale to the increase of nitrogen content. 

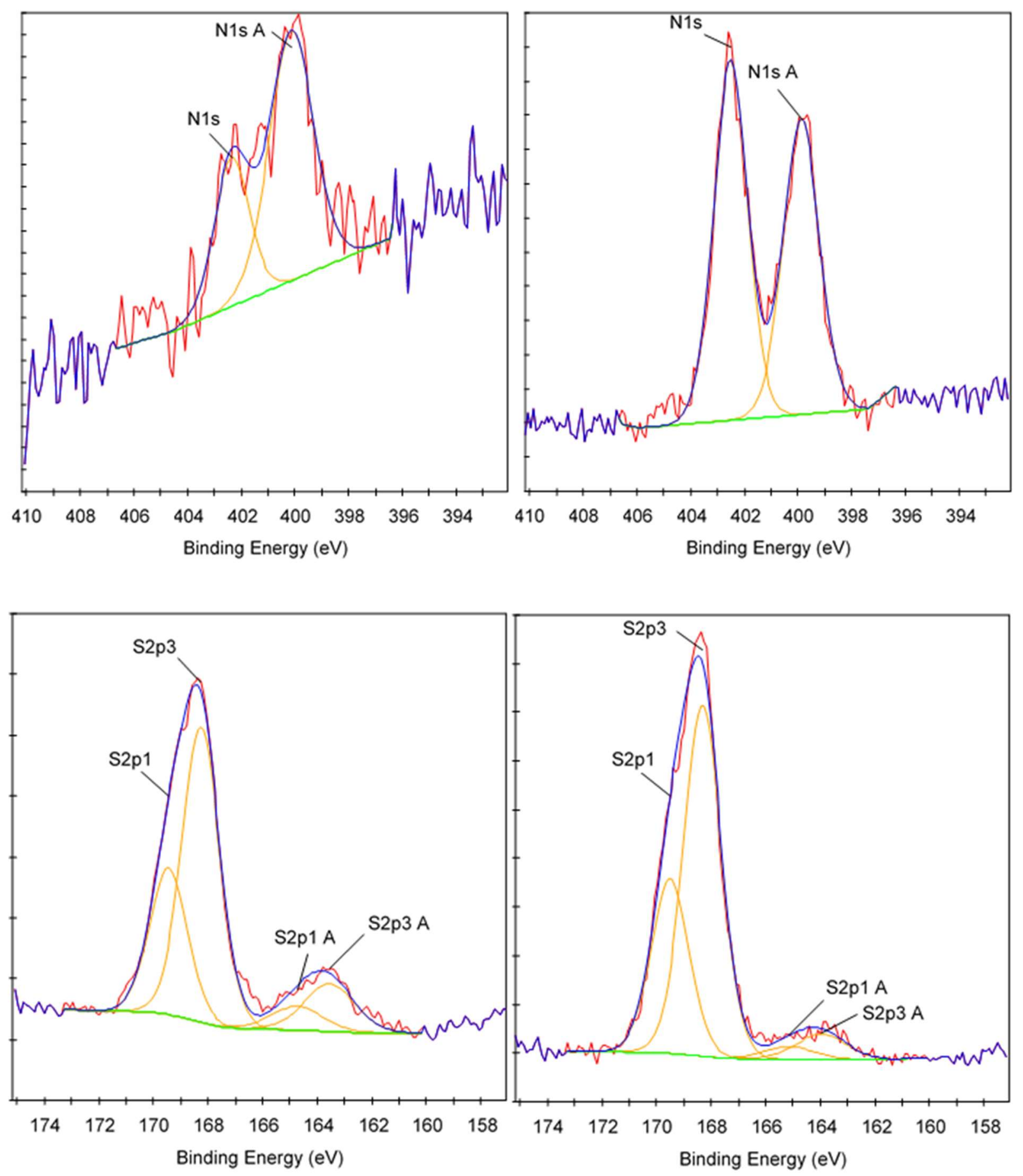

Figure 11 - (B) XPS data corresponding to the nitrogen content (top) and sulfur content (bottom) for control (left) and 5a treated (right) CPVC samples. 
Table 7 - (B) Select XPS survey data for control and 5a treated CPVC samples.

\begin{tabular}{l|ccc} 
Sample & \multicolumn{1}{c}{ Element } & Atomic Concentration & Sensitivity Factor \\
\hline Control CPVC & C1s & 77.16 & 1.000 \\
\hline Control CPVC & N1s & 0.35 & 1.800 \\
\hline Control CPVC & S2p & 0.93 & 1.670 \\
\hline 5a treated CPVC & C1s & 73.17 & 1.000 \\
\hline 5a treated CPVC & N1s & 1.84 & 1.800 \\
\hline 5a treated CPVC & S2p & 1.24 & 1.670
\end{tabular}

(A) To compliment the XPS data collected for surface characterization, time-of-flight secondary ion mass spectrometry (ToF-SIMS) was performed on treated and control CPVC samples (Figure 12). ${ }^{98}$ For this experiment, data collection was performed on a $0.25 \mathrm{~mm}^{2}$ sample area using bismuth $\left(\mathrm{Bi}_{3}{ }^{2+}\right)$ as the primary ion source. Positive and negative ion fragmentation patterns of the treated and control surfaces were analyzed. From the data obtained during ToFSIMS imaging, fragments peaks relating to benzoylphenolate, tetracarbonyl ammonium and brominium ions are present on the treated sample. These peaks are consistent with the composition of 1a and would be expected during negative ion fragmentation, considering the key functional groups used to form benzophenone-anchored QAC antimicrobials. Since bromine is unique to 1a 
and absent from the CPVC substrate, it can be used to estimate the total coverage of treated sample and this was found to be around $84 \%$, as determined using ImageJ measurement software. ${ }^{99}$

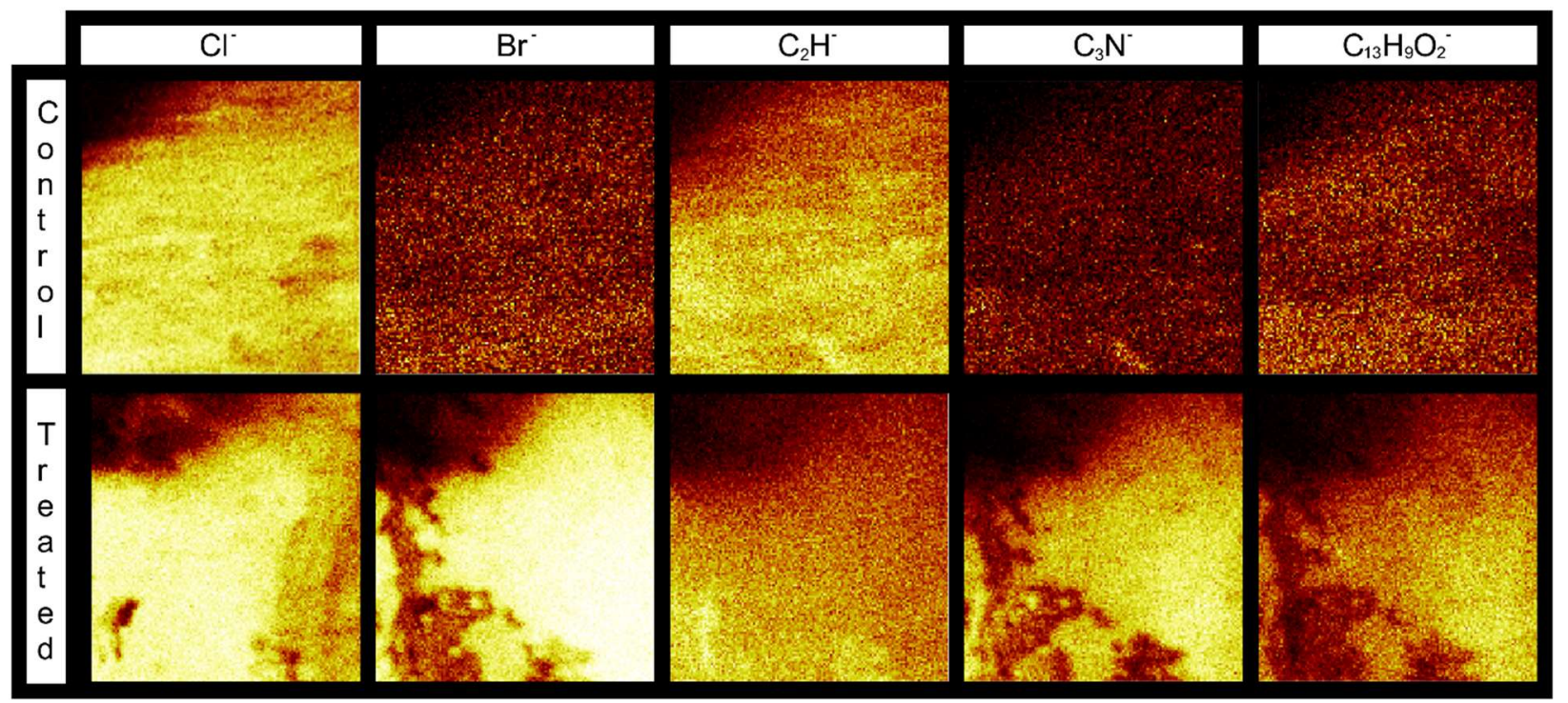

Figure 12 - (A) Composite negative ion ToF-SIMS image of $500.0 \times 500.0 \mu \mathrm{m}$ section of control and 1a treated samples. Intensity is a function of fragment quantity during analysis. Images correspond to negative ionic fragmentation products of chlorine $\left(\mathrm{Cl}^{-}\right)$, bromine $\left(\mathrm{Br}^{-}\right)$, ethane $\left(\mathrm{C}_{2} \mathrm{H}^{-}\right.$ ), tetracarbonyl ammonium $\left(\mathrm{C}_{4} \mathrm{~N}^{-}\right)$, and hydroxybenzophenone $\left(\mathrm{C}_{13} \mathrm{H}_{9} \mathrm{O}_{2}{ }^{-}\right)$.

(B) ToF-SIMS was also performed on 5a treated and control CPVC samples (Figure 13) to identify and correlate changes in surface structure as related to specific fragments of surface material. ${ }^{98}$ From positive and negative ion fragmentation patterns analyzed from sample materials, the presence of benzoylphenolate, tetracarbonyl ammonium and bromide ions were determined to exist on the treated surfaces and are consistent with the composition of 5a. Through the graphical analysis of ionic fragments found exclusively upon the treated sample, the coating appears to form a relatively irregular patterned surface with 40-80 $\mu \mathrm{m}$ hemi-spherical structures. Interestingly, 
there also appears to be small $20 \mu \mathrm{m}$ diameter structures present when analyzing the 5a coated surface for benzoylphenolate, indicative of the benzophenone moiety used to anchor the compound to the CPVC surface.

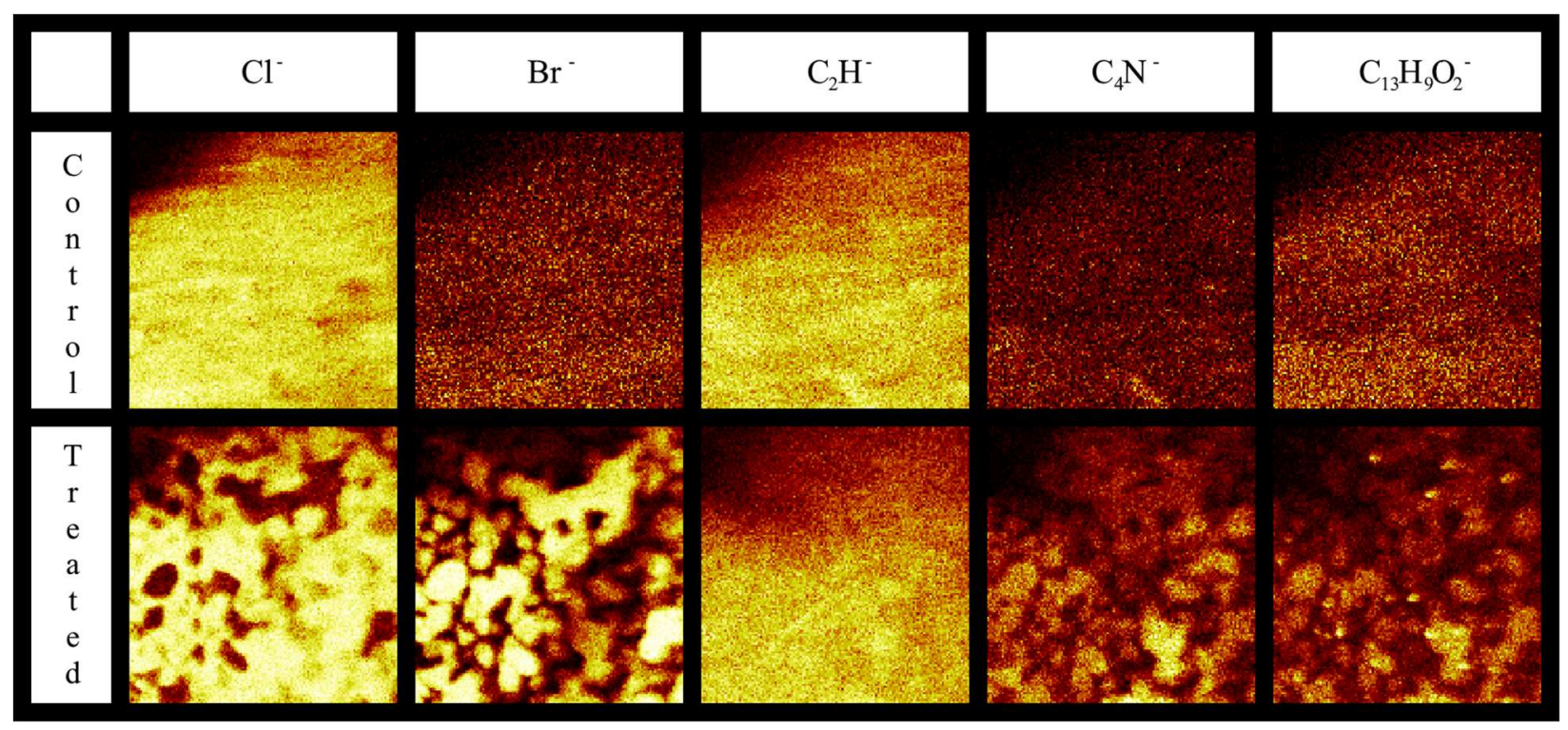

Figure 13 - (B) Composite negative ion ToF-SIMS image of $500.0 \times 500.0 \mu \mathrm{m}$ section of control and 5a treated samples. Intensity is a function of fragment quantity during analysis. Images correspond to negative ionic fragmentation products of chlorine $\left(\mathrm{Cl}^{-}\right)$, bromine $\left(\mathrm{Br}^{-}\right)$, ethane $\left(\mathrm{C}_{2} \mathrm{H}^{-}\right.$ ), tetracarbonyl ammonium $\left(\mathrm{C}_{4} \mathrm{~N}^{-}\right)$, and hydroxybenzophenone $\left(\mathrm{C}_{13} \mathrm{H}_{9} \mathrm{O}_{2}{ }^{-}\right)$.

\subsection{AFM and SP analysis}

(A) In-depth surface characterization and structural analysis of a 1a coated polystyrene sample was also performed using AFM and SP. To provide surface thickness data, the sample was partially covered using adhesive tape (Scotch $3 \mathrm{M}{ }^{\circledR}$ ) prior to the coating and curing steps. After treatment, the tape was removed, and the surface was vortexed for 1 min in distilled water to remove any excess coating material and tape residue. This produced a partially-treated sample for 
analysis. AFM was performed at three locations found along the separation line of the partially coated sample. Coating thickness was determined taking the height differences between the coated and non-coated areas of the sample surface. To limit the impact of coating damage that occurred during tape removal, height measurements were taken at least $15 \mu \mathrm{m}$ away from the highest point found along the edge of the coated half of the sample.

(A) The average coating thickness of a sample coated with two treatments of $\mathbf{1 a}$ is $366 \pm$ $148 \mathrm{~nm}$, which translates to a height of $\sim 80$ molecules stacked end to end (Figure 14, Table 8). This suggests that multiple layers of coating are applied during each coating and curing step, which presumably immobilizes the antimicrobial to the plastic substrate, as well as extensive grafting of molecules. With regards to data collected by Locklin et al., ${ }^{92}$ these coating thickness values obtained are $\sim 9$ times greater, and correlates to an increased charge density value. To confirm accuracy of AFM measurements, SP was also performed on a $500 \mu \mathrm{m}^{2}$ section along the separation line of the partially-treated sample.

(A) Coating structural features were also determined by imaging areas found to be completely within the treated and untreated portions of the samples. These images were obtained at locations $>50 \mu \mathrm{m}$ away from the separation line formed by tape removal. The control sample image indicates a relatively smooth surface with a maximum height variation of $\sim 48 \mathrm{~nm}$. The PS treated sample image reveals a significantly rough, random surface. Although these ridges are less structured and generally larger than the antimicrobial nanopili found on the surface of dragonfly wings $(\sim 200 \mathrm{~nm})$, there are a number of smaller ridges that are similar in size. ${ }^{57}$ The large variations in ridge height would also correspond to an increased effective surface area when compared to a flat coating and would manifest itself as a higher surface charge density. 

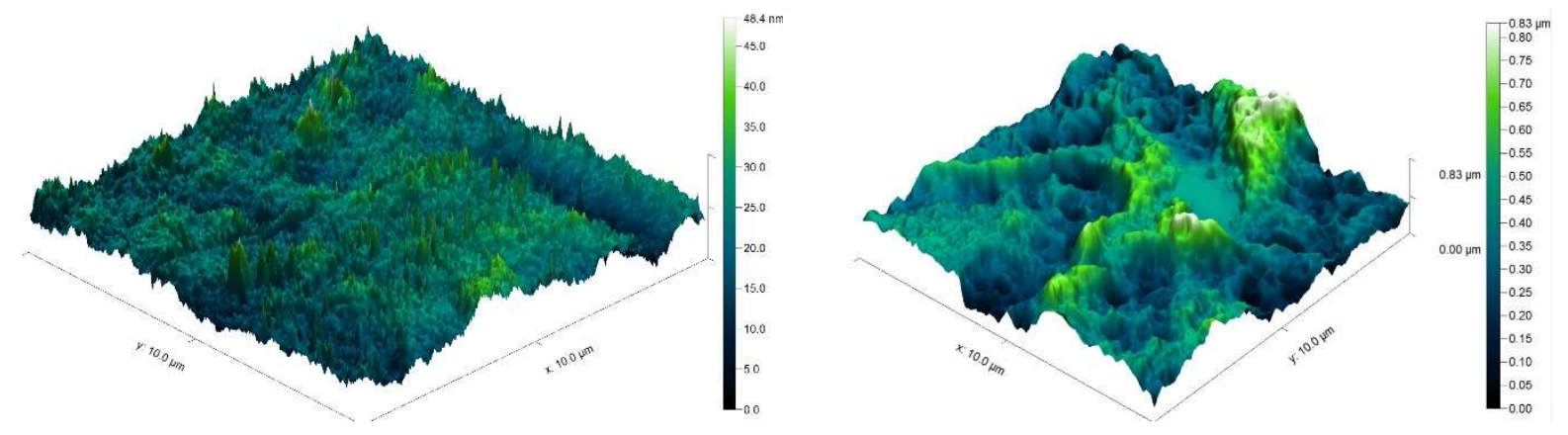

Figure 14 - (A) AFM images of PS control (left) and $\times 2$ Coating of 1a on PS (right).

(B) To ascertain additional details regarding the coating thickness (Table 8) and structure of sulfa QAC treated materials, AFM (Figures 15-16) and SP (Figures (B) 18-19) were performed on 5a and 10a treated PC coupons. Samples were similarly prepared by masking a section of the sample surface with an adhesive tape (Scotch $3 \mathrm{M} \AA$ ) prior to treatment, followed by a water rinse after tape removal to remove any adhesive residue. The coating thickness of sulfa QACs (5a, 10a) on PC samples (Table 9) is considerably thinner than those found previously for the long-chain alkyl QAC 11, which could relate to differences in compound solubility. ${ }^{1}$ When analyzing the images created from contact-mode AFM scanning on 3a treated PC plastic, the most strikingly apparent detail involved the roughness of the coated surface when compared to the relatively smooth control material. From the $10 \mu \mathrm{m}^{2}$ image from Figure 15, numerous peaks and valleys which have a maximum height difference around $\sim 0.15 \mu \mathrm{m}$ can be found scattered across the surface. Collectively, these features provide a root mean square (RMS) roughness measurement of $\sim 20 \mathrm{~nm}$ for a 3a coated surface, compared to $\sim 4 \mathrm{~nm}$ for the control. 

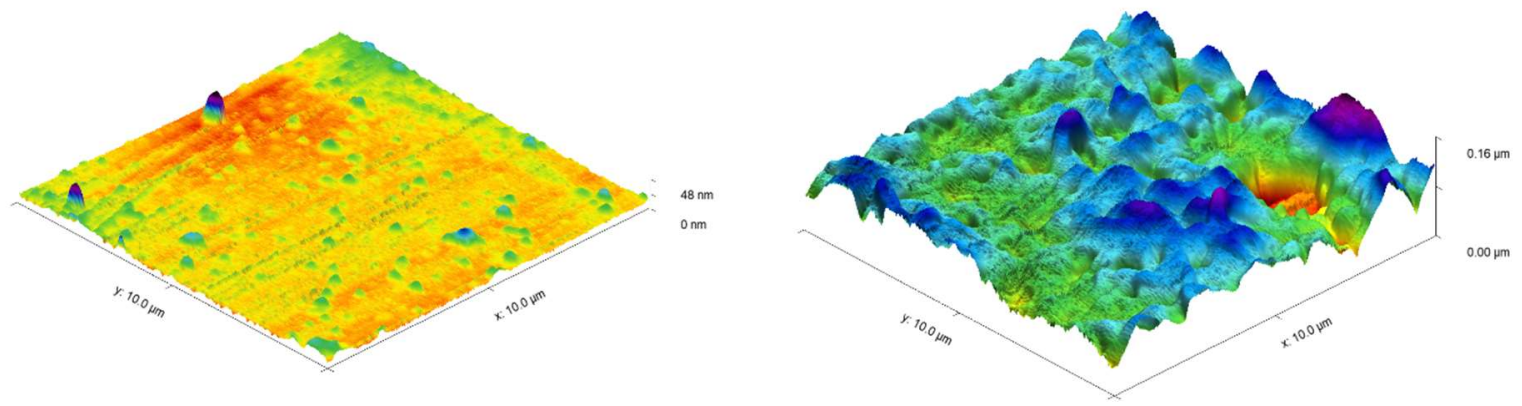

Figure 15 - (A) AFM images of PC control (left) and 5a treated PC (right).

(B) For analysis of 10a treated PC material, tapping-mode AFM was required to obtain a surface image since there was powerful deflection of the cantilever probe when trying to position the disengaged probe head over the coated surface. The image obtained (Figure 16) shows a similar change in surface coarseness, providing a RMS roughness value of $\sim 51 \mathrm{~nm}$, but was found to have smoother plateau regions followed by sharp pits and valleys.
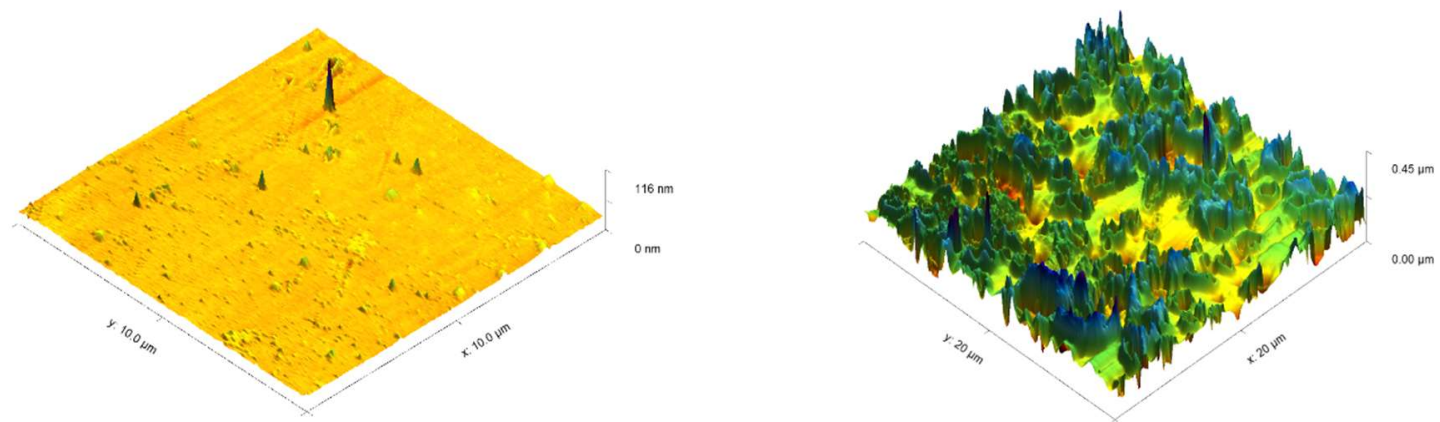

Figure 16 - (B) AFM images of PC control (left) and 10a treated PC (right). 
Table 8 - Thickness measurements of surface-attached benzophenone antimicrobials. ${ }^{1,2}$

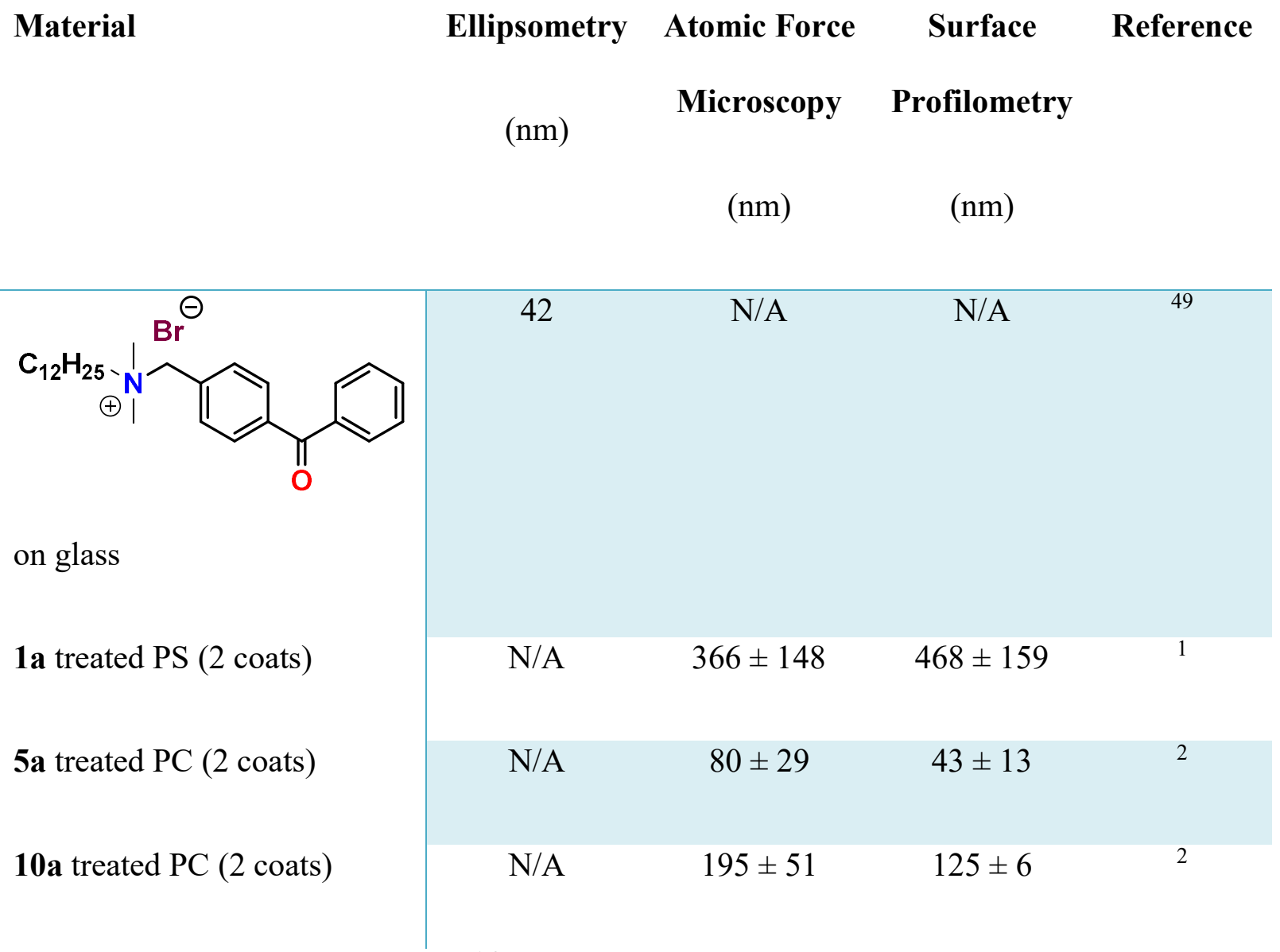

* Results collected from references ${ }^{1,2}$ were taken at three separate sample points. 


\subsection{Antimicrobial Treatment Biotesting at Solid/Air Interfaces (LDI method)}

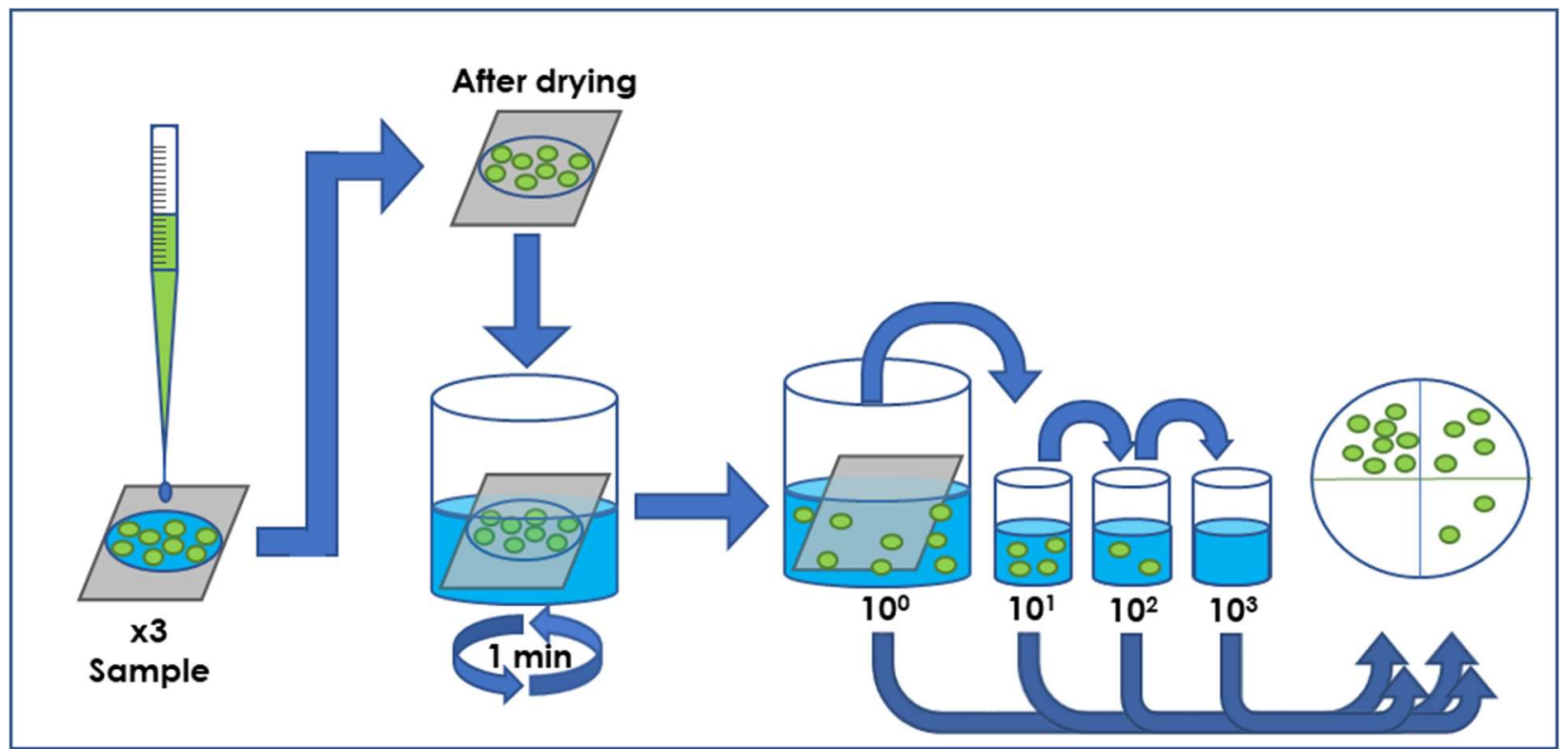

Figure 17 - (B) Visual representation of the large droplet inoculum (LDI) procedure.

(A) To ascertain and compare the survival of selected bacterial species when exposed to a QAC-based antimicrobial coating, the large droplet inoculation (LDI) method was performed on treated and control test samples previously prepared using the stated methods. The LDI method was developed and used previously by Wolfaardt et al. for the examination of biofilm-producing microorganisms on solid surfaces, ${ }^{82,83,100}$ although the origin of this technique has roots in the study of how humidity and desiccation affect the survival of microbes such as Yersinia pestis, ${ }^{101}$ methicillin resistant Staphylococcus aureus, ${ }^{10}$ Acinetobacter baumannii, ${ }^{102,103}$ and other pathogenic microbial strains. ${ }^{104,105}$ The LDI method (Figure 17) relies on the deposition of a droplet containing a consistent relative quantity of viable cells onto the desired test surface, and allowing the inoculated sample to completely dry within a sterile environment. The desiccated samples are then collected and vortexed for one minute with an isotonic saline solution to remove 
any adherent cells, allowing for the optimal recovery of previously inoculated cells.$^{83}$ The resulting collection fluid is then serially diluted and plated on an appropriate growth media and incubated accordingly, allowing for the enumeration of viable colony forming units.

(A) The LDI method was developed to simulate real-world conditions that result in the deposition of concentrated bacteria onto available material surfaces, while also providing a consistent and reproducible approach across multiple sample materials. ${ }^{83}$ This method best represents the deposition of aerosol- and droplet-suspended microbial organisms, which have long been considered a primary method for pathogenic transmission. This, in turn, has influenced aerosol reduction methods, ${ }^{15}$ standard biology practices and procedures, ${ }^{106}$ and healthcare and institutional design choices. ${ }^{15,16,107}$ This is in comparison to ISO 22196/JIS Z 2801 and ASTM E2149, which are commonly used standard procedures when assessing antimicrobial activity on material surfaces. ${ }^{58}$ The ISO 22196:2011 and the closely related JIS Z 2801:2010 methods rely on covering the inoculated microbial samples with a cover slip. This cover slip keeps the inoculated surface consistently wet and is less likely to simulate one where a microbe-containing droplet has landed and dried out. The ASTM E2149 procedure operates by dynamically shaking samples within an inoculated buffered solution. This method also relies on solid-liquid mediated interactions between material and microbes, but can lead to biased results from material leachates, biofilm growth on and within test materials and does not force cells directly into contact with the material surface..$^{58}$

(A) To increase the consistency and reduce environmental variability between test samples, factors such as growth phase and nutrient availability were carefully established. To control for growth factors and lifecycle, broth cultures were grown to the late exponential phase, occurring 16-18h after broth inoculation. ${ }^{83}$ For nutrient control, the cultured cells were washed twice with 
sterilized tap water to remove nutrients, and to limit experiment-imposed osmotic shock while desiccating. The LDI method also provides a more consistent measure of bacterial inoculation when compared to spray inoculation tests, as spray-based techniques rely on random droplet placement onto coated, control and other areas not accounted for during analysis within the spray chamber. ${ }^{58,85,108}$ Additional benefits of using a large droplet over an aerosol spray includes the known application of a greater number of cells to a sample surface, ${ }^{58,82,85}$ increased cell viability during desiccation, ${ }^{83,100}$ and a reduced the potential for accidental exposure to pathogeniccontaining aerosols during testing. ${ }^{106}$

(A) For these tests, three bacterial strains were used for the evaluation of test samples. The first was an airborne bacterial isolate of Arthrobacter species (IAI-3) used to provide a model organism for microbiological testing when comparing bacterial survival on treated and control samples. The Arthrobacter genus represents a Gram-positive, weakly-motile, non-sporulating bacteria commonly found in soil. ${ }^{109}$ This strain was isolated by Wolfaardt et al. for the purpose of studying non-aqueous biofilms and interspecies interactions during biofilm formation, and is notable for its ability to resist desiccation at room temperature. ${ }^{82,83,100}$ With the additional demonstrated inability to form spores, and preferred growth temperature of $20-30^{\circ} \mathrm{C}$, results obtained using IAI-3 are highly representative of general solid-air interactions since these factors prevent any impact on viability of these cells during testing. P. aeruginosa (PAO1) was another bacterial species used to determine whether QAC-coated plastic surfaces could effectively kill Gram-negative bacteria. This species is of medical importance and has been studied extensively for its ability to produce biofilms, cause secondary hospital infections and resist antimicrobial agents. ${ }^{11,16,17,85,107}$ Listeria monocytogenes (Scott A), a facultative anerobic Gram-positive bacterial species and an important food borne pathogen, was also investigated. This bacterial strain 
is a clinical isolate retrieved during a 1983 listeriosis outbreak in Massachusetts, and has been well characterized and widely used for testing in food and healthcare related industries. ${ }^{110}$

(A) The Gram-positive indoor air isolate Arthrobacter sp. was used as a representative member of the indoor bacterial flora, members of which continuously undergo deposition from the air onto exposed surfaces. While these species may not be dangerous to healthy individuals, they can lead to infection in patients with a compromised immune system, and are also able to protectively provide niches in which exogenous pathogens in the hospital environment survive. ${ }^{83}$ Arthrobacter sp. survival was tested on several clinically relevant plastics, and in each case, no surviving cells were detected on the coated surfaces, while the uncoated control surfaces still contained high cell counts (log 4-6 CFU) even $24 \mathrm{~h}$ after inoculation and drying (Figure 18). Antimicrobial efficacy on treated PEEK plastic is of interest since it is often used in medical implants due to its high resistance to chemical and physical stress. 


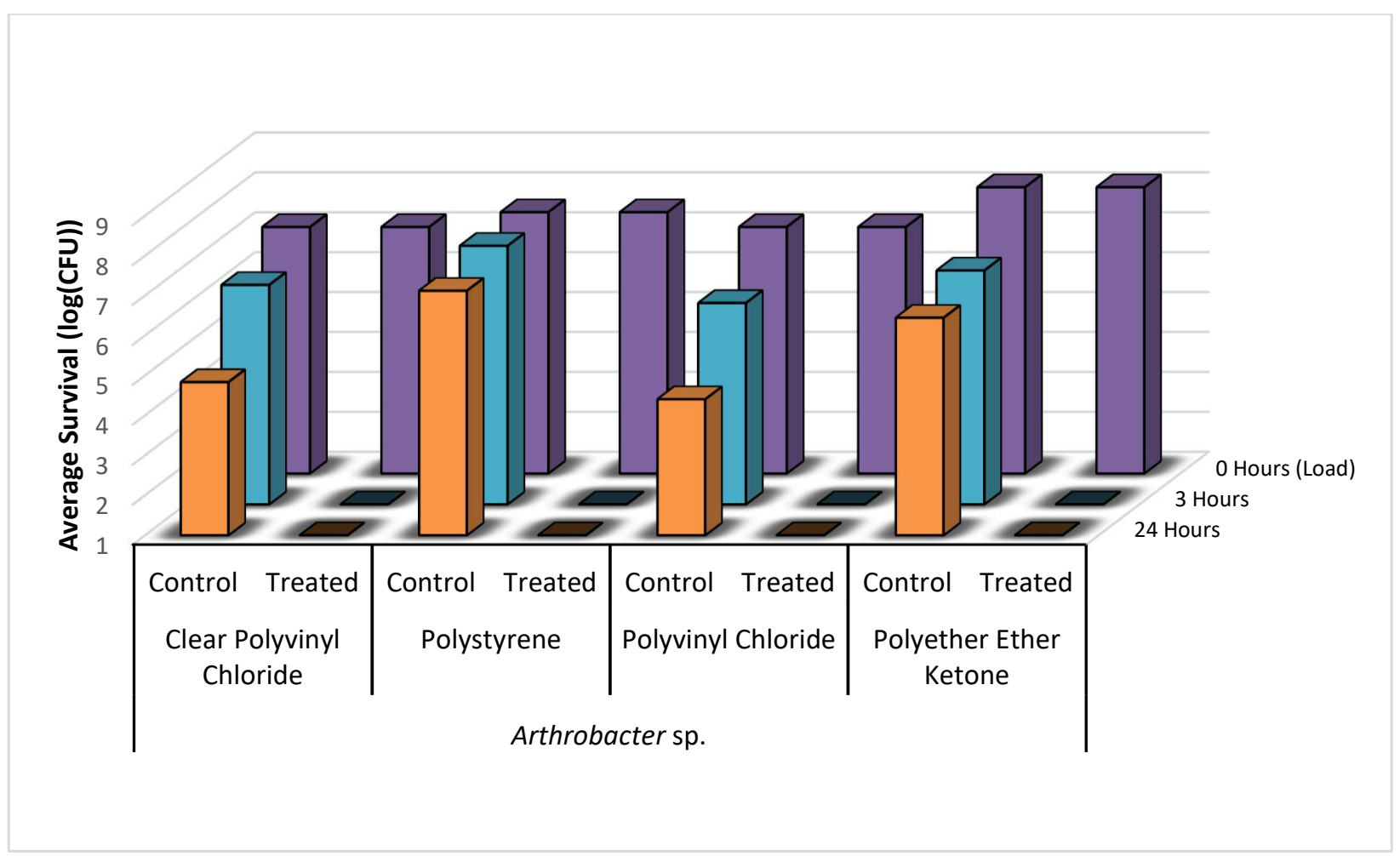

Figure 18 - (A) Survivability of Arthrobacter sp. when inoculated onto a variety of $\mathbf{1 a}$ treated and control sample materials. The measurement at $0 \mathrm{~h}(\log 7 \mathrm{CFU})$ indicated the initial number of bacterial cells being inoculated onto the surface material and was determined concurrently to inoculation $(n=3)$.

(A) The coating was also tested against two bacteria strains which are often implicated in HCAI infections. The Gram-negative P. aeruginosa and Gram-positive L. monocytogenes were unable to survive after $3 \mathrm{~h}$ when inoculated onto coated CPVC surfaces (Figure 19). The effectiveness of the compound against both Gram-positive and Gram-negative bacterial species suggests that the treated surfaces are non-selective. 


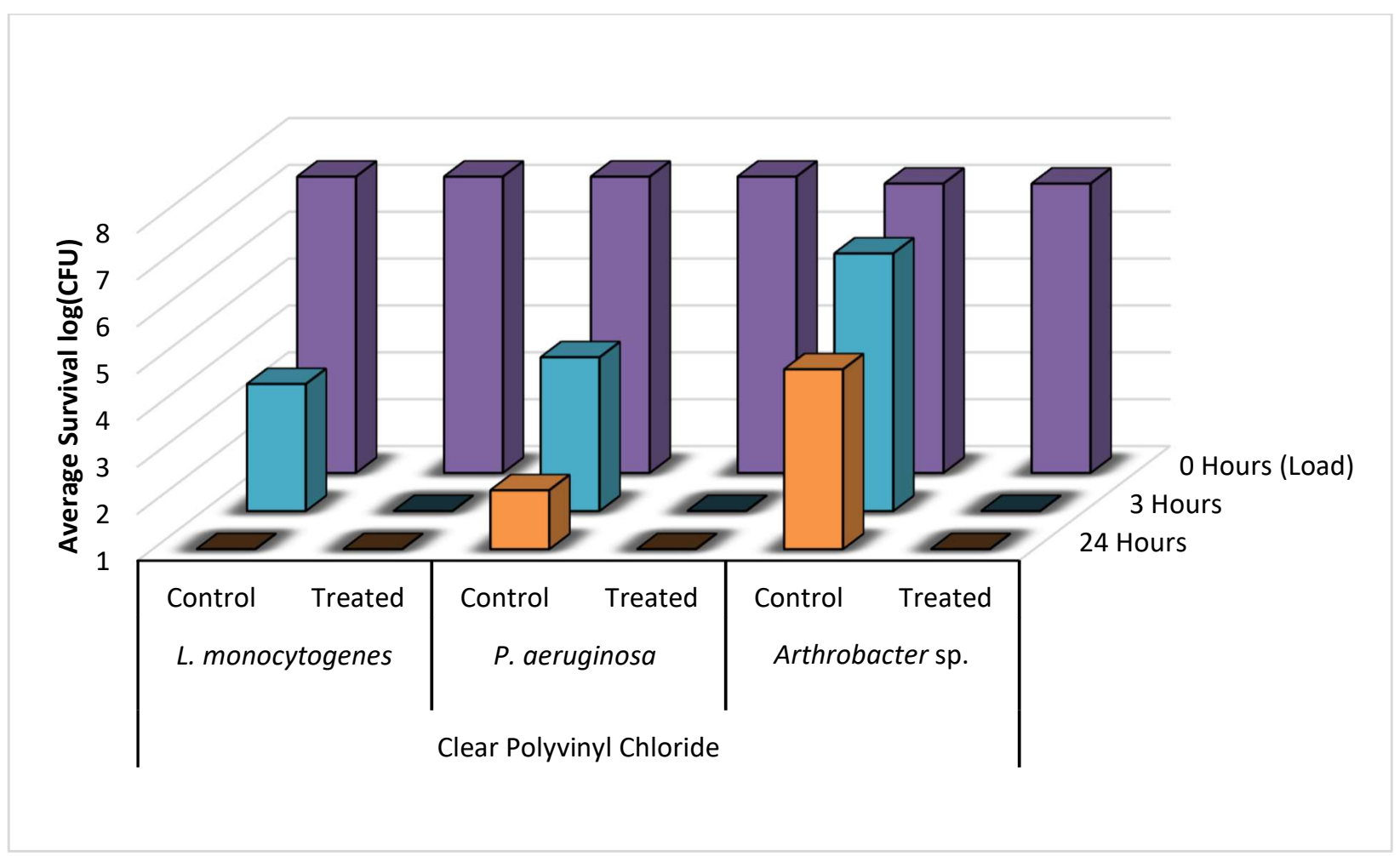

Figure 19 - (A) Survivability of L. monocytogenes, P. aeruginosa and Arthrobacter sp., when inoculated onto QAC-treated (1a) and control samples of CPVC $(\mathrm{n}=3)$.

(A) When subjected to the same antimicrobial testing methods mentioned above, compound 1a exhibited similar antimicrobial properties to that of materials coated with compound 2a (Figure 20). 


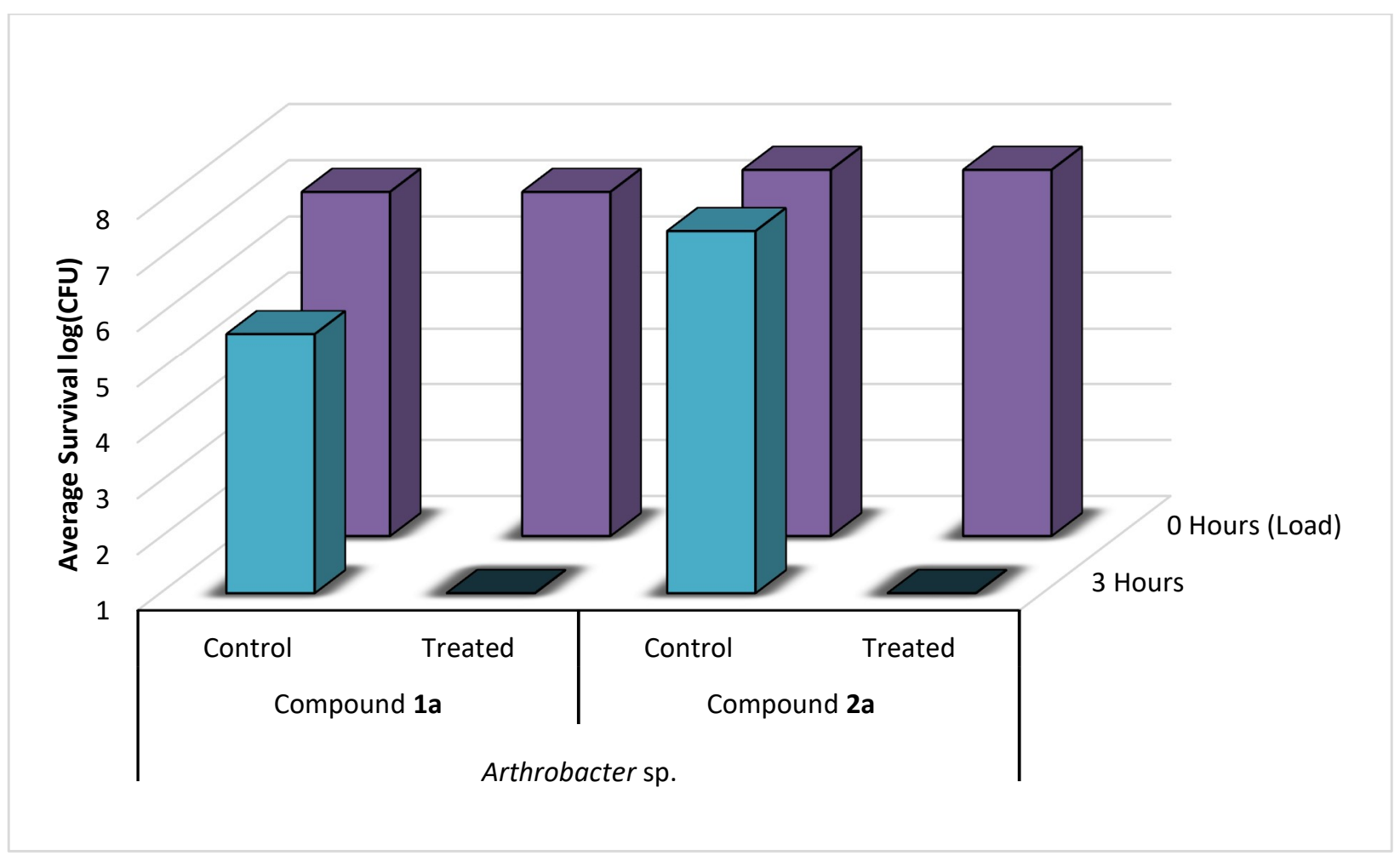

Figure 20 - (B) Survivability of Arthrobacter sp. when inoculated onto a variety of $\mathbf{1 a}$ and $\mathbf{2 a}$ treated and control samples $(\mathrm{n}=3)$.

(B) The viability and effectiveness of treating non-porous polymer surfaces with benzophenone-anchored sulfa QACs, 3a-7a, were also investigated using the LDI biotesting procedure. ${ }^{1,83}$ Treated samples were tested in triplicate against an uncoated set of controls by inoculating each sample with a subsequently determined microbial cell load and allowing the samples to dry under sterile conditions. The results of these tests (Figure 21) show promising antimicrobial activity against the Gram-positive representative species, Arthrobacter sp. 


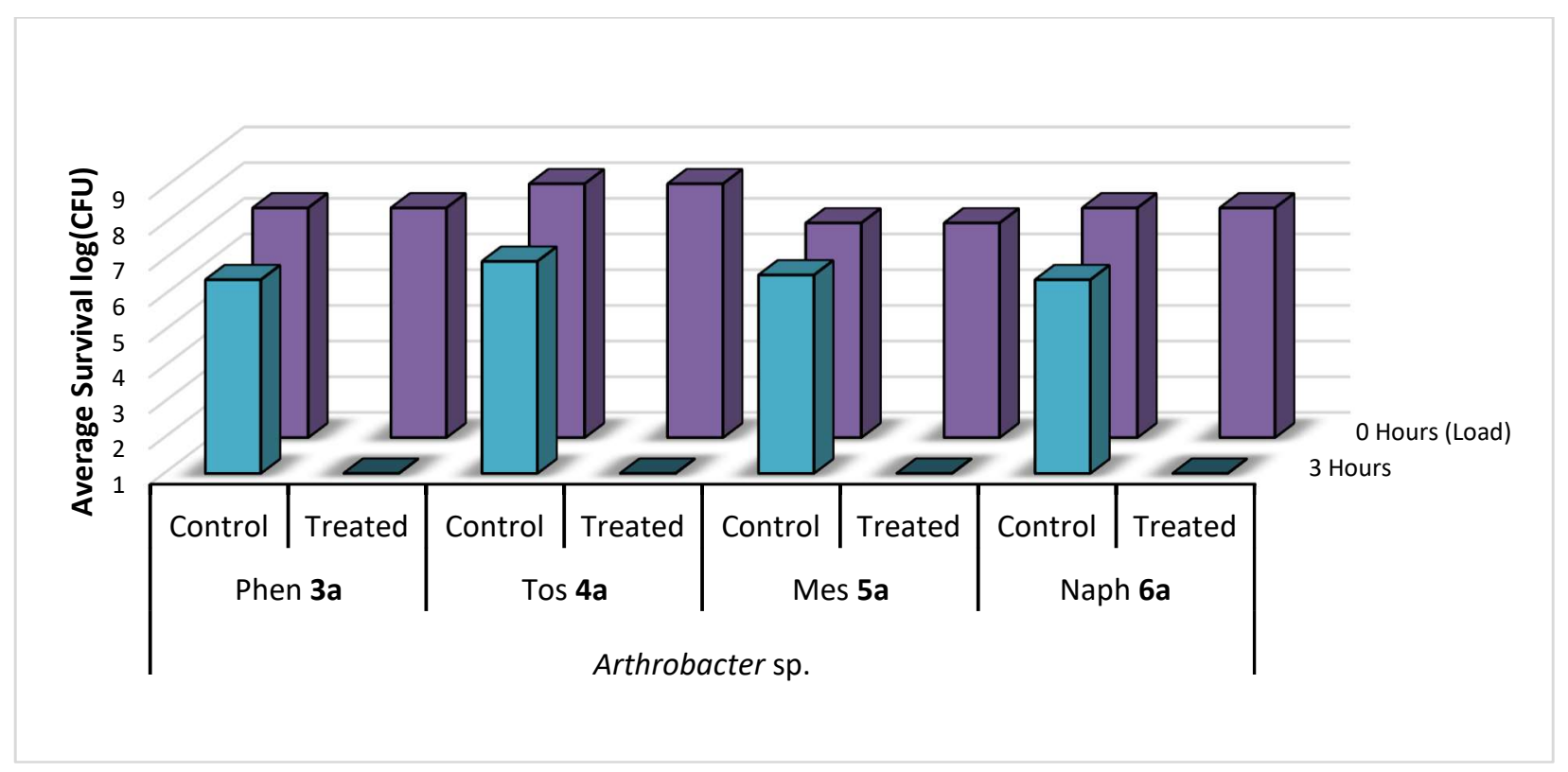

Figure 21 - (B) Survivability of Arthrobacter sp. when inoculated onto plastic coupons treated with compounds 1a-4a, compared against untreated controls $(n=3)$.

(B) A similar LDI experiment with Gram-positive Arthrobacter sp. was also investigated for silane-anchored sulfonamide QACs, 3b-6b, on virgin cotton fabric to determine whether these antimicrobial treatments remain effective on porous fabric materials (Figure 22). 


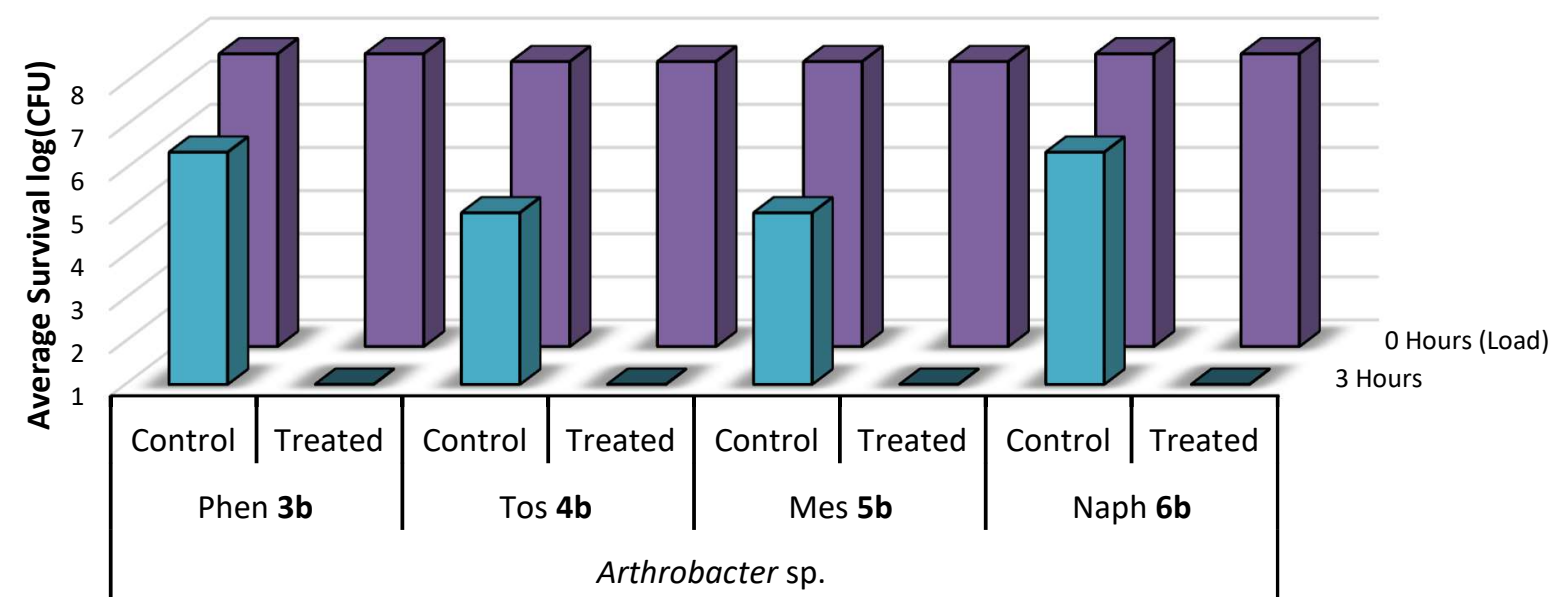

Figure 22 - (B) Survivability of Arthrobacter sp. when inoculated onto cotton samples treated with $\mathbf{1 b}-\mathbf{4 b}$, compared against untreated cotton controls $(\mathrm{n}=3)$.

(B) This test was also expanded to include fluorinated sulfa QACs, 9a and 10a. In comparison to the non-fluorinated 3a-6a, these more hydrophobic coatings are still effective surface attached antimicrobials as shown through microbiological testing (Figure 23). This would represent a step towards making tailored, hydrophobic antimicrobial coatings. Interestingly, shortchain sulfa QACs 7a and 8a do not exhibit any significant antimicrobial activity against Arthrobacter sp. at solid/air interfaces, which may be related to stubbed functional group length (Figure 23). 


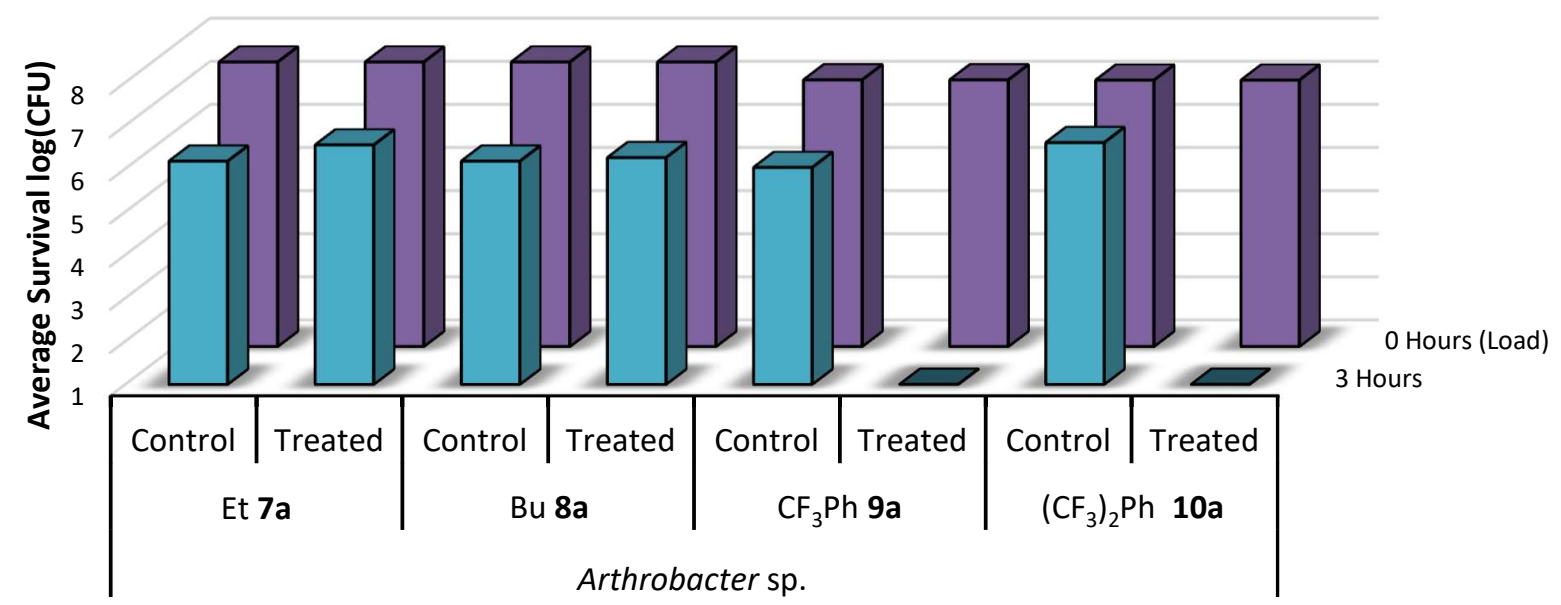

Figure 23 - (B) Survivability of Arthrobacter sp. when inoculated onto plastic coupons treated with compounds $\mathbf{7 a - 1 0 a}$, compared against untreated controls $(\mathrm{n}=3)$.

(B) A complimentary set of Gram-negative trials were also performed on treated plastic and cotton samples using E. coli as the test species (Figures $24-25$ ). It was determined that these treated surfaces were similarly effective against the Gram-negative E. coli species at solid/air interfaces, suggesting that the presence of a large exterior peptidoglycan wall does not appear to impact the mechanism of kill during desiccation. 


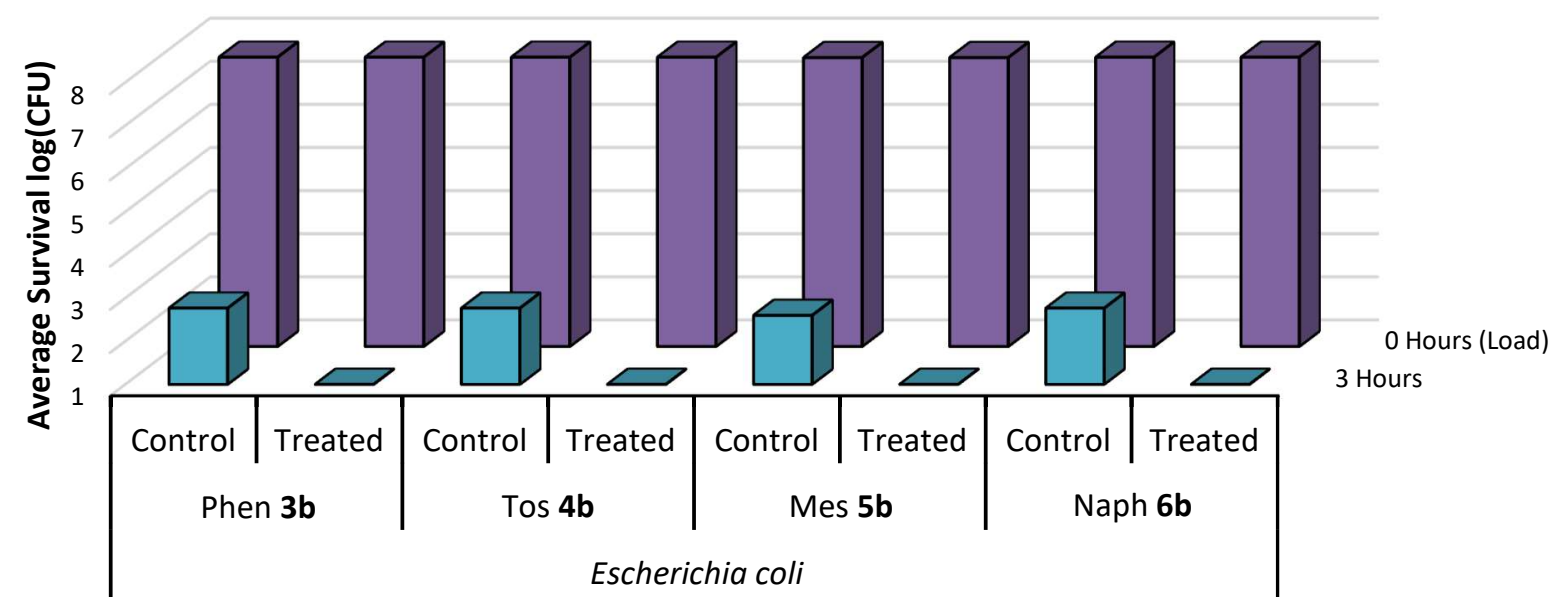

Figure 24 - (B) Survivability of Escherichia coli when inoculated onto plastic coupons treated with compounds 3a-6a, compared against untreated controls $(n=3)$.

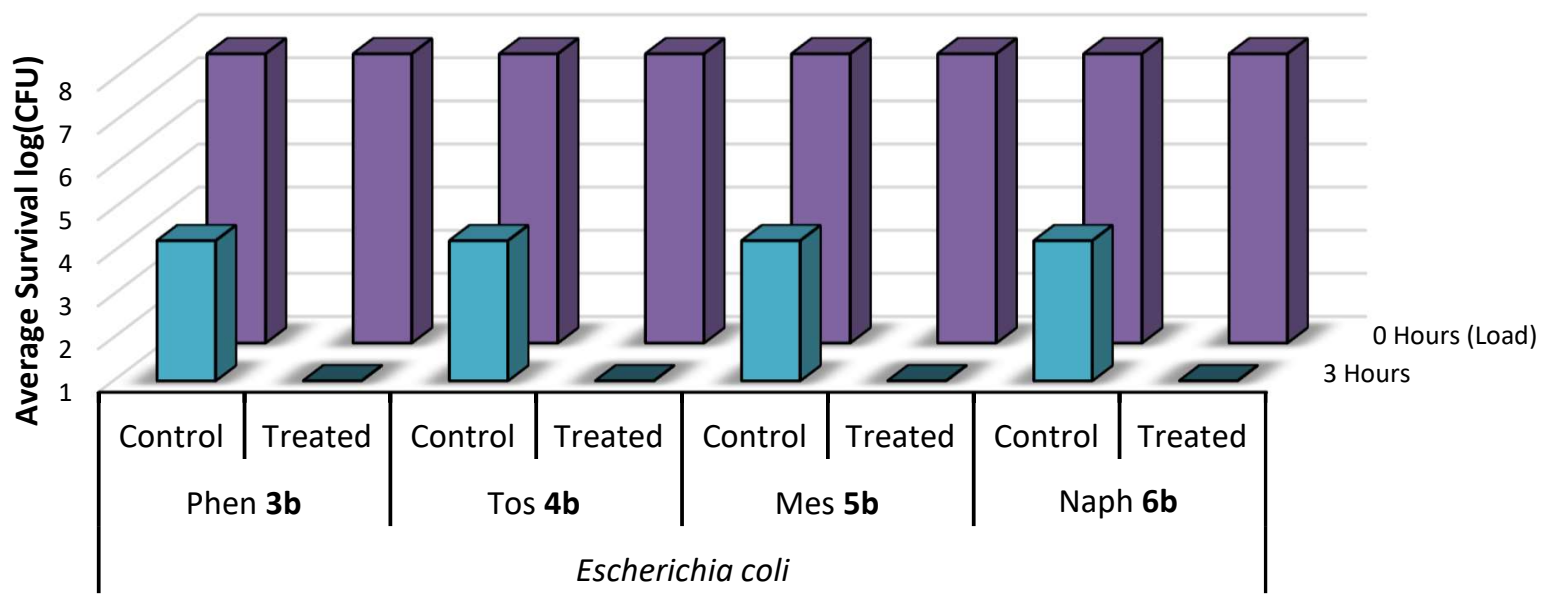

Figure 25 - (B) Survivability of Escherichia coli when inoculated onto cotton fabric treated with compounds $\mathbf{3 b}-\mathbf{6 b}$, compared against untreated controls $(n=3)$. 
(B) To evaluate the comparative antimicrobial activity of sulfa QAC treated UV-cured materials, representative Gram-positive and Gram-negative species were chosen for microbiological testing (Figure 26). Primary tests were performed using an airborne isolate of Arthrobacter species, as used previously for LDI testing. ${ }^{1}$ This Gram-positive bacterial species acts as a model organism for solid/air interface testing, due to its heightened survivability against desiccation at room temperature. Additional tests were performed with Gram-positive S. aureus and Gram-negative E. coli due to their importance in nosocomial infections, as well as their relation to prevalent antibiotic resistant strains.

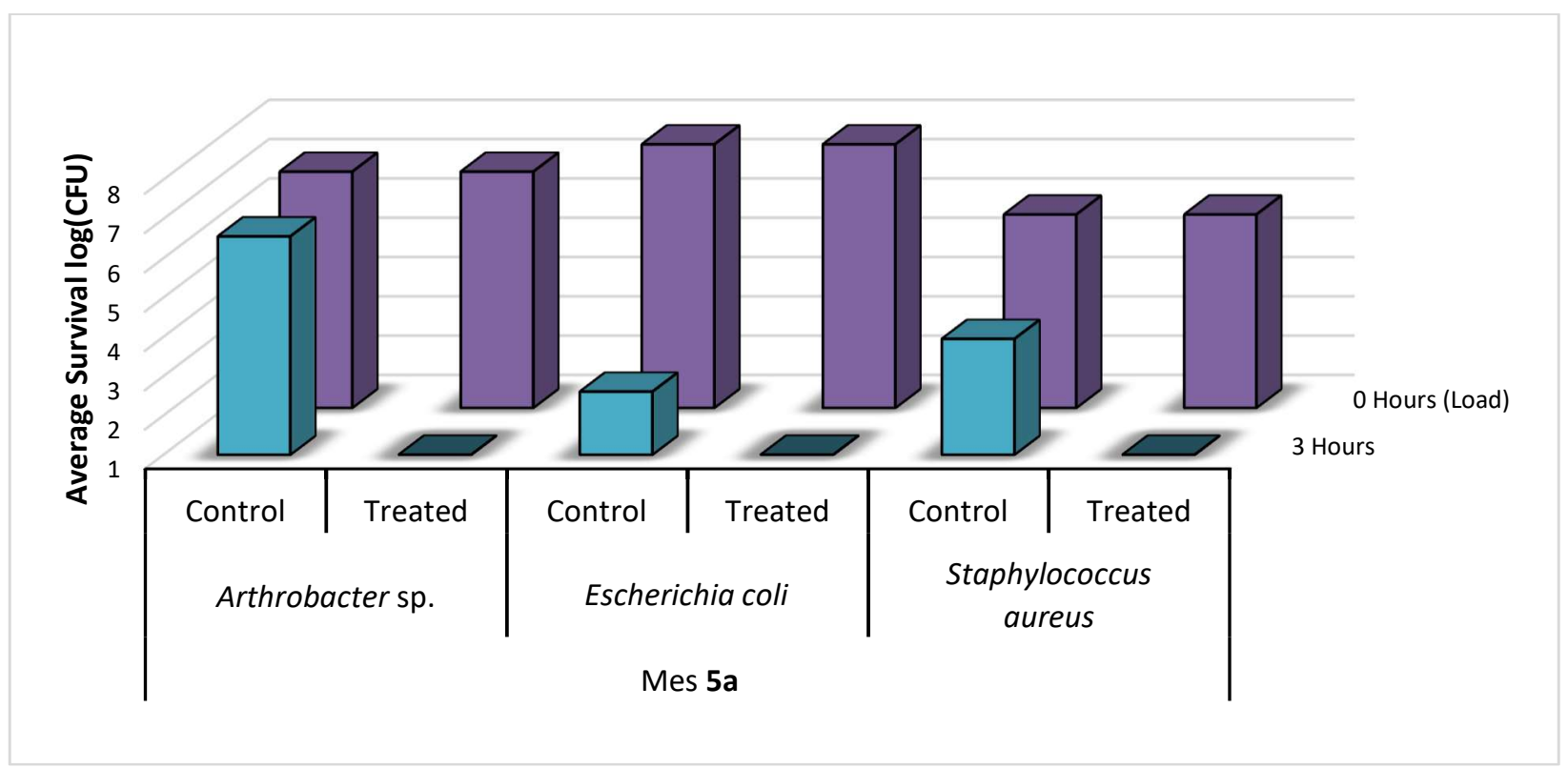

Figure 26 - (B) Survivability of various microorganisms when inoculated onto plastic samples treated with compound 5a, compared against untreated plastic controls. The measurement at $0 \mathrm{~h}$ $\left(>10^{7} \mathrm{CFU}\right.$ for Arthrobacter sp. and Escherichia. coli, $>10^{5} \mathrm{CFU}$ for Staphylococcus. aureus) indicated the initial number of bacterial cells inoculated onto sample material and was determined concurrently to inoculation $(\mathrm{n}=3)$. 
(B) To further evaluate how the sulfonamide functionality may impact the antimicrobial activity of QAC coatings, an analogous neutral UV-curable sulfonamide compound 11a (Scheme 3) was tested using the LDI procedure. For this test, PS sample materials were treated with mesitylbased sulfa QAC 3a or mesityl-based sulfonamide 11a and tested for antimicrobial activity using Arthrobacter sp. at 3 h. As shown in Figure 27, the ammonium-free mesityl sulfonamide coating prepared from 11a exhibited no antimicrobial activity. This would suggest that the sulfonamide functionality of sulfa QACs are independently unable to act as antimicrobial agents without the inclusion of quaternary ammonia.

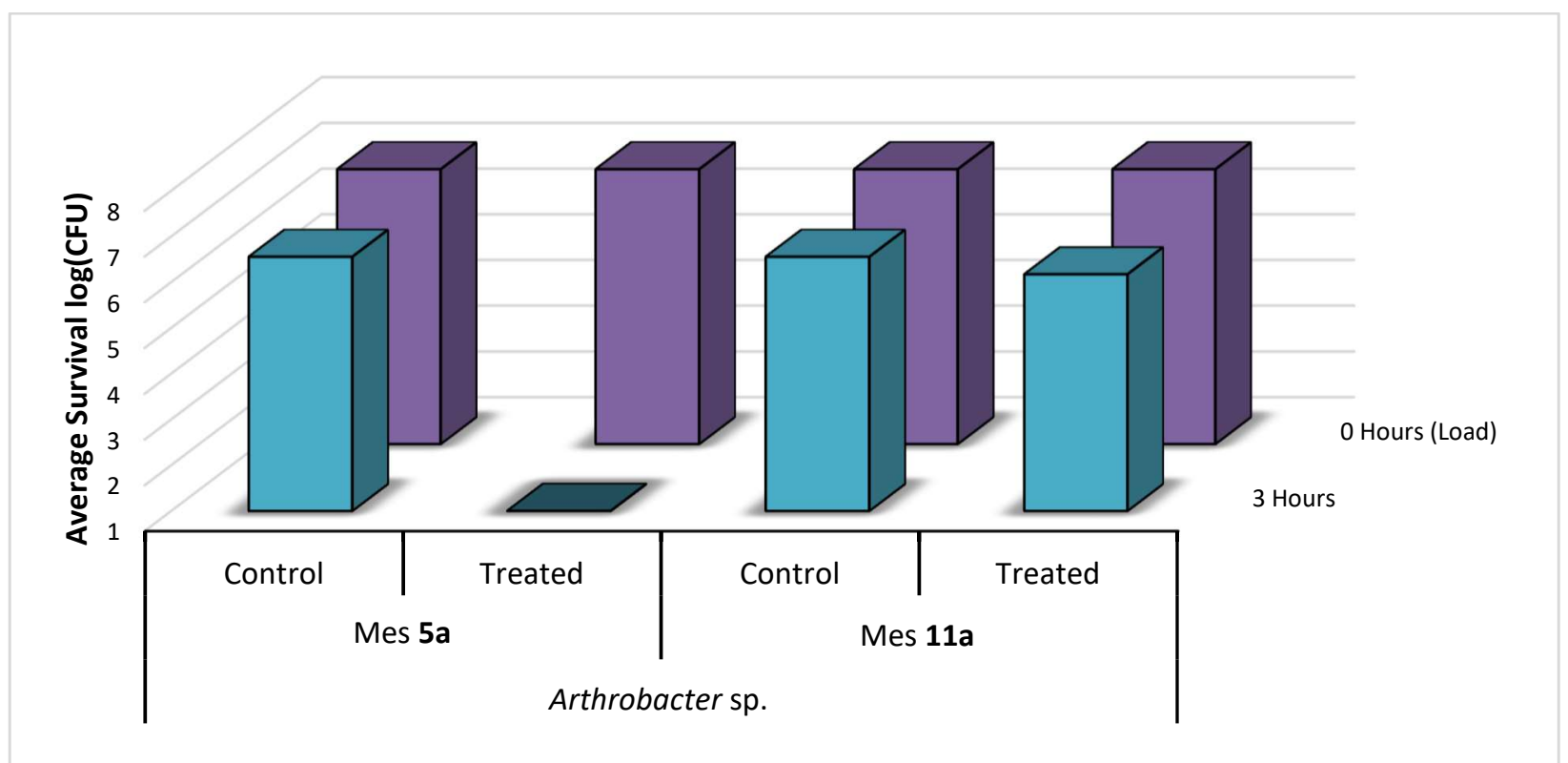

Figure 27 - (B) Survivability of Arthrobacter sp. when inoculated onto PS samples treated with compounds 5a and 11, compared against untreated PS controls $(n=3)$.

Considering the possibility that the coating may have a limited viability before becoming permanently inactivated, a re-challenge trial was performed using $\mathbf{1 a}$ and $\mathbf{5 a}$ as model coatings. 
For the first trial, two identical sets of control, 1a and 5a treated samples were inoculated with Arthrobacter sp. and allowed to dry for three hours before recovering the first set for enumeration (Figure 28). After 24 hours, the remaining set were consecutively inoculated and enumerated in similar fashion to yield single and double inoculated samples without cell removal in-between. This design of this test was to simulate a surface that has not been cleaned between repeated exposure to microorganisms, and the results found that cells would be able to survive surface exposure under these circumstances. This could be explained by the buildup of cellular debris on top of the surface of the coated sample, thereby acting as a protective layer and preventing microbial contact with the antimicrobial surface.

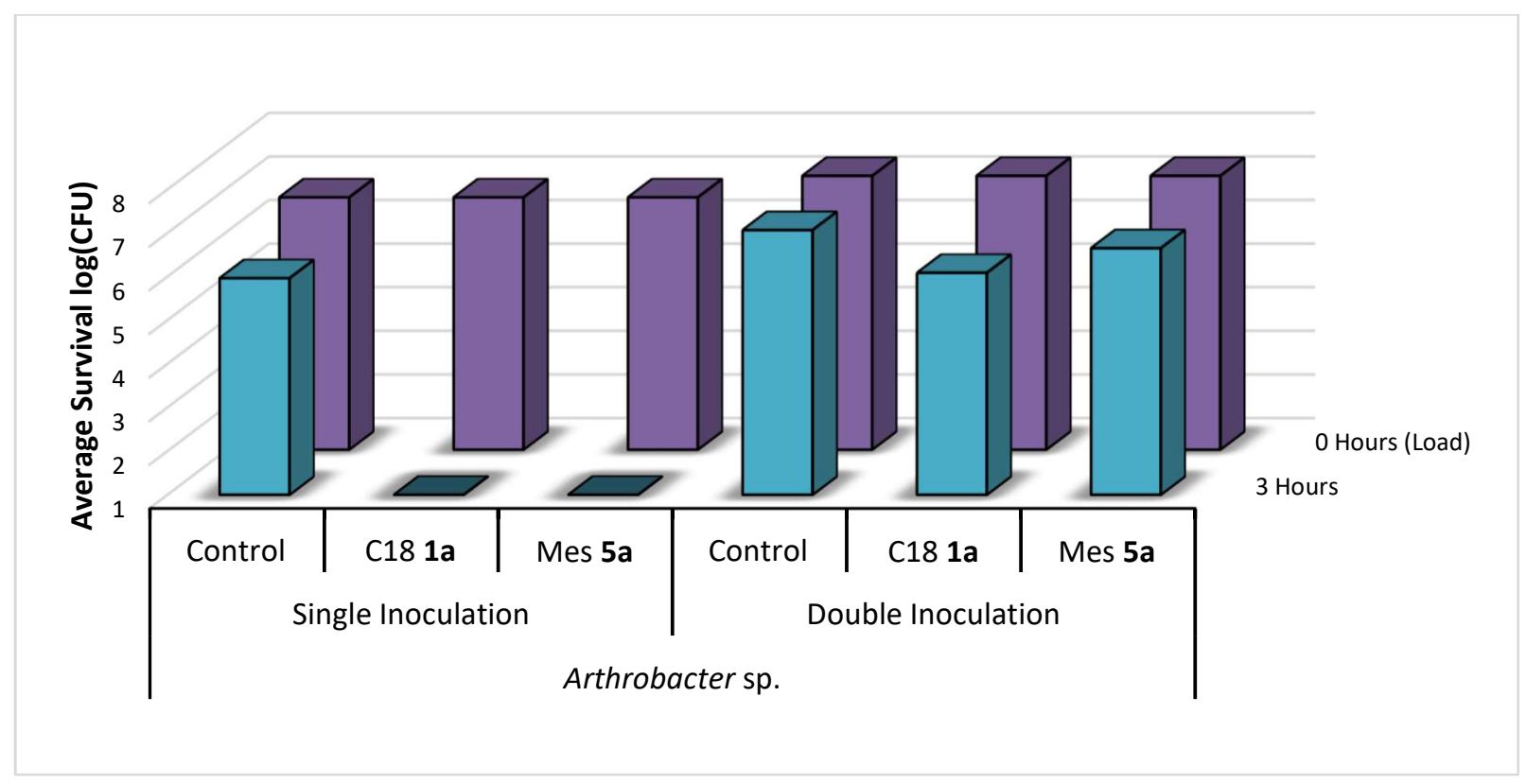

Figure 28 - Survivability of Arthrobacter sp. when repeatedly inoculated onto PS samples treated with compounds 1a and 5a without rinsing, compared against untreated PS controls $(n=3)$. 


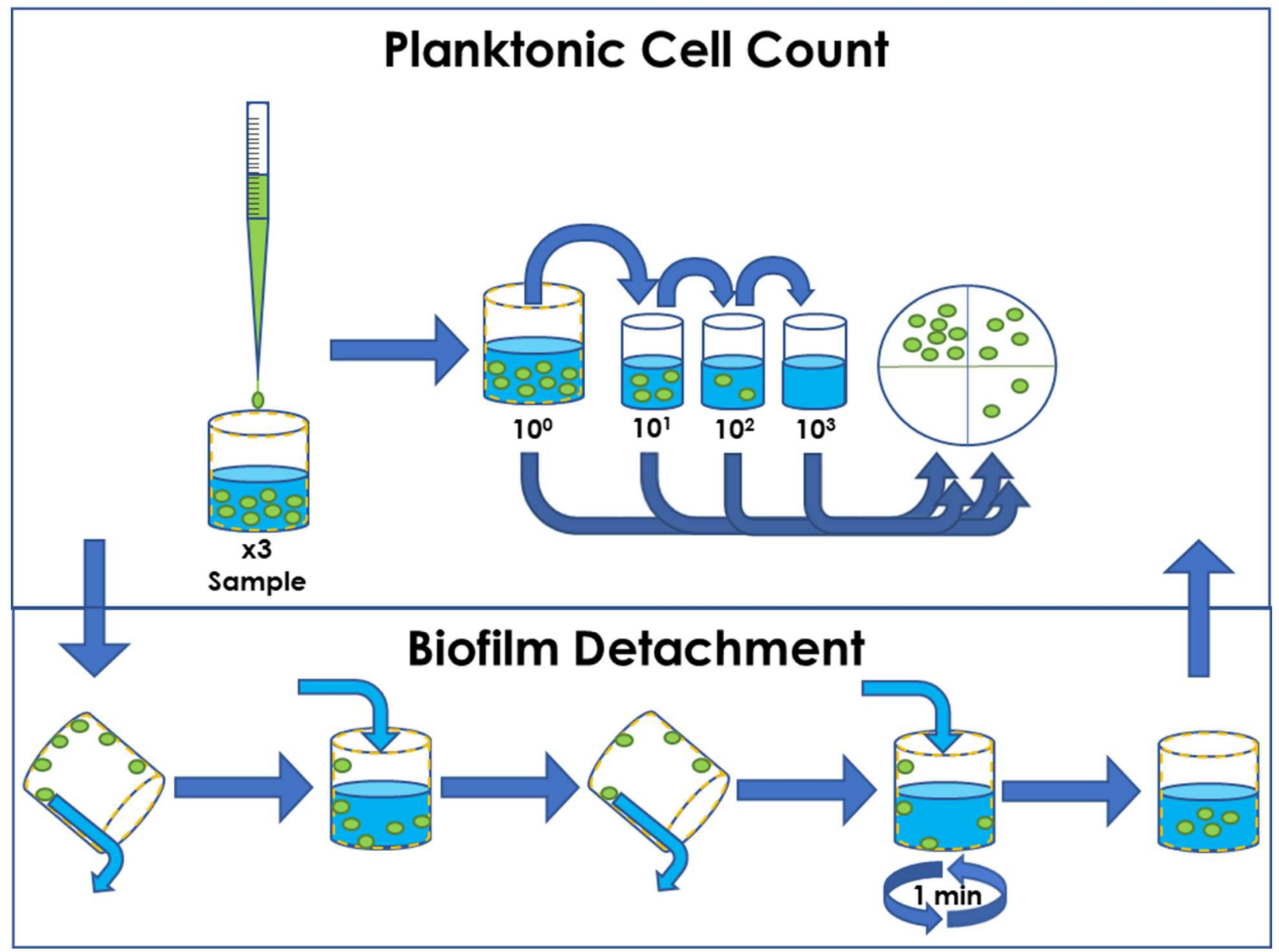

Figure 29 - (B) Visual representation of the liquid reservoir inoculum (LRI) procedure.

(B) The LRI method (Figure 29) was designed to complement the LDI method and takes inspiration from industrial standard practices ASTM E214977 and ISO 22196/JIS Z 2801. ${ }^{87,88}$ The predominant feature of this procedure that differentiates it from the LDI method is that the inoculum remains wet instead of drying out. This prevents desiccation stress from negatively impacting cell survival, but also gives microbial species an avenue to avoid contact with the coated material. To account for this avoidance, the test involved enumerating planktonic cells during the inoculation period and using a harsh rinse procedure to strip and enumerate wall-coated biofilm 
cells at the end of the test period. The LRI method provides additional advantages in relation to established standard practices (ASTM E2149 and ISO 22196/JIS Z 2801) currently used to test material surfaces for antimicrobial activity. With relation to the ASTM E2149 method, both tests use a liquid inoculum reservoir to inoculate test materials and use mechanical agitation to evenly distribute cells within the test chamber. The advantage brought about by the LRI method involves using the test chamber as the subject of study by applying the microbial treatment directly to the walls of the container, instead of the studied material being placed into the uncoated test chamber. Regarding the ISO 22196/JIS Z 2801 protocol, the sample is kept hydrated by using a cover film to seal and press the inoculum into the test surface. Although this alleviates desiccation stress from the inoculated cells, the cover slip can assist cells in avoiding direct contact with an antimicrobial material by providing a non-antimicrobial surface and a thin liquid gap between the coverslip and the test surface. In contrast, the LRI method avoids untreated surface contact with the liquid inoculum and allows for separate sampling of free-floating planktonic cells and surface-adherent biofilm cells. $^{76}$

(B) To determine whether long alkyl chain or sulfonamide QAC antimicrobial coatings can be effective at solid/liquid interfaces, $1 \mathbf{a}$ and $\mathbf{5 a}$ were selected as representative candidates for the LRI method. The treated and control LDPE samples containing either 1a or 5a were tested against Gram-positive Arthrobacter sp. and Gram-negative E. coli, bacterial species respectively, and showed varying levels of antimicrobial activity. 


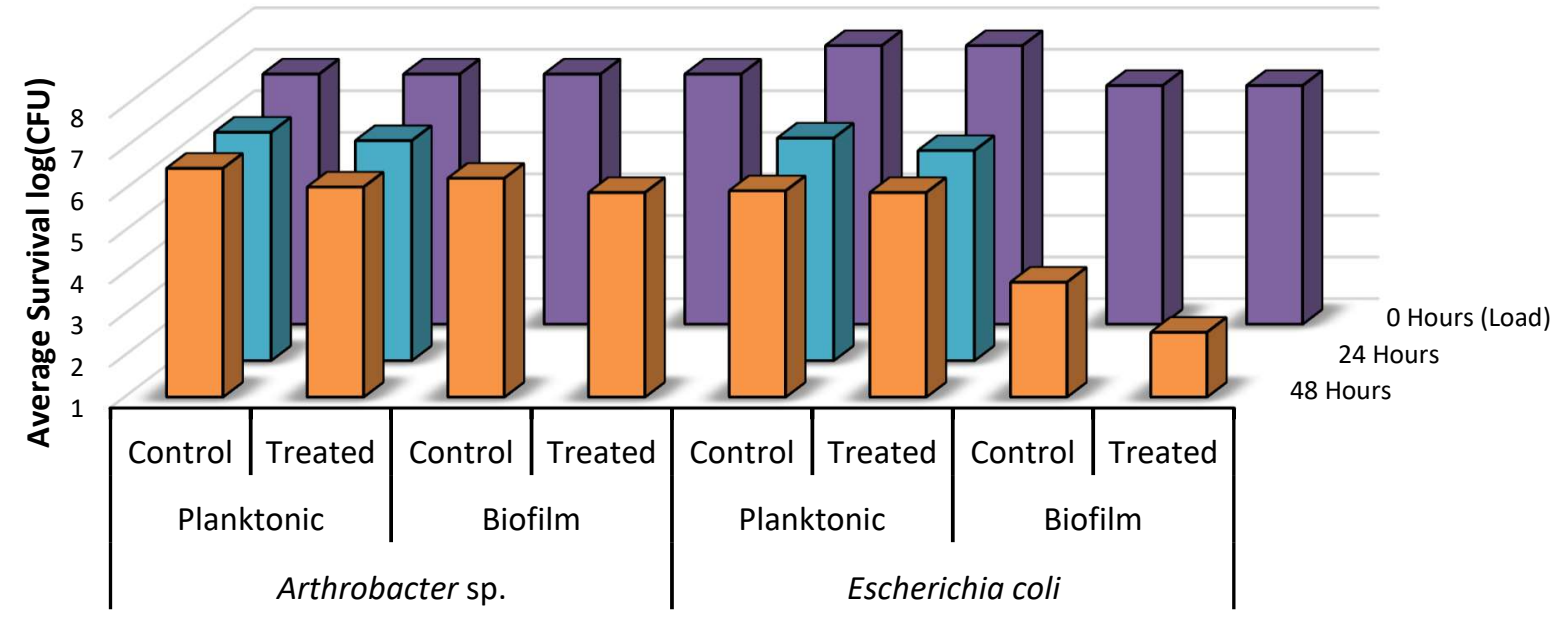

Figure 30 - (B) Survivability of Arthrobacter sp. and Escherichia coli when inoculated into LDPE vials treated with compound 1a, compared against untreated LDPE controls. $(n=3)$.

(B) As shown in Figure 30, there was no evidence of kill from the long alkyl chain-QAC coating prepared from 1a when compared against control samples except for a slight drop in survivability on both the treated $\left(>10^{3} \mathrm{CFU}\right)$ and control $\left(<10^{3} \mathrm{CFU}\right.$ remaining $)$ E. coli biofilm samples. The drop itself could be related to the lower initial inoculum cell count compared to the other samples but should not affect the result of comparison between the respective treated and control sets. Compared to the results obtained for 5a (Figure 31), the slight drop in E. coli biofilm retrievals for 1a is conserved, indicating some slight antimicrobial activity for QAC compounds against Gram-negative species. In contrast, against Gram-positive Arthrobacter sp., 5a showed excellent antimicrobial activity after $24 \mathrm{~h}$ and $48 \mathrm{~h}$ regarding planktonic cells (Figure 31 ). This represents a significant drop in cell survivability compared to control samples at these timepoints $\left(>10^{6} \mathrm{CFU}\right.$ and $\left.>10^{4} \mathrm{CFU}\right)$. Against Gram-positive biofilm cells, 5a can completely reduce the number of viable cells below measurable CFU quantities when compared against untreated 
controls ( $\left.>10^{4} \mathrm{CFU}\right)$. With Gram-negative E. coli. cells, 5a shows reduced antimicrobial activity when compared to the Gram-positive trials. At $24 \mathrm{~h}\left(<10^{6} \mathrm{CFU}\right.$ remaining $)$ and $48 \mathrm{~h}\left(<10^{5} \mathrm{CFU}\right.$ remaining), there is a modest reduction in the number of viable planktonic cells when compared against untreated controls $\left(>10^{6} \mathrm{CFU}\right.$ and $\left.>10^{5} \mathrm{CFU}\right)$. This trend of reduced antimicrobial activity is also apparent when comparing treated and control Gram-negative biofilms cells, which shows moderate biocidal activity $\left(<10^{5} \mathrm{CFU}\right.$ remaining) when compared against untreated controls $(>$ $\left.10^{6} \mathrm{CFU}\right)$.

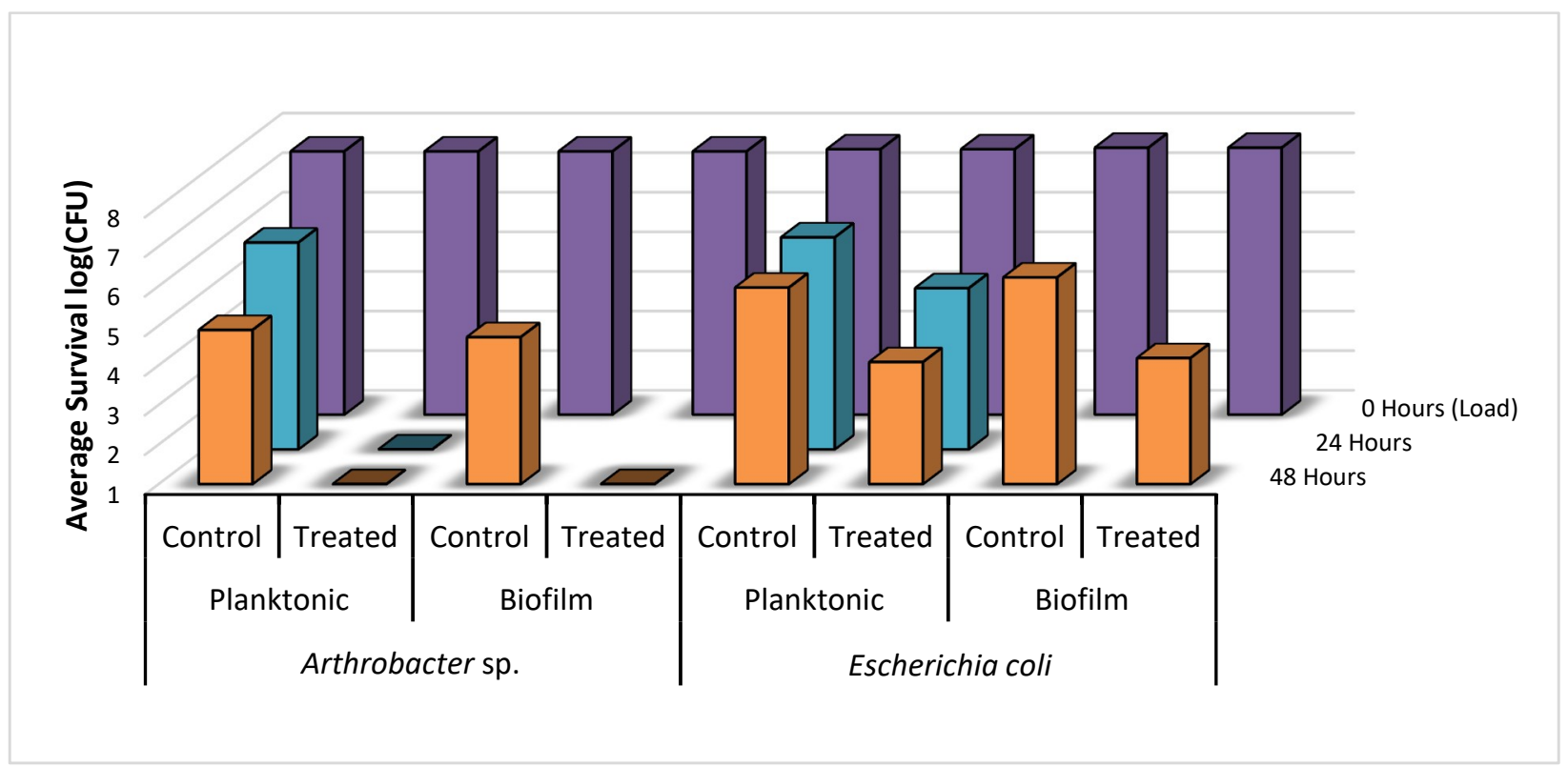

Figure 31 - (B) Survivability of Arthrobacter sp. and Escherichia coli when inoculated into LDPE vials treated with compound 5a (Mesityl sulfa QAC), compared against untreated LDPE controls. $(\mathrm{n}=3)$.

\subsection{Evidence Towards Antimicrobial Mechanism}

Beyond the ability to demonstrate antimicrobial activity (or lack thereof) of 1a-11a at solid/air and solid/liquid interfaces, many of the performed tests were also designed to help 
elucidate the antimicrobial mechanism of QAC coatings, based on the proposed phospholipid sponge and polymeric spacer effects. Key to this was the use of novel QAC compounds with variations made to the structure and composition of the hydrophobic tail section of these materials. Of all these changes, the largest was the switch from long-chain alkyl QACs to short-chain aryl sulfonamide QACs. From there, several smaller changes were made to the sulfonamide section to adjust the characteristics of these compounds. Finally, a non-QAC analogue was synthesized to determine the antimicrobial activity of the base sulfonamide coating material.

Since surface charge and wettability studies have been previously used to provide evidence of a phospholipid sponge effect for QAC coatings, ${ }^{54,55,85}$ these tests were also performed on 1a, 3a-6a, 9a and 10a in hope to provide information towards determining the mechanism of kill. From these tests, it was found that the sulfa QAC coatings had significantly less charge then alkyl QAC-treated materials even though they exhibited similar antimicrobial activity during LDI testing. The sulfa QACs were also demonstrated to have a lower charge that the reported minimum required to observe antimicrobial activity using the standard fluorescein dye method. ${ }^{55}$ This inconsistency seems to be the result of a previously established assumption where fluorescein dye and quaternary ammonium molecules would complex at a ratio of 1:1, which is unlikely to hold up against the bulky sulfonamide structure located near each quaternary ammonium charge of 3a6a, 9a and 10a.

XPS and ToF-SIMS experiments were performed to illuminate any compositional details and distributions for 1a and 5a coated CPVC, while AFM and SP was performed to examine the structure and thickness of 1a, 5a, and 10a coated PC samples. These trials were performed to examine how these coatings may interact with microorganisms at a microscopic level and provide evidence towards the currently proposed QAC mechanisms. To that end, one of the most striking 
observations involved the surface structure of the coated materials, which exhibited a high degree of roughness across the coated surface. This roughness consisted of a random assortment of peaks, valley and ridges that can span the full thickness of the coating layer. Since these coatings can have height variations that are greater that the thickness of the cell wall of many bacterial strains, ${ }^{59,111,112}$ it lends credibility to the polymeric spacer effect for these QAC coatings.

Based on the collected microbiological data, it has been demonstrated that 1a-6a, 9a and 10a were able to function as antimicrobial coatings while 7a, 8a and 11a exhibited no significant antimicrobial activity. In comparison of 7a and 8a to the active QAC antimicrobials, the largest difference between these two groups is structure of the shorter sulfonamide tail section. Considering that the phospholipid sponge effect relies on the similarity between the phospholipids that make up the cellular membrane of microorganisms, the change in length combined with the largely polar nature of the non-aryl sulfonamide tail is suspected to be responsible for preventing this mechanism from occurring. With regards to $11 \mathrm{a}$, the absence of the quaternary ammonium moiety completely neutralized the antimicrobial activity exhibited by this sulfonamide analogue to $\mathbf{5 a}$. Seeing that $\mathbf{5 a}$ is highly capable of acting as an antimicrobial coating at both solid/air and solid/liquid environments, it further strengthens the phospholipid sponge case by indicating at cationic charge followed by a hydrophobic tail as required to exhibit antimicrobial activity. 


\subsection{Conclusion and Future Studies}

Novel QAC compounds were investigated for their use in antimicrobial coatings, which centered around developing treatment strategies for commercial materials, examining the surface structure and characteristics of treated materials, and evaluating that antimicrobial efficacy of treated materials. These compounds included alkyl QACs 1a and 2a and sulfa QACs 3a-11a and 3b-6b. From a characterization standpoint, it was found that QAC coatings exhibited varying degrees of non-correlating hydrophobicity and surface charge depending on hydrophobic tail composition. Advanced characterization and microscopy techniques determined that the coating structure of 1a, 5a and 10a had a wide degree of variation in height and distribution, marked by numerous pits, peaks and ridges. With regards to microbiological data, it was found that 1a-6a, 9a and 10a exhibited antimicrobial activity at a solid/air interface, while 5a exhibited antimicrobial activity at a solid/liquid interface. Regarding mechanisms of kill, there is not enough evidence to claim a specific mechanism of action for QAC coatings although the results obtained during testing indicates the possibility of both prominently proposed "phospholipid sponge" and "polymeric spacer" mechanisms.

With the goal of discovering and improving cationic antimicrobial coatings, further testing with cationic analogues, different microbial strains and advanced imaging techniques recommended to shed further light on this topic. Cationic analogues potentially include phosphonium and sulfonium analogues, where size and stability could contribute to more robust and effective antimicrobial compounds. Different microbial strains that have unique or modified cellular membrane properties could also be used to focus on specific aspects of the antimicrobial mechanism of these coatings. Finally, advanced imaging techniques such as environmental SEM could provide a snapshot of the antimicrobial mechanism in action. 


\section{APPENDICIES}

\section{(A) “UV-Curable Contact Active Benzophenone Terminated Quaternary Ammonium Antimicrobials for Applications in Polymer Plastics and Related Devices" Supplementary Information}

\section{List of Tables (A)}

Table (A) 1 - Quantification XPS data for control and 1a treated CPVC samples. 81 Table (A) 2 - Alkyl QAC 1a-2a microbiology data (LDI). Microbiological testing was performed with triplicate treated and untreated controls. The inoculum load represents the quantity of viable cells placed onto each sample material and was determined concurrently to sample data $( \pm$ indicates standard deviation $n=3)$. A value of $1.70 \log (\mathrm{CFU})$ represents the lowest number of detectable cells spot plated onto $3 \mathrm{~g} \mathrm{~L}^{-1} \mathrm{TSA}$ (LOD: $50 \mathrm{CFU}, 1$ colony in $5 \mathrm{~mL}$ undiluted collection fluid). 92

Table (A) 3 - Multi-load alkyl QAC 1a microbiology data (LDI). Microbiological testing was performed with triplicate treated and untreated controls. The inoculum load represents the quantity of viable cells placed onto each sample material and was determined concurrently to sample data ( \pm indicates standard deviation $n=3$ ). A value of $1.70 \log (\mathrm{CFU})$ represents the lowest number of detectable cells spot plated onto $3 \mathrm{~g} \mathrm{~L}^{-1} \mathrm{TSA}$ (LOD: $50 \mathrm{CFU}, 1$ colony in $5 \mathrm{~mL}$ undiluted collection fluid). 93 


\section{List of Figures (A)}

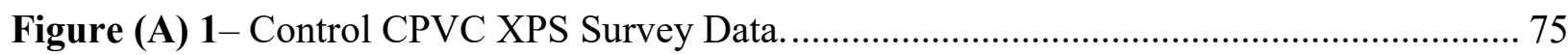

Figure (A) 2 - 1a Treated CPVC XPS Survey Data................................................................ 76

Figure (A) 3 - Control CPVC Identification XPS data. …………………………................... 77

Figure (A) 4 - Control CPVC Identification XPS data (continued) ……………………......... 78

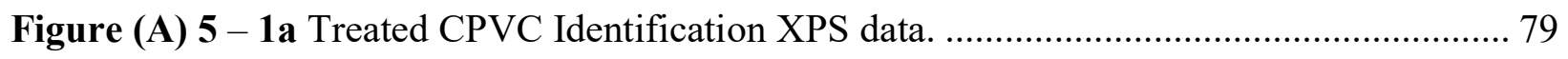

Figure (A) 6 - 1a Treated CPVC Identification XPS data (continued) ………......................... 80

Figure (A) 8 - Positive ion ToF-SIMS survey of control CPVC material. ................................ 82

Figure (A) 9 - Positive ion ToF-SIMS survey of 1a treated CPVC material............................. 83

Figure (A) 10 - Negative ion ToF-SIMS survey of control CPVC material.............................. 84

Figure (A) 11 - Negative ion ToF-SIMS survey of 1a treated CPVC material. ......................... 85

Figure (A) 12 - Composite negative ion ToF-SIMS image of $500.0 \times 500.0 \mu \mathrm{m}$ section of control and 1a treated samples. Intensity is a function of fragment quantity during analysis. Images correspond to negative ionic fragmentation products of chlorine $\left(\mathrm{Cl}^{-}\right)$, bromine $\left(\mathrm{Br}^{-}\right)$, ethane $\left(\mathrm{C}_{2} \mathrm{H}^{-}\right.$ ), tetracarbonyl ammonium $\left(\mathrm{C}_{4} \mathrm{~N}^{-}\right)$, and hydroxybenzophenone $\left(\mathrm{C}_{13} \mathrm{H}_{9} \mathrm{O}_{2}{ }^{-}\right) \ldots \ldots \ldots \ldots \ldots \ldots \ldots \ldots \ldots \ldots . . . . . . . . . . . . .66$

Figure (A) 13 - AFM imaging of location A, found along the separation line between the previously taped (left) and untaped (right) sections of twice coated PS using antimicrobial 1a.

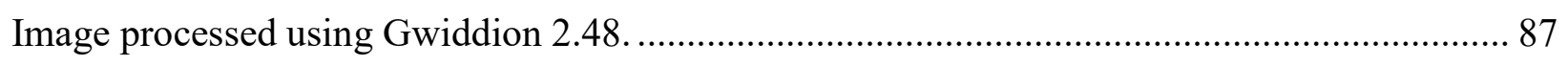

Figure (A) 14 - AFM imaging of location B, found along the separation line between the previously taped (left) and untaped (right) sections of twice coated PS using antimicrobial 1a.

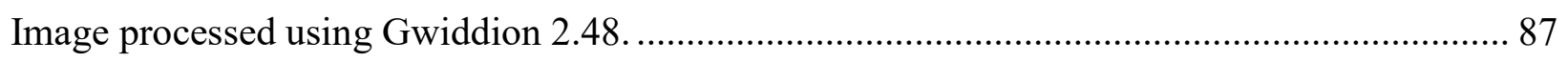


Figure (A) 15 - AFM imaging of location C, found along the separation line between the previously taped (left) and untaped (right) sections of twice coated PS using antimicrobial 1a.

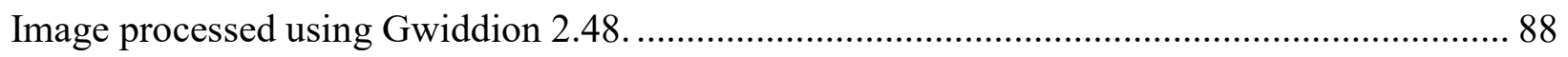

Figure (A) 16 - 3D graphical representation using surface profilometry of a $0.25 \mathrm{~mm}^{2}$ area found along the separation line between the previously taped (left) and untaped (right) sections of twice coated PS using antimicrobial 1a. 89

Figure (A) 17 - SP Mean profile of Figure (A) $16(n=51)$. 90

Figure (A) 18 - Spectroscopic images of polypropylene fabric samples under white light (left) and GFP2-filtered UV light (right). Sample coatings supplemented with dansyl fluorophore 12a (above) appeared to brightly fluoresce when exposed to UV light. 91

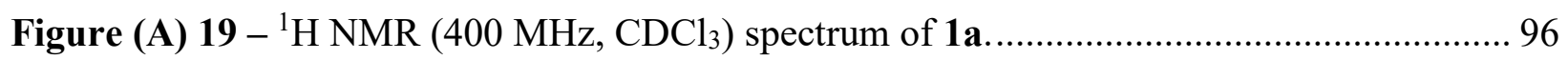

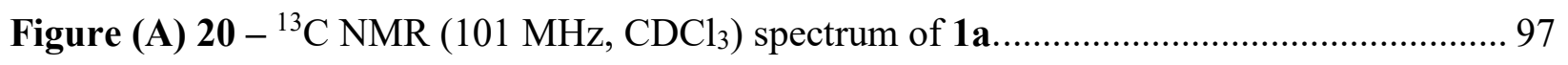

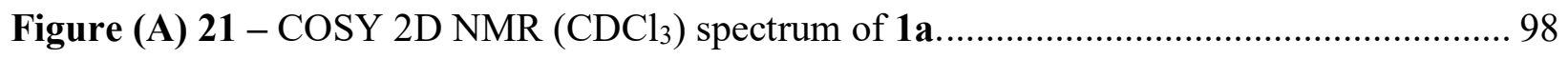

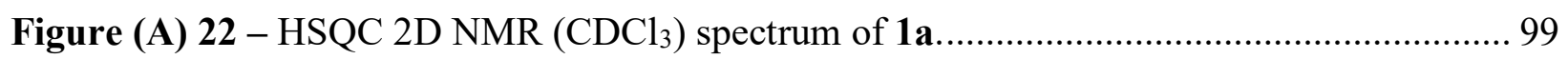

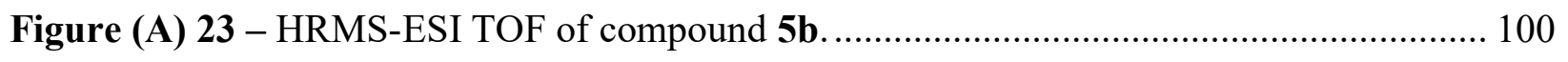

Figure (A) $24-{ }^{1} \mathrm{H}$ NMR $\left(400 \mathrm{MHz}, \mathrm{CDCl}_{3}\right)$ spectrum of 2a...................................... 101

Figure (A) $25-{ }^{13} \mathrm{C}$ NMR $\left(101 \mathrm{MHz}, \mathrm{CDCl}_{3}\right)$ spectrum of 2a........................................ 102

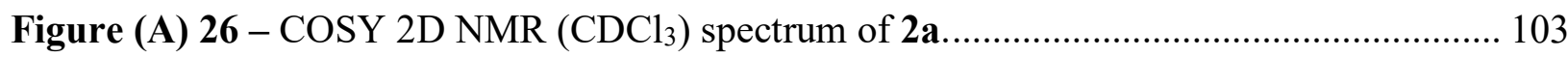

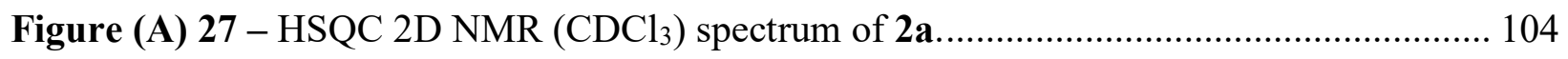

Figure (A) 28 - HRMS-ESI TOF of compound 2a................................................... 105 


\section{X-ray Photoelectric Spectroscopy and ToF-SIMS Data}

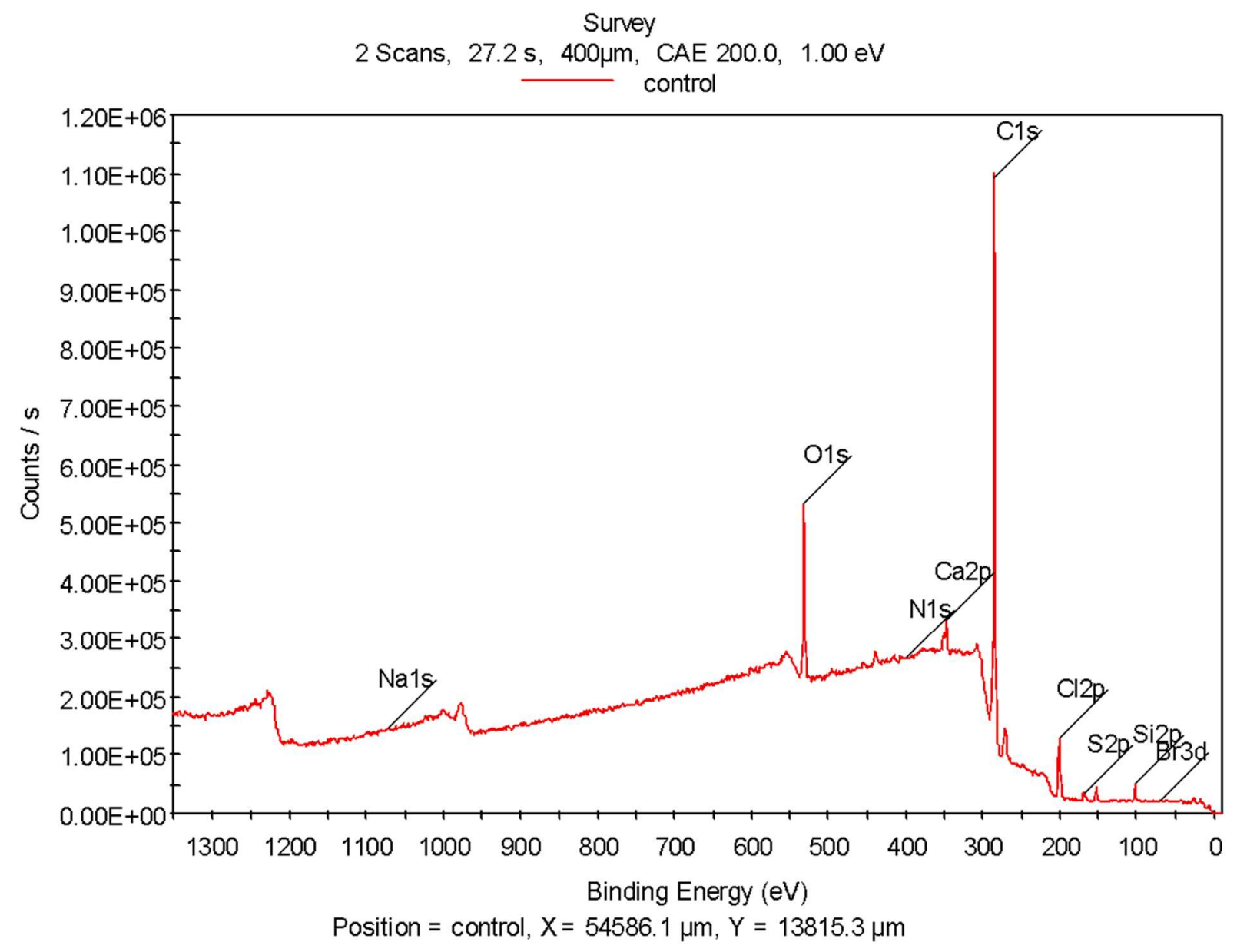

Figure (A) 1-Control CPVC XPS Survey Data. 


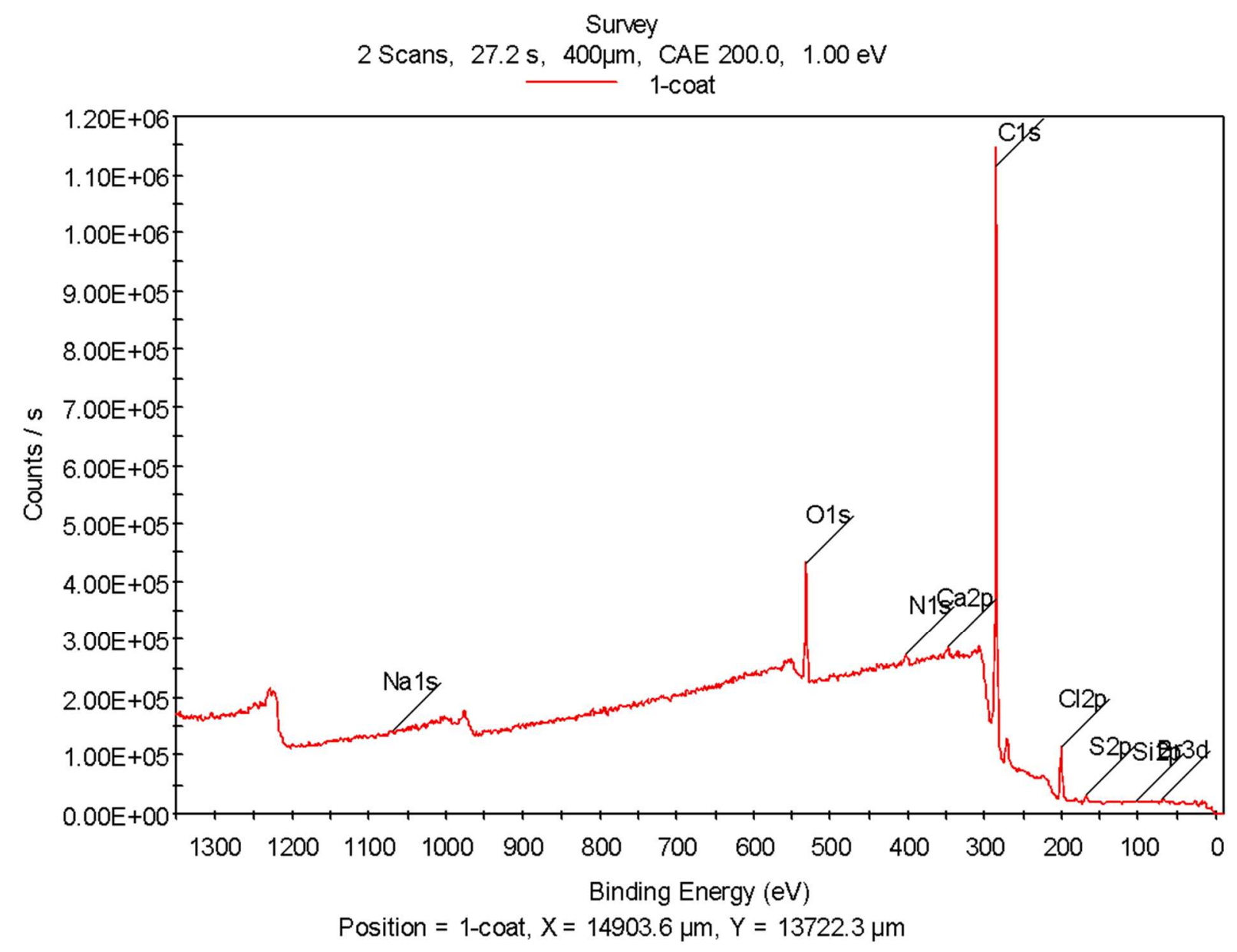

Figure (A) 2 - 1a Treated CPVC XPS Survey Data. 

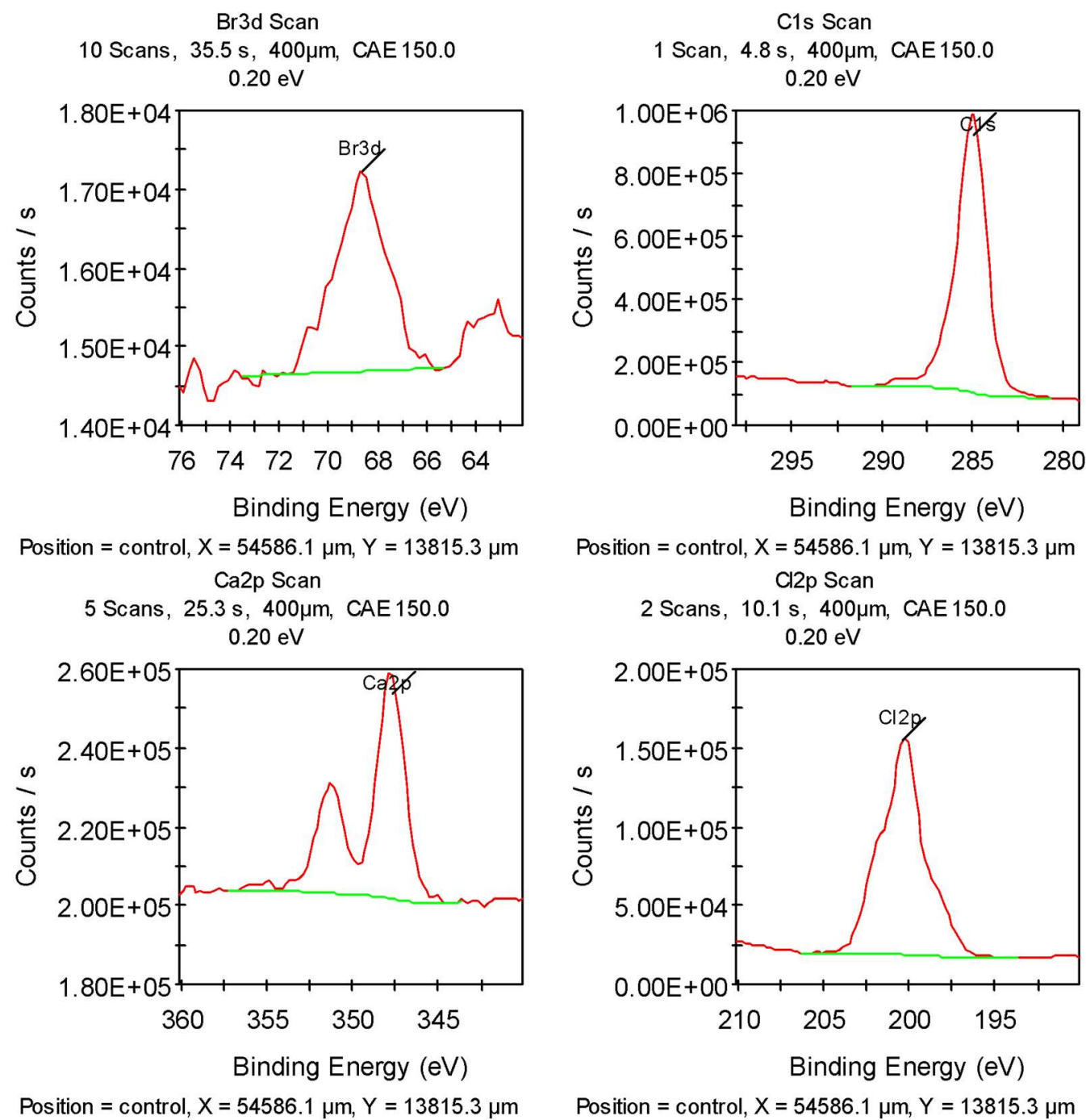

Position = control, $X=54586.1 \mu \mathrm{m}, Y=13815.3 \mu \mathrm{m}$

$\mathrm{Cl} 2 \mathrm{p}$ Scan

2 Scans, $10.1 \mathrm{~s}, 400 \mu \mathrm{m}, \mathrm{CAE} 150.0$ $0.20 \mathrm{eV}$

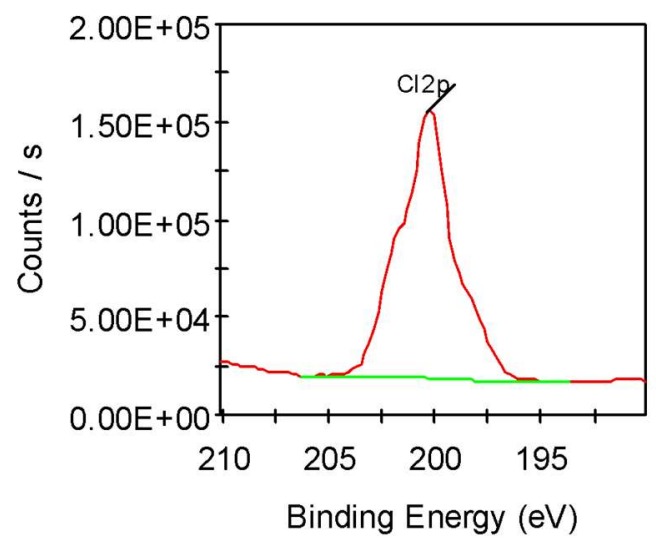

Position $=$ control, $X=54586.1 \mu \mathrm{m}, Y=13815.3 \mu \mathrm{m}$

Figure (A) 3 - Control CPVC Identification XPS data. 


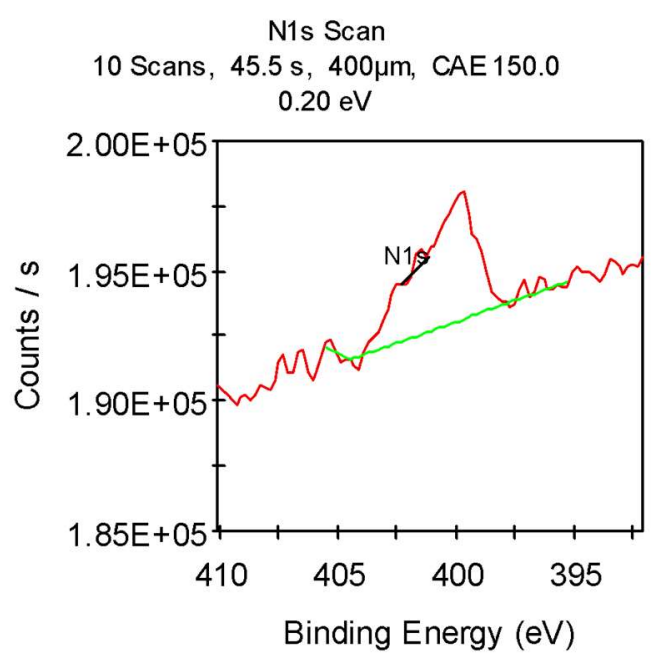

Position $=$ control, $X=54586.1 \mu \mathrm{m}, Y=13815.3 \mu \mathrm{m}$

O1s Scan

1 Scan, $5.1 \mathrm{~s}, 400 \mu \mathrm{m}, \mathrm{CAE} 150.0$

$0.20 \mathrm{eV}$

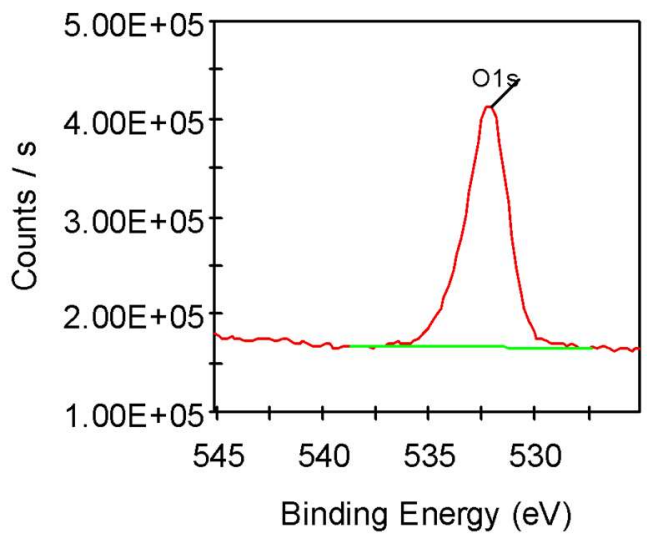

Position $=$ control, $X=54586.1 \mu \mathrm{m}, \mathrm{Y}=13815.3 \mu \mathrm{m}$
Na1s Scan

5 Scans, $21.5 \mathrm{~s}, 400 \mu \mathrm{m}, \mathrm{CAE} 150.0$

$0.20 \mathrm{eV}$

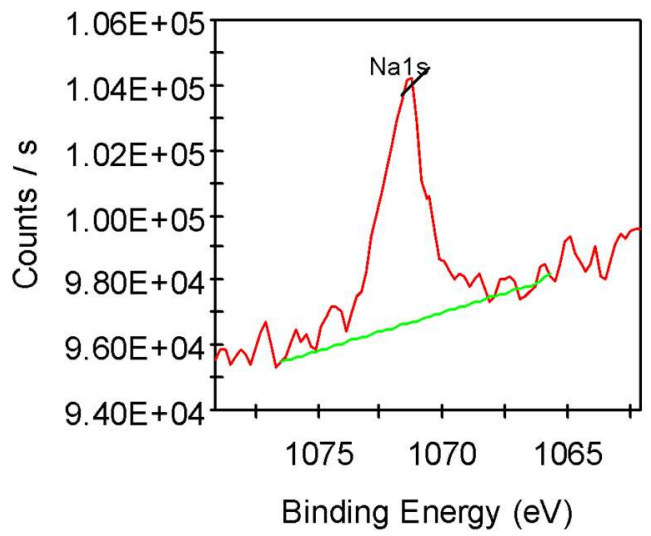

Position = control, $X=54586.1 \mu \mathrm{m}, Y=13815.3 \mu \mathrm{m}$

S2p Scan

10 Scans, $45.5 \mathrm{~s}, 400 \mu \mathrm{m}, \mathrm{CAE} 150.0$ $0.20 \mathrm{eV}$

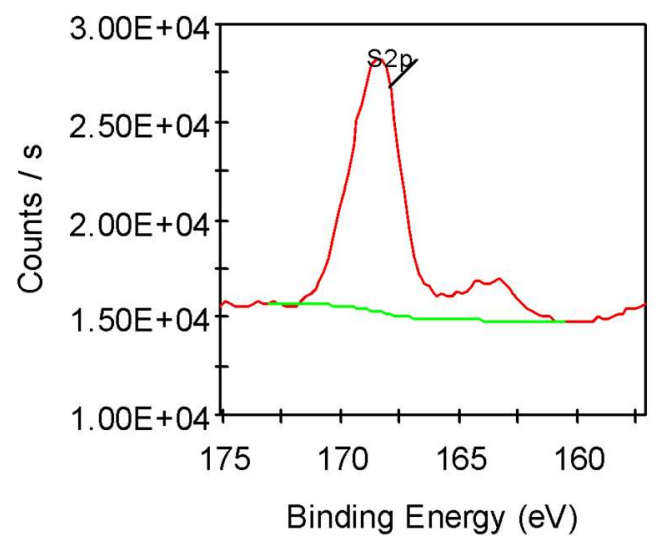

Position $=$ control, $X=54586.1 \mu \mathrm{m}, Y=13815.3 \mu \mathrm{m}$

Si2p Scan

5 Scans, $19.0 \mathrm{~s}, 400 \mu \mathrm{m}, \mathrm{CAE} 150.0$

$0.20 \mathrm{eV}$

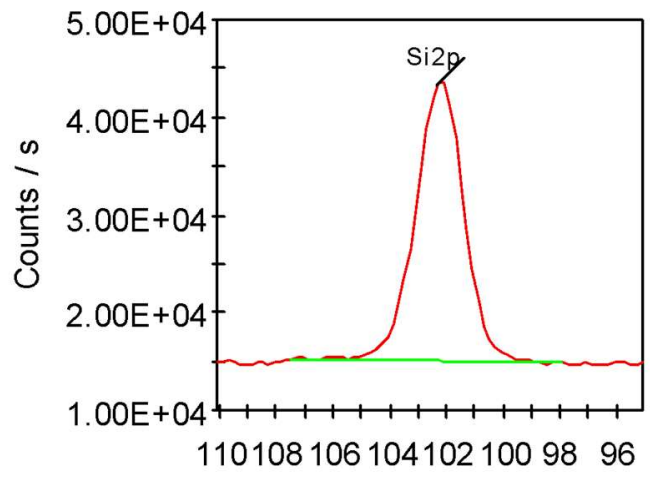

Binding Energy (eV)

Position $=$ control $, X=54586.1 \mu \mathrm{m}, Y=13815.3 \mu \mathrm{m}$

Figure (A) 4 - Control CPVC Identification XPS data (continued). 

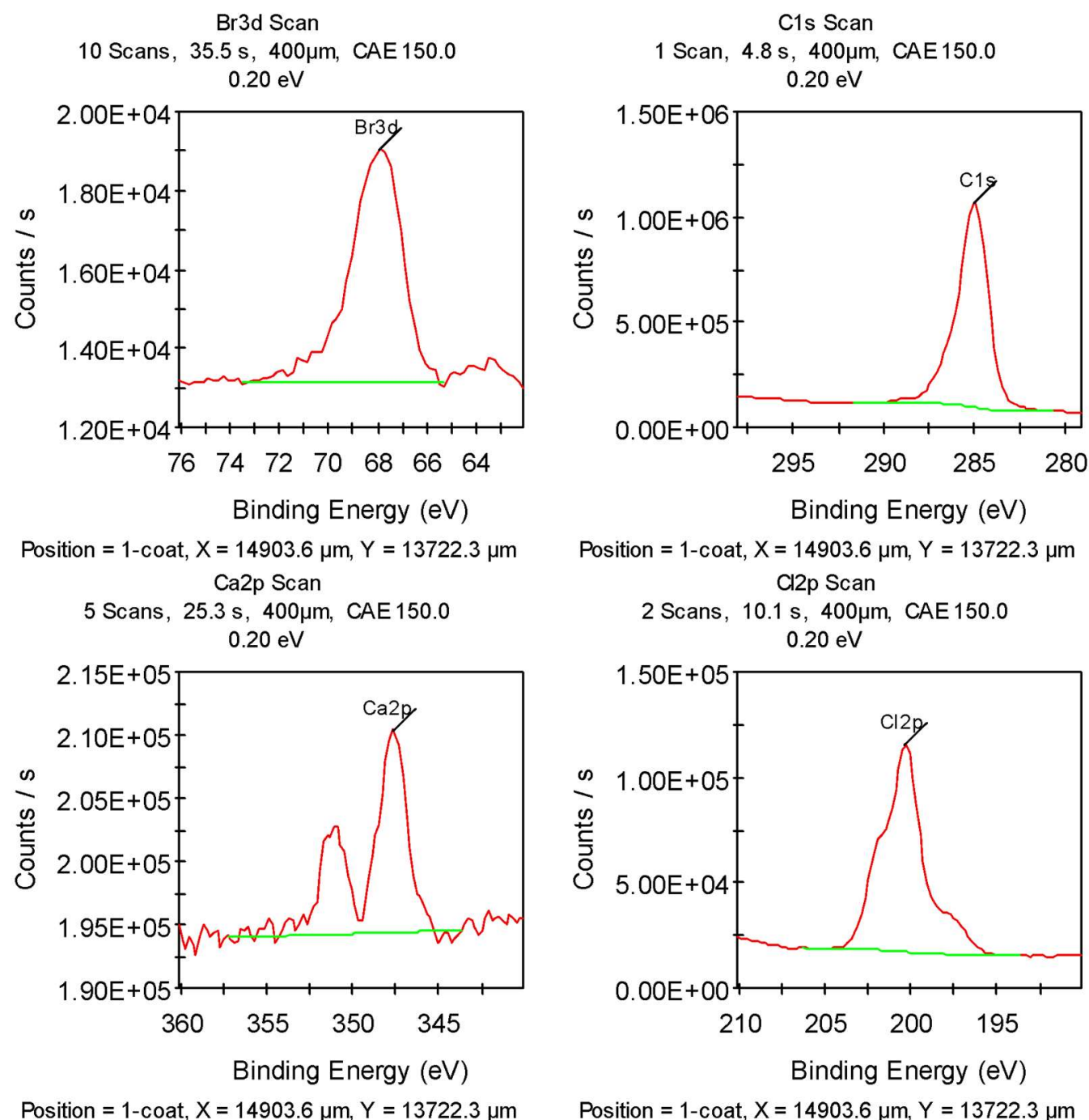

Position $=1$-coat, $X=14903.6 \mu \mathrm{m}, Y=13722.3 \mu \mathrm{m}$

Cl2p Scan

2 Scans, $10.1 \mathrm{~s}, 400 \mu \mathrm{m}, \mathrm{CAE} 150.0$ $0.20 \mathrm{eV}$

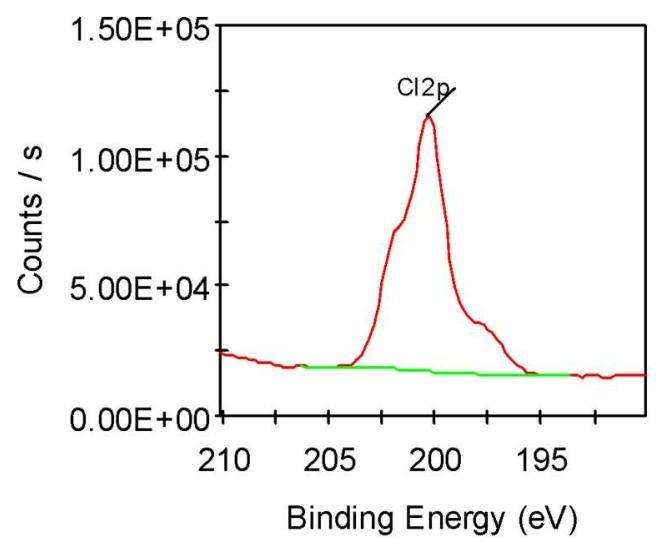

Position $=1$-coat $, X=14903.6 \mu \mathrm{m}, Y=13722.3 \mu \mathrm{m}$

Figure (A) 5 - 1a Treated CPVC Identification XPS data. 

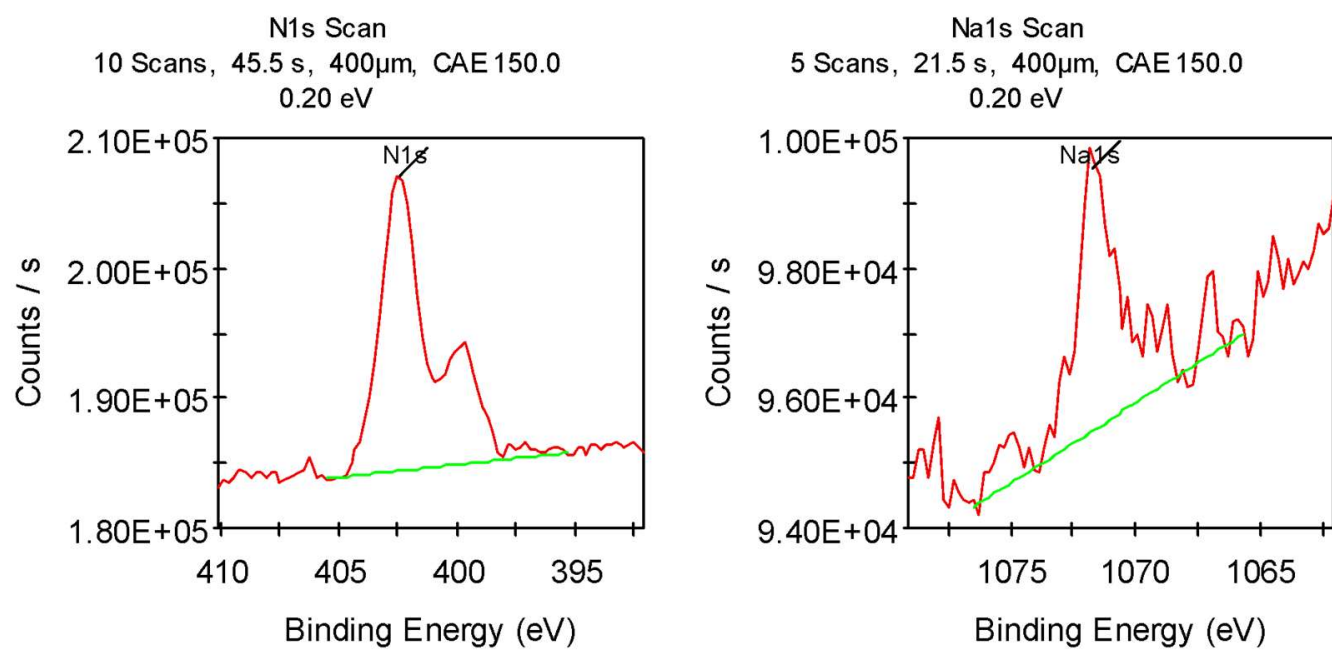

Position $=1$-coat, $X=14903.6 \mu \mathrm{m}, Y=13722.3 \mu \mathrm{m}$

O1s Scan

Position $=1$-coat $, X=14903.6 \mu \mathrm{m}, Y=13722.3 \mu \mathrm{m}$

S2p Scan

1 Scan, $5.1 \mathrm{~s}, 400 \mu \mathrm{m}, \mathrm{CAE} 150.0$

$0.20 \mathrm{eV}$
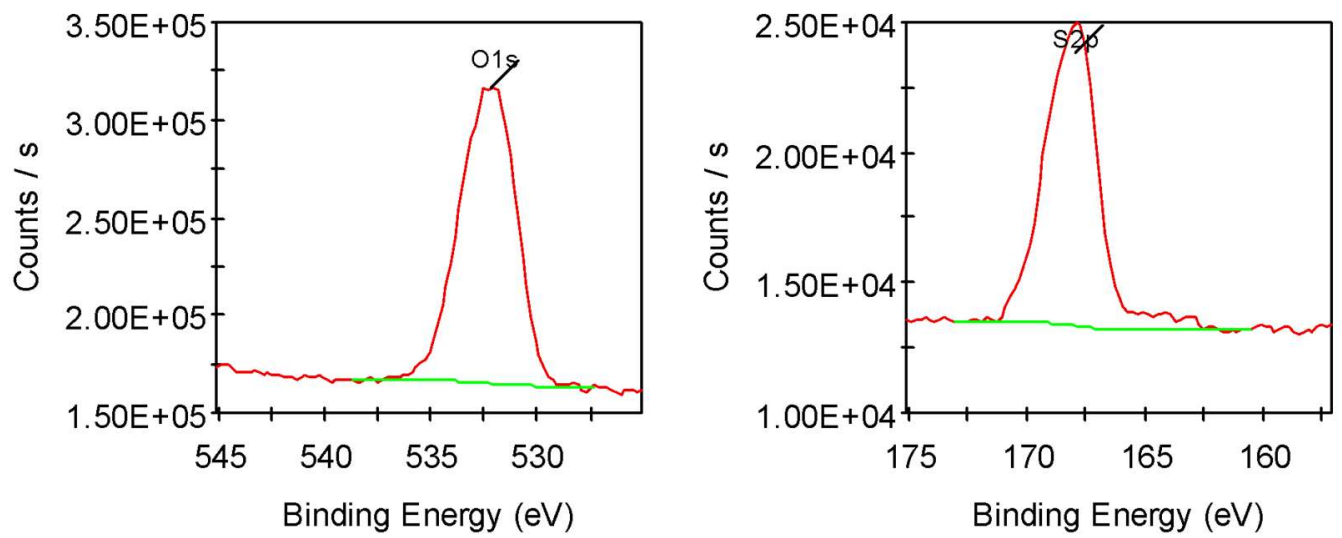

Position $=1$-coat, $X=14903.6 \mu \mathrm{m}, Y=13722.3 \mu \mathrm{m}$

Position $=1$-coat $, X=14903.6 \mu \mathrm{m}, Y=13722.3 \mu \mathrm{m}$

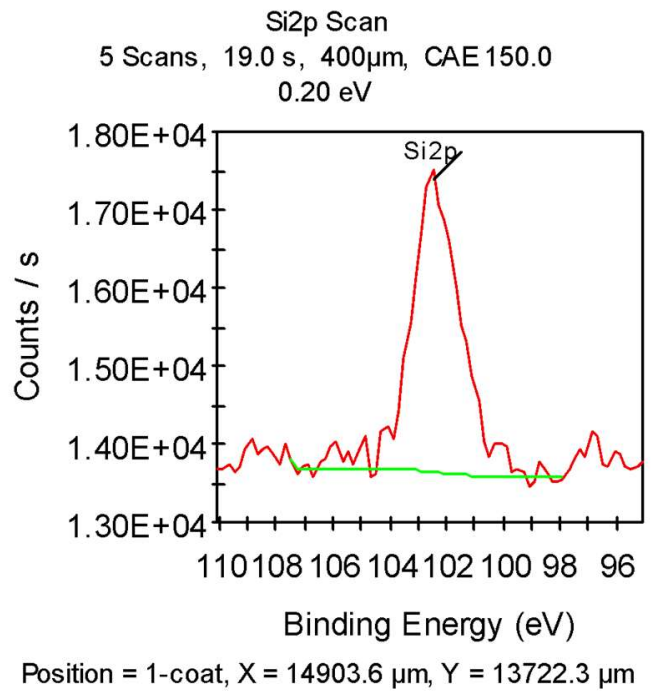

Figure (A) 6 - 1a Treated CPVC Identification XPS data (continued). 
Table (A) 1 - Quantification XPS data for control and 1a treated CPVC samples.

\begin{tabular}{|c|c|c|c|c|c|}
\hline \multicolumn{3}{|c}{ Control } & \multicolumn{3}{c|}{ Compound 1a } \\
\hline Element & $\begin{array}{c}\text { Concentration } \\
\%\end{array}$ & $\begin{array}{c}\text { Sensitivity } \\
\text { Factor }\end{array}$ & Element & $\begin{array}{c}\text { Concentration } \\
\%\end{array}$ & $\begin{array}{c}\text { Sensitivity } \\
\text { Factor }\end{array}$ \\
\hline Br3d & 0.08 & 2.840 & Br3d & 0.19 & 2.840 \\
\hline C1s & 77.16 & 1.000 & C1s & 84.24 & 1.000 \\
\hline Ca2p & 1.47 & 5.070 & Ca2p & 0.40 & 5.070 \\
\hline C12p & 7.25 & 2.285 & C12p & 4.92 & 2.285 \\
\hline N1s & 0.35 & 1.800 & N1s & 1.46 & 1.800 \\
\hline Na1s & 0.17 & 8.520 & Na1s & 0.10 & 8.520 \\
\hline O1s & 9.97 & 2.930 & O1s & 7.62 & 2.930 \\
\hline S2p & 0.93 & 1.670 & S2p & 0.72 & 1.670 \\
\hline Si2p & 2.62 & 0.817 & Si2p & 0.36 & 0.817 \\
\hline
\end{tabular}



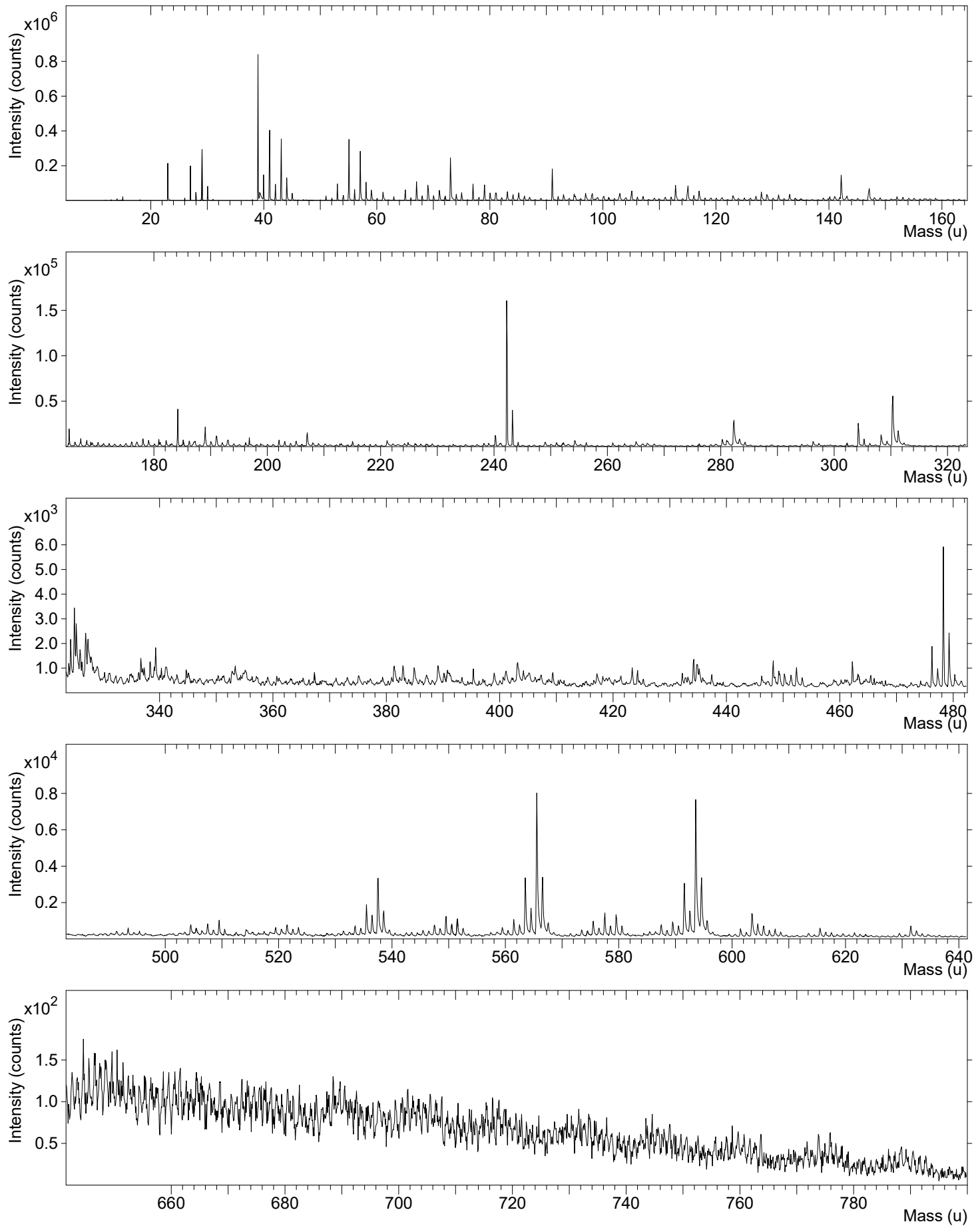

Figure (A) 7 - Positive ion ToF-SIMS survey of control CPVC material. 

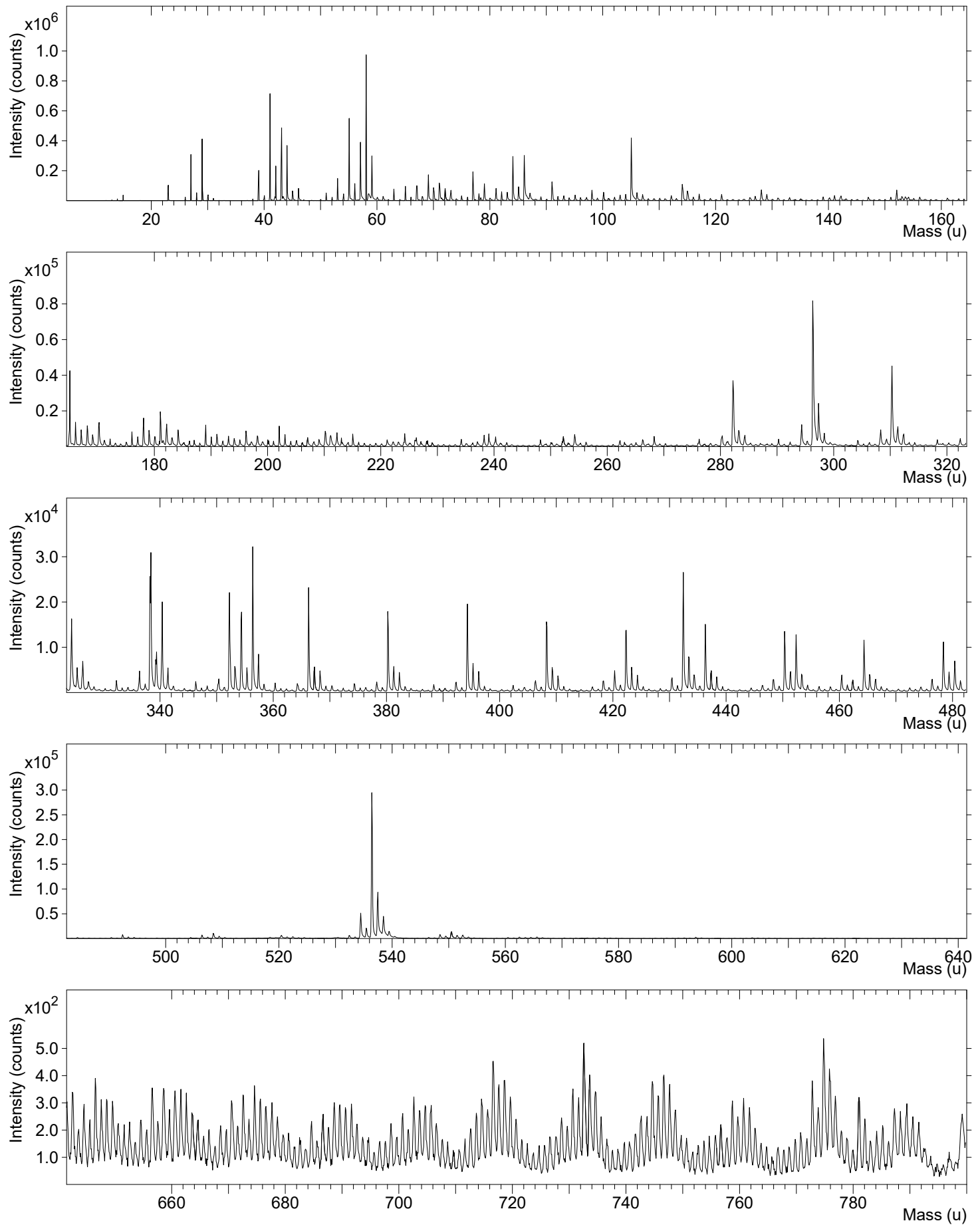

Figure (A) 8 - Positive ion ToF-SIMS survey of 1a treated CPVC material. 

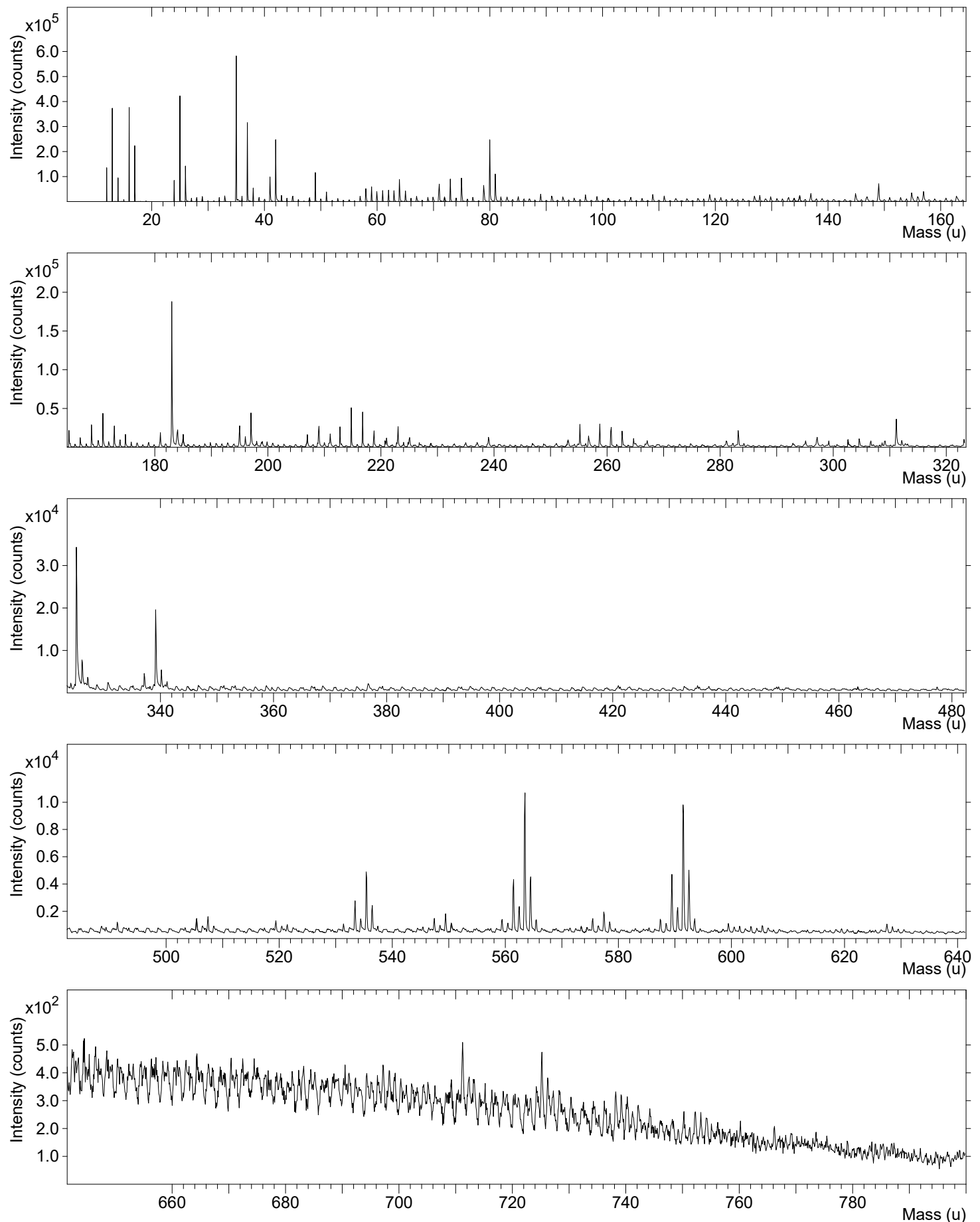

Figure (A) 9 - Negative ion ToF-SIMS survey of control CPVC material. 

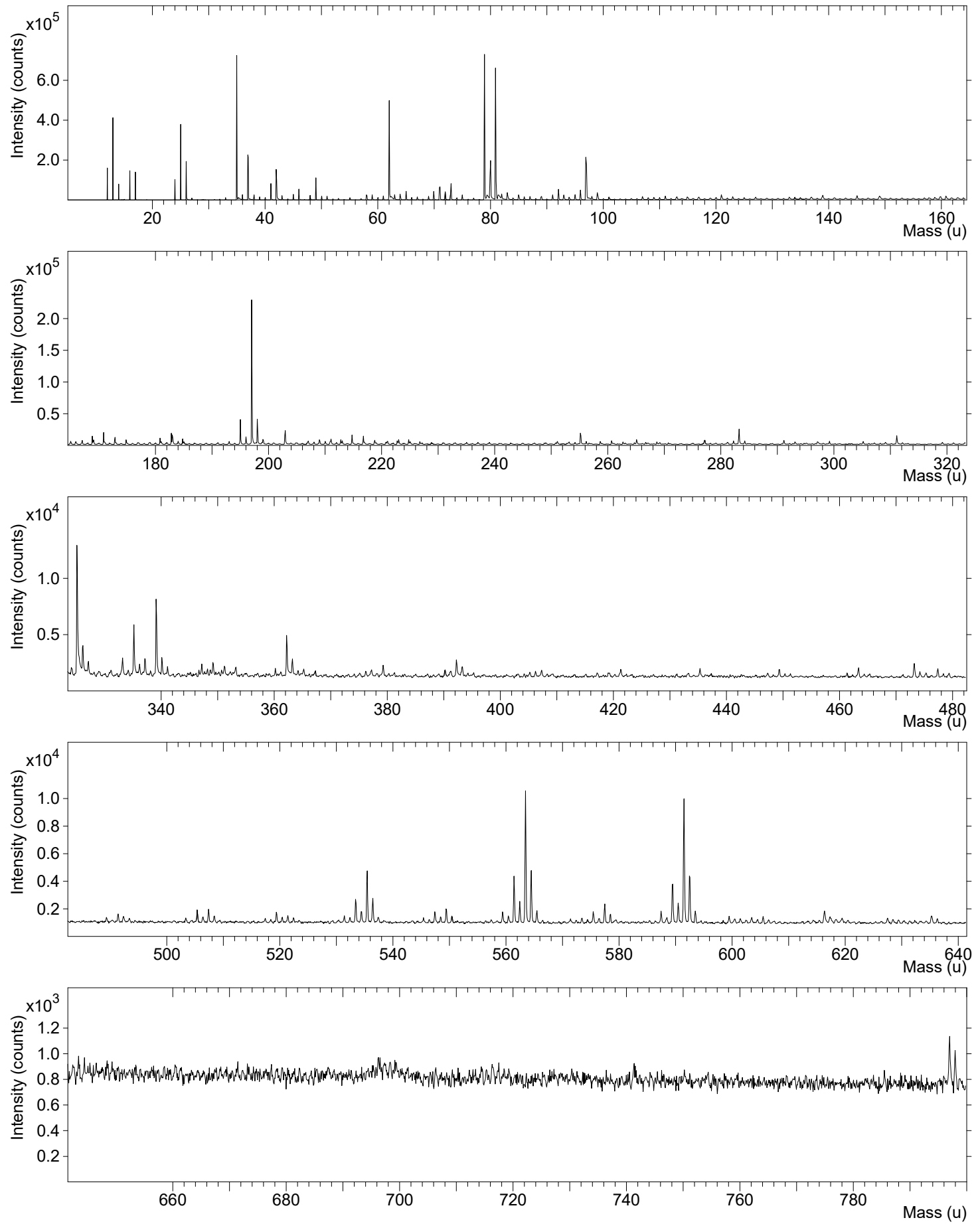

Figure (A) 10 - Negative ion ToF-SIMS survey of 1a treated CPVC material. 


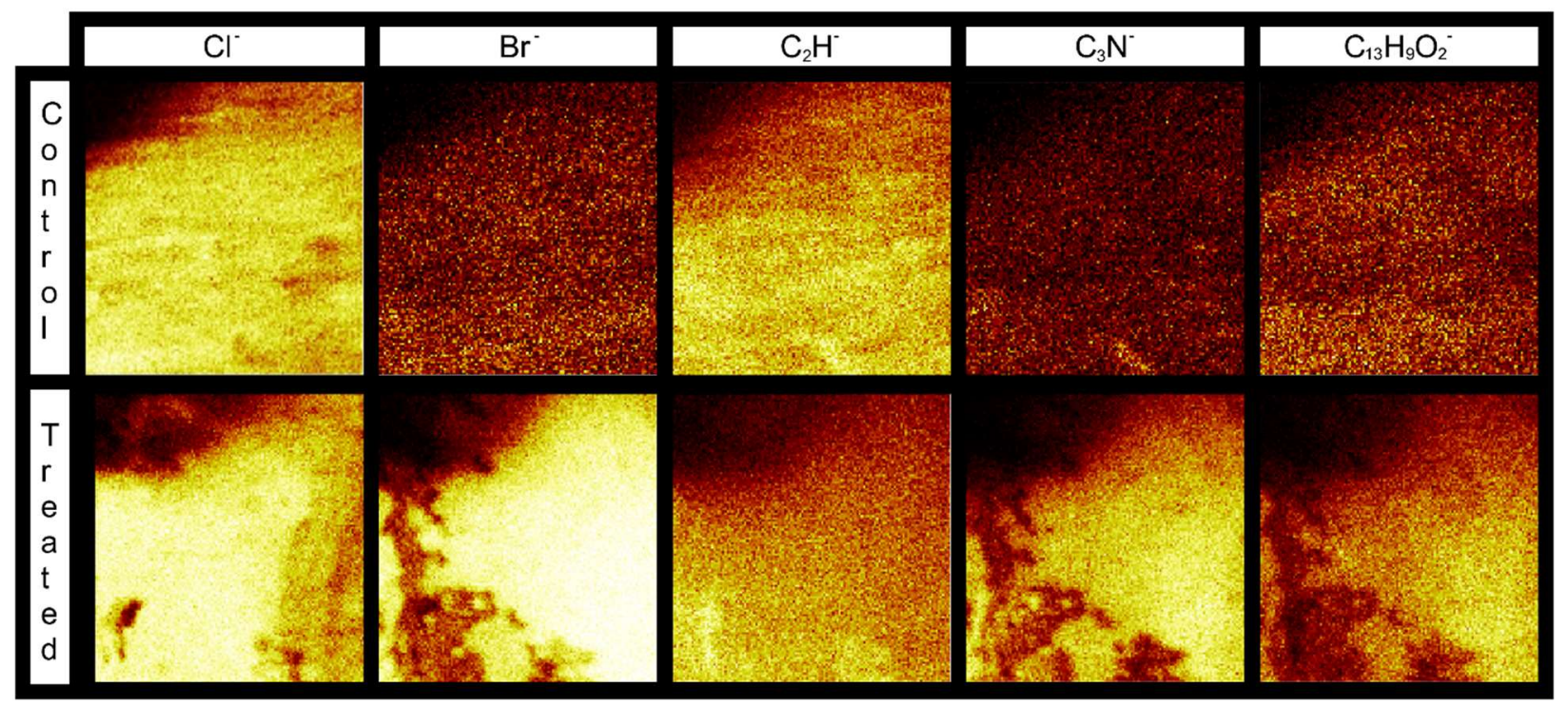

Figure (A) 11 - Composite negative ion ToF-SIMS image of $500.0 \times 500.0 \mu \mathrm{m}$ section of control and 1a treated samples. Intensity is a function of fragment quantity during analysis. Images correspond to negative ionic fragmentation products of chlorine $\left(\mathrm{Cl}^{-}\right)$, bromine $\left(\mathrm{Br}^{-}\right)$, ethane $\left(\mathrm{C}_{2} \mathrm{H}^{-}\right)$, tetracarbonyl ammonium $\left(\mathrm{C}_{4} \mathrm{~N}^{-}\right)$, and hydroxybenzophenone $\left(\mathrm{C}_{13} \mathrm{H}_{9} \mathrm{O}_{2}{ }^{-}\right)$. 


\section{Atomic Force Microscopy and Surface Profilometry Data}

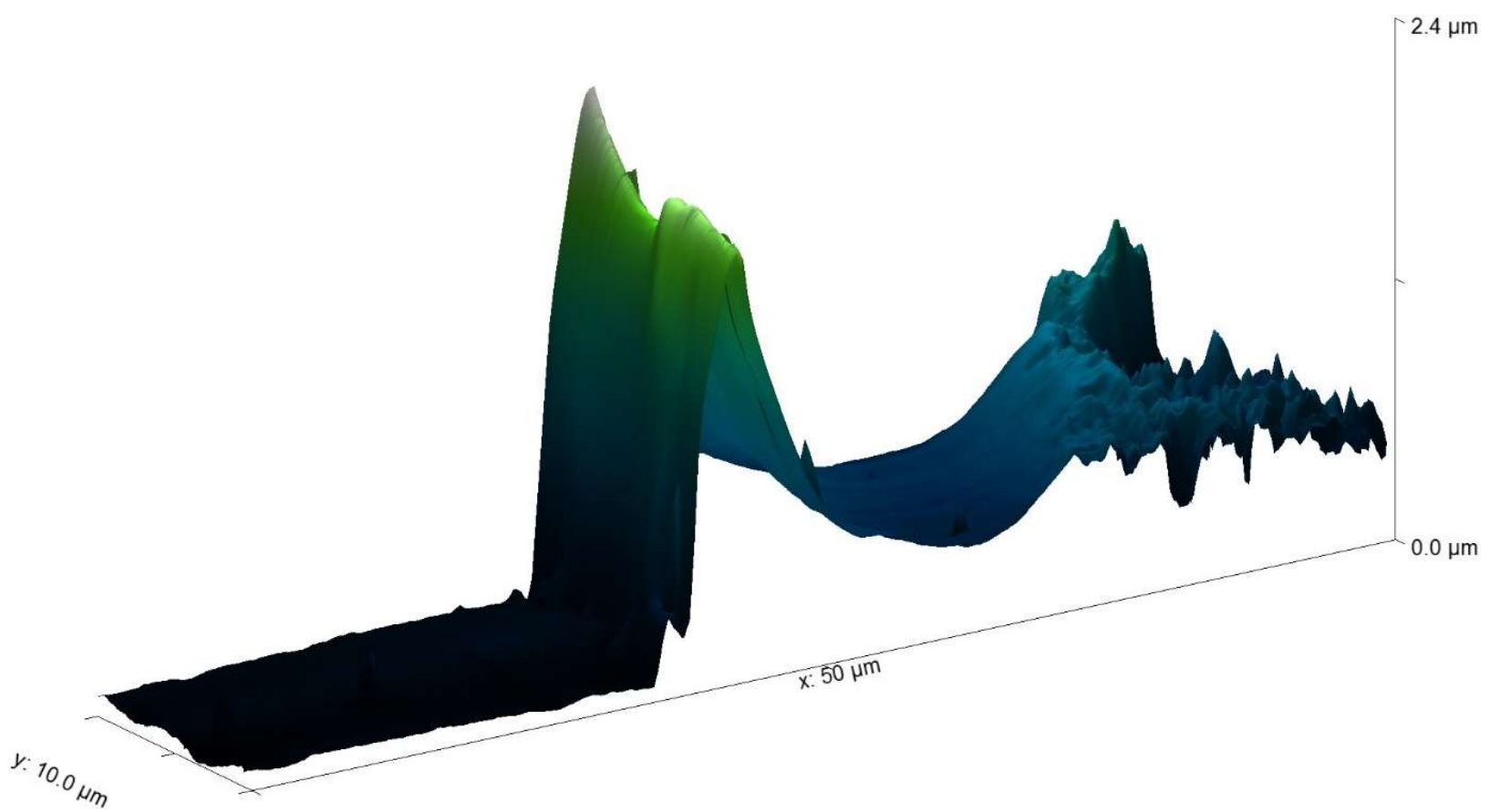

Figure (A) 12 - AFM imaging of location A, found along the separation line between the previously taped (left) and untaped (right) sections of twice coated PS using antimicrobial 1a. Image processed using Gwiddion 2.48.

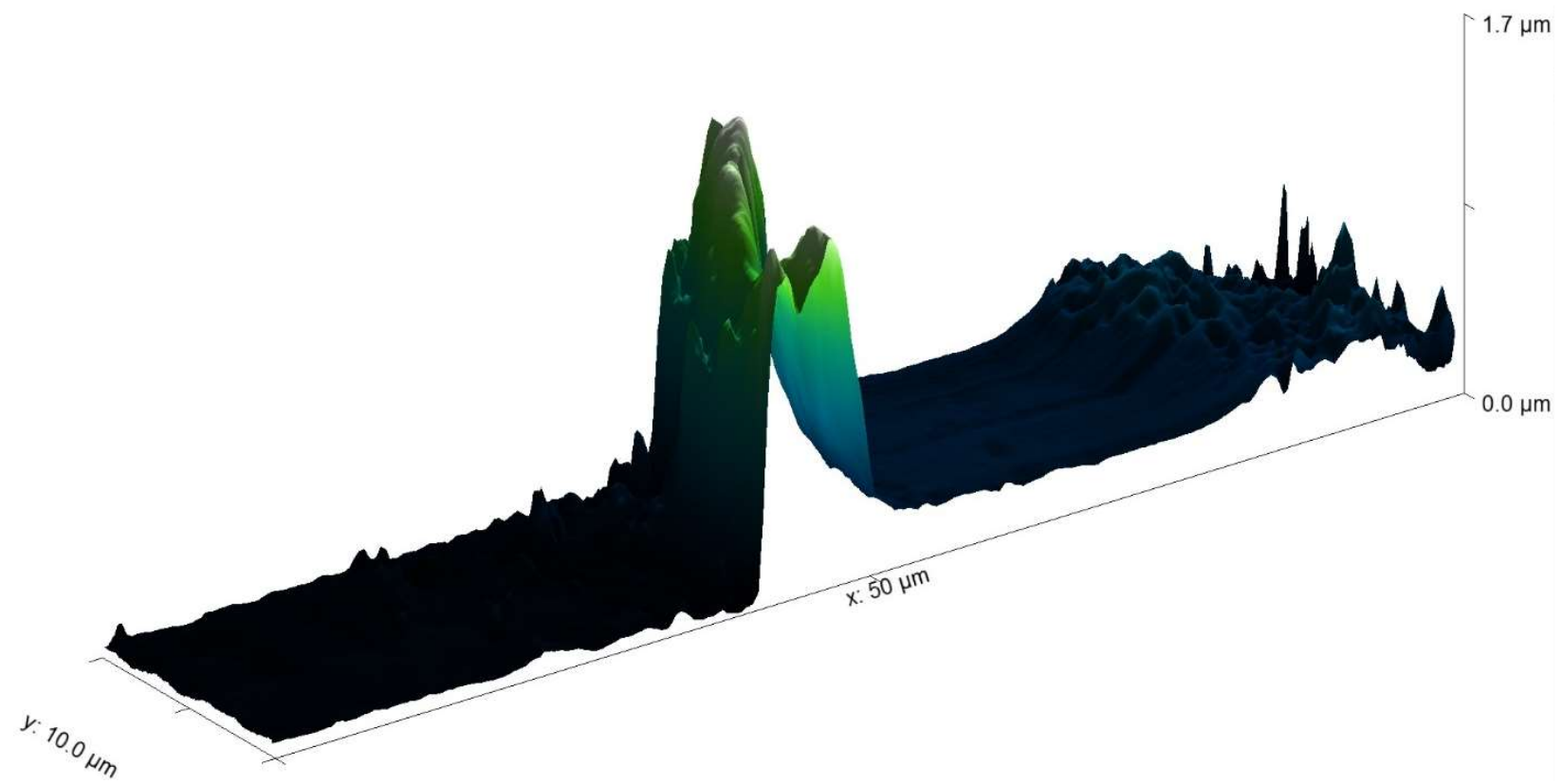

Figure (A) 13 - AFM imaging of location B, found along the separation line between the previously taped (left) and untaped (right) sections of twice coated PS using antimicrobial 1a. Image processed using Gwiddion 2.48. 


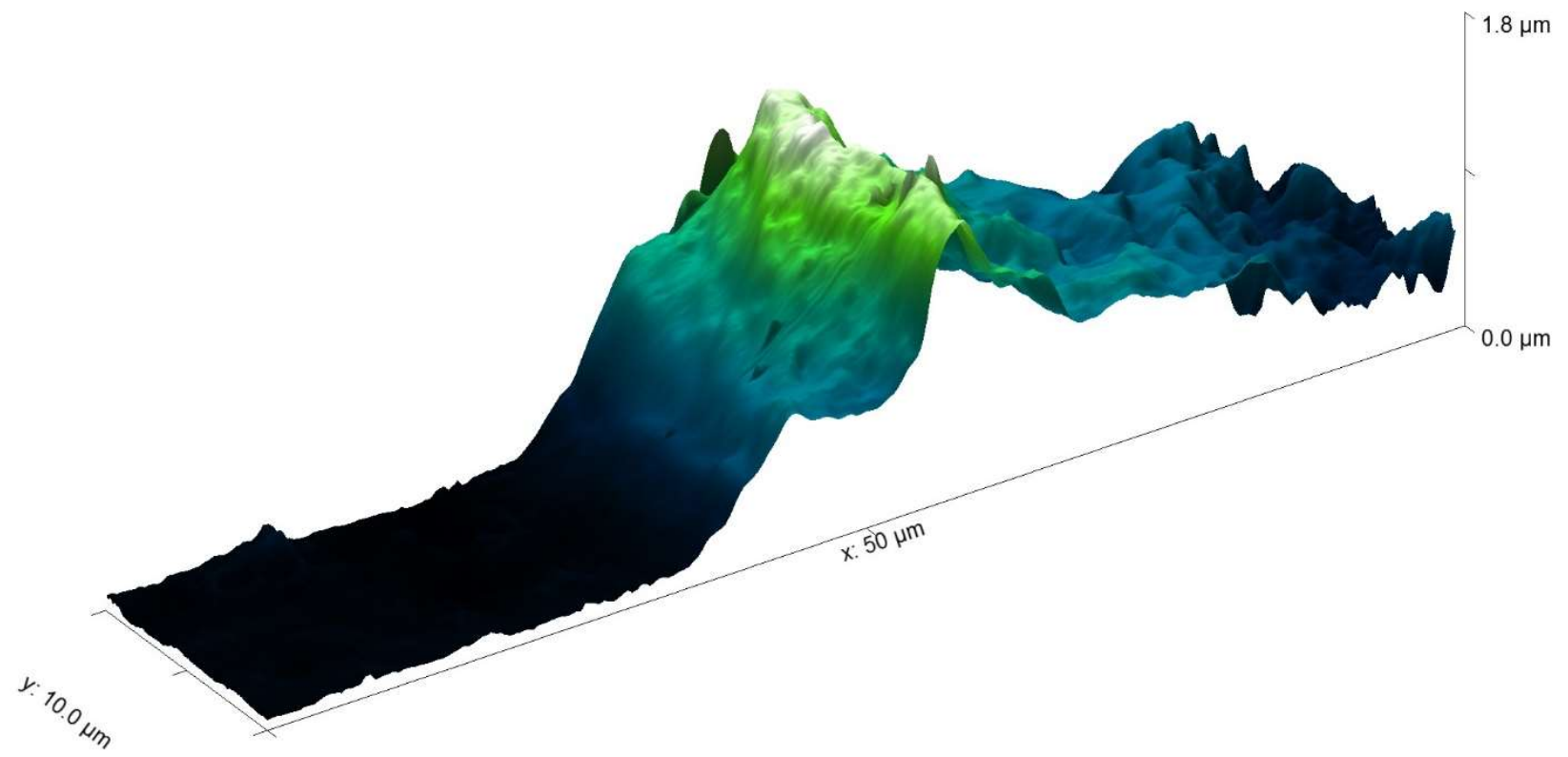

Figure (A) 14 - AFM imaging of location C, found along the separation line between the previously taped (left) and untaped (right) sections of twice coated PS using antimicrobial 1a. Image processed using Gwiddion 2.48. 


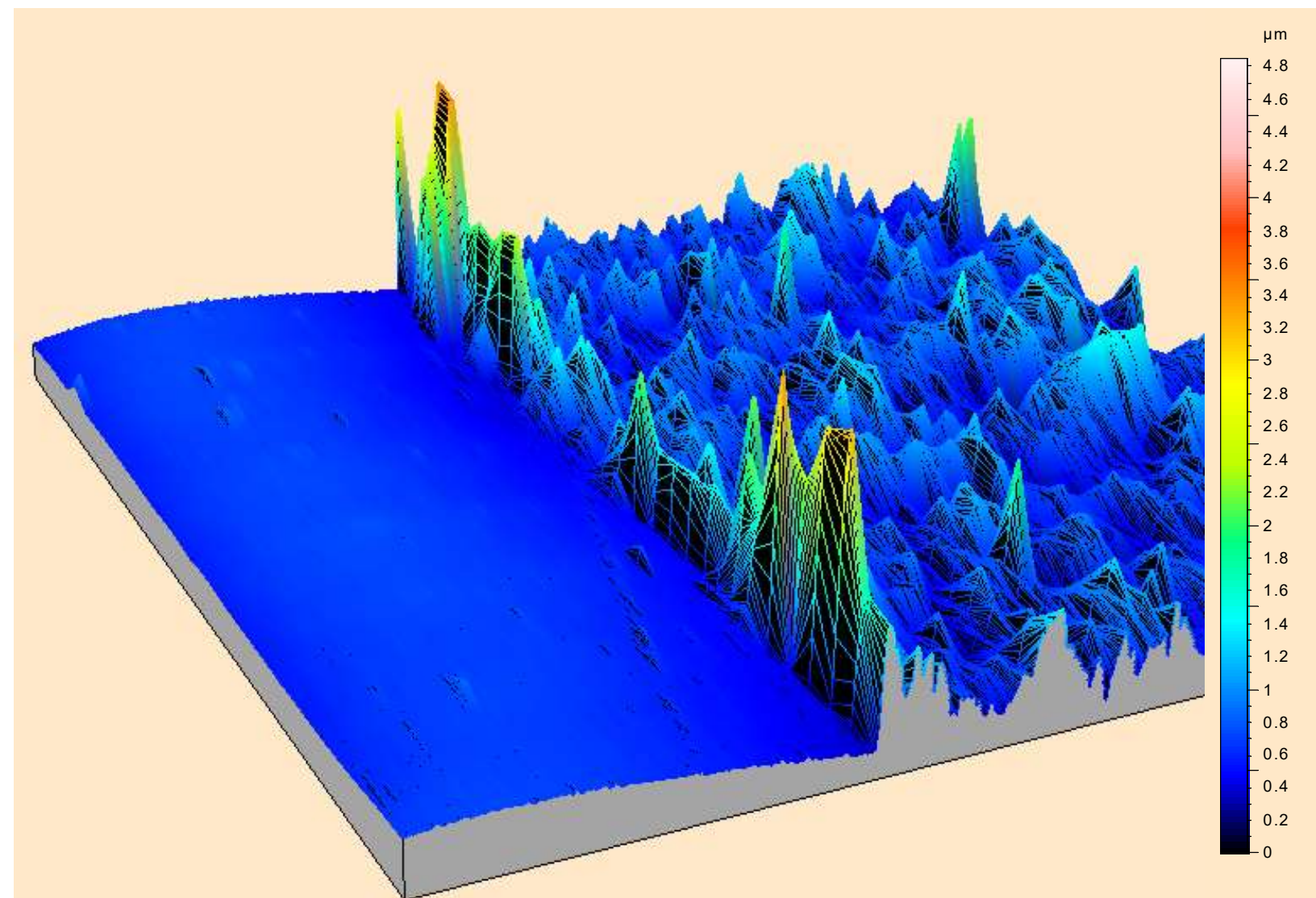

Figure (A) 15 - 3D graphical representation using surface profilometry of a $0.25 \mathrm{~mm}^{2}$ area found along the separation line between the previously taped (left) and untaped (right) sections of twice coated PS using antimicrobial $\mathbf{1 a}$. 


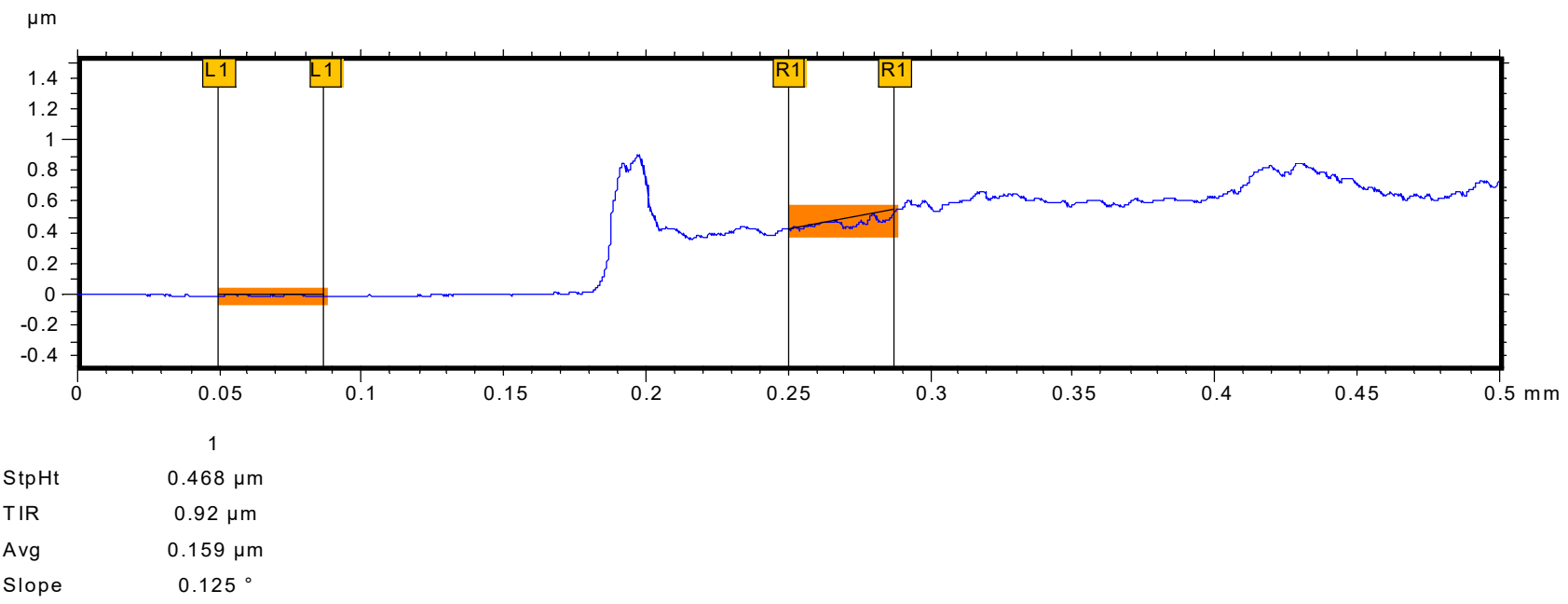

Figure (A) 16 - SP Mean profile of Figure (A) 16 (n=51). 


\section{Epifluorescence Compound Imaging}
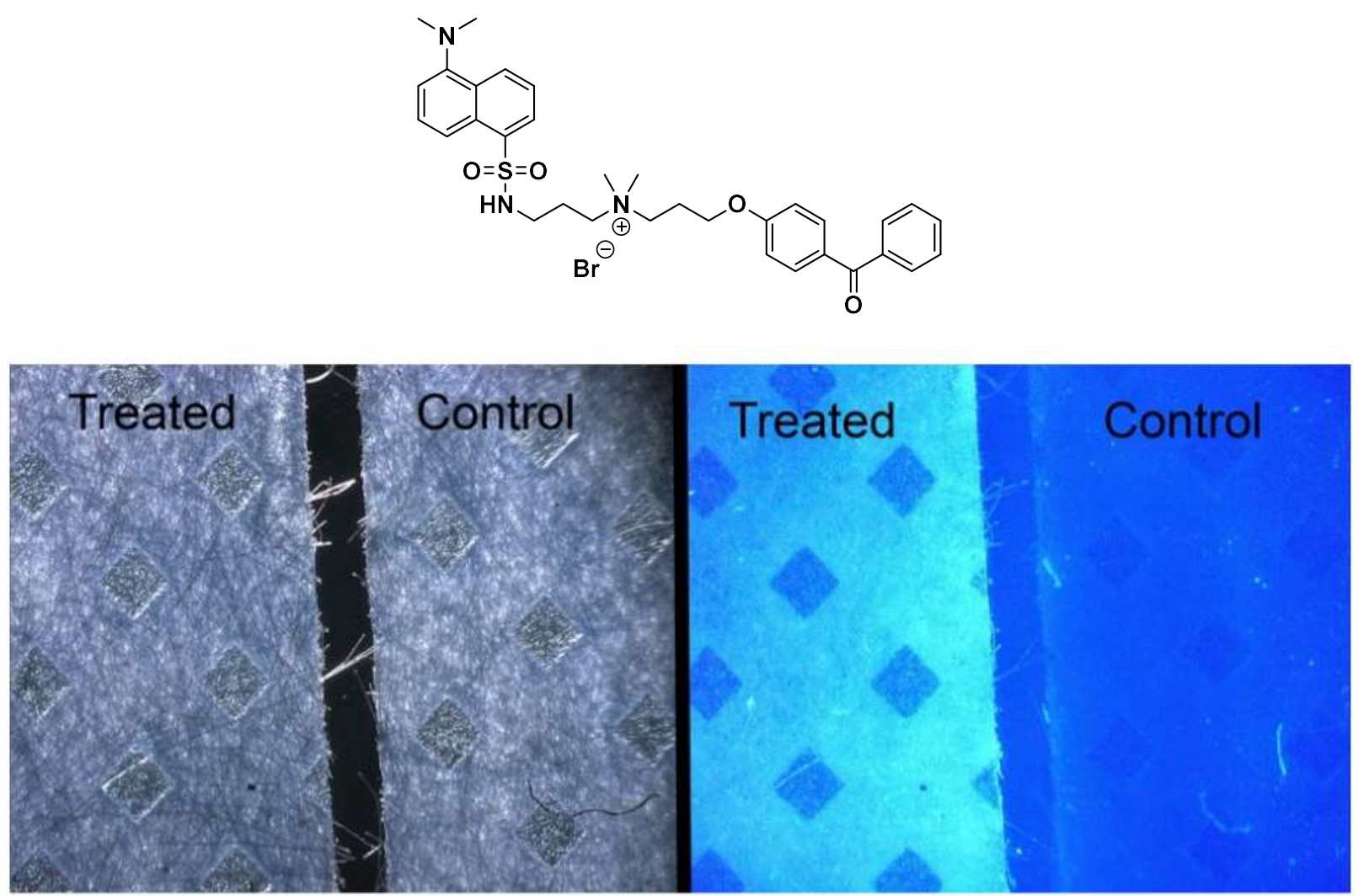

Figure (A) 17 - Spectroscopic images of polypropylene fabric samples under white light (left) and GFP2-filtered UV light (right). Sample coatings supplemented with dansyl fluorophore 12a (above) appeared to brightly fluoresce when exposed to UV light. 


\section{Microbiology Data}

Table (A) 2 - Alkyl QAC 1a-2a microbiology data (LDI). Microbiological testing was performed with triplicate treated and untreated controls. The inoculum load represents the quantity of viable cells placed onto each sample material and was determined concurrently to sample data ( \pm indicates standard deviation $n=3$ ). A value of $1.70 \log (\mathrm{CFU})$ represents the lowest number of detectable cells spot plated onto $3 \mathrm{~g} \mathrm{~L}^{-1} \mathrm{TSA}$ (LOD: $50 \mathrm{CFU}, 1$ colony in $5 \mathrm{~mL}$ undiluted collection fluid).

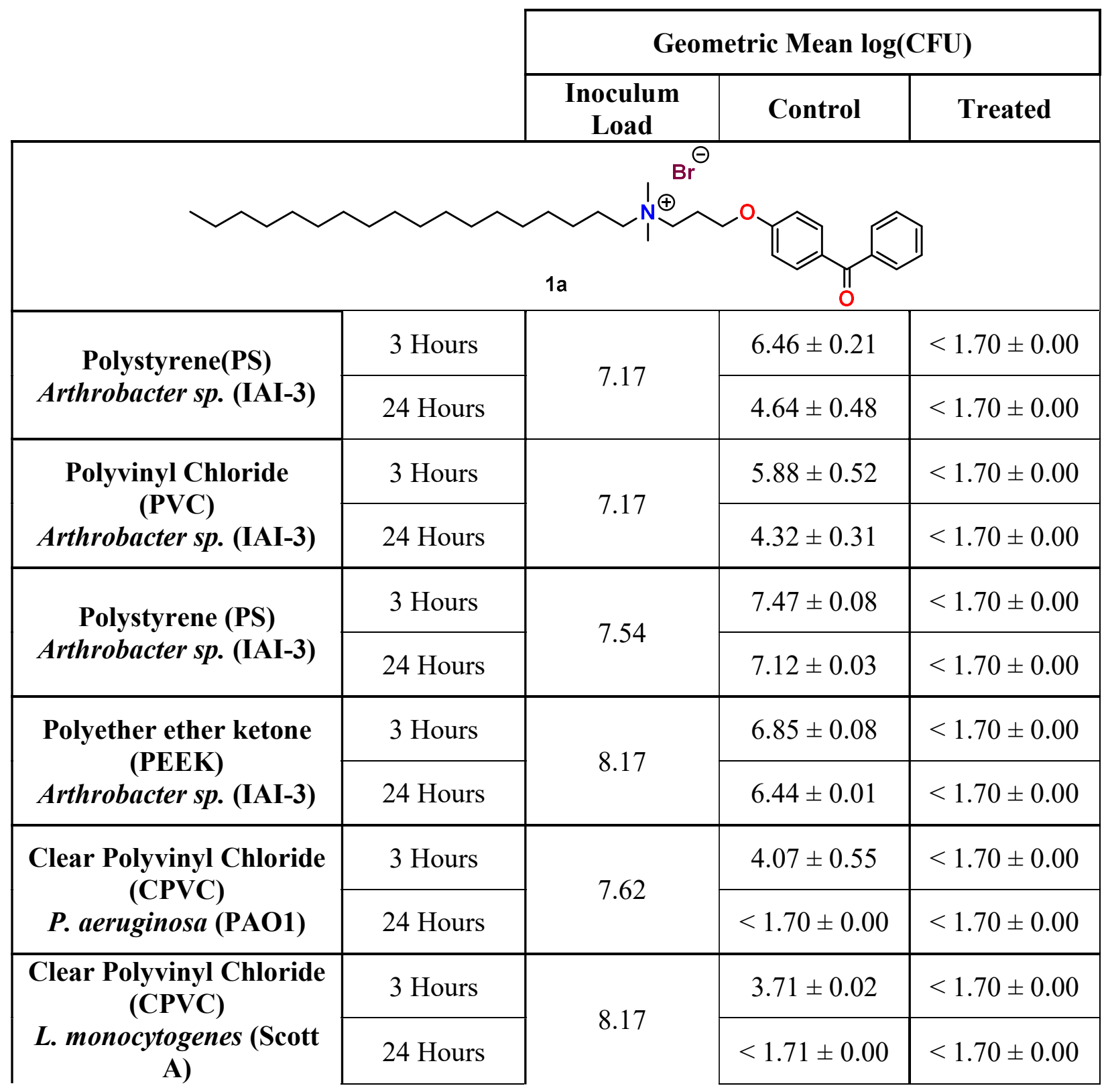




\begin{tabular}{|l|c|c|c|c|}
\hline \multicolumn{2}{|c|}{ 2a } & & \\
\hline $\begin{array}{c}\text { Polystyrene (PS) } \\
\text { Arthrobacter sp. (IAI-3) }\end{array}$ & 3 Hours & 7.15 & $5.63 \pm 0.10$ & $<1.70 \pm 0.00$ \\
\hline
\end{tabular}

Table (A) 3 - Multi-load alkyl QAC 1a microbiology data (LDI). Microbiological testing was performed with triplicate treated and untreated controls. The inoculum load represents the quantity of viable cells placed onto each sample material and was determined concurrently to sample data ( \pm indicates standard deviation $n=3$ ). A value of $1.70 \log (\mathrm{CFU})$ represents the lowest number of detectable cells spot plated onto $3 \mathrm{~g} \mathrm{~L}^{-1} \mathrm{TSA}$ (LOD: $50 \mathrm{CFU}, 1$ colony in $5 \mathrm{~mL}$ undiluted collection fluid).

\begin{tabular}{|c|c|c|c|c|}
\cline { 3 - 4 } \multicolumn{2}{c|}{} & \multicolumn{3}{c|}{ Geometric Mean $\log (\mathbf{C F U})$} \\
\cline { 3 - 5 } & $\begin{array}{c}\text { Inoculum } \\
\text { Load }\end{array}$ & Control & Treated \\
\hline $\begin{array}{c}\text { Polystyrene(PS) } \\
\text { Arthrobacter sp. (IAI-3) }\end{array}$ & $\begin{array}{c}\text { Single } \\
\text { Inoculation }\end{array}$ & 6.79 & $5.96 \pm 0.10$ & $<1.70 \pm 0.00$ \\
\hline $\begin{array}{c}\text { Polystyrene(PS) } \\
\text { Arthrobacter sp. (IAI-3) }\end{array}$ & $\begin{array}{c}\text { Double } \\
\text { Inoculation }\end{array}$ & 7.28 & $7.07 \pm 0.04$ & $6.09 \pm 0.03$ \\
\hline
\end{tabular}

\section{Synthetic Procedure}

Precursor 4-(3-bromopropyoxy)benzophenone was synthesized according to published work and NMR spectra $\left({ }^{1} \mathrm{H}\right.$ and $\left.{ }^{13} \mathrm{C}\right)$ corresponded well with previously published NMR data. ${ }^{84}$ Synthetic procedure and NMR data for this publication was prepared by Joseph Bedard. 


\section{Synthesis of $N$-(3-(4-benzoylphenyl)propyl)- $N, N$-dimethyloctadecan-1-aminium bromide 1a}

In a 5-10 $\mathrm{mL}$ microwave vial equipped with a magnetic stir bar, 4-(3bromopropoxy)benzophenone (0.617 g, $1.93 \mathrm{mmol}, 1.0$ eq.) was dissolved in $\mathrm{MeCN}(10 \mathrm{~mL})$. $N, N$-dimethyloctadecylamine $(0.608 \mathrm{~g}, 2.04 \mathrm{mmol}, 1.1$ eq.) was carefully added to the solution and the reaction vessel was slightly heated using a heat gun to fully dissolve reactants into the solution. The vial was then capped, placed in the microwave, and with constant stirring run at 150 ${ }^{\circ} \mathrm{C}$ for $2 \mathrm{~min}$. The resultant clear mixture was poured into cold $\mathrm{Et}_{2} \mathrm{O}(\sim 10 \mathrm{~mL})$ for the desired product to precipitate out of solution. The product was isolated from excess solvent via decantation then dried under vacuum to yield a white powder. Recovered yield: $1.10 \mathrm{~g}(93 \%)$. Mp $=77-79$ ${ }^{\circ} \mathrm{C}$. UV-Vis $\left(\mathrm{H}_{2} \mathrm{O}, 1.62 \times 10^{-5} \mathrm{M}\right.$ to $\left.1.62 \times 10^{-4} \mathrm{M}\right): \lambda_{\mathrm{ABS} \max }=292 \mathrm{~nm}, \varepsilon_{1}=11400 \mathrm{M}^{-1} \mathrm{~cm}^{-1} \mathbf{1}_{\mathbf{H}}$ $\operatorname{NMR}\left(400 \mathrm{MHz}, \mathrm{CDCl}_{3}\right) \delta=7.73(\mathrm{~d}, J=8.8 \mathrm{~Hz}, 2 \mathrm{H}, \mathrm{H} 7), 7.67(\mathrm{~d}, J=7.0 \mathrm{~Hz}, 2 \mathrm{H}, \mathrm{H} 3), 7.51(\mathrm{t}$, $J=7.4 \mathrm{~Hz}, 1 \mathrm{H}, \mathrm{H} 1), 7.41(\mathrm{t}, J=7.5 \mathrm{~Hz}, 2 \mathrm{H}, \mathrm{H} 2), 6.90(\mathrm{~d}, J=8.8 \mathrm{~Hz}, \mathrm{H} 8,2 \mathrm{H}), 4.17(\mathrm{t}, J=5.5$ Hz, 2H, H10), 3.83 - 3.79 (m, 2H, H12), $3.54-3.50$ (m, 2H, H14), 3.40 (s, 6H, H13), $2.34-2.27$ (m, 2H, H11), $1.74-1.65$ (m, 2H, H15), $1.36-1.18$ (m, 30H, H16-H30 overlap), 0.82 (t, $J=6.8$ Hz, 3H, H31) ppm. ${ }^{13} \mathbf{C}\{\mathbf{H}\}$ NMR (101 MHz, $\left.\mathrm{CDCl}_{3}\right) \delta=195.5$ (C5), 161.6 (C9), 138.0 (C4), 132.5 (C7), 132.1 (C1), 130.7 (C6), 129.7 (C3), 128.3 (C2), 114.1 (C8), 64.5 (C10+C12 overlap), 61.1 (C14), 51.5 (C13), 31.9 (C29), 29.7-29.2 (C17-C28 overlap), 26.3 (C16), 23.2 (C11), 22.8 (C15), 22.7 (C30), 14.1 (C31) ppm. HRMS (ESI-TOF) (m/z): [M+ - Br] for $\mathrm{C}_{36} \mathrm{H}_{58} \mathrm{BrNO}_{2}$ : calculated 536.4462; found 536.5578.

Synthesis of $N$-(3-(4-benzoylphenyl)propyl)- $N, N$-dimethyldodecan-1-ammonium bromide 2 
In a $500 \mathrm{~mL}$ glass vial equipped with a magnetic stir bar, 4-(3chloropropoxy)benzophenone (22.434 g, 70.29 mmol, 1.0 eq.) was dissolved in EtOAc (70 mL). $N, N$-dimethyloctadecylamine $(15.000 \mathrm{~g}, 1.00 \mathrm{mmol}, 1.0 \mathrm{eq}$.$) was carefully added to the solution$ before the vial was capped and left to stir in a $100{ }^{\circ} \mathrm{C}$ sand bath for 48 hours. After removing the magnetic stirrer and allowing the solution to cool to RT, the product precipitated out of solution as a white powder. The excess solvent was poured out, and the product was triturated with another $70 \mathrm{~mL}$ of EtOAc to obtain the title compound after further drying under high vacuum. Recovered yield: $36.377 \mathrm{~g}(97.2 \%)$. A $1 \%$ solution of the recovered product $(1000 \mathrm{mg} / 100 \mathrm{~mL})$ was recrystallized from water over a period of three months by slow evaporation as long, clear needles for X-ray analysis. $\mathrm{Mp}=50-52^{\circ} \mathrm{C} .{ }^{1} \mathbf{H} \mathbf{N M R}\left(\mathrm{CDCl}_{3}, 400 \mathrm{MHz}\right) \delta=7.75(\mathrm{~d}, J=8.8 \mathrm{~Hz}, 2 \mathrm{H}, \mathrm{H} 7)$, $7.69(\mathrm{~d}, J=7.0 \mathrm{~Hz}, 2 \mathrm{H}, \mathrm{H} 3), 7.53$ (t, $J=7.3 \mathrm{~Hz}, 1 \mathrm{H}, \mathrm{H} 1), 7.43$ (t, $J=7.5 \mathrm{~Hz}, 2 \mathrm{H}, \mathrm{H} 2), 6.93$ (d, $J$ $=8.8 \mathrm{~Hz}, 2 \mathrm{H}, \mathrm{H} 8), 4.19(\mathrm{t}, J=5.1 \mathrm{~Hz} 2 \mathrm{H}, \mathrm{H} 10), 3.82-3.73(\mathrm{~m}, 2 \mathrm{H}, \mathrm{H} 12), 3.52-3.48(\mathrm{~m}, 2 \mathrm{H}$, H14), 3.40 (s, 6H, H13), 2.45 - 2.26 (m, 2H, H11), 1.80 - 1.65 (m, 2H, H15), 1.41 - 1.10 (m, 18H, H16-H24), $0.83(\mathrm{t}, J=6.7 \mathrm{~Hz}, 3 \mathrm{H}, \mathrm{H} 25) \mathrm{ppm} .{ }^{13} \mathbf{C}\{\mathbf{H}\} \mathbf{N M R}\left(\mathrm{CDCl}_{3}, 101 \mathrm{MHz}\right) \delta=195.6(\mathrm{C} 5)$, 161.7 (C9), 138.0 (C4), 132.6 (C7), 132.2 (C1), 130.8 (C6), 129.8 (C3), 128.3 (C2), 114.2 (C8), 64.6 (C10), 64.5 (C12), 61.2 (C14), 51.6 (C13), 31.9 (C23), 29.6-29.3 (C22-C17 overlap), 26.3 (C16), 23.2 (C11), 22.8 (C23), 22.7 (C24), 14.2 (C25) ppm. HRMS (ESI-TOF) (m/z): [M+ - Br] for $\mathrm{C}_{30} \mathrm{H}_{46} \mathrm{BrNO}_{2}$ : calculated 452.3523; found 452.3527 . 


\section{NMR and HRMS Spectra of Synthesized Compounds}

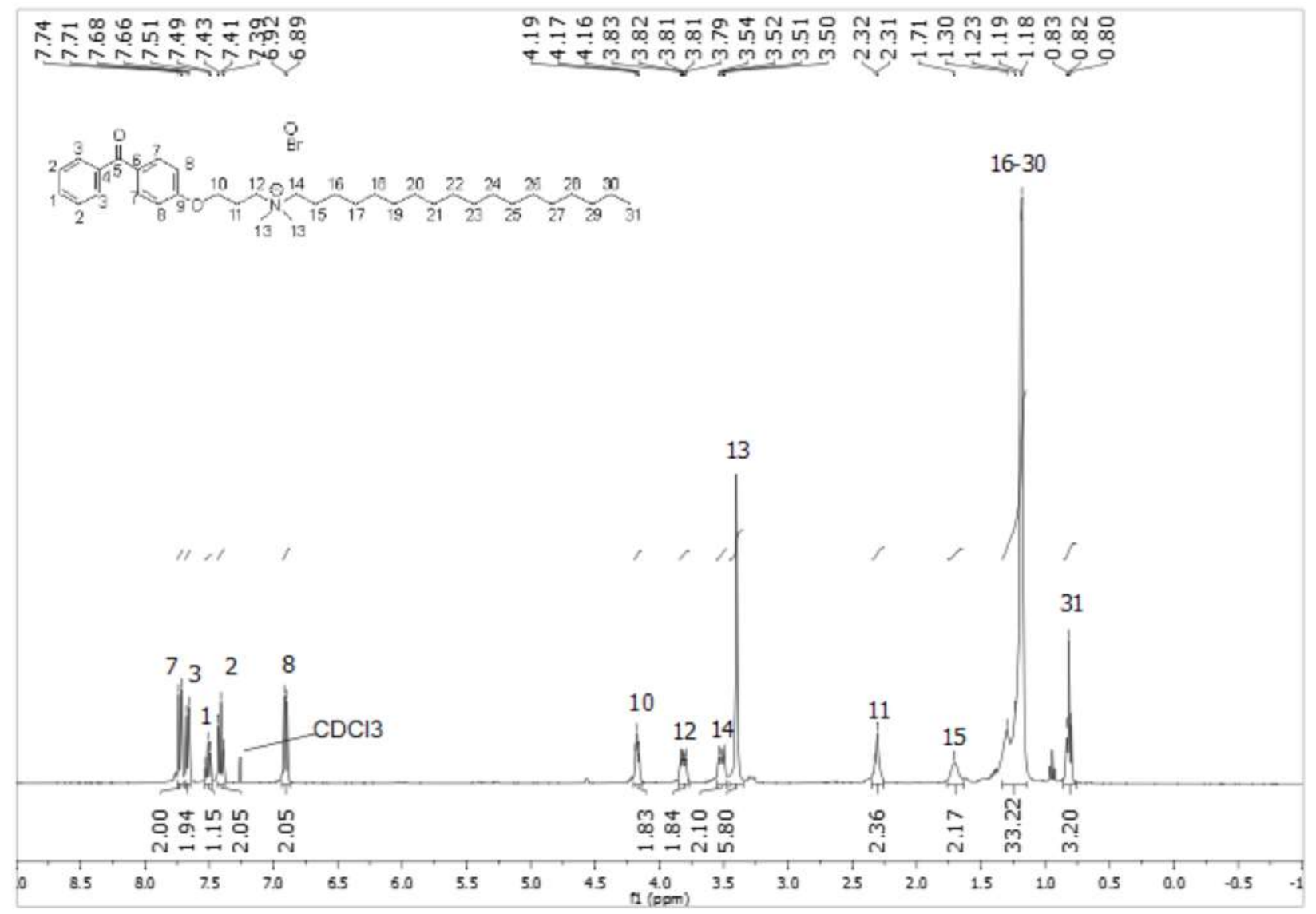

Figure (A) $18-{ }^{1} \mathrm{H} \mathrm{NMR}\left(400 \mathrm{MHz}, \mathrm{CDCl}_{3}\right)$ spectrum of $\mathbf{1 a}$. 


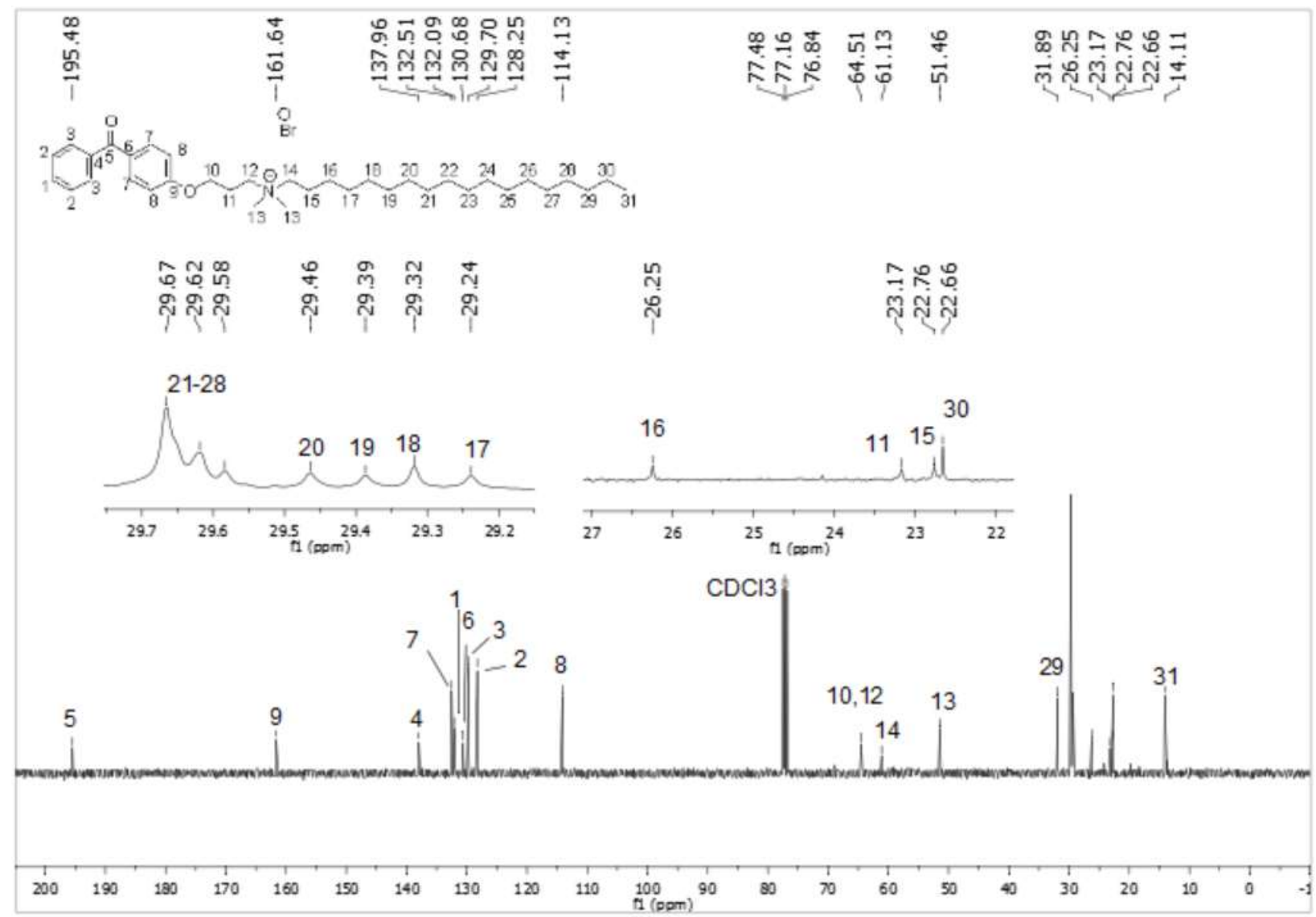

Figure (A) $19-{ }^{13} \mathrm{C}$ NMR $\left(101 \mathrm{MHz}, \mathrm{CDCl}_{3}\right)$ spectrum of $\mathbf{1 a}$. 


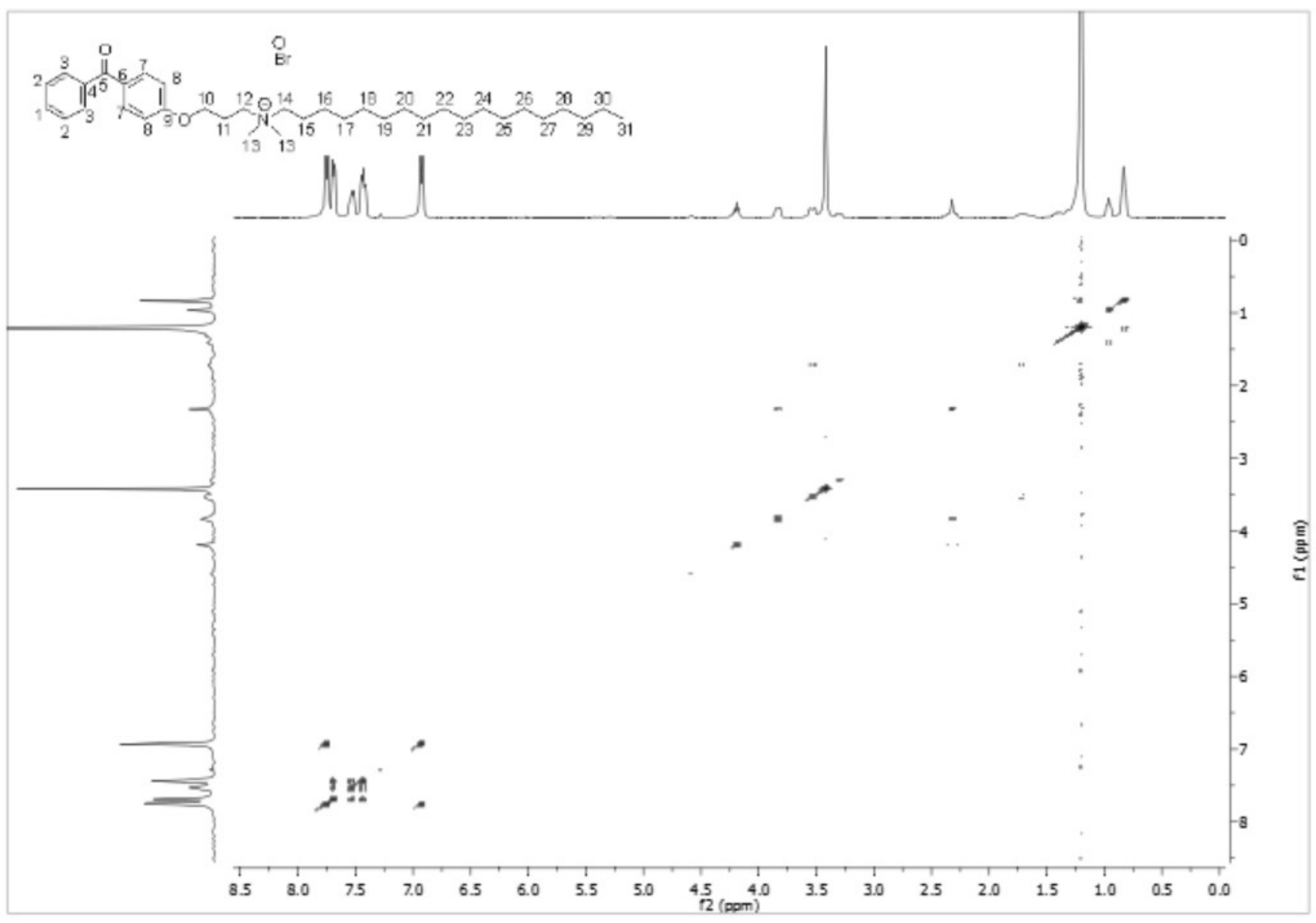

Figure (A) 20 - COSY 2D NMR $\left(\mathrm{CDCl}_{3}\right)$ spectrum of $\mathbf{1 a}$. 


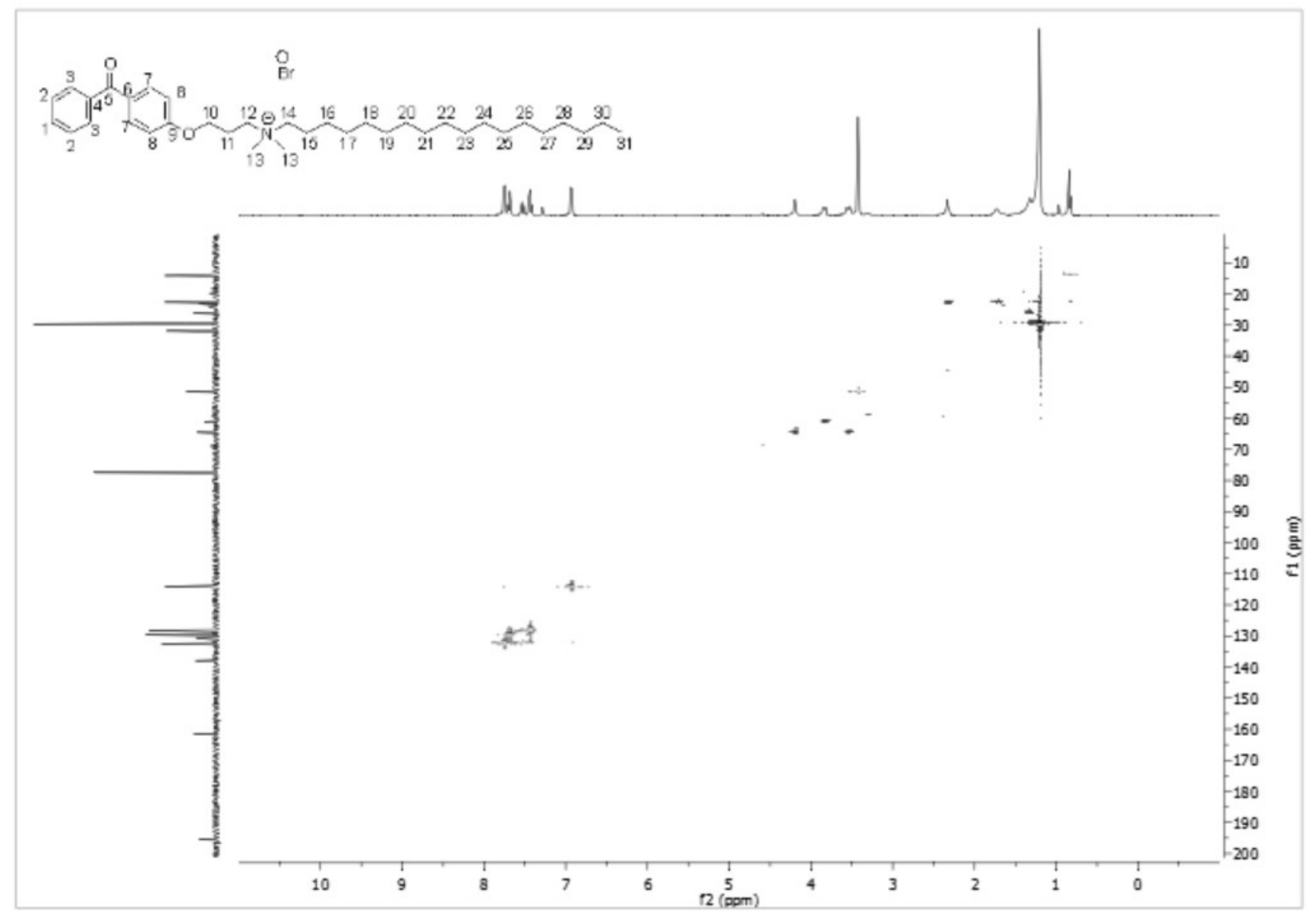

Figure (A) 21 - HSQC 2D NMR $\left(\mathrm{CDCl}_{3}\right)$ spectrum of $\mathbf{1 a}$. 
+TOF MS: 1.384 to $1.417 \mathrm{~min}$ from Sample 2 (A25-6c) of 1207101011 wiff

$a=3.58007847869392780 \mathrm{e}-004, \mathrm{t} 0=6.01084599920209610 \mathrm{e}+001 \mathrm{R}_{\text {; }}$ subtracted $(0.383$ to $0.417 \mathrm{~min})$

Max. 794.7 counts

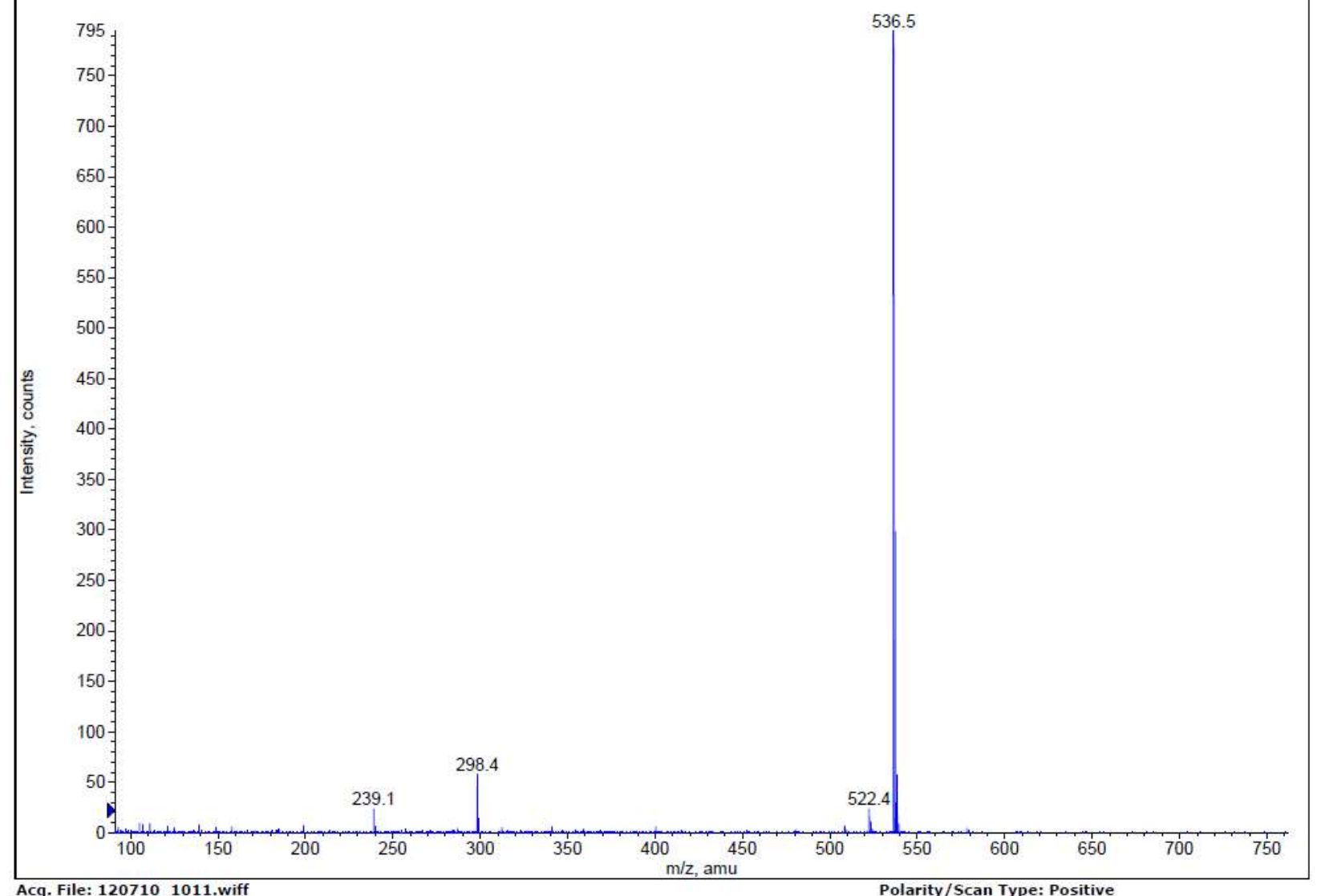

Figure (A) 22 - HRMS-ESI TOF of compound $\mathbf{5 b}$. 


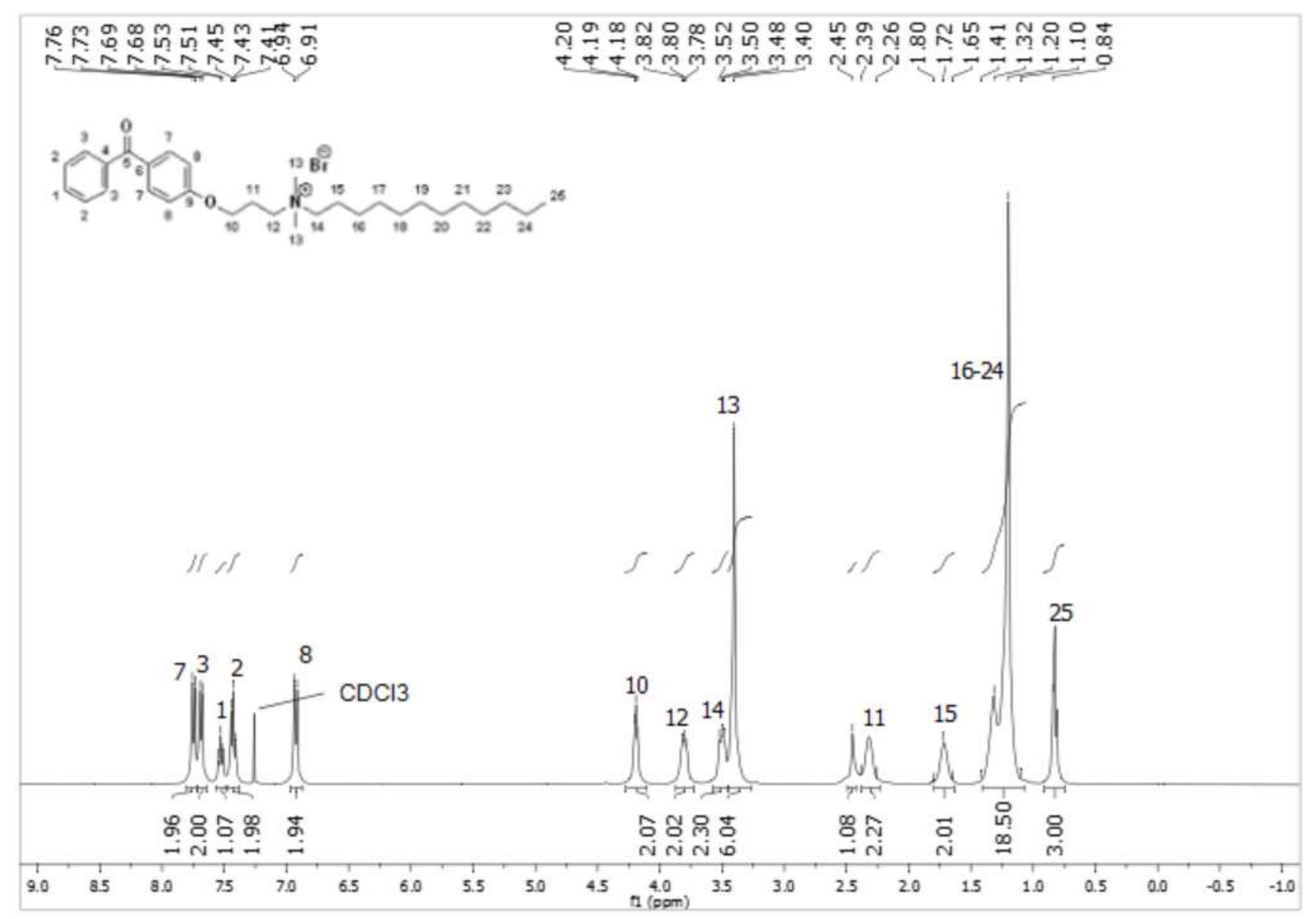

Figure (A) $23-{ }^{1} \mathrm{H} \mathrm{NMR}\left(400 \mathrm{MHz}, \mathrm{CDCl}_{3}\right)$ spectrum of $\mathbf{2 a}$. 


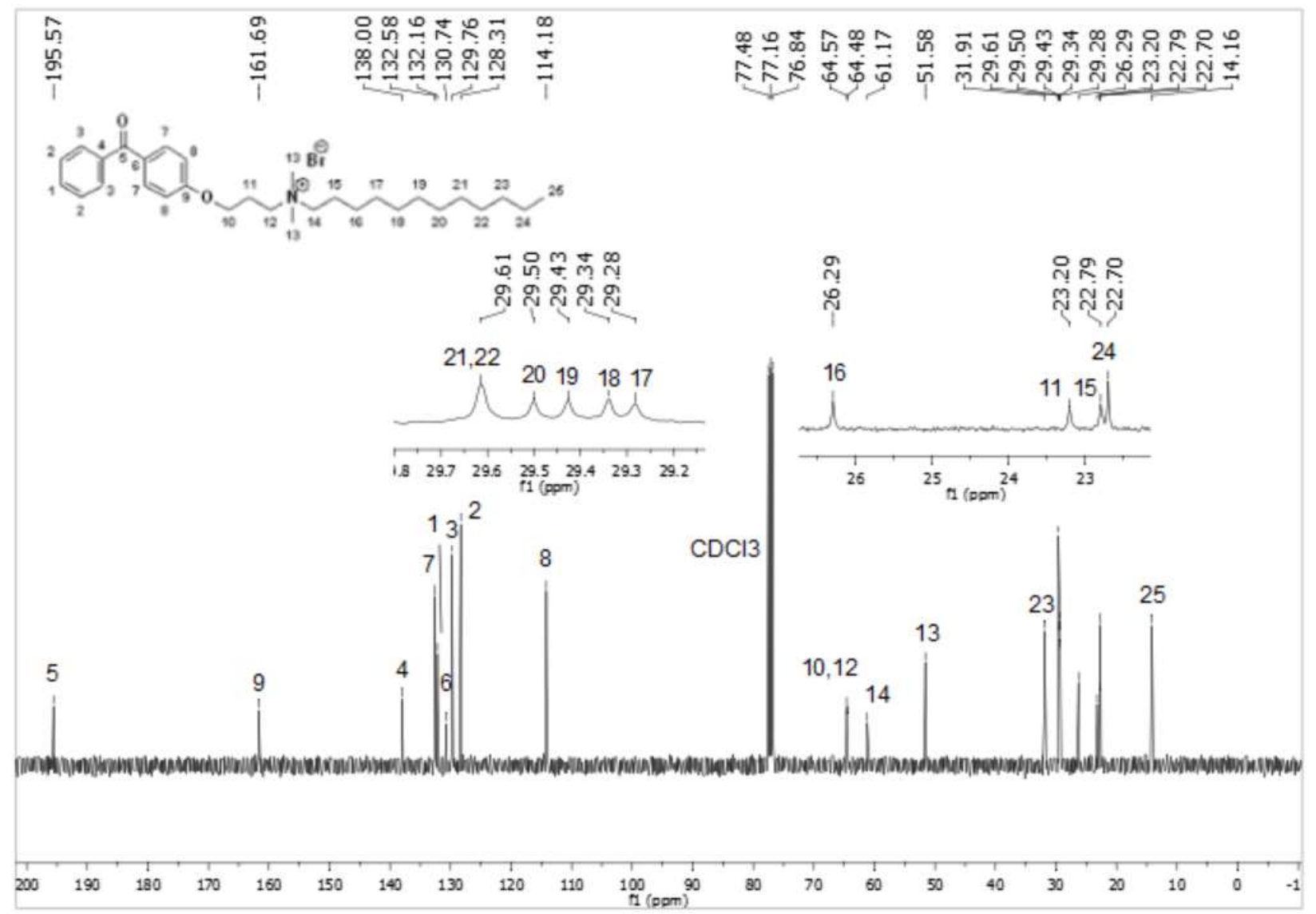

Figure (A) $24-{ }^{13} \mathrm{C}$ NMR (101 $\left.\mathrm{MHz}, \mathrm{CDCl}_{3}\right)$ spectrum of $\mathbf{2 a}$. 


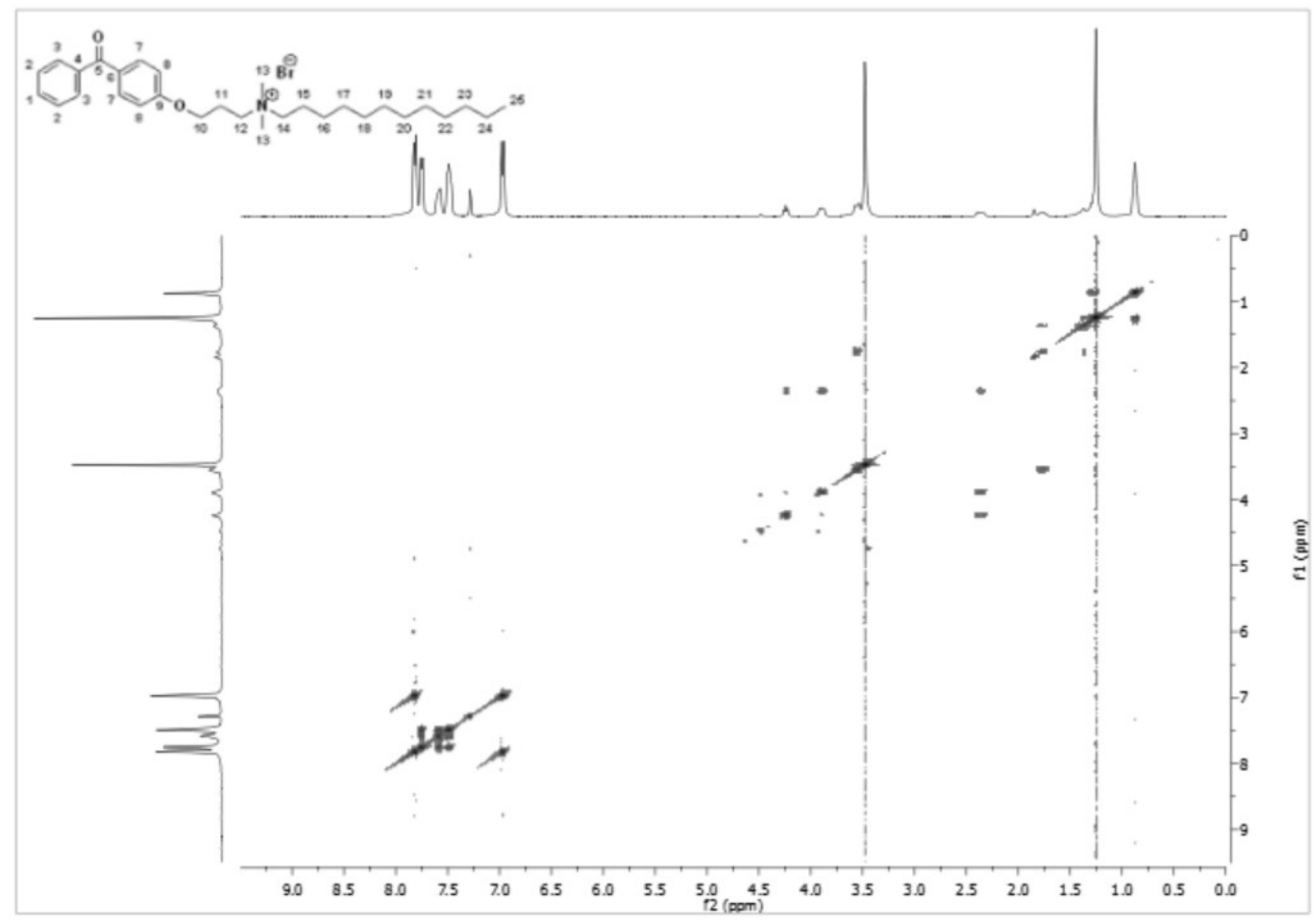

Figure (A) 25 - COSY 2D NMR $\left(\mathrm{CDCl}_{3}\right)$ spectrum of $\mathbf{2 a}$. 


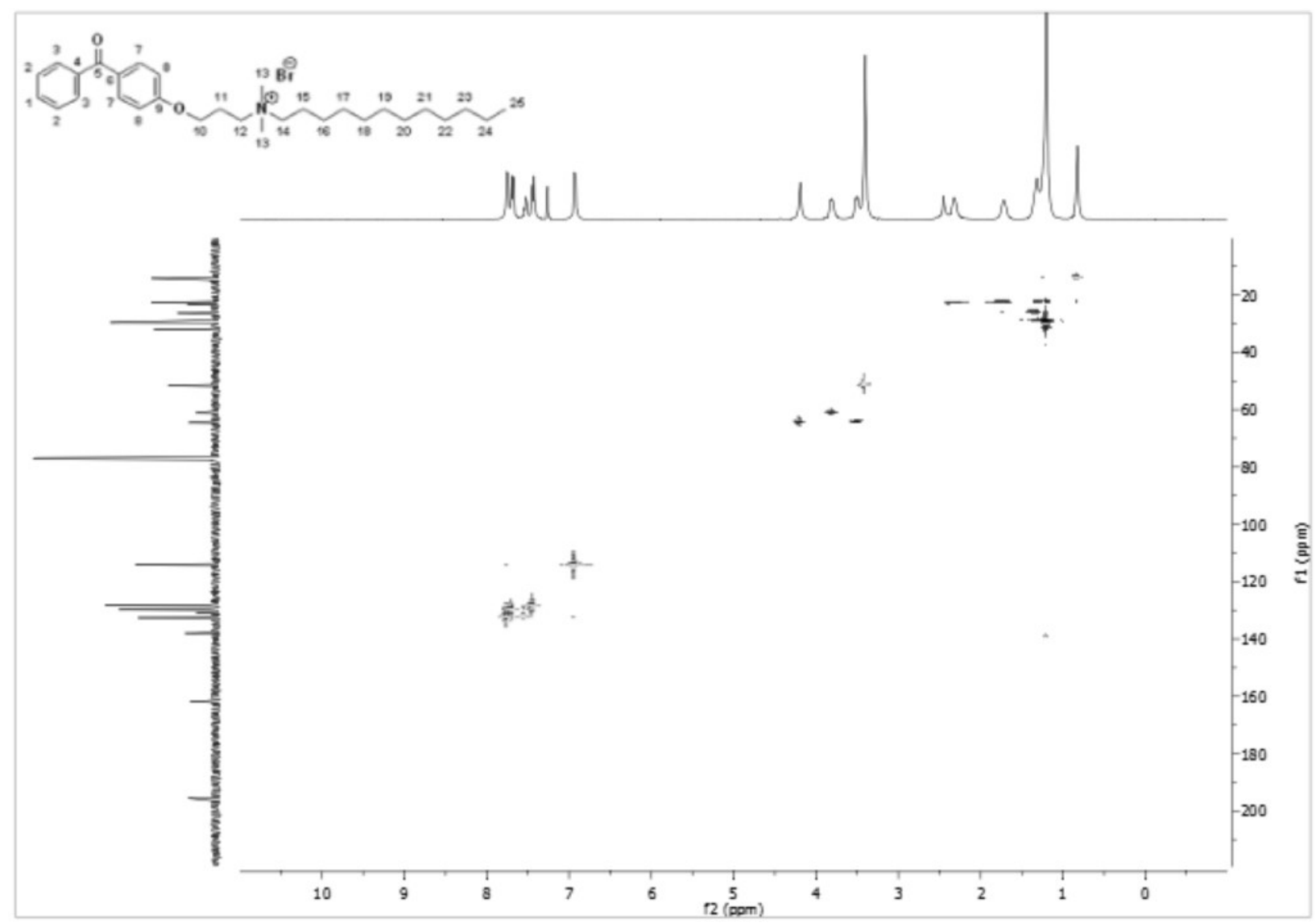

Figure (A) 26 - HSQC 2D NMR $\left(\mathrm{CDCl}_{3}\right)$ spectrum of $\mathbf{2 a}$. 


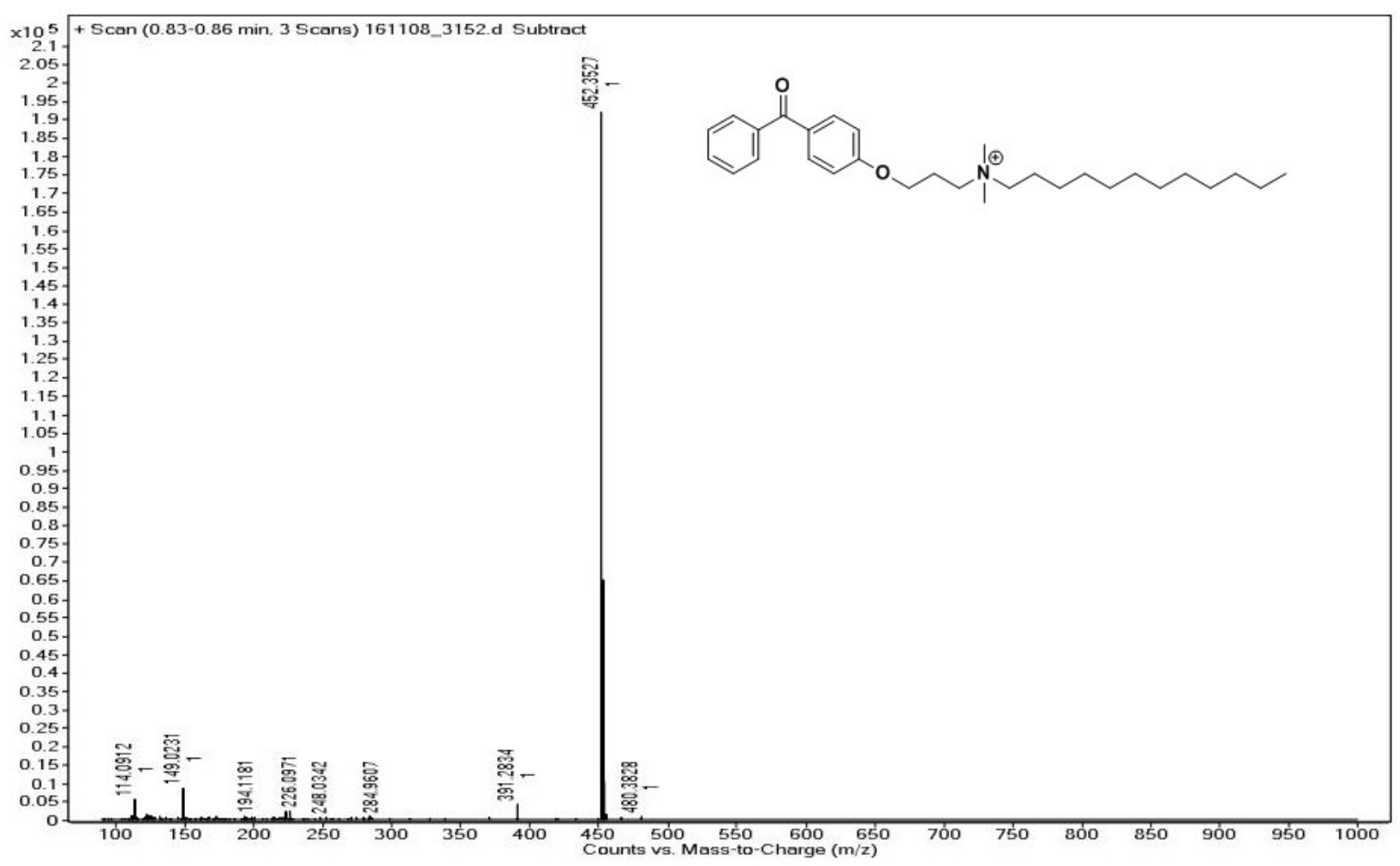

Figure (A) 27 - HRMS-ESI TOF of compound $\mathbf{2 a .}$ 


\section{(B) “ Killing at a Solid/Liquid Interface: Surface-Attached Sulfonamide Containing Quaternary Ammonium Antimicrobials for Textiles and Plastics" Supplementary Information}

\section{List of Tables (B)}

Table (B) 1 - Quantification XPS data for control and 5a treated CPVC samples. 121 Table (B) 2 - Sulfa QAC 3a-11a microbiology data (LDI). Microbiological testing was performed with triplicate treated and untreated controls. The inoculum load represents the quantity of viable cells placed onto each sample material and was determined concurrently to sample data $( \pm$ indicates standard deviation $n=3)$. A value of $1.70 \log (\mathrm{CFU})$ represents the lowest number of detectable cells spot plated onto $3 \mathrm{~g} \mathrm{~L}^{-1} \mathrm{TSA}$ (LOD: $50 \mathrm{CFU}, 1$ colony in $5 \mathrm{~mL}$ undiluted collection fluid). 132

Table (B) 3 - Sulfa QAC 3b-6b microbiology data (LDI). Microbiological testing was performed with triplicate treated and untreated controls. The inoculum load represents the quantity of viable cells placed onto each sample material and was determined concurrently to sample data $( \pm$ indicates standard deviation $n=3)$. A value of $1.70 \log (\mathrm{CFU})$ represents the lowest number of detectable cells spot plated onto $3 \mathrm{~g} \mathrm{~L}^{-1} \mathrm{TSA}$ (LOD: $50 \mathrm{CFU}, 1$ colony in $5 \mathrm{~mL}$ undiluted collection fluid). 135

Table (B) 4 - QAC 1a, 5a planktonic microbiology data (LRI). Microbiological testing was performed with triplicate treated and untreated controls. Planktonic colony counts were collected prior to the collection of biofilm data. The inoculum load represents the quantity of viable cells placed onto each sample material and was determined concurrently to sample data ( \pm indicates 
standard deviation, $\mathrm{n}=3)$. A value of $6.78 \log \left(\mathrm{CFU} \mathrm{ml}{ }^{-1}\right)$ represents the highest number of detectable cells spot plated onto $3 \mathrm{~g} \mathrm{~L}^{-1} \mathrm{TSA}$ (LOD: $6.00 \times 10^{-6} \mathrm{CFU} \mathrm{m}{ }^{-1}, 600$ colonies in $3 \mathrm{~mL}$ collection fluid, diluted by a factor of $\left.10^{3}\right)$. A value of $1.00 \log \left(\mathrm{CFU} \mathrm{ml}{ }^{-1}\right)$ represents the lowest number of detectable cells spot plated onto $3 \mathrm{~g} \mathrm{~L}^{-1} \mathrm{TSA}$ (LOD: $10 \mathrm{CFU} \mathrm{ml}{ }^{-1}, 1$ colony in $3 \mathrm{~mL}$ undiluted collection fluid). 137

Table (B) 5 - Tabulated liquid reservoir inoculation (LRI) biofilm microbiology data. Microbiological testing was performed with triplicate treated and untreated controls. Biofilm colony counts were collected subsequently to the collection of planktonic data. The inoculum load represents the quantity of viable cells placed onto each sample material and was determined concurrently to sample data ( \pm indicates standard deviation, $n=3)$. A value of $1.00 \log (\mathrm{CFU})$ represents the lowest number of detectable cells spot plated onto $3 \mathrm{~g} \mathrm{~L}^{-1} \mathrm{TSA}$ (LOD: $10 \mathrm{CFU}, 1$ colony in $1 \mathrm{~mL}$ undiluted collection fluid). 138

Table (B) 6 - Multi-load sulfa QAC 5a microbiology data (LDI). Microbiological testing was performed with triplicate treated and untreated controls. The inoculum load represents the quantity of viable cells placed onto each sample material and was determined concurrently to sample data ( \pm indicates standard deviation $n=3$ ). A value of $1.70 \log (\mathrm{CFU})$ represents the lowest number of detectable cells spot plated onto $3 \mathrm{~g} \mathrm{~L}^{-1} \mathrm{TSA}$ (LOD: $50 \mathrm{CFU}, 1$ colony in $5 \mathrm{~mL}$ undiluted collection fluid). 139 


\section{List of Figures (B)}

Figure (B) 1 - Control (untreated) CPVC XPS survey data.............................................. 115

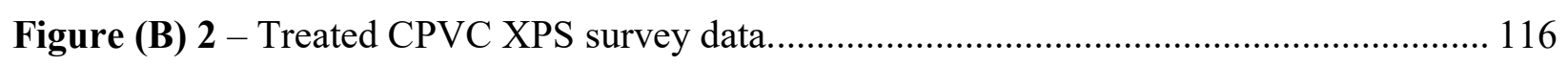

Figure (B) 3 - Control CPVC identification XPS data........................................................ 117

Figure (B) 4 - Control CPVC Identification XPS data, continued.......................................... 118

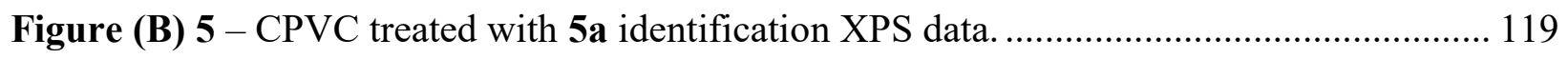

Figure (B) 6 - CPVC treated with 5a identification XPS data, continued. .............................. 120

Figure (B) 7 - Positive ion ToF-SIMS survey of control CPVC material............................... 122

Figure (B) 8 - Positive ion ToF-SIMS survey of 5a treated CPVC material. ........................... 123

Figure (B) 9 - Negative ion ToF-SIMS survey of control CPVC material. ............................. 124

Figure (B) 10 - Negative ion ToF-SIMS survey of 5a treated CPVC material........................ 125

Figure (B) 11 - Composite negative ion ToF-SIMS image of $500.0 \times 500.0 \mu \mathrm{m}$ section of control and 5a treated samples. Intensity is a function of fragment quantity during analysis. Images correspond to negative ionic fragmentation products of chlorine $\left(\mathrm{Cl}^{-}\right)$, bromine $\left(\mathrm{Br}^{-}\right)$, ethane $\left(\mathrm{C}_{2} \mathrm{H}^{-}\right.$ ), tetracarbonyl ammonium $\left(\mathrm{C}_{4} \mathrm{~N}^{-}\right)$, and hydroxybenzophenone $\left(\mathrm{C}_{13} \mathrm{H}_{9} \mathrm{O}_{2}{ }^{-}\right) \ldots \ldots \ldots \ldots \ldots \ldots \ldots \ldots \ldots \ldots . . . . . . . . . . . . .126$

Figure (B) 12 - Contact AFM surface scan of a control polycarbonate (PC) surface............... 127

Figure (B) 13 - Contact AFM surface scan of a polycarbonate (PC) surface treated with 5a. . 127 Figure (B) 14 - Contact AFM profile scan of a polycarbonate (PC) surface partially treated with 5a

Figure (B) 15 - Tapping AFM data for control polycarbonate (PC) surface sample (RMS

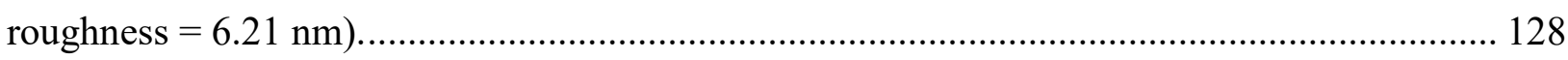

Figure (B) 16 - Tapping AFM data for 10a coated onto a polycarbonate surface (RMS roughness $=51.31 \mathrm{~nm})$ 129 
Figure (B) 17 - Tapping AFM profile scan of a polycarbonate (PC) surface partially treated with $10 a$. 129

Figure (B) 18 - SP profile scan of a polycarbonate (PC) surface partially treated with 5a. .... 130 Figure (B) 19 - SP profile scan of a polycarbonate (PC) surface partially treated with 10a. ... 131 Figure (B) 20 - Successive wash solutions of polystyrene coated with 5a, exposed to 3 drops ( $\sim 0.1$ mL) 1000 ppm bromophenol blue dye. Samples were shaken for 30 seconds in sealed tubes containing $10 \mathrm{~mL}$ of distilled water. The blue colour indicates the first rinse contains the presence QAC, while the purple colour indicates the second rinse does not. 132

Figure (B) 21 - Representative polystyrene samples, one left untreated (left) and treated (right) with 5a, stained with bromophenol blue. 132

Figure (B) $22-{ }^{1} \mathrm{H}$ NMR $\left(400 \mathrm{MHz}, \mathrm{CDCl}_{3}\right)$ spectrum of 3.................................... 158

Figure (B) $23-{ }^{13} \mathrm{C}$ NMR $\left(101 \mathrm{MHz}, \mathrm{CDCl}_{3}\right)$ spectrum of 3.................................... 159

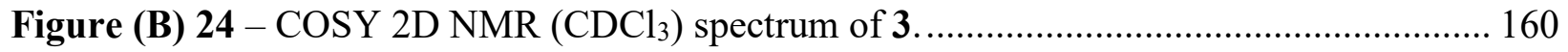

Figure (B) 25 - HSQC 2D NMR $\left(\mathrm{CDCl}_{3}\right)$ spectrum of 3 ........................................... 161

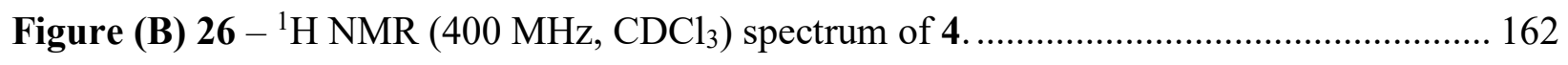

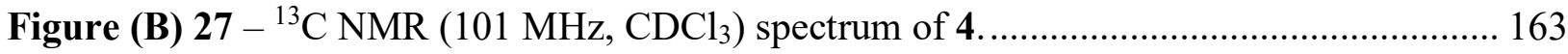

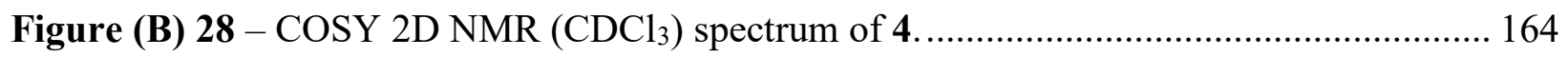

Figure (B) 29 - HSQC 2D NMR $\left(\mathrm{CDCl}_{3}\right)$ spectrum of 4 ......................................... 165

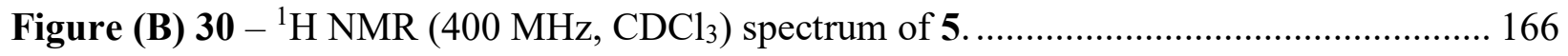

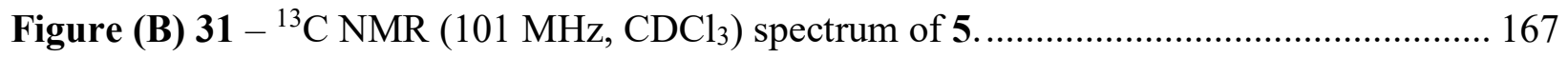

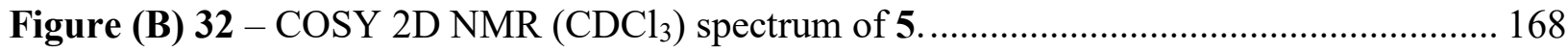

Figure (B) 33 - HSQC 2D NMR $\left(\mathrm{CDCl}_{3}\right)$ spectrum of 5.......................................... 169

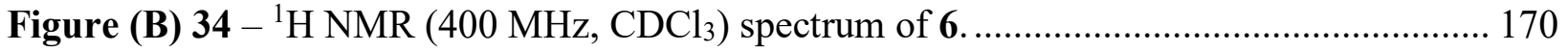




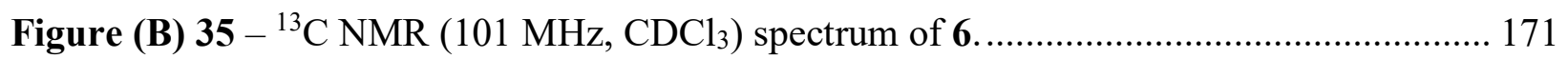

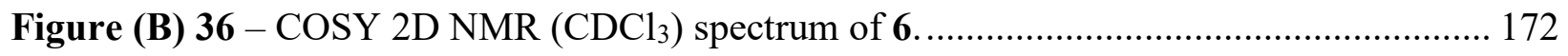

Figure (B) 37 - HSQC 2D NMR ( $\left.\mathrm{CDCl}_{3}\right)$ spectrum of 6................................................ 173

Figure (B) $38-{ }^{1} \mathrm{H}$ NMR $\left(400 \mathrm{MHz}, \mathrm{CDCl}_{3}\right)$ spectrum of 7 .............................................. 174

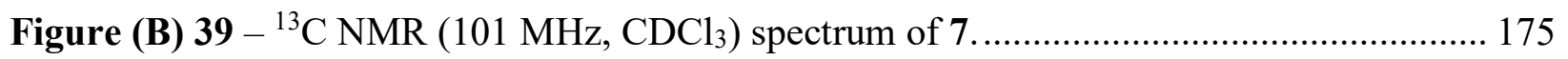

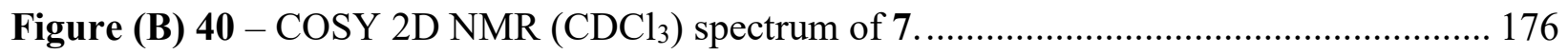

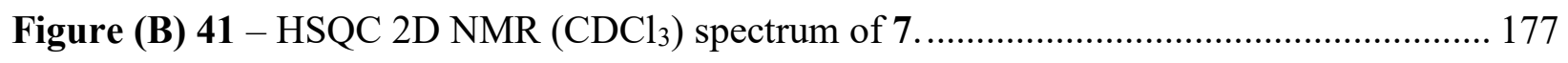

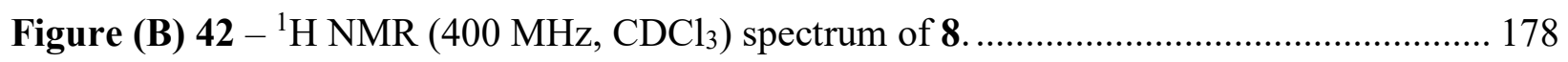

Figure (B) $43-{ }^{13} \mathrm{C}$ NMR $\left(101 \mathrm{MHz}, \mathrm{CDCl}_{3}\right)$ spectrum of 8......................................... 179

Figure (B) 44 - COSY 2D NMR ( $\left.\mathrm{CDCl}_{3}\right)$ spectrum of 8 ............................................... 180

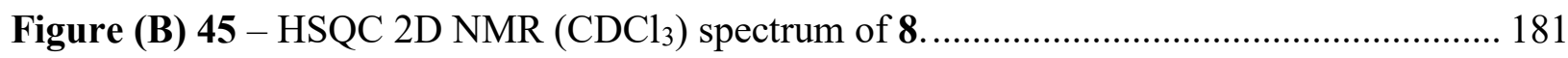

Figure (B) $46-{ }^{1} \mathrm{H}$ NMR (400 MHz, $\left.\mathrm{CDCl}_{3}\right)$ spectrum of 9............................................... 182

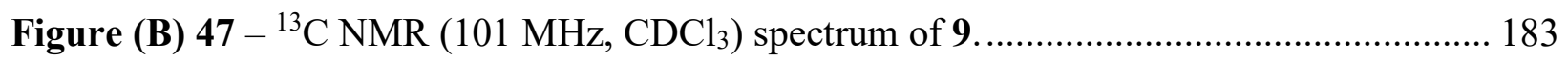

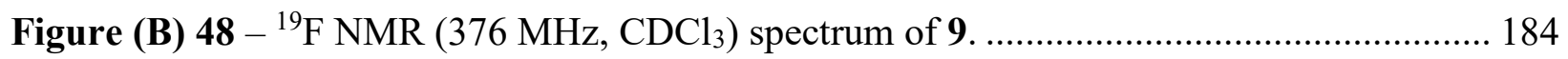

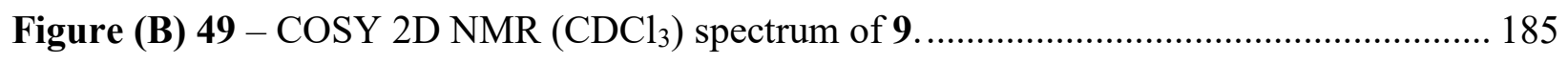

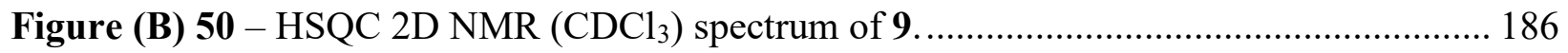

Figure (B) $51-{ }^{1} \mathrm{H}$ NMR (400 MHz, $\left.\mathrm{CDCl}_{3}\right)$ spectrum of 10............................................. 187

Figure (B) $52-{ }^{13} \mathrm{C}$ NMR $\left(101 \mathrm{MHz}, \mathrm{CDCl}_{3}\right)$ spectrum of 10........................................ 188

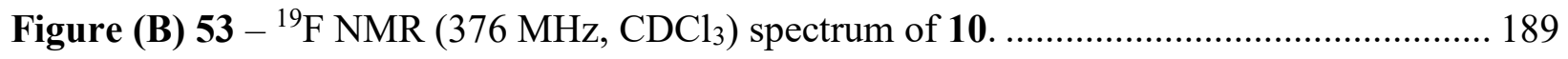

Figure (B) 54 - COSY 2D NMR ( $\left.\mathrm{CDCl}_{3}\right)$ spectrum of 10 ................................................ 190

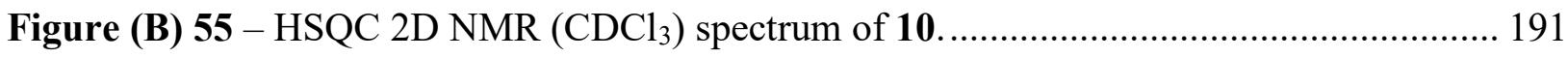

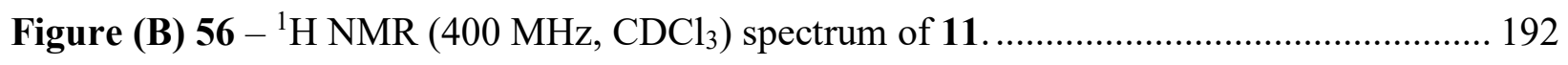

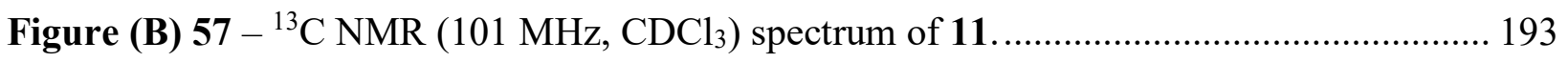


Figure (B) 58 - COSY 2D NMR $\left(\mathrm{CDCl}_{3}\right)$ spectrum of 11................................................ 194

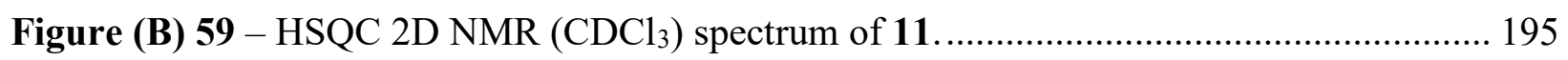

Figure (B) 60 - ${ }^{1} \mathrm{H}$ NMR $\left(400 \mathrm{MHz}, \mathrm{CDCl}_{3}\right)$ spectrum of 3a............................................. 196

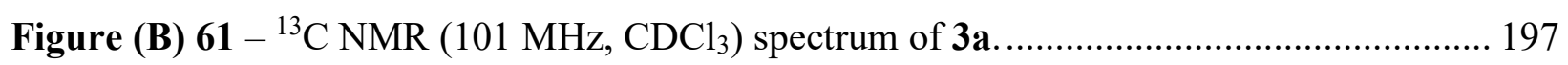

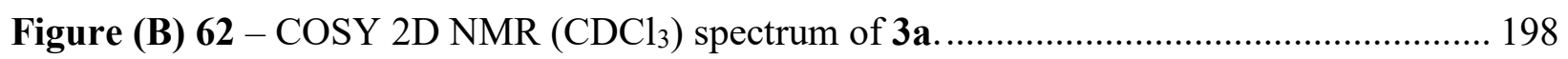

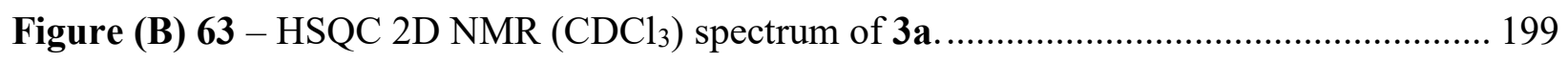

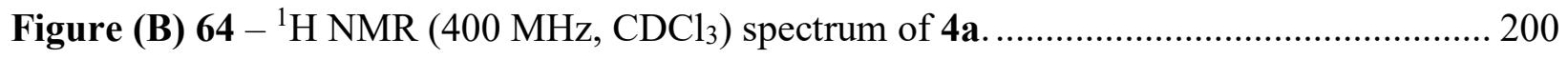

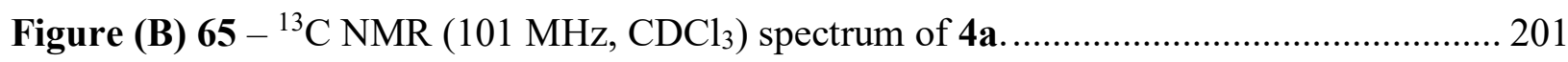

Figure (B) 66 - COSY 2D NMR ( $\left.\mathrm{CDCl}_{3}\right)$ spectrum of 4a .............................................. 202

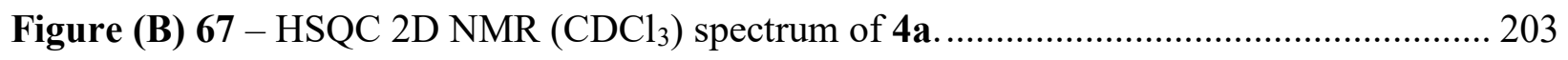

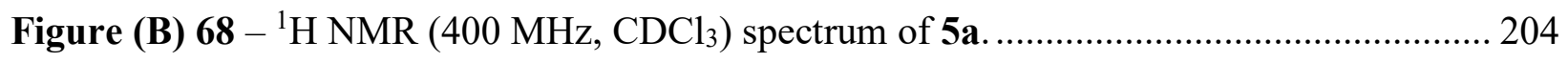

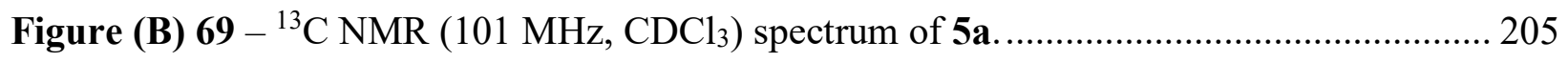

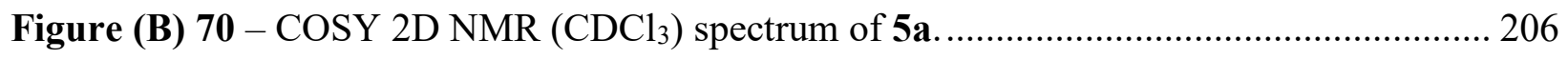

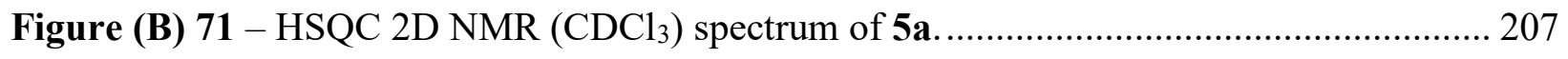

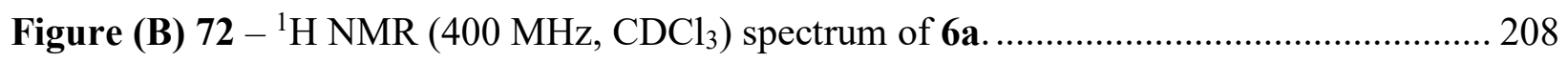

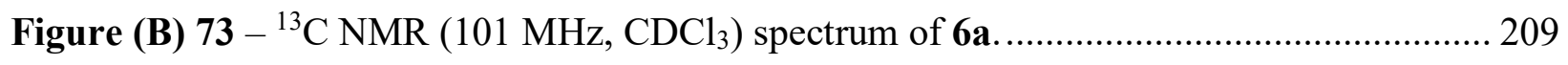

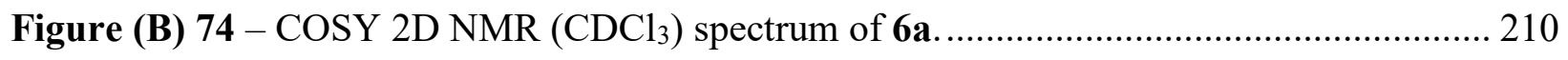

Figure (B) 75 - HSQC 2D NMR $\left(\mathrm{CDCl}_{3}\right)$ spectrum of 6a................................................ 211

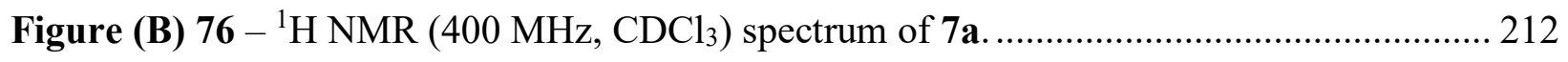

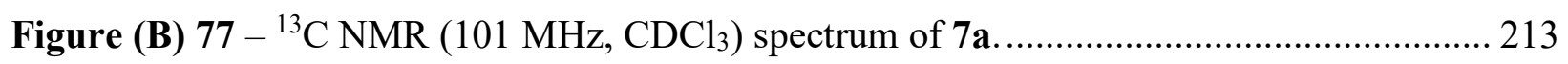

Figure (B) 78 - COSY 2D NMR ( $\left.\mathrm{CDCl}_{3}\right)$ spectrum of 7a ................................................ 214

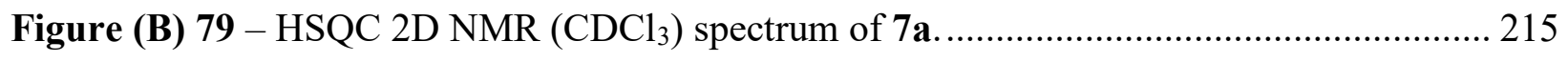

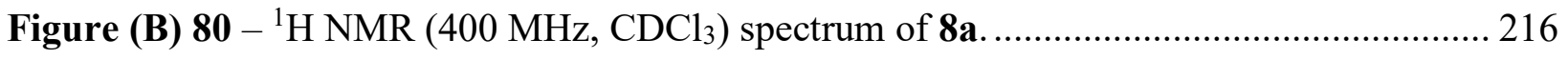




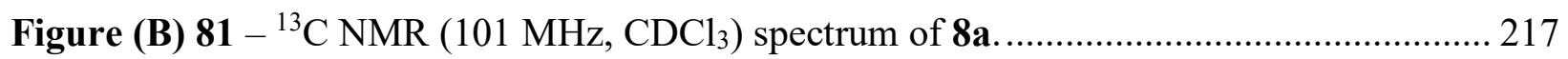

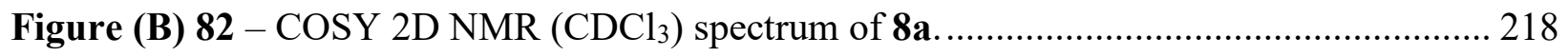

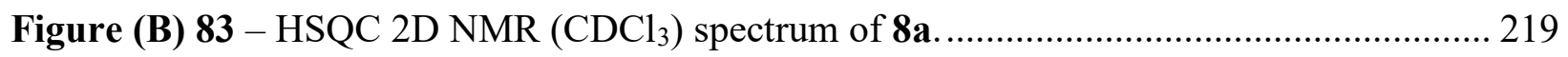

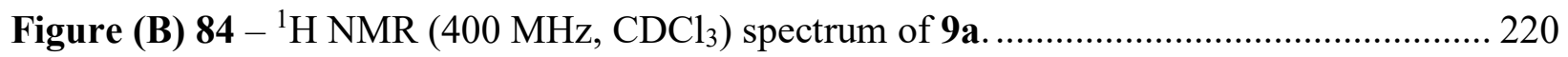

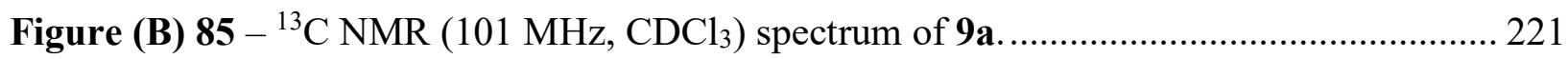

Figure (B) $86-{ }^{19} \mathrm{~F}$ NMR $\left(376 \mathrm{MHz}, \mathrm{CDCl}_{3}\right)$ spectrum of 9a. ........................................... 222

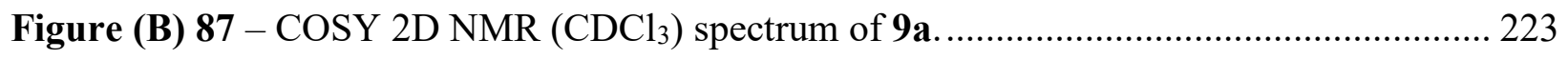

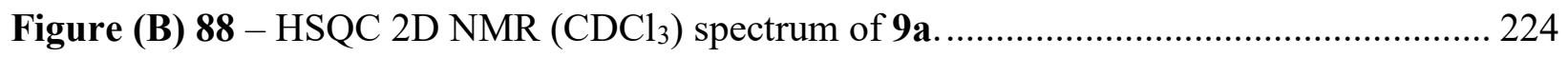

Figure (B) 89 - ${ }^{1} \mathrm{H}$ NMR (400 MHz, DMSO-d 6 ) spectrum of 10a..................................... 225

Figure (B) $90-{ }^{13} \mathrm{C}$ NMR (101 MHz, DMSO-d 6 ) spectrum of 10a. .................................... 226

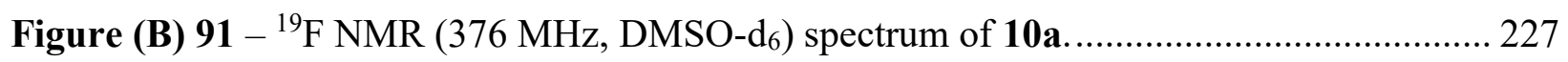

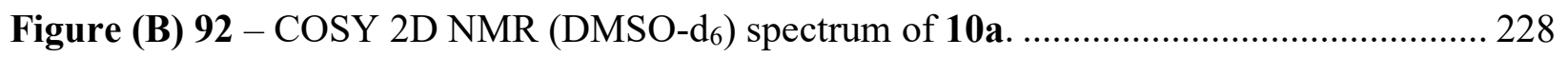

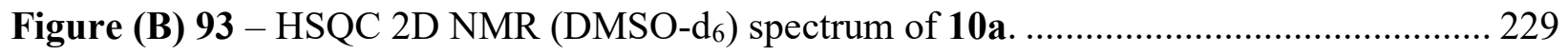

Figure (B) $94-{ }^{1} \mathrm{H}$ NMR $\left(400 \mathrm{MHz}, \mathrm{CDCl}_{3}\right)$ spectrum of 11a ......................................... 230

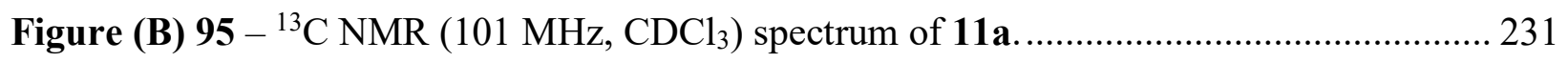

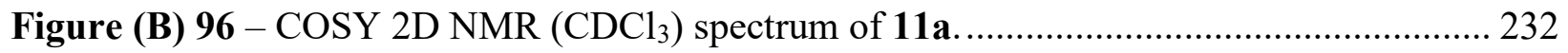

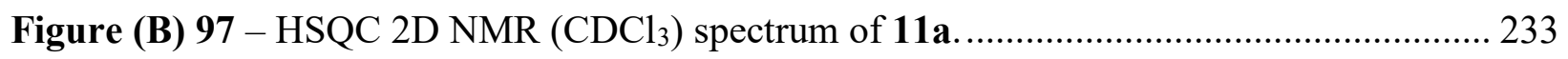

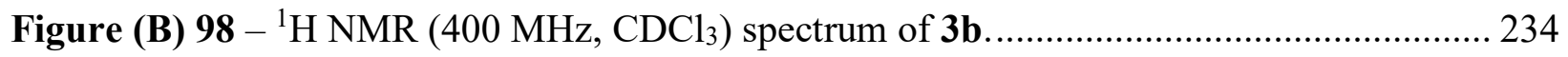

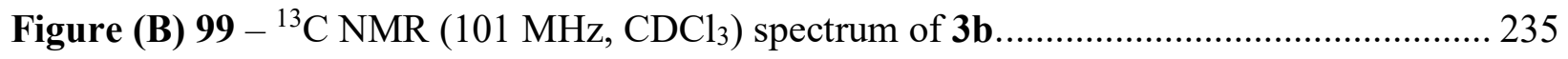

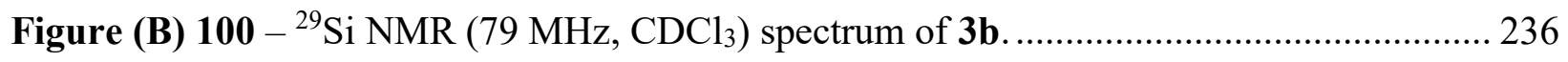

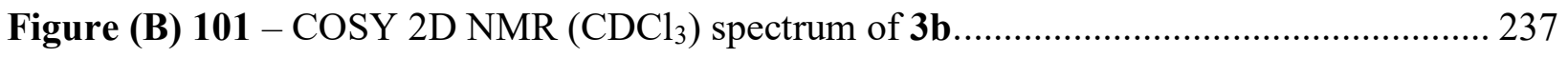

Figure (B) 102 - HSQC 2D NMR $\left(\mathrm{CDCl}_{3}\right)$ spectrum of 3b............................................. 238

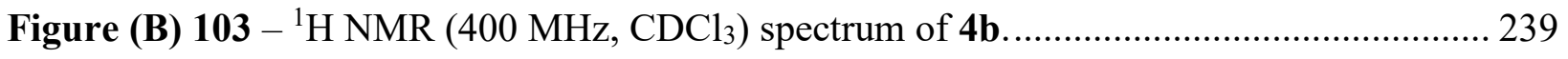




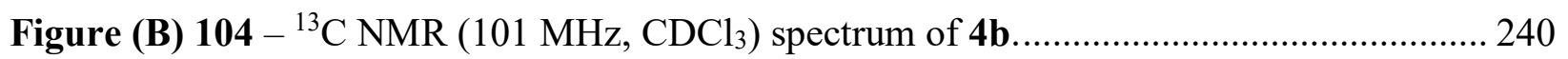

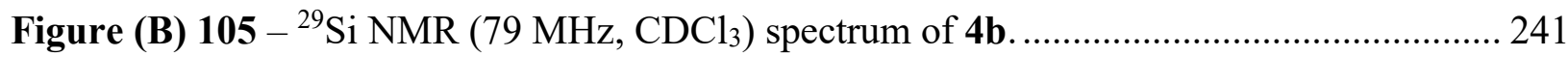

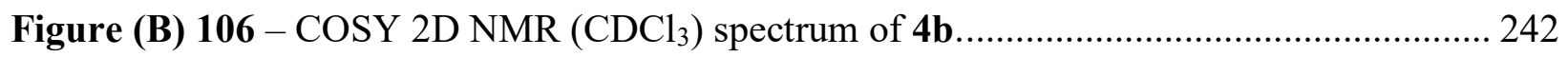

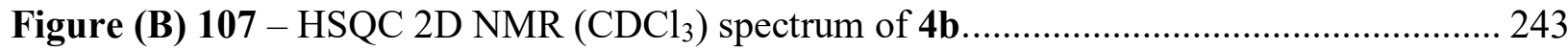

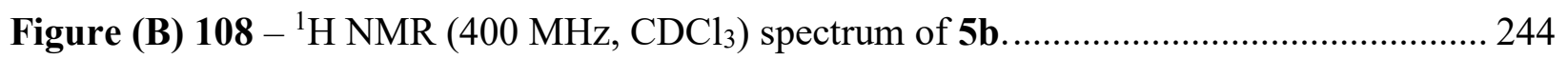

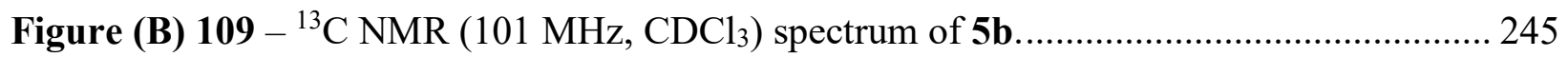

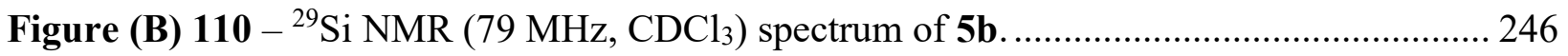

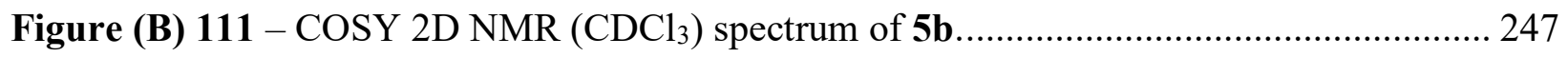

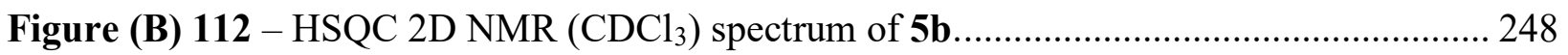

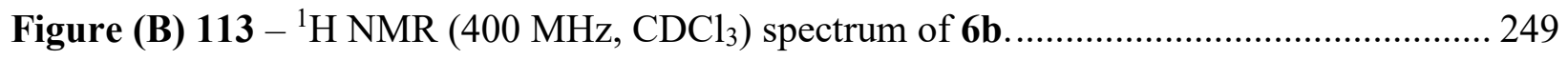

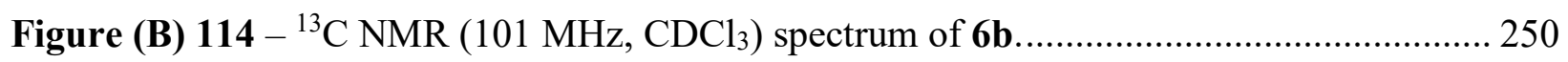

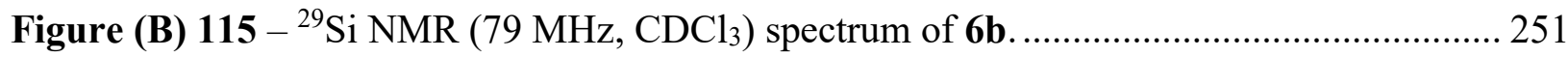

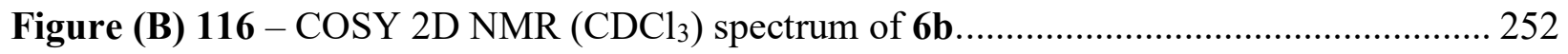

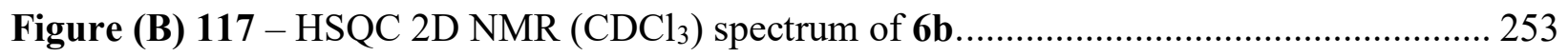

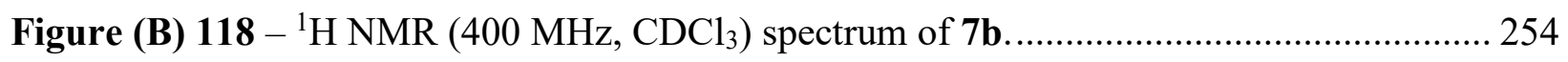

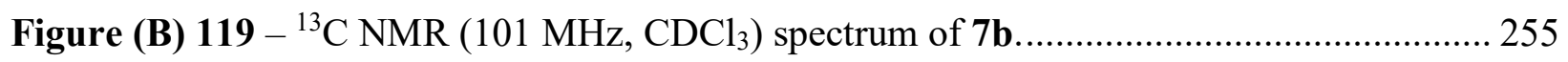

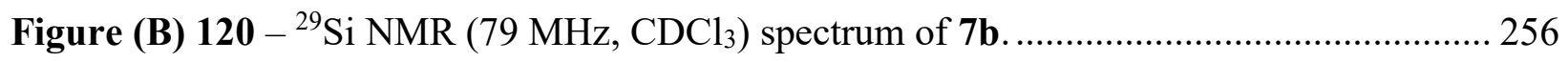

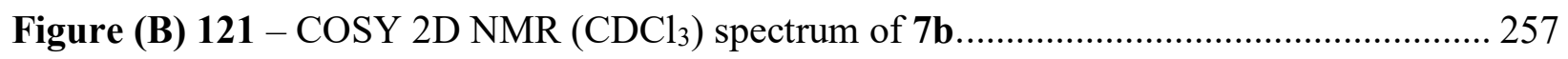

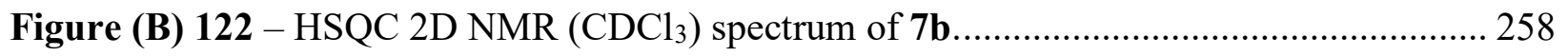

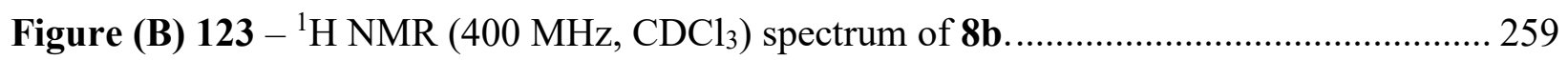

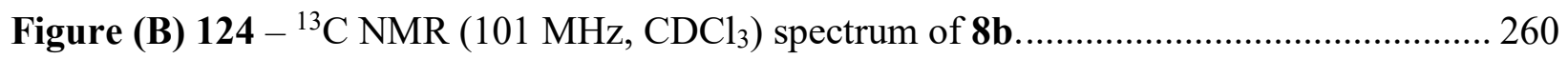

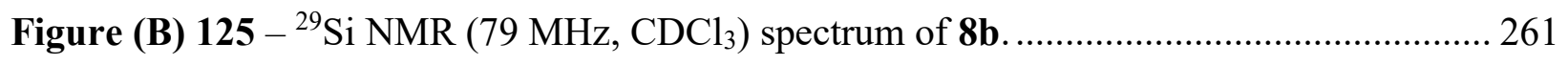

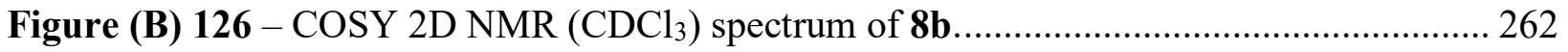




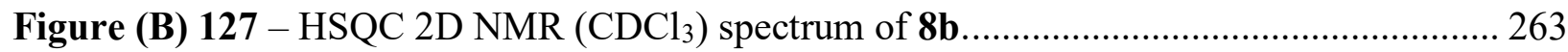




\section{X-ray Photoelectric Spectroscopy and ToF-SIMS Data}

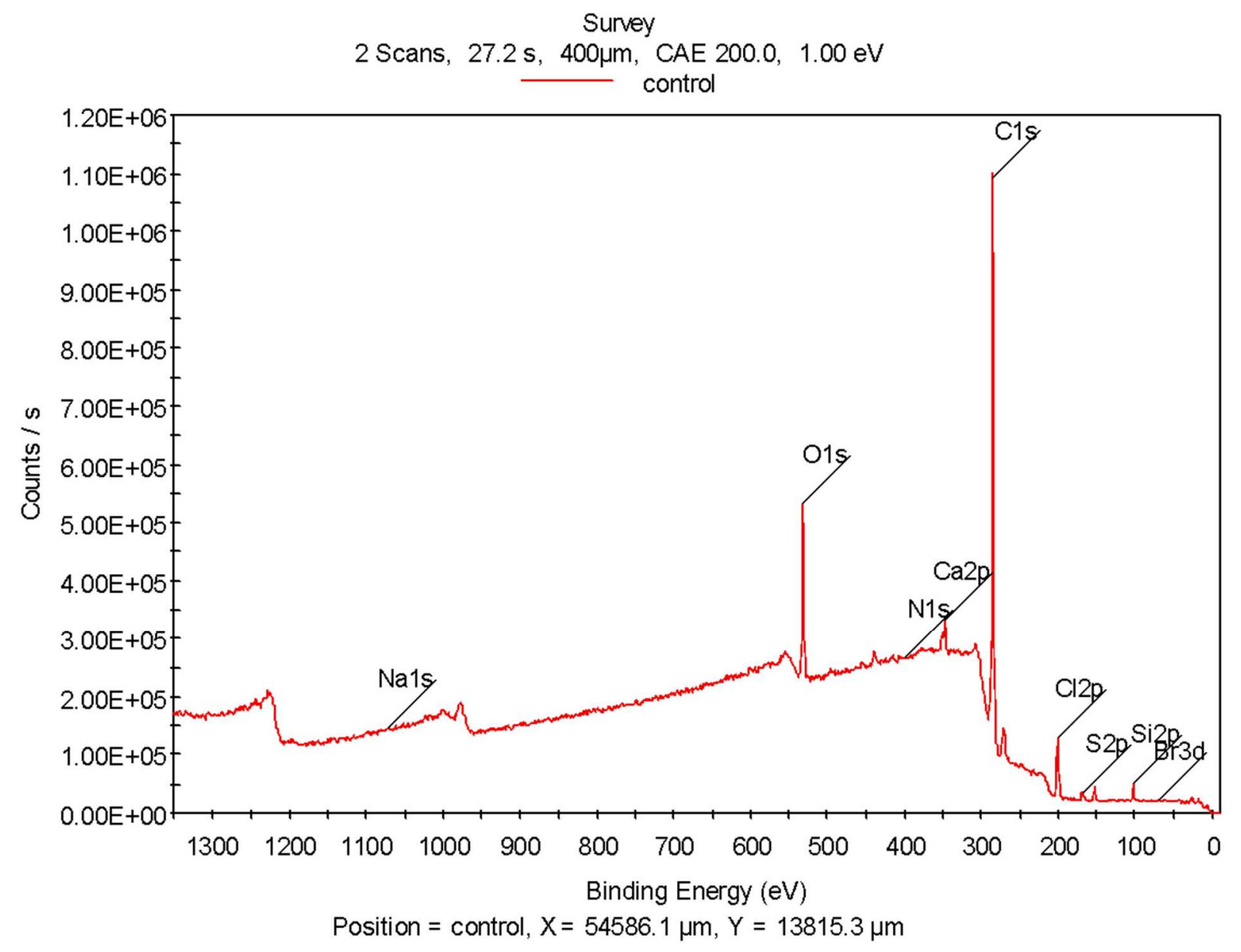

Figure (B) 1 - Control (untreated) CPVC XPS survey data. 
Survey

2 Scans, $27.2 \mathrm{~s}, 400 \mu \mathrm{m}, \mathrm{CAE} 200.0,1.00 \mathrm{eV}$ 1-Coat-M

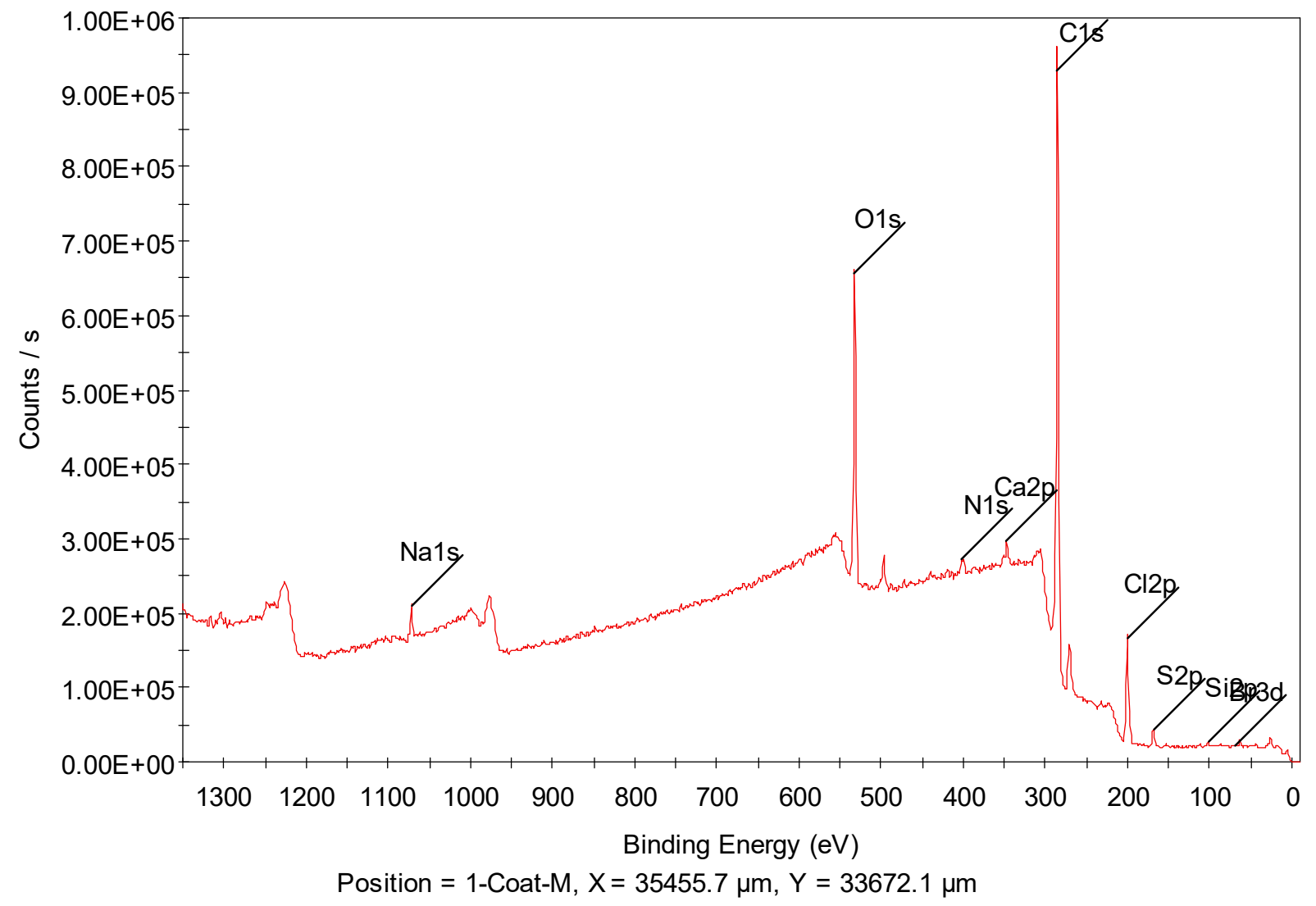

Figure (B) 2 - Treated CPVC XPS survey data. 

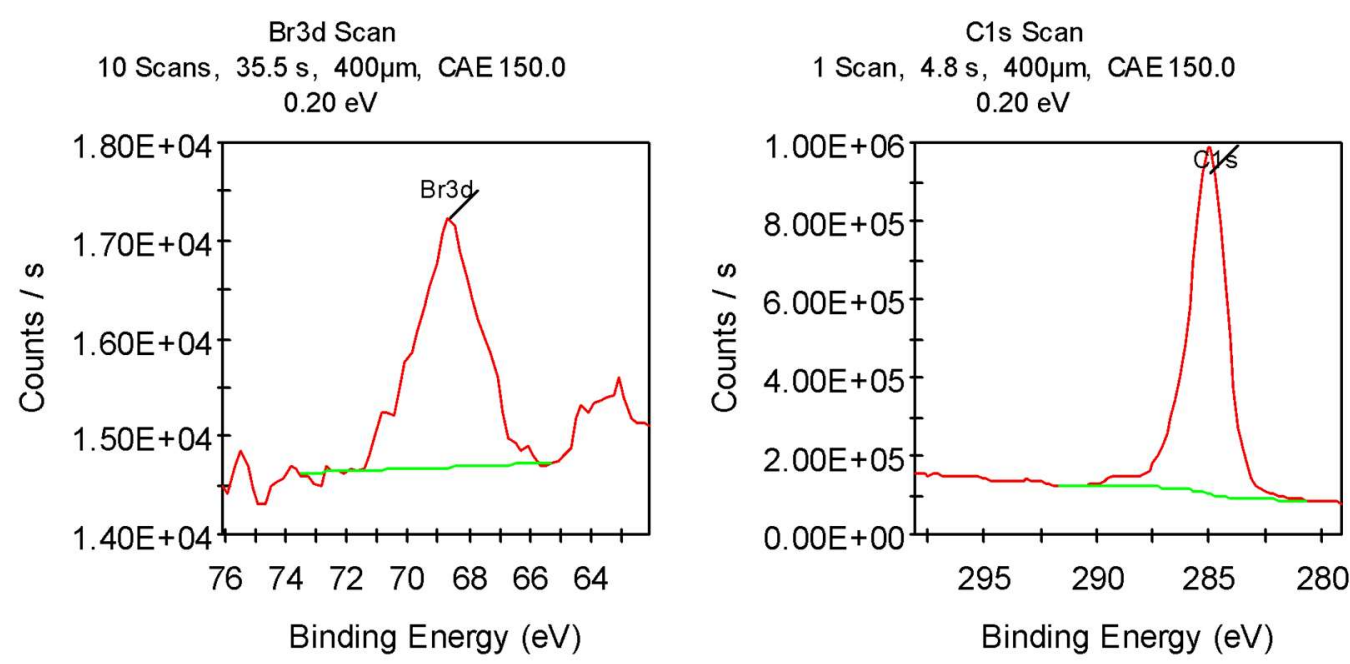

Position $=$ control, $X=54586.1 \mu \mathrm{m}, \mathrm{Y}=13815.3 \mu \mathrm{m}$

Ca2p Scan

5 Scans, $25.3 \mathrm{~s}, 400 \mu \mathrm{m}, \mathrm{CAE} 150.0$

$0.20 \mathrm{eV}$

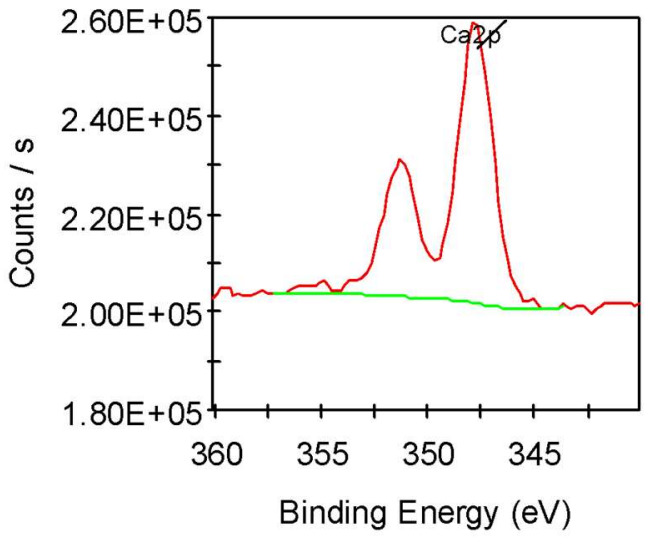

Position $=$ control, $X=54586.1 \mu \mathrm{m}, Y=13815.3 \mu \mathrm{m}$

Position $=$ control, $X=54586.1 \mu \mathrm{m}, Y=13815.3 \mu \mathrm{m}$

$\mathrm{Cl} 2 \mathrm{p}$ Scan

2 Scans, $10.1 \mathrm{~s}, 400 \mu \mathrm{m}, \mathrm{CAE} 150.0$

$0.20 \mathrm{eV}$

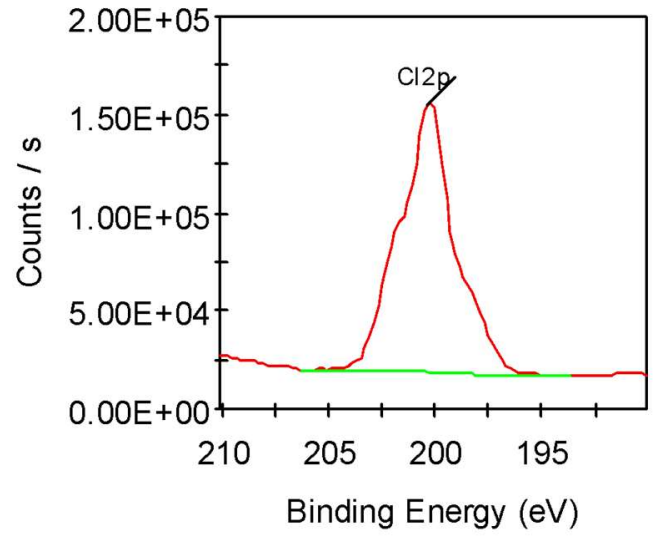

Position $=$ control, $X=54586.1 \mu \mathrm{m}, \mathrm{Y}=13815.3 \mu \mathrm{m}$

Figure (B) 3 - Control CPVC identification XPS data. 


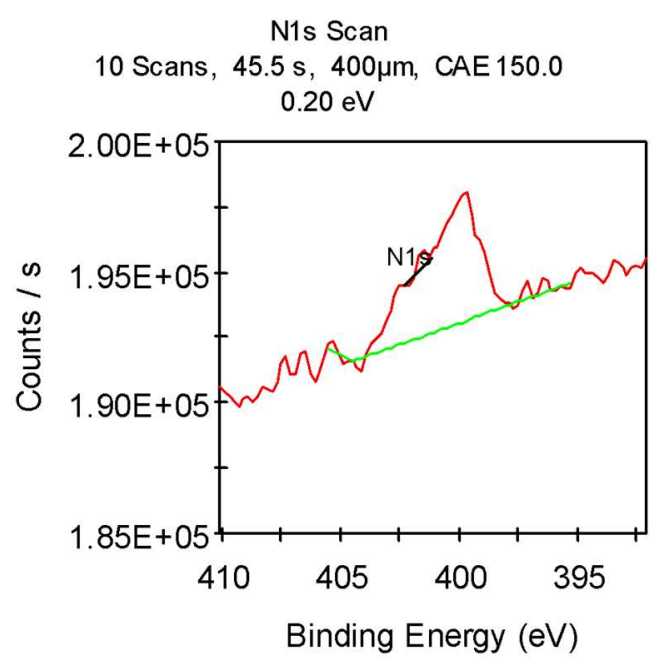

Position $=$ control, $X=54586.1 \mu \mathrm{m}, \mathrm{Y}=13815.3 \mu \mathrm{m}$

O1s Scan

1 Scan, $5.1 \mathrm{~s}, 400 \mu \mathrm{m}, \mathrm{CAE} 150.0$

$0.20 \mathrm{eV}$

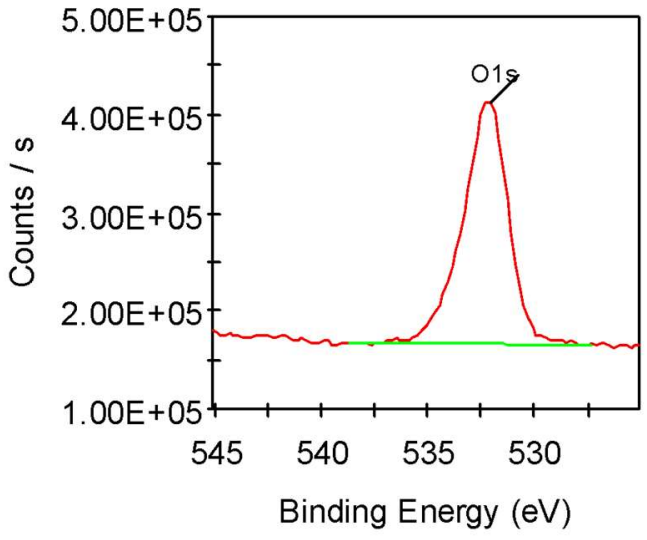

Position $=$ control, $X=54586.1 \mu \mathrm{m}, Y=13815.3 \mu \mathrm{m}$
Na1s Scan

5 Scans, $21.5 \mathrm{~s}, 400 \mu \mathrm{m}, \mathrm{CAE} 150.0$

$0.20 \mathrm{eV}$

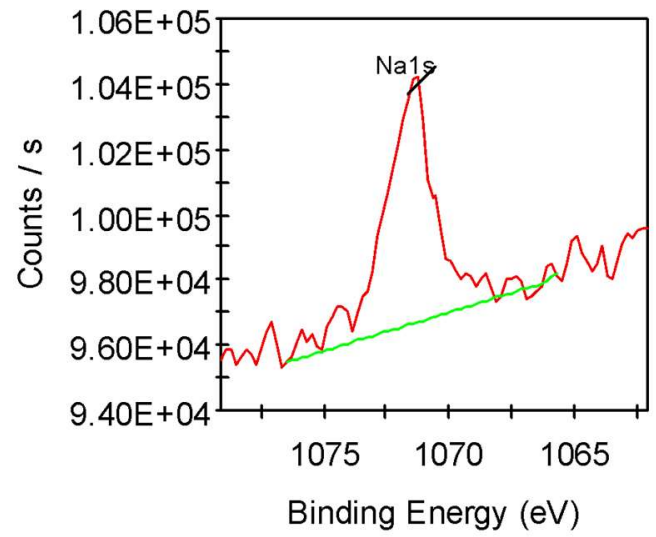

Position $=$ control, $X=54586.1 \mu \mathrm{m}, Y=13815.3 \mu \mathrm{m}$ S2p Scan

10 Scans, $45.5 \mathrm{~s}, 400 \mu \mathrm{m}, \mathrm{CAE} 150.0$ $0.20 \mathrm{eV}$

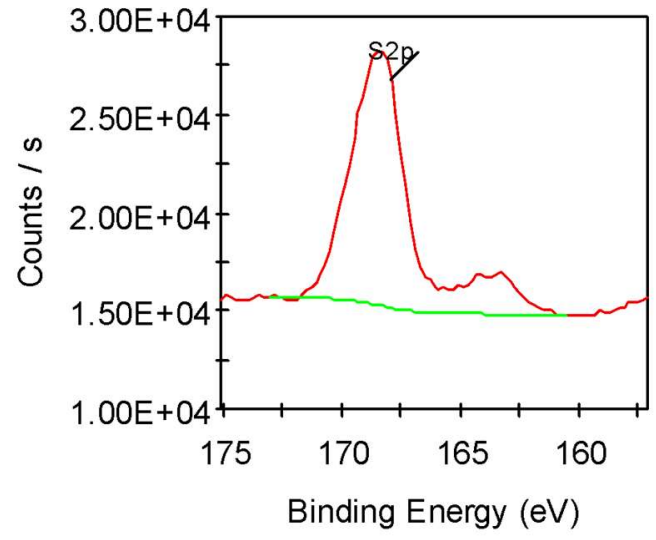

Position $=$ control, $X=54586.1 \mu \mathrm{m}, Y=13815.3 \mu \mathrm{m}$

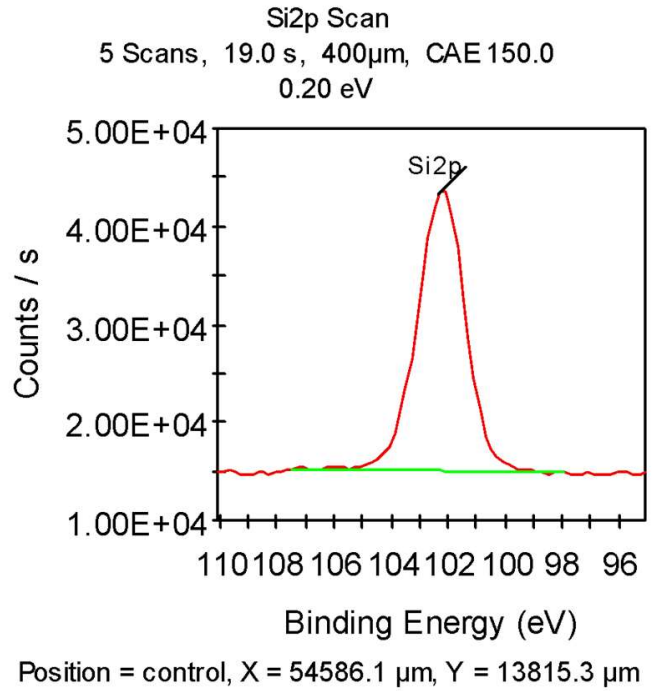

Figure (B) 4 - Control CPVC Identification XPS data, continued. 


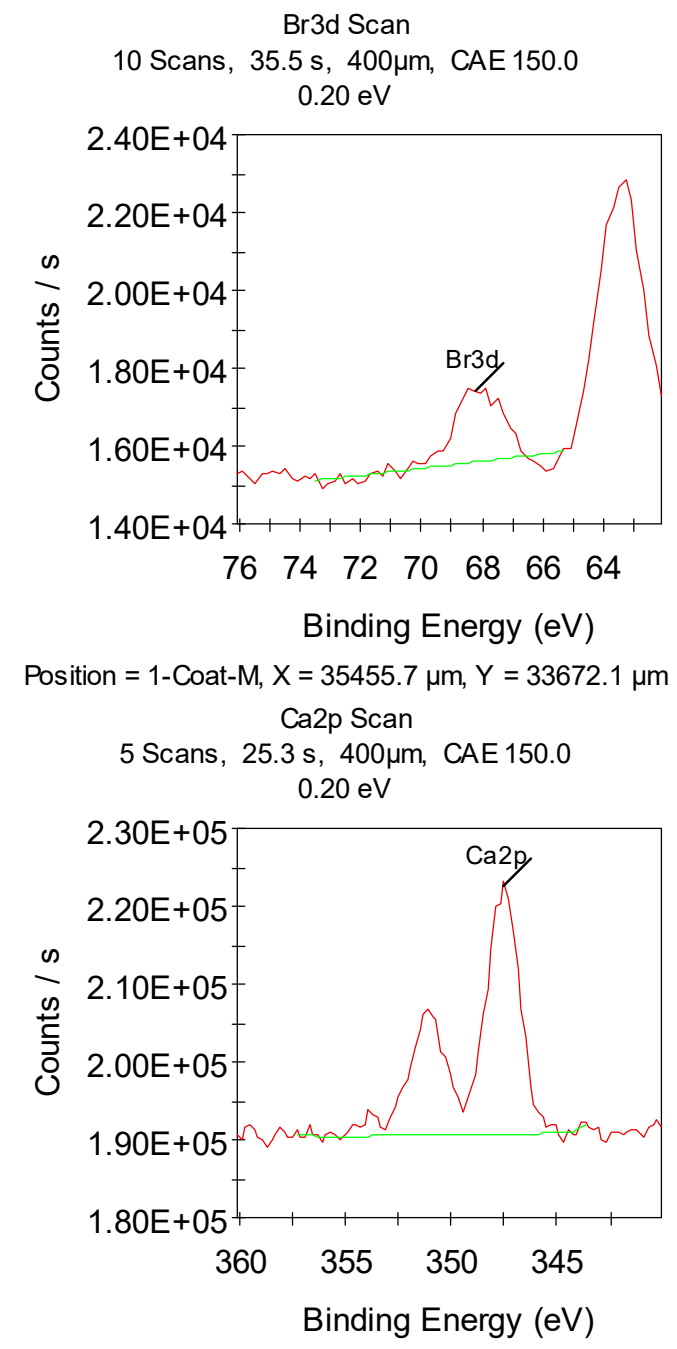

Position $=1$-Coat-M, $X=35455.7 \mu \mathrm{m}, \mathrm{Y}=33672.1 \mu \mathrm{m}$
C1s Scan

1 Scan, $4.8 \mathrm{~s}, 400 \mu \mathrm{m}, \mathrm{CAE} 150.0$

$0.20 \mathrm{eV}$

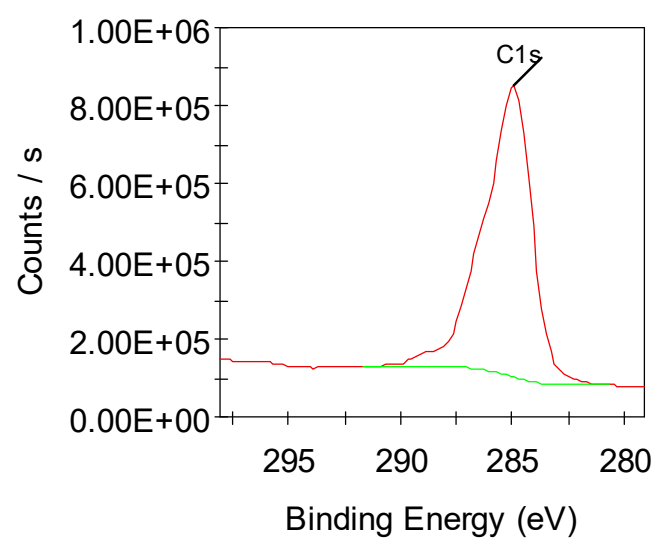

Position $=1$-Coat $-\mathrm{M}, \mathrm{X}=35455.7 \mu \mathrm{m}, \mathrm{Y}=33672.1 \mu \mathrm{m}$ Cl2p Scan

2 Scans, $10.1 \mathrm{~s}, 400 \mu \mathrm{m}, \mathrm{CAE} 150.0$ $0.20 \mathrm{eV}$

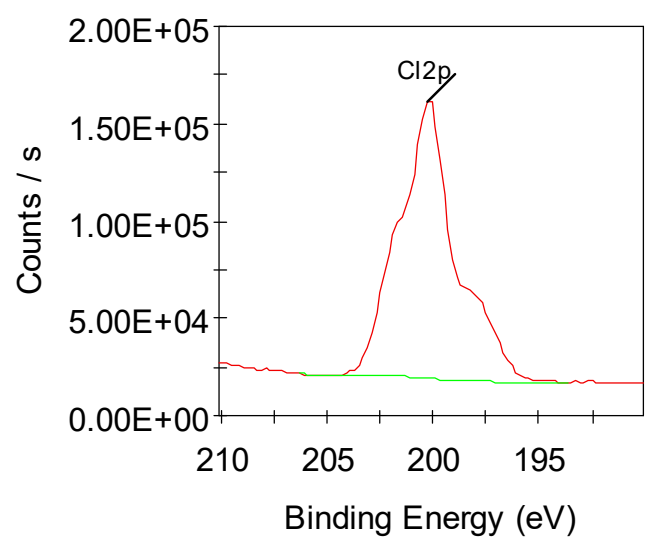

Position $=1$-Coat-M, $X=35455.7 \mu \mathrm{m}, \mathrm{Y}=33672.1 \mu \mathrm{m}$

Figure (B) 5 - CPVC treated with 5a identification XPS data. 

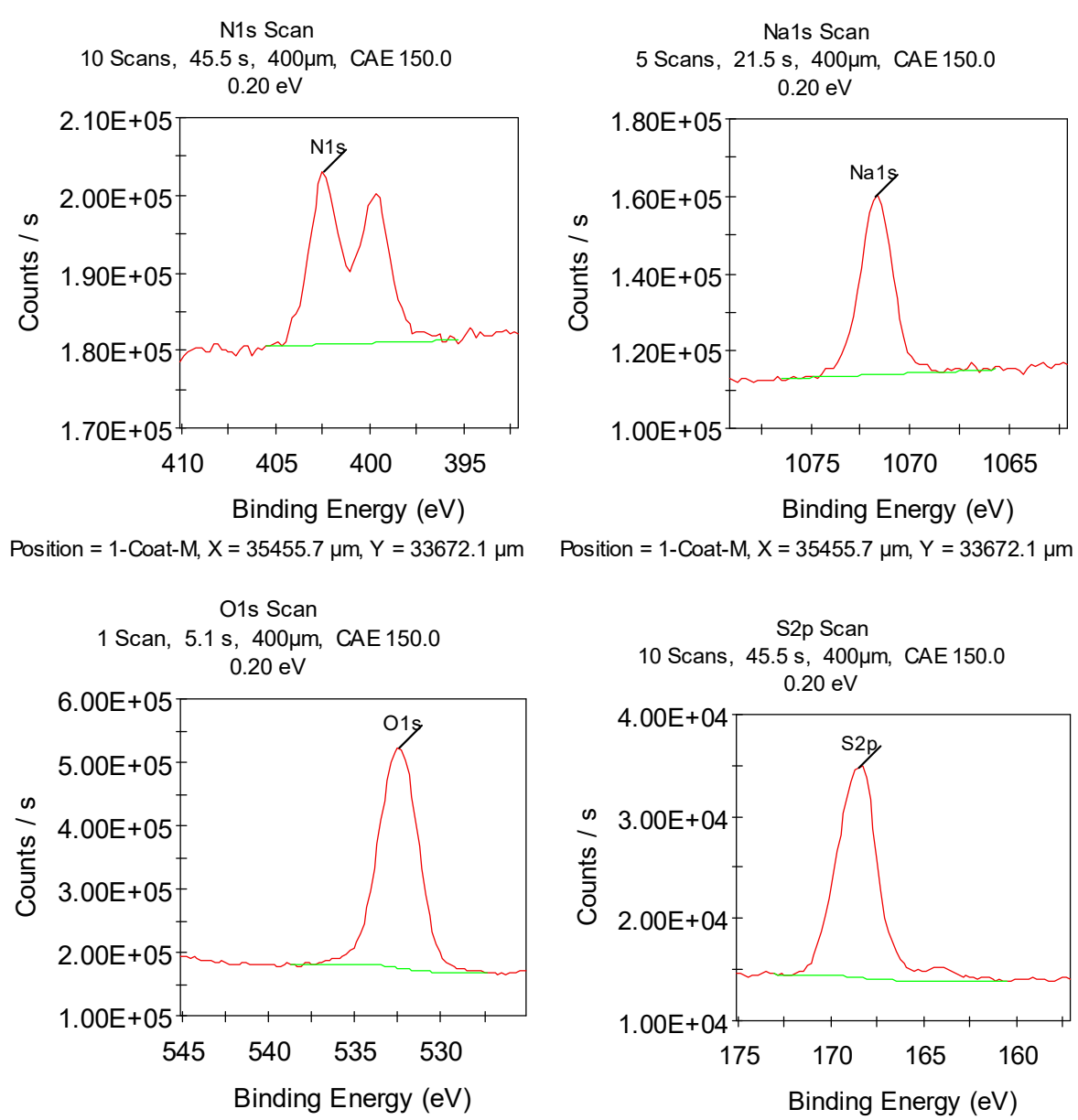

Position = 1-Coat-M, $\mathrm{X}=35455.7 \mu \mathrm{m}, \mathrm{Y}=33672.1 \mu \mathrm{m} \quad$ Position $=1$-Coat-M, $\mathrm{X}=35455.7 \mu \mathrm{m}, \mathrm{Y}=33672.1 \mu \mathrm{m}$

Si2p Scan

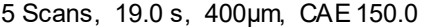

$0.20 \mathrm{eV}$

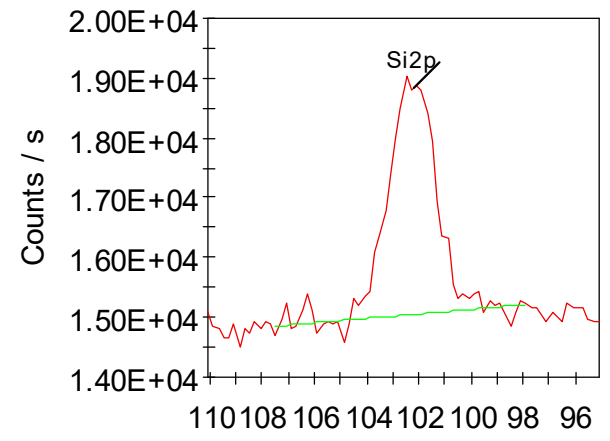

Binding Energy $(\mathrm{eV})$

Position $=1$-Coat-M, $\mathrm{X}=35455.7 \mu \mathrm{m}, \mathrm{Y}=33672.1 \mu \mathrm{m}$

Figure (B) 6 - CPVC treated with 5a identification XPS data, continued. 
Table (B) 1 - Quantification XPS data for control and 5a treated CPVC samples.

\begin{tabular}{|c|c|c|c|c|c|}
\hline \multicolumn{3}{|c}{ Control } & \multicolumn{3}{c|}{ Compound 5a } \\
\hline Element & $\begin{array}{c}\text { Concentration } \\
\%\end{array}$ & $\begin{array}{c}\text { Sensitivity } \\
\text { Factor }\end{array}$ & Element & $\begin{array}{c}\text { Concentration } \\
\%\end{array}$ & $\begin{array}{c}\text { Sensitivity } \\
\text { Factor }\end{array}$ \\
\hline Br3d & 0.08 & 2.840 & Br3d & 0.04 & 2.840 \\
\hline C1s & 77.16 & 1.000 & C1s & 73.17 & 1.000 \\
\hline Ca2p & 1.47 & 5.070 & Ca2p & 0.74 & 5.070 \\
\hline C12p & 7.25 & 2.285 & C12p & 7.23 & 2.285 \\
\hline N1s & 0.35 & 1.800 & N1s & 1.84 & 1.800 \\
\hline Na1s & 0.17 & 8.520 & Na1s & 0.81 & 8.520 \\
\hline O1s & 9.97 & 2.930 & O1s & 14.57 & 2.930 \\
\hline S2p & 0.93 & 1.670 & S2p & 1.24 & 1.670 \\
\hline Si2p & 2.62 & 0.817 & Si2p & 0.36 & 0.817 \\
\hline
\end{tabular}



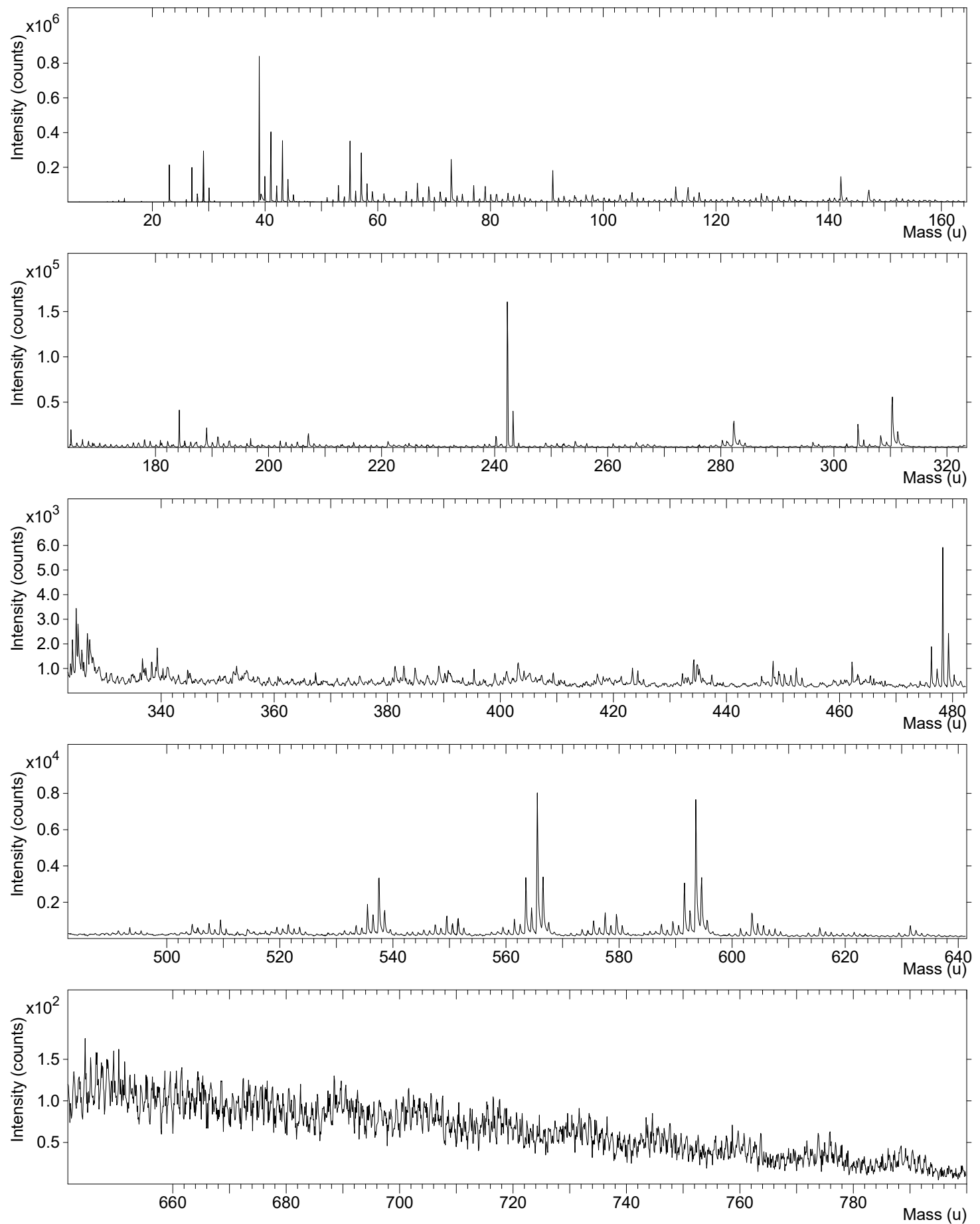

Figure (B) 7 - Positive ion ToF-SIMS survey of control CPVC material. 

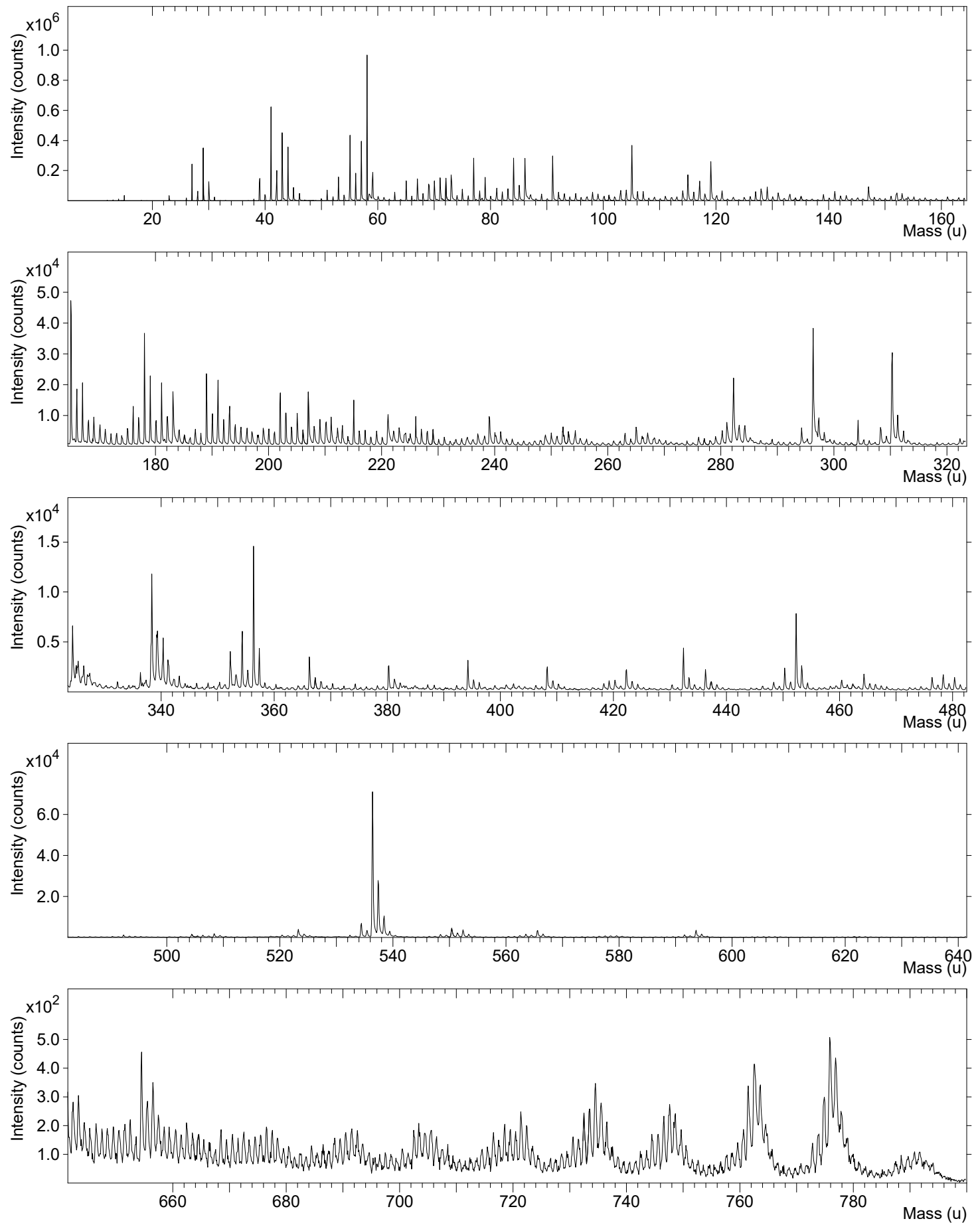

Figure (B) 8 - Positive ion ToF-SIMS survey of 5a treated CPVC material. 

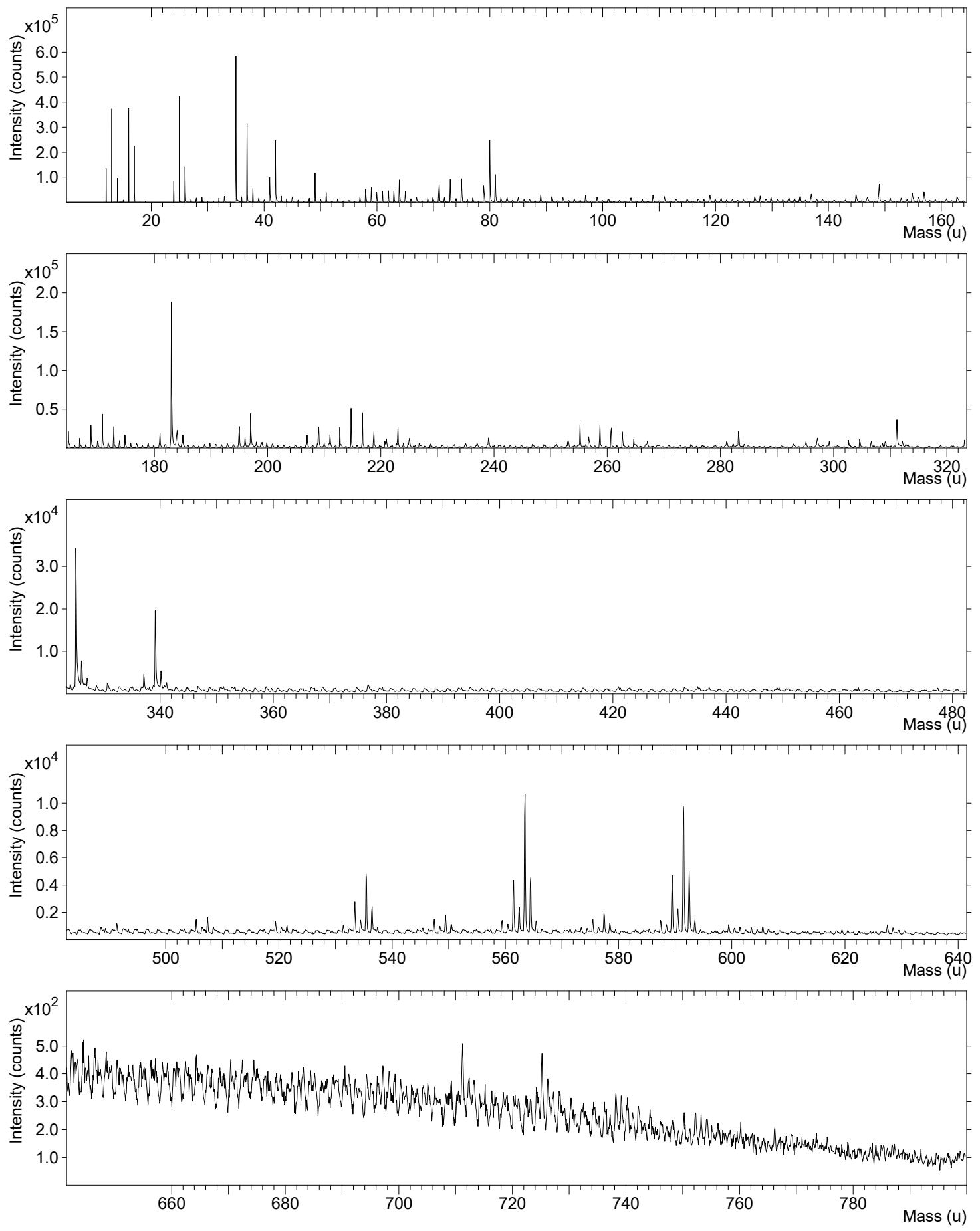

Figure (B) 9 - Negative ion ToF-SIMS survey of control CPVC material. 

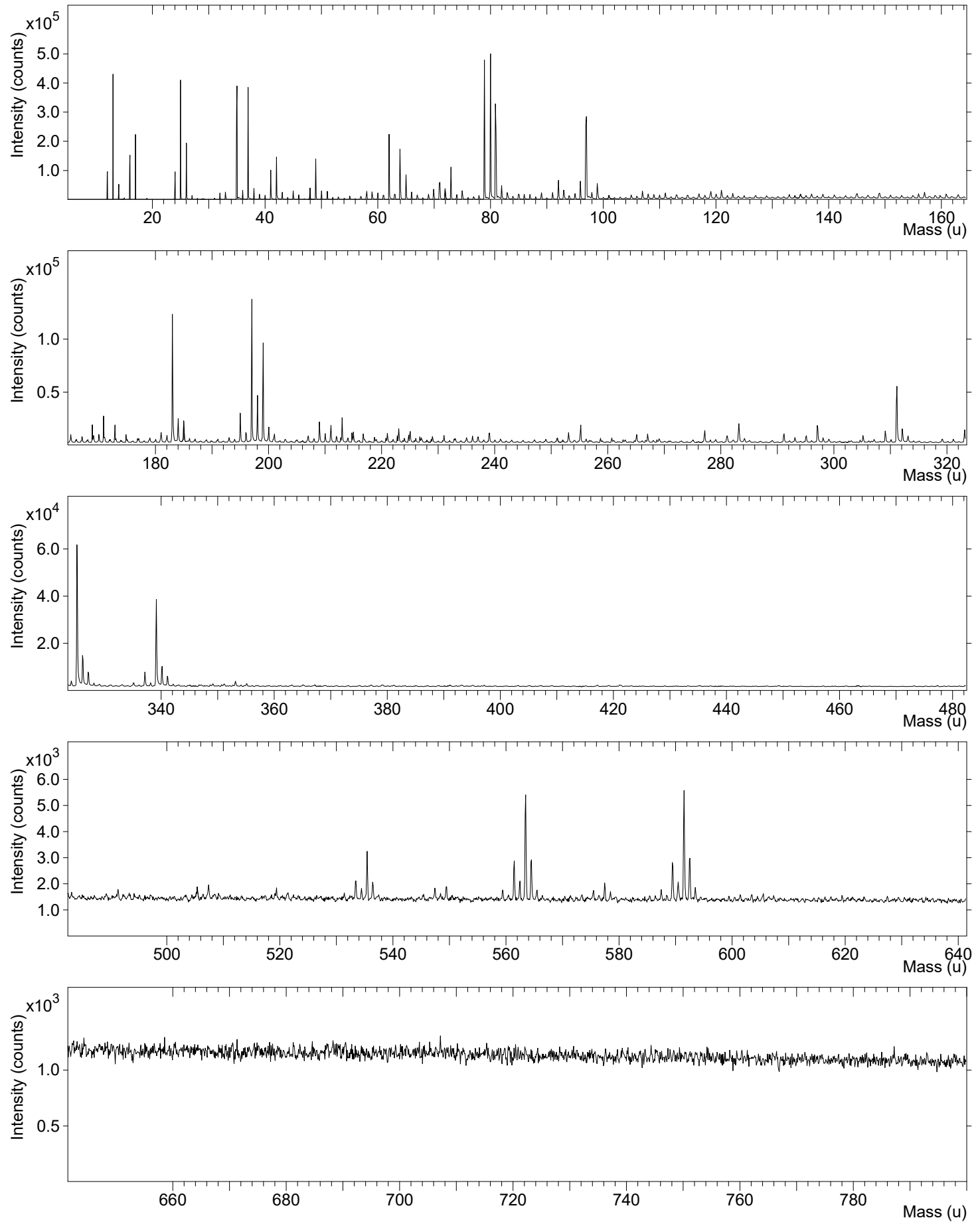

Figure (B) 10 - Negative ion ToF-SIMS survey of 5a treated CPVC material. 


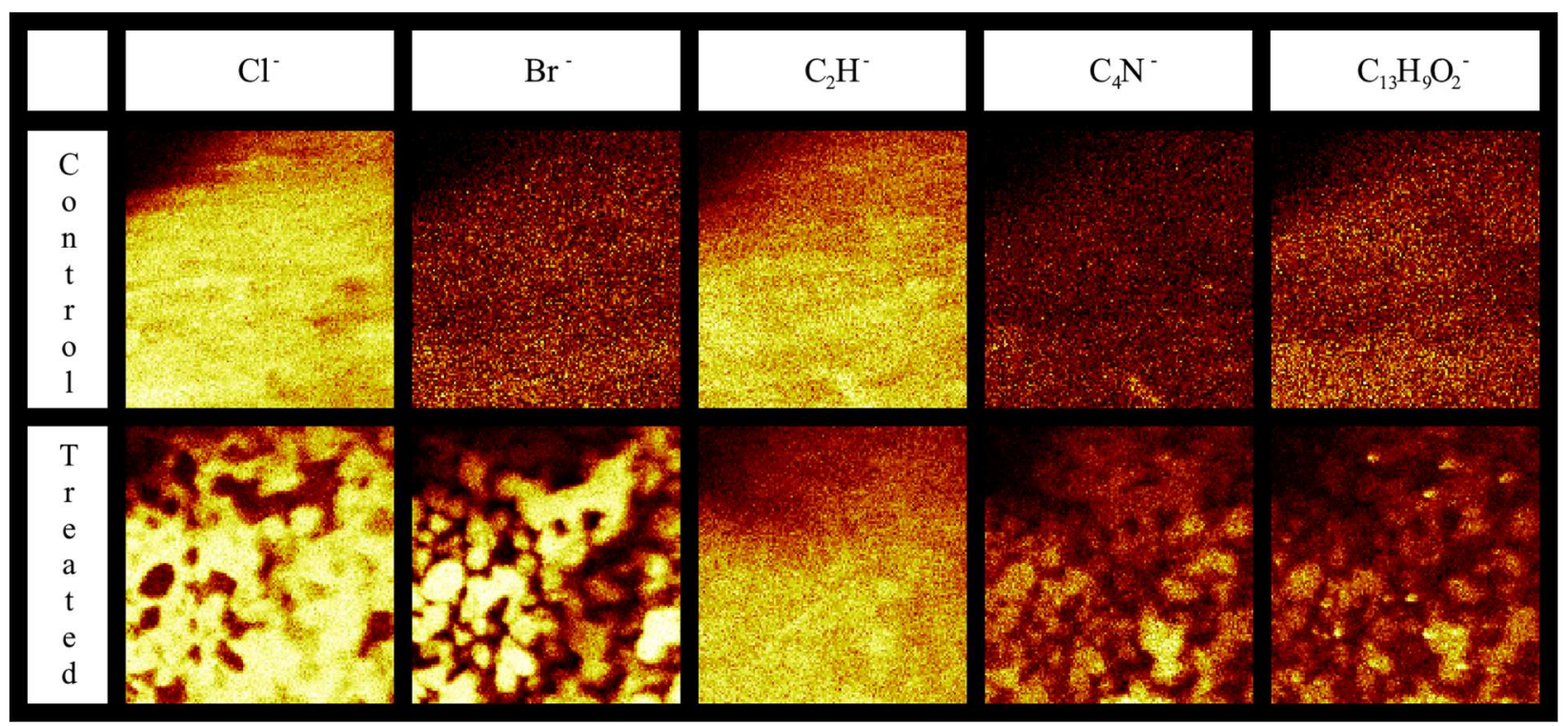

Figure (B) 11 - Composite negative ion ToF-SIMS image of $500.0 \times 500.0 \mu \mathrm{m}$ section of control and 5a treated samples. Intensity is a function of fragment quantity during analysis. Images correspond to negative ionic fragmentation products of chlorine $\left(\mathrm{Cl}^{-}\right)$, bromine $\left(\mathrm{Br}^{-}\right)$, ethane $\left(\mathrm{C}_{2} \mathrm{H}^{-}\right.$ ), tetracarbonyl ammonium $\left(\mathrm{C}_{4} \mathrm{~N}^{-}\right)$, and hydroxybenzophenone $\left(\mathrm{C}_{13} \mathrm{H}_{9} \mathrm{O}_{2}{ }^{-}\right)$. 


\section{Atomic Force Microscopy and Surface Profilometry Data}

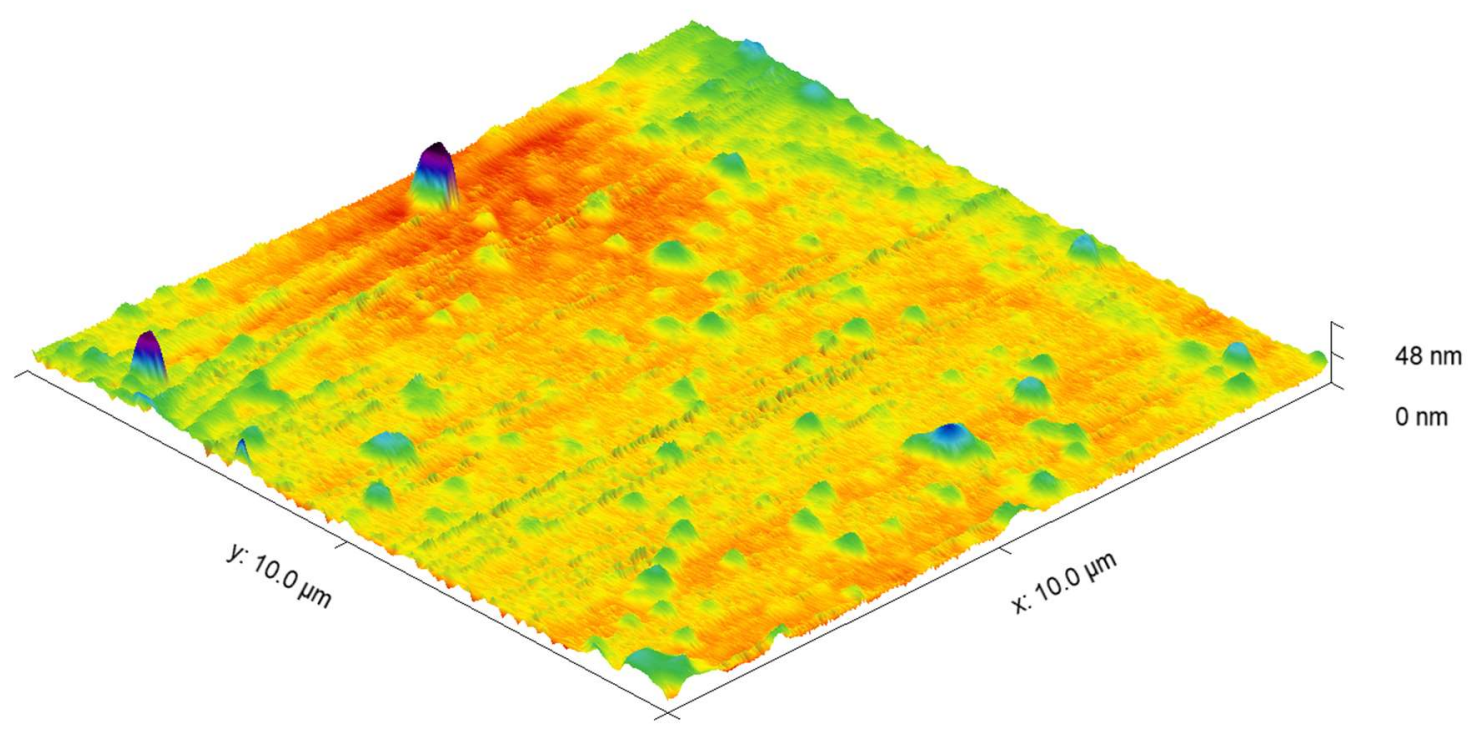

Figure (B) 12 - Contact AFM surface scan of a control polycarbonate (PC) surface.

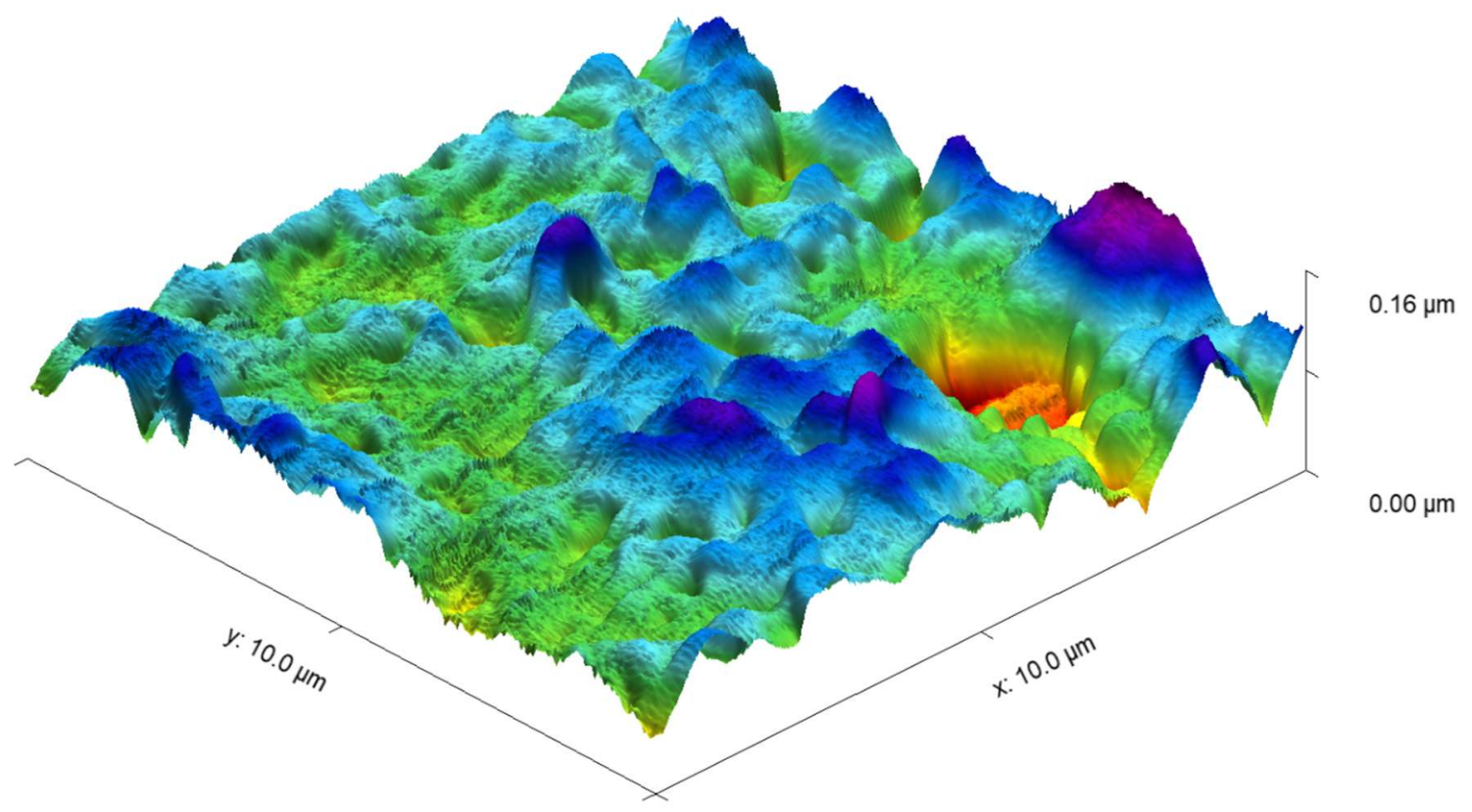

Figure (B) 13 - Contact AFM surface scan of a polycarbonate (PC) surface treated with 5 a. 


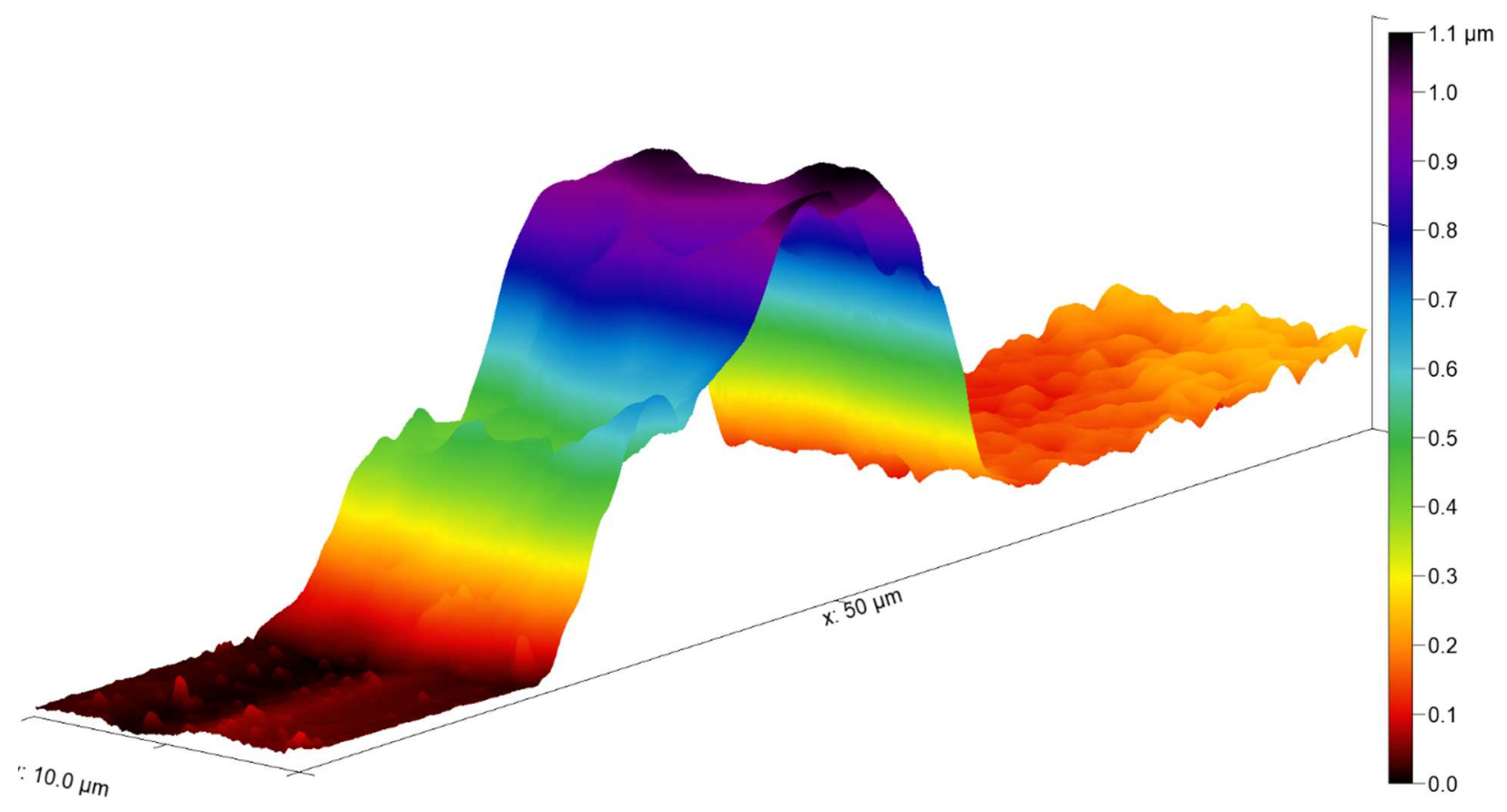

Figure (B) 14 - Contact AFM profile scan of a polycarbonate (PC) surface partially treated with $5 a$.

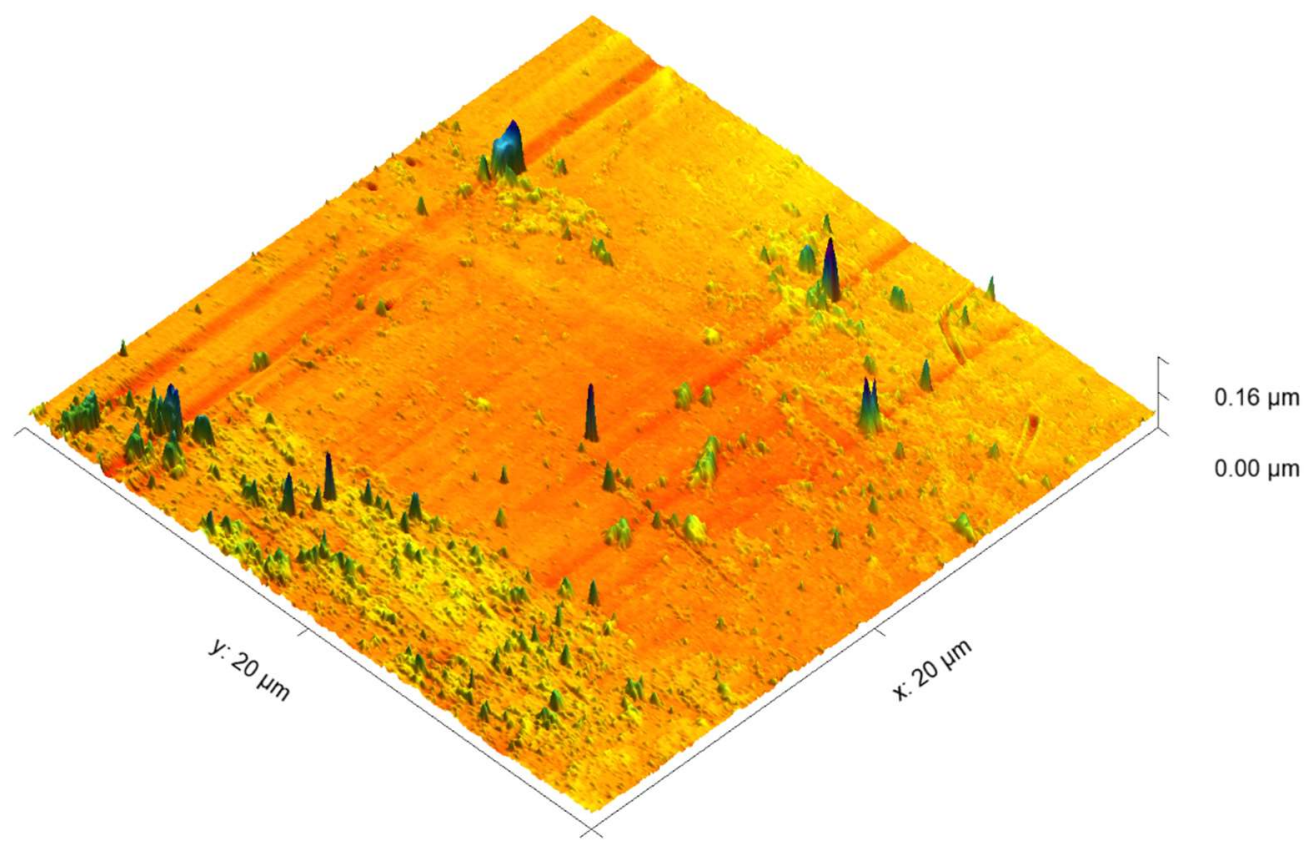

Figure (B) 15 - Tapping AFM data for control polycarbonate (PC) surface sample (RMS roughness $=6.21 \mathrm{~nm})$. 


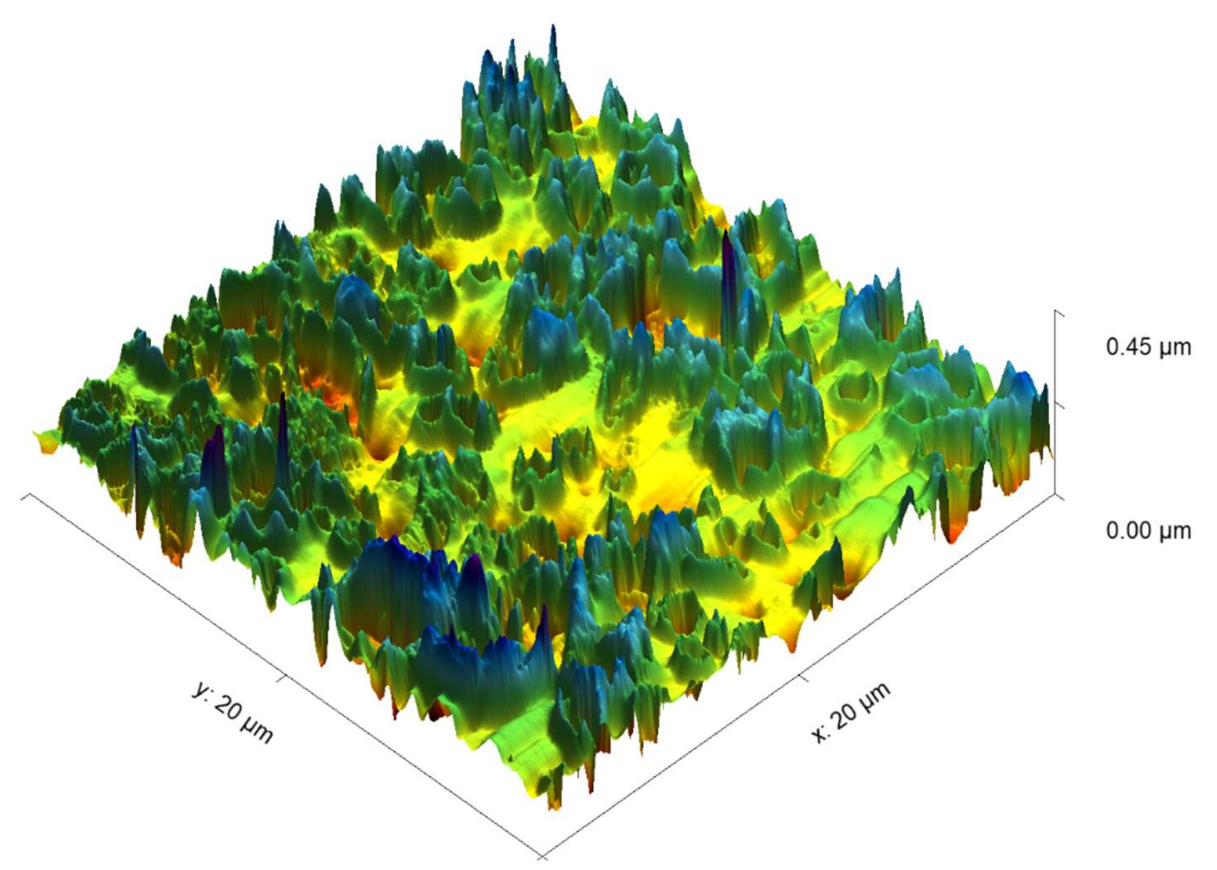

Figure (B) 16 - Tapping AFM data for 10a coated onto a polycarbonate surface (RMS roughness $=51.31 \mathrm{~nm})$.

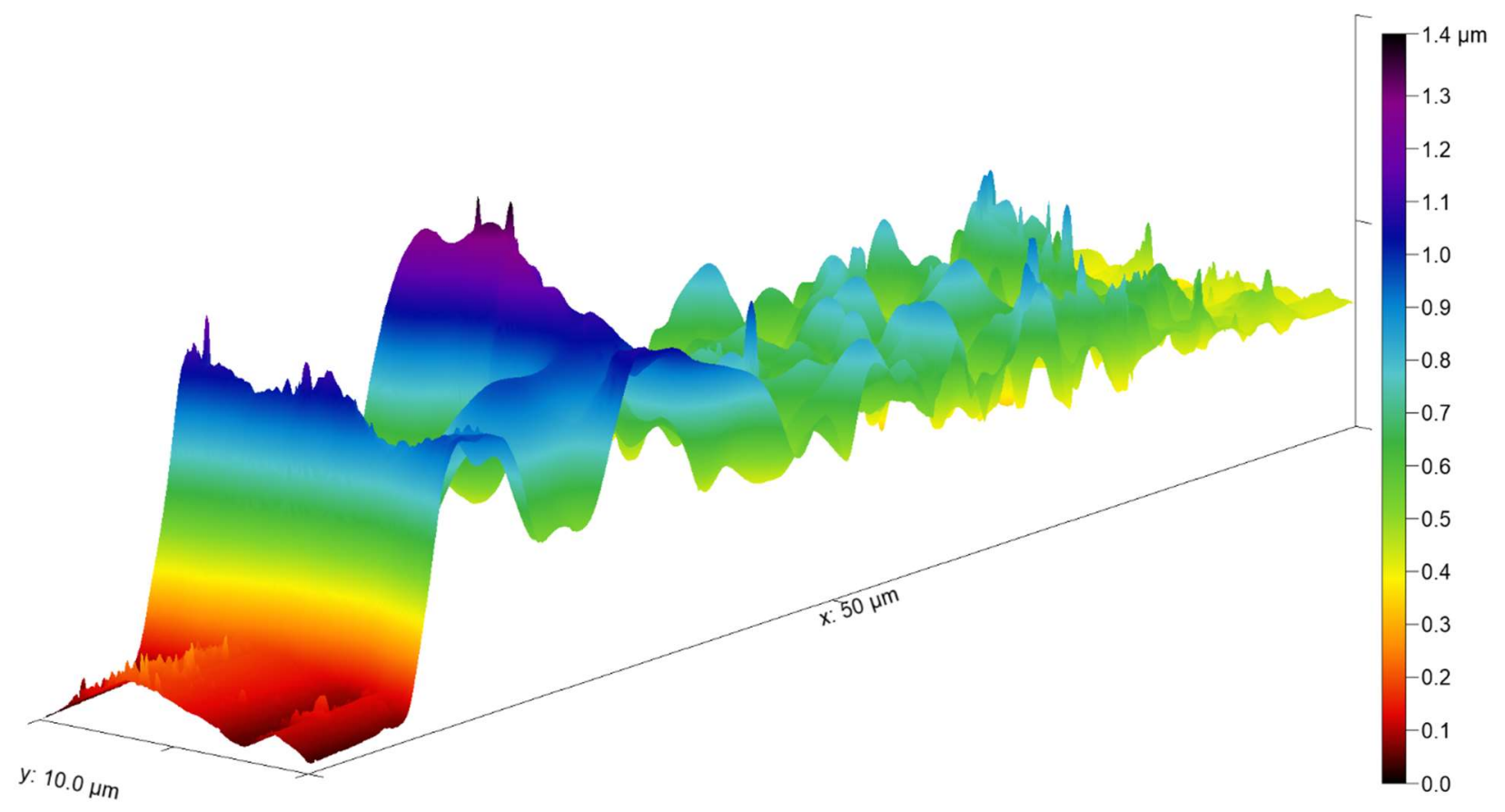

Figure (B) 17 - Tapping AFM profile scan of a polycarbonate (PC) surface partially treated with $10 a$. 


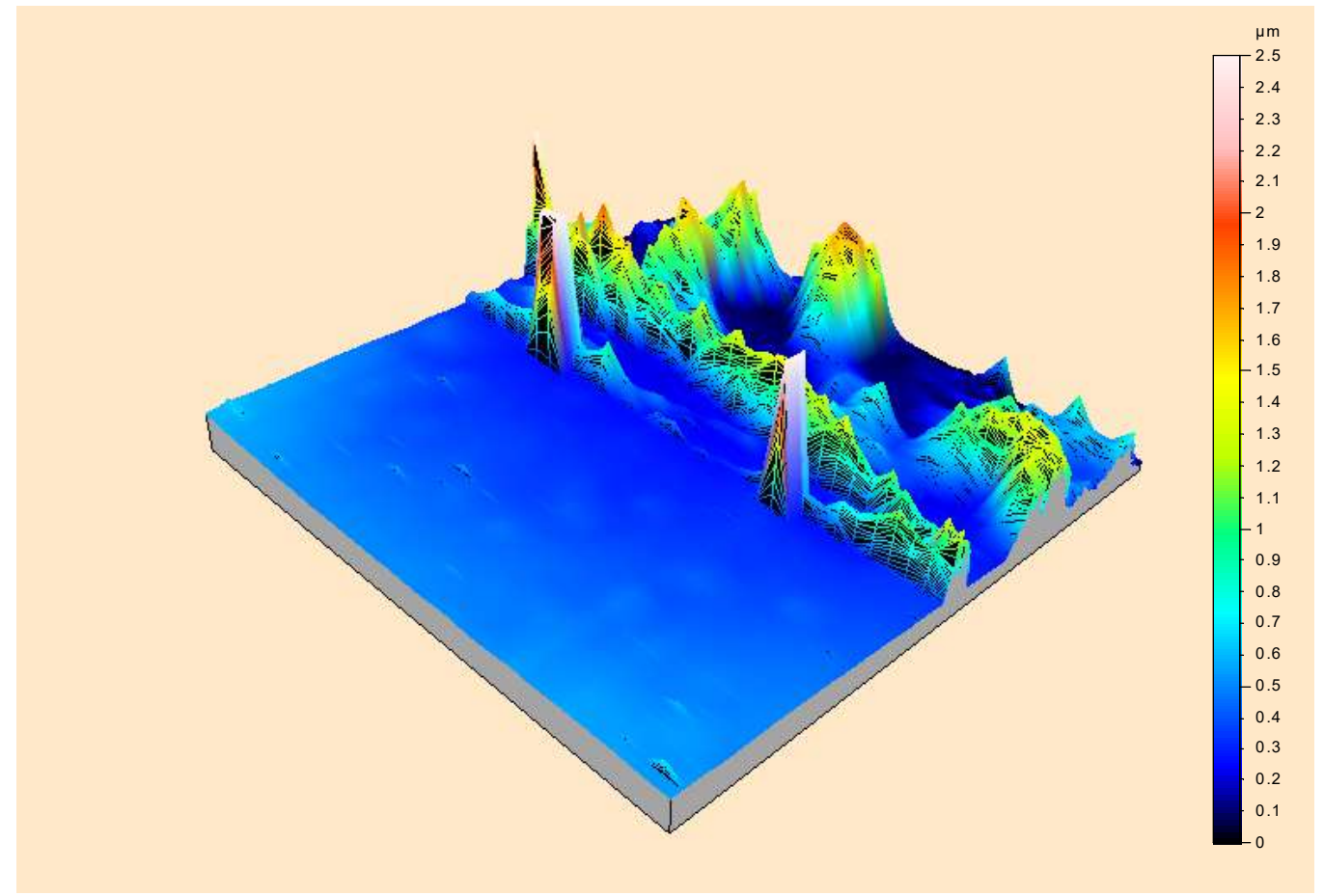

Figure (B) 18 - SP profile scan of a polycarbonate (PC) surface partially treated with $\mathbf{5 a}$. 


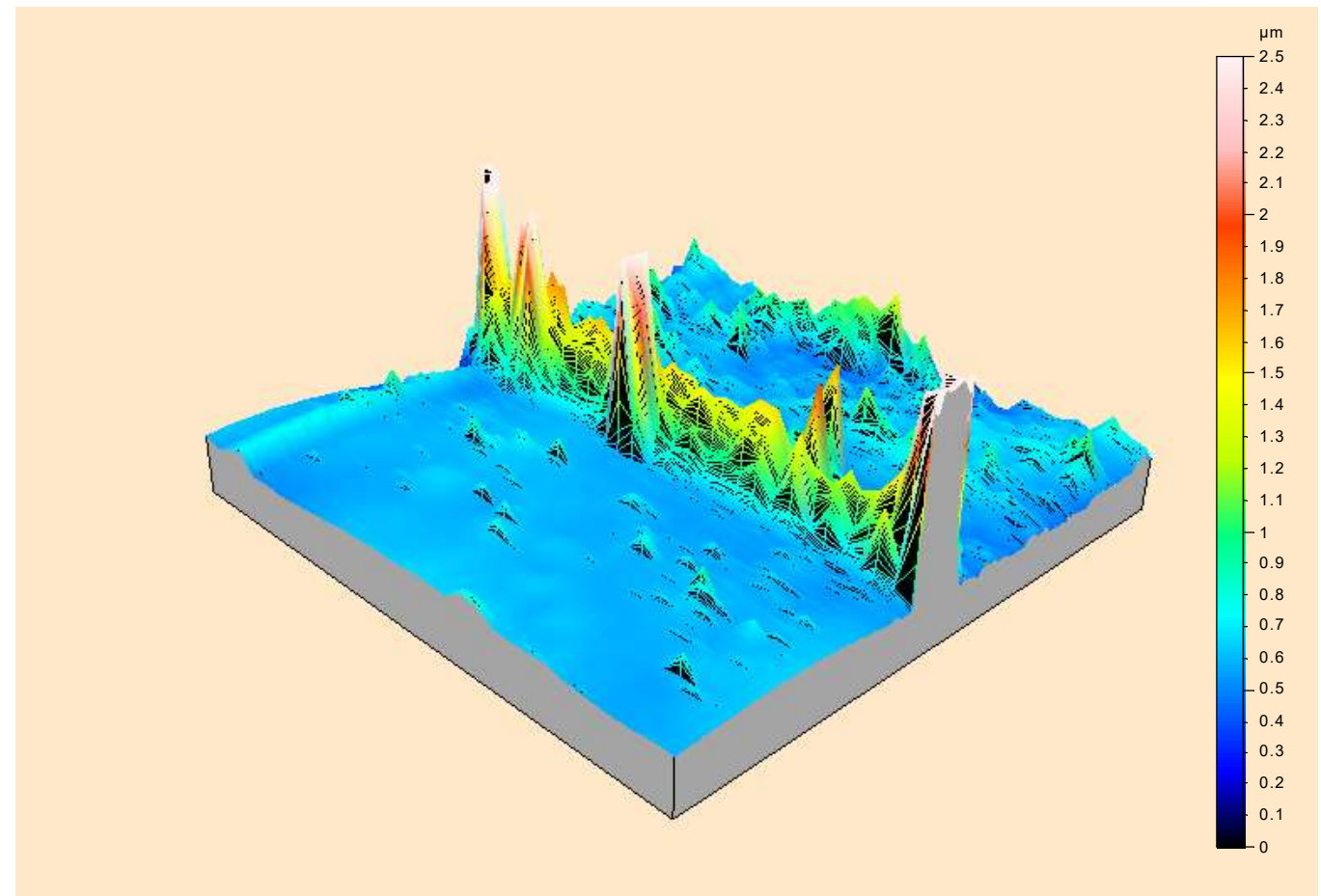

Figure (B) 19 - SP profile scan of a polycarbonate (PC) surface partially treated with 10a. 


\section{Microbiology Data}

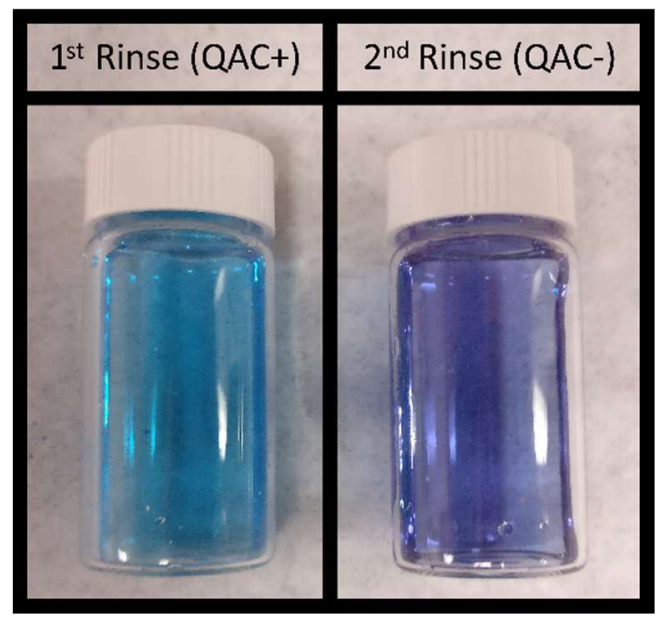

Figure (B) 20 - Successive wash solutions of polystyrene coated with 5a, exposed to 3 drops ( $\sim 0.1 \mathrm{~mL}) 1000 \mathrm{ppm}$ bromophenol blue dye. Samples were shaken for 30 seconds in sealed tubes containing $10 \mathrm{~mL}$ of distilled water. The blue colour indicates the first rinse contains the presence QAC, while the purple colour indicates the second rinse does not.

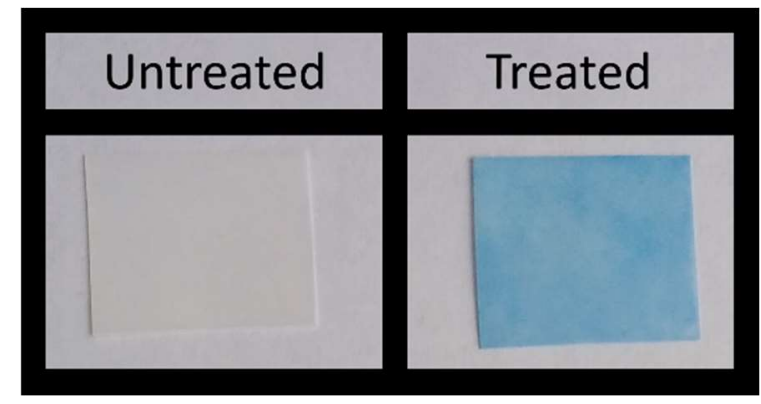

Figure (B) 21 - Representative polystyrene samples, one left untreated (left) and treated (right) with 5a, stained with bromophenol blue.

Table (B) 2 - Sulfa QAC 3a-11a microbiology data (LDI). Microbiological testing was performed with triplicate treated and untreated controls. The inoculum load represents the quantity of viable cells placed onto each sample material and was determined concurrently to sample data ( \pm indicates standard deviation $n=3$ ). A value of $1.70 \log (\mathrm{CFU})$ represents the 
lowest number of detectable cells spot plated onto $3 \mathrm{~g} \mathrm{~L}^{-1} \mathrm{TSA}$ (LOD: $50 \mathrm{CFU}, 1$ colony in $5 \mathrm{~mL}$ undiluted collection fluid).

\begin{tabular}{|c|c|c|c|c|}
\hline & & & \\
\hline & & \multicolumn{3}{|c|}{ Geometric Mean $\log (\mathrm{CFU})$} \\
\hline & & Inoculum Load & Control & Treated \\
\hline \multicolumn{5}{|c|}{$\underbrace{\substack{R \\
S}=0}_{3-10 a}$} \\
\hline \multirow{2}{*}{$\begin{array}{l}\text { 3: } \mathrm{R}= \\
\text { Arthrobacter sp. (IAI-3) } \\
\text { High Density Polyethylene }\end{array}$} & 3 Hours & \multirow{2}{*}{7.43} & $5.68 \pm 1.32$ & $<1.70 \pm 0.00$ \\
\hline & 24 Hours & & $2.72 \pm 0.12$ & $<1.70 \pm 0.00$ \\
\hline \multicolumn{5}{|l|}{$\begin{array}{c}m_{\mathrm{Ph}} \\
\begin{array}{c}\text { Escherichia coli }(\mathrm{DH} 5 \alpha) \\
\text { Polystyrene }\end{array} \\
\end{array}$} \\
\hline \multirow{2}{*}{$\begin{array}{c}\text { 4: } \mathrm{R}=1 \\
\text { Arthrobacter sp. (IAII-3) } \\
\text { Cotton (Fabric) }\end{array}$} & 3 Hours & \multirow{2}{*}{8.11} & $6.94 \pm 0.05$ & $<1.70 \pm 0.00$ \\
\hline & 24 Hours & & $1.60 \pm 1.54$ & $<1.70 \pm 0.00$ \\
\hline \multirow[t]{2}{*}{$\begin{array}{c}\text { Tol } \\
\begin{array}{c}\text { Escherichia coli }(\mathrm{DH5 \alpha}) \\
\text { Polystyrene }\end{array}\end{array}$} & 3 Hours & 7.71 & $2.27 \pm 1.11$ & $<1.70 \pm 0.00$ \\
\hline & 3 Hours & 7.01 & $6.55 \pm 0.06$ & $<1.70 \pm 0.00$ \\
\hline
\end{tabular}




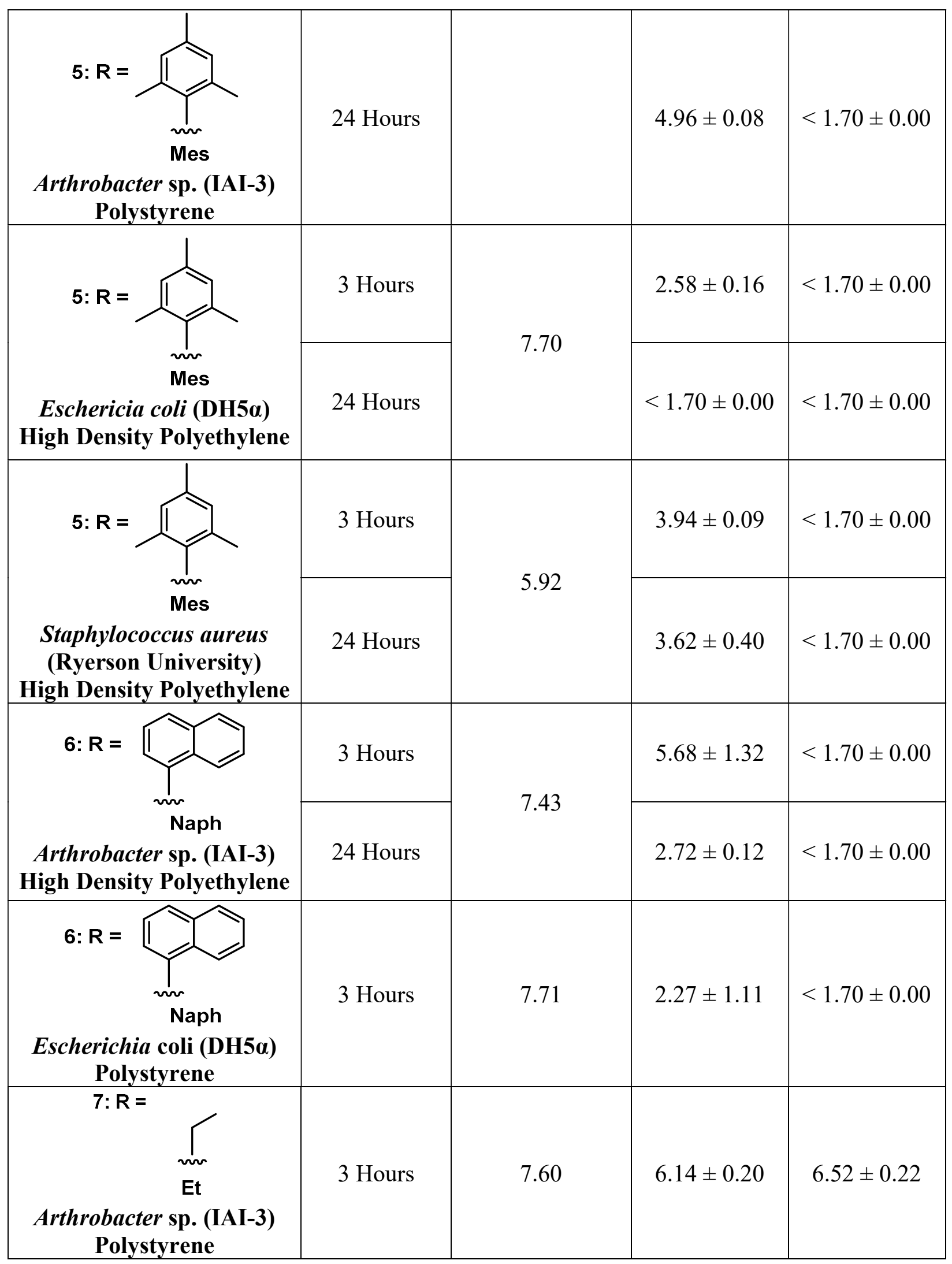




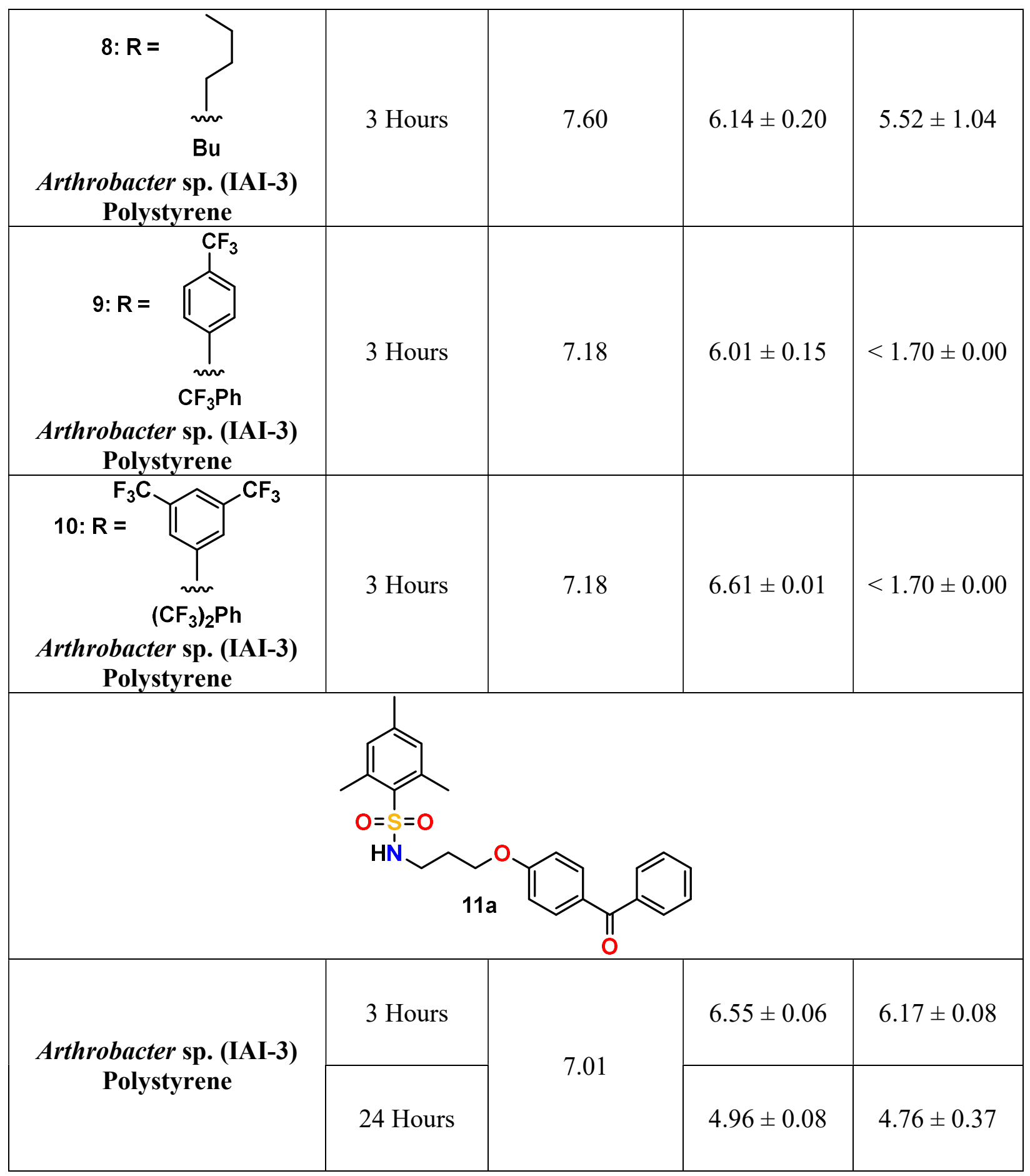

Table (B) 3 - Sulfa QAC 3b-6b microbiology data (LDI). Microbiological testing was performed with triplicate treated and untreated controls. The inoculum load represents the quantity of viable cells placed onto each sample material and was determined concurrently to 
sample data ( \pm indicates standard deviation $n=3$ ). A value of $1.70 \log (\mathrm{CFU})$ represents the lowest number of detectable cells spot plated onto $3 \mathrm{~g} \mathrm{~L}^{-1} \mathrm{TSA}$ (LOD: $50 \mathrm{CFU}, 1$ colony in $5 \mathrm{~mL}$ undiluted collection fluid).

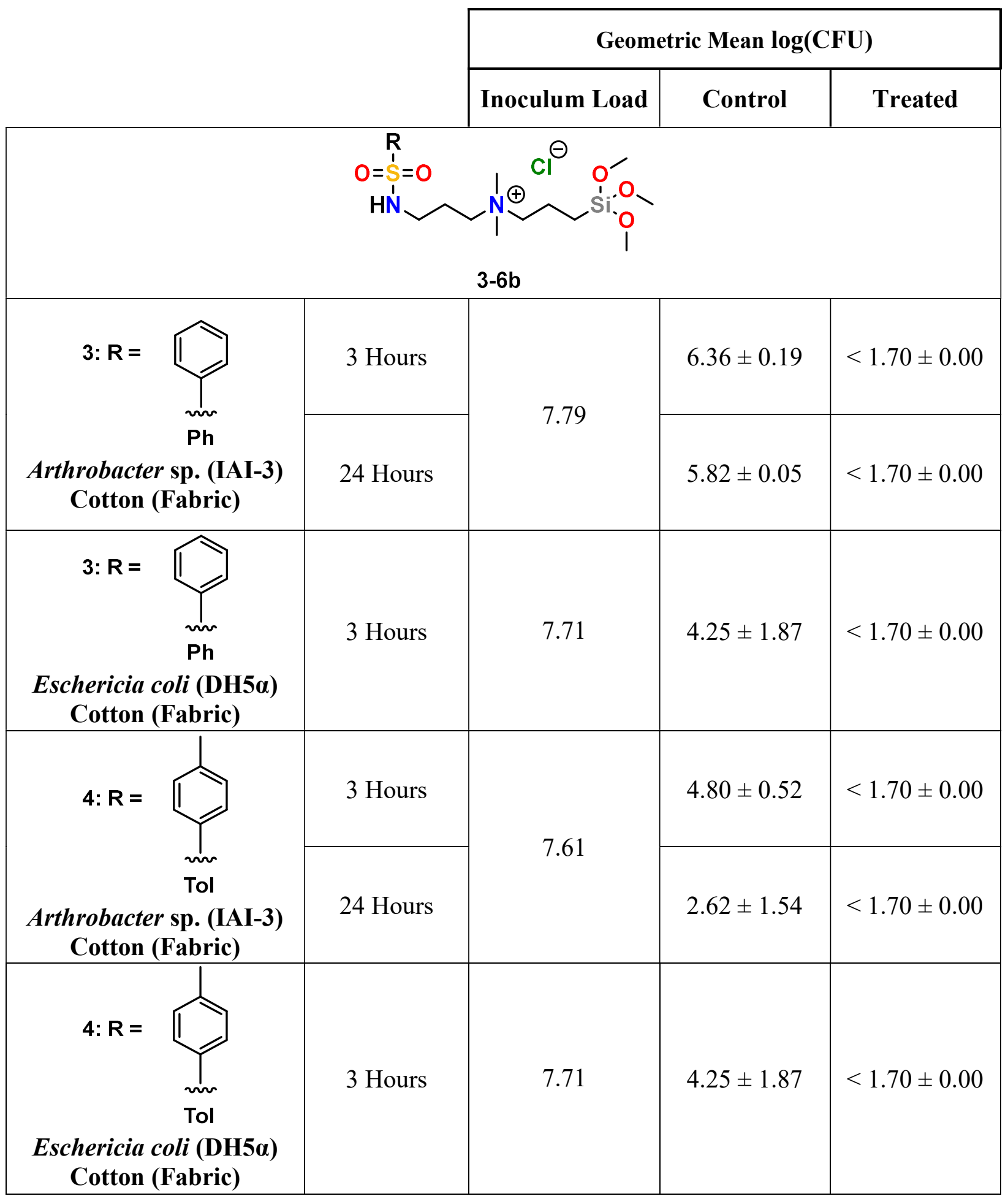




\begin{tabular}{|c|c|c|c|c|}
\hline 5: $R=$ & 3 Hours & \multirow{2}{*}{7.61} & $4.80 \pm 0.52$ & $<1.70 \pm 0.00$ \\
\hline $\begin{array}{c}\text { Mes } \\
\text { Arthrobacter sp. (IAI-3) } \\
\text { Cotton (Fabric) } \\
\end{array}$ & 24 Hours & & $2.62 \pm 1.54$ & $<1.70 \pm 0.00$ \\
\hline $\begin{array}{c}\text { Mes } \\
\text { Eschericia coli (DH5a) } \\
\text { Cotton (Fabric) }\end{array}$ & 3 Hours & 7.71 & $4.25 \pm 1.87$ & $<1.70 \pm 0.00$ \\
\hline \multirow{2}{*}{$\begin{array}{l}\text { 6: } \mathrm{R}=1 \\
\text { Arthrobacter sp. (IAII-3) } \\
\text { Cotton (Fabric) }\end{array}$} & 3 Hours & \multirow{2}{*}{7.79} & $6.36 \pm 0.19$ & $<1.70 \pm 0.00$ \\
\hline & 24 Hours & & $5.82 \pm 0.05$ & $<1.70 \pm 0.00$ \\
\hline $\begin{array}{c}\text { Naph } \\
\text { Eschericia coli (DH5a) } \\
\text { Cotton (Fabric) }\end{array}$ & 3 Hours & 7.71 & $4.25 \pm 1.87$ & $<1.70 \pm 0.00$ \\
\hline
\end{tabular}

Table (B) 4 - QAC 1a, 5a planktonic microbiology data (LRI). Microbiological testing was performed with triplicate treated and untreated controls. Planktonic colony counts were collected prior to the collection of biofilm data. The inoculum load represents the quantity of viable cells placed onto each sample material and was determined concurrently to sample data ( \pm indicates standard deviation, $\mathrm{n}=3)$. A value of $6.78 \log \left(\mathrm{CFU} \mathrm{m}{ }^{-1}\right)$ represents the highest number of detectable cells spot plated onto $3 \mathrm{~g} \mathrm{~L}^{-1}$ TSA (LOD: $6.00 \times 10^{-6} \mathrm{CFU} \mathrm{ml}^{-1}, 600$ colonies in $3 \mathrm{~mL}$ collection fluid, diluted by a factor of $\left.10^{3}\right)$. A value of $1.00 \log \left(\mathrm{CFU} \mathrm{ml}^{-1}\right)$ represents the lowest number of detectable cells spot plated onto $3 \mathrm{~g} \mathrm{~L}^{-1} \mathrm{TSA}$ (LOD: $10 \mathrm{CFU} \mathrm{ml} l^{-1}, 1$ colony in $3 \mathrm{~mL}$ undiluted collection fluid).

\section{Geometric Mean $\log \left(\mathrm{CFU} \mathrm{ml}^{-1}\right)$}




\begin{tabular}{|c|c|c|c|c|}
\hline & & Inoculum Load & Control & Treated \\
\hline & 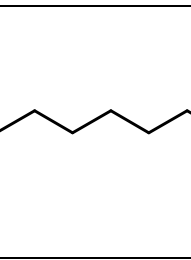 & $1 \mathrm{a}$ & & \\
\hline Arthrobacter sp. (IAI-3) & 24 Hours & & $6.48 \pm 0.11$ & $6.29 \pm 0.08$ \\
\hline Low Density Polyethylene & 48 Hours & & $6.50 \pm 0.04$ & $6.05 \pm 0.09$ \\
\hline Escherichia coli (DH5a) & 24 Hours & & $6.35 \pm 0.05$ & $5.38 \pm 0.61$ \\
\hline Low Density Polyethylene & 48 Hours & & $5.96 \pm 0.06$ & $4.16 \pm 0.81$ \\
\hline & $5 \mathbf{a}$ & & & \\
\hline Arthrobacter sp. (IAI-3) & 24 Hours & 765 & $6.22 \pm 0.07$ & $<1.00 \pm 0.00$ \\
\hline Low Density Polyethylene & 48 Hours & 1.05 & $4.77 \pm 0.40$ & $<1.00 \pm 0.00$ \\
\hline Escherichia coli (DH5a) & 24 Hours & & $6.35 \pm 0.05$ & $5.06 \pm 0.11$ \\
\hline Low Density Polyethylene & 48 Hours & & $5.96 \pm 0.06$ & $4.07 \pm 0.14$ \\
\hline
\end{tabular}

Table (B) 5 - Tabulated liquid reservoir inoculation (LRI) biofilm microbiology data. Microbiological testing was performed with triplicate treated and untreated controls. Biofilm colony counts were collected subsequently to the collection of planktonic data. The inoculum load represents the quantity of viable cells placed onto each sample material and was determined concurrently to sample data ( \pm indicates standard deviation, $n=3)$. A value of $1.00 \log (\mathrm{CFU})$ represents the lowest number of detectable cells spot plated onto $3 \mathrm{~g} \mathrm{~L}^{-1} \mathrm{TSA}$ (LOD: $10 \mathrm{CFU}, 1$ colony in $1 \mathrm{~mL}$ undiluted collection fluid).

\begin{tabular}{|c|c|c|}
\hline \multicolumn{3}{|c|}{ Geometric Mean $\log (\mathrm{CFU})$} \\
\hline $\begin{array}{c}\text { Inoculum } \\
\text { Load }\end{array}$ & Control & Treated \\
\hline
\end{tabular}




\begin{tabular}{|c|c|c|c|c|}
\hline & 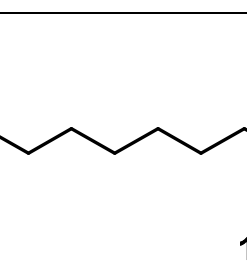 & 1 & W & \\
\hline $\begin{array}{l}\text { Arthrobacter sp. (IAI-3) } \\
\text { Low Density Polyethylene }\end{array}$ & $\begin{array}{c}\text { Biofilm at } 48 \\
\text { Hours }\end{array}$ & 7.02 & $6.26 \pm 0.08$ & $5.87 \pm 0.25$ \\
\hline $\begin{array}{l}\text { Escherichia coli (DH5a) } \\
\text { Low Density Polyethylene }\end{array}$ & $\begin{array}{l}\text { Biofilm at } 48 \\
\text { Hours }\end{array}$ & 6.74 & $3.72 \pm 0.25$ & $2.37 \pm 0.52$ \\
\hline & & & & \\
\hline $\begin{array}{l}\text { Arthrobacter sp. (IAI-3) } \\
\text { Low Density Polyethylene }\end{array}$ & $\begin{array}{c}\text { Biofilm at } 48 \\
\text { Hours }\end{array}$ & 7.65 & $4.63 \pm 0.33$ & $<1.00 \pm 0.00$ \\
\hline $\begin{array}{l}\text { Escherichia coli (DH5a) } \\
\text { Low Density Polyethylene }\end{array}$ & $\begin{array}{c}\text { Biofilm at } 48 \\
\text { Hours }\end{array}$ & 7.74 & $6.22 \pm 0.04$ & $4.04 \pm 0.50$ \\
\hline
\end{tabular}

Table (B) 6 - Multi-load sulfa QAC 5a microbiology data (LDI). Microbiological testing was performed with triplicate treated and untreated controls. The inoculum load represents the quantity of viable cells placed onto each sample material and was determined concurrently to sample data ( \pm indicates standard deviation $n=3)$. A value of $1.70 \log (\mathrm{CFU})$ represents the lowest number of detectable cells spot plated onto $3 \mathrm{~g} \mathrm{~L}^{-1} \mathrm{TSA}$ (LOD: $50 \mathrm{CFU}, 1$ colony in $5 \mathrm{~mL}$ undiluted collection fluid). 


\begin{tabular}{|c|c|c|c|c|}
\hline & & \multicolumn{3}{|c|}{ Geometric Mean $\log (\mathrm{CFU})$} \\
\hline & & $\begin{array}{c}\text { Inoculum } \\
\text { Load }\end{array}$ & Control & Treated \\
\hline & $3 a$ & & & \\
\hline $\begin{array}{l}\text { Arthrobacter sp. (IAI-3) } \\
\text { Polystyrene (PS) }\end{array}$ & $\begin{array}{c}\text { Single } \\
\text { Inoculation }\end{array}$ & 6.79 & $5.96 \pm 0.10$ & $<1.70 \pm 0.00$ \\
\hline $\begin{array}{l}\text { Arthrobacter sp. (IAI-3) } \\
\text { Polystyrene (PS) }\end{array}$ & $\begin{array}{l}\text { Double } \\
\text { Inoculation }\end{array}$ & 7.28 & $7.07 \pm 0.04$ & $6.65 \pm 0.29$ \\
\hline
\end{tabular}

\section{Synthetic Procedure}

Precursor 4-(3-bromopropyoxy)benzophenone was synthesized according to published work and NMR spectra $\left({ }^{1} \mathrm{H}\right.$ and $\left.{ }^{13} \mathrm{C}\right)$ corresponded well with previously published NMR data. ${ }^{1,84}$ Synthetic procedure and NMR data for this publication was prepared by Joseph Bedard.

\section{Method (B)1: General procedure for aromatic sulfonamide synthesis}

To a flame dried, round bottom flask in an ice bath equipped with a stir bar containing an appropriate amount of anhydrous DCM, an adequate amount of respective sulfonyl chloride was added, followed by an equimolar amount of $\mathrm{Et}_{3} \mathrm{~N}$ and dropwise addition of a stoichiometric quantity of 3-(dimethylamino)propylamine. After $30 \mathrm{~min}$. the reaction mixture was removed from the ice bath and allowed to stir at room temperature for the indicated time. The reaction was then transferred to a separatory funnel and extracted with an appropriate amount of distilled water. 
Volatiles and/or solvent were removed from the organic phase using a rotary evaporator followed by drying under high vacuum.

\section{Method (B)2: General procedure for aliphatic sulfonamide synthesis}

To a flame dried, round bottom flask in an ice bath equipped with a stir bar containing appropriate amount of anhydrous DCM a stoichiometric amount of 3-(dimethylamino)propylamine was added followed by the dropwise addition of the respective sulfonyl chlorides. The reaction mixture was removed from the ice bath and allowed to stir for the indicated time at room temperature. Upon completion, the reaction solvent was evaporated using a rotary evaporator. The resultant residue was then dissolved in an appropriate amount of potassium carbonate solution $(0.05 \mathrm{M})$ and extracted using appropriate amount of DCM. Volatiles were removed in vacuo.

\section{Method (B)3: General procedure for Menshutkin quaternization reaction}

In an appropriately sized round bottom flask or scintillation/microwave vial, an appropriate amount of a tertiary amine-terminated sulfonamide and a trimethoxy silane, diallyl phosphonate or benzophenone alkyl halide starting material was dissolved in acetonitrile. The reaction mixture was stirred at $110{ }^{\circ} \mathrm{C}$ for the indicated time. The crude material was purified by addition of $\mathrm{Et}_{2} \mathrm{O}$ directly into the reaction mixture followed by decanting $\left(\mathrm{Et}_{2} \mathrm{O}\right.$ wash $\left.\times 3\right)$ and dried in vacuo.

\section{Synthesis of N-(3-(dimethylamino)propyl)benzenesulfonamide 3}

This compound was synthesized according to Method (B)1 with benzenesulfonyl chloride (1.4 $\mathrm{mL}, \quad 11.32 \mathrm{mmol})$, triethylamine $(2.4 \mathrm{~mL}, \quad 16.99 \mathrm{mmol}, \quad 1.5$ eqv. $)$, and $3-$ (dimethylamino)propylamine (2.1 mL, $16.99 \mathrm{mmol}, 1.5 \mathrm{eqv}$.$) in DCM (30 mL) stirring for 4$ hours, 
yielding a clear solution. The solution was then washed using distilled water $(40 \mathrm{~mL})$, and the organic layer was removed in vacuo to yield a green yellow coloured oil. The product was further dried under reduced pressure, yielding the desired product as a pale yellow coloured waxy solid. Yield: $98 \%$ (2.69 g). ${ }^{1} \mathrm{H}$ NMR $\left(\mathrm{CDCl}_{3}, 400 \mathrm{MHz}, \delta\right): 7.68\left(2 \mathrm{H}, \mathrm{d},{ }^{3} \mathrm{~J}_{\mathrm{H} 3-\mathrm{H} 2}=8.3 \mathrm{~Hz}, \mathrm{H} 3\right), 7.35(3 \mathrm{H}$, m, H1 and H2), $2.86\left(2 \mathrm{H}, \mathrm{t},{ }^{3} \mathrm{~J}_{\mathrm{H} 6-\mathrm{H} 7}=5.8 \mathrm{~Hz}, \mathrm{H} 6\right), 2.11\left(2 \mathrm{H}, \mathrm{t},{ }^{3} \mathrm{~J}_{\mathrm{H} 8-\mathrm{H} 7}=5.9 \mathrm{~Hz}, \mathrm{H} 8\right), 1.98(6 \mathrm{H}, \mathrm{s}$, $\mathrm{H} 9), 1.41\left(2 \mathrm{H}, \mathrm{m}, \quad{ }^{3} \mathrm{~J}_{\mathrm{H} 7-\mathrm{H} 6}=9.0 \mathrm{~Hz},{ }^{3} \mathrm{~J}_{\mathrm{H} 7-\mathrm{H} 8}=3.1 \mathrm{~Hz}, \mathrm{H} 7\right) \mathrm{ppm} ;{ }^{13} \mathrm{C}\left\{{ }^{1} \mathrm{H}\right\} \mathrm{NMR}\left(\mathrm{CDCl}_{3}, 101 \mathrm{MHz}\right.$, б): 140.20 (C4), 132.33 (C1), 128.99 (C2), 126.96 (C3), 59.13 (C8), 45.28 (C9), 44.05 (C6), 25.12 (C7) ppm. HRMS-ESI-TOF (m/z): $\left[\mathrm{M}^{+}+\mathrm{H}^{+}\right]$calculated for $\mathrm{C}_{11} \mathrm{H}_{19} \mathrm{~N}_{2} \mathrm{O}_{2} \mathrm{~S}$, 243.1162, found, 243.1170 .

\section{Synthesis of N-(3-(dimethylamino)propyl)-4-methylbenzenesulfonamide 4}

This compound was synthesized according to Method (B)1 with p-toluenesulfonyl chloride (10.505 g, $55.10 \mathrm{mmol})$, triethylamine (11.5 mL, $82.65 \mathrm{mmol}, 1.5$ eqv.), and 3(dimethylamino)propylamine (10.4 mL, $82.65 \mathrm{mmol}, 1.5 \mathrm{eqv}$.$) in DCM (100 \mathrm{~mL})$ stirred for 4 hours, yielding a milky white solution. The solution was then washed using distilled water (100 $\mathrm{mL}$ ), and the volatile organic layer removed in vacuo to yield a pale yellow coloured oil. The product was further dried under reduced pressure, yielding the desired product as a pale white coloured waxy solid. Yield: $98 \%$ (13.85 g). ${ }^{1} \mathrm{H}$ NMR $\left(\mathrm{CDCl}_{3}, 400 \mathrm{MHz}, \delta\right): 7.73\left(2 \mathrm{H}, \mathrm{d},{ }^{3} \mathrm{~J}_{\mathrm{H} 4-\mathrm{H} 2}=\right.$ $8.3 \mathrm{~Hz}, \mathrm{H} 4), 7.29\left(2 \mathrm{H}, \mathrm{d},{ }^{3} \mathrm{~J}_{\mathrm{H} 2-\mathrm{H} 4}=7.9 \mathrm{~Hz}, \mathrm{H} 2\right), 3.03\left(2 \mathrm{H}, \mathrm{t},{ }^{3} \mathrm{~J}_{\mathrm{H} 7-\mathrm{H} 8}=5.8 \mathrm{~Hz}, \mathrm{H} 7\right), 2.42(3 \mathrm{H}, \mathrm{s}, \mathrm{H} 1)$, $2.29\left(2 \mathrm{H}, \mathrm{t},{ }^{3} \mathrm{~J}_{\mathrm{H} 9-\mathrm{H} 8}=5.8 \mathrm{~Hz}, \mathrm{H} 9\right), 2.16(6 \mathrm{H}, \mathrm{s}, \mathrm{H} 10), 1.58\left(2 \mathrm{H}, \mathrm{tt},{ }^{3} \mathrm{~J}_{\mathrm{H} 8-\mathrm{H} 7}=9.2 \mathrm{~Hz},{ }^{3} \mathrm{~J}_{\mathrm{H} 8-\mathrm{H} 9}=2.5\right.$ $\mathrm{Hz}, \mathrm{H} 8) \mathrm{ppm} ;{ }^{13} \mathrm{C}\left\{{ }^{1} \mathrm{H}\right\} \mathrm{NMR}\left(\mathrm{CDCl}_{3}, 101 \mathrm{MHz}, \delta\right): 142.83$ (C5), 137.11 (C3), 129.44 (C2), 
126.88 (C4), 58.76 (C9), 45.15 (C10), 43.65 (C7), 25.23 (C8), 21.32 (C1) ppm. HRMS-ESI-TOF $(\mathrm{m} / \mathrm{z}):\left[\mathrm{M}^{+}+\mathrm{H}^{+}\right]$calculated for $\mathrm{C}_{12} \mathrm{H}_{21} \mathrm{~N}_{2} \mathrm{O}_{2} \mathrm{~S}, 257.1318$, found, 257.1322 .

\section{Synthesis of N-(3-(dimethylamino)propyl)-2,4,6-trimethylbenzenesulfonamide 5}

This compound was synthesized according to Method (B)1 with 2,4,6-trimethylbenzene-1sulfonyl chloride ( $2 \mathrm{~g}, 9.14 \mathrm{mmol})$, triethylamine (1.9 mL, $13.72 \mathrm{mmol}, 1.5 \mathrm{eqv}$.$) , and 3-$ (dimethylamino)propylamine (1.7 mL, $13.72 \mathrm{mmol}, 1.5$ eqv.) in DCM $(50 \mathrm{~mL})$ for 3 hours yielding a clear solution. The solution was then washed using distilled water $(75 \mathrm{~mL})$, and the volatile organic layer removed in vacuo to yield a clear oil. The product was further dried under reduced pressure, yielding the desired product as a pale white coloured waxy solid. Yield $98.5 \%$ (2.56 g). ${ }^{1} \mathrm{H}$ NMR $\left(\mathrm{CDCl}_{3}, 400 \mathrm{MHz}, \delta\right): 7.04$ (1H, br s, H7), $6.93(2 \mathrm{H}, \mathrm{s}, \mathrm{H} 3), 2.94\left(2 \mathrm{H}, \mathrm{t},{ }^{3} \mathrm{~J}_{\mathrm{H} 8-\mathrm{H} 9}\right.$ $=5.7 \mathrm{~Hz}, \mathrm{H} 8), 2.61(6 \mathrm{H}, \mathrm{s}, \mathrm{H} 4), 2.32\left(2 \mathrm{H}, \mathrm{t},{ }^{3} \mathrm{~J}_{\mathrm{H} 10-\mathrm{H} 9}=5.6 \mathrm{~Hz}, \mathrm{H} 10\right), 2.27(3 \mathrm{H}, \mathrm{s}, \mathrm{H} 1), 2.18(6 \mathrm{H}, \mathrm{s}$,

$\mathrm{H} 11), 1.62\left(2 \mathrm{H}, \mathrm{tt},{ }^{3} \mathrm{~J}_{\mathrm{H} 9-\mathrm{H} 8}=9.5 \mathrm{~Hz},{ }^{3} \mathrm{~J}_{\mathrm{H} 9-\mathrm{H} 10}=2.2 \mathrm{~Hz}, \mathrm{H} 9\right) \mathrm{ppm} ;{ }^{13} \mathrm{C}\left\{{ }^{1} \mathrm{H}\right\} \mathrm{NMR}\left(\mathrm{CDCl}_{3}, 101 \mathrm{MHz}\right.$, б): 141.74 (C6), 139.07 (C2), 133.80 (C5), 131.87 (C3), 59.66 (C10), 45.48 (C11), 6043.72 (C8), 24.99 (C9), 22.88 (C4), 20.95 (C1) ppm. HRMS-ESI-TOF (m/z): $\left[\mathrm{M}^{+}+\mathrm{H}^{+}\right]$calculated for $\mathrm{C}_{14} \mathrm{H}_{25} \mathrm{~N}_{2} \mathrm{O}_{2} \mathrm{~S}, 285.1631$, found, 285.1643.

\section{Synthesis of N-(3-(dimethylamino)propyl)naphthalene-1-sulfonamide 6}

This compound was synthesized according to Method (B)1 with naphthalene-1-sulfonyl chloride (4 g, $18.04 \mathrm{mmol}$ ), triethylamine $(3.8 \mathrm{~mL}, \quad 27.06 \mathrm{mmol}, \quad 1.5$ eqv.), and $3-$ (dimethylamino)propylamine (3.4 mL, $27.06 \mathrm{mmol}, 1.5 \mathrm{eqv}$.) in DCM $(50 \mathrm{~mL})$ for 3 hours yielding a clear solution. The solution was then washed using distilled water $(50 \mathrm{~mL})$, and the organic layer was evaporated to yield a greenish yellow coloured oil. The product was further dried 
under reduced pressure, yielding the desired product as a pale white coloured waxy solid. Yield $99.7 \%(5.27 \mathrm{~g}) .{ }^{1} \mathrm{H}$ NMR $\left(\mathrm{CDCl}_{3}, 400 \mathrm{MHz}, \delta\right): 8.67\left(1 \mathrm{H}, \mathrm{d},{ }^{3} \mathrm{~J}_{\mathrm{H} 1-\mathrm{H} 2}=8.5 \mathrm{~Hz}, \mathrm{H} 1\right), 8.25(1 \mathrm{H}, \mathrm{d}$, $\left.{ }^{3} \mathrm{~J}_{\mathrm{H} 8-\mathrm{H} 7}=6.2 \mathrm{~Hz}, \mathrm{H} 8\right), 8.05\left(1 \mathrm{H}, \mathrm{d},{ }^{3} \mathrm{~J}_{\mathrm{H} 6-\mathrm{H} 7}=8.2 \mathrm{~Hz}, \mathrm{H} 6\right), 7.95\left(1 \mathrm{H}, \mathrm{d},{ }^{3} \mathrm{~J}_{\mathrm{H} 4-\mathrm{H} 3}=7.8 \mathrm{~Hz}, \mathrm{H} 4\right), 7.65$ $(1 \mathrm{H}, \mathrm{m}, \mathrm{H} 2), 7.59(1 \mathrm{H}, \mathrm{m}, \mathrm{H} 3), 7.52(1 \mathrm{H}, \mathrm{m}, \mathrm{H} 7), 2.95\left(2 \mathrm{H}, \mathrm{t},{ }^{3} \mathrm{~J}_{\mathrm{H} 12-\mathrm{H} 13}=5.6 \mathrm{~Hz}, \mathrm{H} 12\right), 2.21(2 \mathrm{H}$, $\left.\mathrm{t},{ }^{3} \mathrm{~J}_{\mathrm{H} 14-\mathrm{H} 13}=5.6 \mathrm{~Hz}, \mathrm{H} 14\right), 2.12(6 \mathrm{H}, \mathrm{s}, \mathrm{H} 15), 1.55(2 \mathrm{H}, \mathrm{m}, \mathrm{H} 13) \mathrm{ppm} ;{ }^{13} \mathrm{C}\left\{{ }^{1} \mathrm{H}\right\} \mathrm{NMR}\left(\mathrm{CDCl}_{3}, 101\right.$ MHz, ס): 134.85 (C9), 134.45 (C5), 133.96 (C4), 129.79 (C6), 129.16 (C2), 128.42 (C10), 128.21 (C3), 126.82 (C8), 124.76 (C7), 124.28 (C1), 59.80 (C14), 45.56 (C15), 44.77 (C12), 24.68 (C13) ppm. HRMS-ESI-TOF (m/z): [M+ $-\mathrm{Br}]$ calculated for $\mathrm{C}_{15} \mathrm{H}_{21} \mathrm{~N}_{2} \mathrm{O}_{2} \mathrm{~S}, 293.1318$, found, 293.1319.

\section{Synthesis of N-(3-(dimethylamino)propyl)ethanesulfonamide 7}

This compound was synthesized according to Method (B)2, with ethanesulfonyl chloride $(0.7 \mathrm{~mL}$, $7.78 \mathrm{mmol})$ and 3-(dimethylamino)propylamine (1.5 mL, $11.67 \mathrm{mmol}, 1.5$ eq.) in DCM (50 mL)

for 4 hours. The solution was washed with $\mathrm{K}_{2} \mathrm{CO}_{3}(0.05 \mathrm{M}, 50 \mathrm{~mL})$, and the volatile organic layer was removed in vacuo yielding in clear oil. Yield: $61 \%(0.92 \mathrm{~g}) .{ }^{1} \mathrm{H} \mathrm{NMR}\left(\mathrm{CDCl}_{3}, 400 \mathrm{MHz}, \delta\right)$ : $3.19\left(2 \mathrm{H}, \mathrm{t},{ }^{3} \mathrm{~J}_{\mathrm{H} 4-\mathrm{H} 5}=5.8 \mathrm{~Hz}, \mathrm{H} 4\right), 3.0\left(2 \mathrm{H}, \mathrm{q},{ }^{3} \mathrm{~J}_{\mathrm{H} 2-\mathrm{H} 1}=7.4 \mathrm{~Hz}, \mathrm{H} 2\right), 2.42\left(2 \mathrm{H}, \mathrm{t},{ }^{3} \mathrm{~J}_{\mathrm{H} 6-\mathrm{H} 5}=5.8 \mathrm{~Hz}\right.$, H6), $2.22(6 \mathrm{H}, \mathrm{s}, \mathrm{H} 7), 1.70(2 \mathrm{H}, \mathrm{m}, \mathrm{H} 5), 1.34\left(3 \mathrm{H}, \mathrm{t},{ }^{3} \mathrm{~J}_{\mathrm{H} 1-\mathrm{H} 2}=7.4 \mathrm{~Hz}, \mathrm{H} 1\right) \mathrm{ppm} ;{ }^{13} \mathrm{C}\left\{{ }^{1} \mathrm{H}\right\} \mathrm{NMR}$ (CDCl $, 101 \mathrm{MHz}, \delta): 59.33$ (C6), 46.05 (C2), 45.41 (C7), 44.11 (C4), 25.91 (C5), 8.35 (C1) ppm. HRMS-ESI-TOF (m/z): $\left[\mathrm{M}^{+}+\mathrm{H}^{+}\right]$calculated for $\mathrm{C}_{9} \mathrm{H}_{23} \mathrm{~N}_{2} \mathrm{O}_{2} \mathrm{~S}, 223.1475$, found, 223.1480.

\section{Synthesis N-(3-(dimethylamino)propyl)butane-1-sulfonamide 8}

This compound was synthesized according to Method (B)2, with butanesulfonyl chloride (1.7 $\mathrm{mL}$, $12.77 \mathrm{mmol}$ ) and 3-(dimethylamino)propylamine (2.4 mL, $19.15 \mathrm{mmol}, 1.5$ equiv) in DCM (50 $\mathrm{mL})$ for 4 hours. The solution was washed with $\mathrm{K}_{2} \mathrm{CO}_{3}(0.05 \mathrm{M}, 50 \mathrm{~mL})$, and the volatile organic 
layer was removed in vacuo yielding in a clear oil. Yield: $81 \%(2.31 \mathrm{~g}) .{ }^{1} \mathrm{H}$ NMR $\left(\mathrm{CDCl}_{3}, 400\right.$ $\mathrm{MHz}, \delta): 3.15\left(2 \mathrm{H}, \mathrm{t},{ }^{3} \mathrm{~J}_{\mathrm{H} 6-\mathrm{H} 7}=5.9 \mathrm{~Hz}, \mathrm{H} 6\right), 2.94\left(2 \mathrm{H}, \mathrm{t},{ }^{3} \mathrm{~J}_{\mathrm{H} 4-\mathrm{H} 3}=7.9 \mathrm{~Hz}, \mathrm{H} 4\right), 2.38\left(2 \mathrm{H}, \mathrm{t},{ }^{3} \mathrm{~J}_{\mathrm{H} 8-\mathrm{H} 7}\right.$ $=5.9 \mathrm{~Hz}, \mathrm{H} 8), 2.18(6 \mathrm{H}, \mathrm{s}, \mathrm{H} 9), 1.78-1.61(4 \mathrm{H}, \mathrm{m}, \mathrm{H} 3$ and H7), 1.48-1.34 (2H, m, H2), $0.91(3 \mathrm{H}$, $\left.\mathrm{t},{ }^{3} \mathrm{~J}_{\mathrm{H} 1-\mathrm{H} 2}=7.3 \mathrm{~Hz}, \mathrm{H} 1\right) \mathrm{ppm} ;{ }^{13} \mathrm{C}\left\{{ }^{1} \mathrm{H}\right\} \mathrm{NMR}\left(\mathrm{CDCl}_{3}, 101 \mathrm{MHz}, \delta\right): 59.08$ (C8), 51.56 (C4), 45.38 (C9), 43.83 (C6), 26.05 (C3), 25.70 (C7), 21.54 (C2), 13.63 (C1) ppm. HRMS ESI-TOF (m/z): $\left[\mathrm{M}^{+}+\mathrm{H}^{+}\right]$calculated for $\mathrm{C}_{7} \mathrm{H}_{10} \mathrm{~N}_{3} \mathrm{O}_{2} \mathrm{~S}, 210.1271$, found, 210.1276 .

\section{Synthesis of N-(3-(dimethylamino)propyl)-4-(trifluoromethyl)benzenesulfonamide 9}

This compound was synthesized according to Method (B)1, with 4(trifluoromethyl)benzenesulfonyl chloride $(5.2 \mathrm{~g}, 20.44 \mathrm{mmol})$, triethylamine $(3.30 \mathrm{~mL}, 22.48$ mmol) and 3-(dimethylamino)-1-propylamine (2.98 mL, $22.48 \mathrm{mmol})$ in DCM (40 mL) for 21 hours, yielding a pale yellow solution. The solution was then washed with distilled water (120 $\mathrm{mL}$ ), dried over $\mathrm{MgSO}_{4}$ and the volatiles removed in vacuo, giving an off-white coloured powder. From the powder, $0.100 \mathrm{~g}$ was taken and recrystallized in heptanes layered over $\mathrm{ACN}$, giving small, cubic crystals. Yield: $89 \%(5.29 \mathrm{~g}) . \mathrm{Mp}=69-70{ }^{\circ} \mathrm{C} .{ }^{1} \mathrm{H}$ NMR $\left(\mathrm{CDCl}_{3}, 400 \mathrm{MHz}, \delta\right): 8.01$ $\left(2 \mathrm{H}, \mathrm{d},{ }^{3} \mathrm{~J}_{\mathrm{H} 3-\mathrm{H} 4}=8.1 \mathrm{~Hz}, \mathrm{H} 3\right), 7.80\left(2 \mathrm{H}, \mathrm{d},{ }^{3} \mathrm{~J}_{\mathrm{H} 4-\mathrm{H} 3}=8.2 \mathrm{~Hz}, \mathrm{H} 4\right), 3.11\left(2 \mathrm{H}, \mathrm{t},{ }^{3} \mathrm{~J}_{\mathrm{H} 9-\mathrm{H} 8}=5.74 \mathrm{~Hz}\right.$, H9), $2.39\left(2 \mathrm{H}, \mathrm{t},{ }^{3} \mathrm{~J}_{\mathrm{H} 7-\mathrm{H} 8}=5.69, \mathrm{H} 7\right), 2.23(6 \mathrm{H}, \mathrm{s}, \mathrm{H} 10), 1.69-1.63(2 \mathrm{H}, \mathrm{m}, \mathrm{H} 8) \mathrm{ppm} .{ }^{13} \mathrm{C}\left\{{ }^{1} \mathrm{H}\right\}$ $\operatorname{NMR}\left(\mathrm{CDCl}_{3}, 101 \mathrm{MHz}, \delta\right): 143.96$ (s, C5), $134.01\left(\mathrm{~d},{ }^{2} \mathrm{~J}_{\mathrm{C}-\mathrm{F}}=32.9 \mathrm{~Hz}, \mathrm{C} 2\right), 127.48$ (s, C4), 126.12 $\left(\mathrm{q},{ }^{3} \mathrm{~J}_{\mathrm{C}-\mathrm{F}}=3.7 \mathrm{~Hz}, \mathrm{C} 3\right), 126.10\left(\mathrm{q}, \mathrm{J}_{\mathrm{C}-\mathrm{F}}=272.8 \mathrm{~Hz}, \mathrm{C} 1\right), 59.54(\mathrm{~s}, \mathrm{C} 9), 45.22(\mathrm{~s}, \mathrm{C} 10), 44.48(\mathrm{~s}$, C7), 24.61 (s, C8) ppm. ${ }^{19} \mathrm{~F}\left\{{ }^{1} \mathrm{H}\right\}$ NMR $\left(\mathrm{CDCl}_{3}, 376 \mathrm{MHz}, \delta\right):-63.05 \mathrm{ppm}$. HRMS-ESI-TOF (m/z): $\left[\mathrm{M}^{+}\right]$calculated for $\mathrm{C}_{12} \mathrm{H}_{17} \mathrm{~F}_{3} \mathrm{~N}_{2} \mathrm{O}_{2} \mathrm{~S}, 311.0996$; found, 311.1035 . 
This compound was synthesized according to Method (B)1, with 3,5bis(trifluoromethyl)benzenesulfonyl chloride $(4.37 \mathrm{~g}, 13.98 \mathrm{mmol})$, triethylamine $(3 \mathrm{~mL}, 21.50$ mmol) and 3-(dimethylamino)-1-propylamine (2.72 mL, $21.50 \mathrm{mmol})$ in DCM (25 mL) for 12 hours, yielding a pale-yellow solution. The solution was then washed with distilled water (150 $\mathrm{mL}$ ), dried over $\mathrm{MgSO}_{4}$ and the volatiles removed in vacuo, yielding the product as yellow-tinged coloured crystals. Yield: $77 \%$ (4.03 g). $\mathrm{Mp}=93-94{ }^{\circ} \mathrm{C} .{ }^{1} \mathrm{H} \mathrm{NMR}\left(\mathrm{CDCl}_{3}, 400 \mathrm{MHz}, \delta\right): 8.30(2 \mathrm{H}$, $\mathrm{s}, \mathrm{H} 4), 8.05(1 \mathrm{H}, \mathrm{s}, \mathrm{H} 3), 3.12\left(2 \mathrm{H}, \mathrm{t},{ }^{3} \mathrm{~J}_{\mathrm{H} 9-\mathrm{H} 8}=5.66 \mathrm{~Hz}, \mathrm{H} 9\right), 2.41\left(2 \mathrm{H}, \mathrm{t},{ }^{3} \mathrm{~J}_{\mathrm{H} 7-\mathrm{H} 8}=5.66 \mathrm{H} 7\right), 2.21$ $(6 \mathrm{H}, \mathrm{s}, \mathrm{H} 10), 1.69-1.63(2 \mathrm{H}, \mathrm{m}, \mathrm{H} 8) \mathrm{ppm} .{ }^{13} \mathrm{C}\left\{{ }^{1} \mathrm{H}\right\} \mathrm{NMR}\left(\mathrm{CDCl}_{3}, 101 \mathrm{MHz}, \delta\right): 143.39$ (C5), $132.79\left(\mathrm{q},{ }^{2} \mathrm{~J}_{\mathrm{C}-\mathrm{F}}=34.5 \mathrm{~Hz}, \mathrm{C} 2\right), 127.23\left(\mathrm{q},{ }^{3} \mathrm{~J}_{\mathrm{C}-\mathrm{F}}=3.1 \mathrm{~Hz}, \mathrm{C} 4\right), 125.77(\mathrm{~m}, \mathrm{C} 3), 122.54\left(\mathrm{q}, \mathrm{J}_{\mathrm{C}-\mathrm{F}}=\right.$ $272.5 \mathrm{~Hz}, \mathrm{C} 1), 59.77$ (C9), 45.13 (C10), 44.83 (C7), 24.19 (C8) ppm. ${ }^{19} \mathrm{~F}\left\{{ }^{1} \mathrm{H}\right\} \mathrm{NMR}(376 \mathrm{MHz}$, $\left.\mathrm{CDCl}_{3}, \delta\right)$ : -62.94 ppm. HRMS DART $(\mathrm{m} / \mathrm{z})$ : $\left[\mathrm{M}^{+}\right]$calculated for $\mathrm{C}_{13} \mathrm{H}_{16} \mathrm{~F}_{6} \mathrm{~N}_{2} \mathrm{O}_{2} \mathrm{~S}, 379.0870$; found, 379.0914 .

\section{Synthesis of N-(3-bromopropyl)-2,4,6-trimethylbenzenesulfonamide 11}

A $250 \mathrm{~mL}$ round bottom flask was charged with 2-mesitylenesulfonyl chloride (4.89 mL, 22.3 $\mathrm{mmol})$, and anhydrous DCM $(50 \mathrm{~mL})$. To this mixture, triethylamine $(8.0 \mathrm{~mL}, \sim 2.5$ equiv. $)$ and 3 bromopropylamine hydrobromide ( $7.55 \mathrm{~g}, \sim 1.5$ equiv.) were carefully added consecutively. The resultant clear mixture was then allowed to react at room temperature ( $\sim 3 \mathrm{hrs})$ under static vacuum. The reaction mixture was then extracted using two aliquots of distilled water $(25 \mathrm{~mL})$, which were then discarded. The collected organic phase was then gravity filtered through magnesium sulfate to remove excess moisture and evaporated overnight to obtain 7.39 g of crude, off-white semicrystalline product. The crude product was packed onto silica and purified by flash column chromatography $(4.5 \mathrm{~cm} \times 5.0 \mathrm{~cm}$ frit, $40 \mathrm{~g}$ silica) by eluting with DCM $(120 \mathrm{~mL})$ to afford 4.86 
$\mathrm{g}$ of the desired product, as confirmed using TLC. The resulting white semi-crystalline solid was recrystallized from minimal DCM to yield clear, colourless crystals. Yield: $68 \%$ (4.86 g). Mp = 93-94 ${ }^{\circ} \mathrm{C} ;{ }^{1} \mathrm{H} \mathrm{NMR}\left(\mathrm{CDCl}_{3}, 400 \mathrm{MHz}, \delta\right) 6.97$ (s, 2H, H3), 4.60 (s, 1H, H10), $3.40\left(\mathrm{t},{ }^{3} \mathrm{~J}_{\mathrm{H} 9-\mathrm{H} 8}=6.3\right.$ $\mathrm{Hz}, 2 \mathrm{H}, \mathrm{H} 9), 3.08$ (q, $\left.{ }^{3} \mathrm{~J}_{\mathrm{H} 7-\mathrm{H} 8}=6.5 \mathrm{~Hz}, 2 \mathrm{H}, \mathrm{H} 7\right), 2.65$ (s, 6H, H5), 2.31 (s, 3H, H1), $2.01\left(8, \mathrm{p},{ }^{3} \mathrm{~J}_{\mathrm{H} 8-}\right.$ $\left.\mathrm{H} 7=6.5 \mathrm{~Hz},{ }^{3} \mathrm{~J}_{\mathrm{H} 8-\mathrm{H} 9}=6.3 \mathrm{~Hz}, 2 \mathrm{H}, \mathrm{H} 8\right) \mathrm{ppm} .{ }^{13} \mathrm{C}\left\{{ }^{1} \mathrm{H}\right\} \mathrm{NMR}(\mathrm{CDCl} 3,101 \mathrm{MHz}, \delta) 142.39(\mathrm{C} 2)$, 139.06 (C4), 133.49 (C5), 132.07 (C3), 40.86 (C7), 32.25 (C8), 30.29 (C9), 22.96 (C3), 20.93 (C1) ppm; HRMS-DART (m/z): [M+] calculated for $\mathrm{C}_{12} \mathrm{H}_{18} \mathrm{BrNO}_{2} \mathrm{~S}, 320.03199$; found, 320.03249 .

\section{Synthesis of 3-(4-benzoylphenoxy)-N,N-dimethyl-N-(3-(phenylsulfonamido)propyl)propan- 1-aminium bromide $3 a$}

This compound was synthesized according to Method (B)3, using N-(3(dimethylamino)propyl)phenylsulfonamide $\quad\left(\begin{array}{llll}0.921 & \mathrm{~g}, & 3.8 & \mathrm{mmol})\end{array}\right.$ and $4-(3-$ bromopropoxy)benzophenone $(1.29 \mathrm{~g}, 4.0 \mathrm{mmol})$ in $\mathrm{ACN}(10 \mathrm{~mL})$ for 48 hours; yielding in viscous pale yellow solution. The product was obtained as fluffy pale yellow-coloured powder after purification. Yield: 82\% (1.74 g). ${ }^{1} \mathrm{H} \mathrm{NMR}\left(\mathrm{CDCl}_{3}, 400 \mathrm{MHz}, \delta\right): 7.93(2 \mathrm{H}, \mathrm{m}, \mathrm{H} 3), 7.82$ (1H, m, H5), $7.74-7.62$ (4H, m, H15 \& H19), 7.53 (1H, m, H21), $7.49-7.37$ (5H, m, (H1, H2, \& H20)), $6.89\left(2 \mathrm{H}, \mathrm{d},{ }^{3} \mathrm{~J}_{\mathrm{H} 14-\mathrm{H} 15}=8.9 \mathrm{~Hz}, \mathrm{H} 14\right), 4.11\left(2 \mathrm{H} \mathrm{t},{ }^{3} \mathrm{~J}_{\mathrm{H} 12-\mathrm{H} 11}=5.3 \mathrm{~Hz}, \mathrm{H} 12\right), 3.79-3.56$ (4H, m, H8 \& H10), 3.27 (6H, s, H9), 3.01 (2H, m, H6), 2.29 (2H, m, H11), 2.10 (2H, m, H7) ppm. ${ }^{13} \mathrm{C}\left\{{ }^{1} \mathrm{H}\right\}$ NMR $\left(\mathrm{CDCl}_{3}, 101 \mathrm{MHz}, \delta\right): 195.58$ (C17), 161.80 (C13), 139.64 (C1), 137.99 (C4), 132.71 (C18), 132.51 (C15), 132.19 (C21), 130.60 (C16), 139.75 (C2), 129.32 (C19), 128.35 (C20), 127.22 (C3), 114.31 (C14), 64.68 (C12), 62.44 (C8), 62.06 (C10), 39.98 (C6), 23.08 (C11), 22.75 (C7) ppm. HRMS-ESI-TOF (m/z): [ $\mathrm{M}^{+}$- Br-] calculated for $\mathrm{C}_{27} \mathrm{H}_{33} \mathrm{~N}_{2} \mathrm{O}_{4} \mathrm{~S}, 481.2156$; found 481.2155. 
Synthesis

of

3-(4-benzoylphenoxy)-N,N-dimethyl-N-(3-(4methylphenylsulfonamido)propyl)propan-1- aminium bromide $4 a$

This compound was synthesized using N-(3-(dimethylamino)propyl)-4methylphenyl)sulfonamide (1.05 g, $4.1 \mathrm{mmol})$ and 4-(3-bromopropoxy)benzophenone (1.417 g, $4.44 \mathrm{mmol})$ in ACN $(10 \mathrm{~mL})$ for 48 hours; yielding in viscous pale yellow solution. The product was obtained as fluffy white coloured powder after purification. Yield: $80 \%$ (1.88 g). ${ }^{1} \mathrm{H}$ NMR $\left(\mathrm{CDCl}_{3}, 400 \mathrm{MHz}, \delta\right): 7.80\left(2 \mathrm{H}, \mathrm{d},{ }^{3} \mathrm{~J}_{\mathrm{H} 4-\mathrm{H} 2}=8.2 \mathrm{~Hz}, \mathrm{H} 4\right), 7.73-7.65(4 \mathrm{H}, \mathrm{m}, \mathrm{H} 16$ \& H20), $7.56-$ $7.59(1 \mathrm{H}, \mathrm{m}, \mathrm{H} 22), 7.42\left(2 \mathrm{H}, \mathrm{t},{ }^{3} \mathrm{~J}_{\mathrm{H} 22-\mathrm{H} 21}=7.2 \mathrm{~Hz}, \mathrm{H} 22\right), 7.21\left(2 \mathrm{H}, \mathrm{d},{ }^{3} \mathrm{~J}_{\mathrm{H} 2-\mathrm{H} 4}=8.2 \mathrm{~Hz}, \mathrm{H} 2\right), 6.89$ $\left(2 \mathrm{H}, \mathrm{d},{ }^{3} \mathrm{~J}_{\mathrm{H} 15-\mathrm{H} 16}=8.8 \mathrm{~Hz}, \mathrm{H} 15\right), 4.12\left(2 \mathrm{H}, \mathrm{t},{ }^{3} \mathrm{~J}_{\mathrm{H} 13-\mathrm{H} 12}=5.4 \mathrm{~Hz}, \mathrm{H} 13\right), 3.79-3.59(4 \mathrm{H}, \mathrm{m}, \mathrm{H} 9$ \& H11), 3.29 (6H, s, H10), $3.07-2.90$ (2H, m, H7), 2.35 - 2.23 (5H, m, H1 \& H12), $2.19-2.03$ (2H, m, H8) ppm. ${ }^{13} \mathrm{C}\left\{{ }^{1} \mathrm{H}\right\} \mathrm{NMR}\left(\mathrm{CDCl}_{3}, 101 \mathrm{MHz}, \delta\right): 195.57$ (C18), 161.82 (C14), 143.50 (C3), 138.05 (C5), 136.53 (C19), 132.54 (C16), 132.19 (C22), 130.69 (C17), 129.90 (C20), 129.80 (C2), 128.36 (C21), 127.34 (C4), 114.32 (C15), 64.71 (C13), 62.53 (C9), 62.11 (C11), 51.62 (C10), 40.01 (C7), 23.15 (C12), 22.75 (C8), 21.57 (C1) ppm. HRMS-ESI-TOF (m/z): [M+ - Br-] calculated for $\mathrm{C}_{28} \mathrm{H}_{35} \mathrm{~N}_{2} \mathrm{O}_{4} \mathrm{~S}, 495.2312$; found 495.2319.

\section{Synthesis of 3-(4-benzoylphenoxy)-N,N-dimethyl-N-(3- (2,4,6-trimethylphenylsulfonamido)propyl)propan-1-aminium bromide 5a}

This compound was synthesized according to Method (B)3, using N-(3-(dimethylamino)propyl)2,4,6- trimethylphenyl)sulfonamide $(0.853 \mathrm{~g}, 3.0 \mathrm{mmol})$ and 4-(3-bromopropoxy)benzophenone $(1.0 \mathrm{~g}, 3.13 \mathrm{mmol})$ in $\mathrm{ACN}(10 \mathrm{~mL})$ for 48 hours; yielding in viscous pale yellow solution. The product was obtained as fluffy white-coloured powder after purification. Yield: $67 \%(1.20 \mathrm{~g}) .{ }^{1} \mathrm{H}$ $\operatorname{NMR}\left(\mathrm{CDCl}_{3}, 400 \mathrm{MHz}, \delta\right): 7.76\left(2 \mathrm{H}, \mathrm{d},{ }^{3} \mathrm{~J}_{\mathrm{H} 17-\mathrm{H} 16}=8.7 \mathrm{~Hz}, \mathrm{H} 17\right), 7.72\left(\mathrm{~d}, 2 \mathrm{H},{ }^{3} \mathrm{~J}_{\mathrm{H} 21-\mathrm{H} 22}=7.2 \mathrm{~Hz}\right.$, 
$\mathrm{H} 21), 7.56\left(2 \mathrm{H}, \mathrm{t},{ }^{3} \mathrm{~J}_{\mathrm{H} 23-\mathrm{H} 22}=7.4 \mathrm{~Hz}, \mathrm{H} 23\right), 7.56(2 \mathrm{H}, \mathrm{m}, \mathrm{H} 22), 7.22\left(1 \mathrm{H}, \mathrm{t},{ }^{3} \mathrm{~J}_{\mathrm{H} 7-\mathrm{H} 8}=6.2 \mathrm{~Hz}, \mathrm{H} 7\right)$, $6.94\left(2 \mathrm{H}, \mathrm{t},{ }^{3} \mathrm{~J}_{\mathrm{H} 16-\mathrm{H} 17}=6.0 \mathrm{~Hz}, \mathrm{H} 16\right), 6.90(2 \mathrm{H}, \mathrm{s}, \mathrm{H} 3), 4.21\left(2 \mathrm{H}, \mathrm{t},{ }^{3} \mathrm{~J}_{\mathrm{H} 14-\mathrm{H} 13}=5.4 \mathrm{~Hz}, \mathrm{H} 14\right), 3.85$ (2H, m, H10), 3.75 (2H, m, H12), 3.37 (6H, s, H11), 3.04 (2H, m, H8), 2.63 (6H, s, H4), 2.38 (2H, m, H13), 2.25 (3H, s, H1), 2.20 (2H, m, H9) ppm. ${ }^{13} \mathrm{C}\left\{{ }^{1} \mathrm{H}\right\}$ NMR $\left(\mathrm{CDCl}_{3}, 101 \mathrm{MHz}, \delta\right): 195.63$ (C19), 161.81 (C15), 142.40 (C5), 139.24 (C2), 138.15 (20), 133.41 (C6), 132.66 (C17), 132.22 (C23), 132.18 (C3), 130.91 (C18), 129.90 (C21), 128.39 (C22), 64.72 (C14), 62.68 (C10), 62.29 (C12), 51.77 (C11), 39.36 (C8), 23.42 (C4), 23.27 (C13), 23.05 (C9), 21.03 (C1) ppm. HRMSESI-TOF (m/z): [ $\mathrm{M}^{+}$- $\left.\mathrm{Br}^{-}\right]$calculated for $\mathrm{C}_{30} \mathrm{H}_{39} \mathrm{~N}_{2} \mathrm{O}_{4} \mathrm{~S}$, 523.2625; found 523.2636.

\section{Synthesis of 3-(4-benzoylphenoxy)-N,N-dimethyl-N-(3- (naphthalene-1-sulfonamido)propyl)propan-1-aminium bromide 6a}

This compound was synthesized according to Method (B)3, using N-(3-

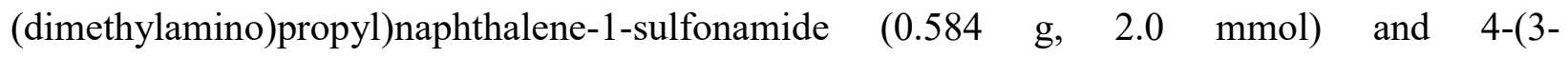
bromopropoxy)benzophenone $(0.702 \mathrm{~g}, 2.2 \mathrm{mmol})$ in $\mathrm{ACN}(10 \mathrm{~mL})$ for 48 hours; yielding in viscous pale yellow solution. The product was obtained as fluffy white coloured powder after purification. Yield: $82 \%(1.0 \mathrm{~g}) .{ }^{1} \mathrm{H} \mathrm{NMR}\left(\mathrm{CDCl}_{3}, 400 \mathrm{MHz}, \delta\right): 8.80\left(1 \mathrm{H}, \mathrm{d},{ }^{3} \mathrm{~J}_{\mathrm{H} 1-\mathrm{H} 2}=8.7 \mathrm{~Hz}\right.$, $\mathrm{H} 1), 8.15\left(1 \mathrm{H}, \mathrm{d},{ }^{3} \mathrm{~J}_{\mathrm{H} 8-\mathrm{H} 7}=7.3 \mathrm{~Hz}, \mathrm{H} 8\right), 7.96(1 \mathrm{H}, \mathrm{s}, \mathrm{H} 11), 7.91\left(1 \mathrm{H}, \mathrm{d},{ }^{3} \mathrm{~J}_{\mathrm{H} 6-\mathrm{H} 7}=8.3 \mathrm{~Hz}, \mathrm{H} 6\right), 7.78$ $\left(1 \mathrm{H}, \mathrm{d},{ }^{3} \mathrm{~J}_{\mathrm{H} 4-\mathrm{H} 3}=8.2 \mathrm{~Hz}, \mathrm{H} 4\right), 7.70-7.55(4 \mathrm{H}, \mathrm{m},(\mathrm{H} 2, \mathrm{H} 25, \& \mathrm{H} 21)), 7.51\left(2 \mathrm{H}, \mathrm{t},{ }^{3} \mathrm{~J}_{\mathrm{H} 27-\mathrm{H} 26}=7.4\right.$ $\mathrm{Hz}, \mathrm{H} 27), 7.46-7.34$ (4H, m, (H3, H26, \& H7), $6.77\left(2 \mathrm{H}, \mathrm{d},{ }^{3} \mathrm{~J}_{\mathrm{H} 20-\mathrm{H} 21}=8.7 \mathrm{~Hz}, \mathrm{H} 20\right), 3.92(2 \mathrm{H}$, m, H18), $3.59-3.37$ (4H, m, H14 \& H16), 3.19 - 2.91 (8H, m, H15 \& H12), 2.04 (2H, m, H17), $1.91(2 \mathrm{H}, \mathrm{m}, \mathrm{H} 13)$ ppm. ${ }^{13} \mathrm{C}\left\{{ }^{1} \mathrm{H}\right\} \mathrm{NMR}\left(\mathrm{CDCl}_{3}, 101 \mathrm{MHz}, \delta\right): 195.59$ (C23), 161.77 (C19), 138.04 (C24), 134.85 (C9), 134.21 (C6), 132.50 (C25), 132.20 (C27), 130.56 (C10), 129.80 (C2), 129.36 (C8), 129.05 (C4), 128.76 (C21), 128.37 (C7), 128.00 (C22), 127.18 (C3), 125.20 (C1), 124.52 
(C26), 114.25 (C20), 64.59 (C18), 62.42 (C14), 62.10 (C16), 51.42 (15), 39.83 (C12), 22.92

(C17+C13) ppm. HRMS-ESI-TOF (m/z): [ $\mathrm{M}^{+}$- $\left.\mathrm{Br}^{-}\right]$calculated for $\mathrm{C}_{31} \mathrm{H}_{35} \mathrm{~N}_{2} \mathrm{O}_{4} \mathrm{~S}, 531.2312$; found 531.2328 .

\section{Synthesis of 3-(4-benzoylphenoxy)-N-(3-(ethylsulfonamido)propyl)-N,N-dimethylpropan-1-} aminium bromide $7 \mathbf{a}$

This compound was synthesized according to Method (B)3 using N-(3(dimethylamino)propyl)ethanesulfonamide $\quad(0.250 \quad \mathrm{~g}, \quad 1.29 \quad \mathrm{mmol})$ and $4-(3-$ bromopropoxy)benzophenone $(0.411 \mathrm{~g}, 1.29 \mathrm{mmol})$ in $\mathrm{ACN}(10 \mathrm{~mL})$ for 48 hours; yielding in viscous pale yellow solution. The product was obtained as fluffy pale yellow coloured powder after purification. Yield: $77 \%(0.52 \mathrm{~g}) .{ }^{1} \mathrm{H} \mathrm{NMR}\left(\mathrm{CDCl}_{3}, 400 \mathrm{MHz}, \delta\right): 7.78\left(2 \mathrm{H}, \mathrm{d},{ }^{3} \mathrm{~J}_{\mathrm{H} 13-\mathrm{H} 12}=8.7\right.$ $\mathrm{Hz}, \mathrm{H} 13), 7.72\left(2 \mathrm{H}, \mathrm{d},{ }^{3} \mathrm{~J}_{\mathrm{H} 17-\mathrm{H} 18}=7.4 \mathrm{~Hz}, \mathrm{H} 17\right), 7.56\left(2 \mathrm{H}, \mathrm{t},{ }^{3} \mathrm{~J}_{\mathrm{H} 19-\mathrm{H} 18}=7.4 \mathrm{~Hz}, \mathrm{H} 19\right), 7.50-7.40$ $(2 \mathrm{H}, \mathrm{m}, \mathrm{H} 18), 7.12\left(1 \mathrm{H}, \mathrm{t},{ }^{3} \mathrm{~J}_{\mathrm{H} 3-\mathrm{H} 4}=6.0 \mathrm{~Hz}, \mathrm{H} 3\right), 6.98\left(2 \mathrm{H}, \mathrm{d},{ }^{3} \mathrm{~J}_{\mathrm{H} 12-\mathrm{H} 13}=8.8 \mathrm{~Hz}, \mathrm{H} 12\right), 4.21(2 \mathrm{H}, \mathrm{t}$, $\left.{ }^{3} \mathrm{~J}_{\mathrm{H} 10-\mathrm{H} 9}=5.3 \mathrm{~Hz}, \mathrm{H} 10\right), 3.80(2 \mathrm{H}, \mathrm{m}, \mathrm{H6}), 3.71(2 \mathrm{H}, \mathrm{m}, \mathrm{H} 8), 3.35(6 \mathrm{H}, \mathrm{s}, \mathrm{H} 7), 3.31-3.22(2 \mathrm{H}, \mathrm{m}$, $\mathrm{H} 4), 3.07\left(2 \mathrm{H}, \mathrm{q},{ }^{3} \mathrm{~J}_{\mathrm{H} 2-\mathrm{H} 3}=7.3 \mathrm{~Hz}, \mathrm{H} 2\right), 2.37(2 \mathrm{H}, \mathrm{m}, \mathrm{H} 9), 2.20(2 \mathrm{H}, \mathrm{m}, \mathrm{H} 5), 1.34\left(3 \mathrm{H}, \mathrm{t},{ }^{3} \mathrm{~J}_{\mathrm{H} 1-\mathrm{H} 2}=\right.$ 7.4 Hz, H1) ppm. ${ }^{13} \mathrm{C}\left\{{ }^{1} \mathrm{H}\right\}$ NMR $\left(\mathrm{CDCl}_{3}, 101 \mathrm{MHz}, \delta\right): 195.55$ (C15), 161.66 (C11), 137.94 (C16), 132.55 (C13), 132.16 (C19), 130.83 (C14), 129.78 (C17), 128.29 (C18), 114.22 (C12), 64.57 (C10), 62.46 (C6), 62.17 (C8), 51.61 (C7), 46.44 (C2), 39.95 (C4), 23.64 (C5), 23.11 (C9), 8.27 (C1) ppm. HRMS-ESI-TOF (m/z): [ $\mathrm{M}^{+}$- Br-] calculated for $\mathrm{C}_{23} \mathrm{H}_{33} \mathrm{~N}_{2} \mathrm{O}_{4} \mathrm{~S}, 433.2156$; found 433.2153. 
This compound was synthesized Method (B)3 using N-(3-(dimethylamino)propyl)butane-1sulfonamide (0.324 g, $1.46 \mathrm{mmol})$ and 4-(3-bromopropoxy)benzophenone (0.466 g, $1.46 \mathrm{mmol})$ in ACN (10 mL) for 48 hours; yielding a viscous pale yellow solution. The product was obtained as fluffy pale yellow coloured powder after purification. Yield: $73 \%(0.58 \mathrm{~g}){ }^{1} \mathrm{H}$ NMR $\left(\mathrm{CDCl}_{3}\right.$, $400 \mathrm{MHz}, \delta): 7.74\left(2 \mathrm{H}, \mathrm{d},{ }^{3} \mathrm{~J}_{\mathrm{H} 15-\mathrm{H} 14}=8.7 \mathrm{~Hz}, \mathrm{H} 15\right), 7.69\left(2 \mathrm{H}, \mathrm{d},{ }^{3} \mathrm{~J}_{\mathrm{H} 19-\mathrm{H} 20}=7.1 \mathrm{~Hz}, \mathrm{H} 19\right), 7.54(1 \mathrm{H}$, $\left.\mathrm{t},{ }^{3} \mathrm{~J}_{\mathrm{H} 21-\mathrm{H} 20}=7.4 \mathrm{~Hz}, \mathrm{H} 21\right), 7.44(2 \mathrm{H}, \mathrm{m}, \mathrm{H} 20), 7.10\left(1 \mathrm{H}, \mathrm{t},{ }^{3} \mathrm{~J}_{\mathrm{H} 5-\mathrm{H} 6}=5.6 \mathrm{~Hz}, \mathrm{H} 5\right), 6.96\left(2 \mathrm{H}, \mathrm{d},{ }^{3} \mathrm{~J}_{\mathrm{H} 14-}\right.$ $\mathrm{H} 15=8.8 \mathrm{~Hz}, \mathrm{H} 14), 4.18\left(1 \mathrm{H}, \mathrm{t},{ }^{3} \mathrm{~J}_{\mathrm{H} 12-\mathrm{H} 11}=5.2 \mathrm{~Hz}, \mathrm{H} 12\right), 3.79-3.61(2 \mathrm{H}, \mathrm{m}, \mathrm{H} 8$ \& H10), $3.33(6 \mathrm{H}$, s, H9), 3.24 (2H, m, H6), 3.02 (2H, m, H4), 2.33 (2H, m, H11), 2.18 (2H, m, H7), $1.73(2 \mathrm{H}, \mathrm{m}$, H3), $1.38(2 \mathrm{H}, \mathrm{m}, \mathrm{H} 2), 0.87\left(3 \mathrm{H}, \mathrm{t},{ }^{3} \mathrm{~J}_{\mathrm{H} 1-\mathrm{H} 2}=7.3 \mathrm{~Hz}, \mathrm{H} 1\right) \mathrm{ppm} .{ }^{13} \mathrm{C}\left\{{ }^{1} \mathrm{H}\right\} \mathrm{NMR}\left(\mathrm{CDCl}_{3}, 101 \mathrm{MHz}\right.$, б): 195.56 (C17), 161.17 (C13), 137.89 (C18), 132.50 (C15), 132.16 (C21), 130.62 (C16), 129.71 (C19), 128.29 (C20), 114.27 (C14), 64.67 (C12), 62.30 (C8), 61.96 (C10), 51.79 (C4), 51.56 (C9), 25.37 (C3), 23.55 (C7), 23.05 (C11), 21.51 (C2), 13.64 (C1) ppm. HRMS-ESI-TOF (m/z): [M+ $\left.\mathrm{Br}^{-}\right]$calculated for $\mathrm{C}_{25} \mathrm{H}_{37} \mathrm{~N}_{2} \mathrm{O}_{4} \mathrm{~S}, 461.2469$; found 461.2458 .

\section{Synthesis of 3-(4-benzoylphenoxy)-N-(3-((4-(trifluoromethyl)phenyl)sulfonamido) propyl)- $\mathrm{N}, \mathrm{N}$-dimethylpropan-1-aminium bromide 9a}

This compound was synthesized according to Method (B)3, using N-(3-(dimethylamino)propyl)4-(trifluoromethyl)benzenesulfonamide $\quad\left(\begin{array}{llll}2.40 & \mathrm{~g}, & 8.06 \quad \mathrm{mmol}) & \text { and }\end{array}\right.$ bromopropoxy)benzophenone $(2.52 \mathrm{~g}, 8.06 \mathrm{mmol})$ in $\mathrm{ACN}(25 \mathrm{~mL})$ for 48 hours. The product was yielded as an off-white coloured powder after purification. Yield: $86 \%(4.38 \mathrm{~g}) . \mathrm{Mp}=111-113^{\circ} \mathrm{C}$. ${ }^{1} \mathrm{H} \mathrm{NMR}\left(\mathrm{CDCl}_{3}, 400 \mathrm{MHz}, \delta\right): 8.14\left(2 \mathrm{H}, \mathrm{d},{ }^{3} \mathrm{~J}_{\mathrm{H} 4-\mathrm{H} 3}=7.45 \mathrm{~Hz}, \mathrm{H} 4\right), 7.76-7.72(\mathrm{~m}, 6 \mathrm{H}, \mathrm{H} 3+\mathrm{H} 16$ $+\mathrm{H} 20$ overlap), $7.57\left(\mathrm{t},{ }^{3} \mathrm{~J}_{\mathrm{H} 22-\mathrm{H} 21}=6.67 \mathrm{~Hz}, 1 \mathrm{H}, \mathrm{H} 22\right), 7.47\left(\mathrm{t},{ }^{3} \mathrm{~J}_{\mathrm{H} 21-\mathrm{H} 22}=6.77 \mathrm{~Hz},{ }^{3} \mathrm{~J}_{\mathrm{H} 21-\mathrm{H} 20}=7.29\right.$ $\mathrm{Hz}, \mathrm{H} 21), 6.96\left(2 \mathrm{H}, \mathrm{d},{ }^{3} \mathrm{~J}_{\mathrm{H} 15-\mathrm{H} 16}=8.81 \mathrm{~Hz}, \mathrm{H} 15\right), 4.18\left(2 \mathrm{H}, \mathrm{t},{ }^{3} \mathrm{~J}_{\mathrm{H} 13-\mathrm{H} 12}=5.35 \mathrm{~Hz}, \mathrm{H} 13\right), 3.83(2 \mathrm{H}$, t, $\left.{ }^{3} \mathrm{~J}_{\mathrm{H} 11-\mathrm{H} 12}=7.79 \mathrm{~Hz}, \mathrm{H} 11\right), 3.71\left(2 \mathrm{H}, \mathrm{t},{ }^{3} \mathrm{~J}_{\mathrm{H} 9-\mathrm{H} 8}=7.85 \mathrm{~Hz}, \mathrm{H} 9\right), 3.35(6 \mathrm{H}, \mathrm{s}, \mathrm{H} 10), 3.08(2 \mathrm{H}, \mathrm{m}$, 
H7), $2.36(2 \mathrm{H}, \mathrm{m}, \mathrm{H} 12), 2.19$ (2H, m, H8) ppm. ${ }^{13} \mathrm{C}\left\{{ }^{1} \mathrm{H}\right\} \mathrm{NMR}\left(\mathrm{CDCl}_{3}, 101 \mathrm{MHz}, \delta\right): 195.53$ (C18), 161.59 (C14), 142.92 (C5), 137.86 (C19), 134.23 (q, $\left.{ }^{2} \mathrm{~J}_{\mathrm{C}-\mathrm{F}}=32.93 \mathrm{~Hz}, \mathrm{C} 2\right), 132.50$ (C16), 132.20 (C22), 130.80 (C17), 129.71 (C20), 128.94 (C21), 127.79, (C4) 126.33 (q, ${ }^{3} \mathrm{~J}_{\mathrm{C}-\mathrm{F}}=3.58 \mathrm{~Hz}$ C3), $123.23\left(\mathrm{q}, \mathrm{J}_{\mathrm{C}-\mathrm{F}}=272.96 \mathrm{~Hz}, \mathrm{C} 1\right), 114.17$ (C15), 64.48 (C13), 62.44 (C11), 62.20 (C9), 51.59 (C10), 39.91 (C7), 23.08 (C12), 22.76 (C8) ppm. ${ }^{19} \mathrm{~F}\left\{{ }^{1} \mathrm{H}\right\}$ NMR $\left(\mathrm{CDCl}_{3}, 376 \mathrm{MHz}, \delta\right):-61.32$ ppm. HRMS-ESI-TOF (m/z): [M+] - Br" calculated for $\mathrm{C}_{28} \mathrm{H}_{32} \mathrm{~F}_{3} \mathrm{~N}_{2} \mathrm{O}_{4} \mathrm{~S}$, 549.2029; found, 549.203.

\section{Synthesis \\ of \\ 3-(4-benzoylphenoxy)-N-(3-((3,5- bistrifluoromethyl)phenyl)sulfonamido)propyl-N,N-dimethylpropan-1-aminium bromide 10a}

This compounds was synthesized according to Method (B)3, using N-(3-(dimethylamino)propyl)3,5-bis-(trifluoromethyl)benzenesulfonamide $\quad(2.99 \quad \mathrm{~g}, \quad 7.93 \quad \mathrm{mmol}), \quad 4-(3-$ bromopropoxy)benzophenone (3.28 $\mathrm{g}, 10.31 \mathrm{mmol})$, and ACN (20 mL) for 60 hours. The volatiles were removed in vacuo, giving a white coloured powder. A small portion $(0.1 \mathrm{~g})$ was taken from the batch, dissolved in ACN $(10 \mathrm{~mL})$, and passed through a $45 \mathrm{~nm}$ PTFE syringe filter into a $100 \mathrm{~mL}$ beaker which was left in the fumehood overnight, resulting in the growth of offwhite coloured crystals. The product was insoluble in $\mathrm{MeOD}, \mathrm{CDCl}_{3}$, and $\mathrm{D}_{2} \mathrm{O}$. Yield: $88 \%$ (4.84 g). $\mathrm{Mp}=180-182{ }^{\circ} \mathrm{C} .{ }^{1} \mathrm{H}$ NMR $\left(\mathrm{DMSO}_{-} \mathrm{d}_{6}, 400 \mathrm{MHz}, \delta\right): 8.55$ (1H, s, H3), 8.39 (2H, s, H4), 8.26 (1H, m, H6), $7.77\left(2 \mathrm{H}, \mathrm{d},{ }^{3} \mathrm{~J}_{\mathrm{H} 16-\mathrm{H} 15}=8.86 \mathrm{~Hz}, \mathrm{H} 16\right)$, 7.69-7.65 (m, 3H, H20 + H22 overlap), 7.56 $\left(2 \mathrm{H}, \mathrm{t},{ }^{3} \mathrm{~J}_{\mathrm{H} 21-\mathrm{H} 22}=7.43 \mathrm{~Hz},{ }^{3} \mathrm{~J}_{\mathrm{H} 21-\mathrm{H} 20}=7.52 \mathrm{~Hz}, \mathrm{H} 21\right), 7.11\left(2 \mathrm{H}, \mathrm{d},{ }^{3} \mathrm{~J}_{\mathrm{H} 15-\mathrm{H} 16}=8.87 \mathrm{~Hz}, \mathrm{H} 15\right), 4.17$ $\left(2 \mathrm{H}, \mathrm{t},{ }^{3} \mathrm{~J}_{\mathrm{H} 13-\mathrm{H} 12}=5.86 \mathrm{~Hz}, \mathrm{H} 13\right), 3.47\left(2 \mathrm{H}, \mathrm{t},{ }^{3} \mathrm{~J}_{\mathrm{H} 11-\mathrm{H} 12}=7.60 \mathrm{~Hz}, \mathrm{H} 11\right), 3.36(2 \mathrm{H}, \mathrm{m}, \mathrm{H} 9), 3.07$ $(6 \mathrm{H}, \mathrm{s}, \mathrm{H} 10), 2.90(2 \mathrm{H}, \mathrm{m}, \mathrm{H} 7), 2.20\left(2 \mathrm{H}\right.$, quint, $\left.{ }^{3} \mathrm{~J}=6.83 \mathrm{~Hz}, \mathrm{H} 12\right), 1.89\left(2 \mathrm{H}\right.$, quint, ${ }^{3} \mathrm{~J}=6.97 \mathrm{~Hz}$, H8) ppm. ${ }^{13} \mathrm{C}\left\{{ }^{1} \mathrm{H}\right\}$ NMR (DMSO-d $, 101 \mathrm{MHz}, \delta$ ): 194.89 (C18), 162.33 (C14), 143.11 (C5), 138.15 (C19), 132.67 (C16), 132.63 (C22), $131.96\left(\mathrm{q},{ }^{2} \mathrm{~J}_{\mathrm{C}-\mathrm{F}}=33.84 \mathrm{~Hz}, \mathrm{C} 2\right), 130.12$ (C17), 129.71 
(C21), $128.94(\mathrm{C} 20), 127.79$ (q, $\left.{ }^{3} \mathrm{~J}_{\mathrm{C}-\mathrm{F}}=3.12 \mathrm{~Hz}, \mathrm{C} 4\right), 127.25$ (m, C3), 123.07 (q, J $\mathrm{J}_{\mathrm{C}-\mathrm{F}}=273.27 \mathrm{~Hz}$ C1), 114.87 (C15), 65.56 (C13), 61.16 (C11), 61.04 (C9), 50.46 (C10), 22.99 (C12), 22.56 (C8) ppm. ${ }^{19} \mathrm{~F}\left\{{ }^{1} \mathrm{H}\right\}$ NMR (DMSO-d $6,376 \mathrm{MHz}, \delta$ ): -61.32 ppm. HRMS-ESI-TOF (m/z): [M+ - $\left.\mathrm{Br}^{-}\right]$ calculated for $\mathrm{C}_{29} \mathrm{H}_{31} \mathrm{~F}_{6} \mathrm{~N}_{2} \mathrm{O}_{4} \mathrm{~S}$, 549.2029; found, 549.203.

\section{Synthesis of N-(3-(4-benzoylphenoxy)propyl)-2,4,6-trimethylbenzenesulfonamide 11a}

A round bottom flask was charged with 1,3-dibromopropane, $\mathrm{K}_{2} \mathrm{CO}_{3}$ and $\mathrm{MeCN}$. A solution of 4hydroxybenzophenone in $\mathrm{MeCN}$ was prepared and added dropwise to the previous mixture under reflux (Scheme 3). The resultant yellow mixture was heated at reflux until a colourless solution was obtained or until thin layer chromatography showed the disappearance of starting material 4hydroxybenzophenone. Excess salt was filtered through diatomaceous earth and washed with acetone. The solution was evaporated under reduced pressure to give the crude product, which was packed onto silica and purified by dry column chromatography, first by pre-eluting with $5 \%$ ethyl acetate/hexanes then eluting acetone to retrieve the purified product. The resulting yellow oil was recrystallized from $20 \%$ ethyl acetate/hexanes to yield translucent yellow crystals. Yield: $96 \%$ (5.24 g). $\mathrm{Mp}=75-76{ }^{\circ} \mathrm{C} .{ }^{1} \mathrm{H} \mathrm{NMR}\left(\mathrm{CDCl}_{3}, 400 \mathrm{MHz}, \delta\right) 7.80\left(\mathrm{~d},{ }^{3} \mathrm{~J}_{\mathrm{H} 12-\mathrm{H} 11}=8.7 \mathrm{~Hz}, 2 \mathrm{H}, \mathrm{H} 12\right)$, $7.75\left(\mathrm{~d},{ }^{3} \mathrm{~J}_{\mathrm{H} 16-\mathrm{H} 17}=7.4 \mathrm{~Hz}, 2 \mathrm{H}, \mathrm{H} 16\right), 7.57\left(\mathrm{t},{ }^{3} \mathrm{~J}_{\mathrm{H} 18-\mathrm{H} 17}=7.5 \mathrm{~Hz}, 1 \mathrm{H}, \mathrm{H} 18\right), 7.48\left(\mathrm{t},{ }^{3} \mathrm{~J}_{\mathrm{H} 17-\mathrm{H} 16}=7.4\right.$ $\left.\mathrm{Hz},{ }^{3} \mathrm{~J}_{\mathrm{H} 17-\mathrm{H} 18}=7.5 \mathrm{~Hz}, 2 \mathrm{H}, \mathrm{H} 17\right), 6.92(\mathrm{~s}, 2 \mathrm{H}, \mathrm{H} 3), 6.87\left(\mathrm{~d},{ }^{3} \mathrm{~J}_{\mathrm{H} 11-\mathrm{H} 12}=8.7 \mathrm{~Hz}, 2 \mathrm{H}, \mathrm{H} 11\right), 4.04(\mathrm{t}$, $\left.{ }^{3} \mathrm{~J}_{\mathrm{H} 9-\mathrm{H} 8}=5.7 \mathrm{~Hz}, 2 \mathrm{H}, \mathrm{H} 9\right), 3.16\left(\mathrm{t},{ }^{3} \mathrm{~J}_{\mathrm{H} 7-\mathrm{H} 18}=6.3 \mathrm{~Hz}, 2 \mathrm{H}, \mathrm{H} 7\right), 2.63$ (s, 6H, H5), 2.27 (s, 3H, H1), $2.08-1.87(\mathrm{~m}, 2 \mathrm{H}, \mathrm{H} 8) .{ }^{13} \mathrm{C}\left\{{ }^{1} \mathrm{H}\right\} \mathrm{NMR}\left(\mathrm{CDCl}_{3}, 101 \mathrm{MHz}\right) \delta 195.51(\mathrm{C} 14), 162.09(\mathrm{C} 10), 142.24$ (C6), 139.03 (C4), 138.19 (C15), 133.53 (C2), 132.51 (C12), 131.99 (C3), 131.98 (C18), 130.40 (C13), 129.72 (C16), 128.22 (C17), 113.93 (C11), 65.70 (C9), 39.97 (C7), 29.07 (C8), 22.93 (C5), 20.91 (C1). HRMS-ESI-TOF (m/z): [ $\left.\mathrm{M}^{+}-\mathrm{Br}^{-}\right]$calculated for $\mathrm{C}_{25} \mathrm{H}_{28} \mathrm{NO}_{4} \mathrm{~S}$, 438.17390; found, 438.17442. 


\section{Synthesis of N,N-dimethyl-3-(phenylsulfonamido)-N-(3-(trimethoxysilyl)propyl)propan-1-}

aminium chloride $3 \mathbf{b}$

This compound was synthesized according to Method (B)3, with N-(3(dimethylamino)propyl)benzenesulfonamide $\quad\left(\begin{array}{llll}1.0 & \mathrm{~g}, & 4.13 \quad \mathrm{mmol}) & \text { and }\end{array}\right.$ chloropropyl)trimethoxysilane (1.1 mL, $6.19 \mathrm{mmol}, 1.5$ eq.) in ACN (3 mL) for 4 hours resulting in viscous golden yellow brown solution. The product was purified using $\mathrm{Et}_{2} \mathrm{O}(10 \mathrm{~mL} \times 3)$ and obtained as clear golden brown coloured gummy oil. Yield: $97.5 \%(1.77 \mathrm{~g}) .{ }^{1} \mathrm{H} \mathrm{NMR}\left(\mathrm{CDCl}_{3}\right.$, $400 \mathrm{MHz}, \delta): 8.39$ (1H, br s, H5), 7.96 (d, 2H, H3), $7.54-7.341$ (3H, m, H1 \& H2), 3.66 (2H, m, H8), 3.51 (9H,s, H13), 3.34 (2H, m, H10), 3.21 (6H, s, H9), 3.00 (2H, m, H6), 2.06 (2H, m, H7), $1.75(2 \mathrm{H}, \mathrm{m}, \mathrm{H} 11), 0.59\left(2 \mathrm{H}, \mathrm{t},{ }^{3} \mathrm{~J}_{\mathrm{H} 12-\mathrm{H} 11}=7.8 \mathrm{~Hz}, \mathrm{H} 12\right) \mathrm{ppm} .{ }^{13} \mathrm{C}\left\{{ }^{1} \mathrm{H}\right\} \mathrm{NMR}\left(\mathrm{CDCl}_{3}, 101 \mathrm{MHz}\right.$,

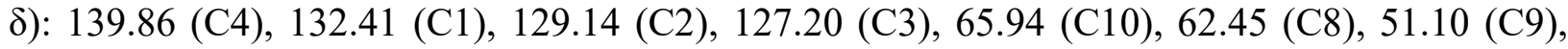
50.72 (C13), 39.93 (C6), 22.61 (C7), 16.45 (C11), 5.57 (C12) ppm. ${ }^{29} \mathrm{Si}\left\{{ }^{1} \mathrm{H}\right\} \mathrm{NMR}\left(\mathrm{CDCl}_{3}, 79.4\right.$ $\mathrm{MHz}, \delta$ ): -44.41 ppm. HRMS-ESI-TOF (m/z): $\left[\mathrm{M}^{+}-\mathrm{Cl}^{-}\right]$calculated for $\mathrm{C}_{17} \mathrm{H}_{33} \mathrm{~N}_{2} \mathrm{O}_{5} \mathrm{SSi}, 405.1874$, found, 405.8166.

\section{Synthesis of N,N-dimethyl-3-(4-methylphenylsulfonamido)-N-(3-} (trimethoxysilyl)propyl)propan-1-aminium chloride $4 \mathrm{~b}$

This compound was synthesized according to Method (B)3, with N-(3-(dimethylamino)propyl)-4methylbenzenesulfonamide (1.0 g, $3.9 \mathrm{mmol})$ and (3-chloropropyl)trimethoxysilane $(1.1 \mathrm{~mL}, 5.85$ mmol, 1.5 eq.) in $\mathrm{ACN}$ (3 mL) for 3.5 hours resulting in viscous golden yellow brown coloured solution. The product was purified using $\mathrm{Et}_{2} \mathrm{O}(10 \mathrm{~mL} \times 3)$ and obtained as clear golden brown gummy oil. Yield: $97 \%$ (1.67 g). ${ }^{1} \mathrm{H} \mathrm{NMR}\left(\mathrm{CDCl}_{3}, 400 \mathrm{MHz}, \delta\right): 8.18(1 \mathrm{H}$, br s, H6), $7.85(2 \mathrm{H}$, $\left.\mathrm{d},{ }^{3} \mathrm{~J}_{\mathrm{H} 4-\mathrm{H} 2}=7.9 \mathrm{~Hz}, \mathrm{H} 4\right), 7.29\left(2 \mathrm{H}, \mathrm{d},{ }^{3} \mathrm{~J}_{\mathrm{H} 2-\mathrm{H} 4}=7.7 \mathrm{~Hz}, \mathrm{H} 2\right), 3.69$ (2H, m, H9), 3.55 (9H, s, H14), 
3.37 (2H, m, H11), 3.25 (6H, s, H10), 3.01 (2H, m, H7), 2.40 (3H, s, H1), 2.10 (2H, m, H8), 1.79 $(2 \mathrm{H}, \mathrm{m}, \mathrm{H} 12), 0.63\left(2 \mathrm{H}, \mathrm{t},{ }^{3} \mathrm{~J}_{\mathrm{H} 13-\mathrm{H} 12}=7.7 \mathrm{~Hz}, \mathrm{H} 13\right) \mathrm{ppm} .{ }^{13} \mathrm{C}\left\{{ }^{1} \mathrm{H}\right\} \mathrm{NMR}\left(\mathrm{CDCl}_{3}, 101 \mathrm{MHz}, \delta\right)$ : 143.08 (C5), 136.85 (C3), 129.70 (C2), 127.85 (C4), 65.82 (C11), 62.45 (C9), 51.10 (C14), 50.70 (C10), 39.91 (C7), 22.66 (C1), 21.46 (C8), 16.44 (C12), 5.57 (C13) ppm. ${ }^{29} \mathrm{Si}\left\{{ }^{1} \mathrm{H}\right\}$ NMR $\left(\mathrm{CDCl}_{3}\right.$, 79.4 MHz, $\delta):-44.37$ ppm. HRMS-ESI-TOF (m/z): $\left[\mathrm{M}^{+}-\mathrm{Cl}^{-}\right]$calculated for $\mathrm{C}_{18} \mathrm{H}_{35} \mathrm{~N}_{2} \mathrm{O}_{5} \mathrm{SSi}$, 419.2030, found, 419.2026 .

Synthesis of N,N-dimethyl-3-(trimethoxysilyl)-N-(3-(2,4,6trimethylphenylsulfonamido)propyl)propan-1-aminium chloride $\mathbf{5 b}$

This compound was synthesized according to Method (B)3, with N-(3-(dimethylamino)propyl)2,4,6- trimethylbenzenesulfonamide (2.0 g, $7.03 \mathrm{mmol}$ ) and (3-chloropropyl)trimethoxysilane (1.9 $\mathrm{mL}, 10.55 \mathrm{mmol}, 1.5$ eq.) in $\mathrm{ACN}(3 \mathrm{~mL})$ for 4.5 hours resulting in viscous golden yellow brown solution. The product was purified using $\mathrm{Et}_{2} \mathrm{O}(10 \mathrm{~mL} \times 3)$ and obtained as clear golden brown coloured gummy oil. Yield: $92.6 \%(3.27 \mathrm{~g}) .{ }^{1} \mathrm{H} \mathrm{NMR}\left(\mathrm{CDCl}_{3}, 400 \mathrm{MHz}, \delta\right): 7.74\left(1 \mathrm{H}, \mathrm{t},{ }^{3} \mathrm{~J}_{\mathrm{H} 7-\mathrm{H} 8}=\right.$ $6.0 \mathrm{~Hz}, \mathrm{H} 7), 6.90$ (2H, s, H3), 3.70 (2H, m, H8), 3.53 (9H, s, H15), 3.37 (2H, m, H12), 3.25 (6H, s, H11), 2.98 (2H, m, H10), 2.62 (6H, br s, H4), 2.25 (3H, s, H1), 2.09 (2H, m, H9), 1.78 (2H, m, $\mathrm{H} 13), 0.62\left(2 \mathrm{H}, \mathrm{t},{ }^{3} \mathrm{~J}_{\mathrm{H} 14-\mathrm{H} 13}=7.9 \mathrm{~Hz}, \mathrm{H} 14\right) \mathrm{ppm} .{ }^{13} \mathrm{C}\left\{{ }^{1} \mathrm{H}\right\} \mathrm{NMR}\left(\mathrm{CDCl}_{3}, 101 \mathrm{MHz}, \delta\right): 142.01$ (C6), 139.22 (C5), 133.83 (C2), 132.01 (C3), 66.06 (C12), 62.51 (C10), 51.22 (C11), 50.81 (C15), 39.33 (C8), 23.28 (C4), 22.88 (C1), 20.95 (C9), 16.57 (C13), 5.70 (C14) ppm. ${ }^{29} \mathrm{Si}\left\{{ }^{1} \mathrm{H}\right\} \mathrm{NMR}$ $\left(\mathrm{CDCl}_{3}, 79.4 \mathrm{MHz}, \delta\right):-44.43 \mathrm{ppm}$. HRMS-ESI-TOF $(\mathrm{m} / \mathrm{z}):\left[\mathrm{M}^{+}-\mathrm{Cl}^{-}\right]$calculated for $\mathrm{C}_{20} \mathrm{H}_{39} \mathrm{~N}_{2} \mathrm{O}_{5} \mathrm{SSi}$, 447.2343, found, 447.2357. 
This compound was synthesized according to Method (B)3 using N-(3-

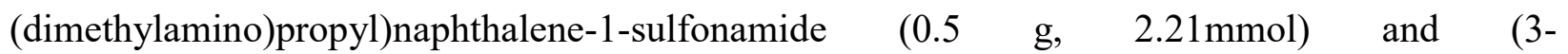
chloropropyl)trimethoxysilane $(0.6 \mathrm{~mL}, 3.31 \mathrm{mmol}, 1.5$ eq. $)$ in $\mathrm{ACN}(3 \mathrm{~mL})$ for 5 hours resulting in viscous golden yellow brown solution. The product was purified using $\mathrm{Et}_{2} \mathrm{O}(10 \mathrm{~mL} \times 3)$ and obtained as clear golden brown coloured gummy oil. Yield: $78.8 \%(0.85 \mathrm{~g}) .{ }^{1} \mathrm{H}$ NMR $\left(\mathrm{CDCl}_{3}\right.$, $400 \mathrm{MHz}, \delta): 8.83\left(1 \mathrm{H}, \mathrm{d},{ }^{3} \mathrm{~J}_{\mathrm{H} 8-\mathrm{H} 7}=8.6 \mathrm{~Hz}, \mathrm{H} 8\right), 8.47\left(1 \mathrm{H}, \mathrm{t},{ }^{3} \mathrm{~J}_{\mathrm{H} 11-\mathrm{H} 12}=5.7 \mathrm{~Hz}, \mathrm{H} 11\right), 8.20(1 \mathrm{H}, \mathrm{d}$, $\left.{ }^{3} \mathrm{~J}_{\mathrm{H} 6-\mathrm{H} 7}=7.3 \mathrm{~Hz}, \mathrm{H} 6\right), 7.99\left(1 \mathrm{H}, \mathrm{d},{ }^{3} \mathrm{~J}_{\mathrm{H} 1-\mathrm{H} 2}=8.1 \mathrm{~Hz}, \mathrm{H} 1\right), 7.87\left(1 \mathrm{H}, \mathrm{d},{ }^{3} \mathrm{~J}_{\mathrm{H} 4-\mathrm{H} 3}=8.1 \mathrm{~Hz}, \mathrm{H} 4\right), 7.69$ (1H, m, H7), 7.55 - 7.46 (2H, m, H3 \& H2), 3.49 (11H, br s, H14 \& H19), 3.20 (2H, m, H16), $3.06\left(8 \mathrm{H}, \mathrm{br} \mathrm{s}, \mathrm{H} 12\right.$ \& H15), $1.98-1.86(2 \mathrm{H}, \mathrm{m}, \mathrm{H} 13), 1.68-1.54(2 \mathrm{H}, \mathrm{m}, \mathrm{H} 17), 0.51\left(2 \mathrm{H}, \mathrm{t},{ }^{3} \mathrm{~J}_{\mathrm{H} 18-}\right.$ $\left.{ }_{\mathrm{H} 17}=7.8 \mathrm{~Hz}, \mathrm{H} 18\right) \mathrm{ppm} .{ }^{13} \mathrm{C}\left\{{ }^{1} \mathrm{H}\right\} \mathrm{NMR}\left(\mathrm{CDCl}_{3}, 101 \mathrm{MHz}, \delta\right): 135.12$ (C9), 134.16 (C5), 133.91 (C1), 129.07 (C6), 128.8 (C4), 128.56 (C7), 128.12 (C10), 127.02 (C3), 125.30 (C8), 124.31 (C2), 65.84 (C16), 62.32 (C14), 50.92 (C15), 50.69 (C19), 39.79 (C12), 22.81 (C13), 16.33 (C17), 5.48

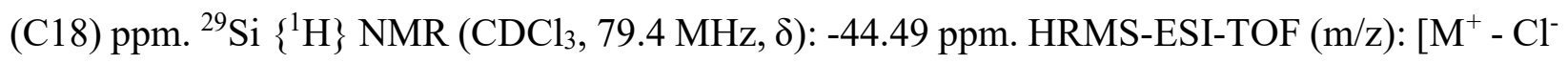
] calculated for $\mathrm{C}_{21} \mathrm{H}_{35} \mathrm{~N}_{2} \mathrm{O}_{2} \mathrm{SSi}$, 455.2030, found, 455.2018.

\section{Synthesis of 3-(ethylsulfonamido)-N,N-dimethyl-N-(3-(trimethoxysilyl)propyl)propan-1- aminium chloride $7 \mathrm{~b}$}

This compound was synthesized according to Method (B)3 with N-(3(dimethylamino)propyl)ethanesulfonamide $\quad\left(\begin{array}{llll}1.0 & \mathrm{~g}, & 5.15 & \mathrm{mmol})\end{array}\right.$ and $\quad$ (3chloropropyl)trimethoxysilane (1.4 mL, $7.72 \mathrm{mmol}, 1.5$ eq.) in ACN ( $3 \mathrm{~mL})$ for 5 hours resulting in viscous golden yellow brown solution. The product was purified using $\mathrm{Et}_{2} \mathrm{O}(10 \mathrm{~mL} \times 3)$ and obtained as clear golden brown coloured gummy oil. Yield: $86.0 \%(1.73 \mathrm{~g}) .{ }^{1} \mathrm{H} \mathrm{NMR}\left(\mathrm{CDCl}_{3}\right.$, $400 \mathrm{MHz}, \delta): 7.63$ (1H, s, H3), 3.66 (2H, m, H6), 3.53 (9H, m, H11), 3.36 (2H, m, H8), 3.25 $3.15(8 \mathrm{H}, \mathrm{m}, \mathrm{H} 7$ \& H4), 3.03 (2H, m, H2), 2.12 (2H, m, H5), 1.78 (2H, m, H9), 1.31 (3H, m, H1), 
$0.62\left(2 \mathrm{H}, \mathrm{t},{ }^{3} \mathrm{~J}_{\mathrm{H} 10-\mathrm{H} 9}=7.8 \mathrm{~Hz}, \mathrm{H} 10\right) \mathrm{ppm} .{ }^{13} \mathrm{C}\left\{{ }^{1} \mathrm{H}\right\} \mathrm{NMR}\left(\mathrm{CDCl}_{3}, 101 \mathrm{MHz}, \delta\right): 65.89(\mathrm{C} 8), 62.40$ (C6), 51.18 (C7), 50.81 (C11), 46.37 (C2), 40.09 (C4), 23.58 (C5), 16.54 (C9), 8.28 (C1), 5.73 (C10) ppm. ${ }^{29} \mathrm{Si}\left\{{ }^{1} \mathrm{H}\right\} \mathrm{NMR}\left(\mathrm{CDCl}_{3}, 79.4 \mathrm{MHz}, \delta\right):-44.51 \mathrm{ppm}$.

\section{Synthesis of 3-(butylsulfonamido)-N,N-dimethyl-N-(3-(trimethoxysilyl)propyl)propan-1- aminium chloride $8 \mathrm{~b}$}

This compound was synthesized according to Method (B)3 with N-(3(dimethylamino)propyl)butanesulfonamide $\quad\left(\begin{array}{llll}1.0 & \mathrm{~g}, & 4.50 \quad \mathrm{mmol})\end{array}\right.$ chloropropyl)trimethoxysilane ( $1.2 \mathrm{~mL}, 6.75 \mathrm{mmol}, 1.5$ eq.) in $\mathrm{ACN}(3 \mathrm{~mL})$ for 5 hours resulting in viscous golden yellow brown solution. The product was purified using $\mathrm{Et}_{2} \mathrm{O}(10 \mathrm{~mL} \times 5)$ and obtained as clear golden brown coloured gummy oil. Yield: $60.0 \%(1.13 \mathrm{~g}) .{ }^{1} \mathrm{H} \mathrm{NMR}\left(\mathrm{CDCl}_{3}\right.$, $400 \mathrm{MHz}, \delta): 7.62$ (1H, br s, H5), 3.64 (2H, m, H8), 3.51 (9H, s, H13), 3.34 (2H, m, H4), 3.24 $3.12(8 \mathrm{H}, \mathrm{m}, \mathrm{H} 9$ and $\mathrm{H} 6), 2.98$ (2H, m, H4), 2.09 (2H, m, H7), $1.83-1.66$ (4H, m, H11 \& H3), $1.38(2 \mathrm{H}, \mathrm{m}, \mathrm{H} 2), 0.86(3 \mathrm{H}, \mathrm{m}, \mathrm{H} 1), 0.60\left(2 \mathrm{H}, \mathrm{t},{ }^{3} \mathrm{~J}_{\mathrm{H} 12-\mathrm{H} 11}=7.3 \mathrm{~Hz}, \mathrm{H} 12\right) \mathrm{ppm} .{ }^{13} \mathrm{C}\left\{{ }^{1} \mathrm{H}\right\} \mathrm{NMR}$ (CDCl $, 101 \mathrm{MHz}, \delta): 65.82$ (C10), 51.81 (C4), 51.12 (C9), 50.74 (C13), 40.04 (C6), 25.38 (C3), 23.50 (C7), 21.58 (C2), 16.50 (C11), $13.62(\mathrm{C} 1), 5.68$ (C12) ppm. ${ }^{29} \mathrm{Si}\left\{{ }^{1} \mathrm{H}\right\} \mathrm{NMR}\left(\mathrm{CDCl}_{3}, 79.4\right.$ $\mathrm{MHz}, \delta):-44.50 \mathrm{ppm}$. HRMS-ESI-TOF (m/z): [ $\left.\mathrm{M}^{+}-\mathrm{Cl}^{-}\right]$calculated for $\mathrm{C}_{15} \mathrm{H}_{37} \mathrm{~N}_{2} \mathrm{O} 5 \mathrm{SSi}, 385.2187$, found, 385.2185 . 


\section{NMR Spectra of Synthesized Compounds}

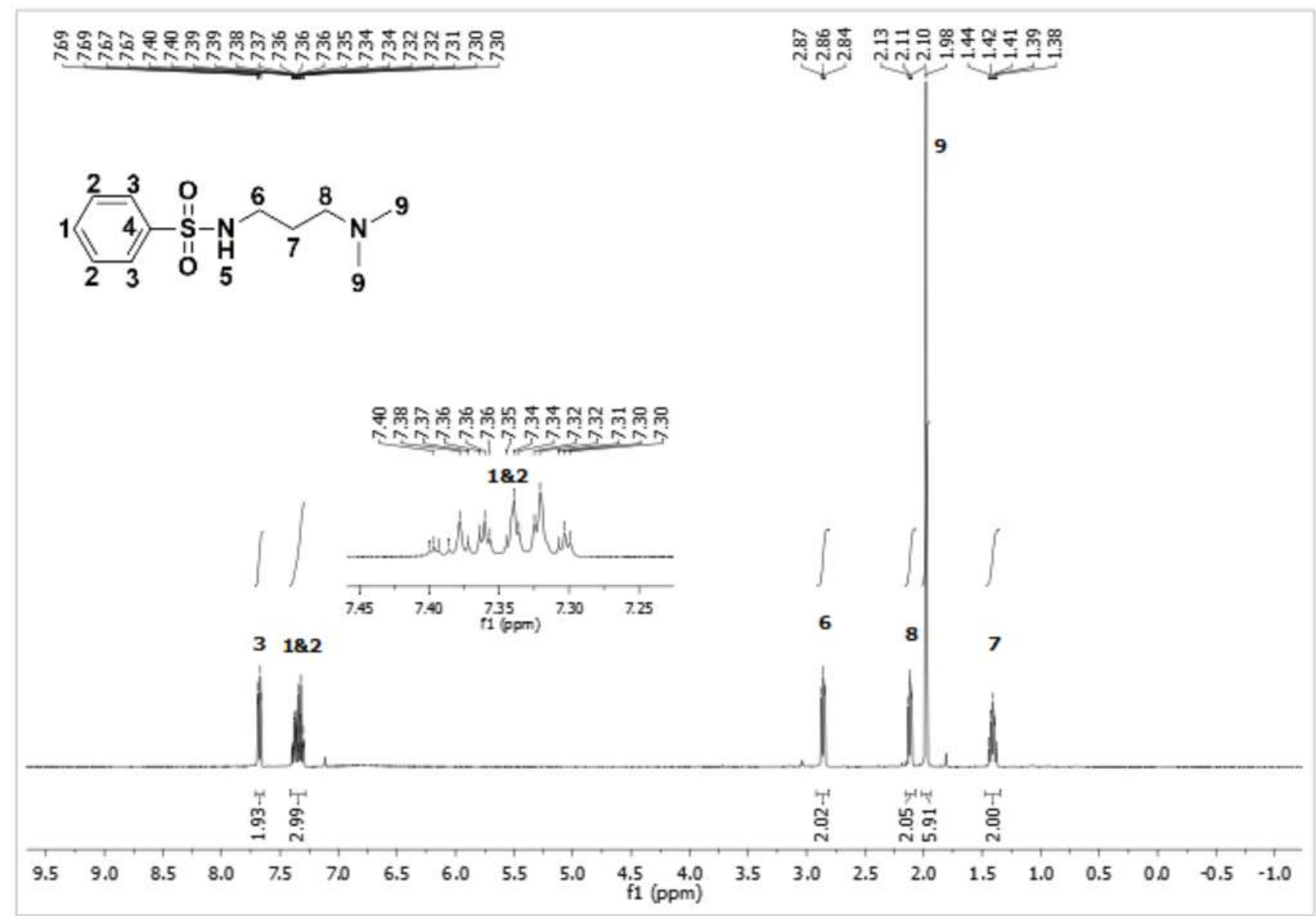

Figure (B) $22-{ }^{1} \mathrm{H}$ NMR $\left(400 \mathrm{MHz}, \mathrm{CDCl}_{3}\right)$ spectrum of 3. 


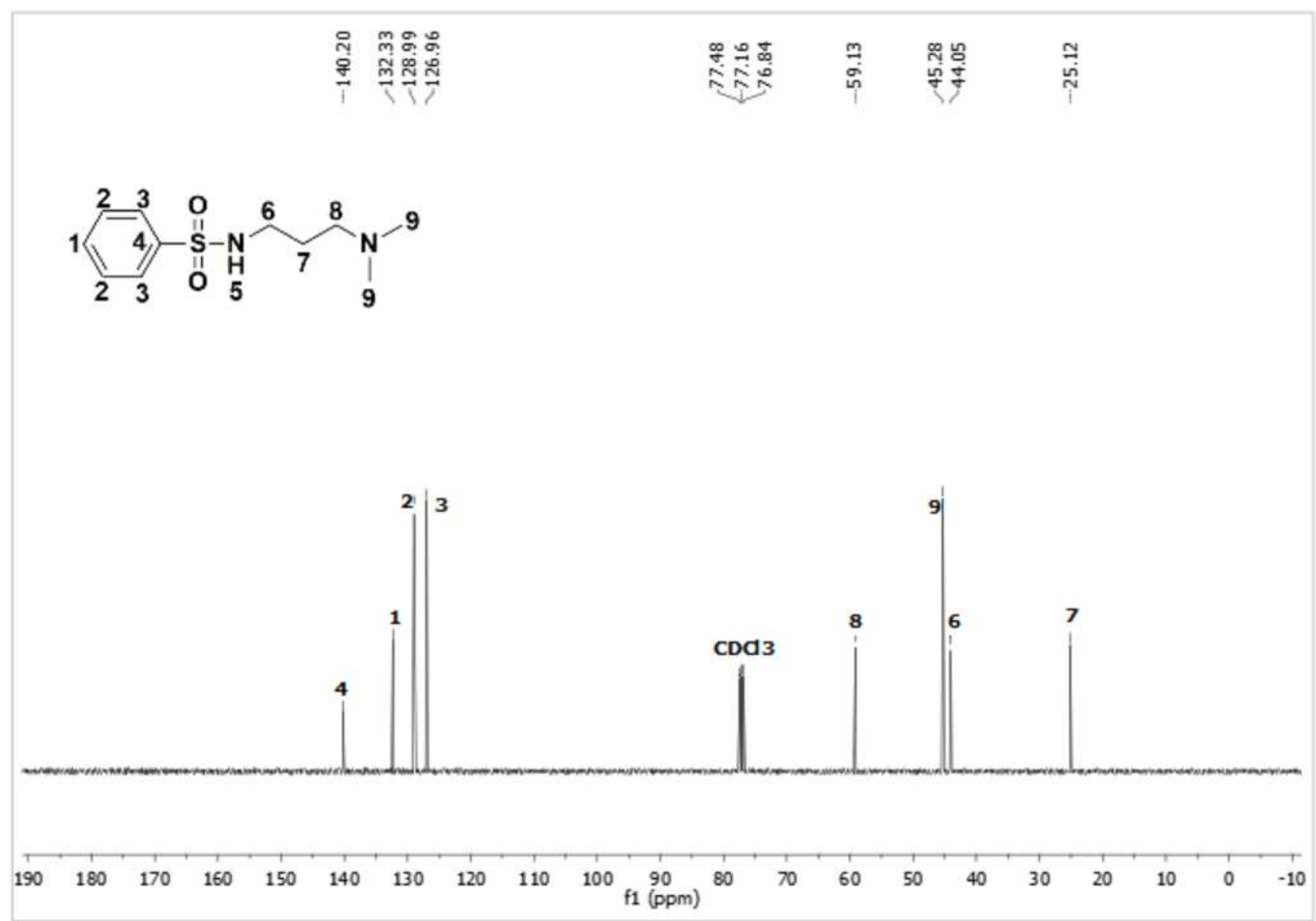

Figure (B) $23-{ }^{13} \mathrm{C}$ NMR (101 MHz, $\left.\mathrm{CDCl}_{3}\right)$ spectrum of 3. 


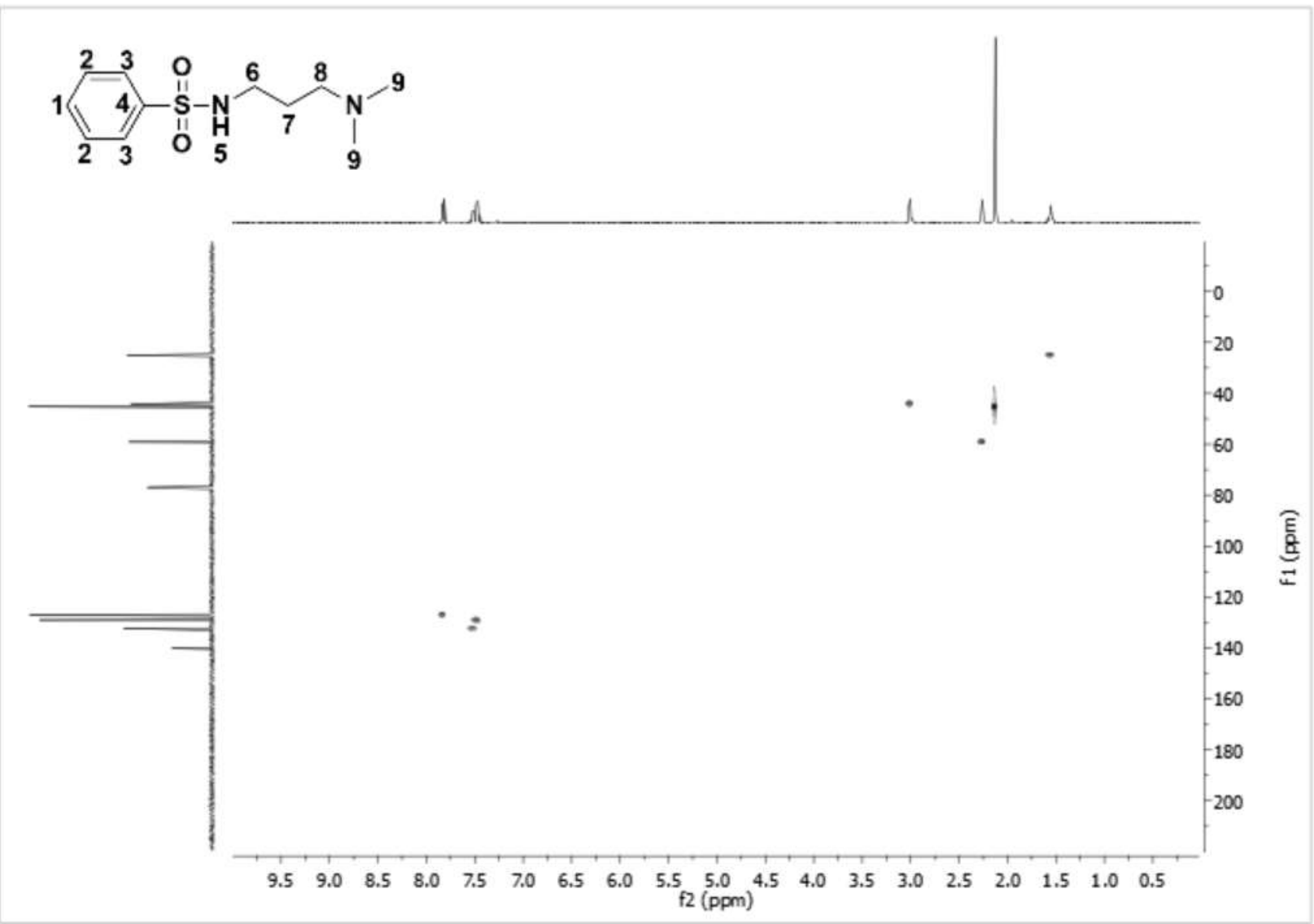

Figure (B) $24-\mathrm{COSY} 2 \mathrm{D}$ NMR $\left(\mathrm{CDCl}_{3}\right)$ spectrum of $\mathbf{3}$. 


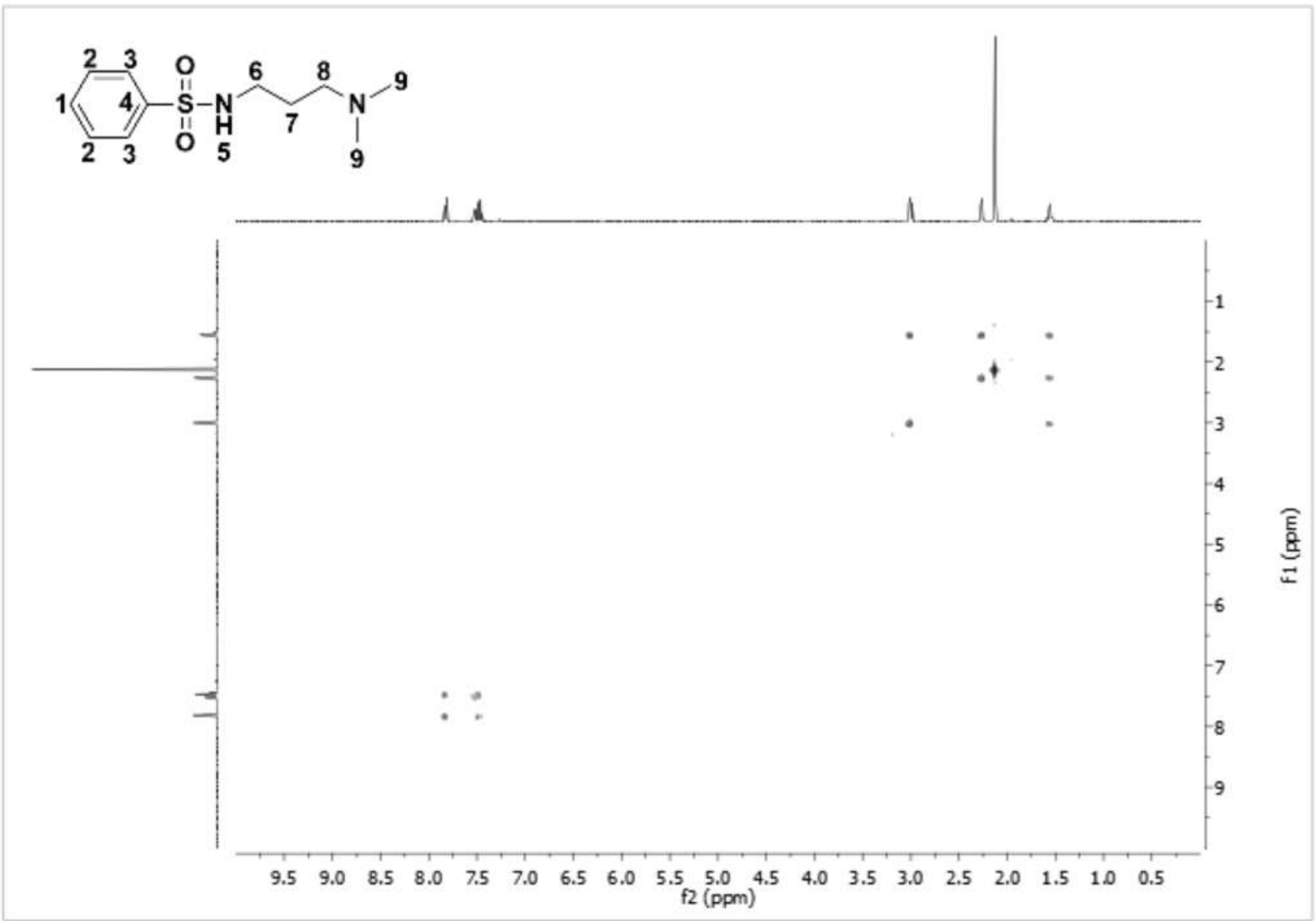

Figure (B) 25 - HSQC 2D NMR $\left(\mathrm{CDCl}_{3}\right)$ spectrum of 3. 


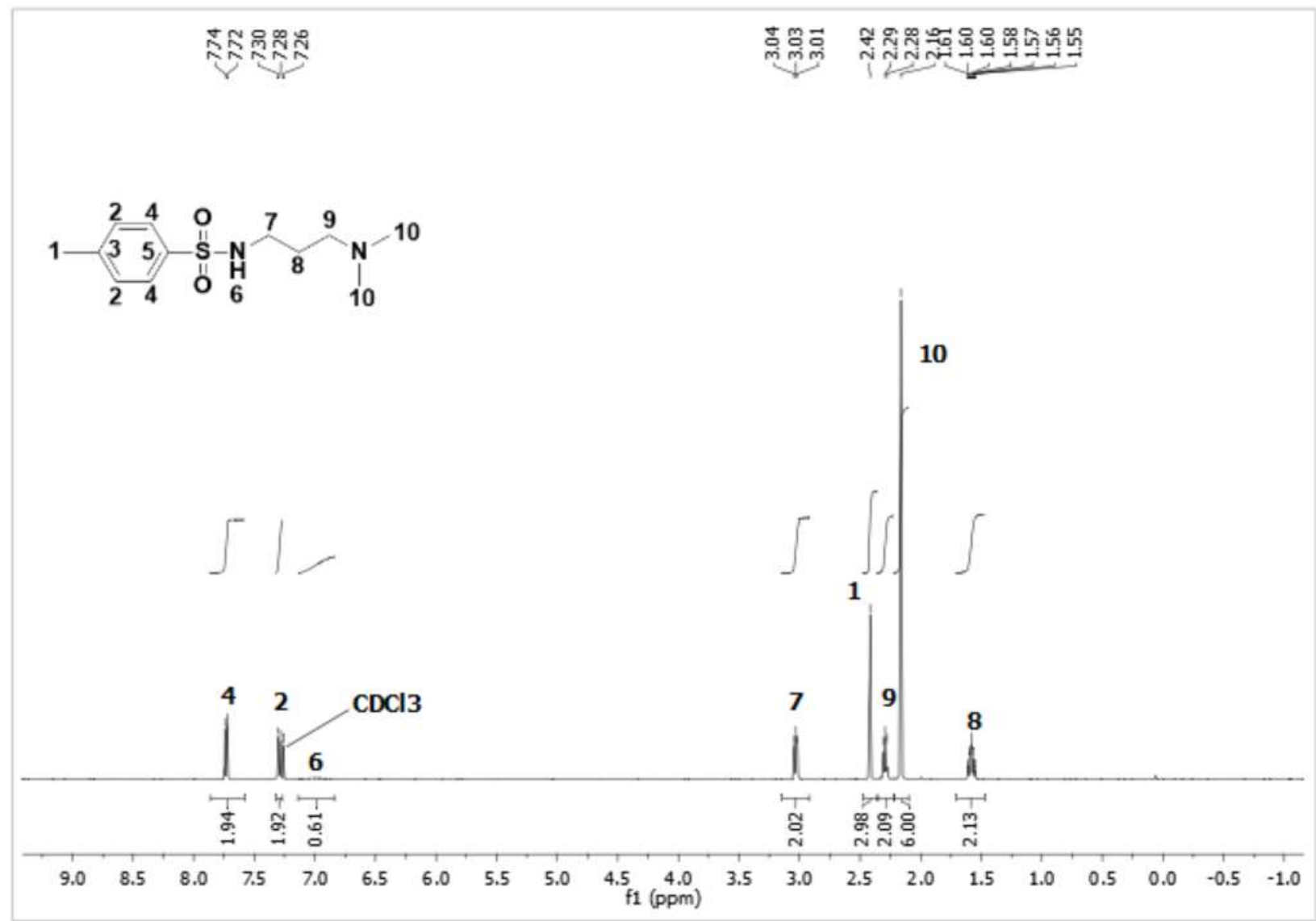

Figure (B) $26-{ }^{1} \mathrm{H}$ NMR (400 MHz, $\left.\mathrm{CDCl}_{3}\right)$ spectrum of 4. 


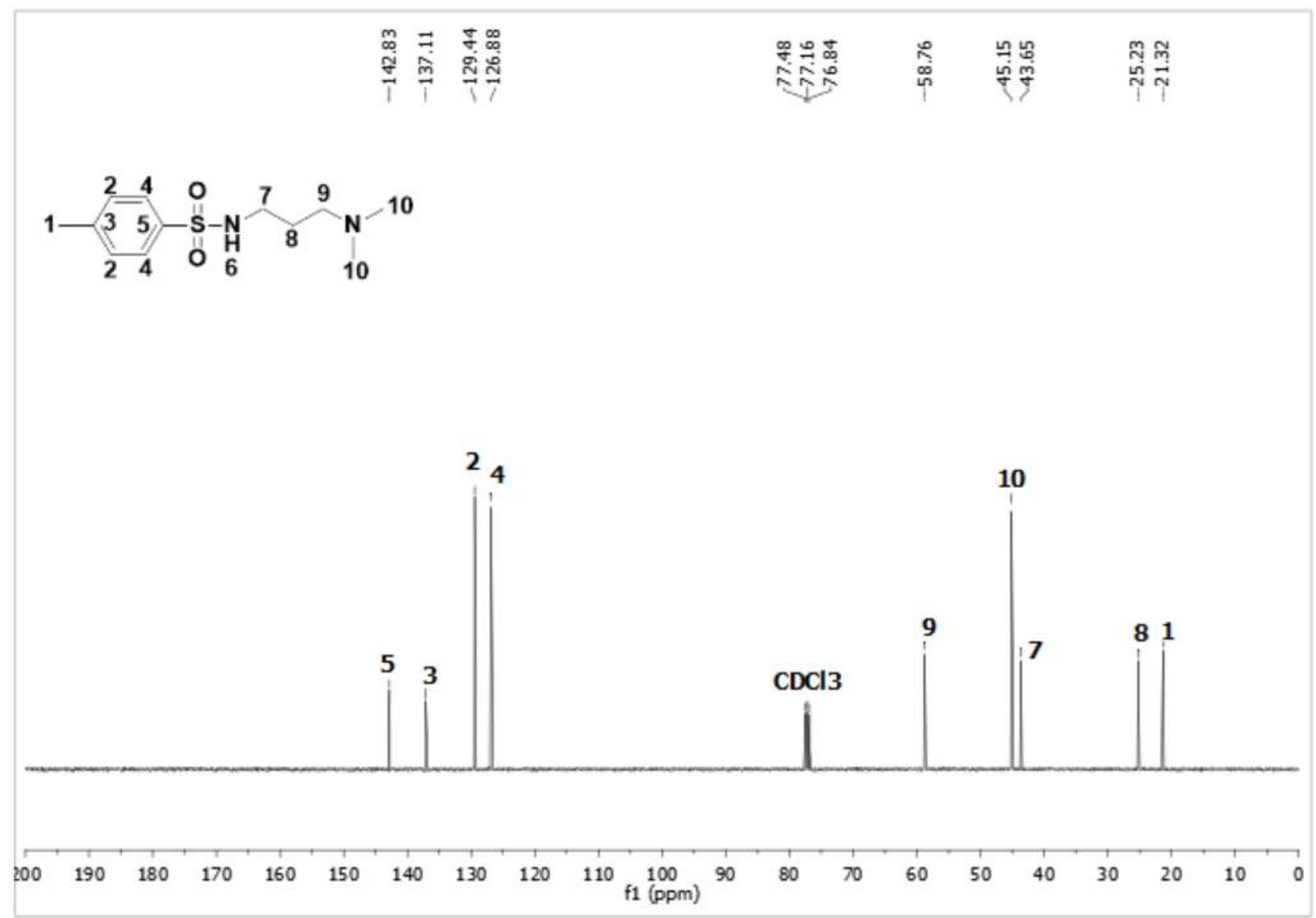

Figure (B) $27-{ }^{13} \mathrm{C}$ NMR (101 MHz, $\left.\mathrm{CDCl}_{3}\right)$ spectrum of 4. 


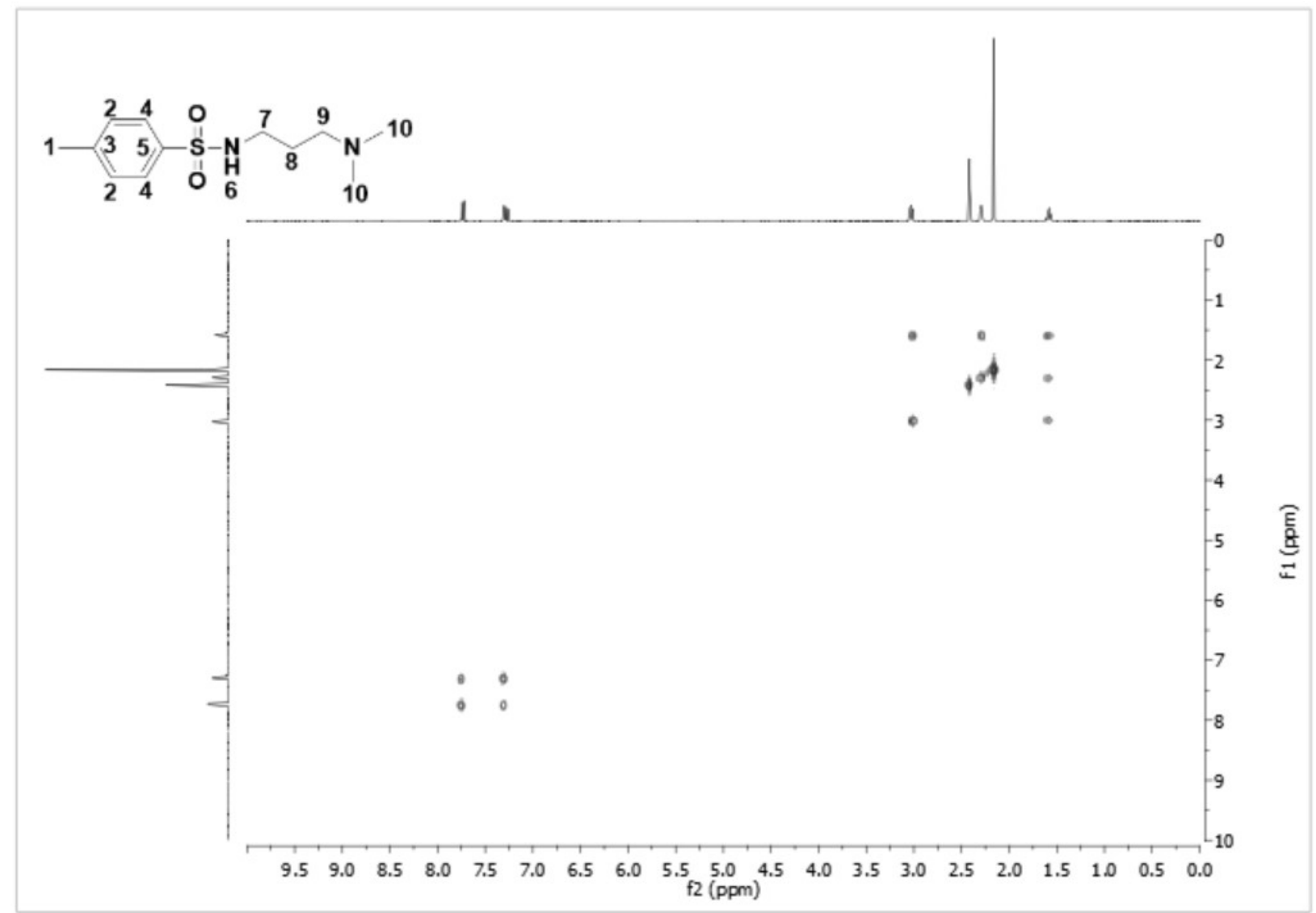

Figure (B) $28-\mathrm{COSY} 2 \mathrm{D}$ NMR $\left(\mathrm{CDCl}_{3}\right)$ spectrum of 4. 


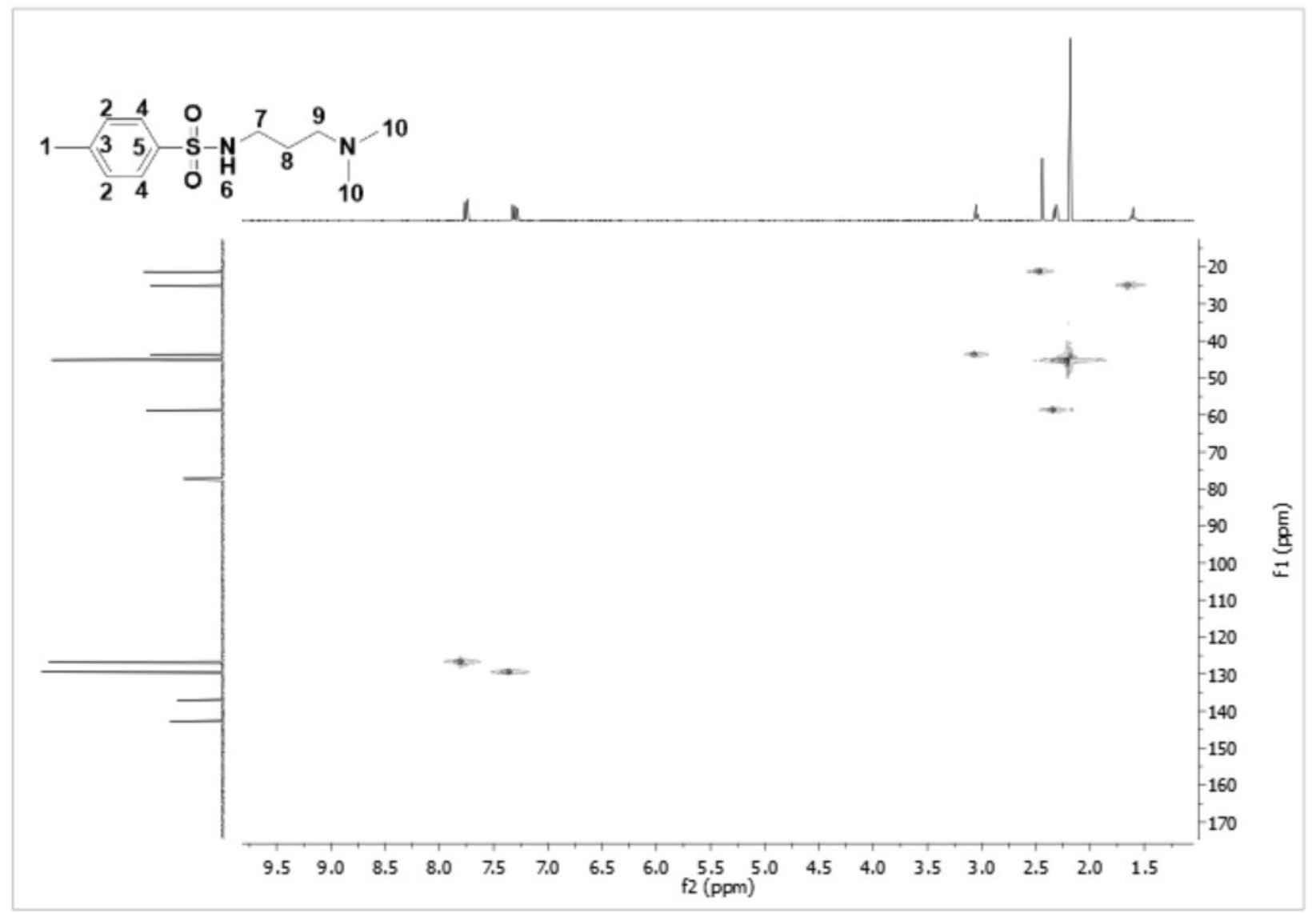

Figure (B) 29 - HSQC 2D NMR $\left(\mathrm{CDCl}_{3}\right)$ spectrum of 4. 


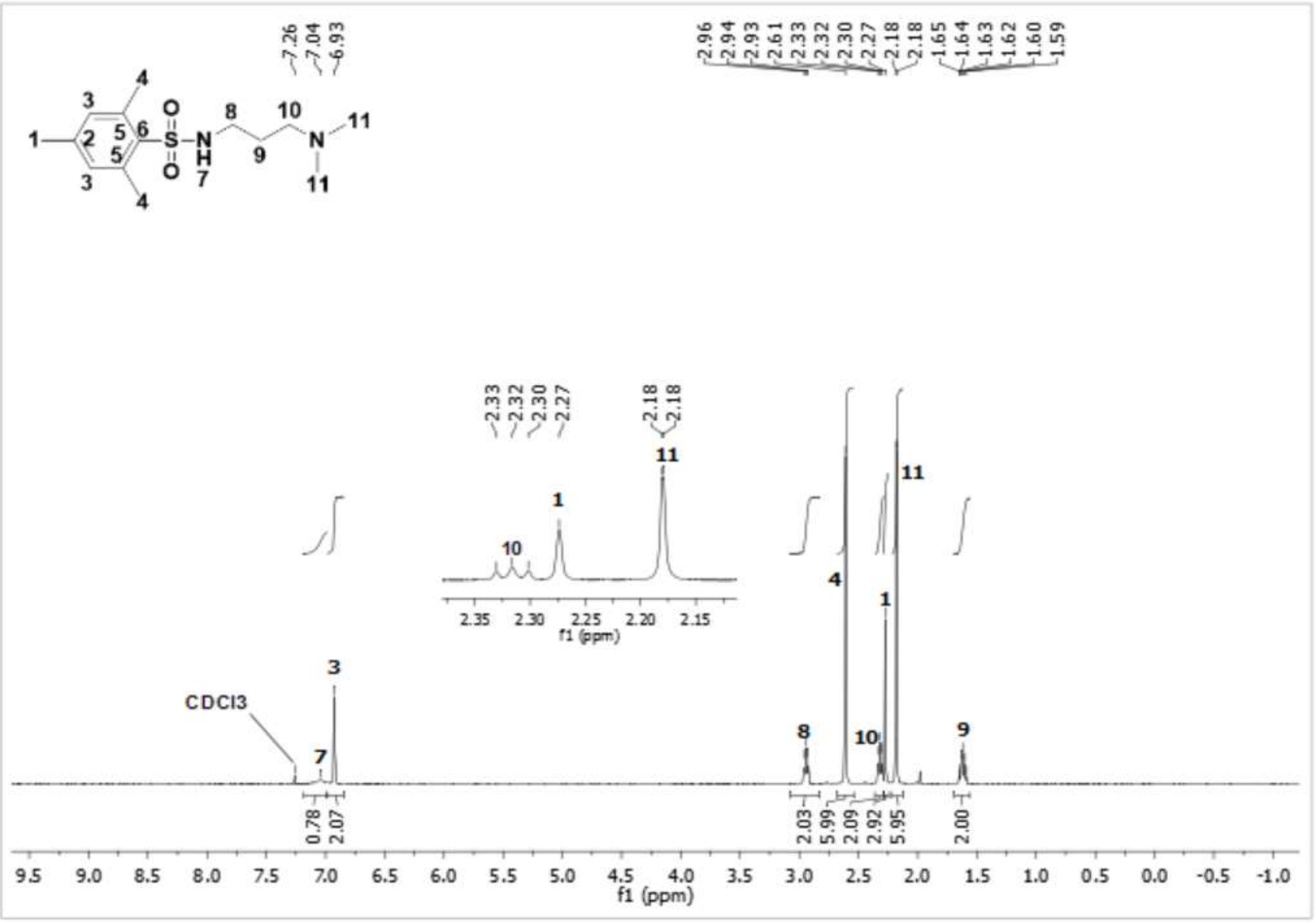

Figure (B) $30-{ }^{1} \mathrm{H} \mathrm{NMR}\left(400 \mathrm{MHz}, \mathrm{CDCl}_{3}\right)$ spectrum of 5. 


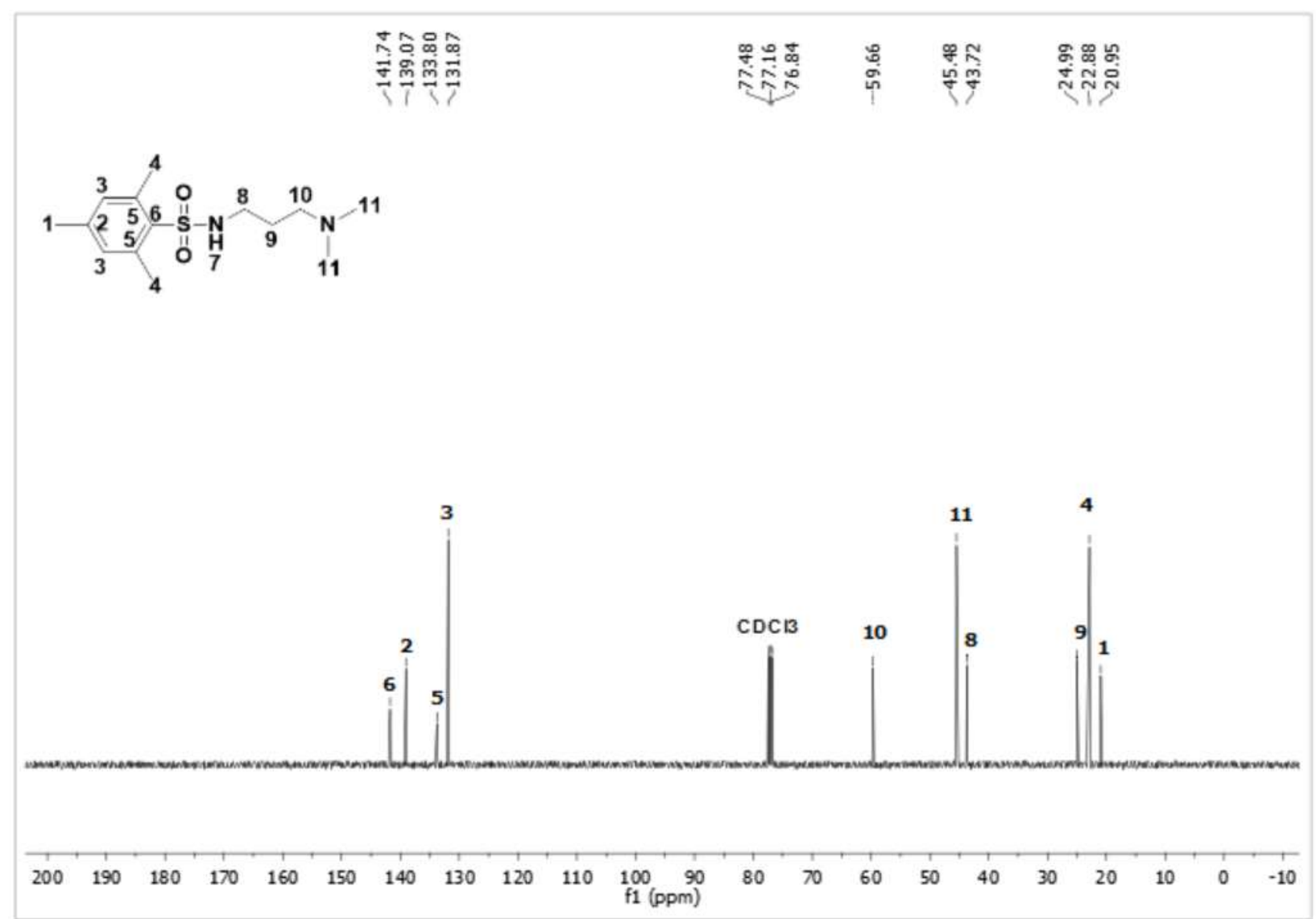

Figure (B) $31-{ }^{13} \mathrm{C}$ NMR $\left(101 \mathrm{MHz}, \mathrm{CDCl}_{3}\right)$ spectrum of 5. 


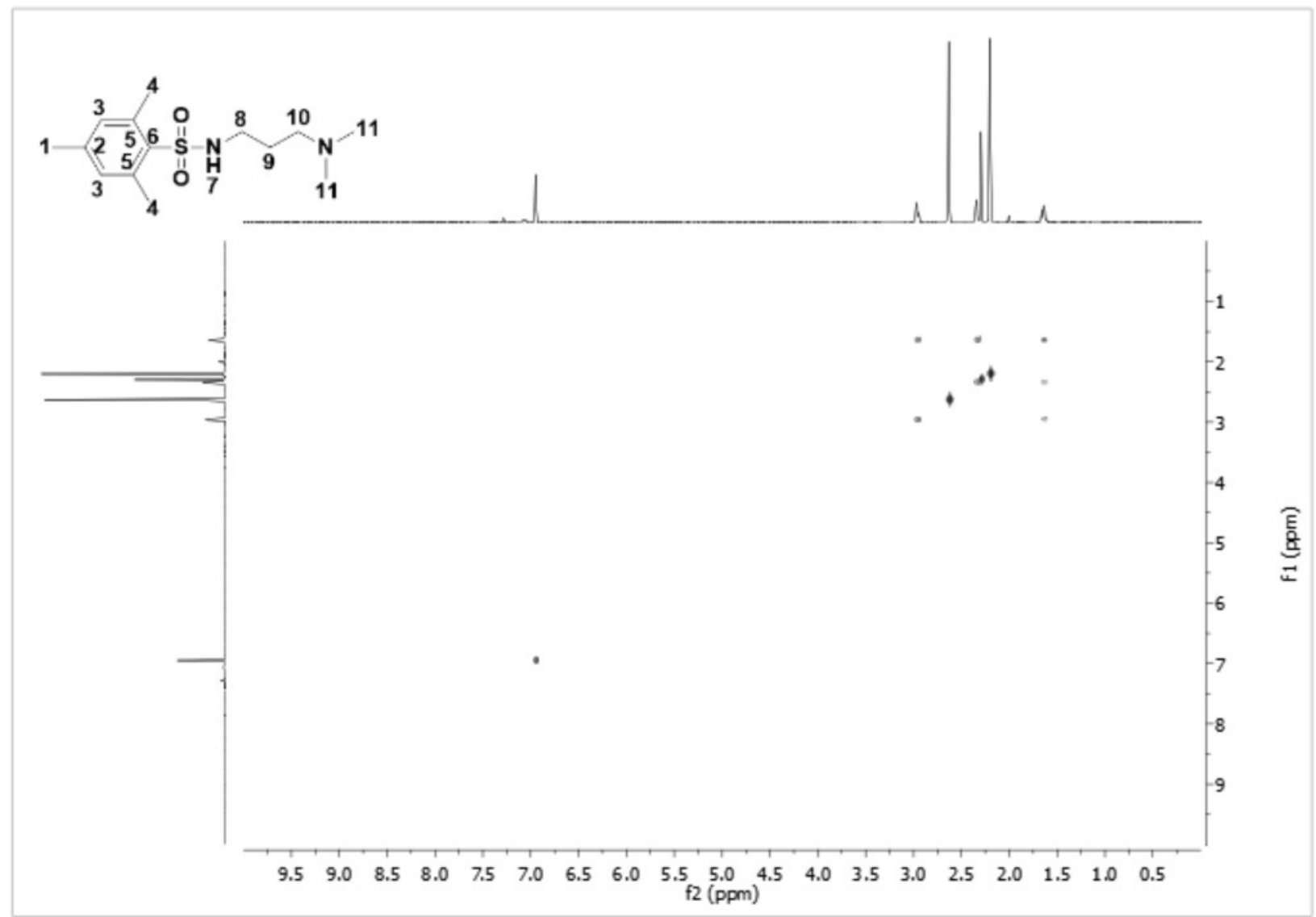

Figure (B) 32 - COSY 2D NMR $\left(\mathrm{CDCl}_{3}\right)$ spectrum of $\mathbf{5}$. 


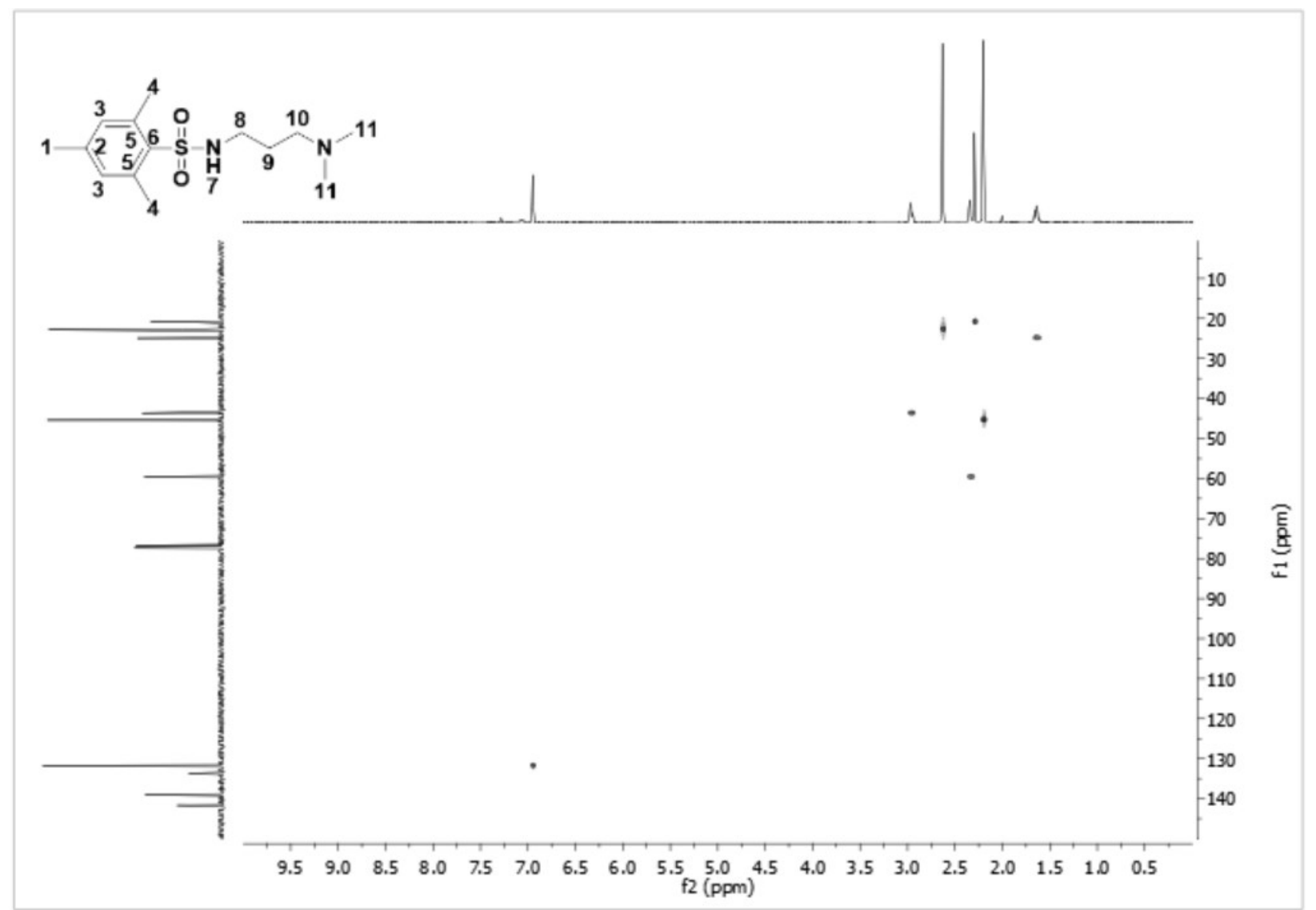

Figure (B) 33 - HSQC 2D NMR $\left(\mathrm{CDCl}_{3}\right)$ spectrum of $\mathbf{5}$. 


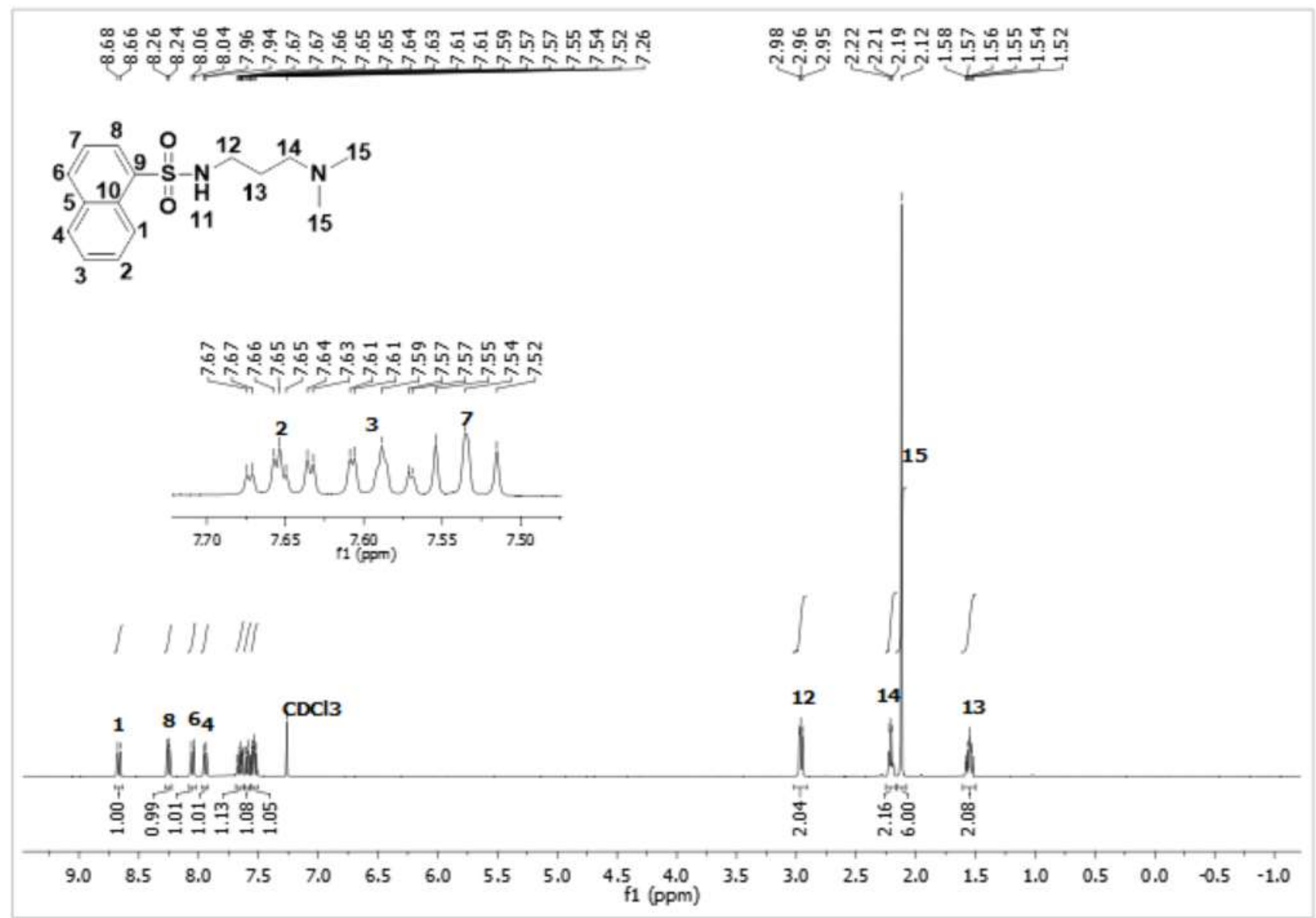

Figure (B) $34-{ }^{1} \mathrm{H}$ NMR (400 MHz, $\left.\mathrm{CDCl}_{3}\right)$ spectrum of 6. 


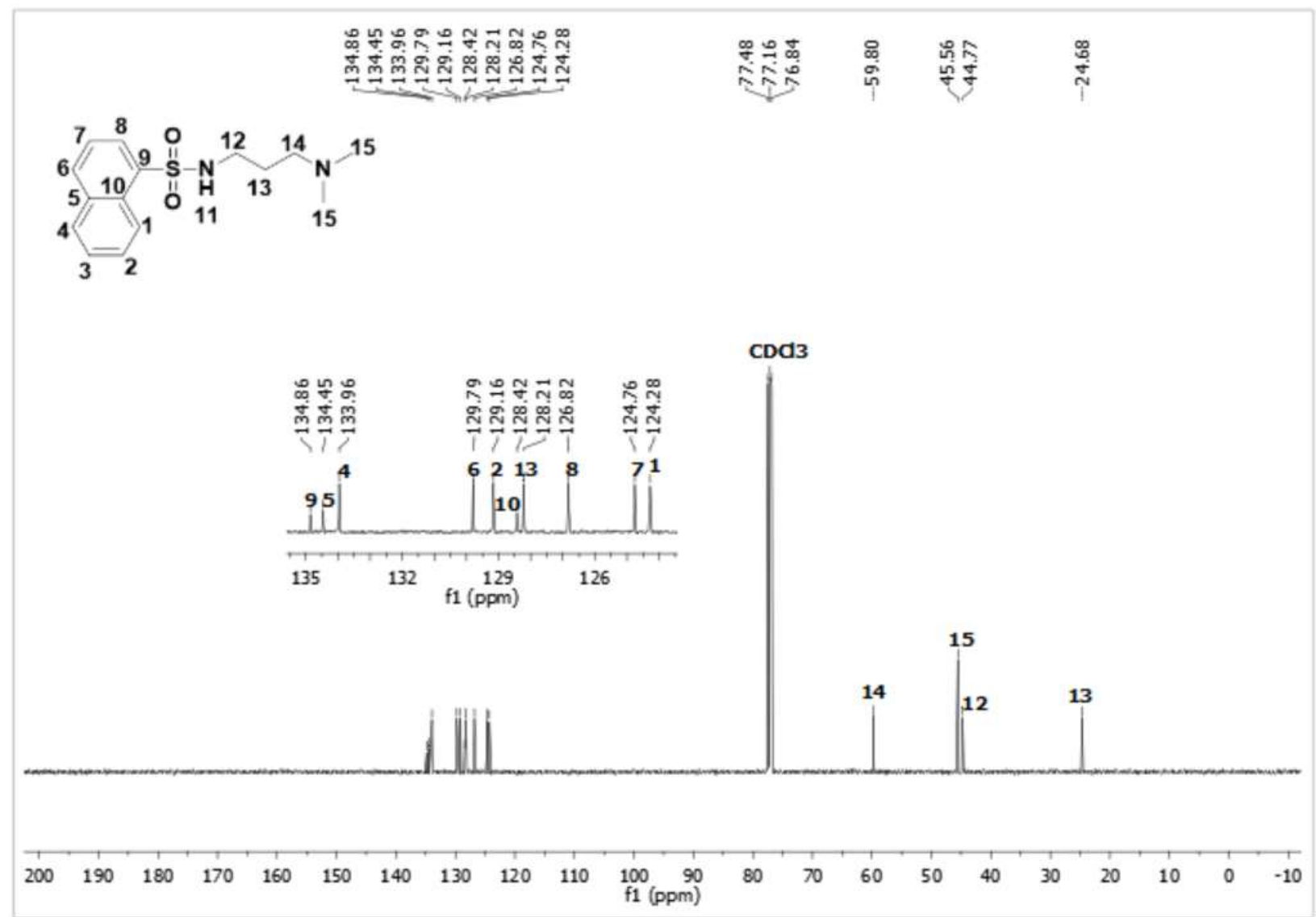

Figure (B) $35-{ }^{13} \mathrm{C}$ NMR (101 MHz, $\left.\mathrm{CDCl}_{3}\right)$ spectrum of 6. 


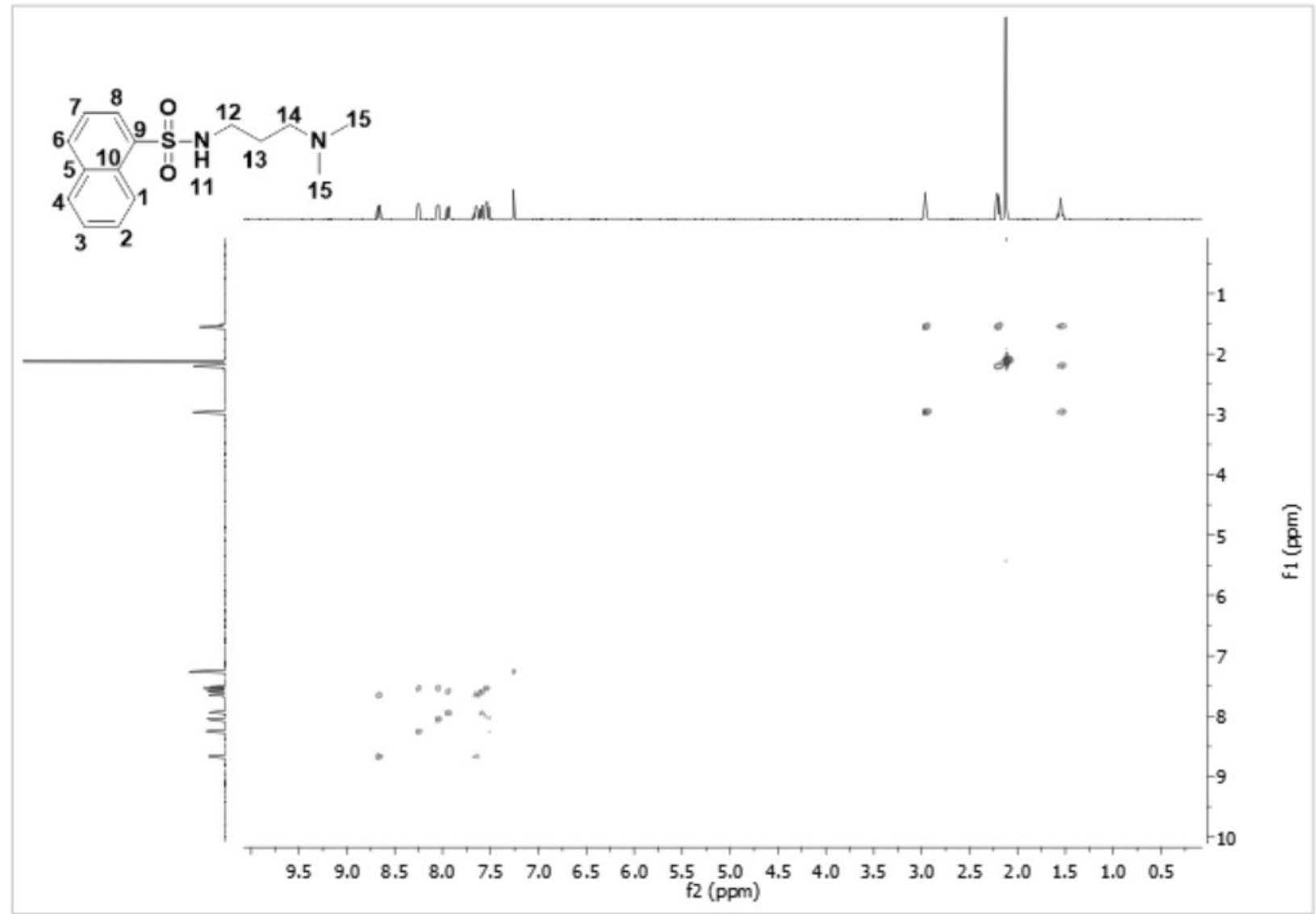

Figure (B) 36 - COSY 2D NMR $\left(\mathrm{CDCl}_{3}\right)$ spectrum of $\mathbf{6}$. 


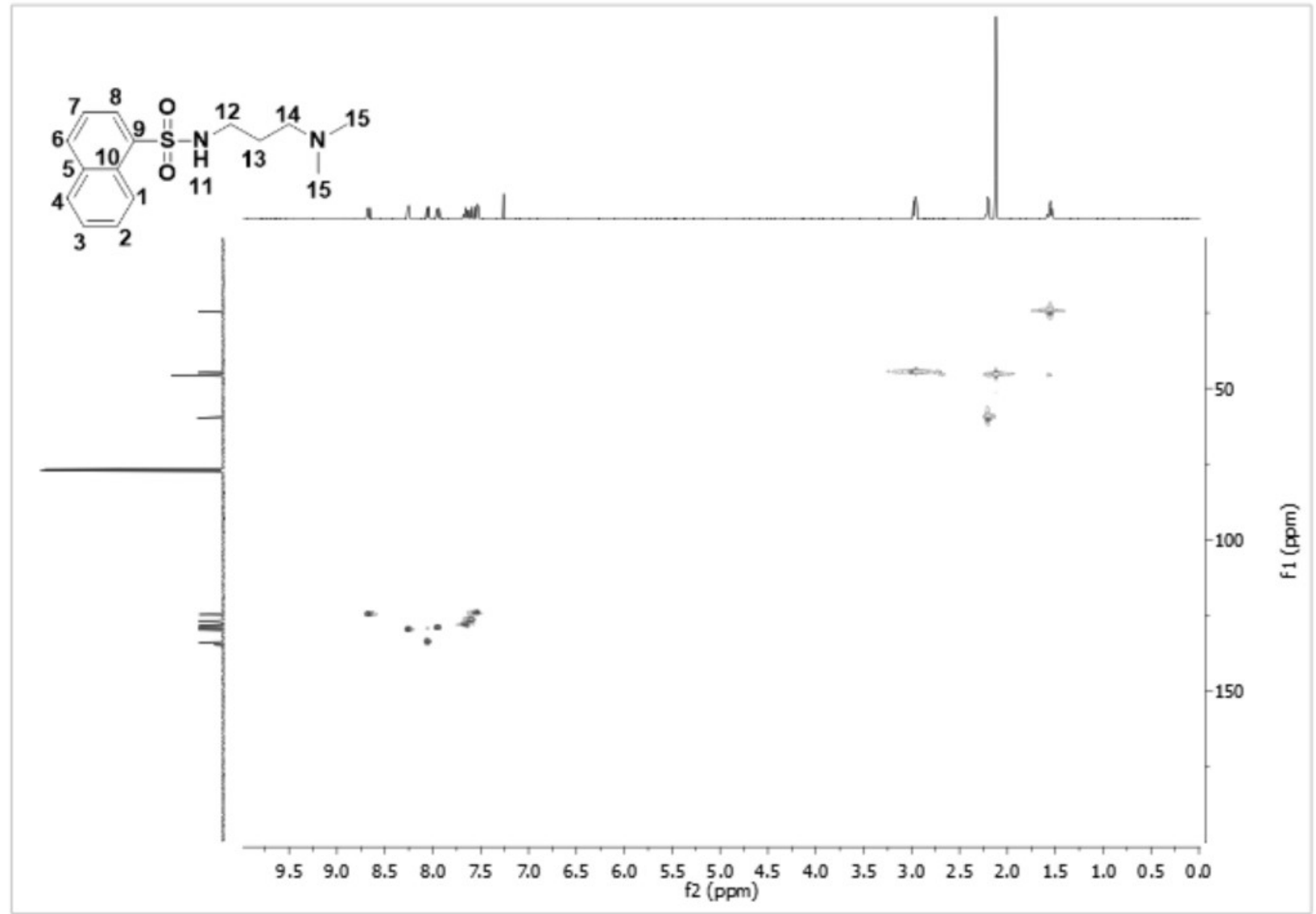

Figure (B) 37 - HSQC 2D NMR $\left(\mathrm{CDCl}_{3}\right)$ spectrum of $\mathbf{6}$. 


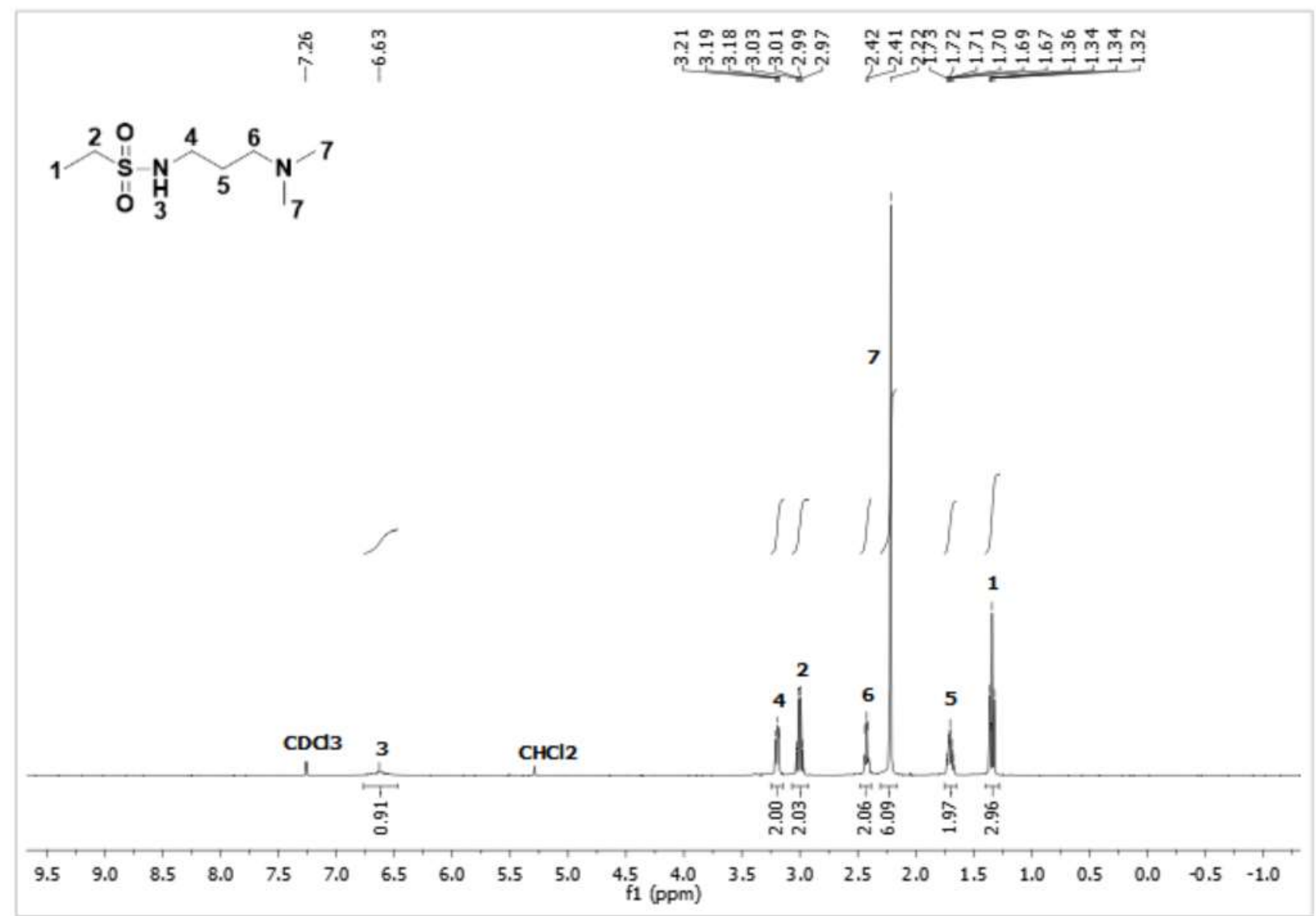

Figure (B) $38-{ }^{1} \mathrm{H}$ NMR (400 MHz, $\left.\mathrm{CDCl}_{3}\right)$ spectrum of 7. 


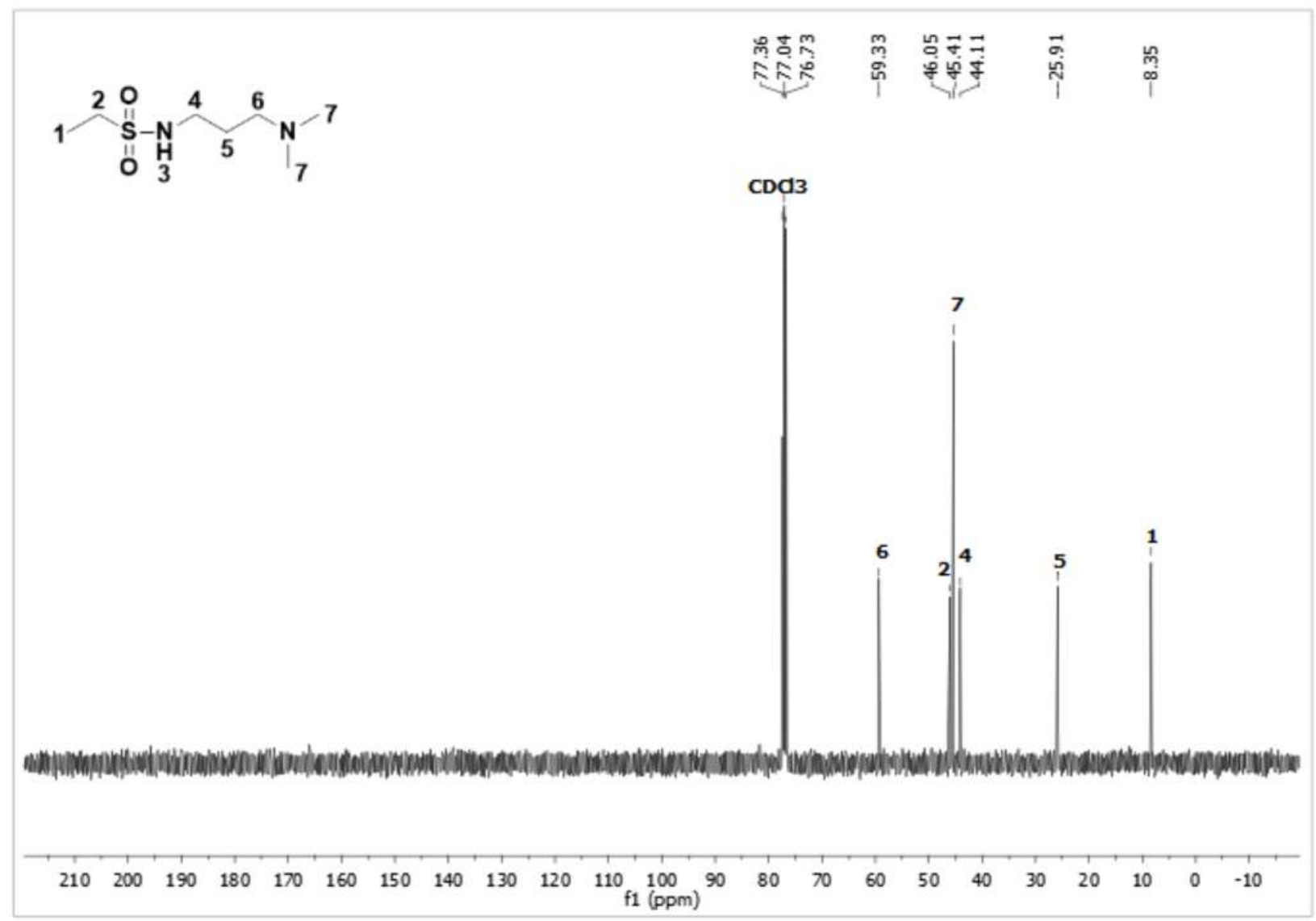

Figure (B) $39-{ }^{13} \mathrm{C}$ NMR $\left(101 \mathrm{MHz}, \mathrm{CDCl}_{3}\right)$ spectrum of 7. 


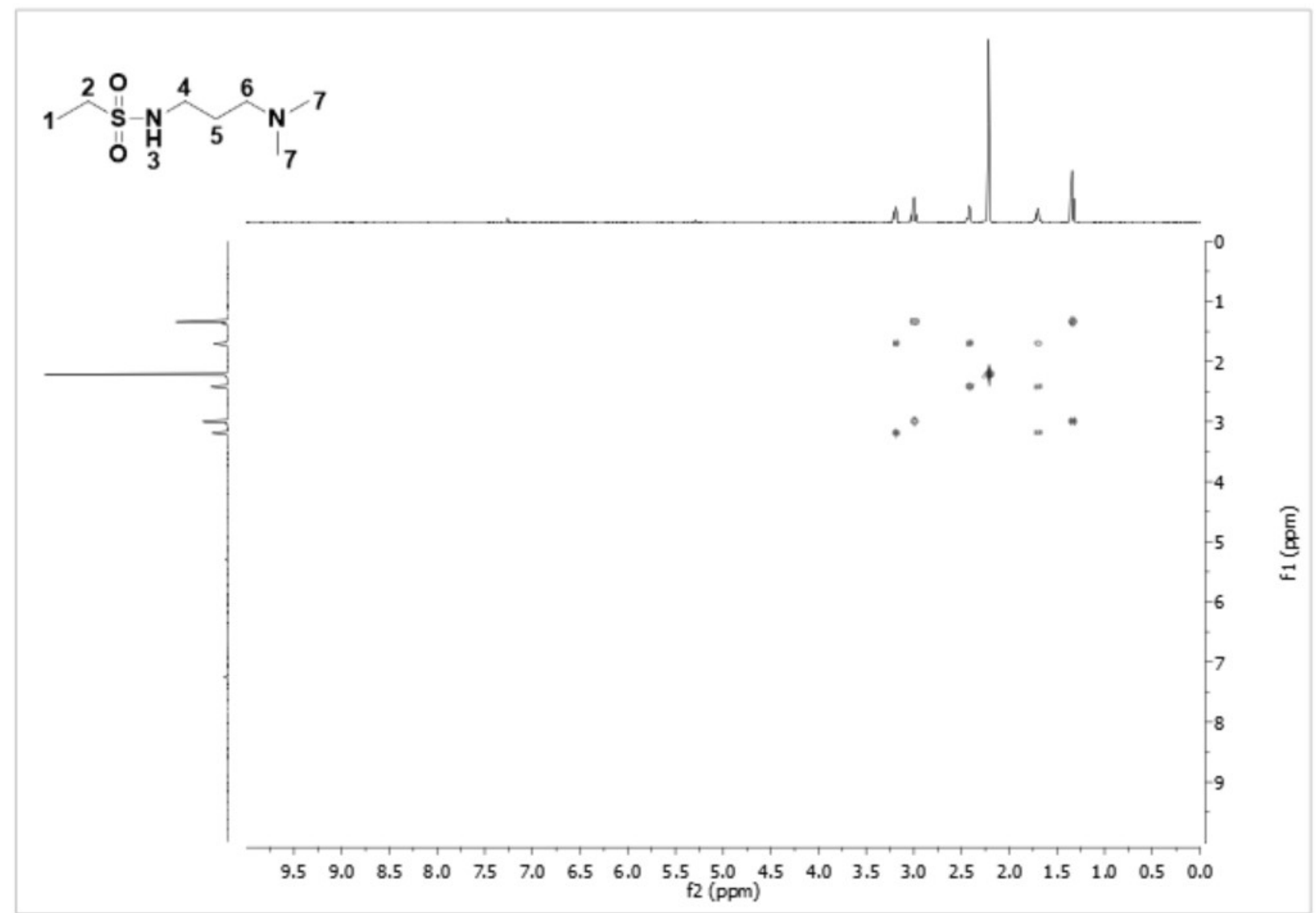

Figure (B) 40 - COSY 2D NMR $\left(\mathrm{CDCl}_{3}\right)$ spectrum of 7. 


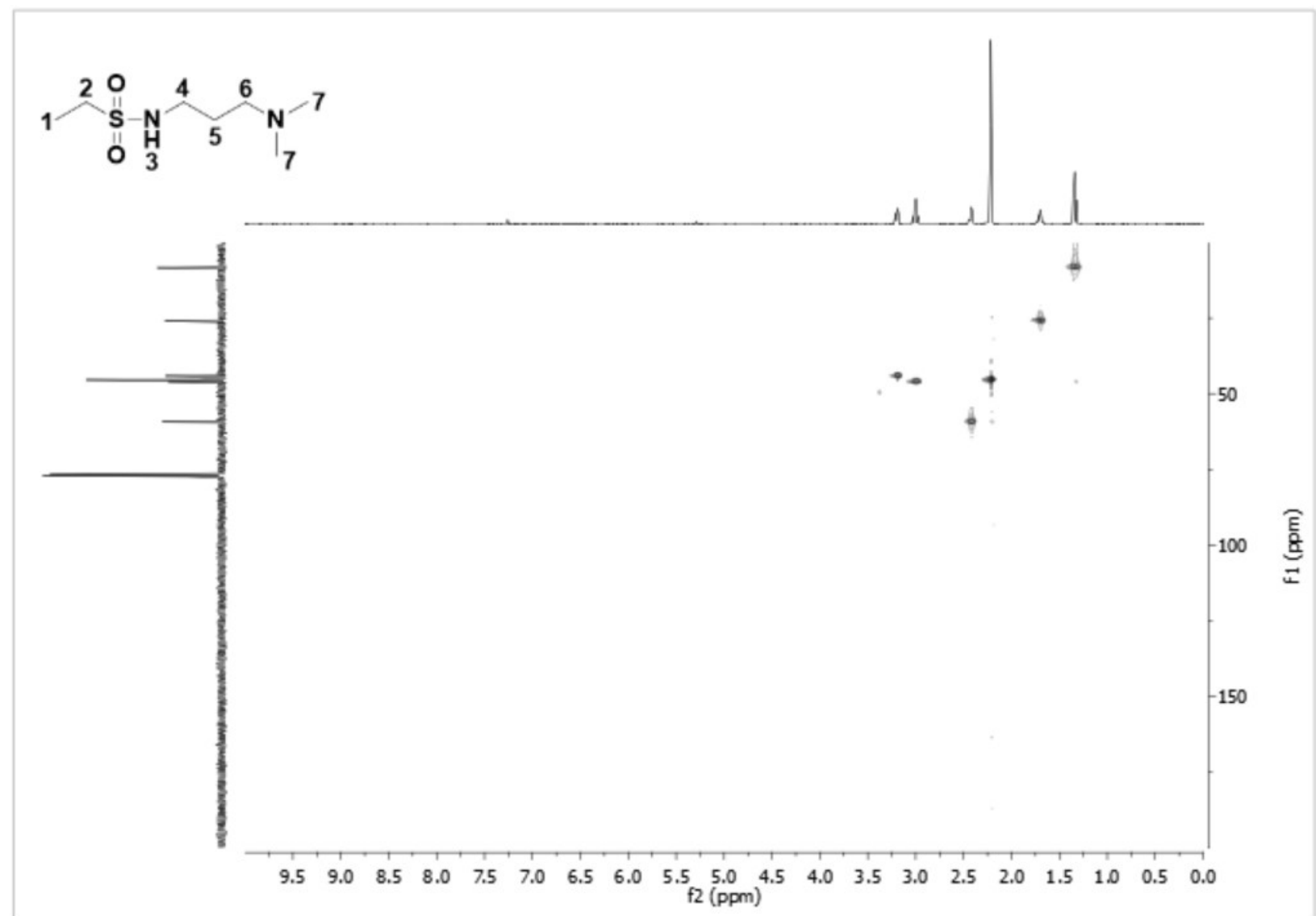

Figure (B) 41 - HSQC 2D NMR $\left(\mathrm{CDCl}_{3}\right)$ spectrum of 7. 


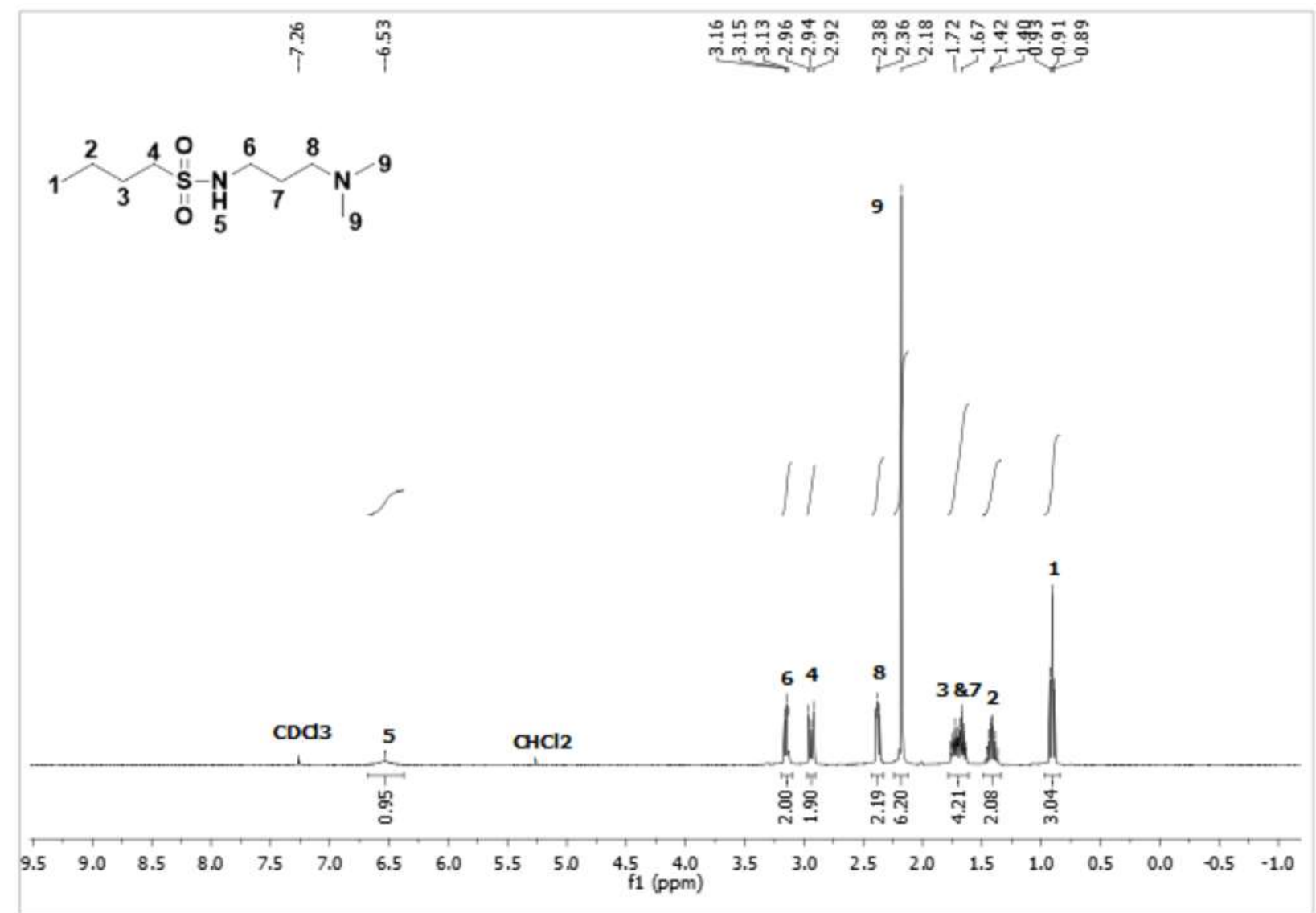

Figure (B) $42-{ }^{1} \mathrm{H}$ NMR $\left(400 \mathrm{MHz}, \mathrm{CDCl}_{3}\right)$ spectrum of 8 . 


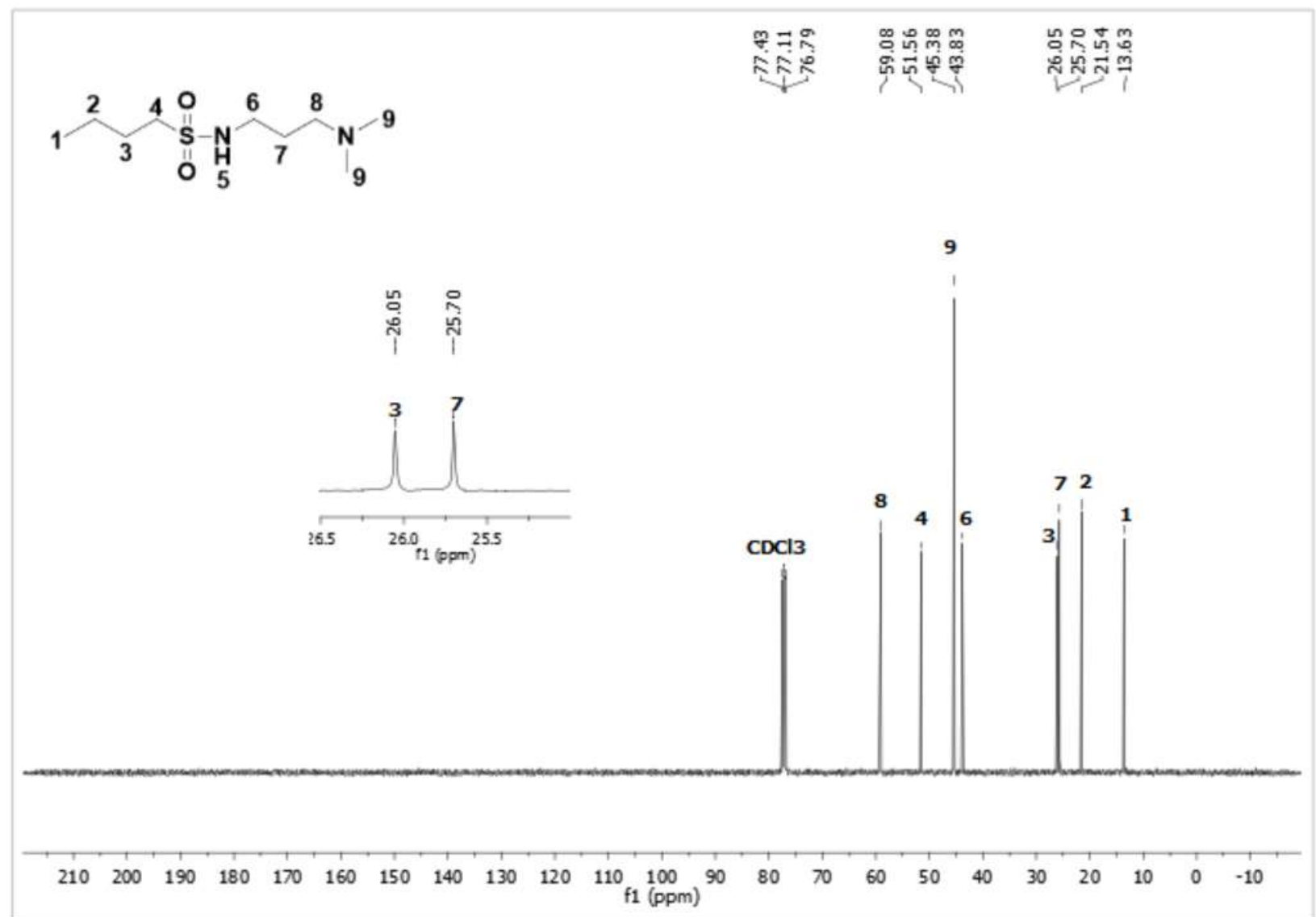

Figure (B) $43-{ }^{13} \mathrm{C}$ NMR (101 MHz, $\left.\mathrm{CDCl}_{3}\right)$ spectrum of 8. 


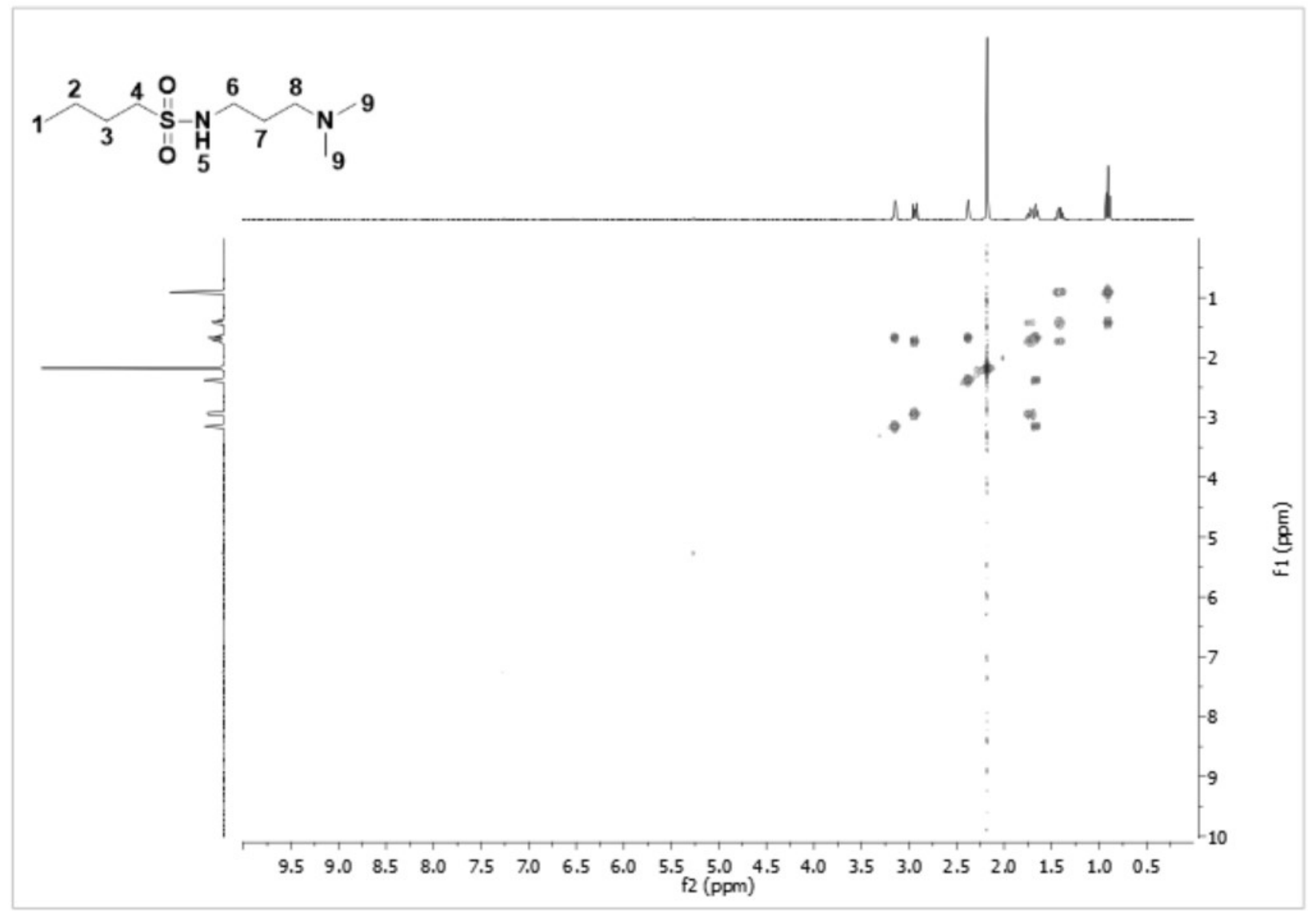

Figure (B) 44 - COSY 2D NMR $\left(\mathrm{CDCl}_{3}\right)$ spectrum of 8 . 


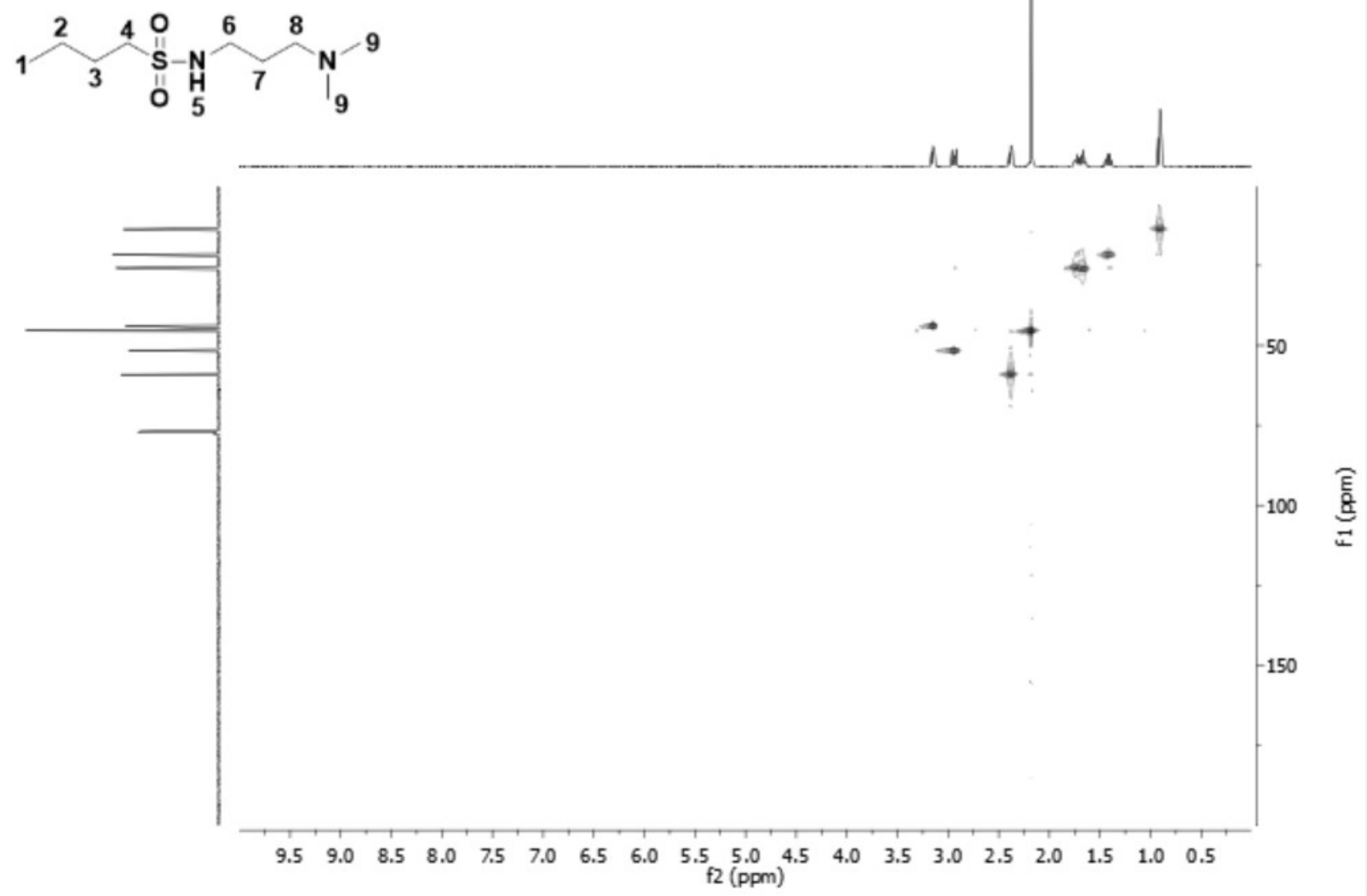

Figure (B) 45 - HSQC 2D NMR $\left(\mathrm{CDCl}_{3}\right)$ spectrum of 8. 


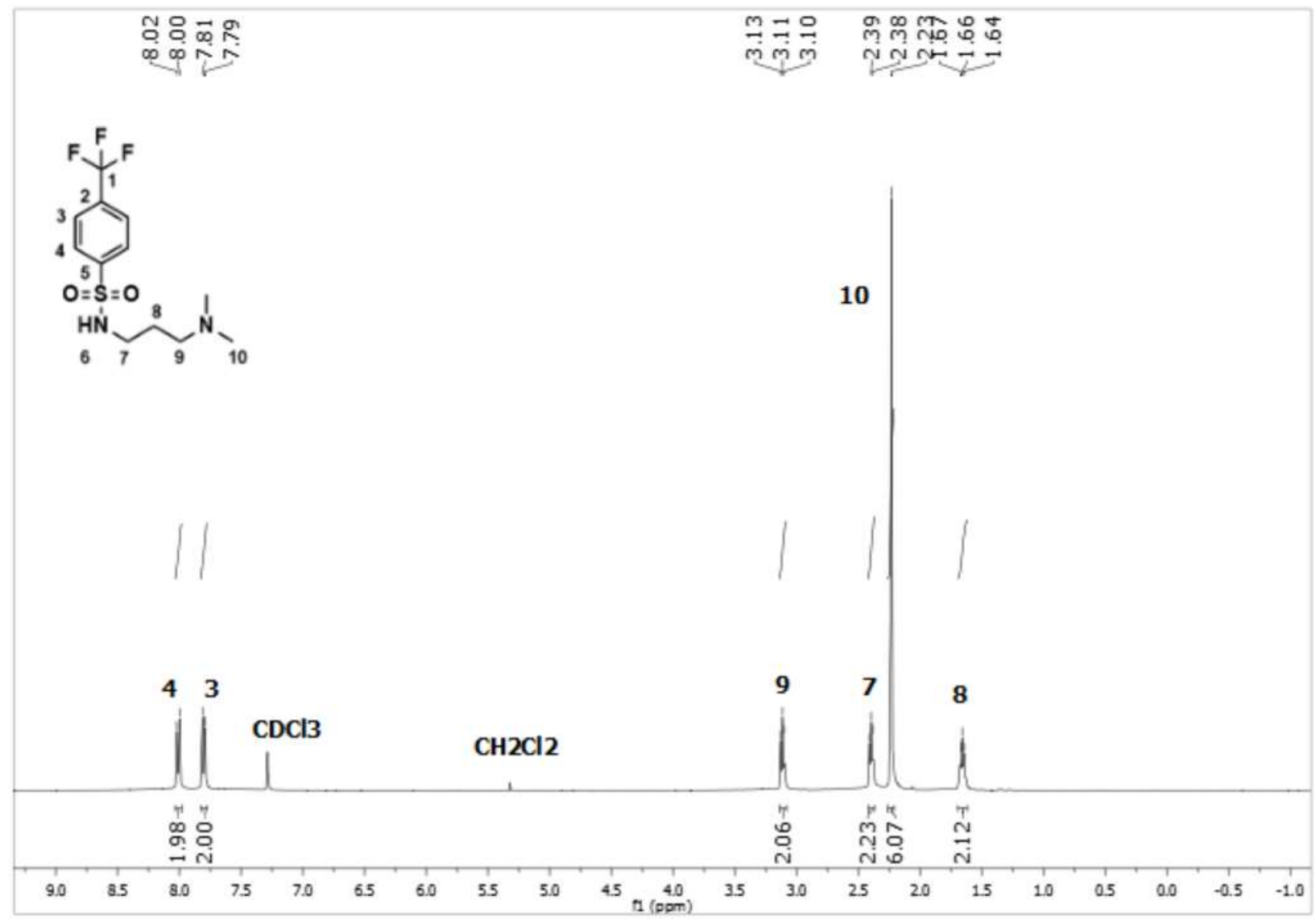

Figure (B) $46-{ }^{1} \mathrm{H}$ NMR (400 MHz, $\left.\mathrm{CDCl}_{3}\right)$ spectrum of 9. 


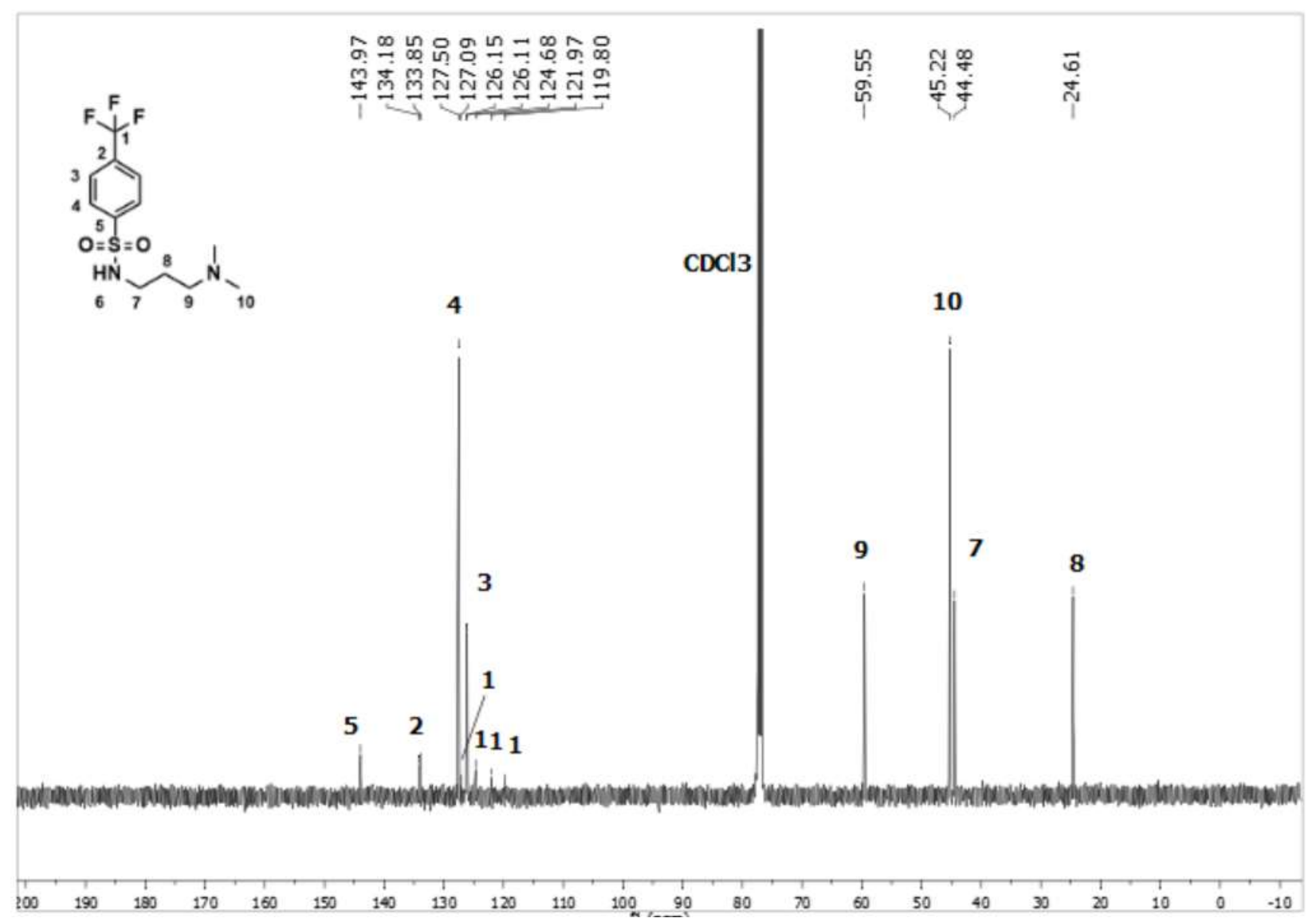

Figure (B) $47-{ }^{13} \mathrm{C}$ NMR $\left(101 \mathrm{MHz}, \mathrm{CDCl}_{3}\right)$ spectrum of 9. 


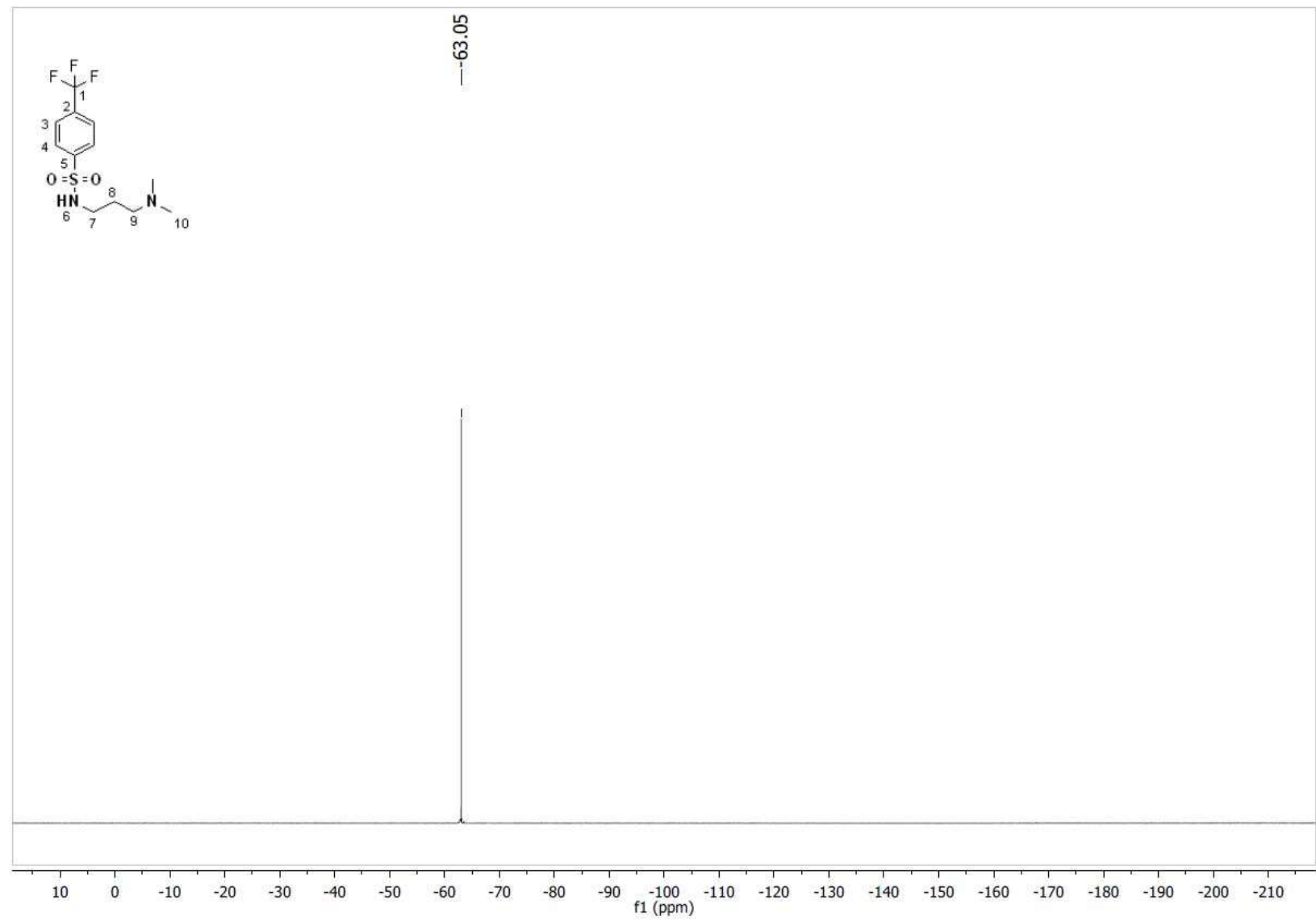

Figure (B) $48-{ }^{19} \mathrm{~F}$ NMR (376 MHz, $\left.\mathrm{CDCl}_{3}\right)$ spectrum of 9. 


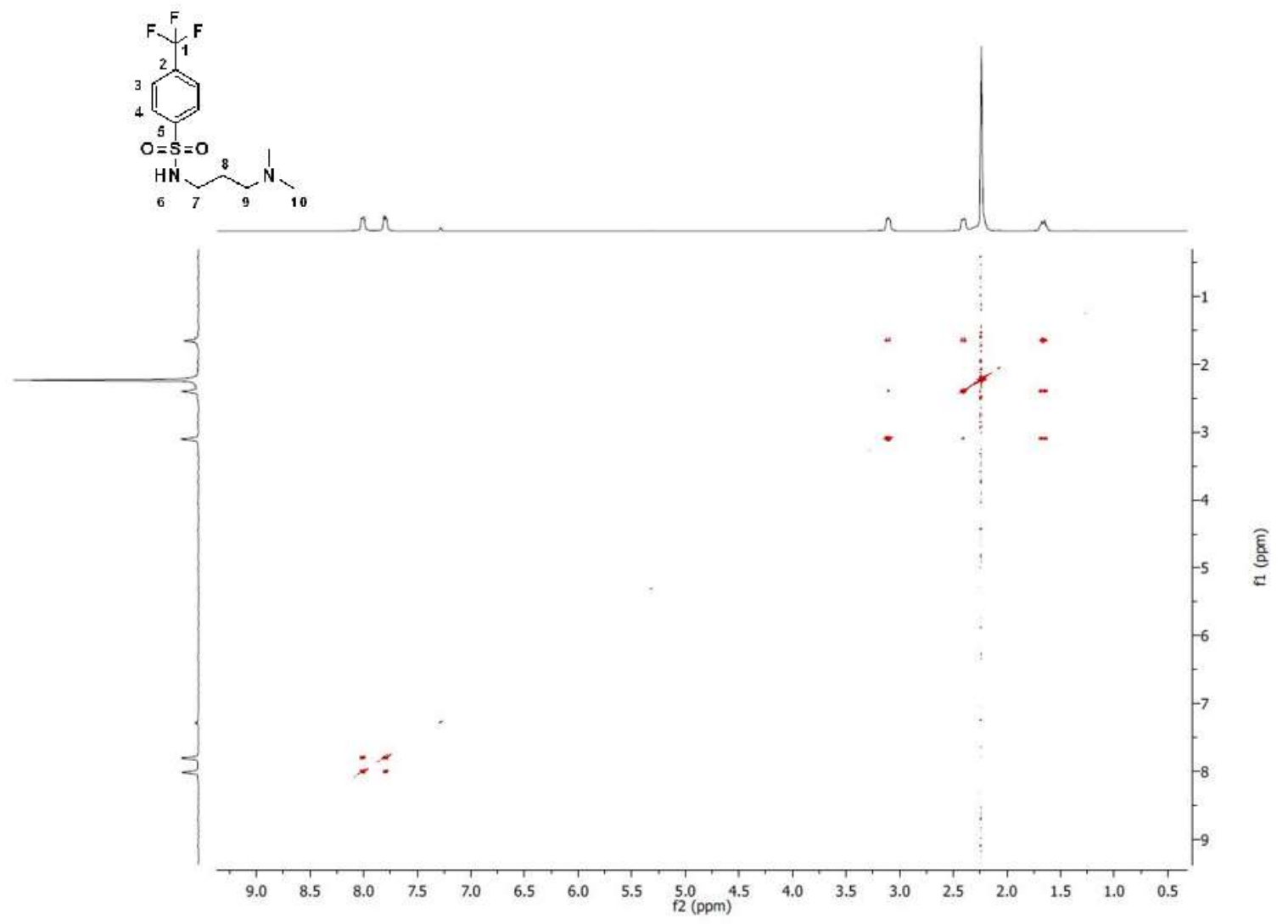

Figure (B) 49 - COSY 2D NMR $\left(\mathrm{CDCl}_{3}\right)$ spectrum of 9. 


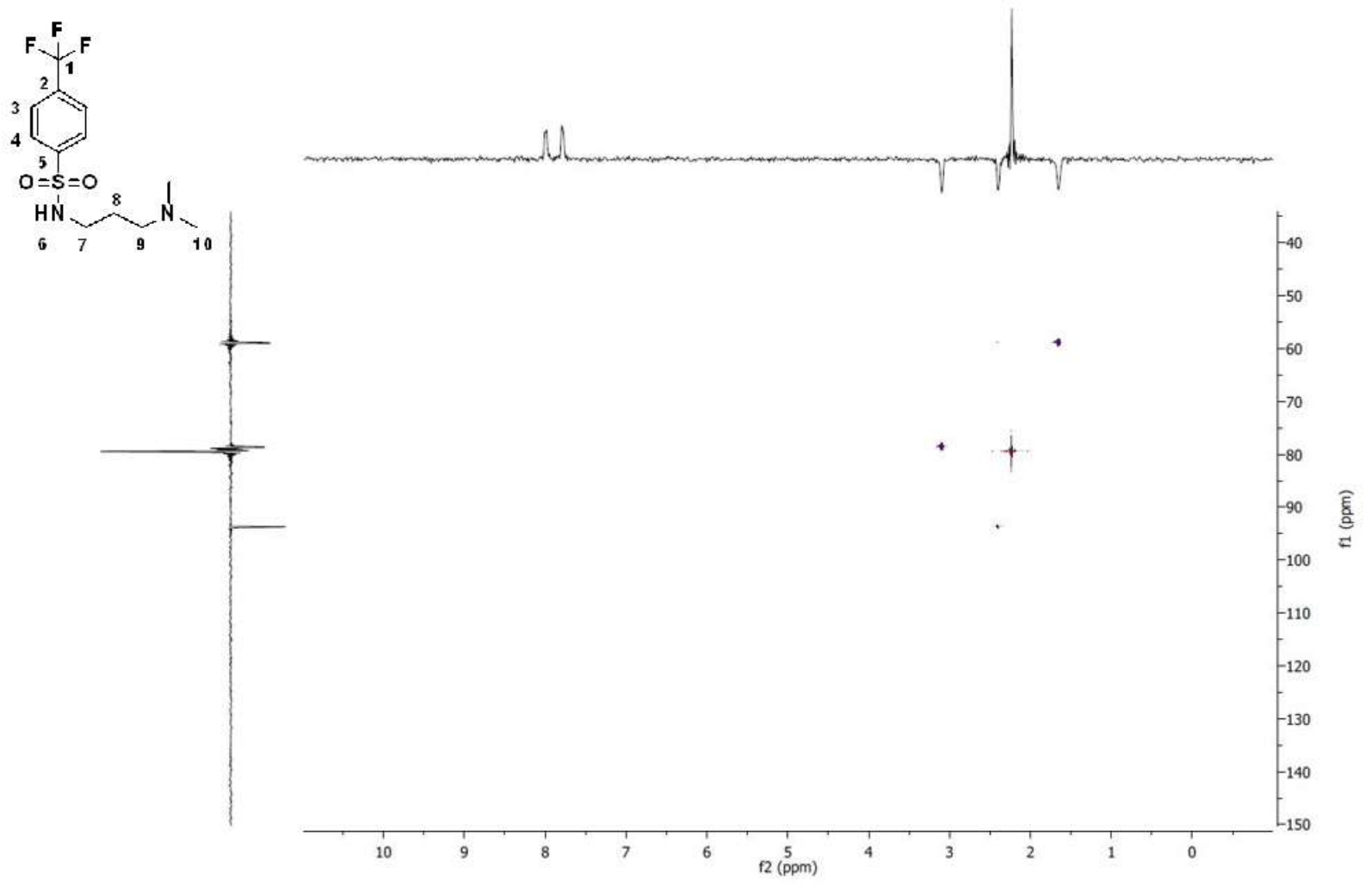

Figure (B) 50 - HSQC 2D NMR $\left(\mathrm{CDCl}_{3}\right)$ spectrum of 9. 


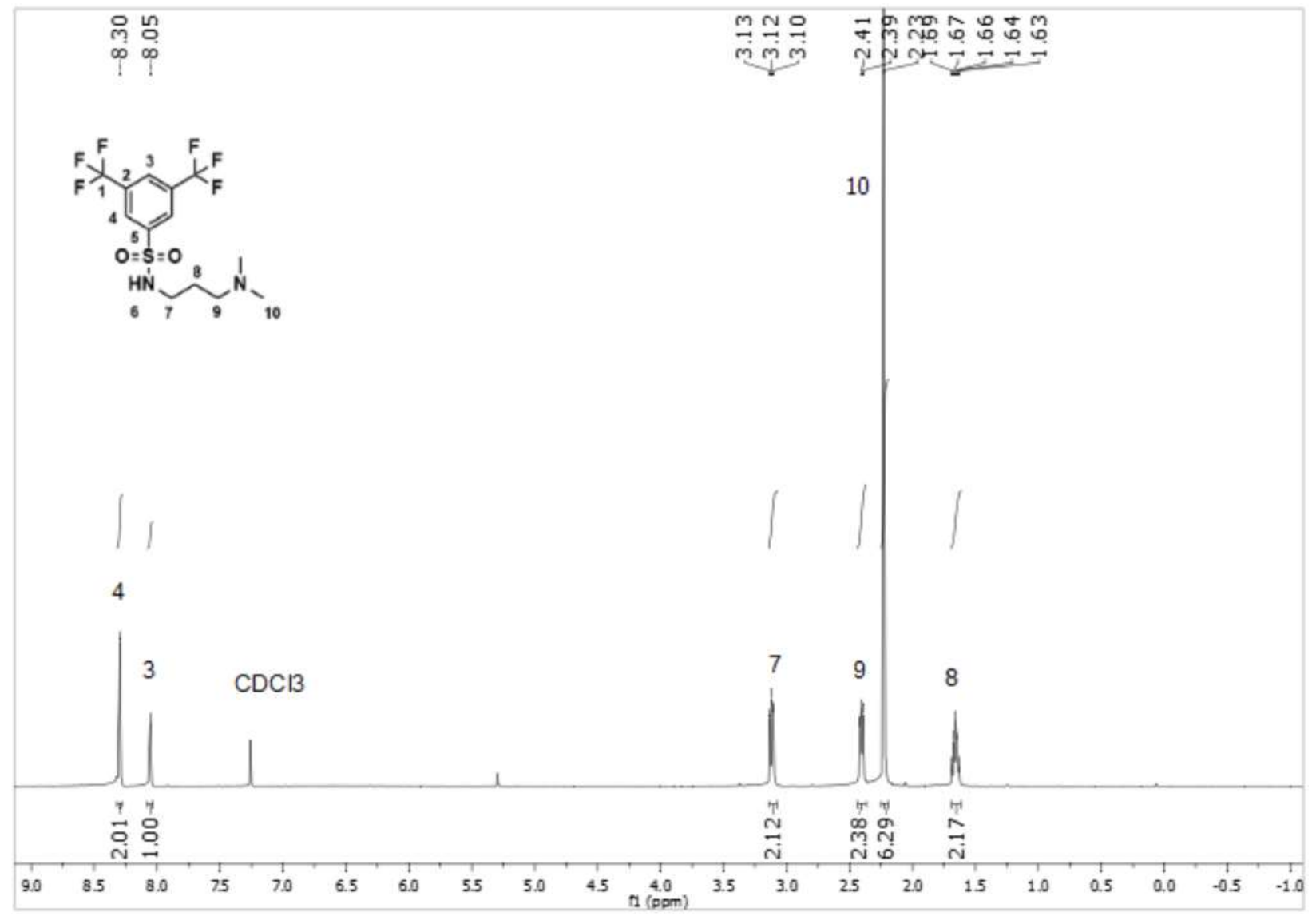

Figure (B) $51-{ }^{1} \mathrm{H}$ NMR $\left(400 \mathrm{MHz}, \mathrm{CDCl}_{3}\right)$ spectrum of $\mathbf{1 0}$. 


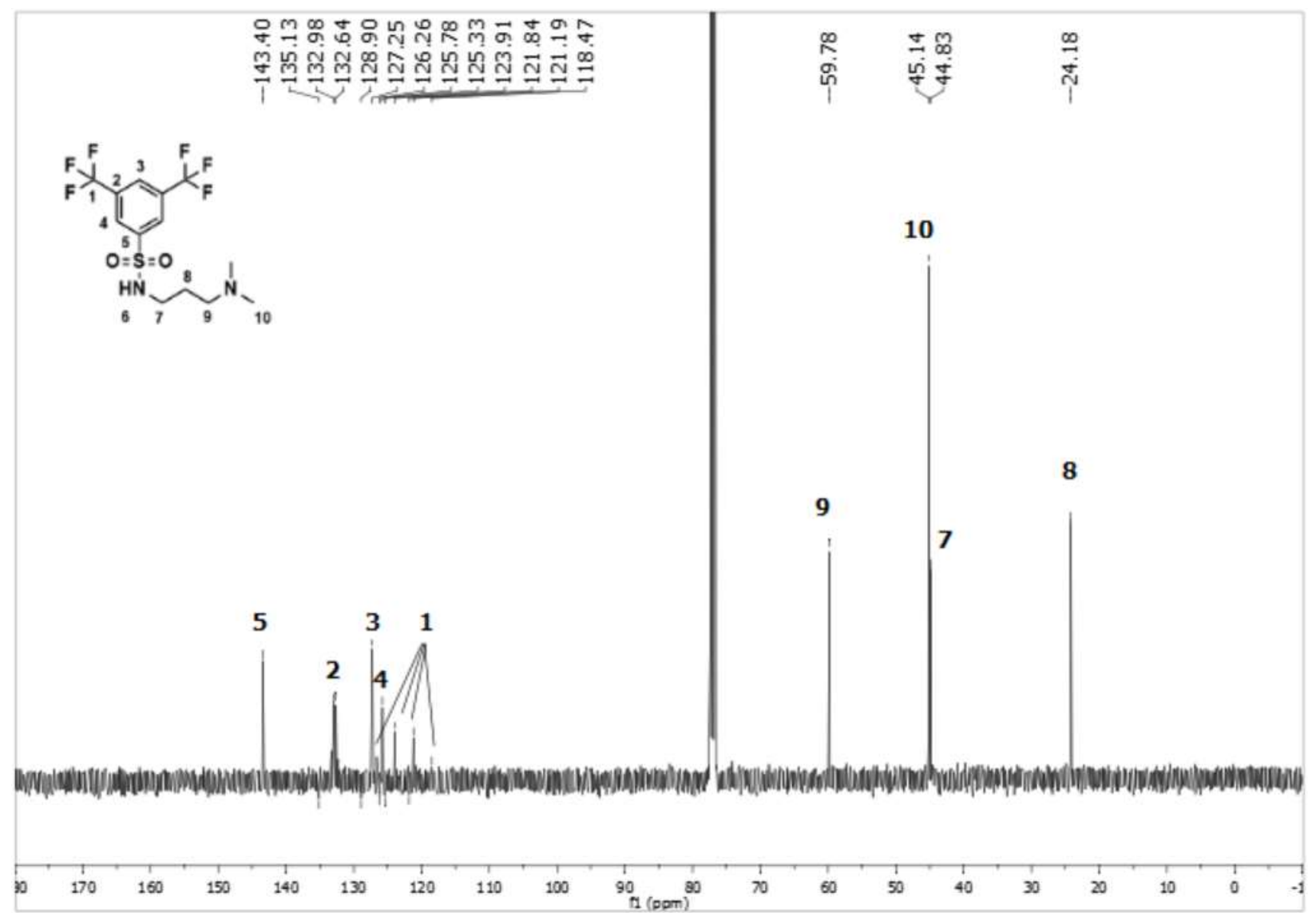

Figure (B) $52-{ }^{13} \mathrm{C}$ NMR $\left(101 \mathrm{MHz}, \mathrm{CDCl}_{3}\right)$ spectrum of 10. 

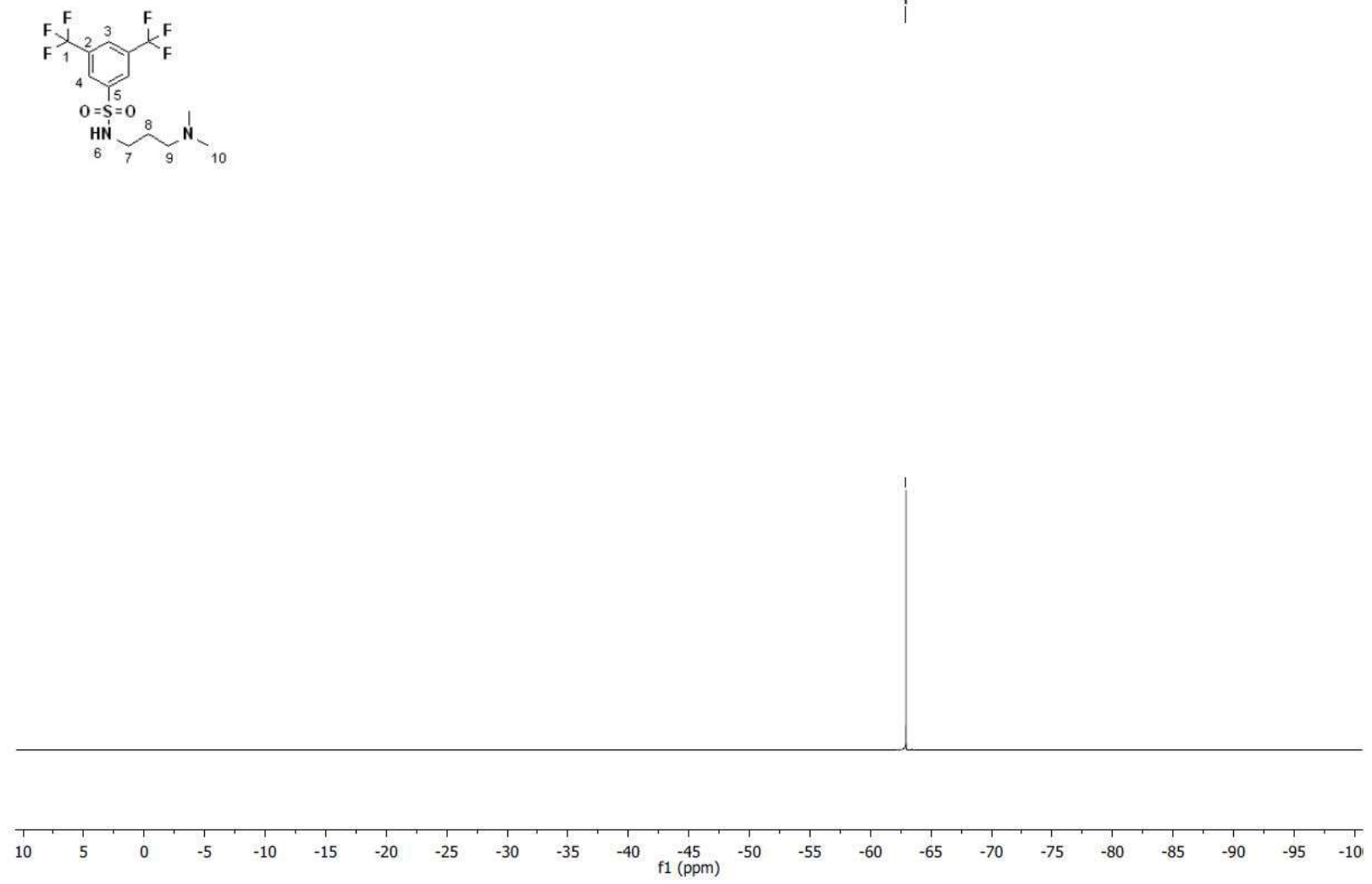

Figure (B) $53-{ }^{19} \mathrm{~F}$ NMR $\left(376 \mathrm{MHz}, \mathrm{CDCl}_{3}\right)$ spectrum of $\mathbf{1 0}$. 


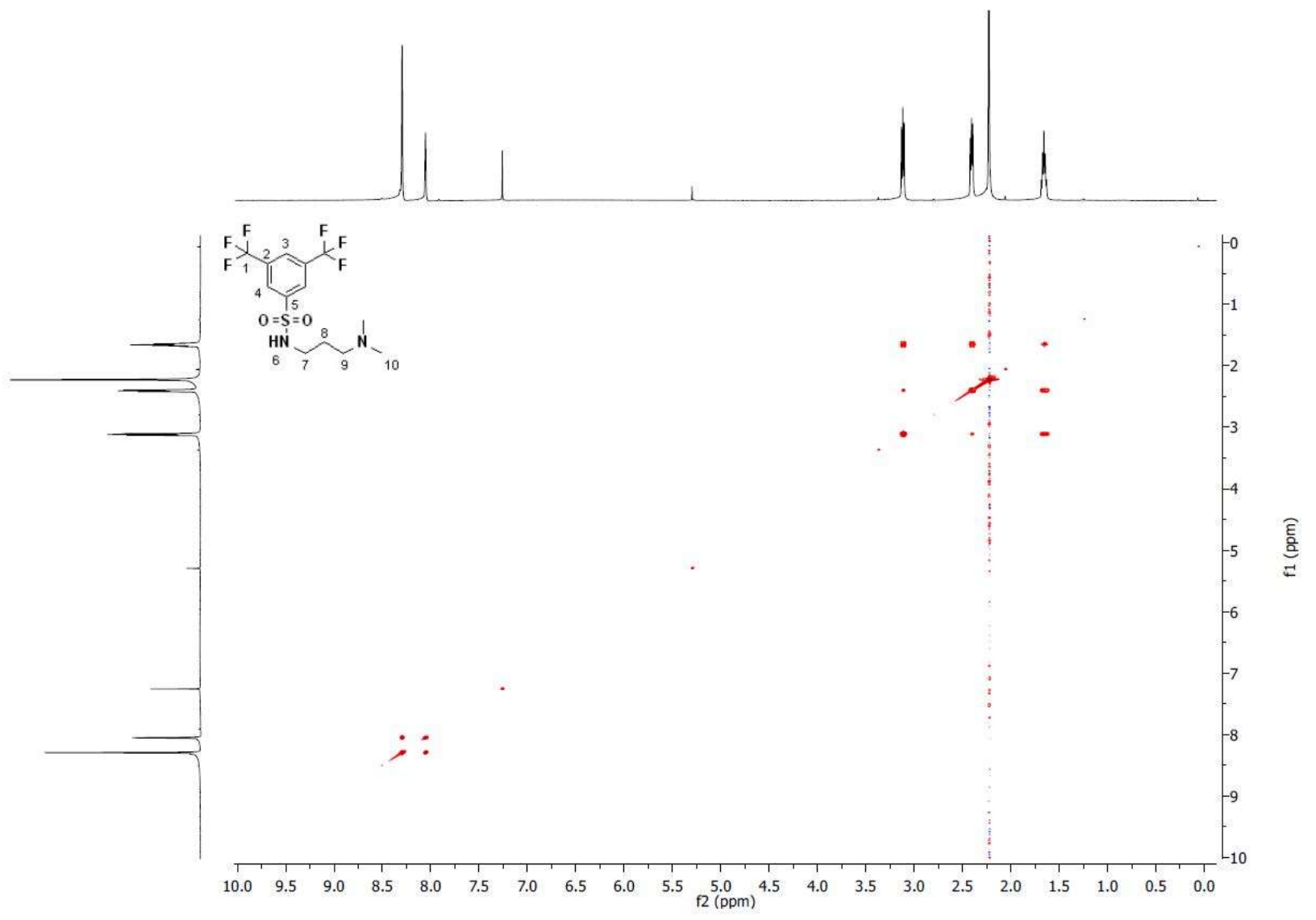

Figure (B) 54 - COSY 2D NMR $\left(\mathrm{CDCl}_{3}\right)$ spectrum of $\mathbf{1 0}$. 


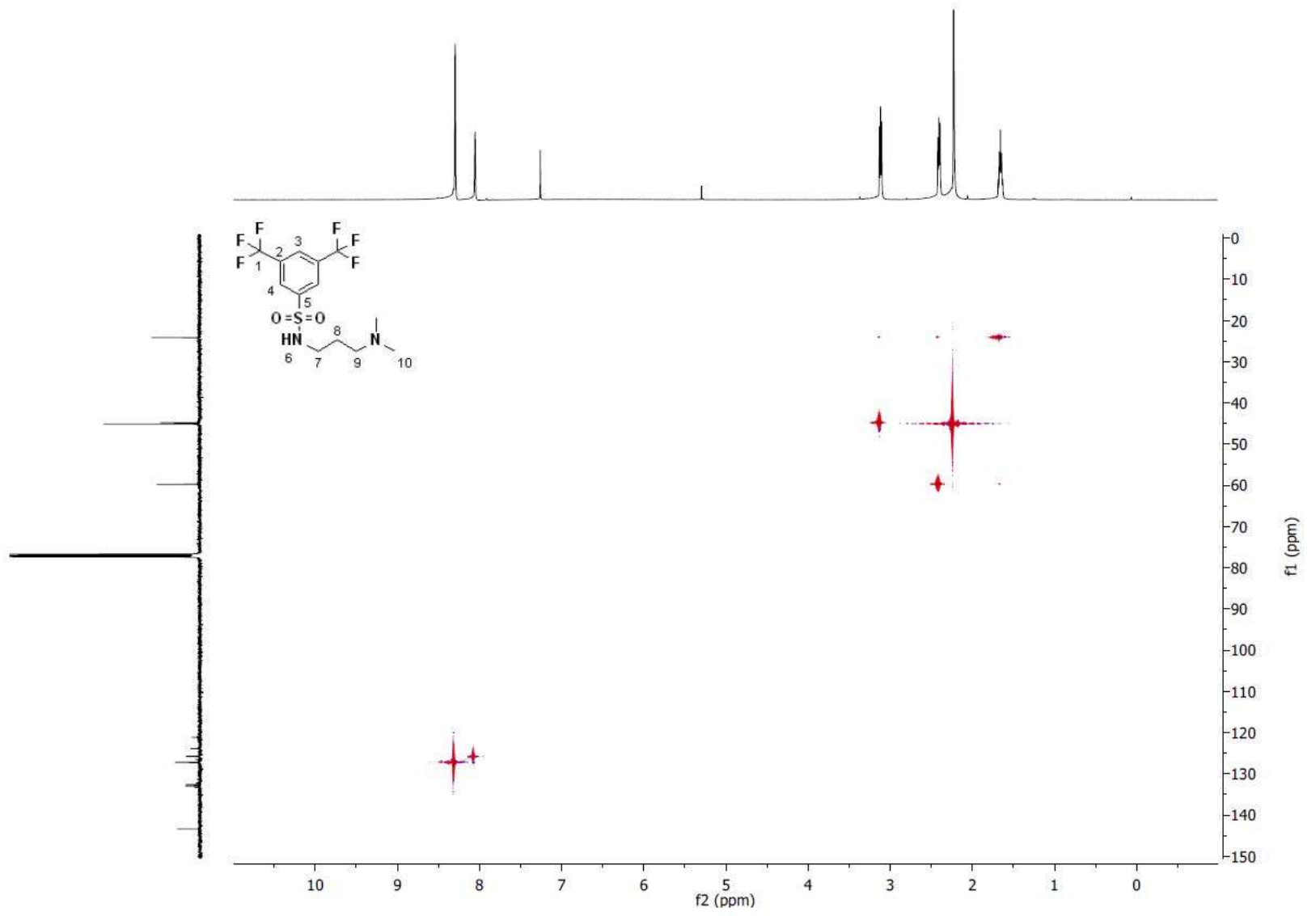

Figure (B) 55 - HSQC 2D NMR $\left(\mathrm{CDCl}_{3}\right)$ spectrum of $\mathbf{1 0}$. 


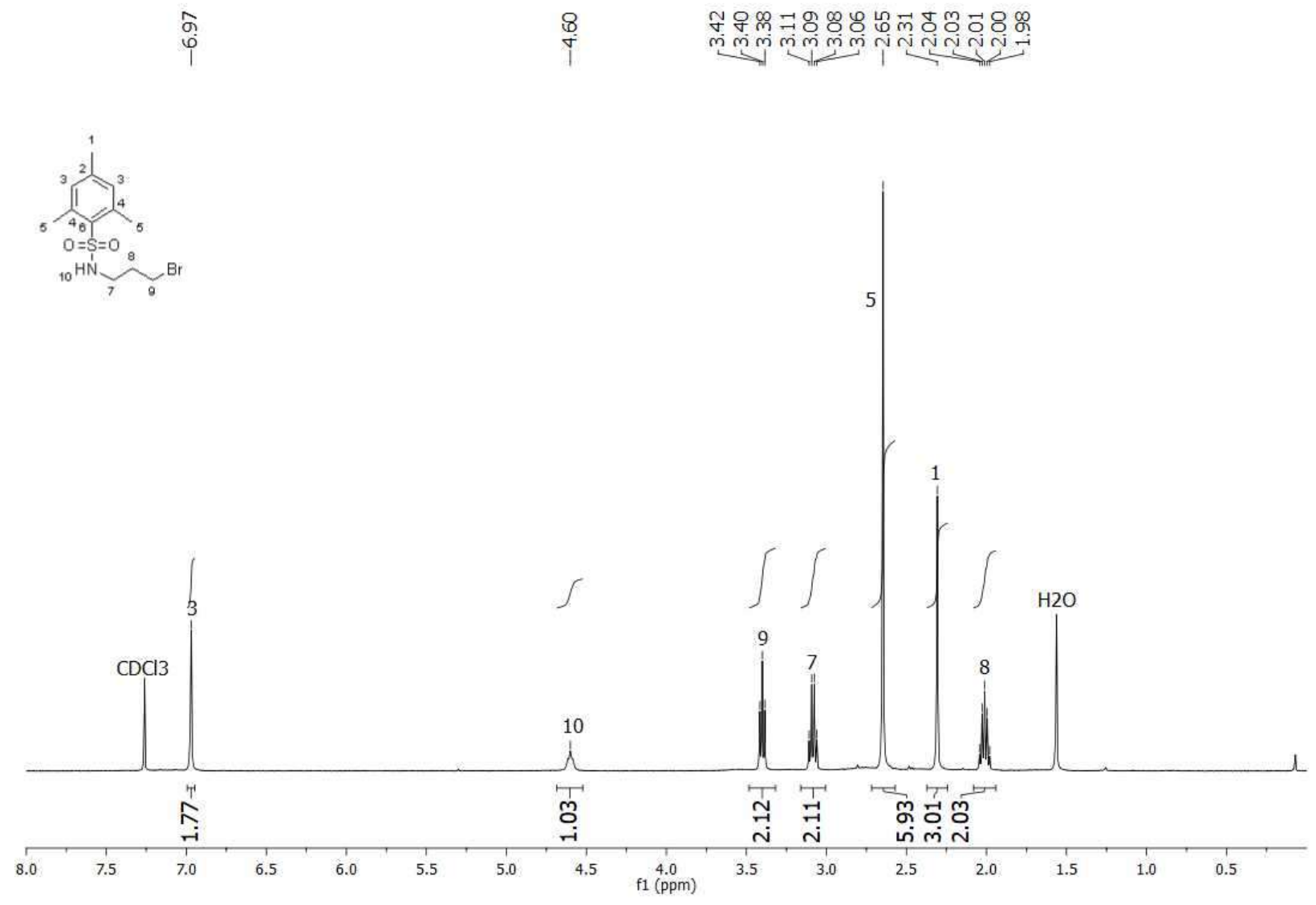

Figure (B) $56-{ }^{1} \mathrm{H} \mathrm{NMR}\left(400 \mathrm{MHz}, \mathrm{CDCl}_{3}\right)$ spectrum of 11. 
gi 8 gô

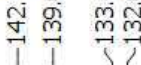

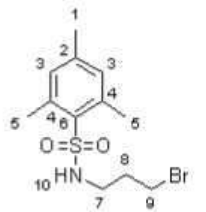

$\infty \quad$ 이

ำ ํํำ

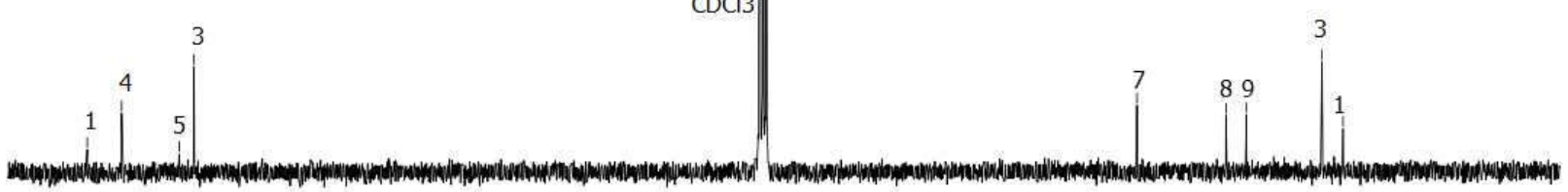

$\begin{array}{llllllllllllllllllllllllllllllll}150 & 145 & 140 & 135 & 130 & 125 & 120 & 115 & 110 & 105 & 100 & 95 & 90 & 85 & 80 & 75 & 70 & 65 & 60 & 55 & 50 & 45 & 40 & 35 & 30 & 25 & 20 & 15 & 10 & 5 & 0\end{array}$

Figure (B) $57-{ }^{13} \mathrm{C} \mathrm{NMR}\left(101 \mathrm{MHz}, \mathrm{CDCl}_{3}\right)$ spectrum of $\mathbf{1 1}$ 


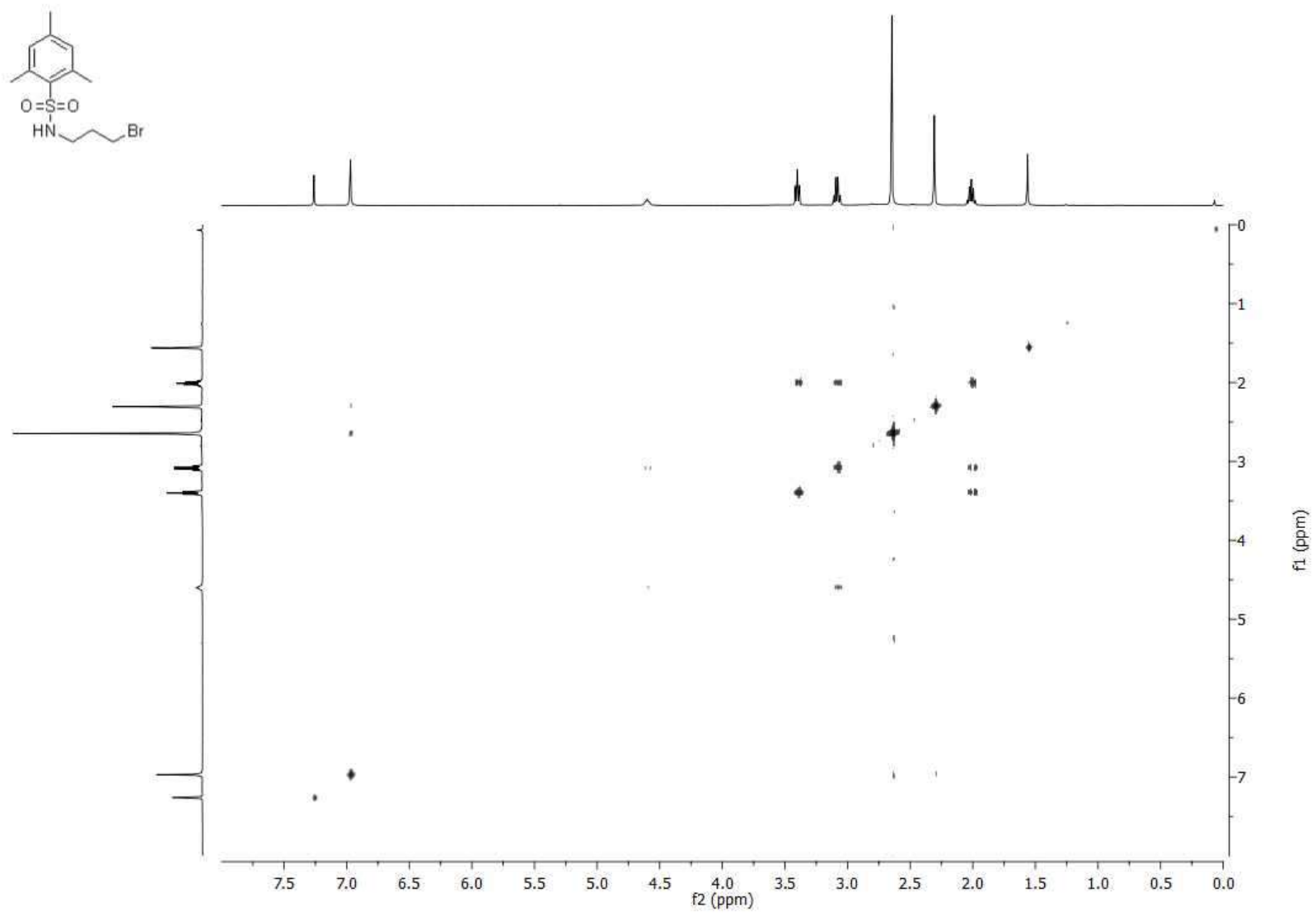

Figure (B) 58 - COSY 2D NMR $\left(\mathrm{CDCl}_{3}\right)$ spectrum of 11. 


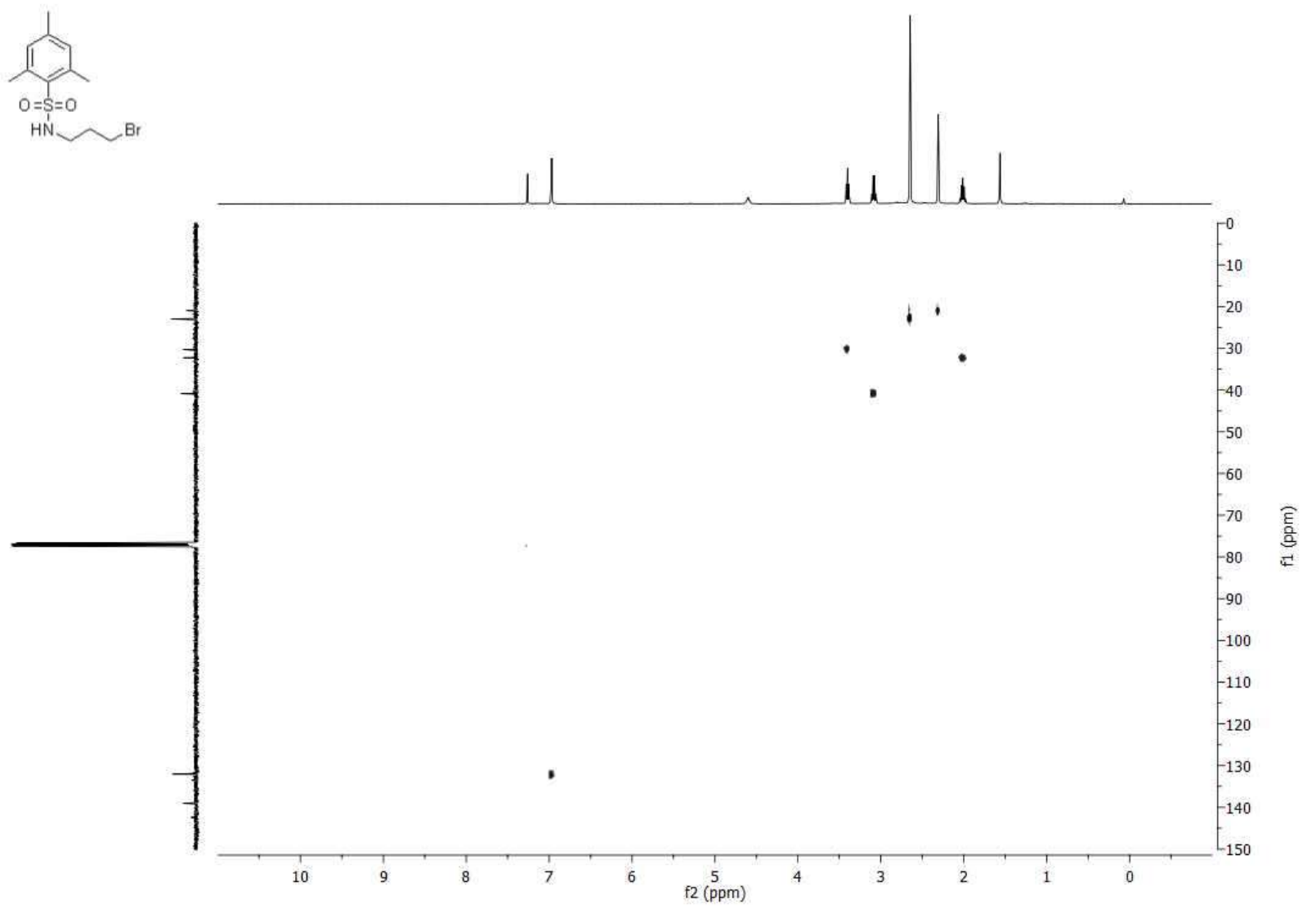

Figure (B) 59 - HSQC 2D NMR $\left(\mathrm{CDCl}_{3}\right)$ spectrum of 11. 


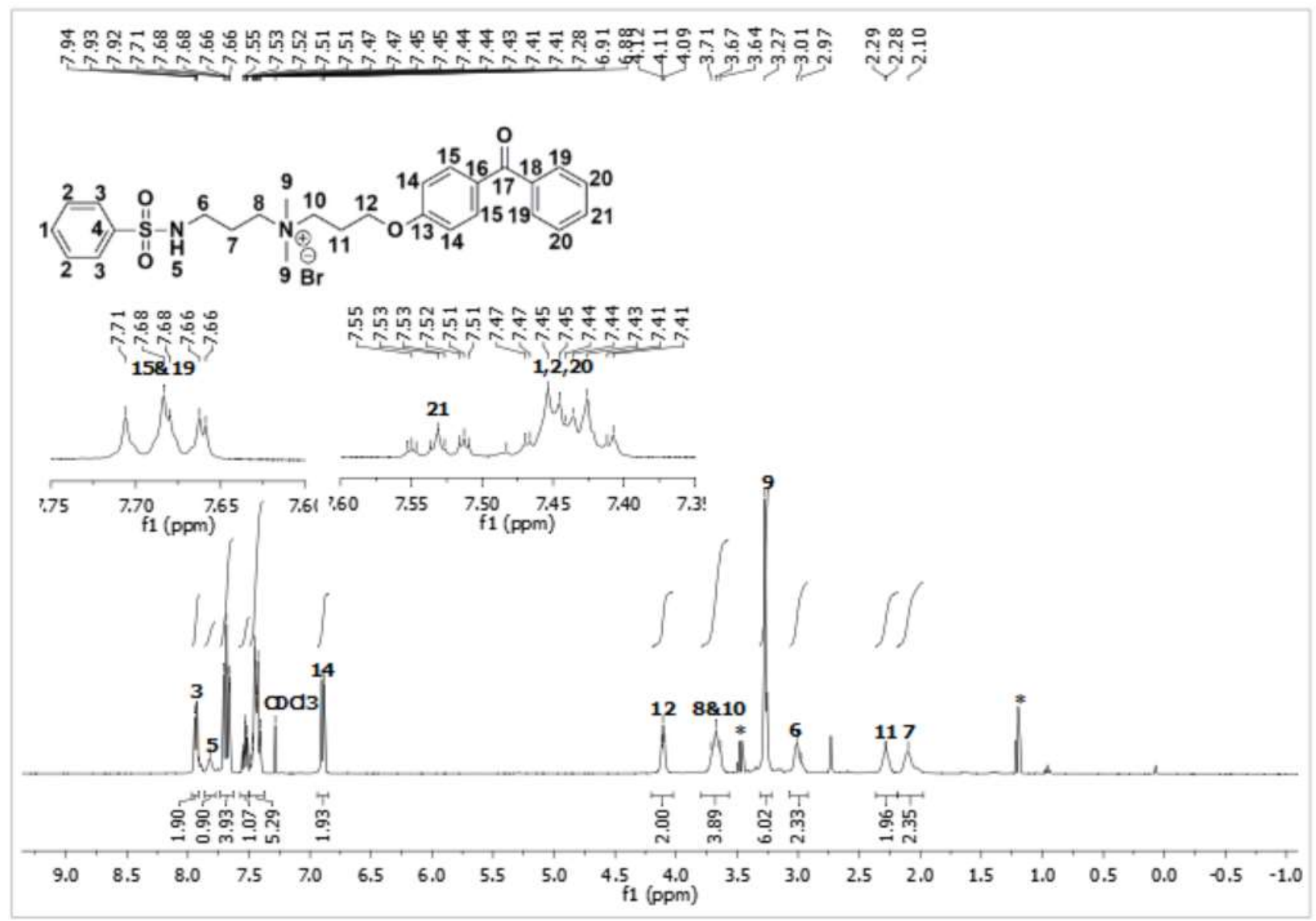

Figure (B) $60-{ }^{1} \mathrm{H}$ NMR $\left(400 \mathrm{MHz}, \mathrm{CDCl}_{3}\right)$ spectrum of $\mathbf{3 a}$. 


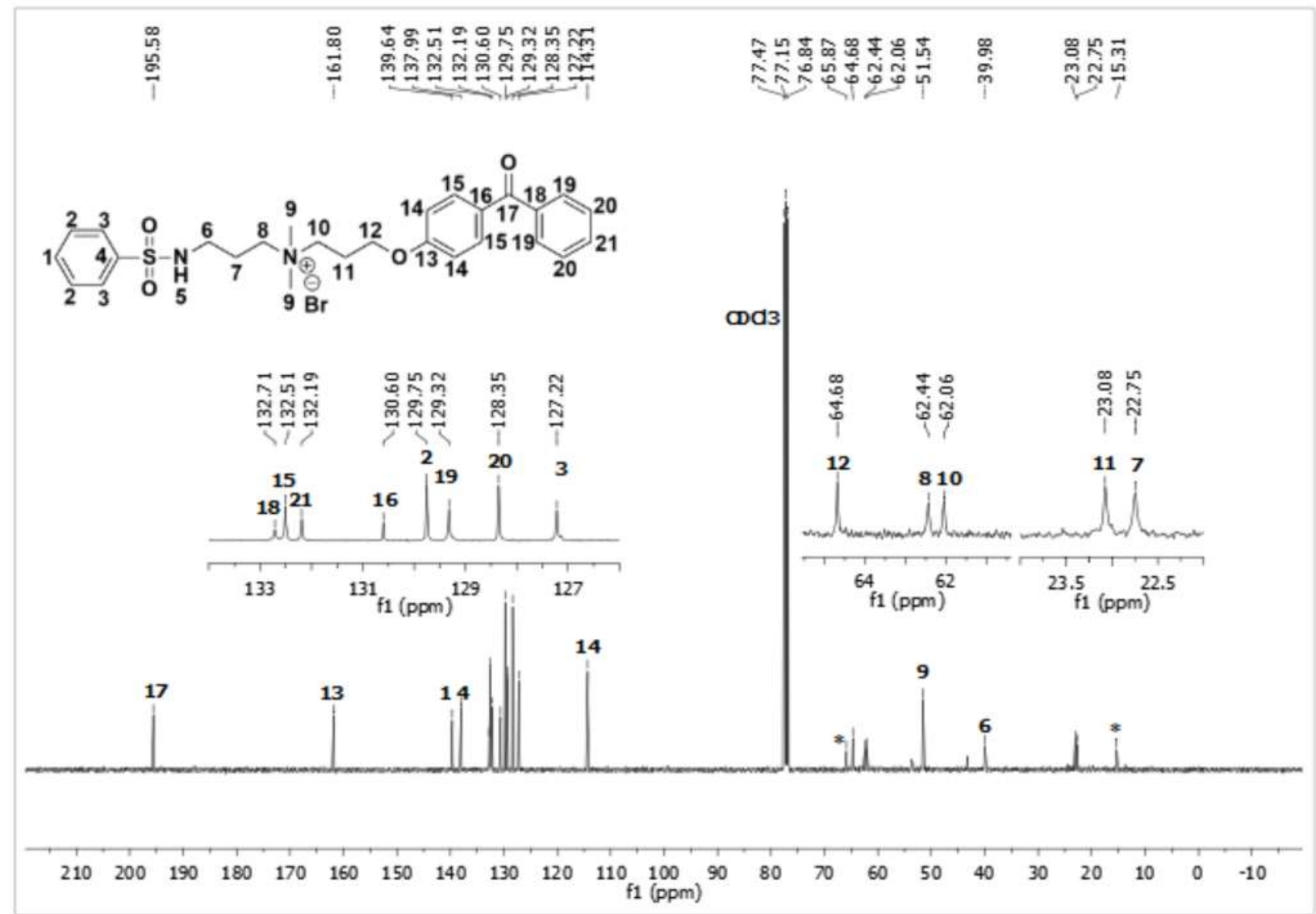

Figure (B) $61-{ }^{13} \mathrm{C} \mathrm{NMR}\left(101 \mathrm{MHz}, \mathrm{CDCl}_{3}\right)$ spectrum of 3a. 


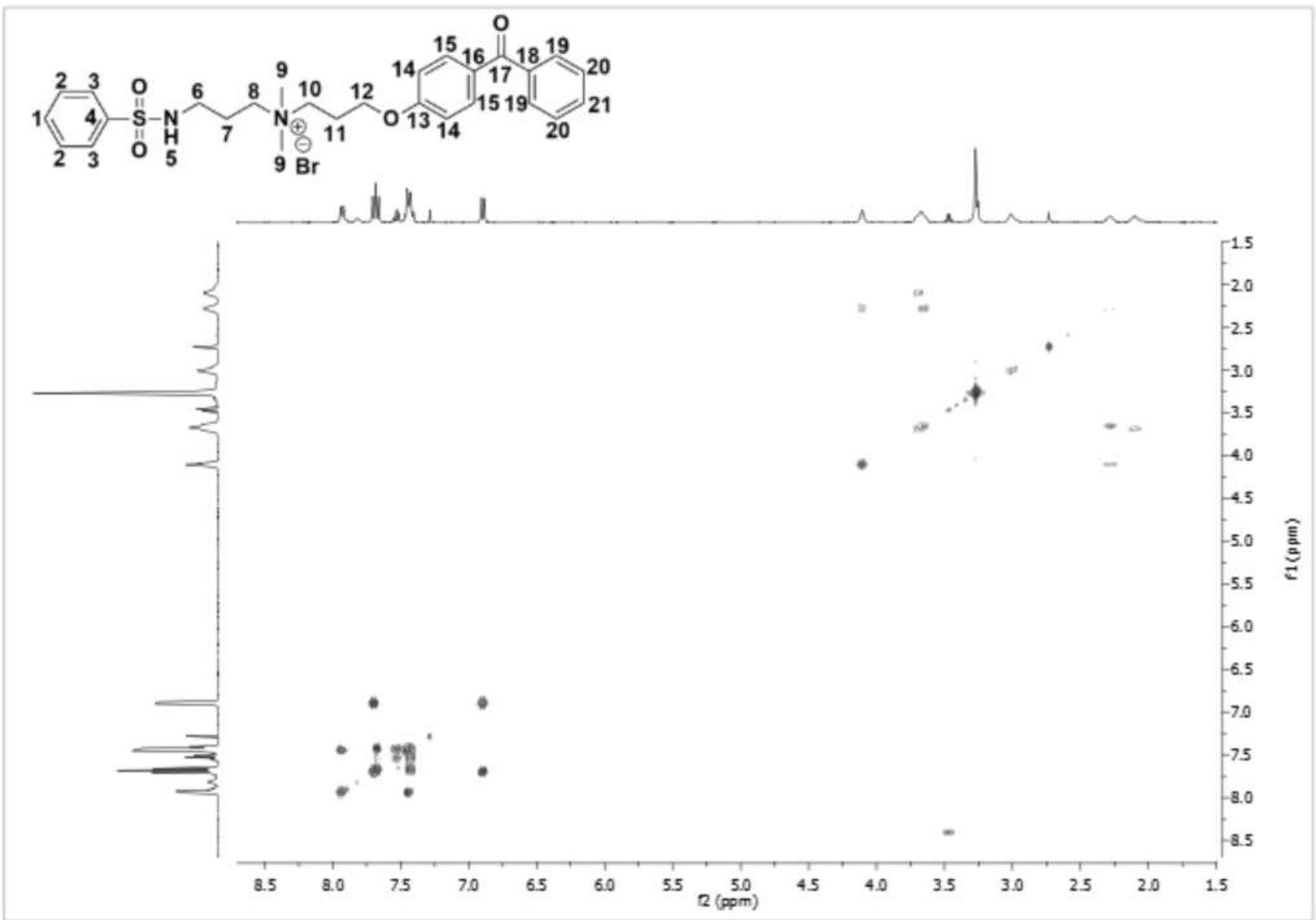

Figure (B) 62 - COSY 2D NMR $\left(\mathrm{CDCl}_{3}\right)$ spectrum of $\mathbf{3 a}$. 


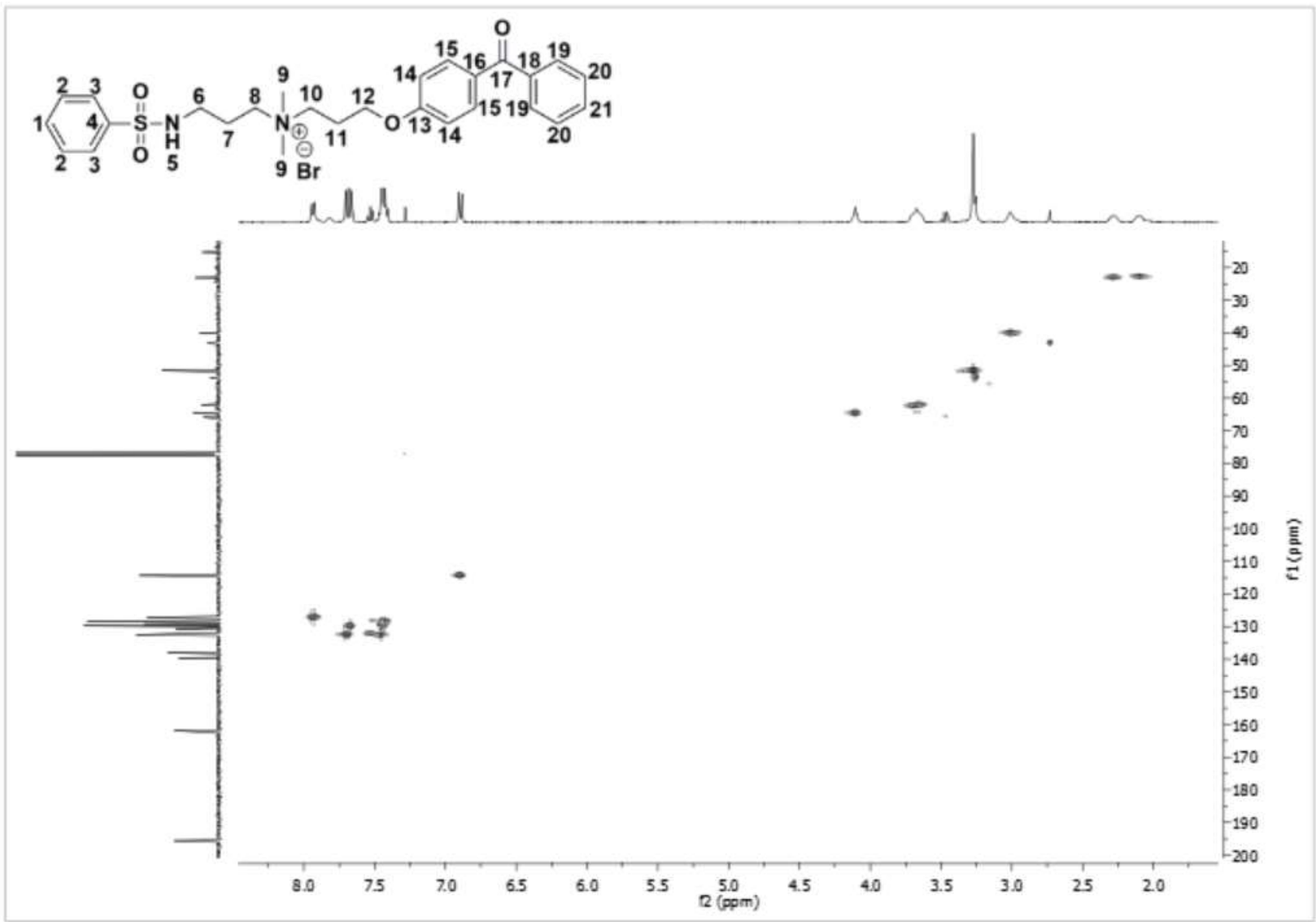

Figure (B) 63 - HSQC 2D NMR $\left(\mathrm{CDCl}_{3}\right)$ spectrum of $\mathbf{3 a}$. 


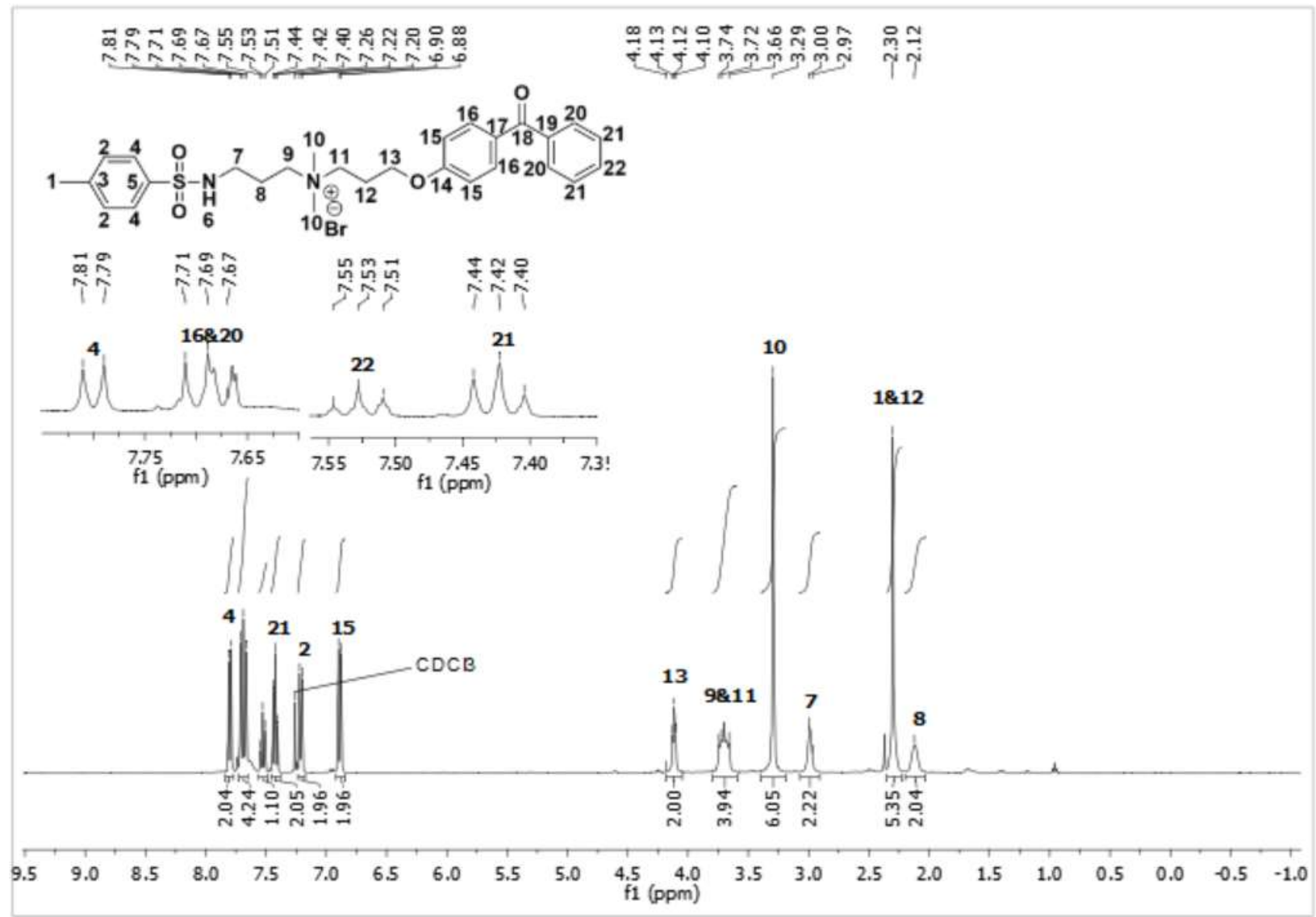

Figure (B) $64-{ }^{1} \mathrm{H} \mathrm{NMR}\left(400 \mathrm{MHz}, \mathrm{CDCl}_{3}\right)$ spectrum of $4 \mathbf{a}$. 


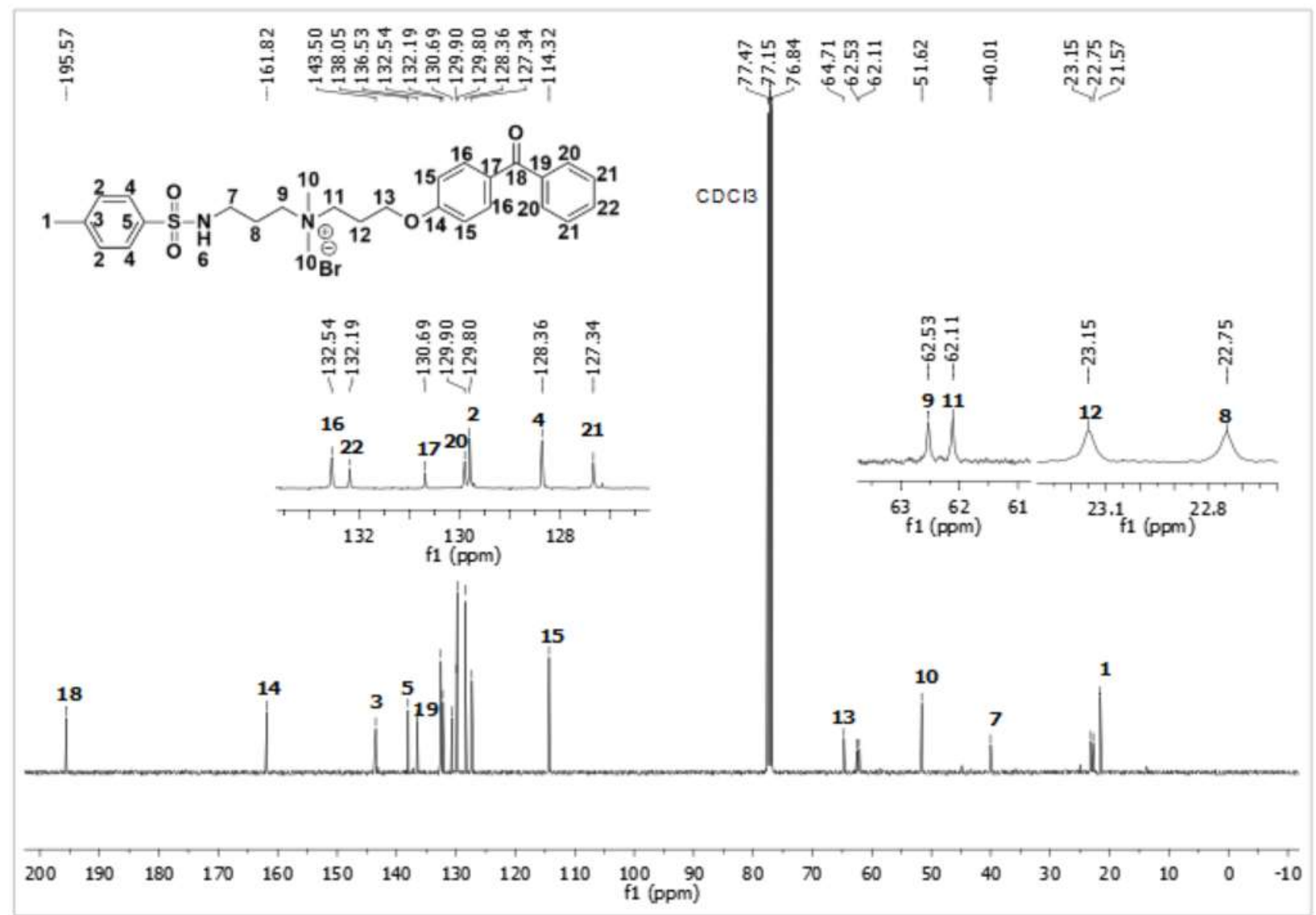

Figure (B) $65-{ }^{13} \mathrm{C}$ NMR $\left(101 \mathrm{MHz}, \mathrm{CDCl}_{3}\right)$ spectrum of $4 \mathbf{a}$. 


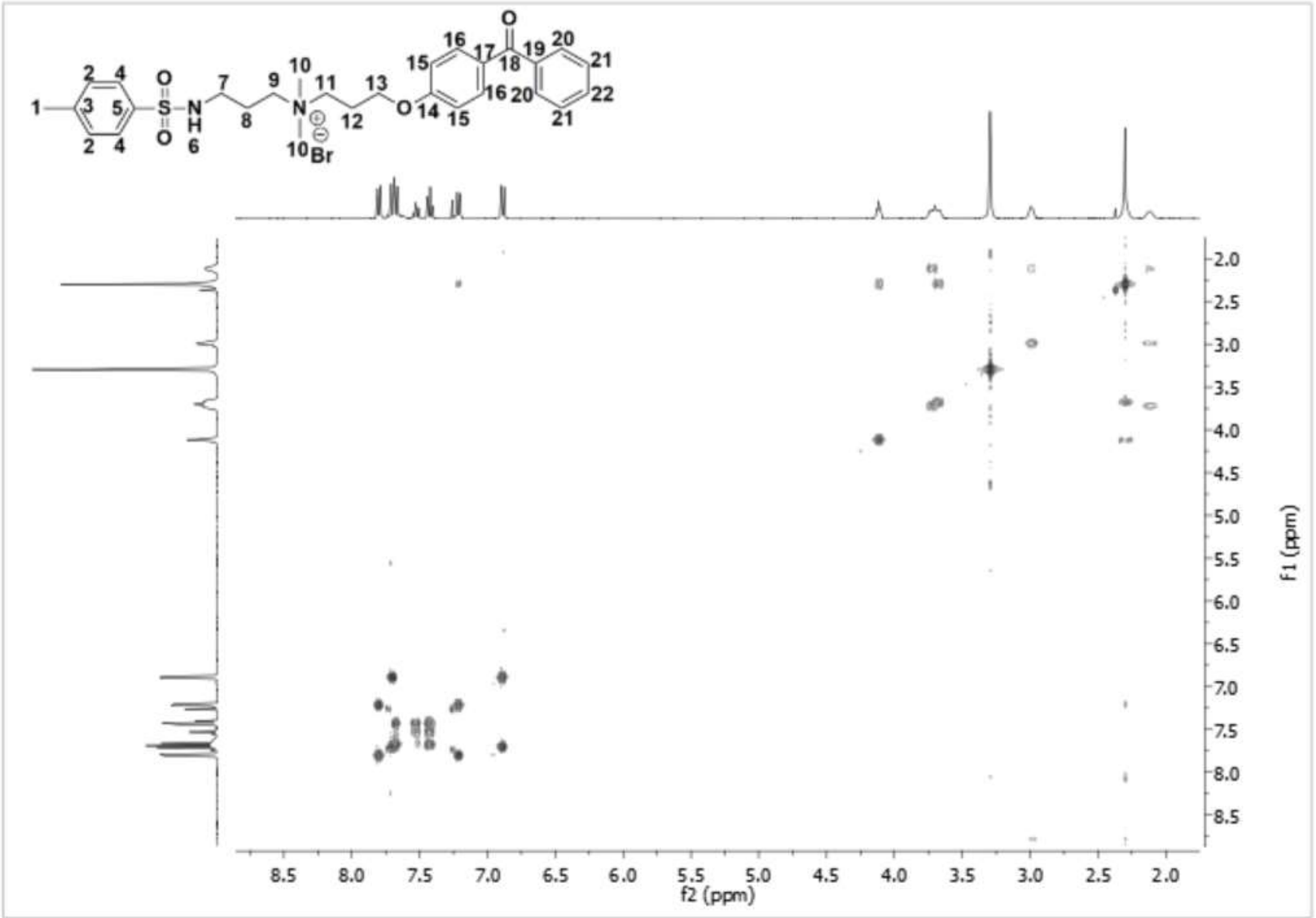

Figure (B) 66 - COSY 2D NMR $\left(\mathrm{CDCl}_{3}\right)$ spectrum of $\mathbf{4 a}$. 


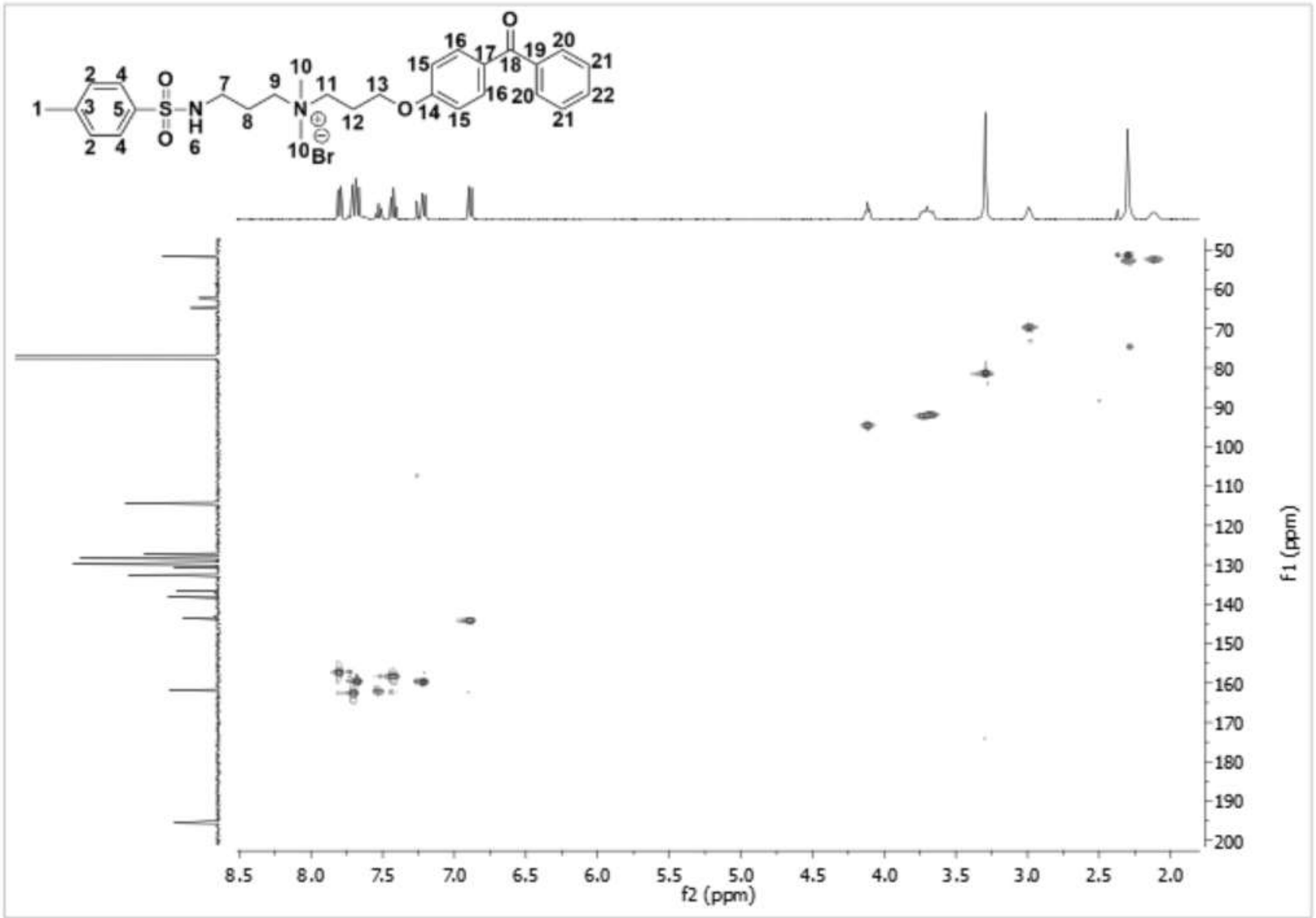

Figure (B) 67 - HSQC 2D NMR $\left(\mathrm{CDCl}_{3}\right)$ spectrum of $\mathbf{4 a}$. 


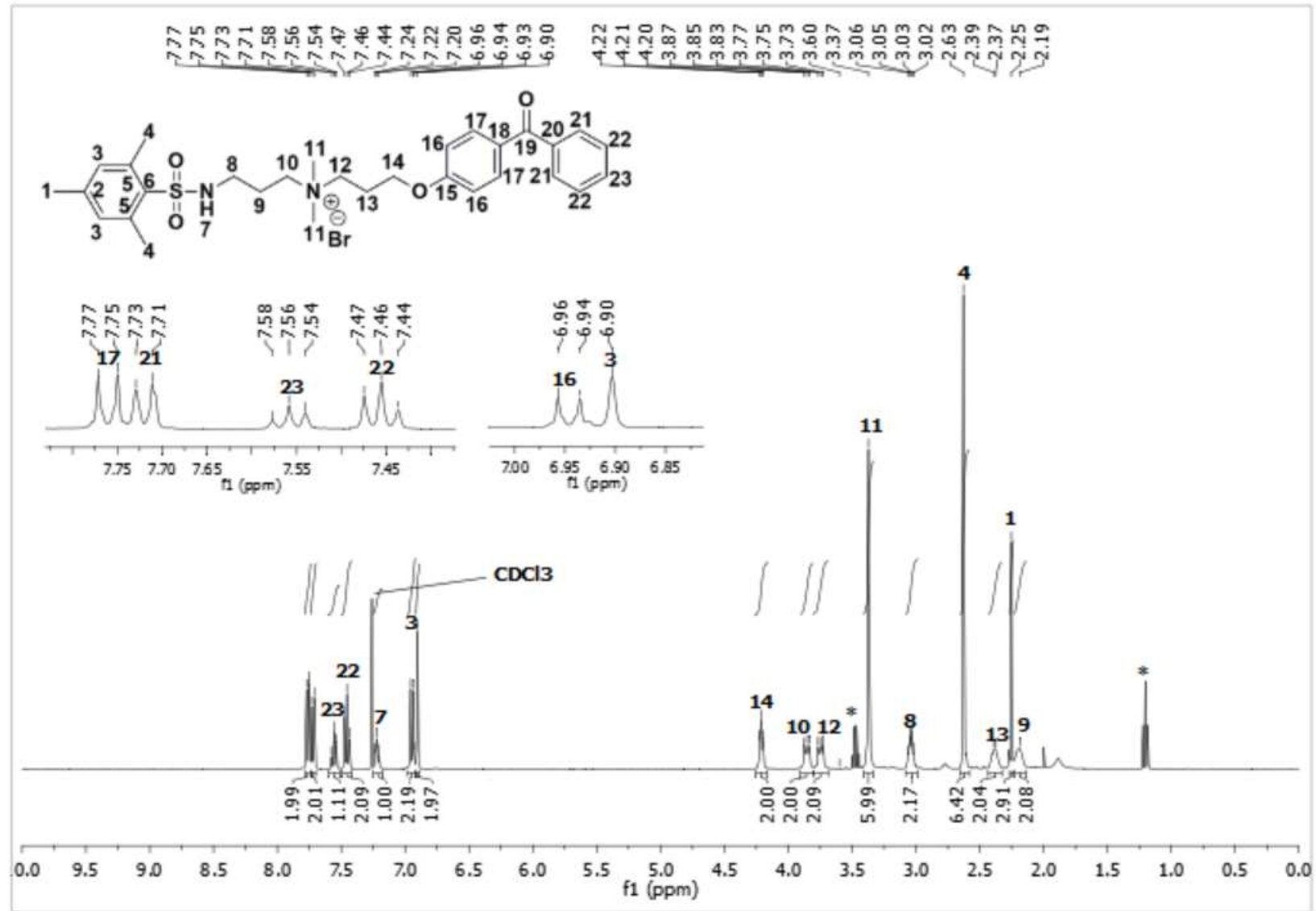

Figure (B) $68-{ }^{1} \mathrm{H} \mathrm{NMR}\left(400 \mathrm{MHz}, \mathrm{CDCl}_{3}\right)$ spectrum of $5 \mathbf{a}$. 


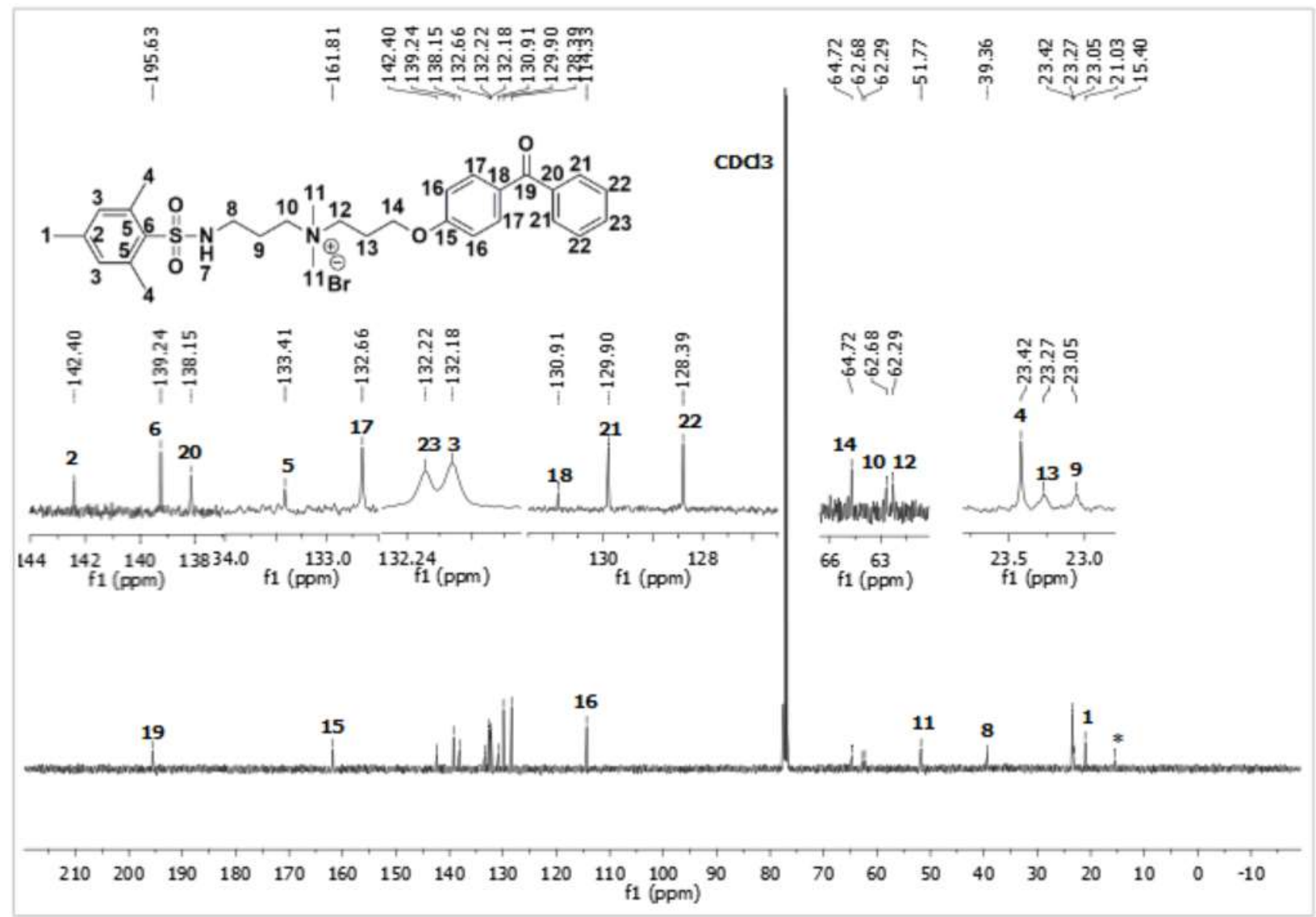

Figure (B) $69-{ }^{13} \mathrm{C}$ NMR $\left(101 \mathrm{MHz}, \mathrm{CDCl}_{3}\right)$ spectrum of $\mathbf{5 a}$. 


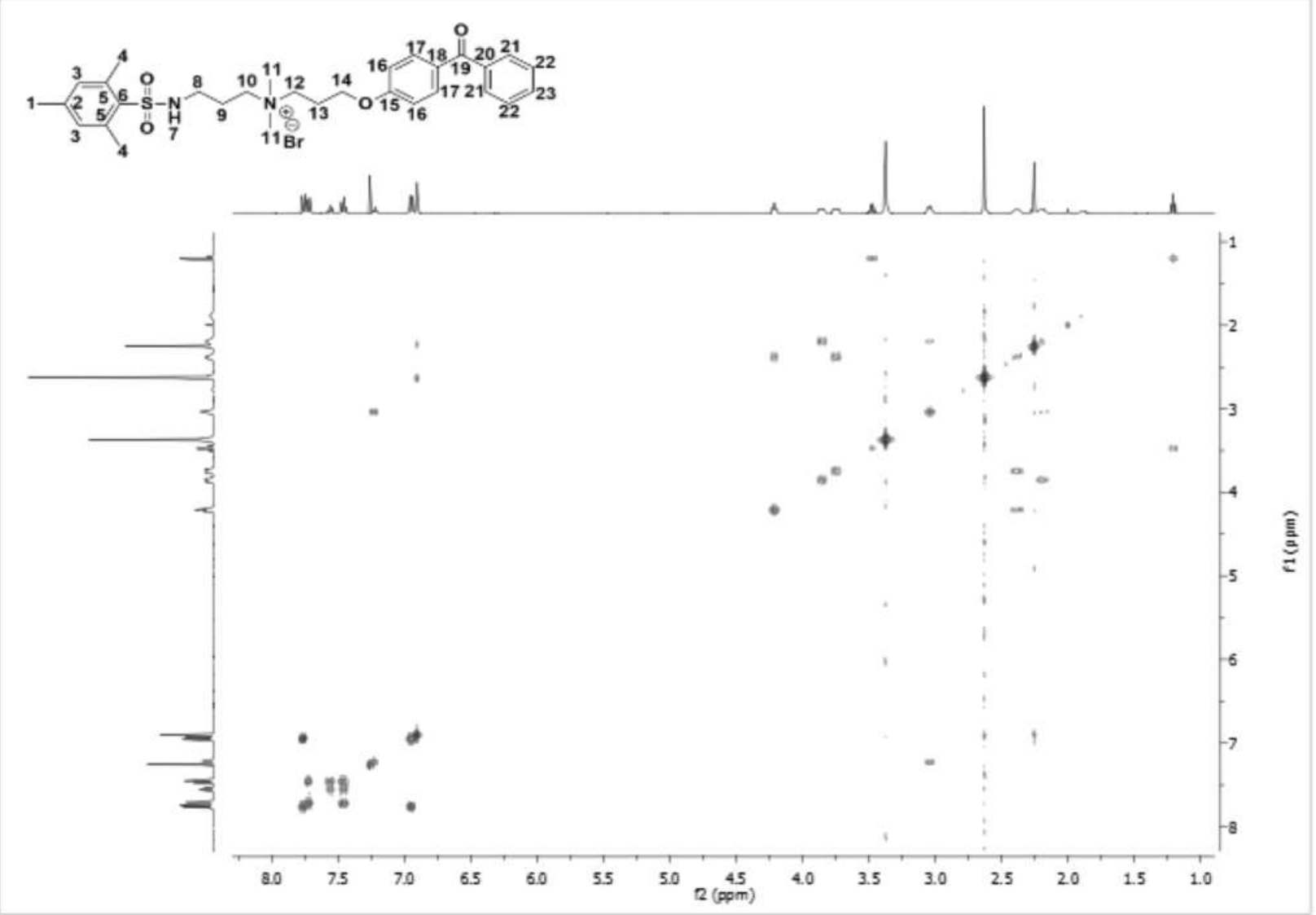

Figure (B) 70 - COSY 2D NMR $\left(\mathrm{CDCl}_{3}\right)$ spectrum of $\mathbf{5 a}$. 


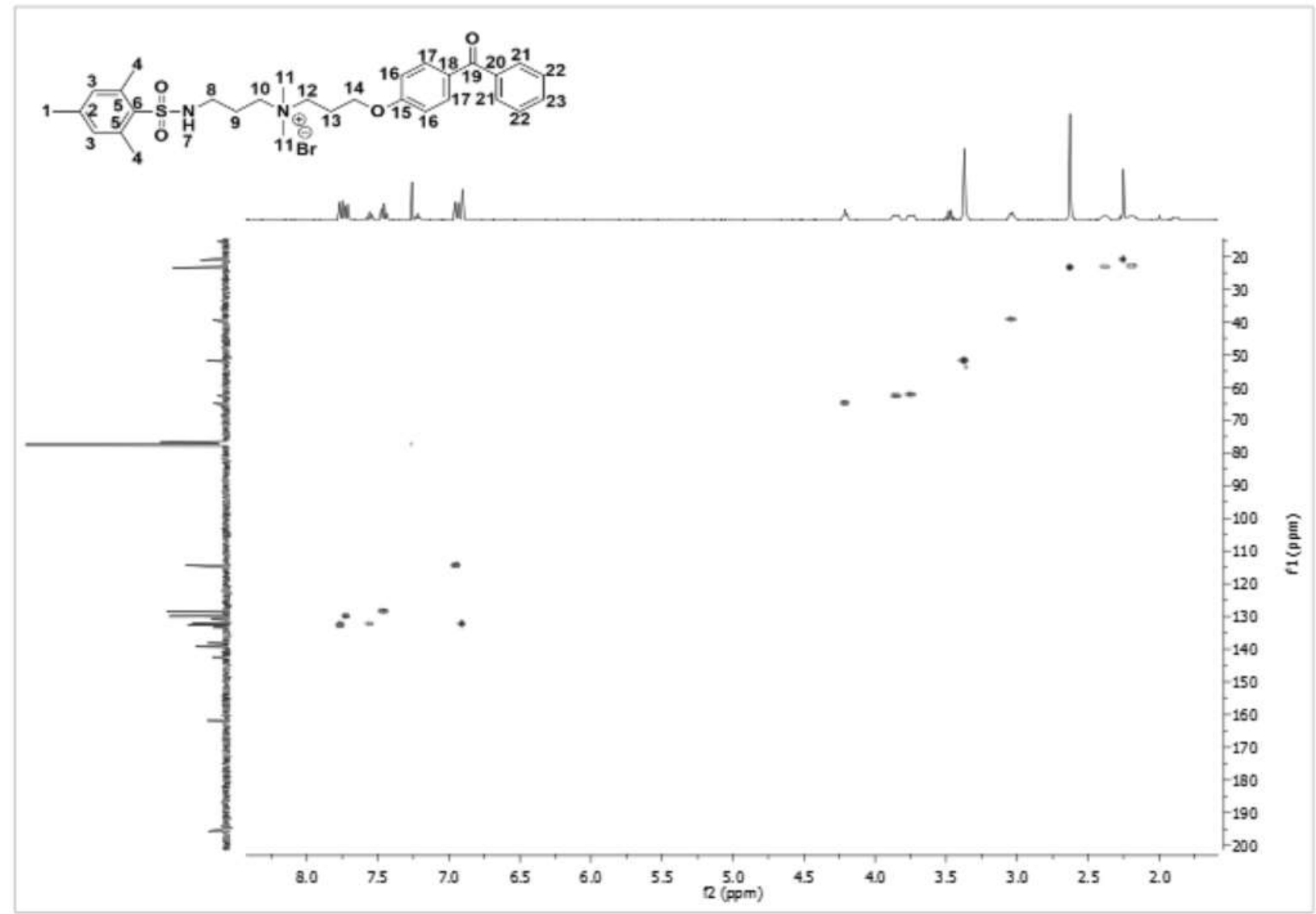

Figure (B) 71 - HSQC 2D NMR $\left(\mathrm{CDCl}_{3}\right)$ spectrum of 5a. 


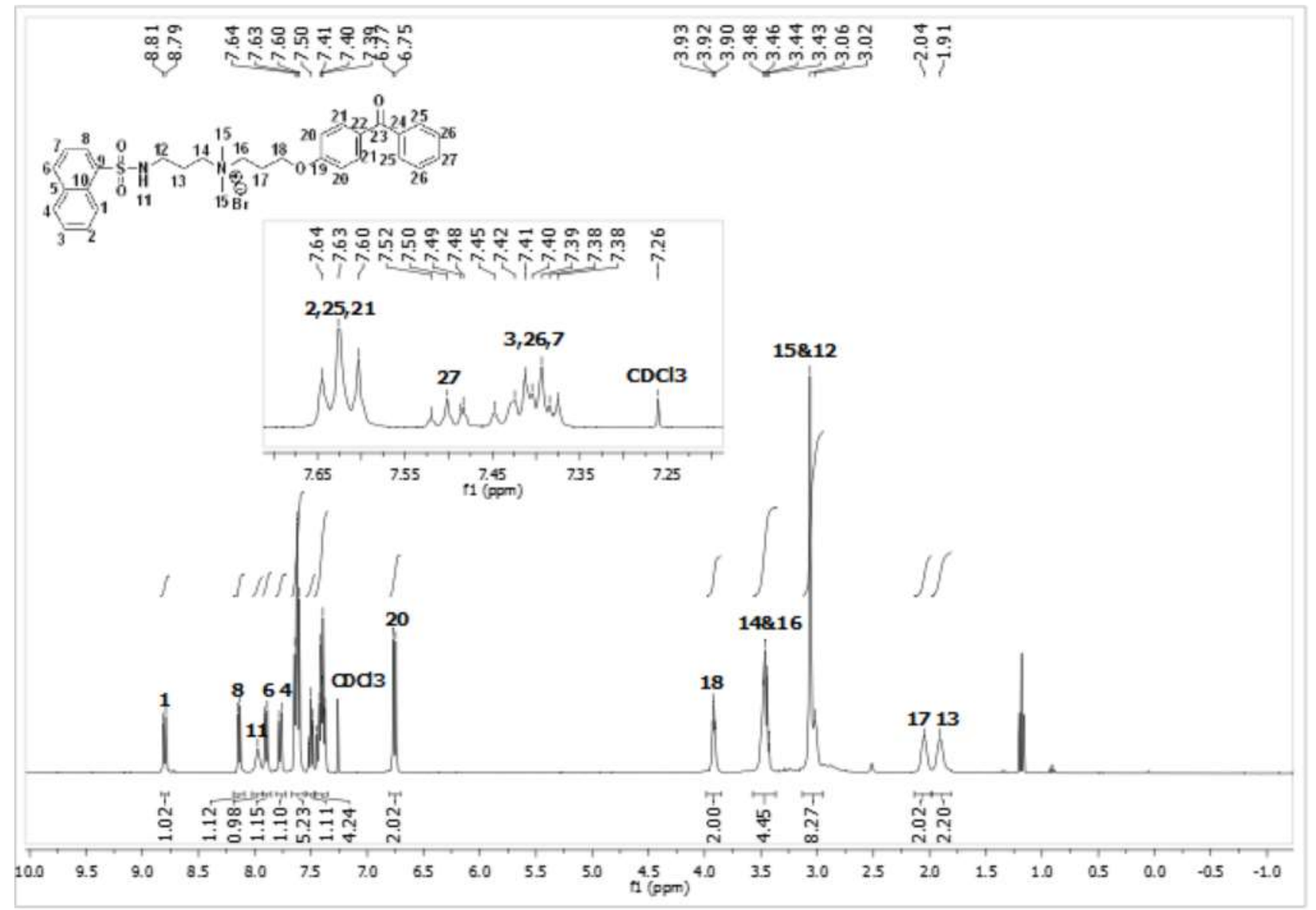

Figure (B) $72-{ }^{1} \mathrm{H}$ NMR (400 $\left.\mathrm{MHz}, \mathrm{CDCl}_{3}\right)$ spectrum of $\mathbf{6 a}$. 


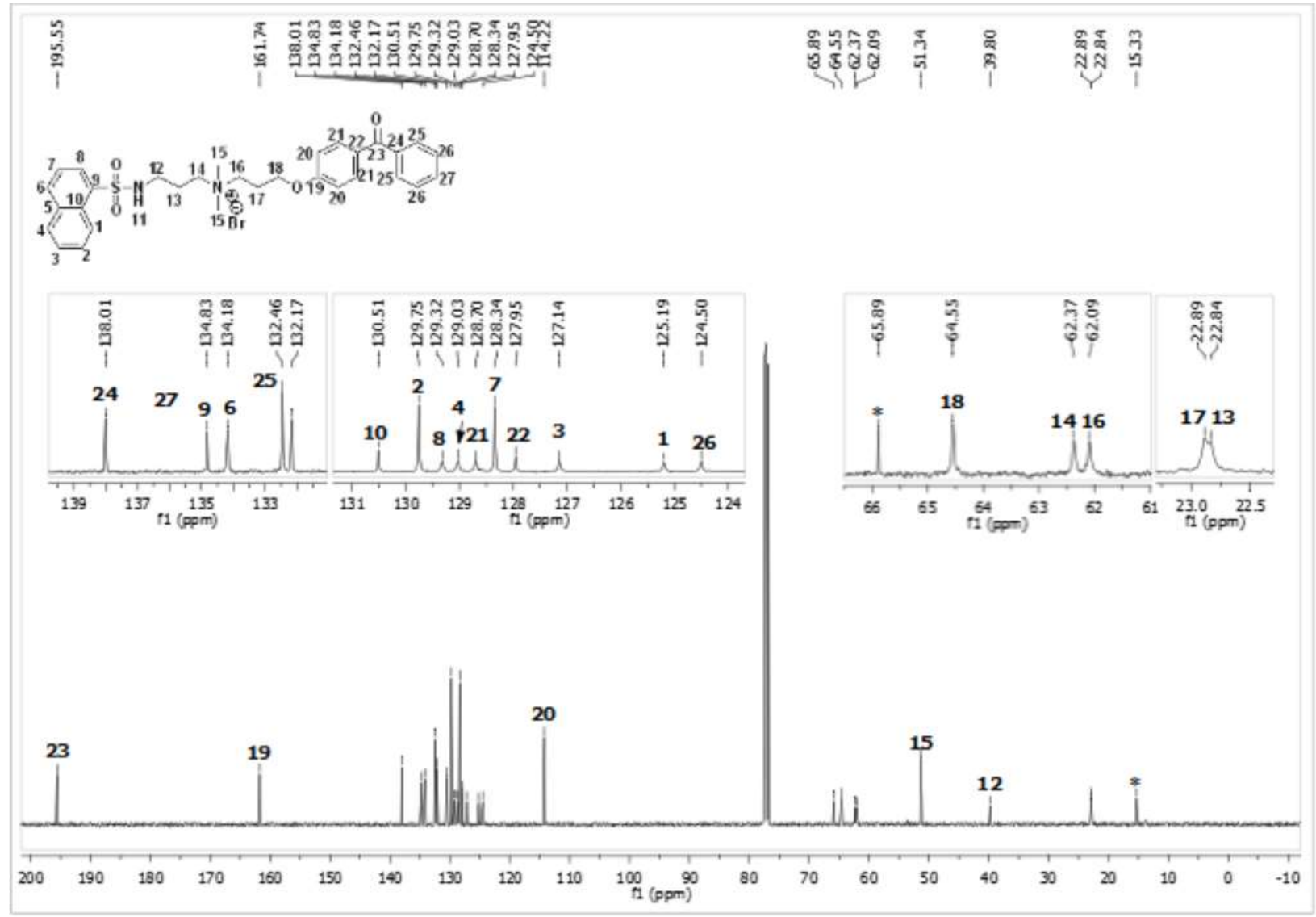

Figure (B) $73-{ }^{13} \mathrm{C}$ NMR $\left(101 \mathrm{MHz}, \mathrm{CDCl}_{3}\right)$ spectrum of $6 \mathbf{a}$. 


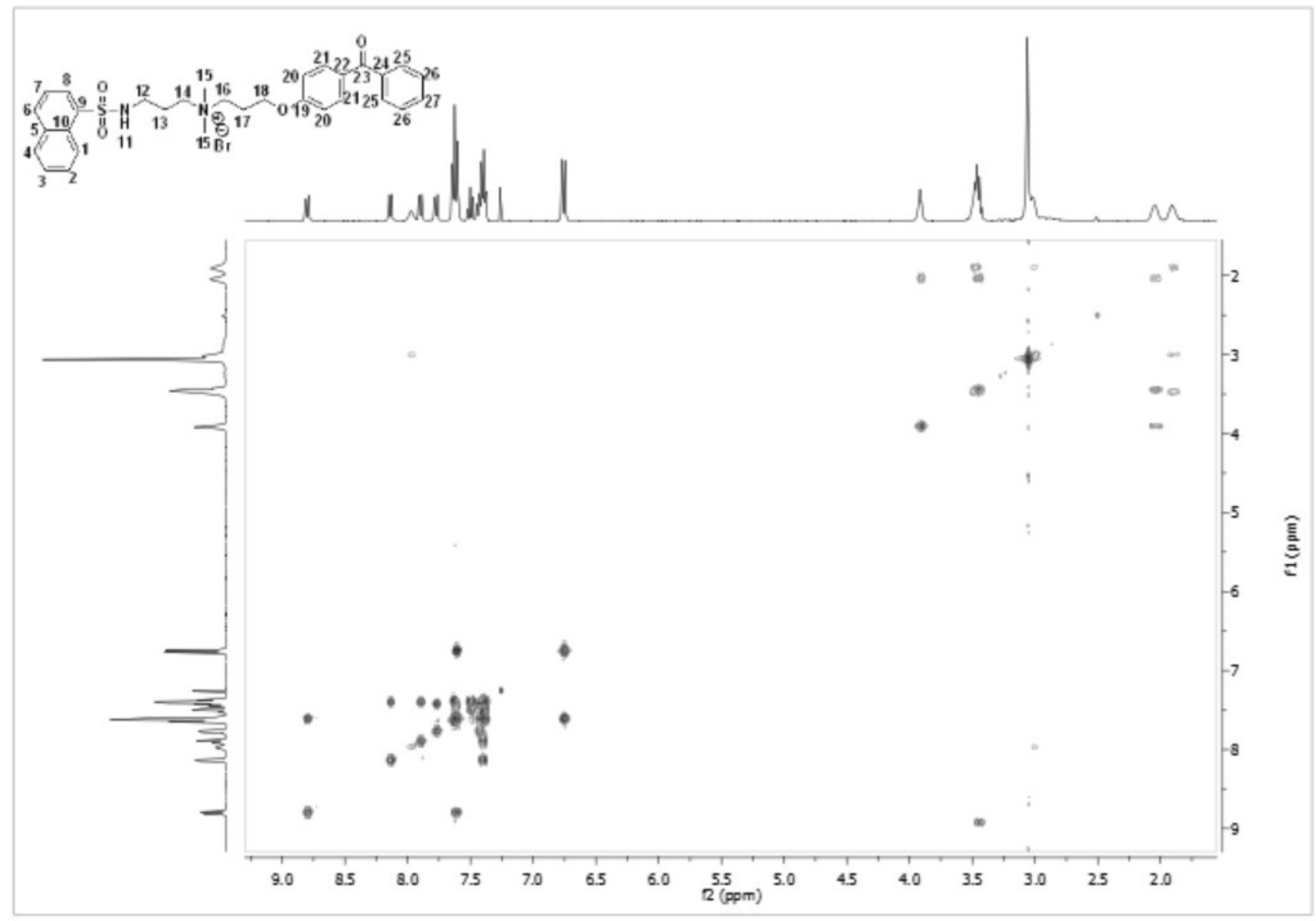

Figure (B) 74 - COSY 2D NMR $\left(\mathrm{CDCl}_{3}\right)$ spectrum of $\mathbf{6 a}$. 


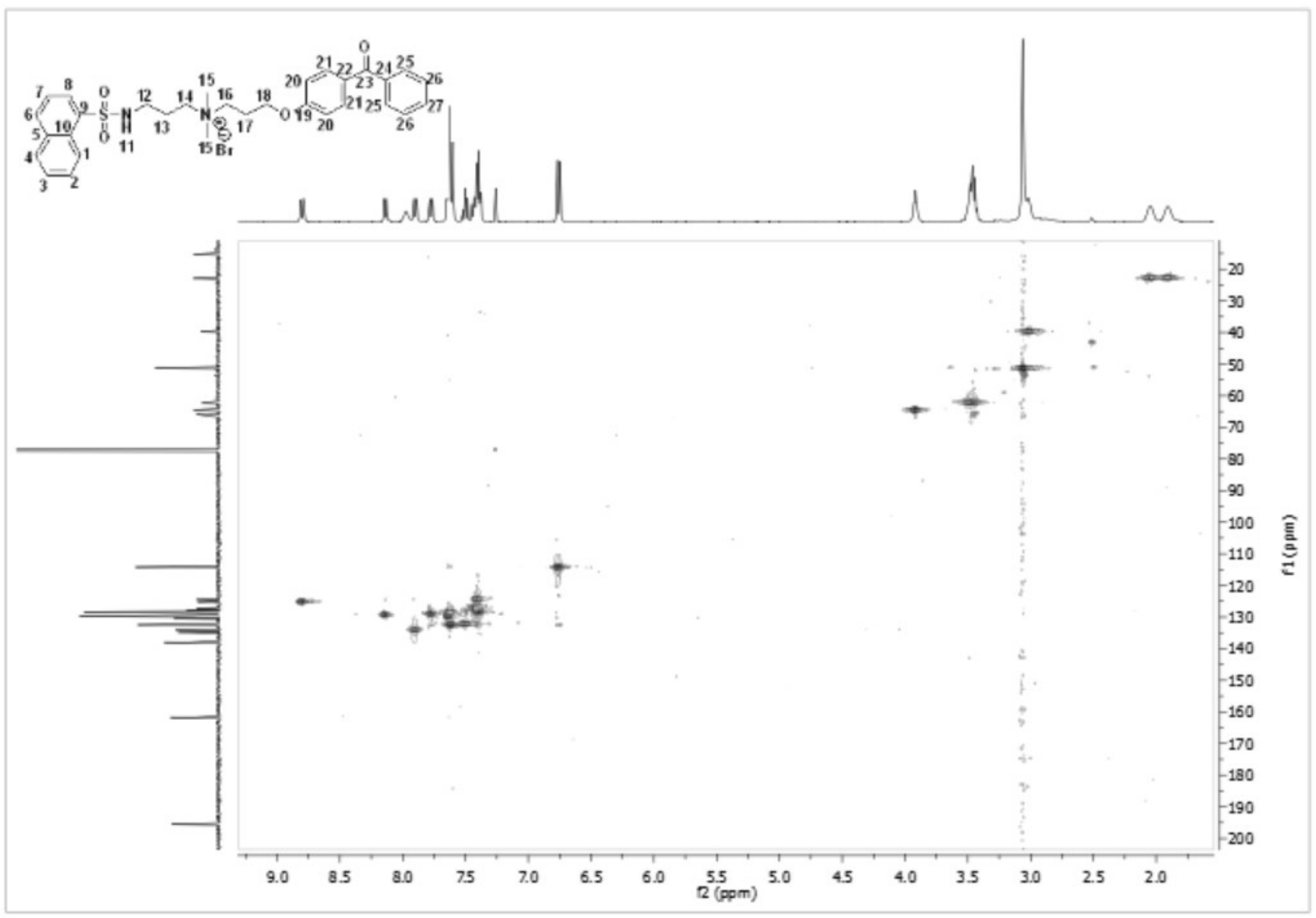

Figure (B) 75 - HSQC 2D NMR $\left(\mathrm{CDCl}_{3}\right)$ spectrum of $\mathbf{6 a}$. 


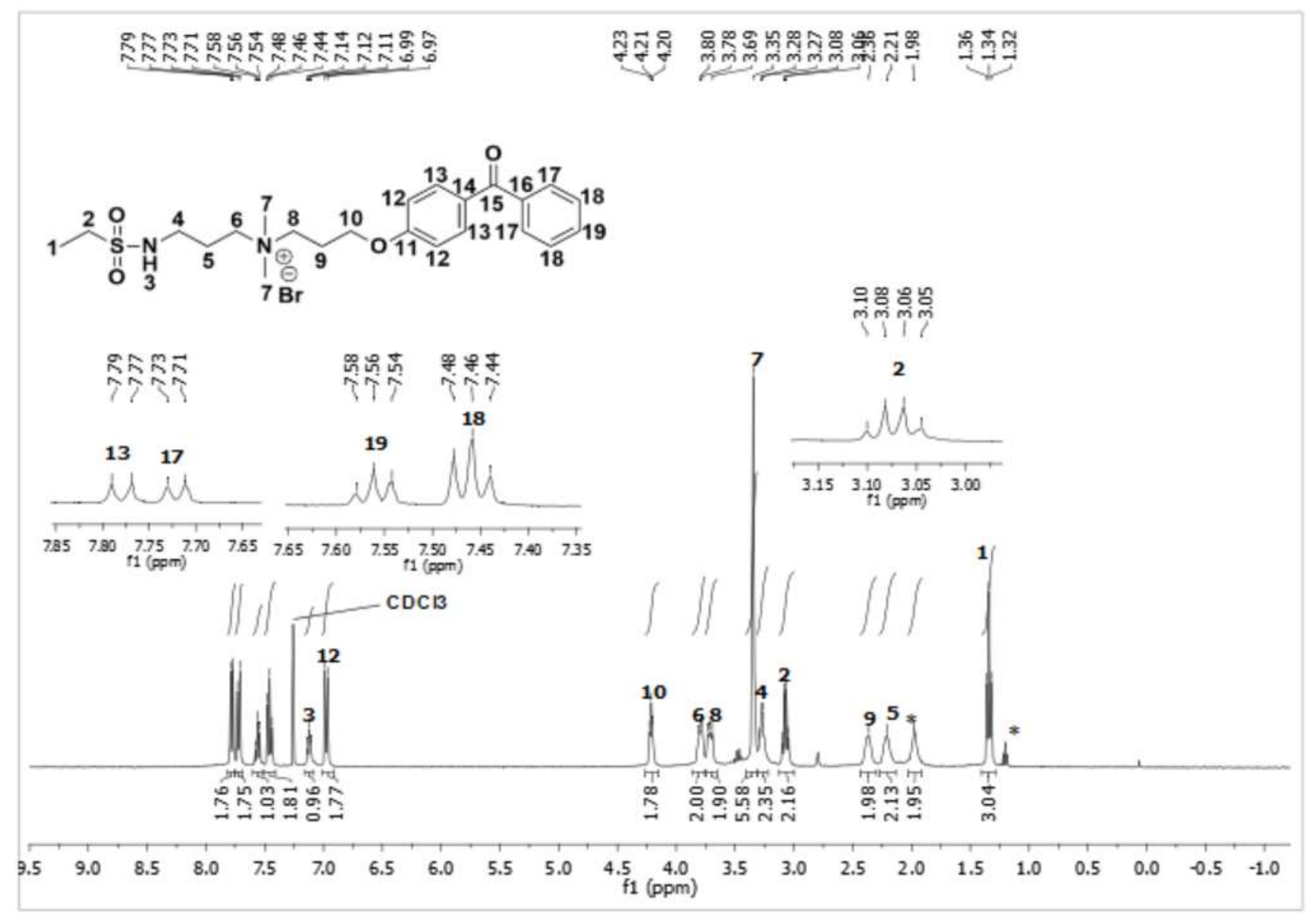

Figure (B) $76-{ }^{1} \mathrm{H} \mathrm{NMR}\left(400 \mathrm{MHz}, \mathrm{CDCl}_{3}\right)$ spectrum of $7 \mathbf{a}$. 


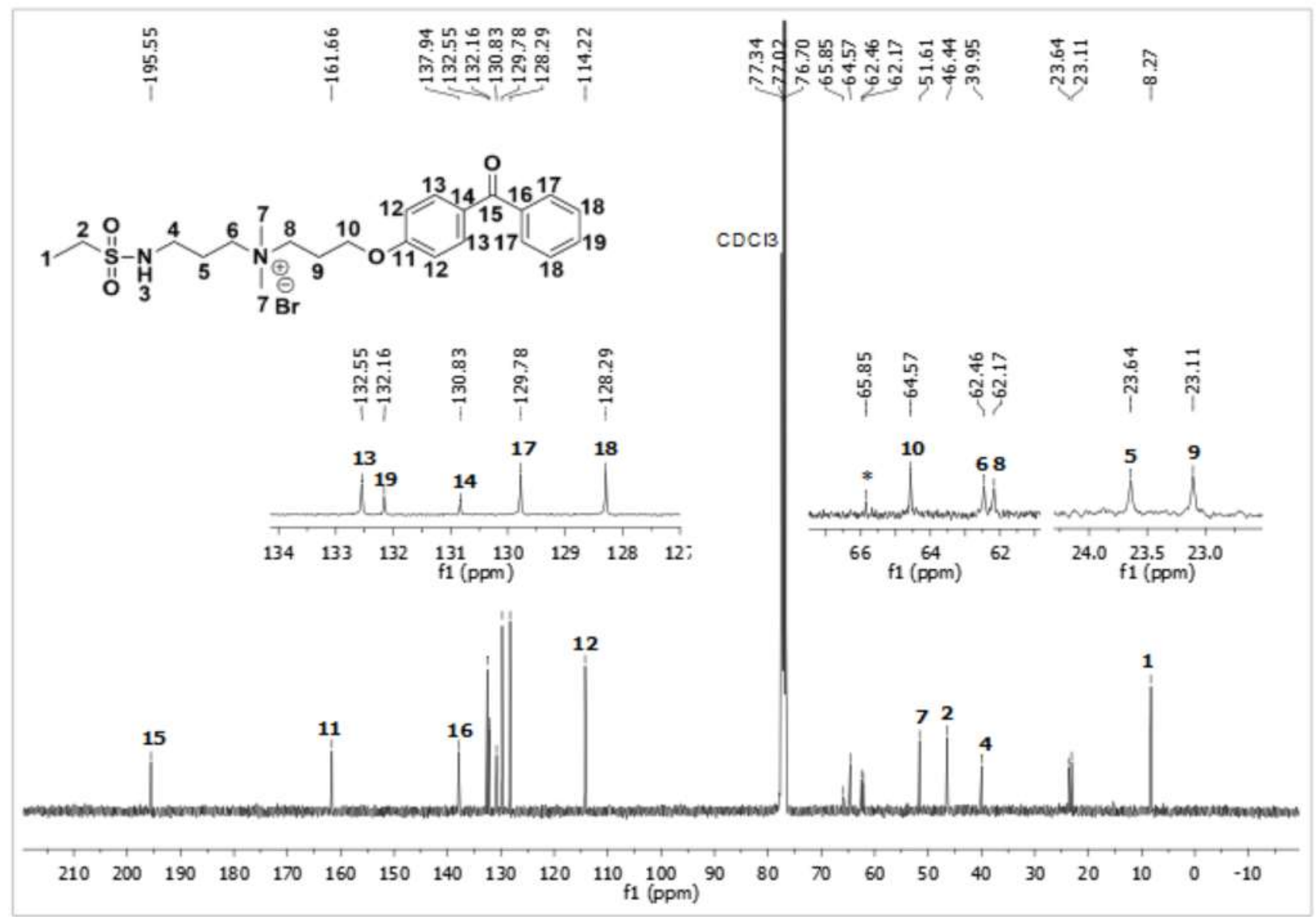

Figure (B) $77-{ }^{13} \mathrm{C} \mathrm{NMR}\left(101 \mathrm{MHz}, \mathrm{CDCl}_{3}\right)$ spectrum of $7 \mathbf{a}$. 


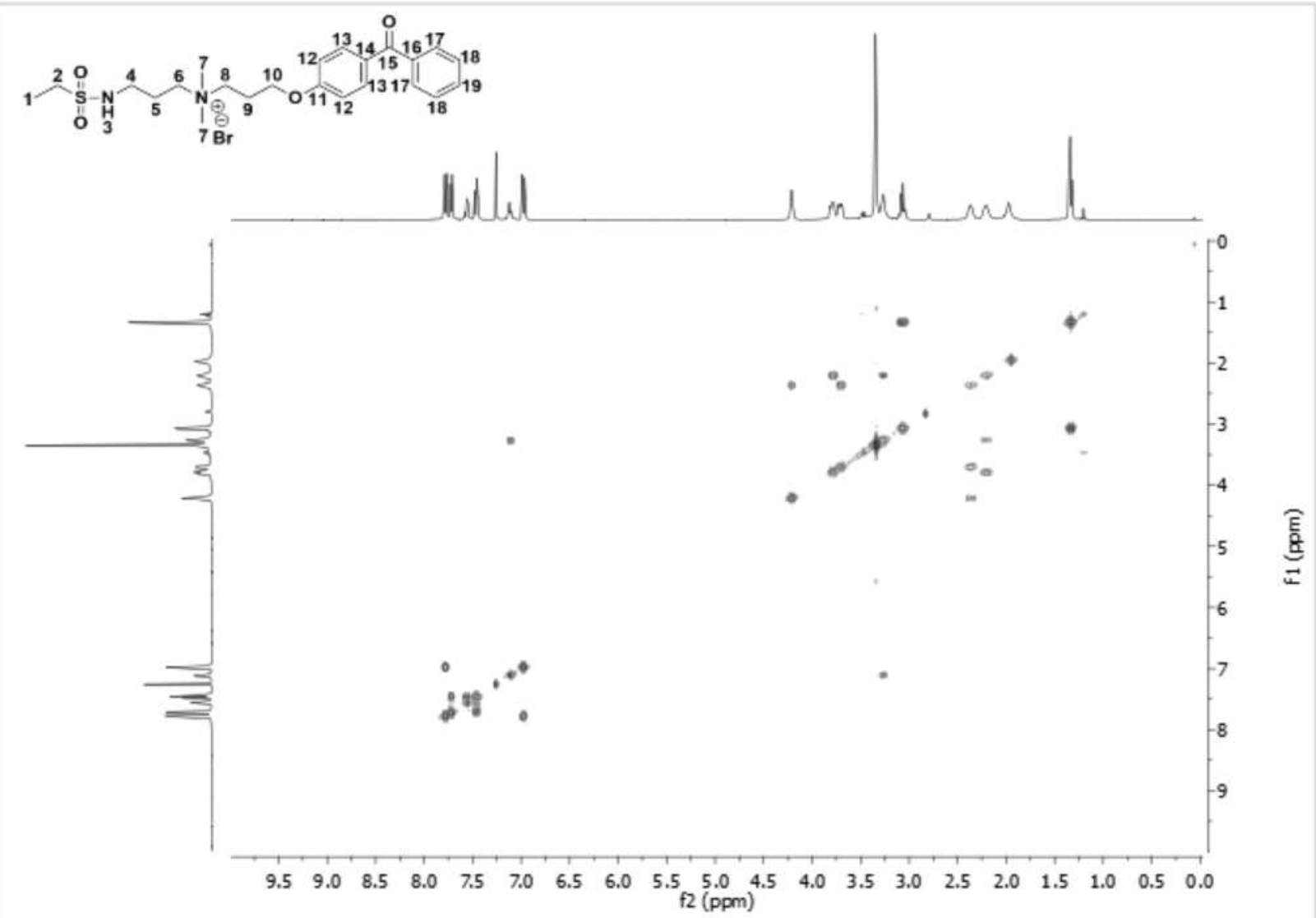

Figure (B) 78 - COSY 2D NMR $\left(\mathrm{CDCl}_{3}\right)$ spectrum of $7 \mathbf{a}$. 


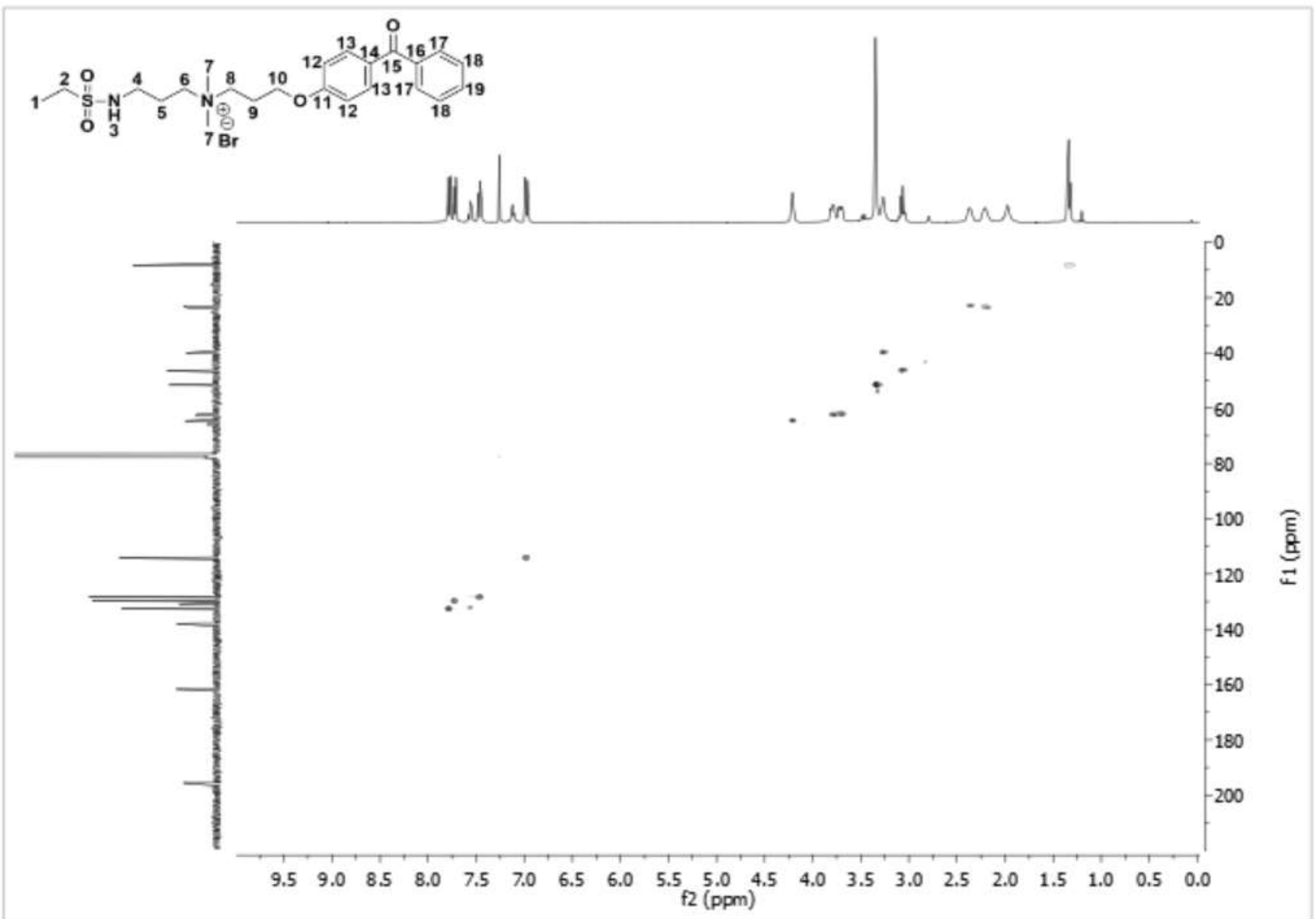

Figure (B) 79 - $\mathrm{HSQC} 2 \mathrm{D}$ NMR $\left(\mathrm{CDCl}_{3}\right)$ spectrum of $7 \mathbf{a}$. 


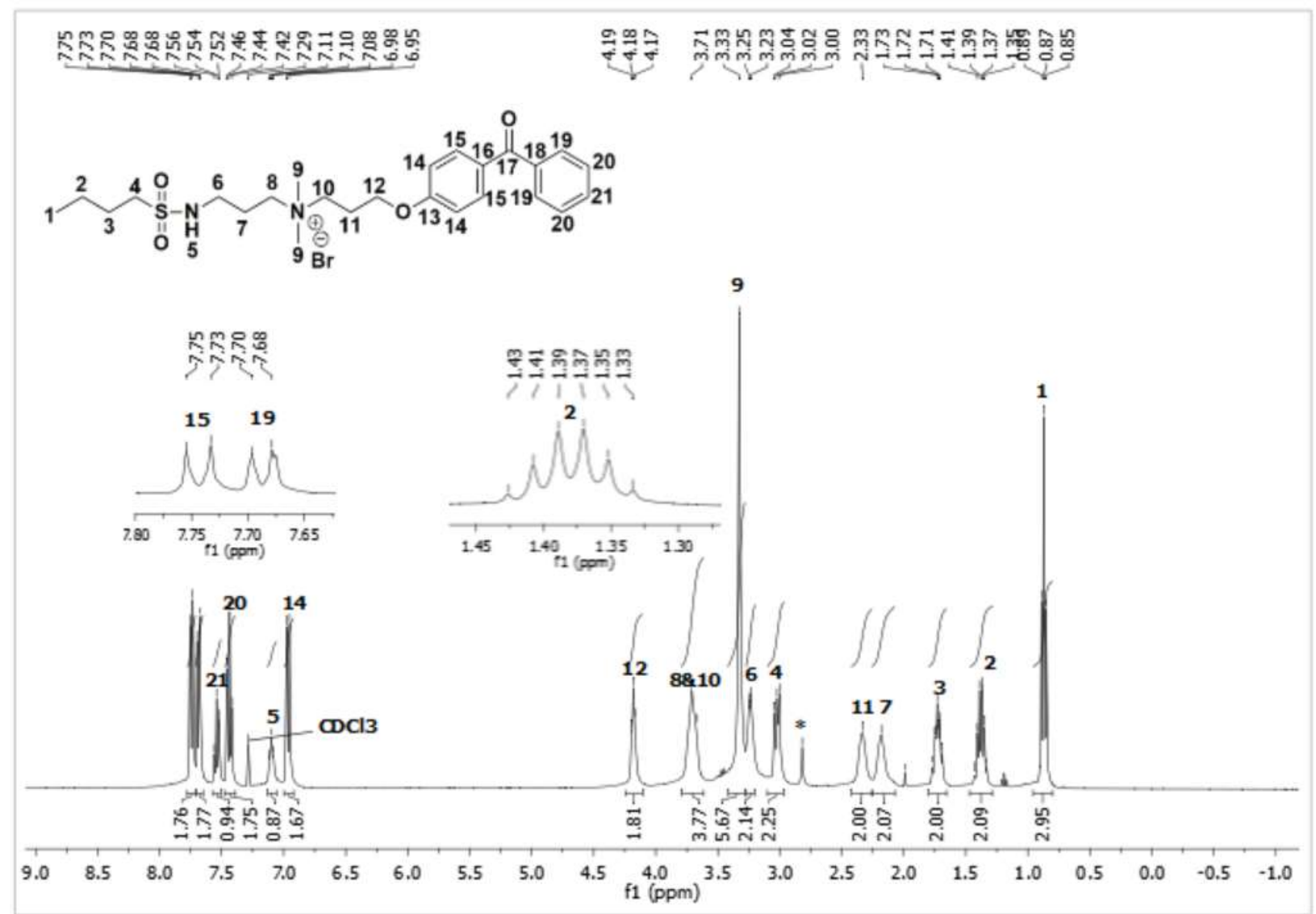

Figure (B) $80-{ }^{1} \mathrm{H}$ NMR $\left(400 \mathrm{MHz}, \mathrm{CDCl}_{3}\right)$ spectrum of $\mathbf{8 a}$. 


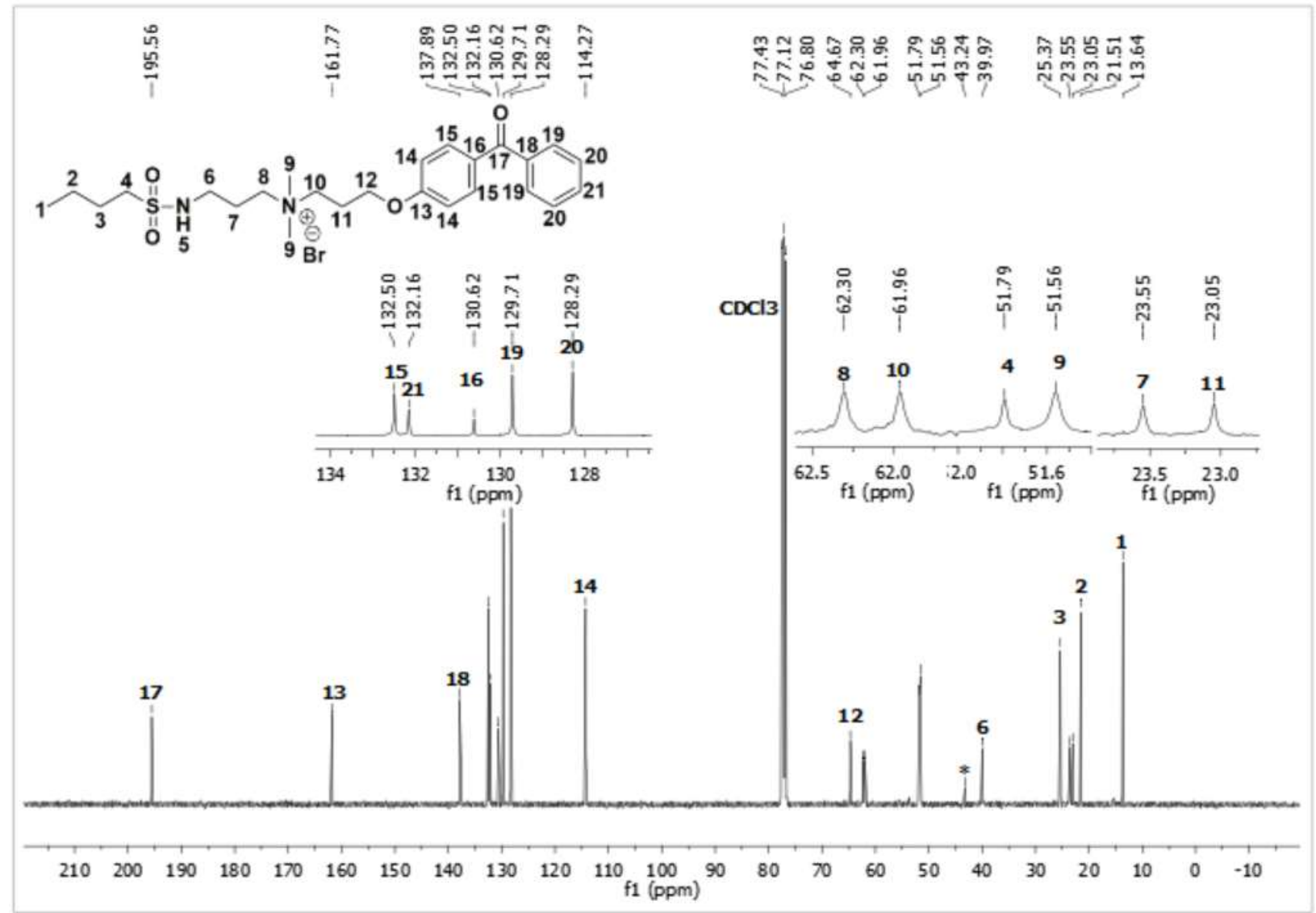

Figure (B) $81-{ }^{13} \mathrm{C}$ NMR $\left(101 \mathrm{MHz}, \mathrm{CDCl}_{3}\right)$ spectrum of $8 \mathbf{a}$. 


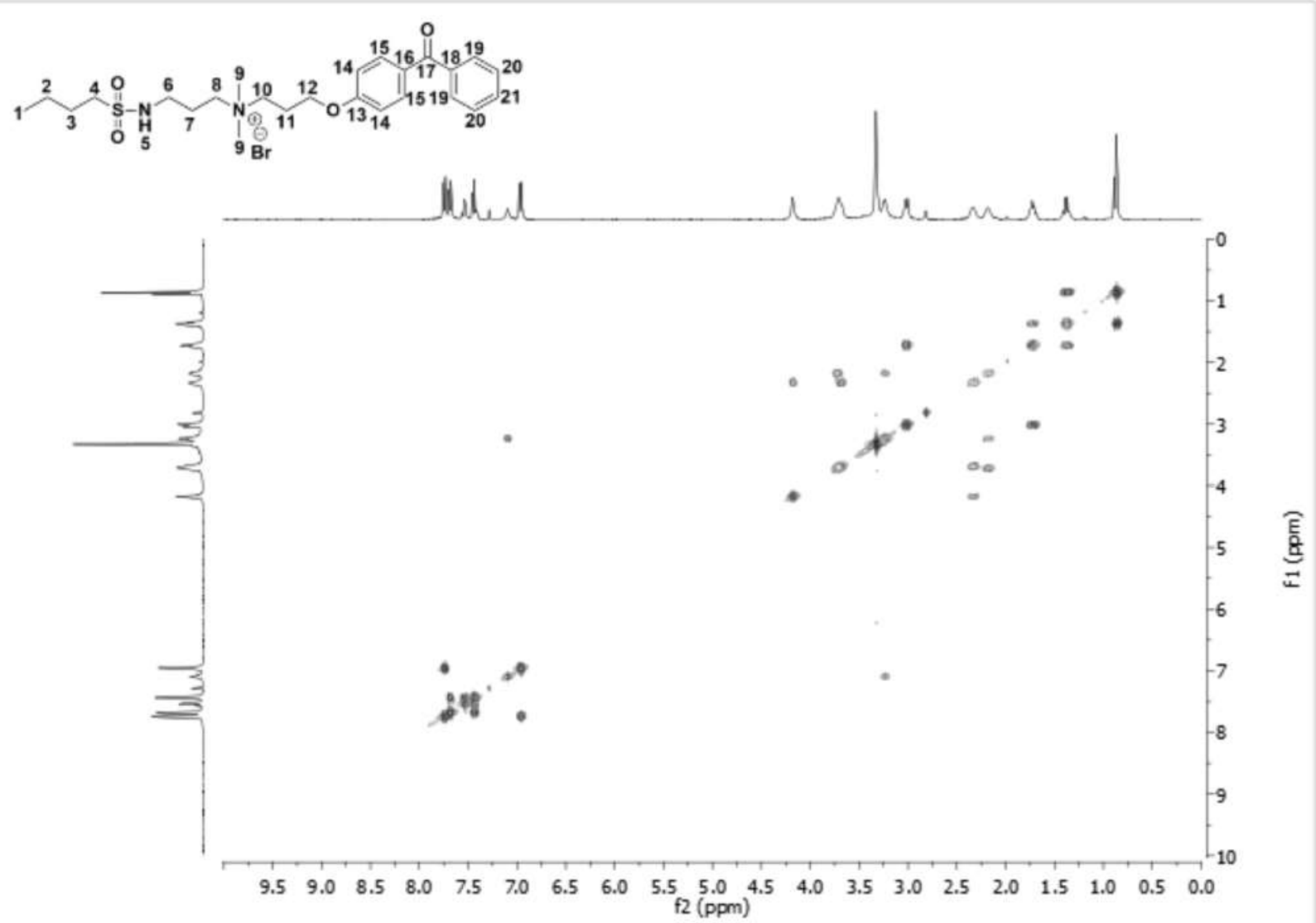

Figure (B) 82 - $\mathrm{COSY} 2 \mathrm{D}$ NMR $\left(\mathrm{CDCl}_{3}\right)$ spectrum of $\mathbf{8 a}$. 


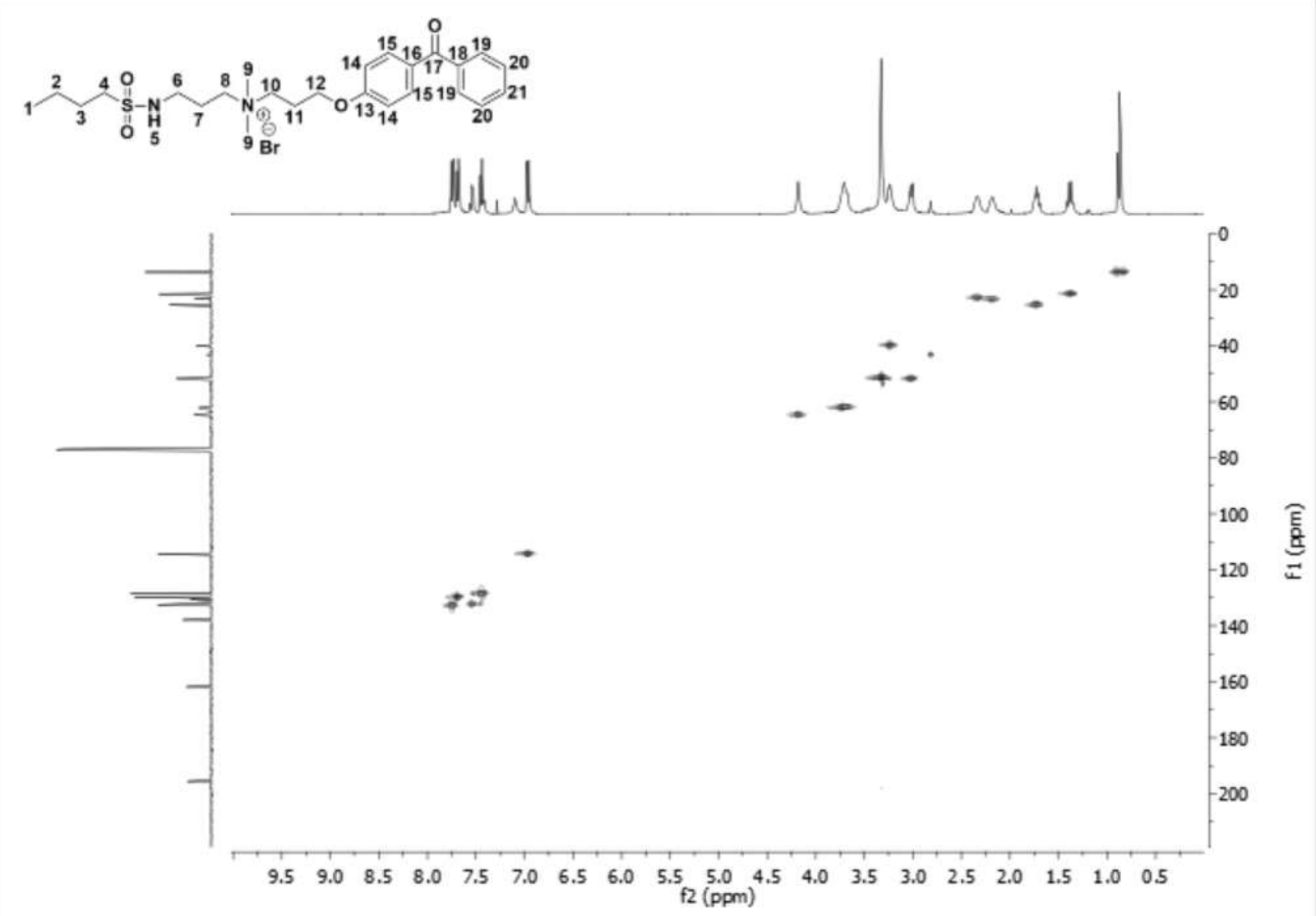

Figure (B) 83 - HSQC 2D NMR $\left(\mathrm{CDCl}_{3}\right)$ spectrum of $\mathbf{8 a}$. 


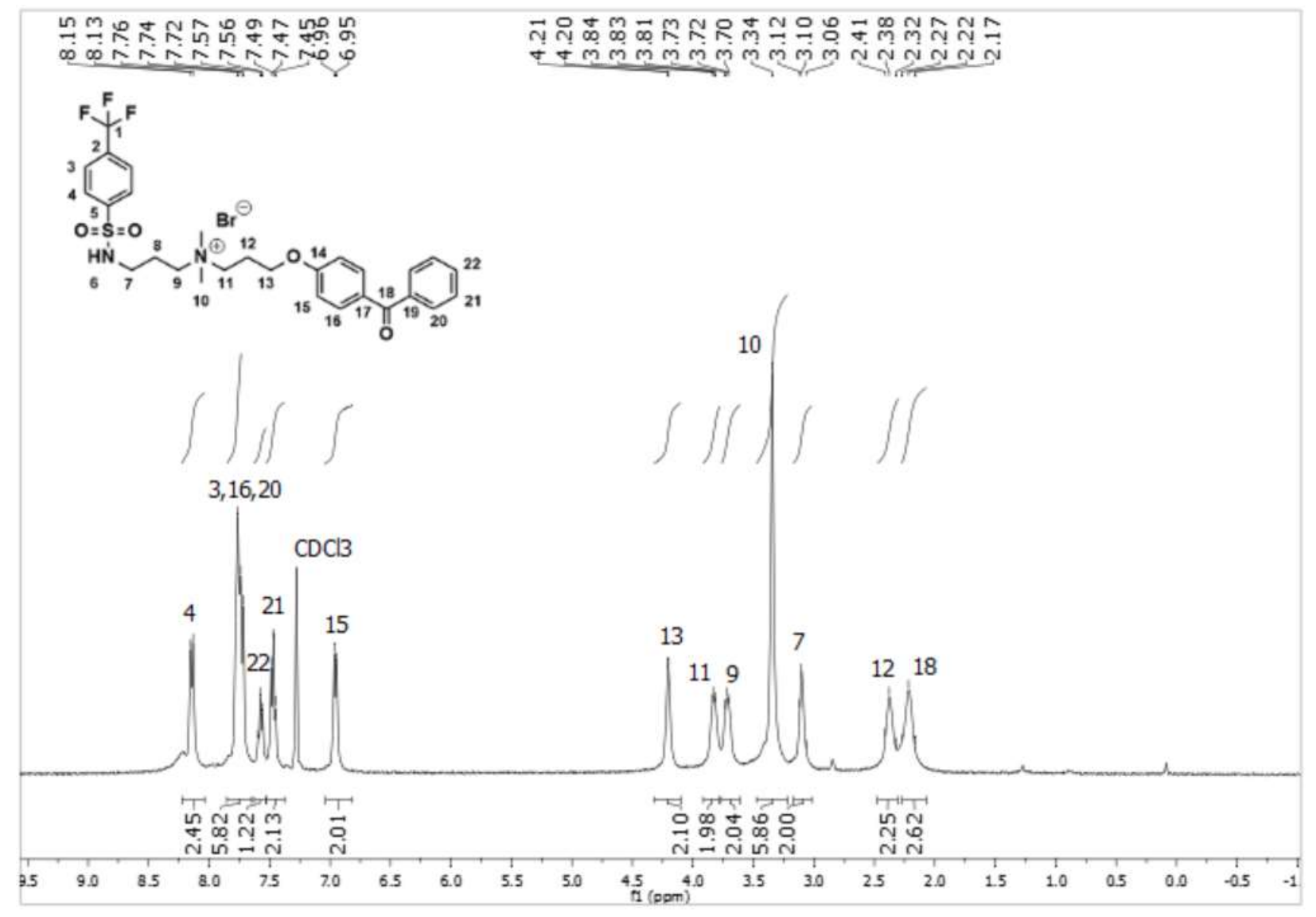

Figure (B) $84-{ }^{1} \mathrm{H} \mathrm{NMR}\left(400 \mathrm{MHz}, \mathrm{CDCl}_{3}\right)$ spectrum of 9a. 


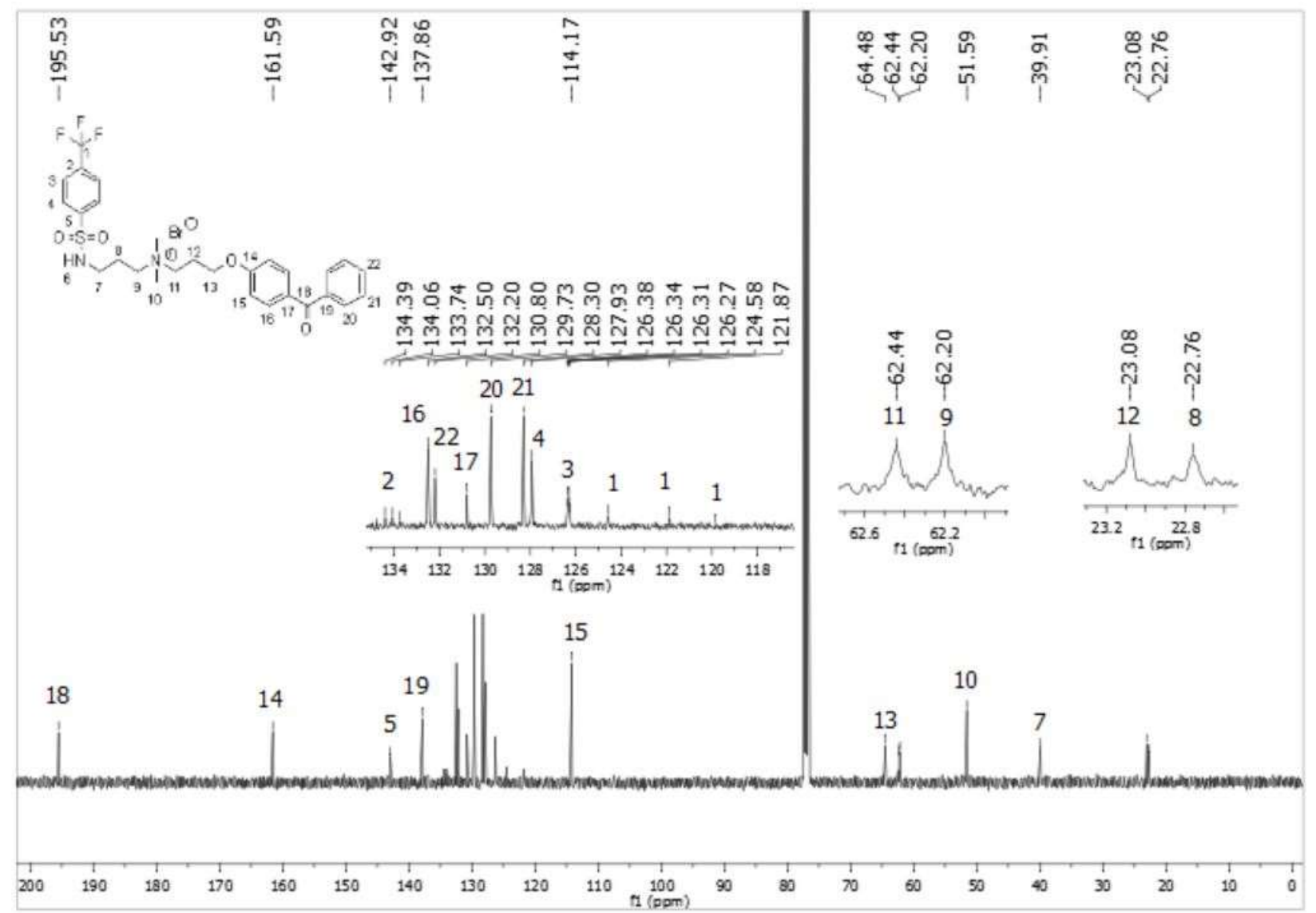

Figure (B) $85-{ }^{13} \mathrm{C}$ NMR $\left(101 \mathrm{MHz}, \mathrm{CDCl}_{3}\right)$ spectrum of 9a. 


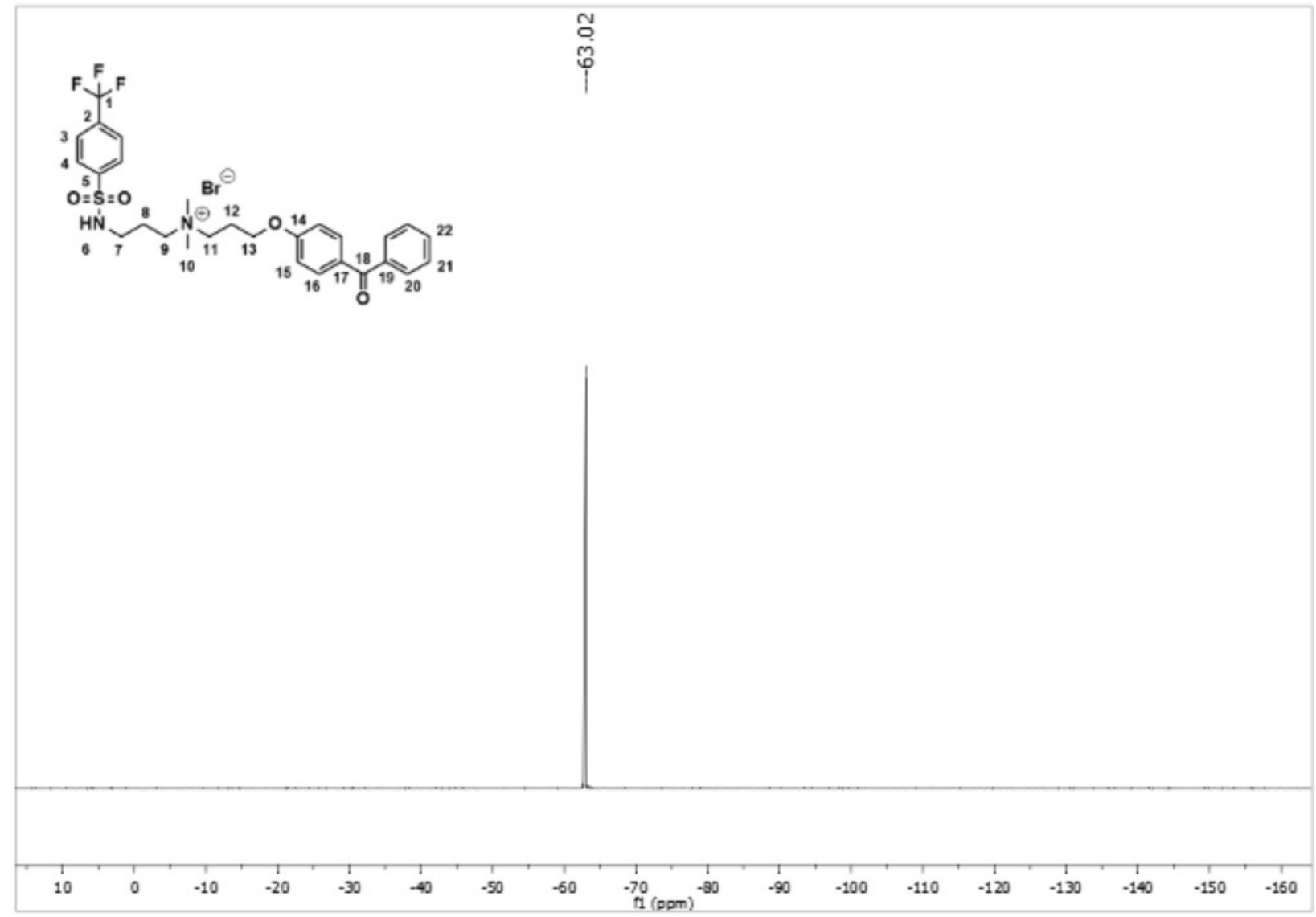

Figure (B) $86-{ }^{19} \mathrm{~F} \mathrm{NMR}\left(376 \mathrm{MHz}, \mathrm{CDCl}_{3}\right)$ spectrum of 9a. 


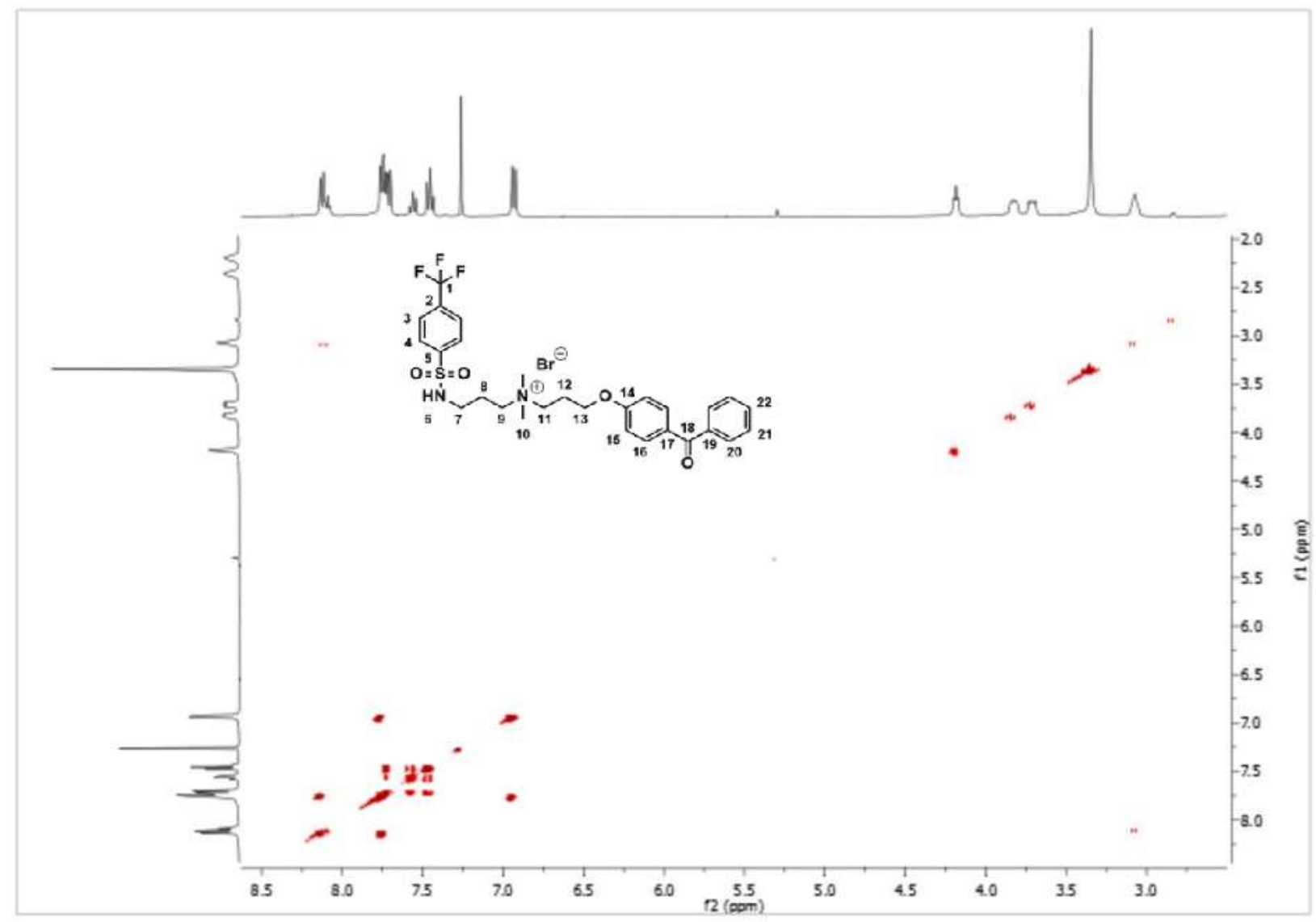

Figure (B) 87 - COSY 2D NMR $\left(\mathrm{CDCl}_{3}\right)$ spectrum of 9a. 


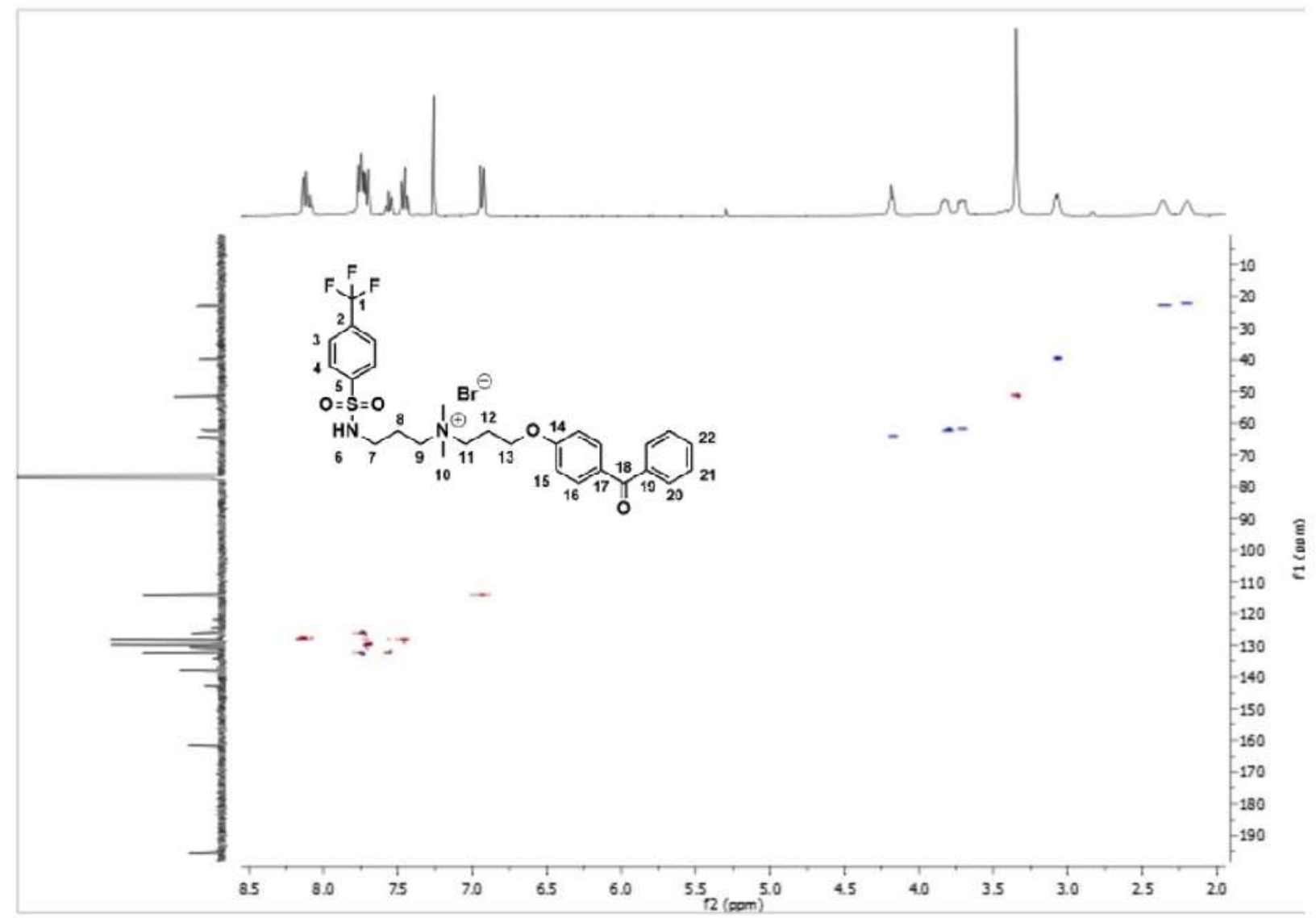

Figure (B) 88 - HSQC 2D NMR $\left(\mathrm{CDCl}_{3}\right)$ spectrum of 9a. 


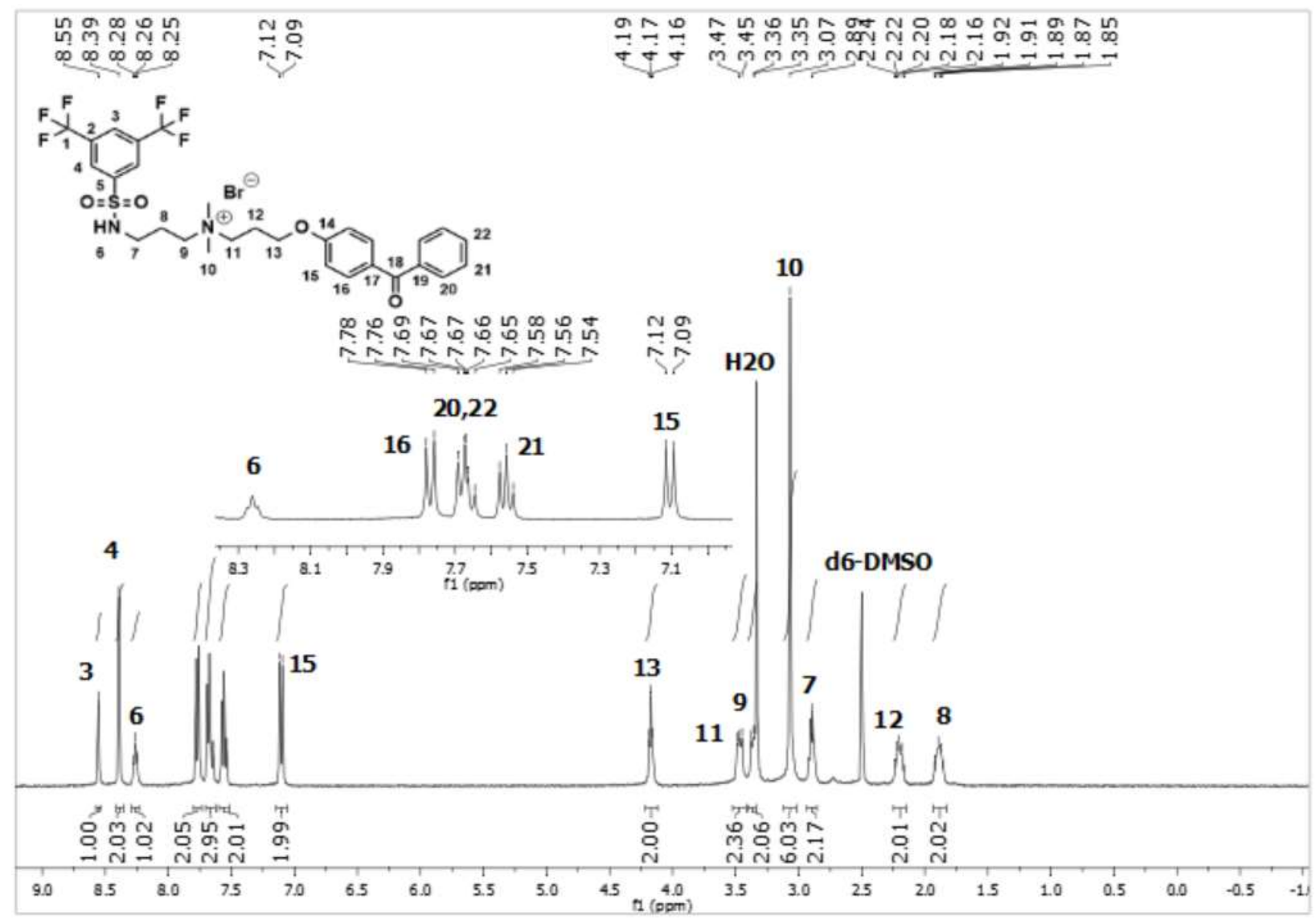

Figure (B) 89 $-{ }^{1} \mathrm{H}$ NMR (400 MHz, DMSO-d 6 ) spectrum of 10a. 


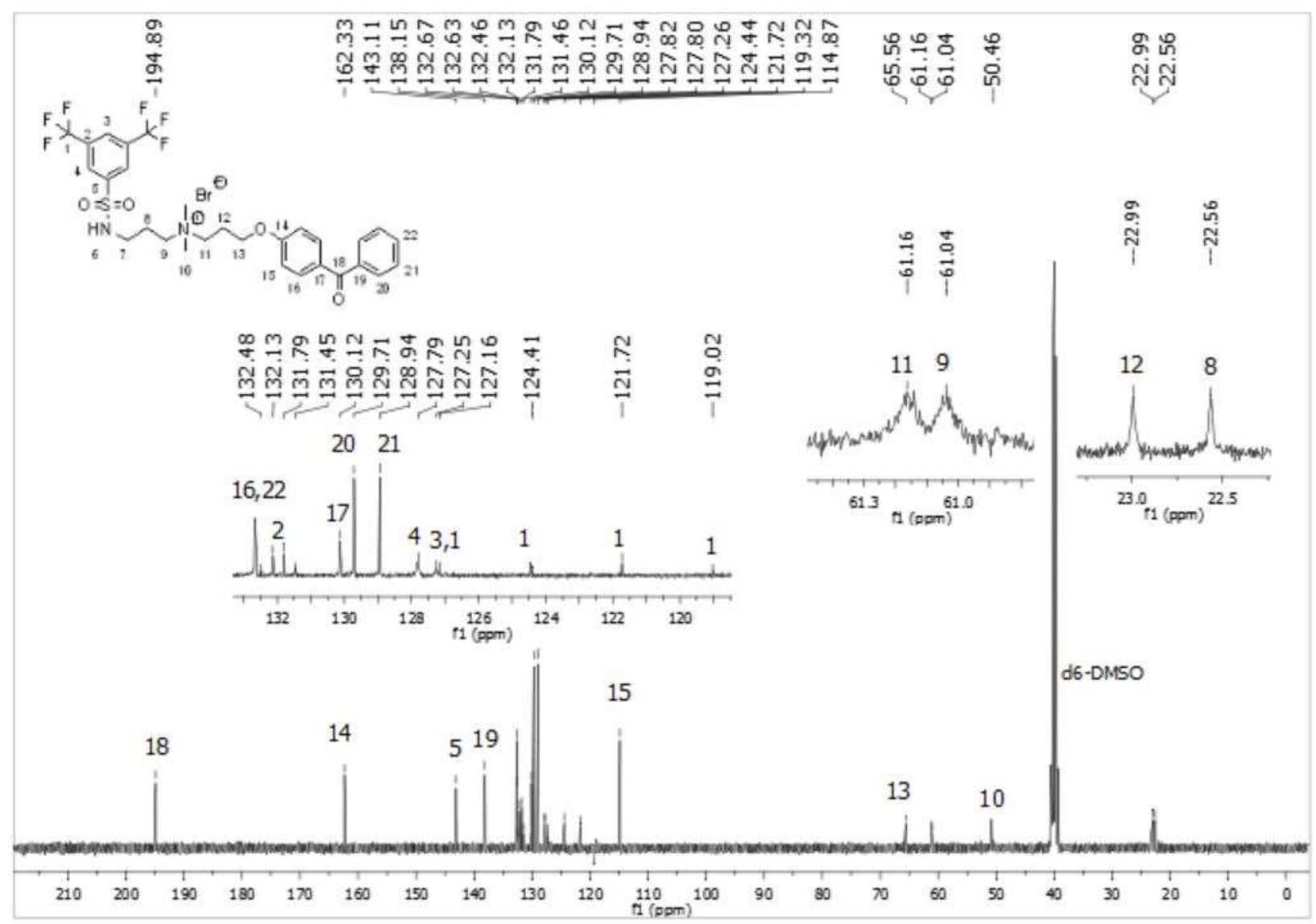

Figure (B) $90-{ }^{13} \mathrm{C}$ NMR (101 MHz, DMSO-d 6 ) spectrum of 10a. 


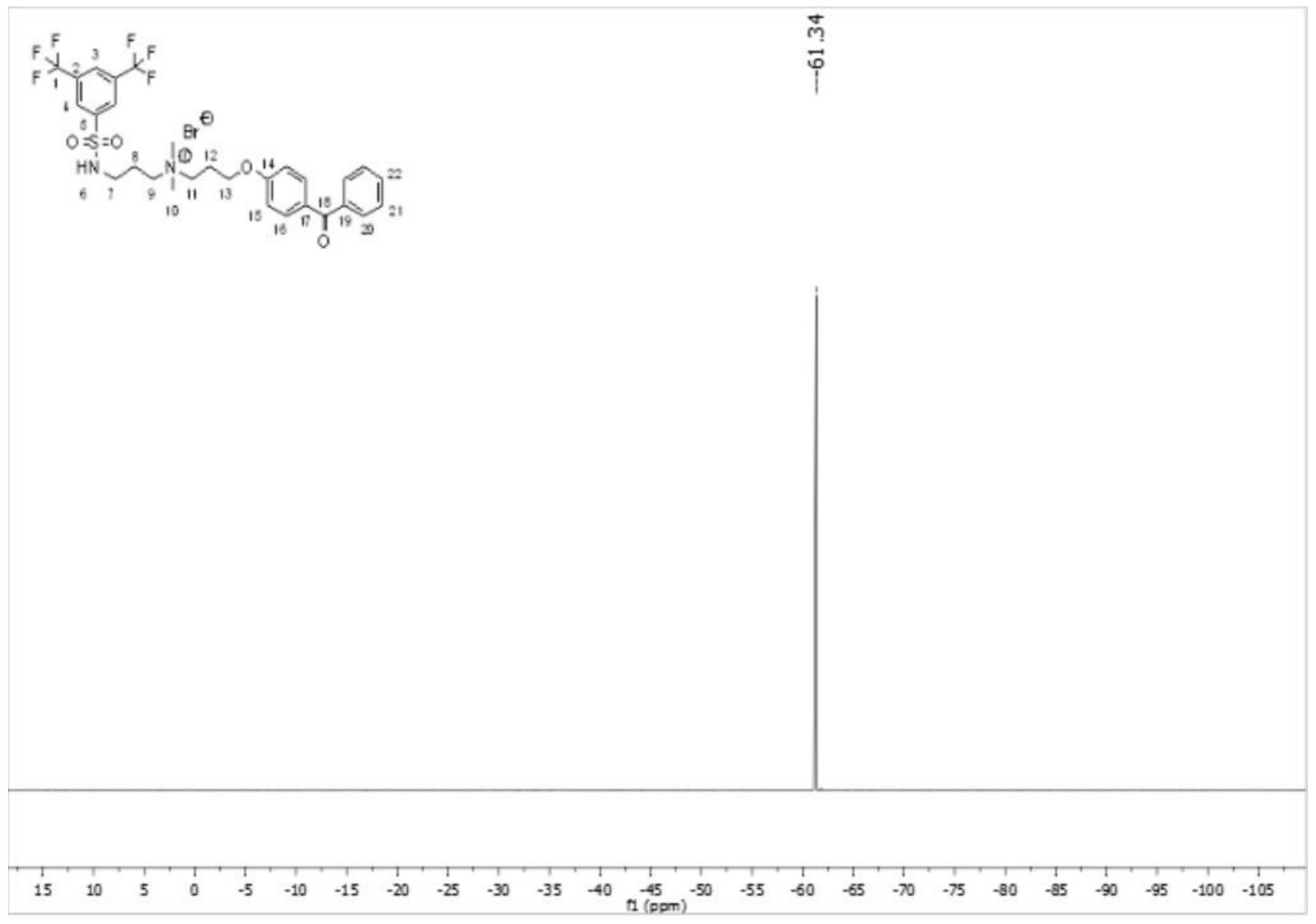

Figure (B) $91-{ }^{19} \mathrm{~F}$ NMR (376 MHz, DMSO-d 6 ) spectrum of 10a. 


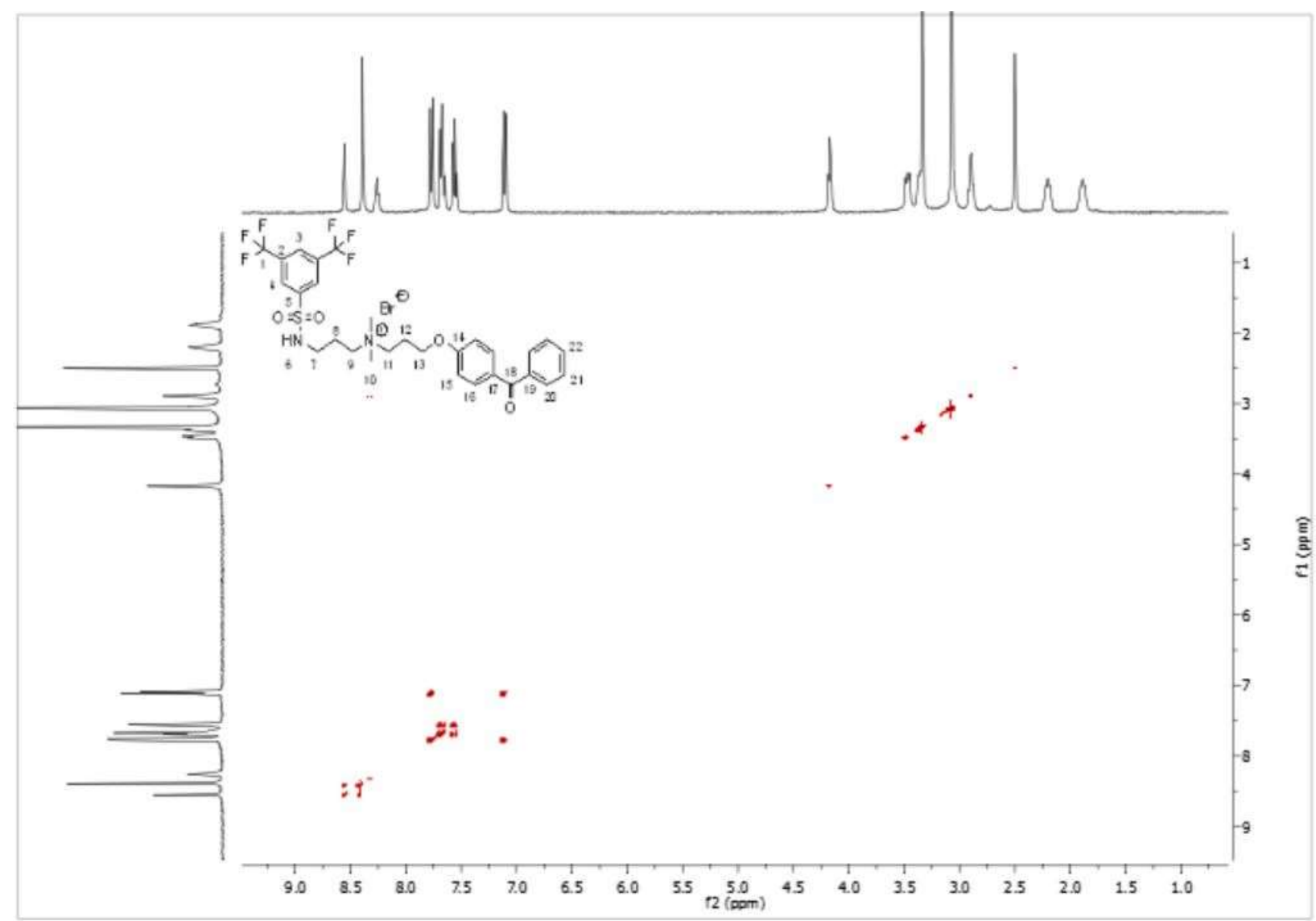

Figure (B) 92 - COSY 2D NMR (DMSO-d ${ }_{6}$ spectrum of 10a. 


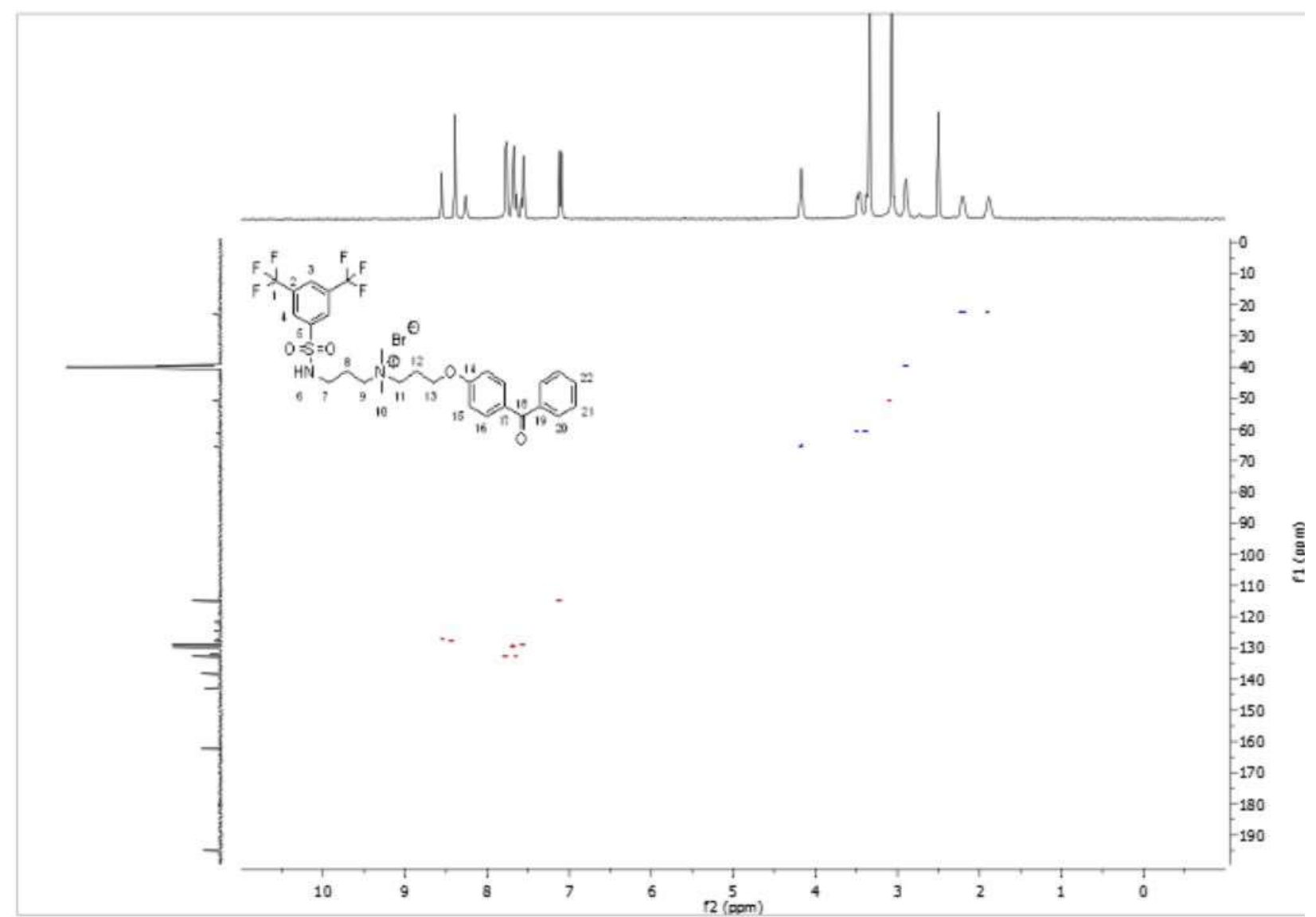

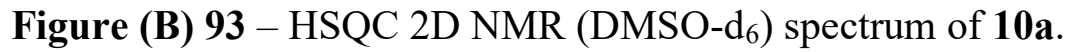




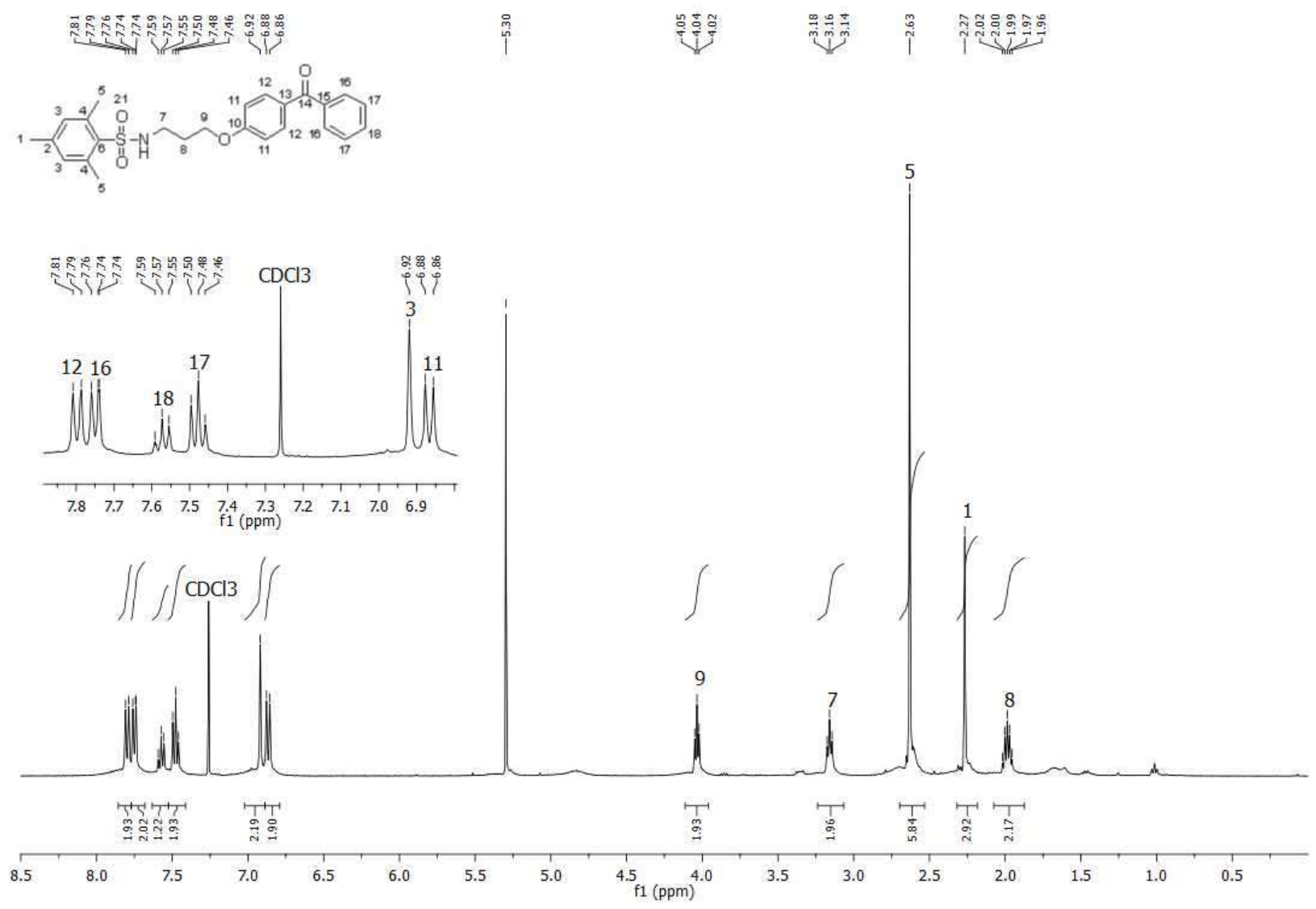

Figure (B) $94-{ }^{1} \mathrm{H}$ NMR $\left(400 \mathrm{MHz}, \mathrm{CDCl}_{3}\right)$ spectrum of 11 a. 

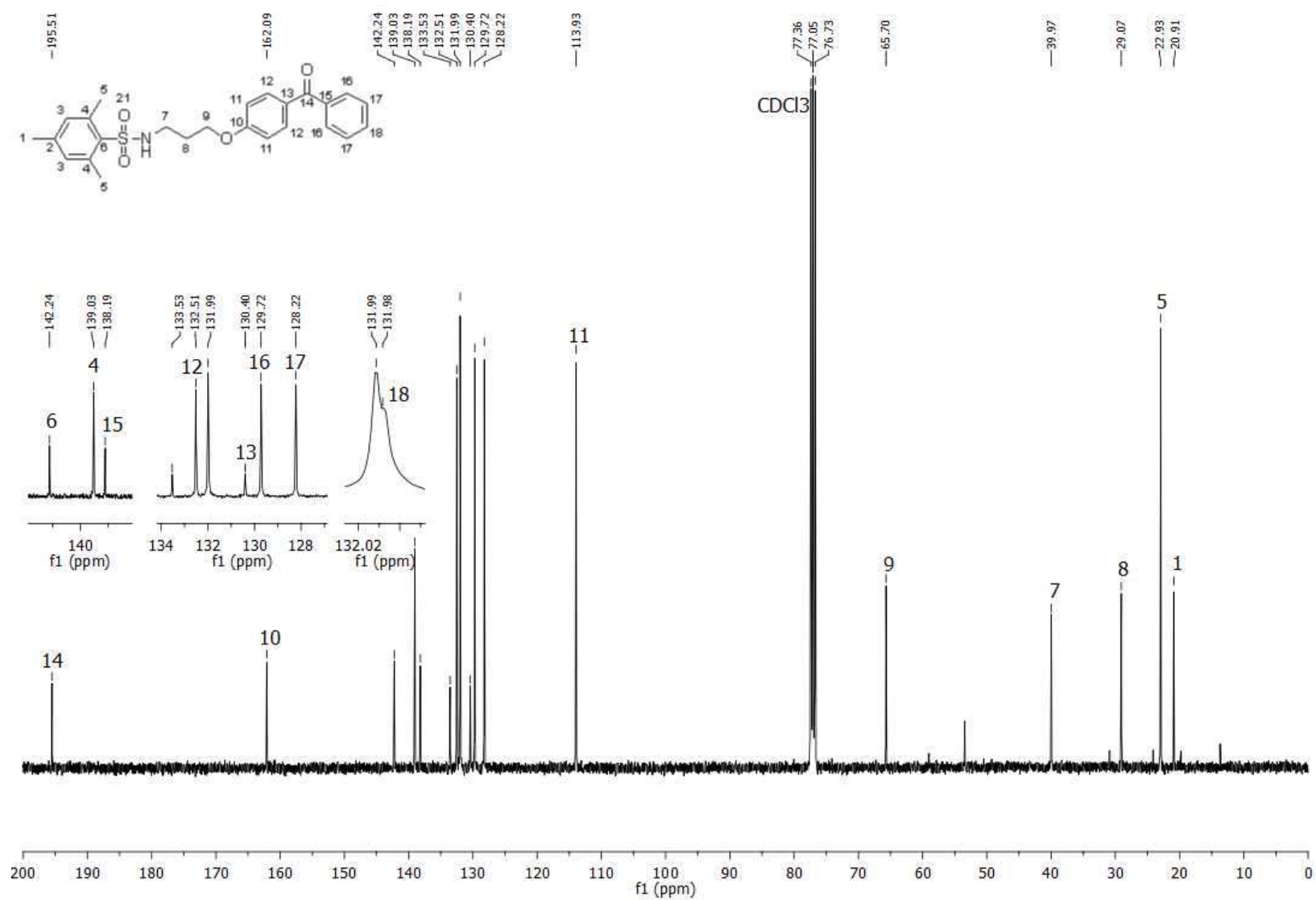

Figure (B) $95-{ }^{13} \mathrm{C}$ NMR $\left(101 \mathrm{MHz}, \mathrm{CDCl}_{3}\right)$ spectrum of $\mathbf{1 1 a}$. 


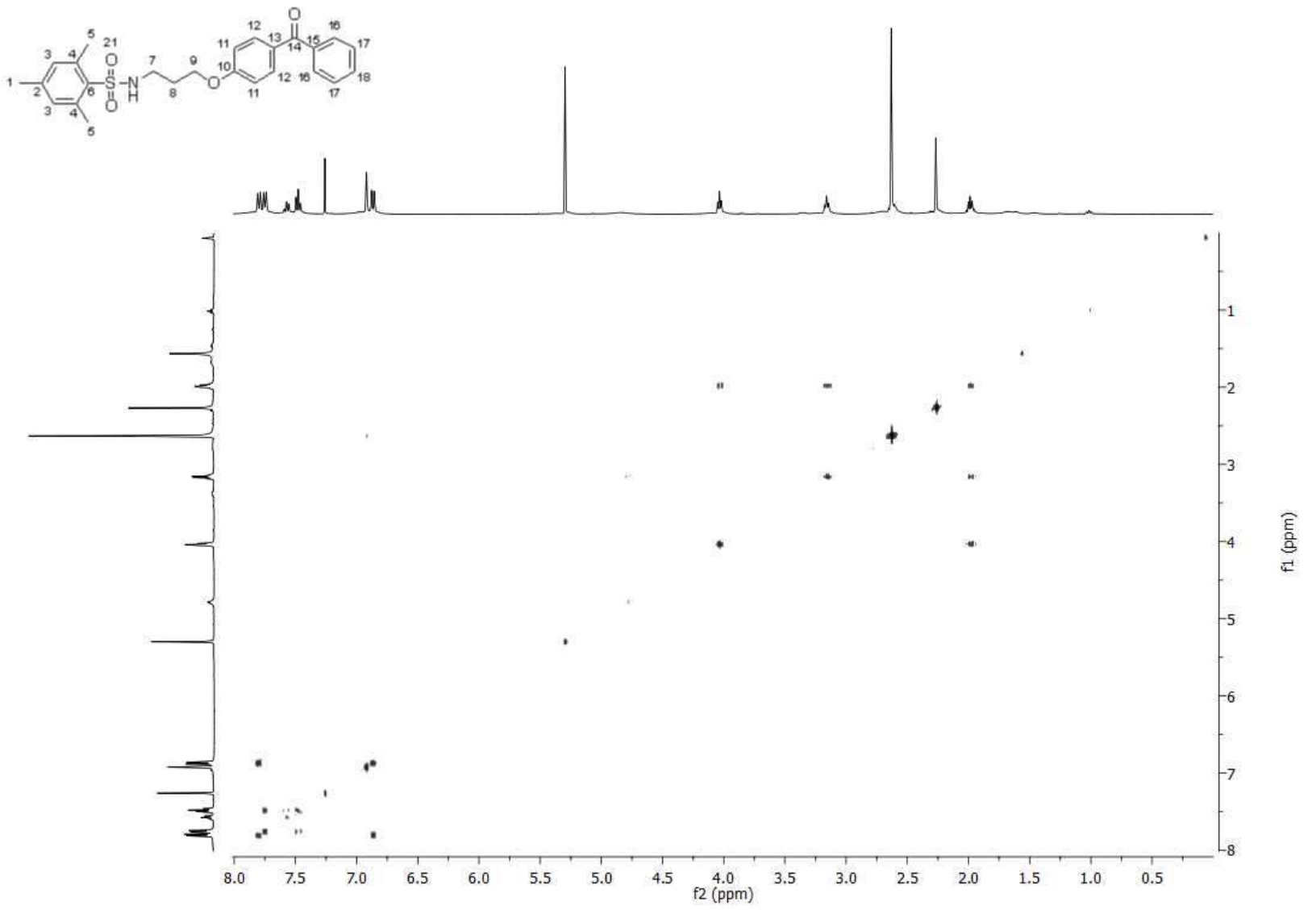

Figure (B) 96 - COSY 2D NMR $\left(\mathrm{CDCl}_{3}\right)$ spectrum of $11 \mathbf{a}$. 


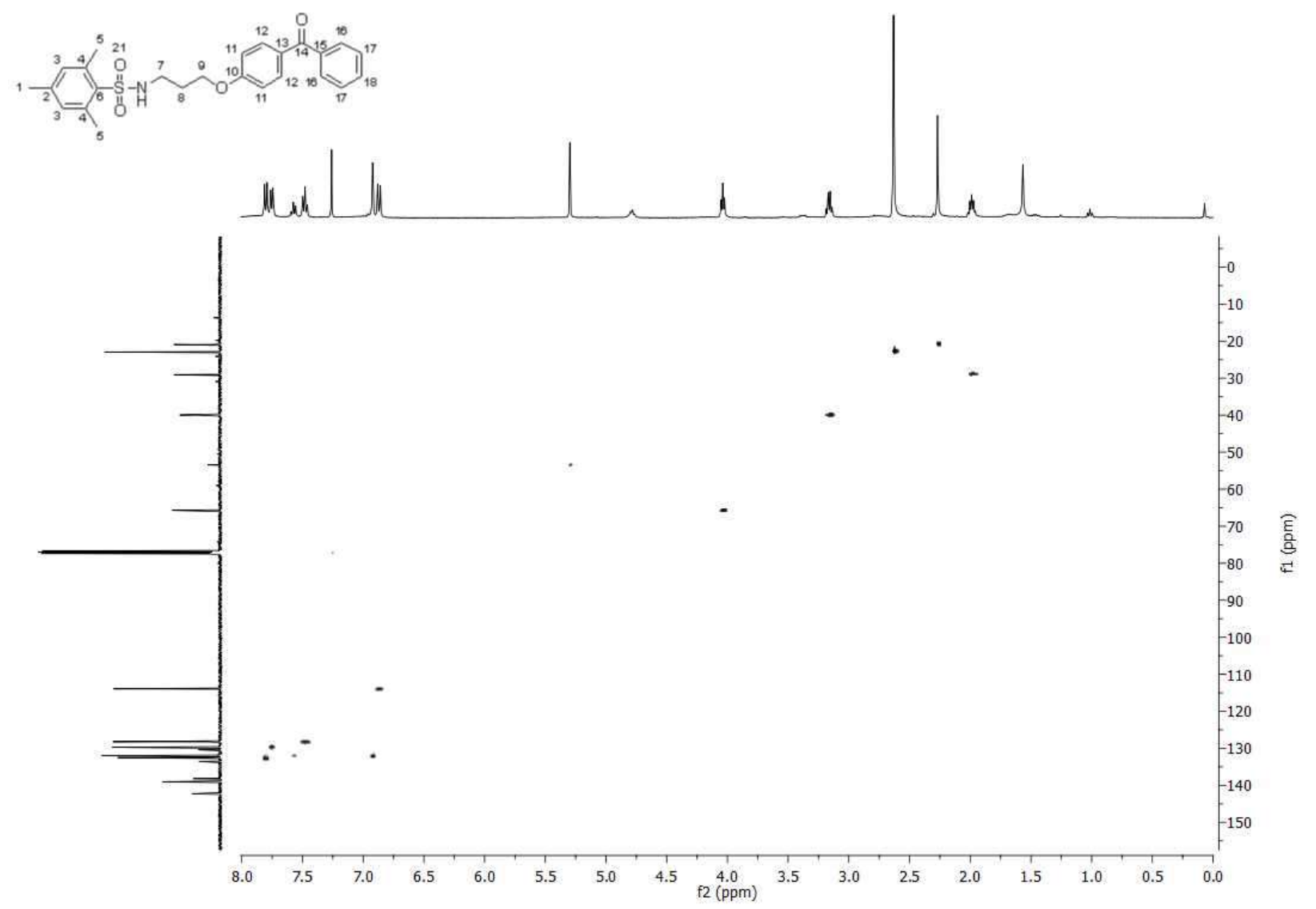

Figure (B) 97 - HSQC 2D NMR $\left(\mathrm{CDCl}_{3}\right)$ spectrum of 11a. 


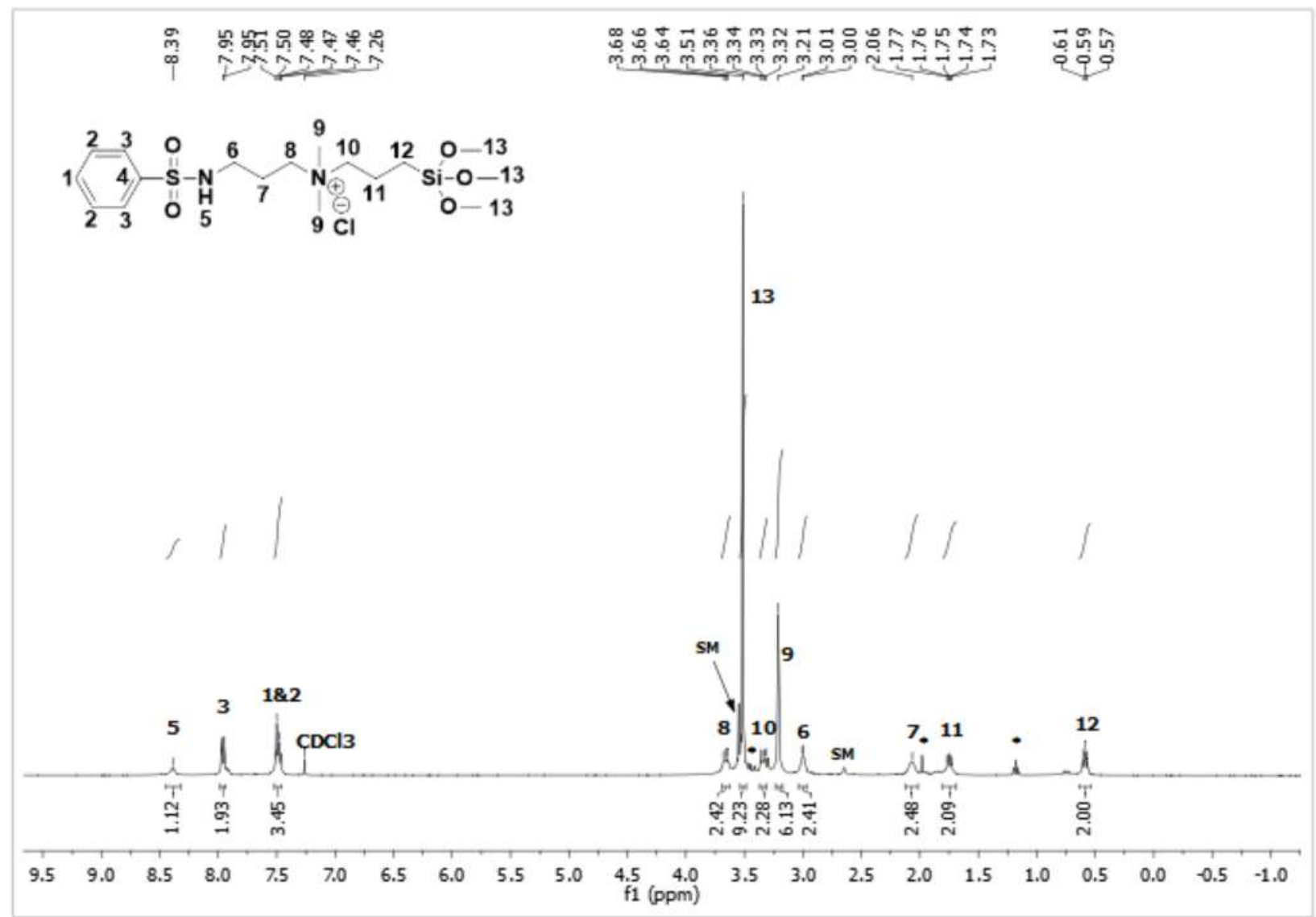

Figure (B) $98-{ }^{1} \mathrm{H} \mathrm{NMR}\left(400 \mathrm{MHz}, \mathrm{CDCl}_{3}\right)$ spectrum of $\mathbf{3 b}$. 


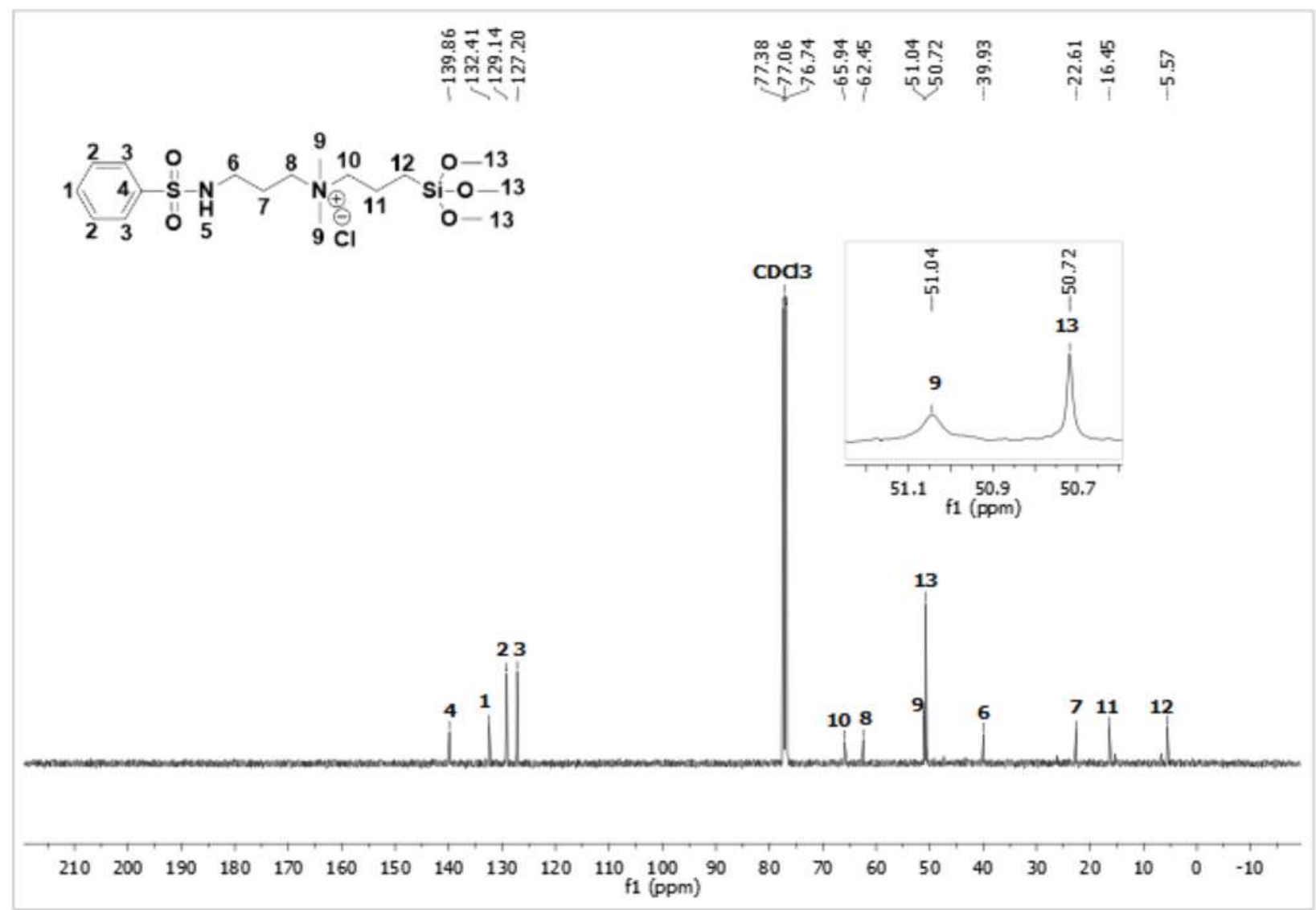

Figure (B) $99-{ }^{13} \mathrm{C} \mathrm{NMR}\left(101 \mathrm{MHz}, \mathrm{CDCl}_{3}\right)$ spectrum of $\mathbf{3 b}$. 


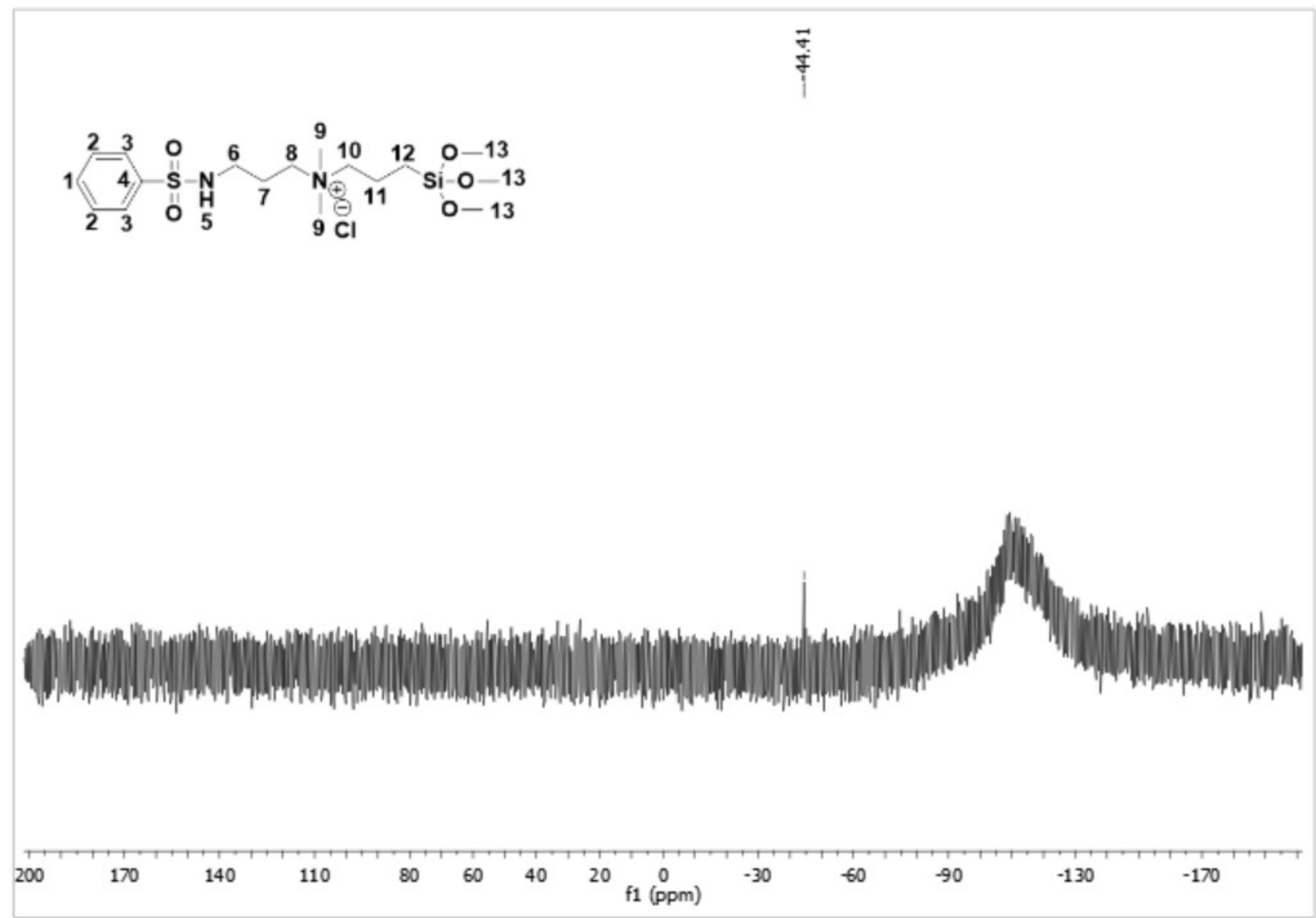

Figure (B) $100-{ }^{29} \mathrm{Si} \mathrm{NMR}\left(79 \mathrm{MHz}, \mathrm{CDCl}_{3}\right)$ spectrum of $\mathbf{3 b}$. 


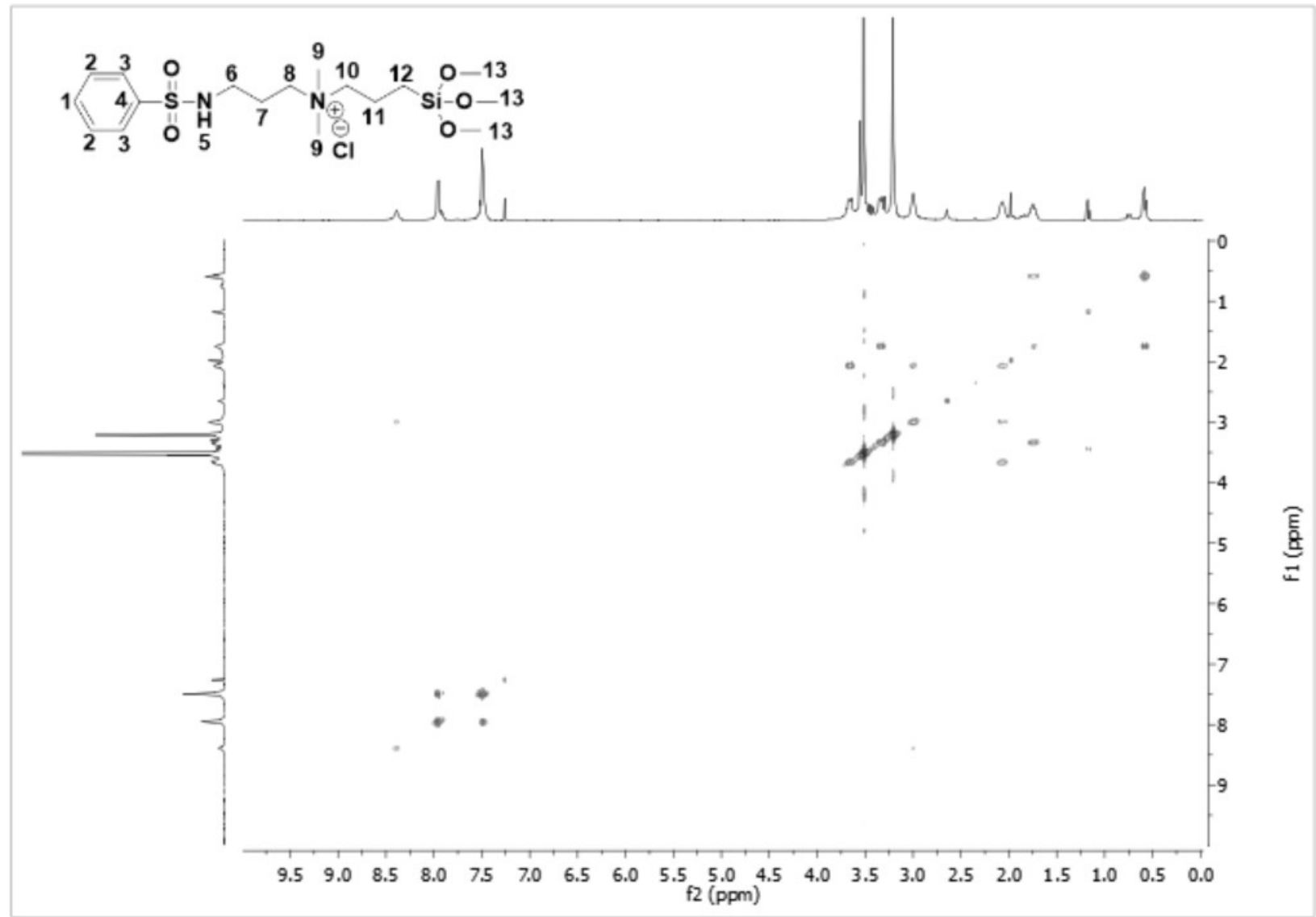

Figure (B) 101 - COSY 2D NMR $\left(\mathrm{CDCl}_{3}\right)$ spectrum of $\mathbf{3 b}$. 


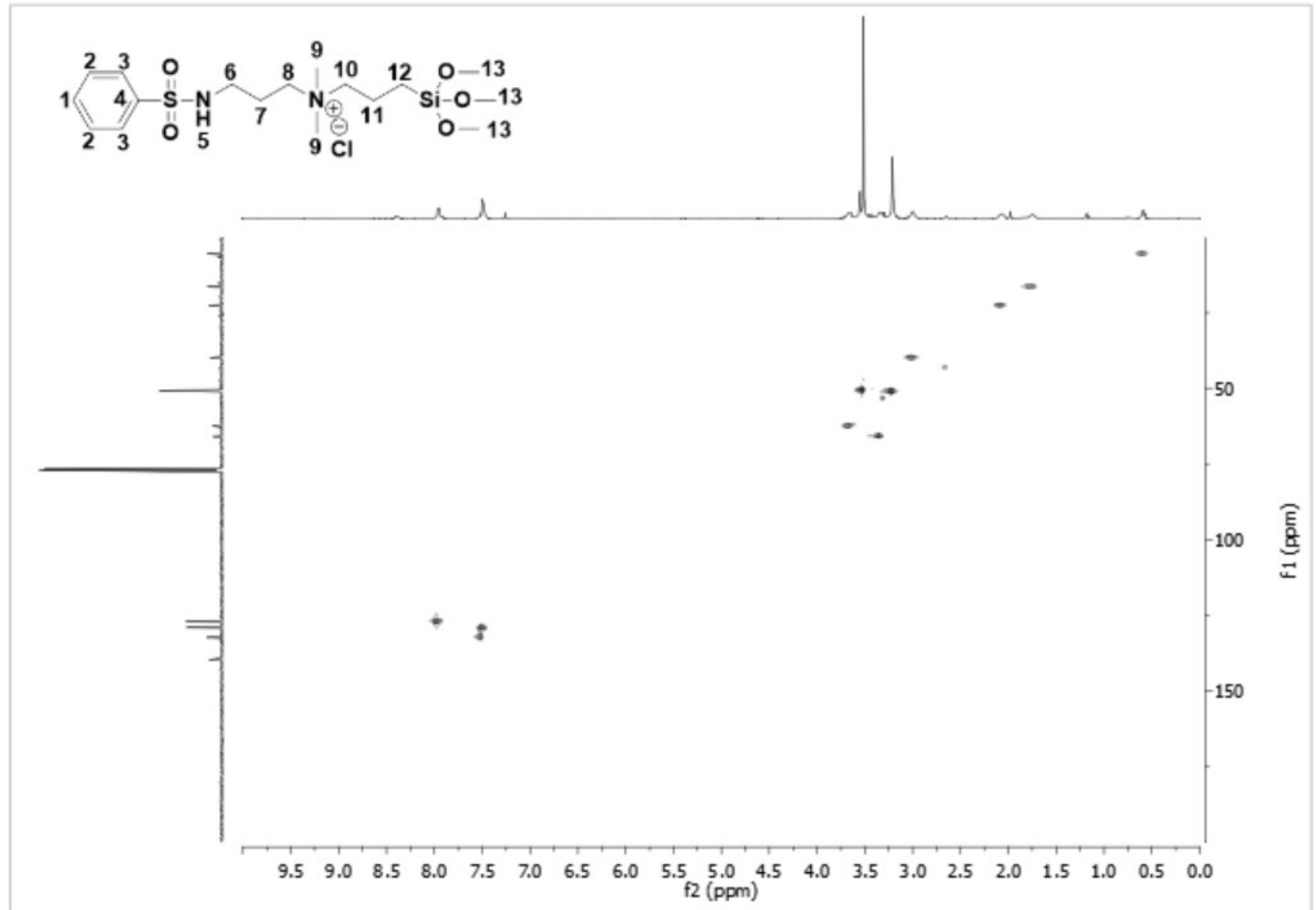

Figure (B) $102-\mathrm{HSQC} 2 \mathrm{D}$ NMR $\left(\mathrm{CDCl}_{3}\right)$ spectrum of $\mathbf{3 b}$. 


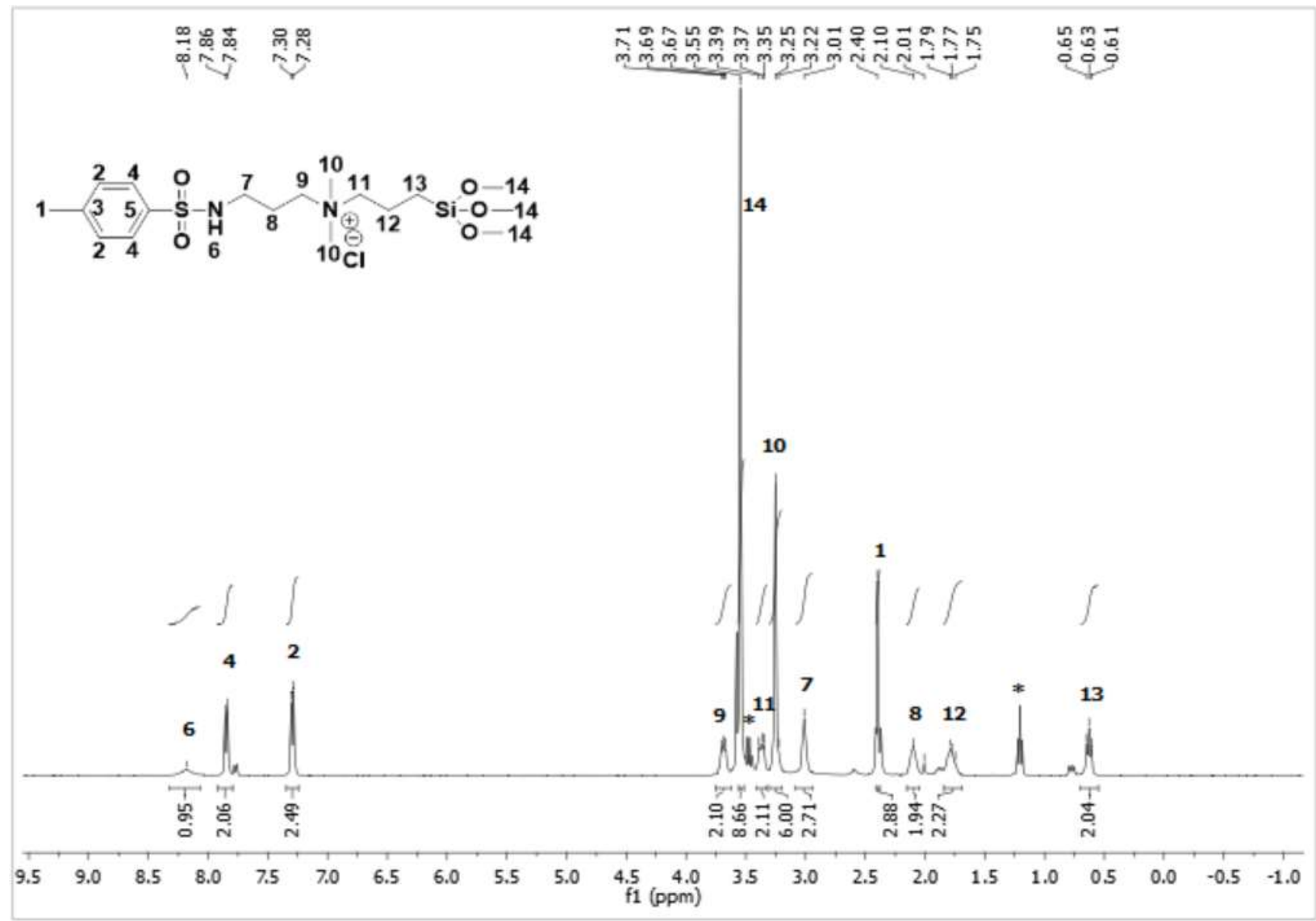

Figure (B) $103-{ }^{1} \mathrm{H}$ NMR $\left(400 \mathrm{MHz}, \mathrm{CDCl}_{3}\right)$ spectrum of $\mathbf{4 b}$. 


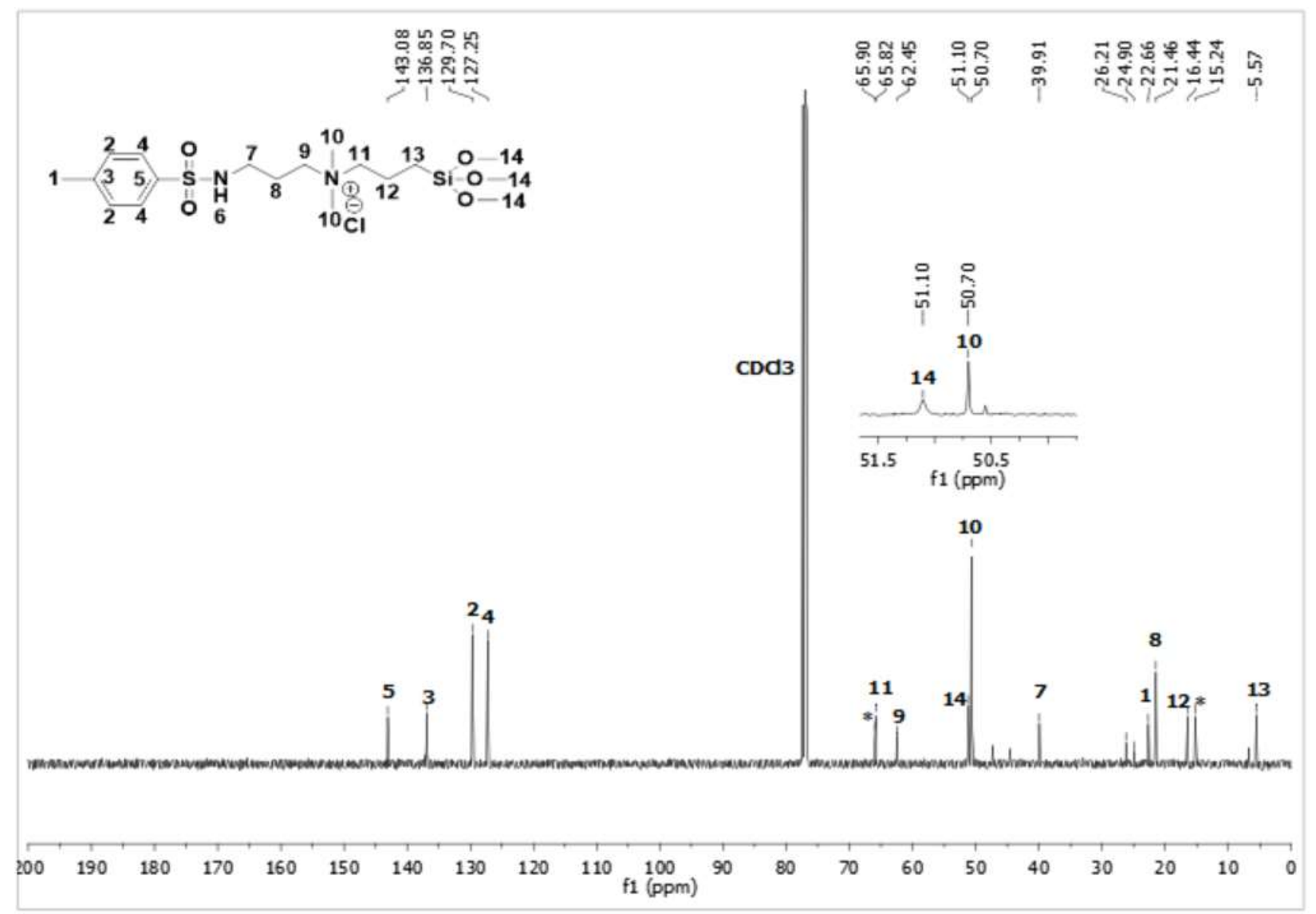

Figure (B) $104-{ }^{13} \mathrm{C}$ NMR $\left(101 \mathrm{MHz}, \mathrm{CDCl}_{3}\right)$ spectrum of $\mathbf{4 b}$. 


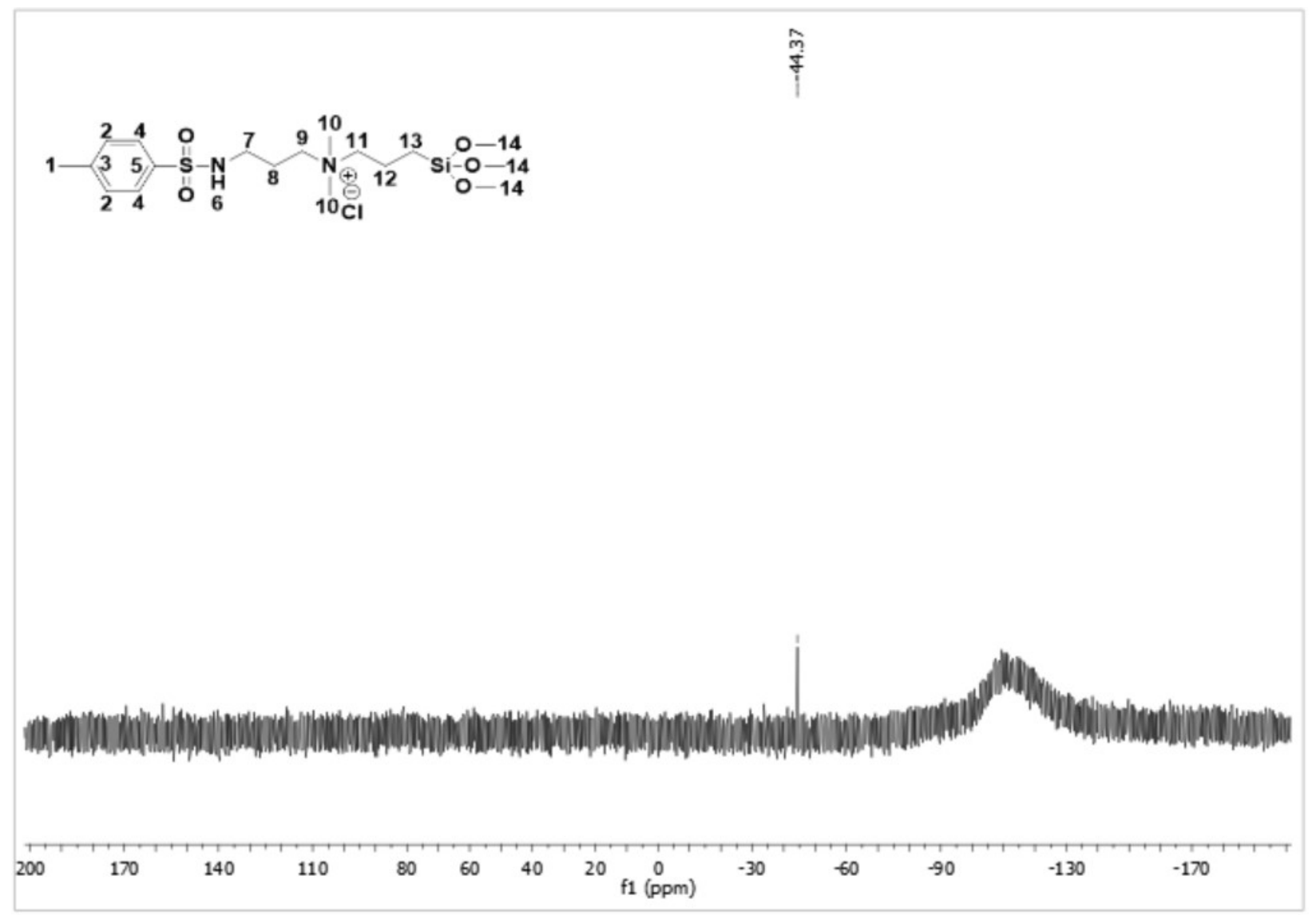

Figure (B) $105-{ }^{29} \mathrm{Si} \mathrm{NMR}\left(79 \mathrm{MHz}, \mathrm{CDCl}_{3}\right)$ spectrum of $\mathbf{4 b}$. 


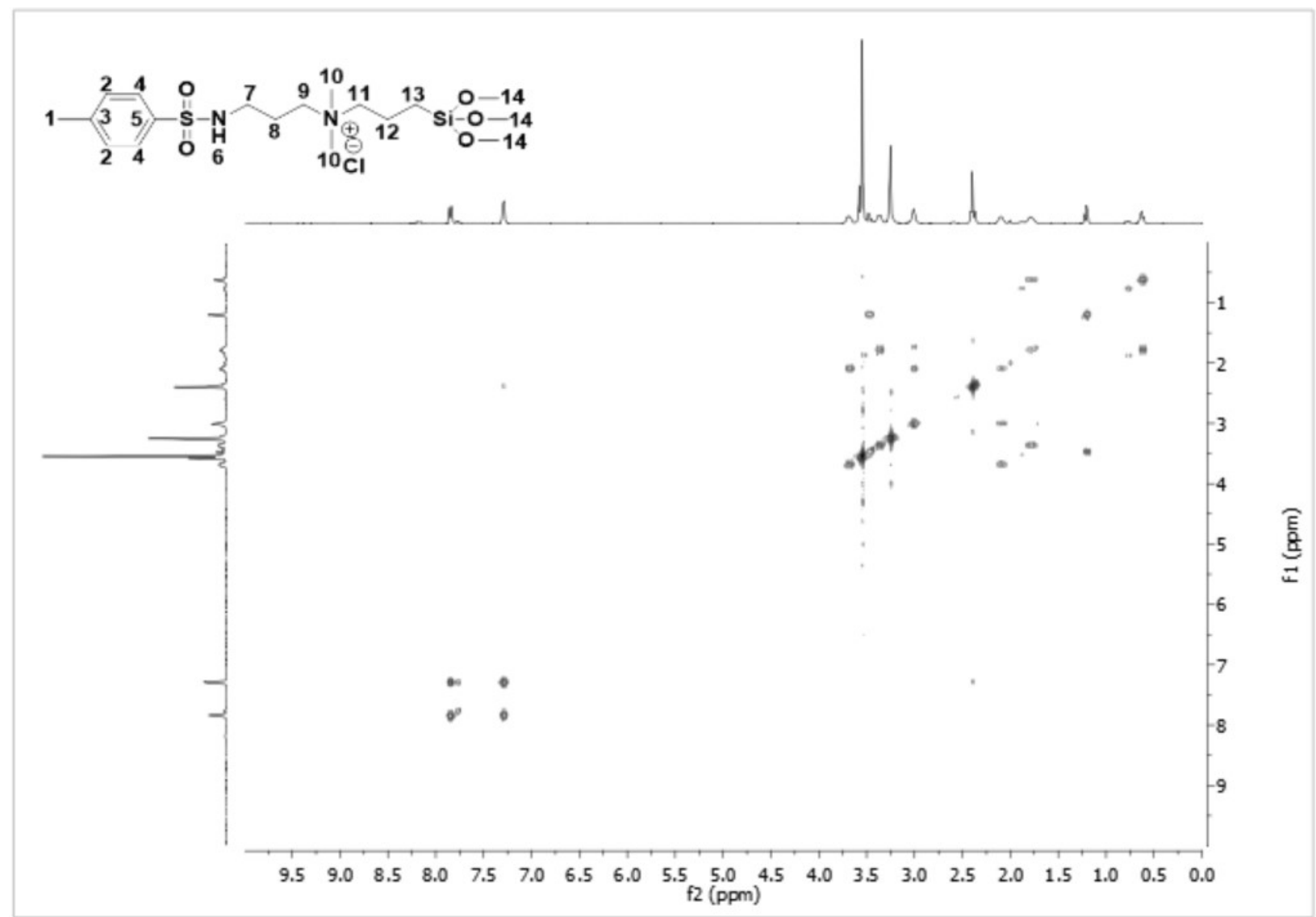

Figure (B) 106 - COSY 2D NMR $\left(\mathrm{CDCl}_{3}\right)$ spectrum of $\mathbf{4 b}$. 


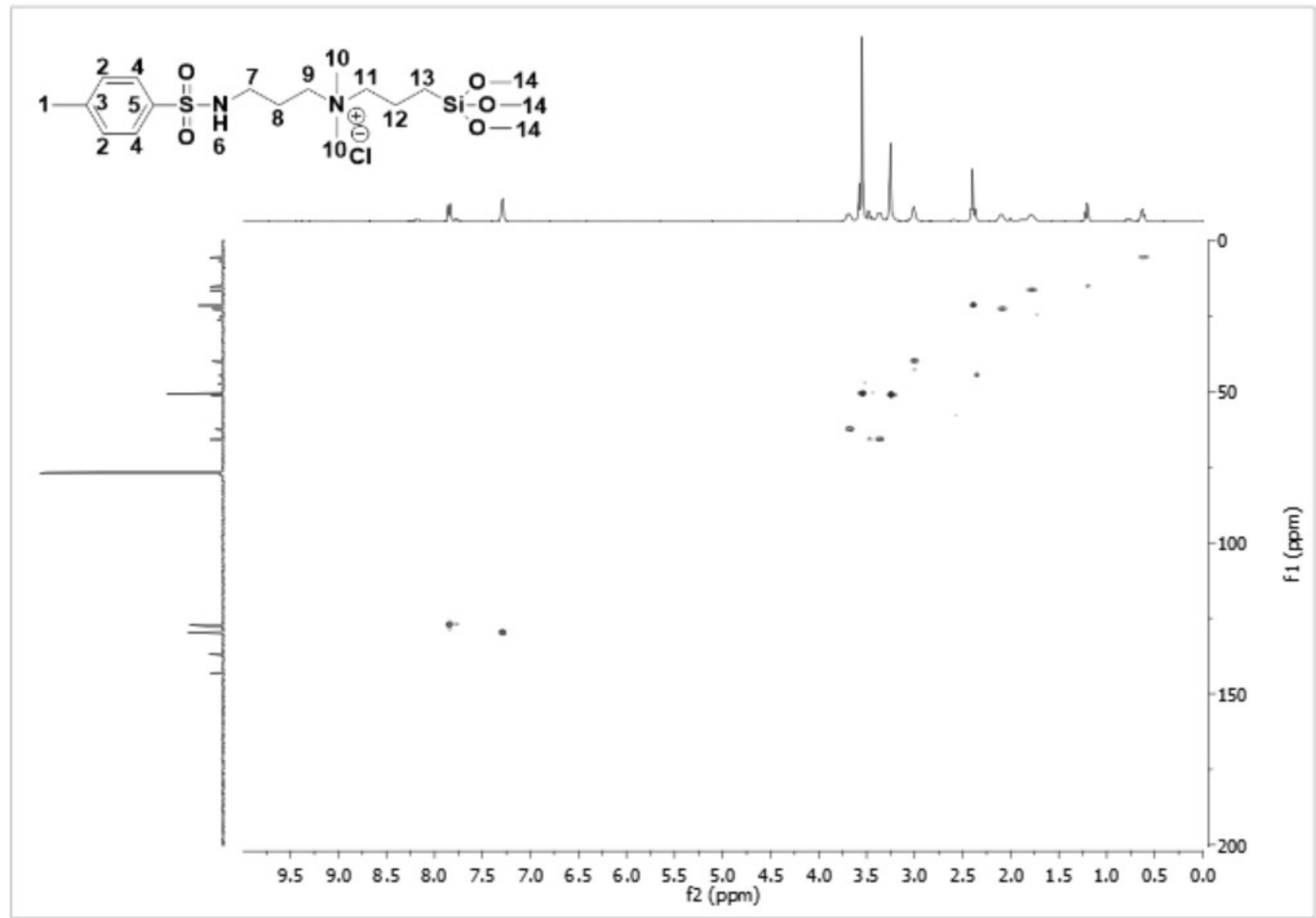

Figure (B) 107 - HSQC 2D NMR $\left(\mathrm{CDCl}_{3}\right)$ spectrum of $\mathbf{4 b}$. 


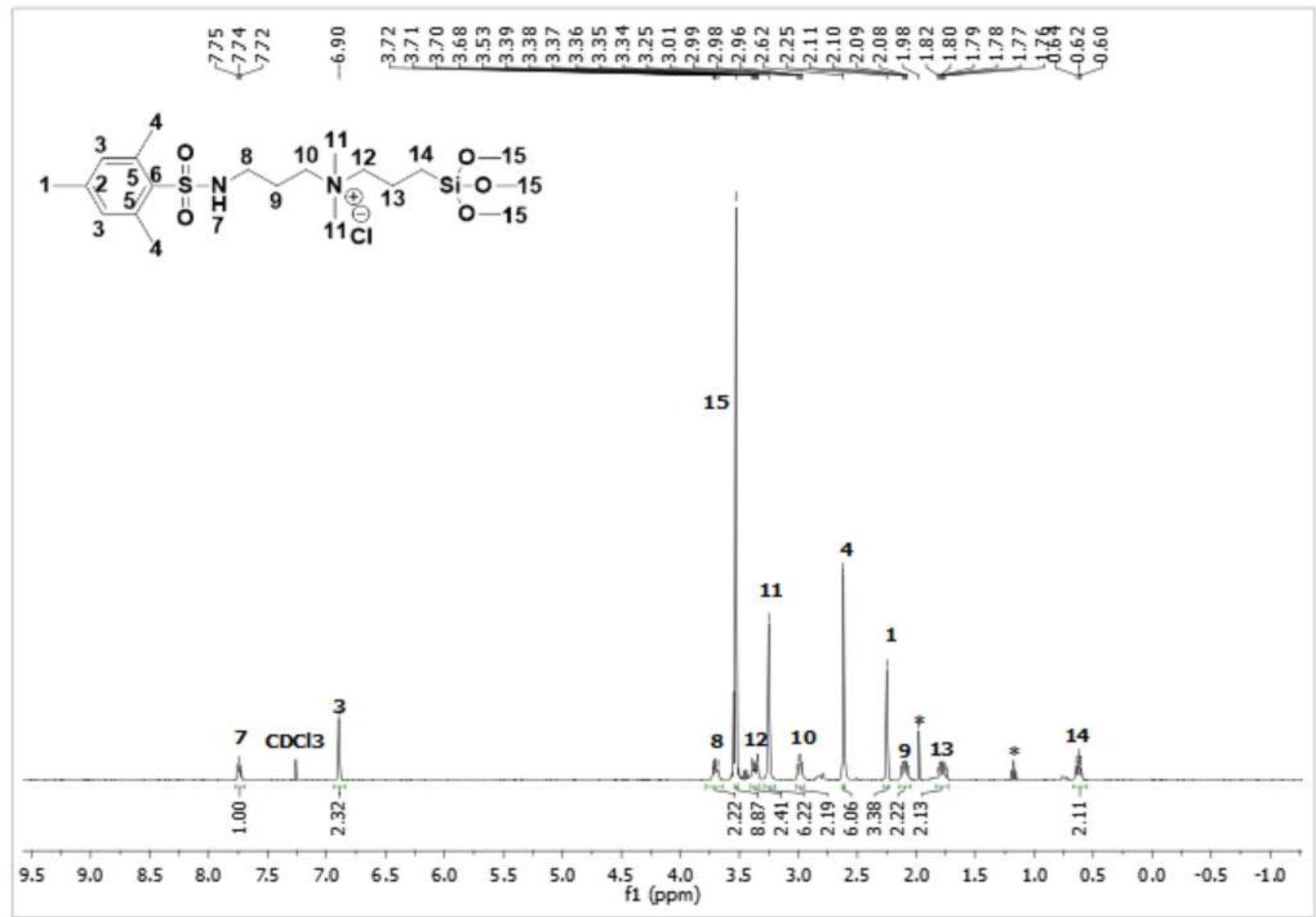

Figure (B) $108-{ }^{1} \mathrm{H}$ NMR $\left(400 \mathrm{MHz}, \mathrm{CDCl}_{3}\right)$ spectrum of $\mathbf{5 b}$. 


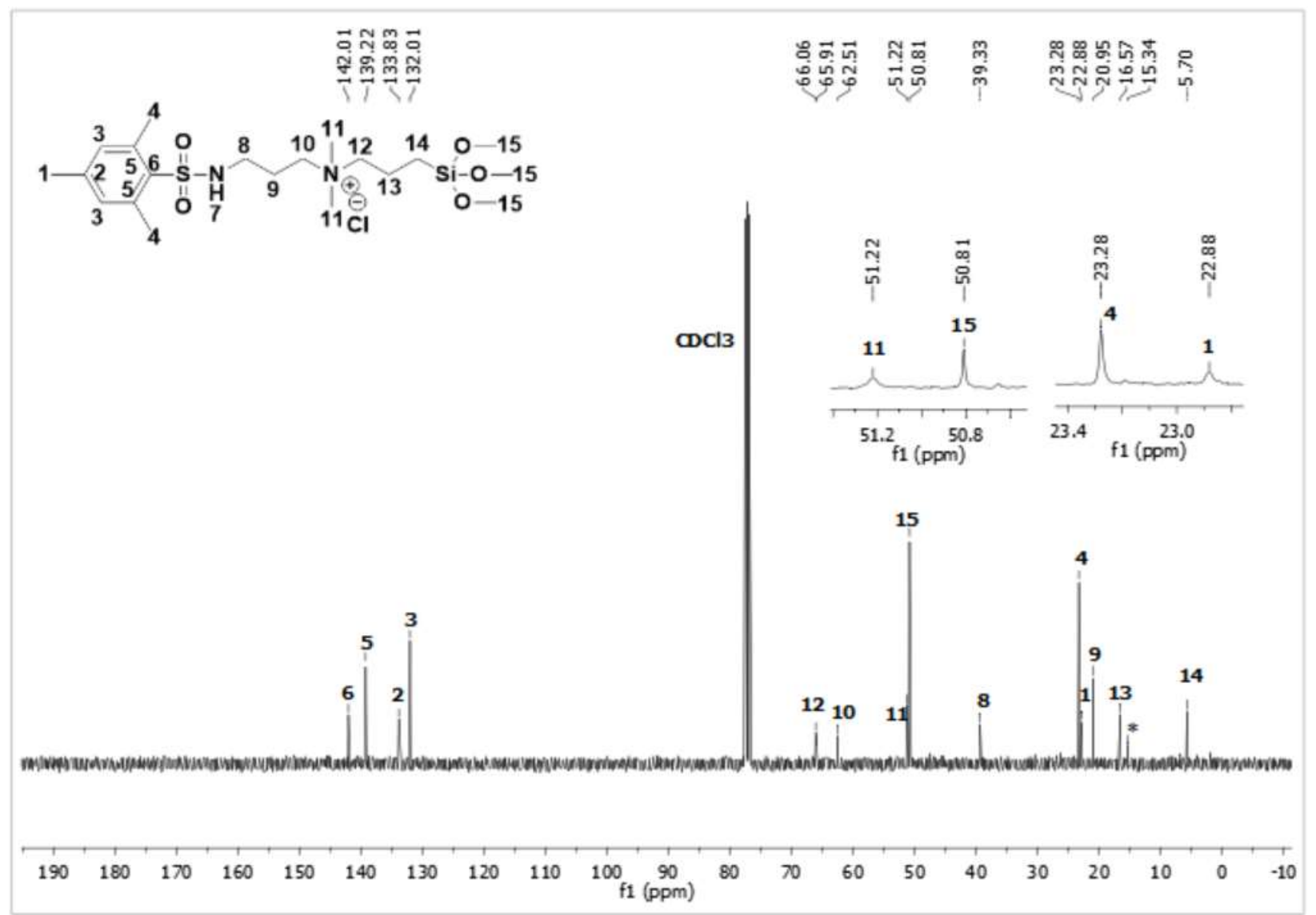

Figure (B) $109-{ }^{13} \mathrm{C} \mathrm{NMR}\left(101 \mathrm{MHz}, \mathrm{CDCl}_{3}\right)$ spectrum of $\mathbf{5 b}$. 


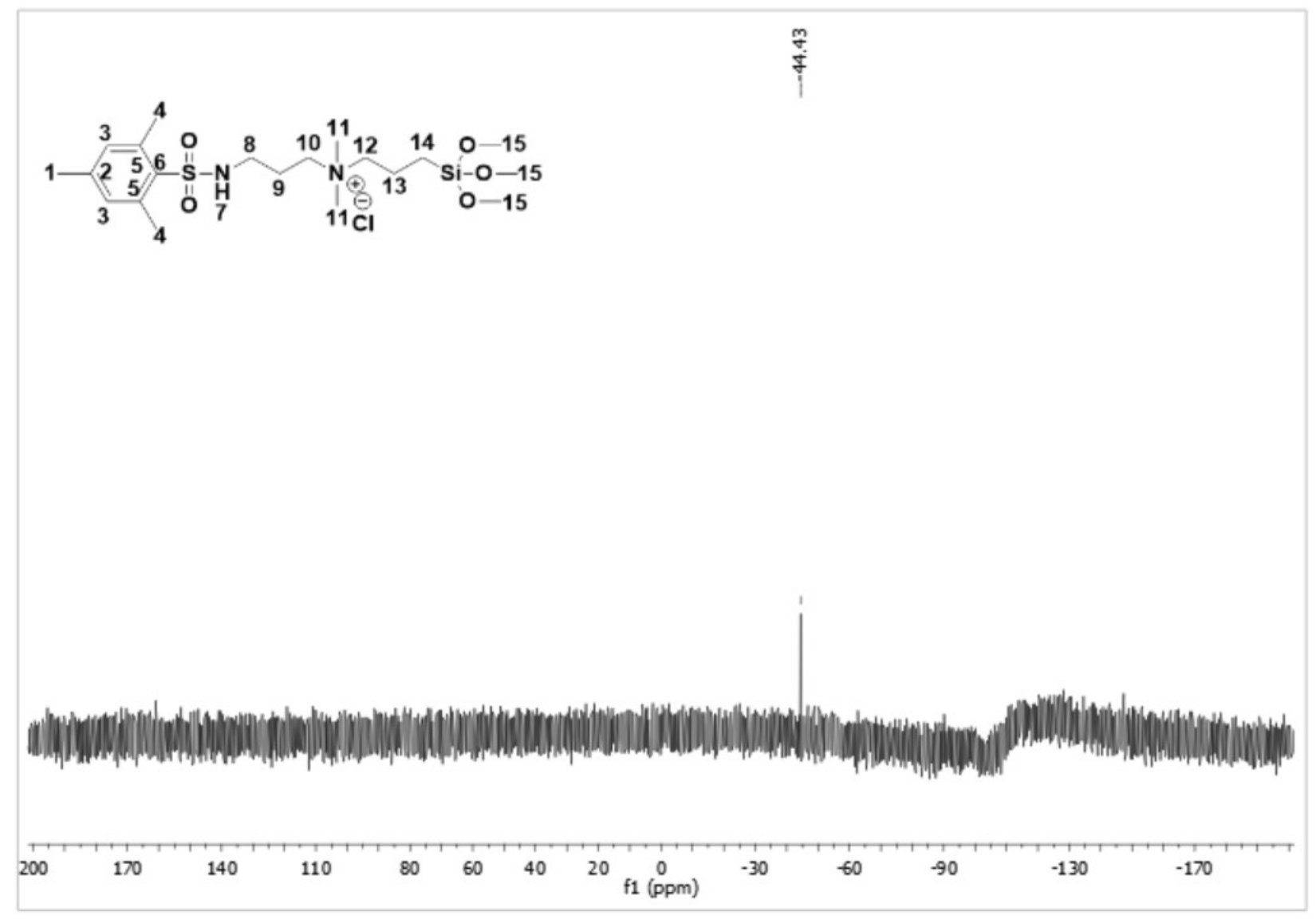

Figure (B) $110-{ }^{29} \mathrm{Si} \mathrm{NMR}\left(79 \mathrm{MHz}, \mathrm{CDCl}_{3}\right)$ spectrum of $\mathbf{5 b}$. 


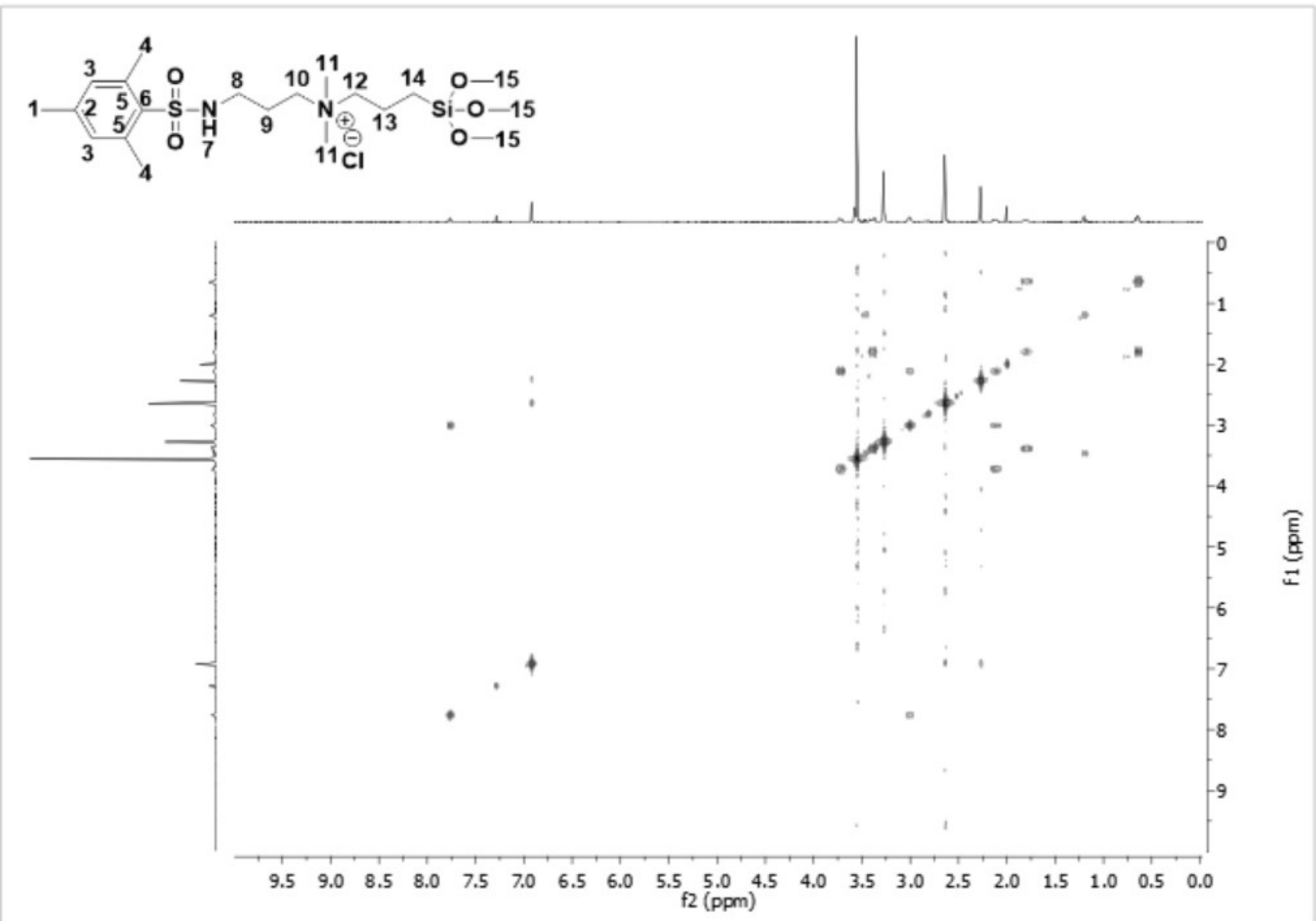

Figure (B) 111 - COSY 2D NMR $\left(\mathrm{CDCl}_{3}\right)$ spectrum of $\mathbf{5 b}$. 


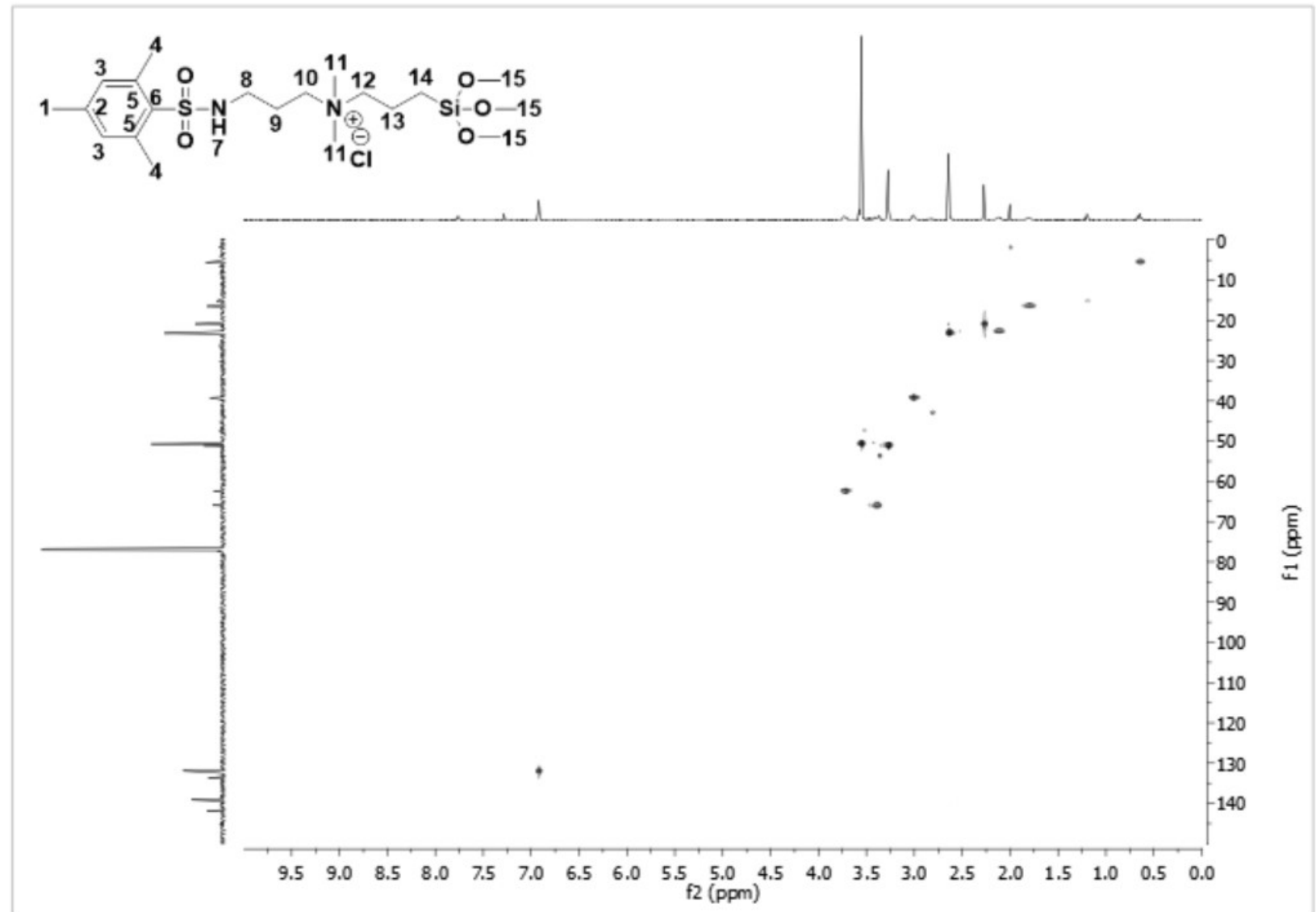

Figure (B) 112 - HSQC 2D NMR $\left(\mathrm{CDCl}_{3}\right)$ spectrum of $\mathbf{5 b}$. 


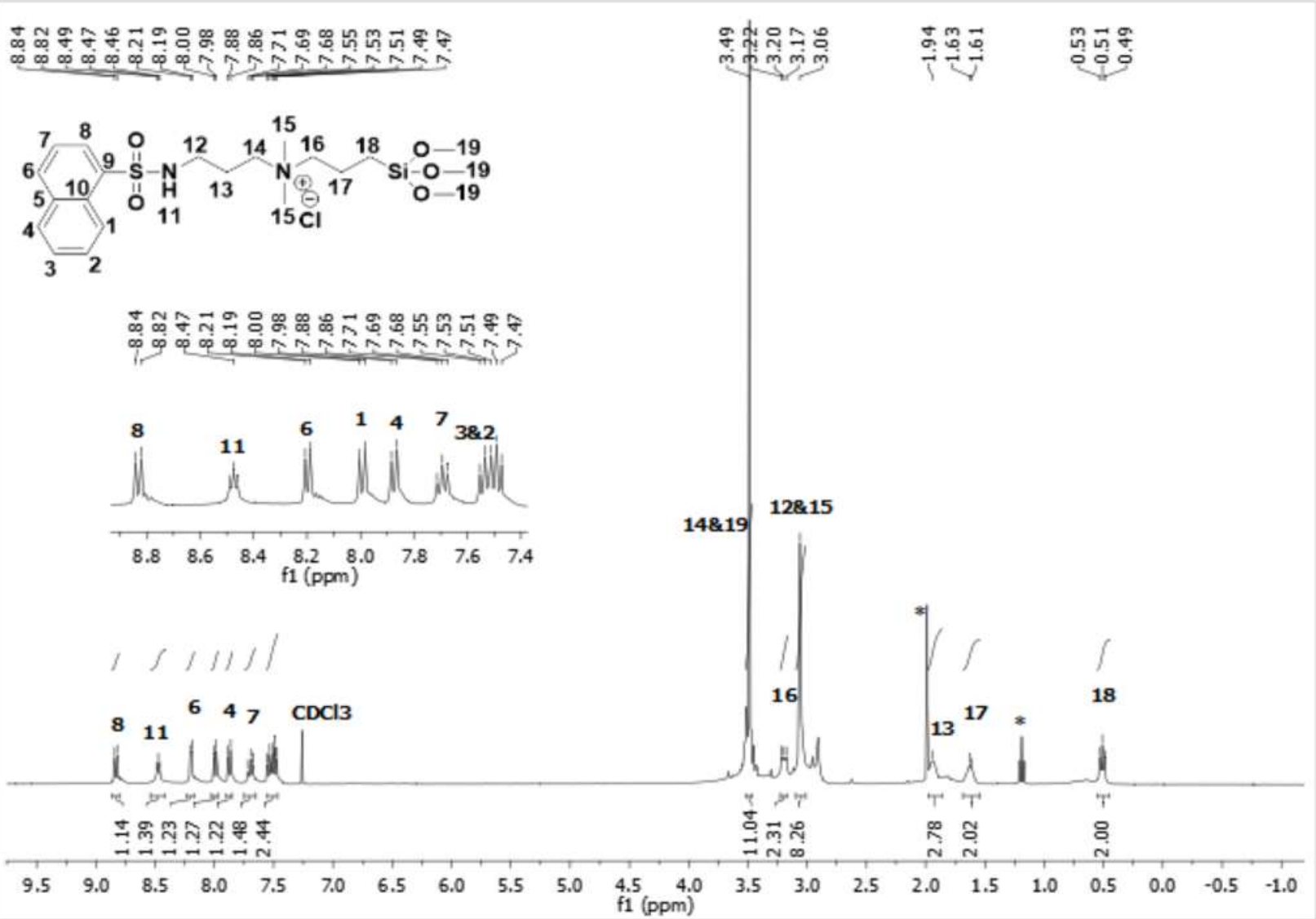

Figure (B) $113-{ }^{1} \mathrm{H}$ NMR $\left(400 \mathrm{MHz}, \mathrm{CDCl}_{3}\right)$ spectrum of $\mathbf{6 b}$. 


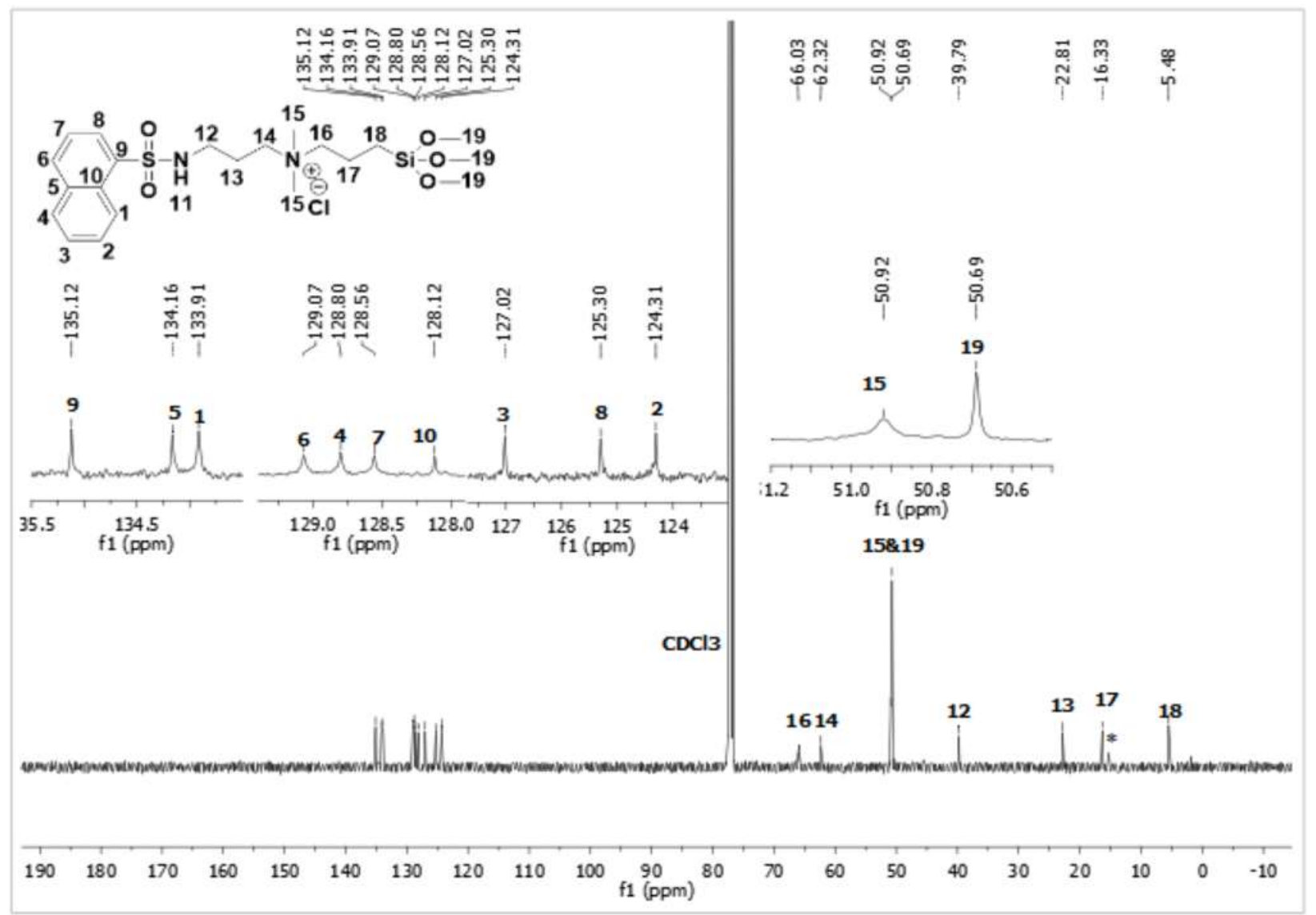

Figure (B) $114-{ }^{13} \mathrm{C}$ NMR (101 MHz, $\left.\mathrm{CDCl}_{3}\right)$ spectrum of $\mathbf{6 b}$. 


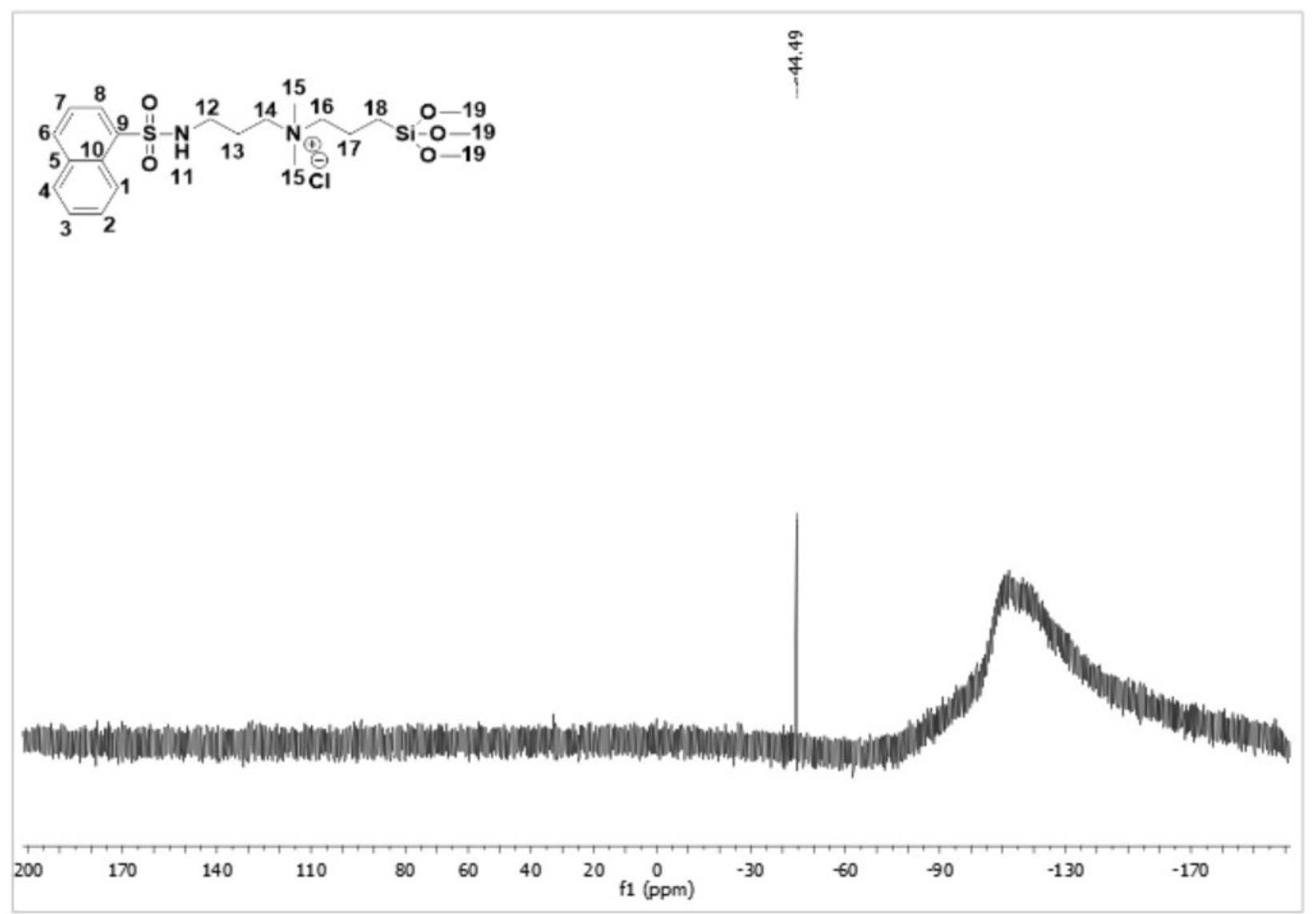

Figure (B) $115-{ }^{29} \mathrm{Si} \mathrm{NMR}\left(79 \mathrm{MHz}, \mathrm{CDCl}_{3}\right)$ spectrum of $\mathbf{6 b}$. 


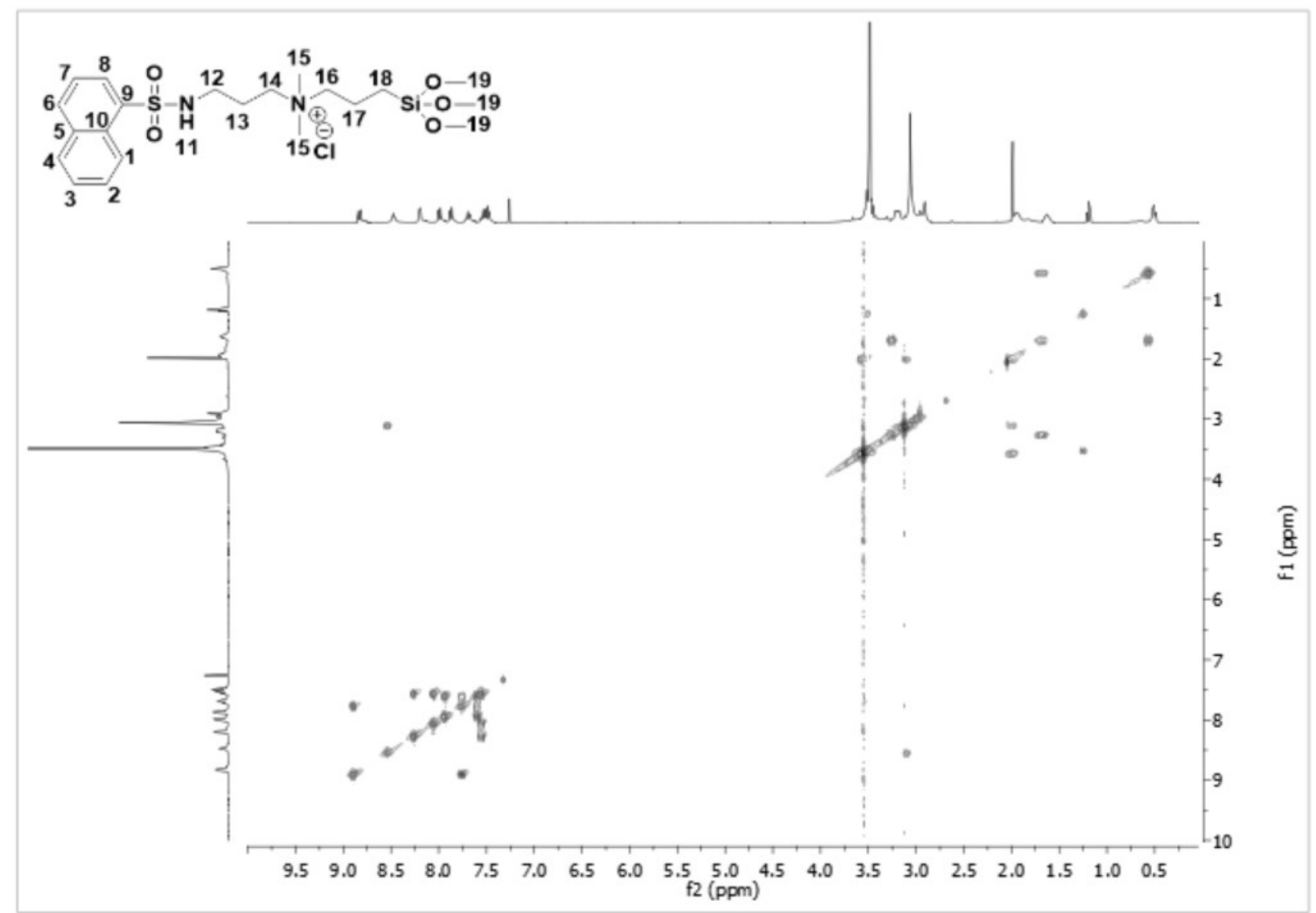

Figure (B) 116 - COSY 2D NMR $\left(\mathrm{CDCl}_{3}\right)$ spectrum of $\mathbf{6 b}$. 


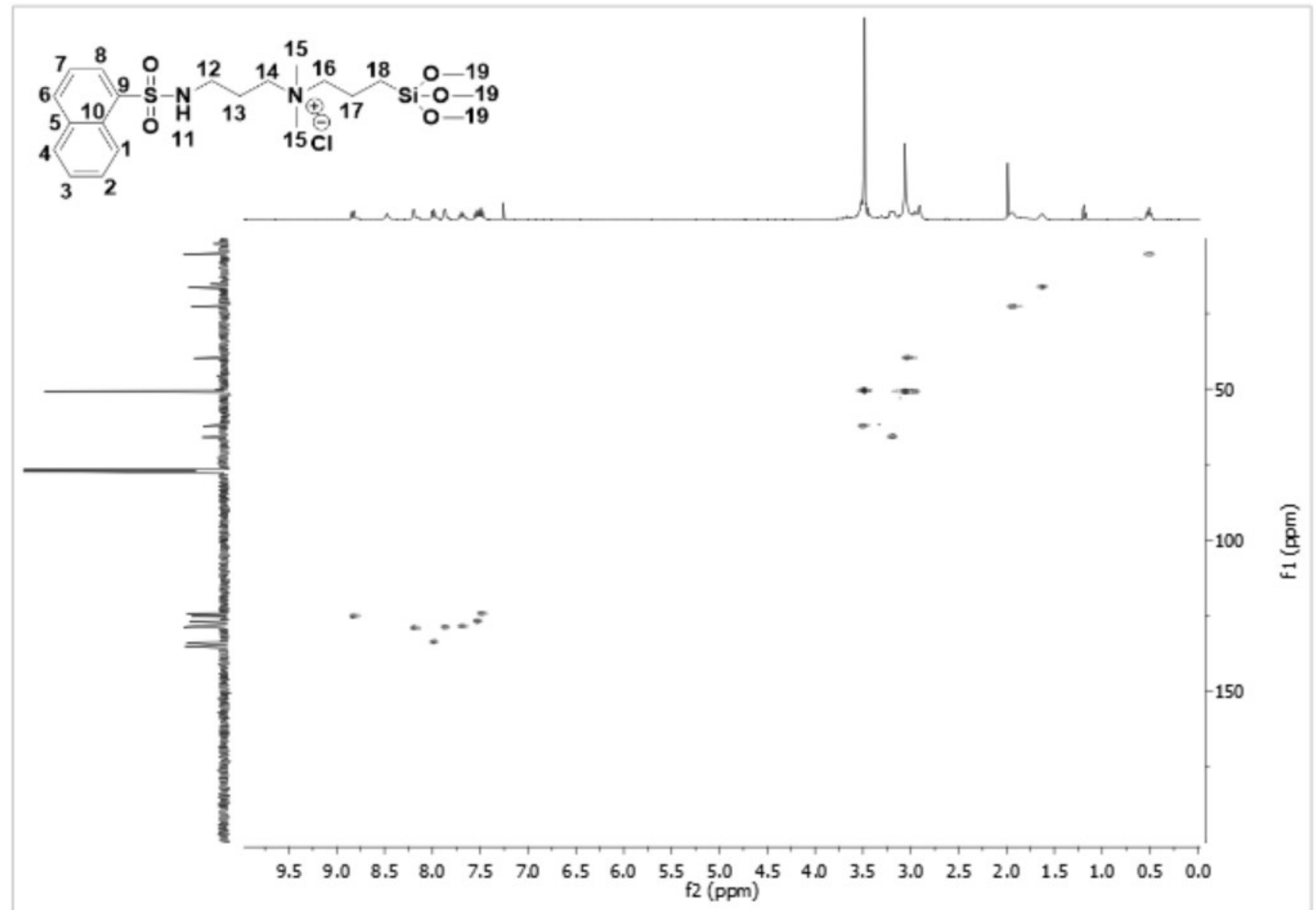

Figure (B) 117 - HSQC 2D NMR $\left(\mathrm{CDCl}_{3}\right)$ spectrum of $\mathbf{6 b}$. 


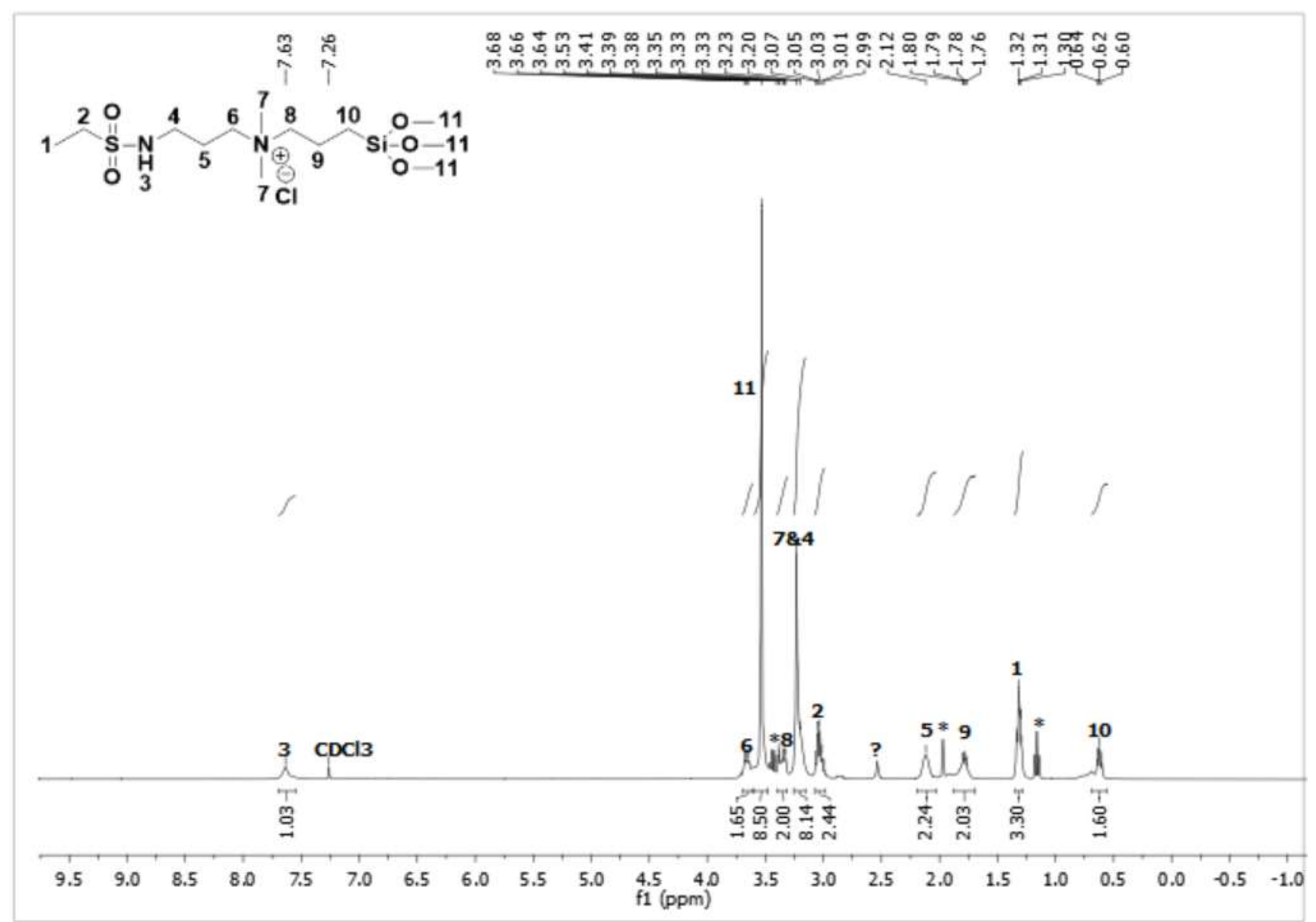

Figure (B) $118-{ }^{1} \mathrm{H}$ NMR $\left(400 \mathrm{MHz}, \mathrm{CDCl}_{3}\right)$ spectrum of $\mathbf{7 b}$. 


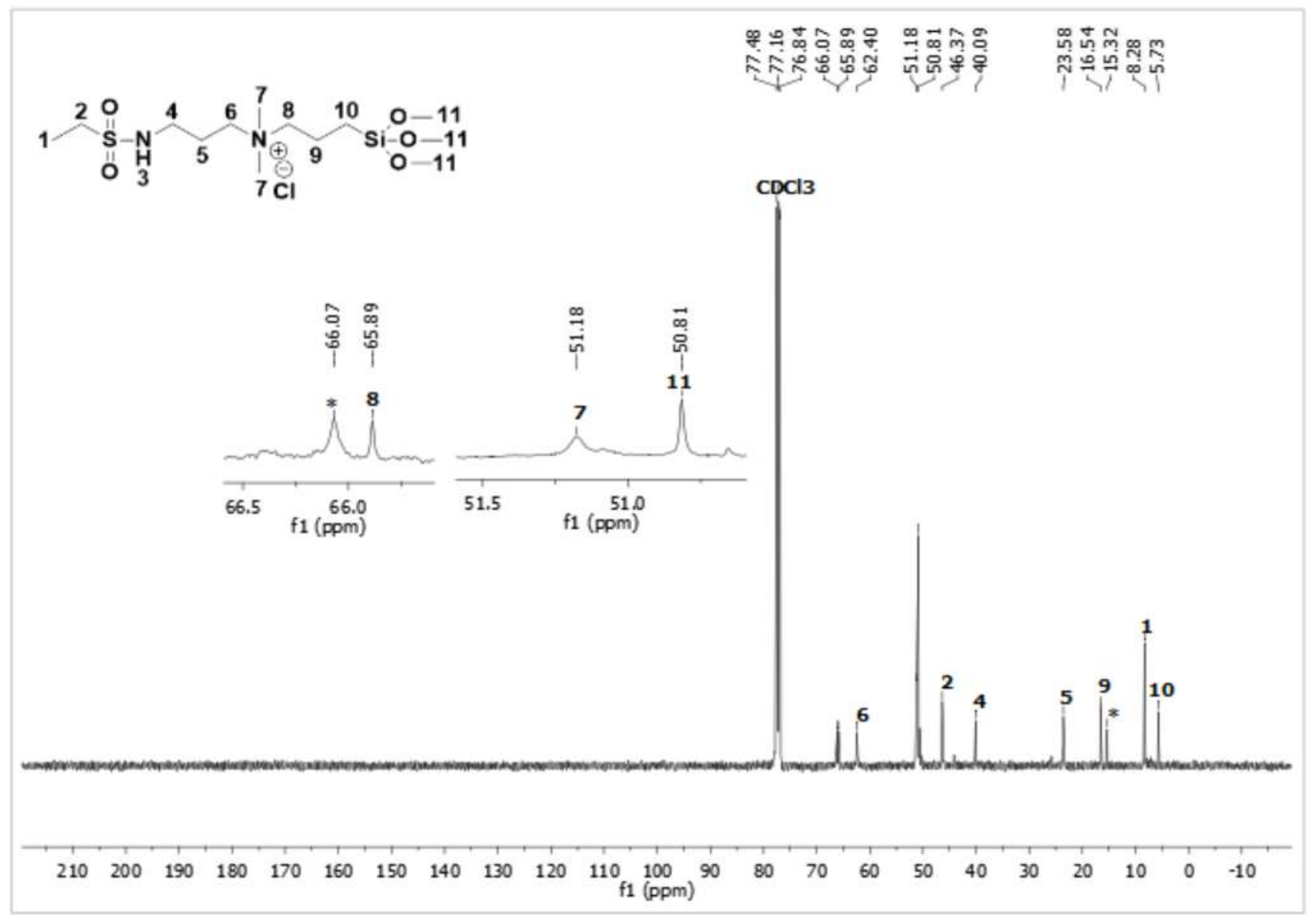

Figure (B) $119-{ }^{13} \mathrm{C} \mathrm{NMR}\left(101 \mathrm{MHz}, \mathrm{CDCl}_{3}\right)$ spectrum of $\mathbf{7 b}$. 


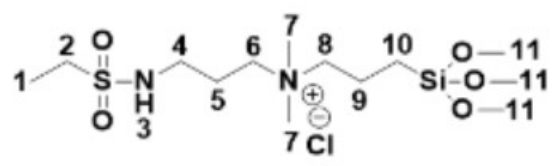

\section{$\overrightarrow{⿱ 乛 龰}$}

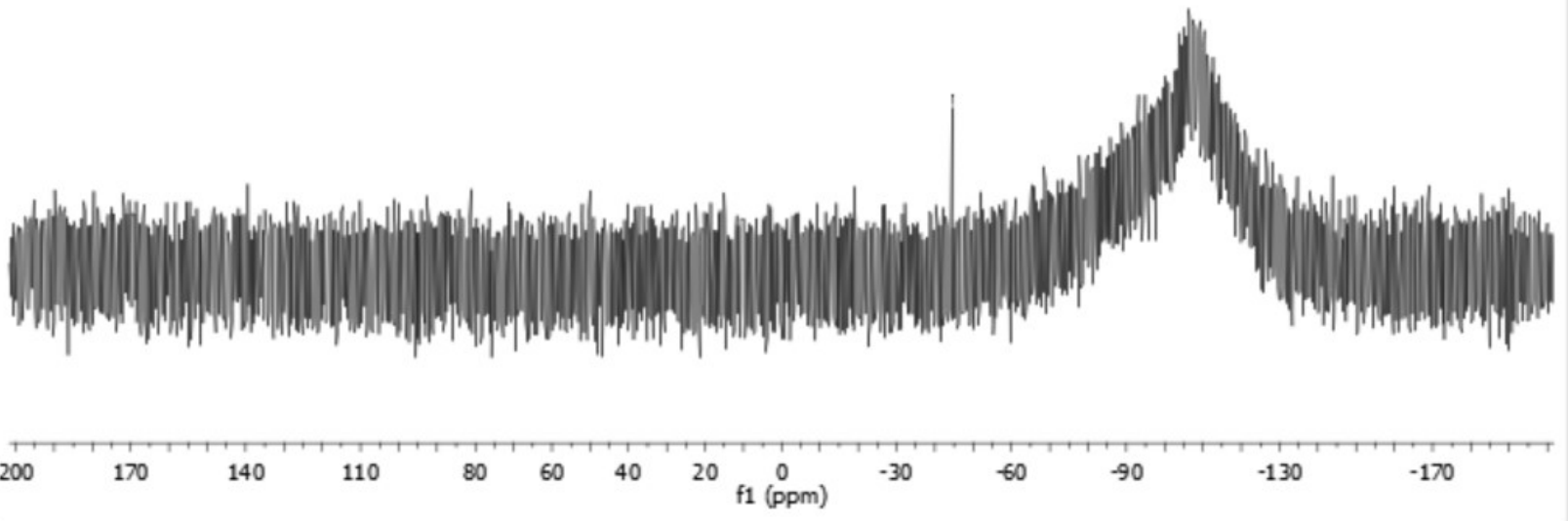

Figure (B) $120-{ }^{29} \mathrm{Si} \mathrm{NMR}\left(79 \mathrm{MHz}, \mathrm{CDCl}_{3}\right)$ spectrum of $\mathbf{7 b}$. 


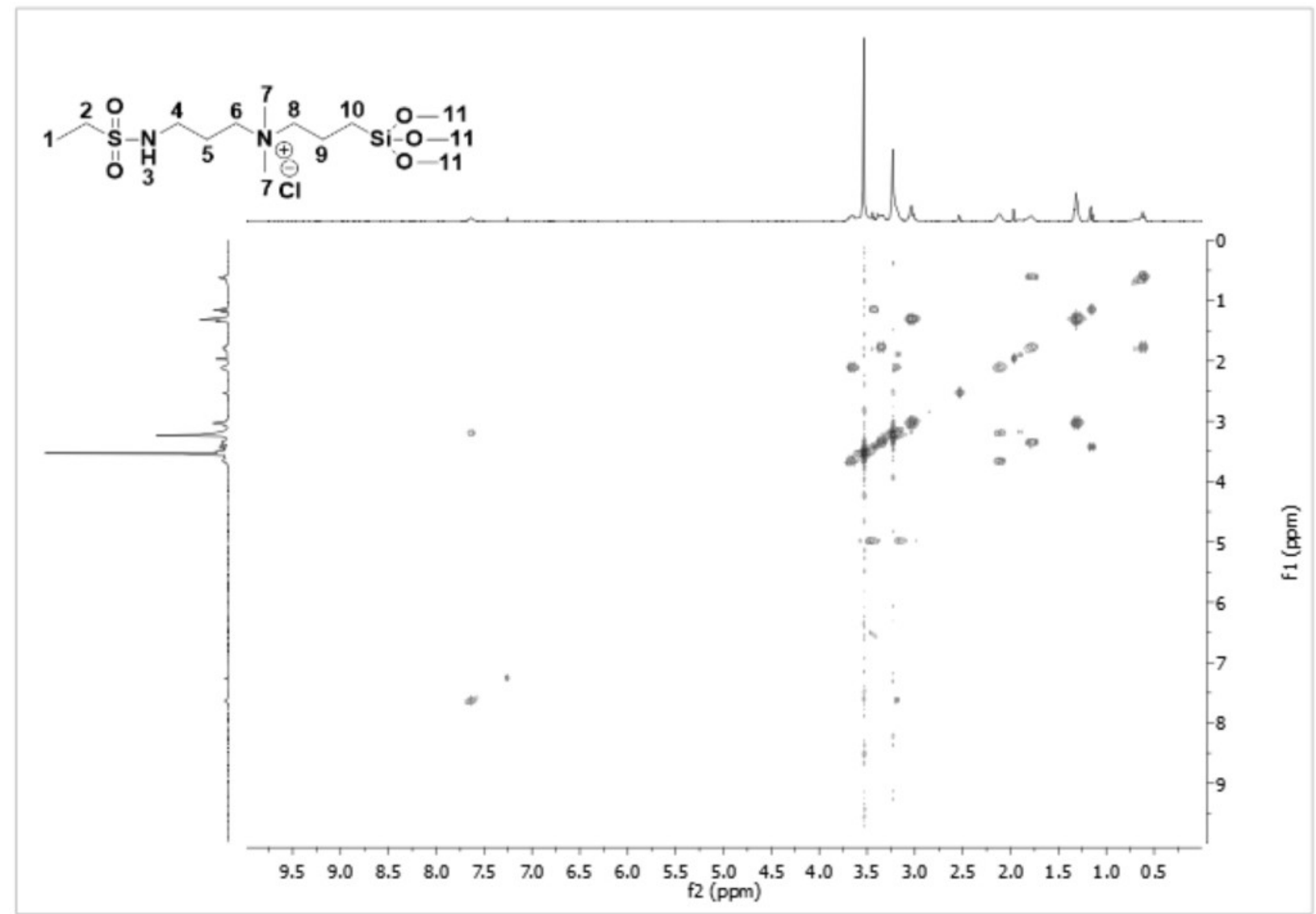

Figure (B) 121 - COSY 2D NMR $\left(\mathrm{CDCl}_{3}\right)$ spectrum of $\mathbf{7 b}$. 


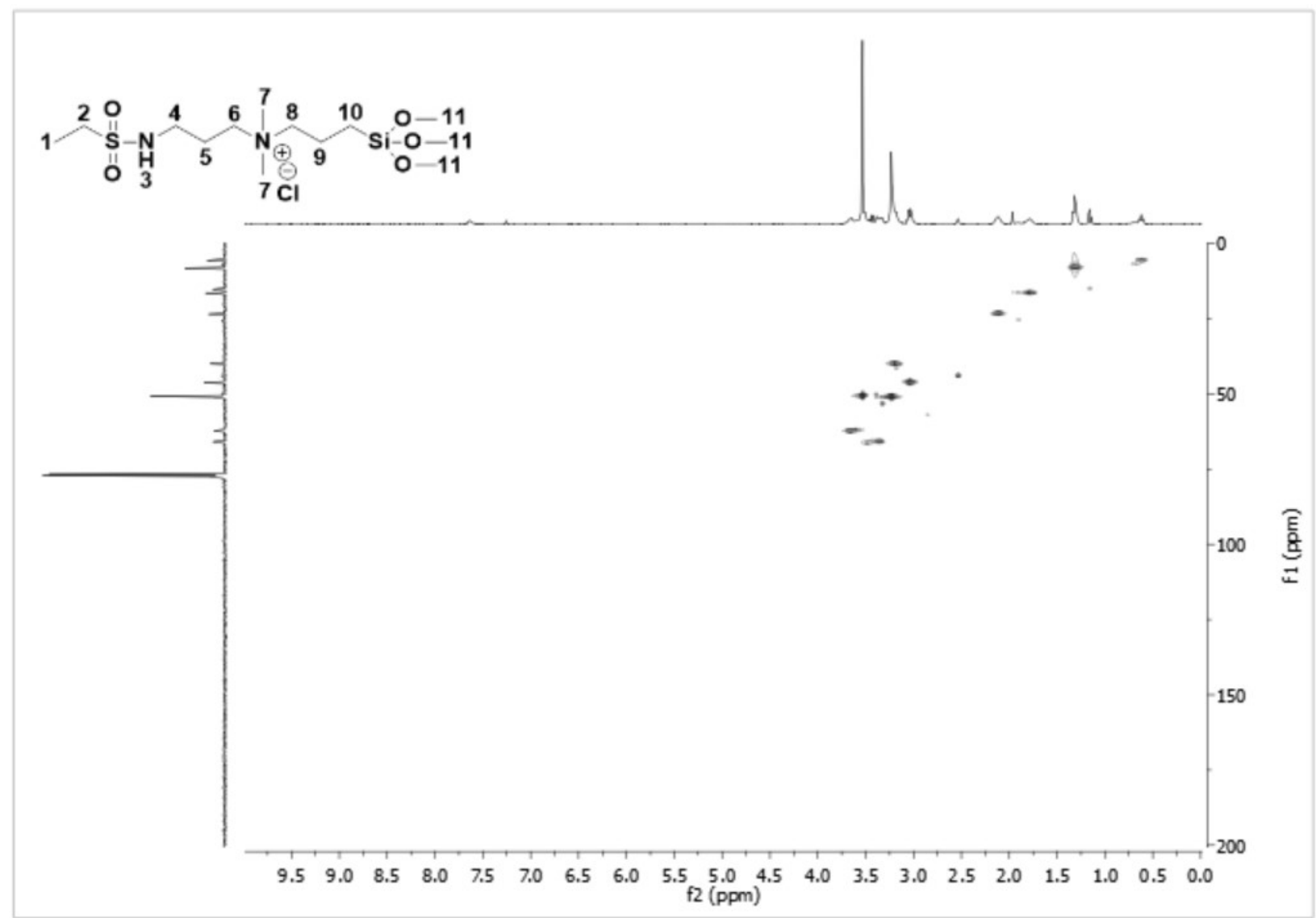

Figure (B) 122 - HSQC 2D NMR $\left(\mathrm{CDCl}_{3}\right)$ spectrum of $\mathbf{7 b}$. 


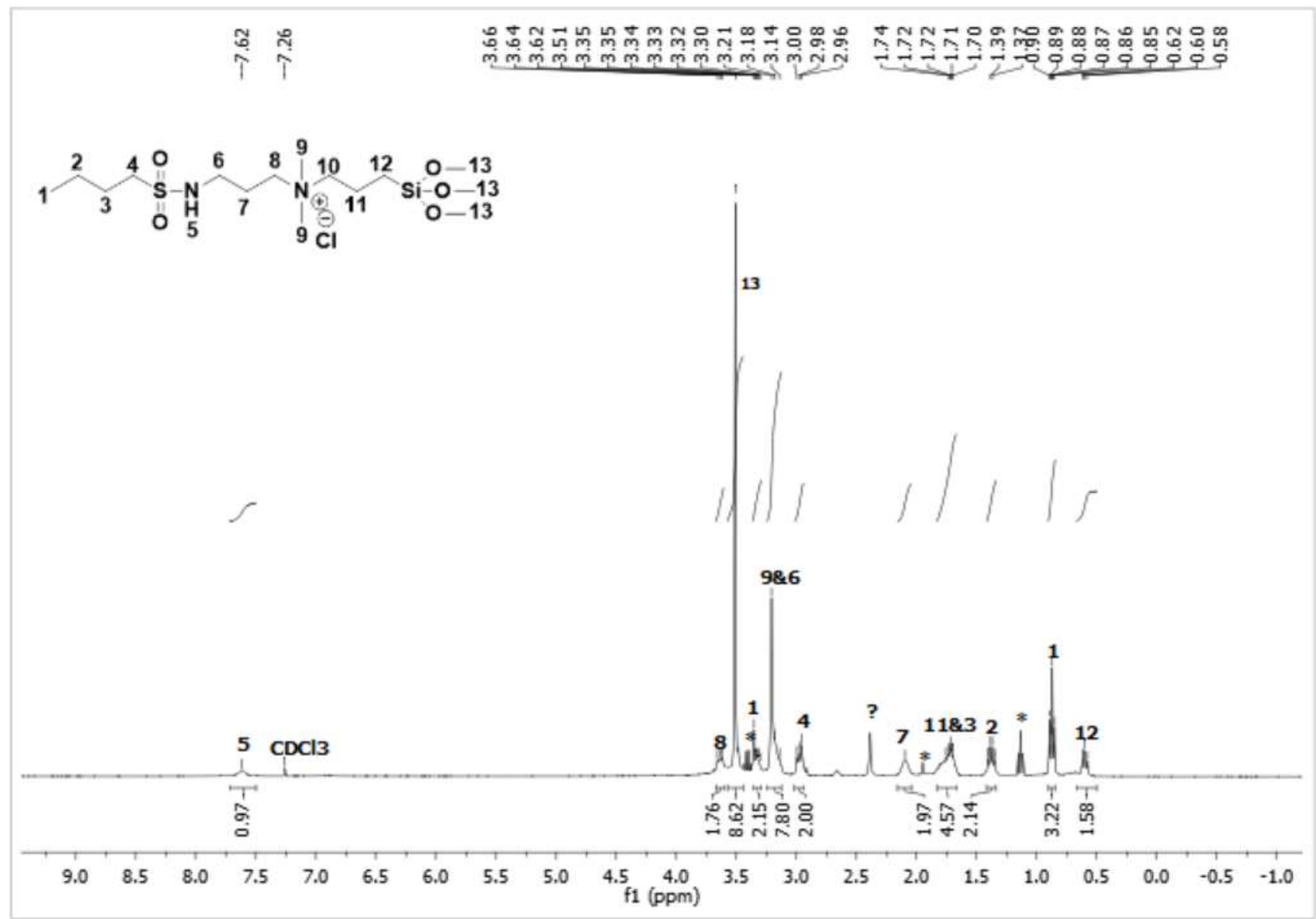

Figure (B) $123-{ }^{1} \mathrm{H}$ NMR $\left(400 \mathrm{MHz}, \mathrm{CDCl}_{3}\right)$ spectrum of $\mathbf{8 b}$. 


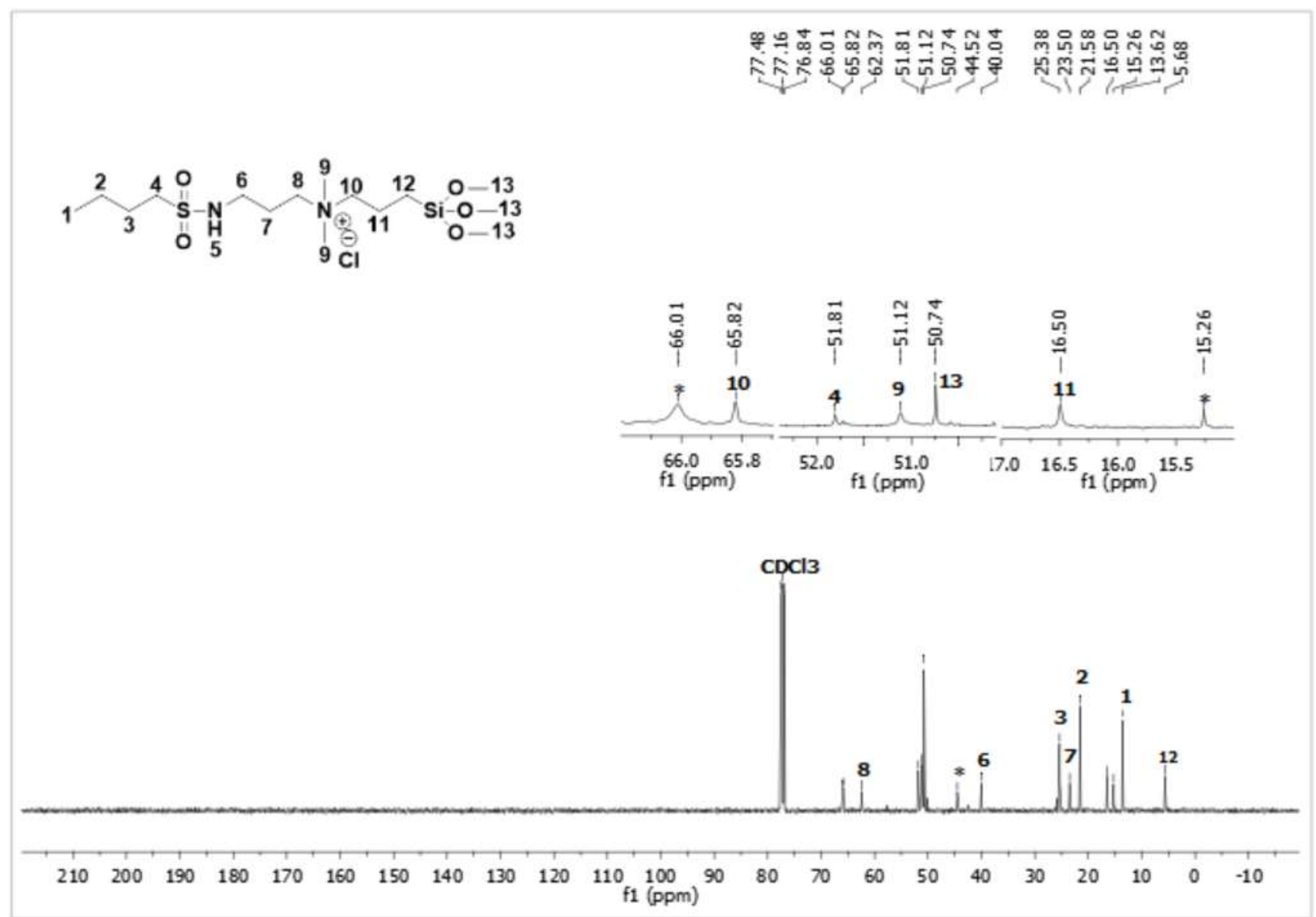

Figure (B) $124-{ }^{13} \mathrm{C} \mathrm{NMR}\left(101 \mathrm{MHz}, \mathrm{CDCl}_{3}\right)$ spectrum of $\mathbf{8 b}$. 


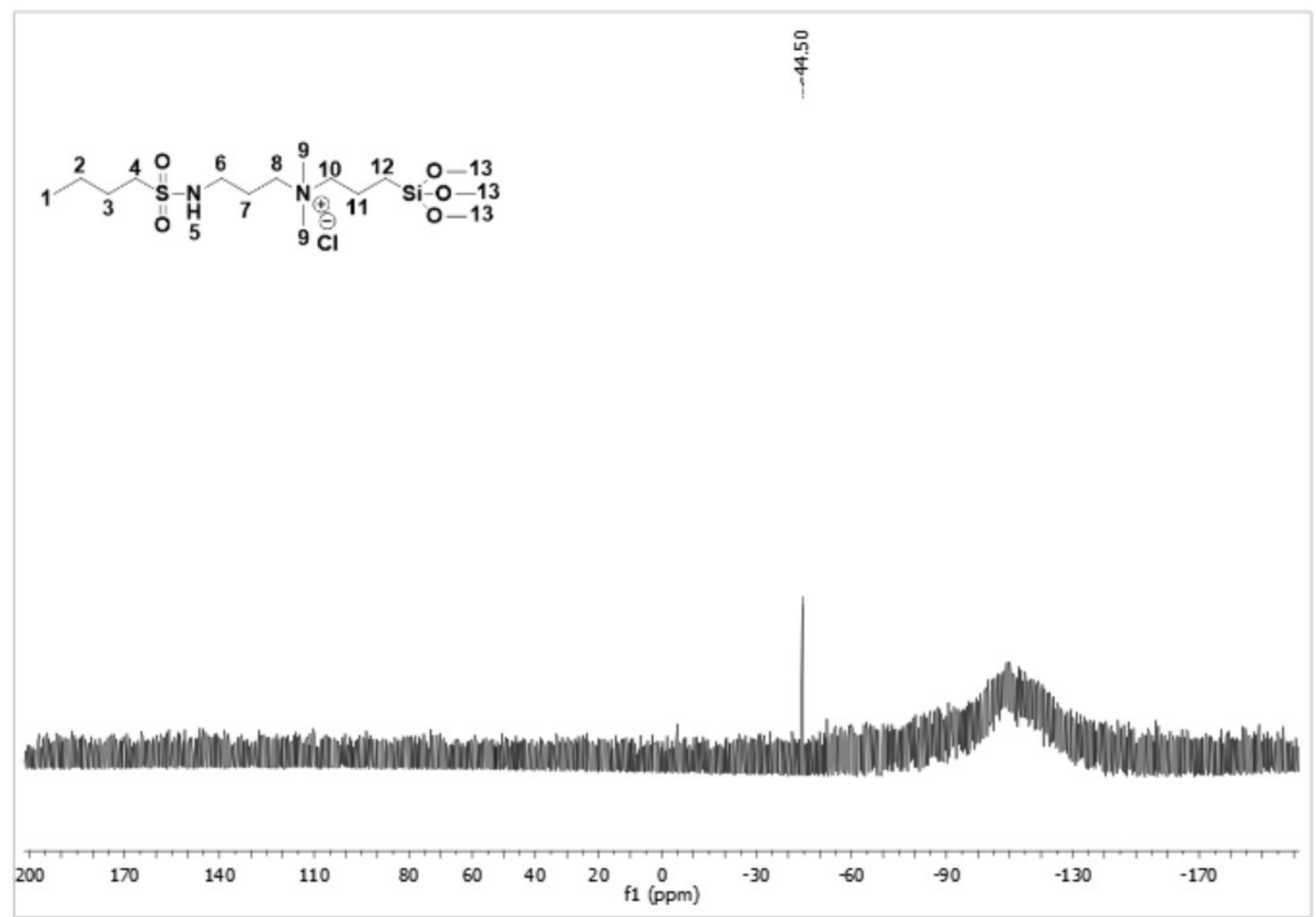

Figure (B) $125-{ }^{29} \mathrm{Si} \mathrm{NMR}\left(79 \mathrm{MHz}, \mathrm{CDCl}_{3}\right)$ spectrum of $\mathbf{8 b}$. 


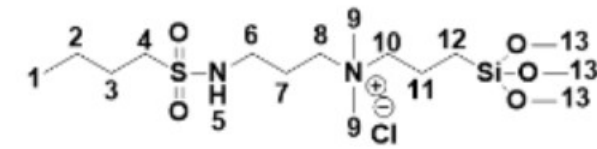

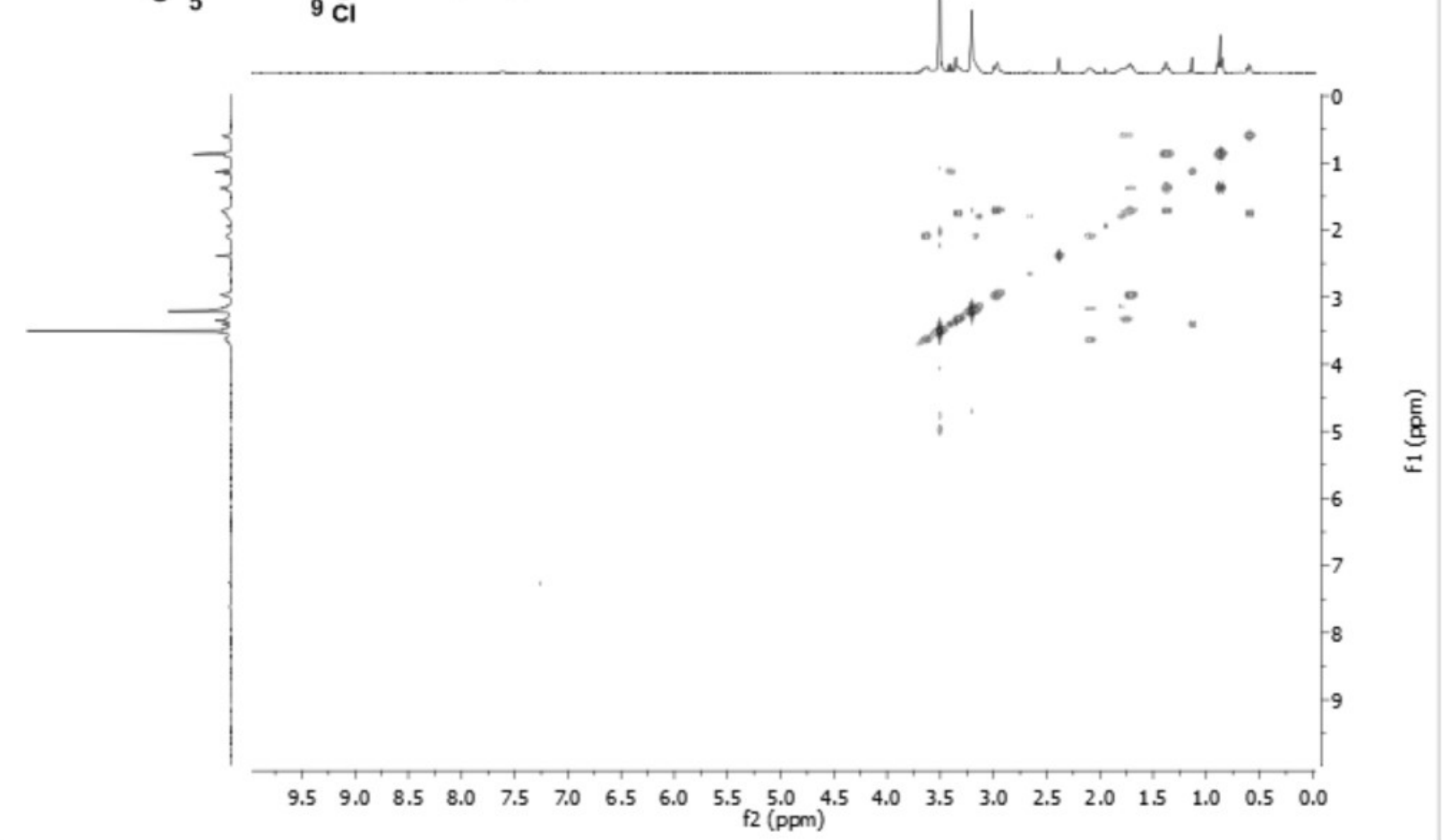

Figure (B) 126 - COSY 2D NMR $\left(\mathrm{CDCl}_{3}\right)$ spectrum of $\mathbf{8 b}$. 


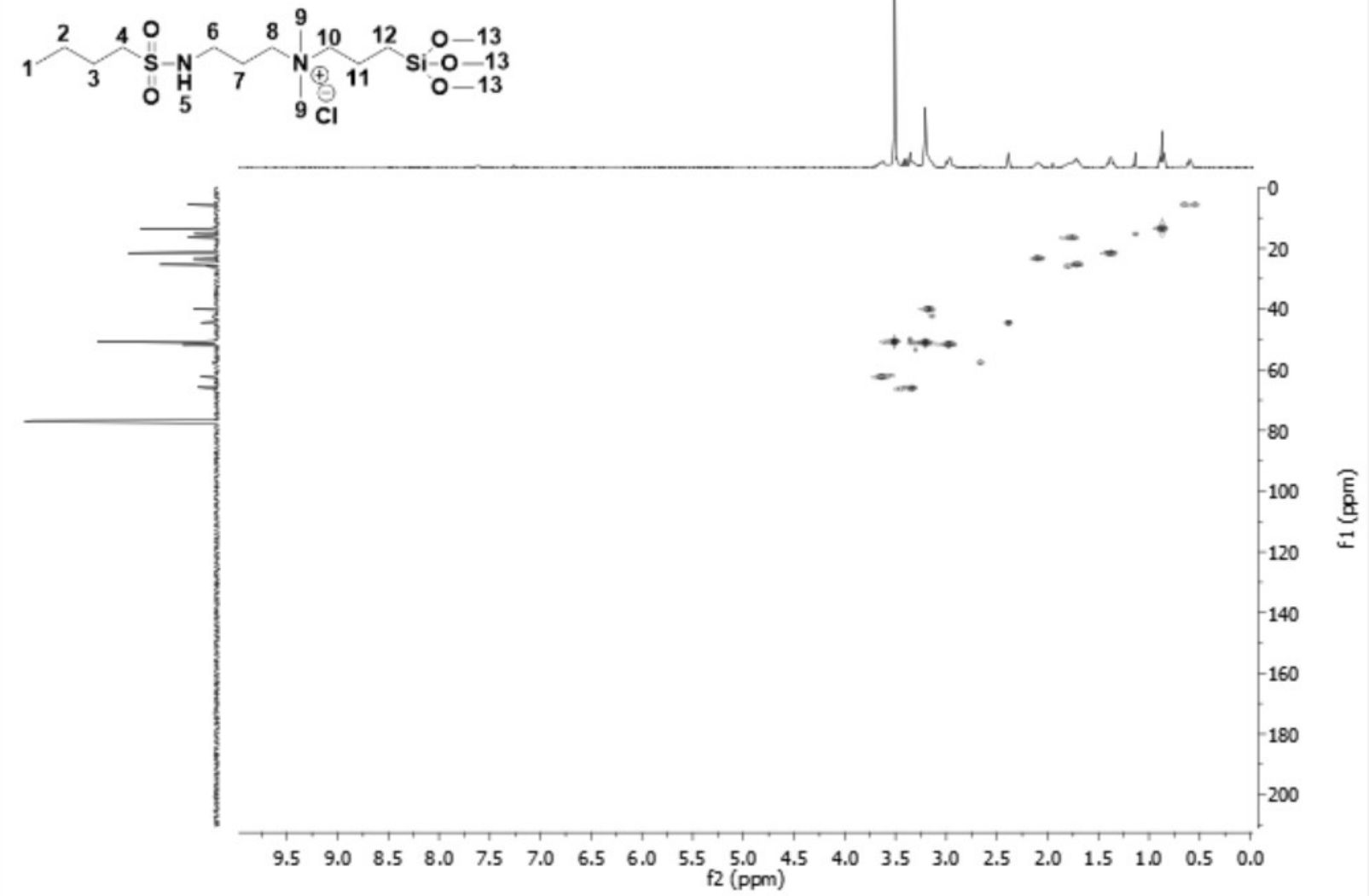

Figure (B) 127 - HSQC 2D NMR $\left(\mathrm{CDCl}_{3}\right)$ spectrum of $\mathbf{8 b}$. 


\section{REFERENCE LIST}

(1) Porosa, L.; Caschera, A.; Bedard, J.; Mocella, A.; Ronan, E.; Lough, A. J.; Wolfaardt, G.; Foucher, D. A. UV-Curable Contact Active Benzophenone Terminated Quaternary Ammonium Antimicrobials for Applications in Polymer Plastics and Related Devices. ACS Appl. Mater. Interfaces 2017, 9, 27491-27503.

(2) Caschera, A.; Mistry, K. B.; Bedard, J.; Ronan, E.; Syed, M. A.; Khan, A. U.; Lough, A. J.; Wolfaardt, G.; Foucher, D. A. Killing at a Solid/Liquid Interface: Surface-Attached Sulfonamide Containing Quaternary Ammonium Antimicrobials for Textiles and Plastics. Submitted 2018, 1-38.

(3) Caschera, A. Silver Nanoparticles - Societal and Environmental Effects, Ryerson University, 2016.

(4) Magill, S. S.; Edwards, J. R.; Bamberg, W.; Beldavs, Z. G.; Dumyati, G.; Kainer, M. A.; Lynfield, R.; Maloney, M.; McAllister-Hollod, L.; Nadle, J.; Ray, S. M.; Thompson, D. L.;Wilson, L. E.; Fridkin, S. K. Multistate Point-Prevalence Survey of Health CareAssociated Infections. N. Engl. J. Med. 2014, 370, 1198-1208.

(5) Simpkin, V. L.; Renwick, M. J.; Kelly, R.; Mossialos, E. Incentivising Innovation in Antibiotic Drug Discovery and Development: Progress, Challenges and next Steps. $J$. Antibiot. (Tokyo). 2017, 70, 1087-1096.

(6) McDonnell, G.; Russell, A. D. Antiseptics and Disinfectants: Activity, Action, and Resistance. Clin. Microbiol. Rev. 1999, 12, 147-179.

(7) van Duijn, P. J.; Bonten, M. J. M. Antibiotic Rotation Strategies to Reduce Antimicrobial 
Resistance in Gram-Negative Bacteria in European Intensive Care Units: Study Protocol for a Cluster-Randomized Crossover Controlled Trial. Trials 2014, 15, 1-8.

(8) Cheng, G.; Dai, M.; Ahmed, S.; Hao, H.; Wang, X. Antimicrobial Drugs in Fighting against Antimicrobial Resistance. Front. Microbiol. 2016, 7, 1-11.

(9) Hensley, B. J.; Monson, J. R. T. Hospital-Acquired Infections. Surg. 2015, 33, 528-533.

(10) Makison, C.; Swan, J. The Effect of Humidity on the Survival of MRSA on Hard Surfaces. Indoor Built Environ. 2006, 15, 85-91.

(11) Kramer, A.; Schwebke, I.; Kampf, G. How Long Do Nosocomial Pathogens Persist on Inanimate Surfaces? A Systematic Review. BMC Infect. Dis. 2006, 6, 1-8.

(12) Fernández Fuentes, M. Á.; Ortega Morente, E.; Abriouel, H.; Pérez Pulido, R.; Gálvez, A. Antimicrobial Resistance Determinants in Antibiotic and Biocide-Resistant GramNegative Bacteria from Organic Foods. Food Control 2014, 37, 9-14.

(13) Allegranzi, B. Report on the Burden of Endemic Health Care-Associated Infection Worldwide Clean Care Is Safer Care; Geneva, Switzerland, 2011.

(14) Scott, R. D. The Direct Medical Costs of Healthcare-Associated Infections in U.S. Hospitals and the Benefits of Prevention; Atlanta, Georgia, 2009.

(15) Ijaz, M. K.; Zargar, B.; Wright, K. E.; Rubino, J. R.; Sattar, S. A. Generic Aspects of the Airborne Spread of Human Pathogens Indoors and Emerging Air Decontamination Technologies. Am. J. Infect. Control 2016, 44, S109-S120.

(16) Hota, S.; Hirji, Z.; Stockton, K.; Lemieux, C.; Dedier, H.; Wolfaardt, G.; Gardam, M. A. Outbreak of Multidrug-Resistant Pseudomonas Aeruginosa Colonization and Infection 
Secondary to Imperfect Intensive Care Unit Room Design • Infect. Control Hosp. Epidemiol. 2009, 30, 25-33.

(17) Page, K.; Wilson, M.; Parkin, I. Antimicrobial Surfaces and Their Potential in Reducing the Role of the Inanimate Environment in the Incidence of Hospital-Acquired Infections. J. Mater. Chem. 2009, 19, 3819-3831.

(18) Bassetti, M.; Poulakou, G.; Ruppe, E.; Bouza, E.; Van Hal, S. J.; Brink, A. Antimicrobial Resistance in the next 30 Years, Humankind, Bugs and Drugs: A Visionary Approach. Intensive Care Med. 2017, 43, 1464-1475.

(19) Carey, D. E.; McNamara, P. J. The Impact of Triclosan on the Spread of Antibiotic Resistance in the Environment. Front. Microbiol. 2015, 6, 1-11.

(20) Buffet-Bataillon, S.; Tattevin, P.; Bonnaure-Mallet, M.; Jolivet-Gougeon, A. Emergence of Resistance to Antibacterial Agents: The Role of Quaternary Ammonium Compoundsa Critical Review. Int. J. Antimicrob. Agents 2012, 39, 381-389.

(21) Harbarth, S.; Tuan Soh, S.; Horner, C.; Wilcox, M. H. Is Reduced Susceptibility to Disinfectants and Antiseptics a Risk in Healthcare Settings? A Point/Counterpoint Review. J. Hosp. Infect. 2014, 87, 194-202.

(22) G. Ducel, J. Fabry, L. N. Prevention of Hospital-Acquired Infections. World Heal. Organ. 2002, 1-64.

(23) Hawn, M. T.; Vick, C. C.; Richman, J.; Holman, W.; Deierhoi, R. J.; Graham, L. A.; Henderson, W. G.; Itani, K. M. F. Surgical Site Infection Prevention. Ann. Surg. 2011, $254,494-501$. 
(24) Page, K.; Wilson, M.; Parkin, I. P. Antimicrobial Surfaces and Their Potential in Reducing the Role of the Inanimate Environment in the Incidence of Hospital-Acquired Infections. J. Mater. Chem. 2009, 19, 3819-3831.

(25) Powers, J. H. Antimicrobial Drug Development - the Past, the Present, and the Future. Clin. Microbiol. Infect. 2004, 10, 23-31.

(26) Chen, X.; Schluesener, H. . J. Nanosilver: A Nanoproduct in Medical Application. Toxicol. Lett. 2008, 176, 1-12.

(27) Rai, M.; Yadav, A.; Gade, A. Silver Nanoparticles as a New Generation of Antimicrobials. Biotechnol. Adv. 2009, 27, 76-83.

(28) Li, X.; Robinson, S. M.; Gupta, A.; Saha, K.; Jiang, Z.; Moyano, D. F.; Sahar, A.; Riley, M. A.; Rotello, V. M. Functional Gold Nanoparticles as Potent Antimicrobial Agents against Multi-Drug-Resistant Bacteria. ACS Nano 2014, 8, 10682-10686.

(29) Hajipour, M. J.; Fromm, K. M.; Ashkarran, A. A.; Aberasturi, D. J. De; Larramendi, I. R. De; Rojo, T. Antibacterial Properties of Nanoparticles. Trends Biotechnol. 2012, 30, 499511.

(30) Juan, L.; Zhimin, Z.; Anchun, M.; Lei, L.; Jingchao, Z. Deposition of Silver Nanoparticles on Titanium Surface for Antibacterial Effect. Int. J. Nanomedicine 2010, 5, 261-267.

(31) Marambio-jones, C.; Hoek, E. M. V. A Review of the Antibacterial Effects of Silver Nanomaterials and Potential Implications for Human Health and the Environment. $J$. Nanopart. Res. 2010, 12, 1531-1551.

(32) Alphonsa, M. B.; Kumar, P. T. S.; Praveen, G.; Biswas, R.; Chennazhi, K. P.; Jayakumar, 
R. Antimicrobial Drugs Encapsulated in Fibrin Nanoparticles for Treating Microbial Infested Wounds. Pharm .Res. 2014, 31, 1338-1351.

(33) Jiraroj, D.; Tungasmita, S.; Tungasmita, D. N. Silver Ions and Silver Nanoparticles in Zeolite A Composites for Antibacterial Activity. Powder Technol. 2014, 264, 418-422.

(34) Banerjee, I.; Pangule, R. C.; Kane, R. S. Antifouling Coatings: Recent Developments in the Design of Surfaces That Prevent Fouling by Proteins, Bacteria, and Marine Organisms. Adv. Mater. 2011, 23, 690-718.

(35) Fabrega, J.; Renshaw, J. C.; Lead, J. R. Interactions of Silver Nanoparticles with Pseudomonas Putida Biofilms. Environ. Sci. Technol. 2009, 43, 9004-9009.

(36) Vertelov, G. K.; Krutyakov, Y. A.; Efremenkova, O. V; Olenin, A. Y.; Lisichkin, G. V. A Versatile Synthesis of Highly Bactericidal Myramistin ${ }^{\circledR}$ Stabilized Silver Nanoparticles. Nanotechnology 2008, 19, 1-7.

(37) Sharma, V. K.; Yngard, R. A.; Lin, Y. Silver Nanoparticles: Green Synthesis and Their Antimicrobial Activities. Adv. Colloid Interface Sci. 2009, 145, 83-96.

(38) Kalishwaralal, K.; Barathmanikanth, S.; Ram, S.; Pandian, K.; Deepak, V.; Gurunathan, S. Silver Nanoparticles Impede the Biofilm Formation by Pseudomonas Aeruginosa and Staphylococcus Epidermidis. Colloids Surf., B 2010, 79, 340-344.

(39) Radzig, M. A.; Nadtochenko, V. A.; Koksharova, O. A.; Kiwi, J.; Lipasova, V. A.; Khmel, I. A. Antibacterial Effects of Silver Nanoparticles on Gram-Negative Bacteria : Influence on the Growth and Biofilms Formation, Mechanisms of Action. Colloids Surf., $B$ 2013, 102, 300-306. 
(40) Losasso, C.; Belluco, S.; Cibin, V.; Zavagnin, P.; Mi, I. Antibacterial Activity of Silver Nanoparticles: Sensitivity of Different Salmonella Serovars. Front. Microbiol. 2014, 5, 19.

(41) Islam, M. S.; Larimer, C.; Ojha, A.; Nettleship, I. Antimycobacterial Efficacy of Silver Nanoparticles as Deposited on Porous Membrane Filters. Mater. Sci. Eng. C 2013, 33, $4575-4581$.

(42) Lu, L.; Sun, R. W.; Chen, R.; Hui, C.; Ho, C.; Luk, J. M.; Lau, G. K. K. Original Article Silver Nanoparticles Inhibit Hepatitis B Virus Replication. Antivir. Ther. 2007, 13, 253262.

(43) Park, H.; Park, S.; Roh, J.; Kim, S.; Choi, K.; Yi, J.; Kim, Y.; Yoon, J. Journal of Industrial and Engineering Chemistry Biofilm-Inactivating Activity of Silver Nanoparticles : A Comparison with Silver Ions. J. Ind. Eng. Chem. 2013, 19, 614-619.

(44) Bibbs, R. K.; Harris, R. D.; Peoples, V. A.; Barnett, C.; Singh, S. R.; Dennis, V. A.; Coats, M. T. Silver Polyvinyl Pyrrolidone Nanoparticles Exhibit a Capsular Polysaccharide Influenced Bactericidal Effect against Streptococcus Pneumoniae. Front. Microbiol. 2014, $5,1-8$.

(45) Jennings, M. C.; Minbiole, K. P. C.; Wuest, W. M. Quaternary Ammonium Compounds: An Antimicrobial Mainstay and Platform for Innovation to Address Bacterial Resistance. ACS Infect. Dis. 2015, 1, 288-303.

(46) Siedenbiedel, F.; Tiller, J. C. Antimicrobial Polymers in Solution and on Surfaces: Overview and Functional Principles. Polymers (Basel). 2012, 4, 46-71. 
(47) Becker, G.; Deng, Z.; Zober, M.; Wagner, M.; Lienkamp, K.; Wurm, F. R. SurfaceAttached Poly(Phosphoester)-Hydrogels with Benzophenone Groups. Polym. Chem. 2018, 9, 315-326.

(48) Porosa, L. M.; Mistry, K. B.; Mocella, A.; Deng, H.; Hamzehi, S.; Caschera, A.; Lough, A. J.; Wolfaardt, G.; Foucher, D. A. Synthesis, Structures and Properties of SelfAssembling Quaternary Ammonium Dansyl Fluorescent Tags for Porous and Non-Porous Surfaces. J. Mater. Chem. B 2014, 2, 1509-1520.

(49) Gao, J.; Huddleston, N. E.; White, E. M.; Pant, J.; Handa, H.; Locklin, J. Surface Grafted Antimicrobial Polymer Networks with High Abrasion Resistance. ACS Biomater. Sci. Eng. 2016, 2, 1169-1179.

(50) Gottenbos, B.; Van Der Mei, H. C.; Klatter, F.; Nieuwenhuis, P.; Busscher, H. J. In Vitro and in Vivo Antimicrobial Activity of Covalently Coupled Quaternary Ammonium Silane Coatings on Silicone Rubber. Biomaterials 2002, 23, 1417-1423.

(51) Metoki, N.; Liu, L.; Beilis, E.; Eliaz, N.; Mandler, D. Preparation and Characterization of Alkylphosphonic Acid Self-Assembled Monolayers on Titanium Alloy by Chemisorption and Electrochemical Deposition. Langmuir 2014, 30, 6791-6799.

(52) Hadjesfandiari, N.; Yu, K.; Mei, Y.; Kizhakkedathu, J. N. Polymer Brush-Based Approaches for the Development of Infection-Resistant Surfaces. J. Mater. Chem. B 2014, $2,4968-4978$.

(53) Liu, Q.; Singha, P.; Handa, H.; Locklin, J. Covalent Grafting of Antifouling Phosphorylcholine-Based Copolymers with Antimicrobial Nitric Oxide Releasing Polymers to Enhance Infection-Resistant Properties of Medical Device Coatings. 
Langmuir 2017, 33, 13105-13113.

(54) Gao, J.; White, E. M.; Liu, Q.; Locklin, J. Evidence for the Phospholipid Sponge Effect as the Biocidal Mechanism in Surface-Bound Polyquaternary Ammonium Coatings with Variable Cross-Linking Density. ACS Appl. Mater. Interfaces 2017, 9, 7745-7751.

(55) Murata, H.; Koepsel, R. R.; Matyjaszewski, K.; Russell, A. J. Permanent, Non-Leaching Antibacterial Surfaces—2: How High Density Cationic Surfaces Kill Bacterial Cells. Biomaterials 2007, 28, 4870-4879.

(56) Zou, P.; Laird, D.; Riga, E. K.; Deng, Z.; Dorner, F.; Perez-Hernandez, H.-R.; GuevaraSolarte, D. L.; Steinberg, T.; Al-Ahmad, A.; Lienkamp, K. Antimicrobial and CellCompatible Surface-Attached Polymer Networks - How the Correlation of Chemical Structure to Physical and Biological Data Leads to a Modified Mechanism of Action. $J$. Mater. Chem. B 2015, 3, 6224-6238.

(57) Bandara, C. D.; Singh, S.; Afara, I. O.; Wolff, A.; Tesfamichael, T.; Ostrikov, K.; Oloyede, A. Bactericidal Effects of Natural Nanotopography of Dragonfly Wing on Escherichia Coli. ACS Appl. Mater. Interfaces 2017, 9, 6746-6760.

(58) Green, J. D.; Fulghum, T.; Nordhaus, M. A. A Review of Immobilized Antimicrobial Agents and Methods for Testing. Biointerphases 2011, 6, MR13-MR28.

(59) Silhavy, T. J.; Kahne, D.; Walker, S. The Bacterial Cell Envelope. Cold Spring Harb. Perspect. Biol. 2010, 2, 1-16.

(60) Beveridge, T. Use of the Gram Stain in Microbiology. Biotech. Histochem. 2001, 76, $111-$ 118. 
(61) Alakomi, H.-L.; Paananen, A.; Suihko, M.-L.; Helander, I. M.; Saarela, M. Weakening Effect of Cell Permeabilizers on Gram-Negative Bacteria Causing Biodeterioration. Appl. Environ. Microbiol. 2006, 72, 4695-4703.

(62) Nicolaou, K. C.; Chen, J. S.; Edmonds, D. J.; Estrada, A. A. Recent Advances in the Chemistry and Biology of Naturally Occurring Antibiotics. Angew. Chem. Int. Ed. 2009, $48,660-719$.

(63) Subramanyam, C.; Nayab Rasool, S.; Janakiramudu, D. B.; Rasheed, S.; Uday Sankar, A.; Naga Raju, C. Synthesis and Bioactivity Evaluation of Some Novel Sulfonamide Derivatives. Phosphorus. Sulfur. Silicon Relat. Elem. 2017, 192, 845-849.

(64) Dalloul, H. M. M.; El-Nwairy, K. A.; Shorafa, A. Z.; Abu Samaha, A. S. Synthesis and Antimicrobial Activities Evaluation of Some New Thiadiazinone and Thiadiazepinone Derivatives Bearing Sulfonamide Moiety. Phosphorus. Sulfur. Silicon Relat. Elem. 2018, 193, 288-293.

(65) Rauner, N.; Mueller, C.; Ring, S.; Boehle, S.; Strassburg, A.; Schoeneweiss, C.; Wasner, M.; Tiller, J. C. A Coating That Combines Lotus-Effect and Contact-Active Antimicrobial Properties on Silicone. Adv. Funct. Mater. 2018, 28, 1-9.

(66) Tolaymat, T. M.; El Badawy, A. M.; Genaidy, A.; Scheckel, K. G.; Luxton, T. P.; Suidan, M. An Evidence-Based Environmental Perspective of Manufactured Silver Nanoparticle in Syntheses and Applications: A Systematic Review and Critical Appraisal of PeerReviewed Scientific Papers. Sci. Total Environ. 2010, 408, 999-1006.

(67) Shah, A.; Mond, J.; Walsh, S. Lysostaphin-Coated Catheters Eradicate Staphylococccus Aureus Challenge and Block Surface Colonization. Antimicrob. Agents Chemother. 2004, 
$48,2704-2707$.

(68) Isquith, A. J.; Abbott, E. A.; Walters, P. A. Surface-Bonded Antimicrobial Activity of an Organosilicon Quaternary Ammonium Chloride. Appl. Microbiol. 1972, 24, 859-863.

(69) Ferreira, L.; Zumbuehl, A. Non-Leaching Surfaces Capable of Killing Microorganisms on Contact. J. Mater. Chem. 2009, 19, 7796-7806.

(70) Francolini, I.; Donelli, G.; Crisante, F.; Taresco, V.; Piozzi, A. Antimicrobial Polymers for Anti-Biofilm Medical Devices: State-of-Art and Perspectives. In Advances in Experimental Medicine and Biology; 2015; Vol. 831, pp 93-117.

(71) Chen, A.; Peng, H.; Blakey, I.; Whittaker, A. K. Biocidal Polymers: A Mechanistic Overview. Polym. Rev. 2016, 3724, 1-35.

(72) Turro, N. J. Modern Molecular Photochemistry; Mill Valley, CA, 1991.

(73) Körner, M.; Prucker, O.; Rühe, J. Kinetics of the Generation of Surface-Attached Polymer Networks through C, H-Insertion Reactions. Macromolecules 2016, 49, 2438-2447.

(74) Ma, H.; Davis, R. H.; Bowman, C. N. A Novel Sequential Photoinduced Living Graft Polymerization. Macromolecules 2000, 33, 331-335.

(75) Shenton, M. J.; Lovell-Hoare, M. C.; Stevens, G. C. Adhesion Enhancement of Polymer Surfaces by Atmospheric Plasma Treatment. J. Phys. D. Appl. Phys. 2001, 34, 2754-2760.

(76) Green, J. D.; Bickner, S.; Carter, P. W.; Fulghum, T.; Luebke, M.; Nordhaus, M. A.; Strathmann, S. Antimicrobial Testing for Surface-Immobilized Agents with a SurfaceSeparated Live-Dead Staining Method. Biotechnol. Bioeng. 2011, 108, 231-236.

(77) ASTM E2149 - 13a: Standard Test Method for Determining the Antimicrobial Activity of 
Antimicrobial Agents Under Dynamic Contact Conditions. ASTM International: West Conshohocken, PA 2013, pp 1-5.

(78) Kroukamp, O.; Dumitrache, R. G.; Wolfaardt, G. M. Pronounced Effect of the Nature of the Inoculum on Biofilm Development in Flow Systems. Appl. Environ. Microbiol. 2010, $76,6025-6031$.

(79) Bester, E.; Wolfaardt, G. M.; Aznaveh, N. B.; Greener, J. Biofilms’ Role in Planktonic Cell Proliferation. Int. J. Mol. Sci. 2013, 14, 21965-21982.

(80) Bester, E.; Edwards, E. A.; Wolfaardt, G. M. Planktonic Cell Yield Is Linked to Biofilm Development. Can. J. Microbiol. 2009, 55, 1195-1206.

(81) Bester, E.; Kroukamp, O.; Hausner, M.; Edwards, E. A.; Wolfaardt, G. M. Biofilm Form and Function: Carbon Availability Affects Biofilm Architecture, Metabolic Activity and Planktonic Cell Yield. J. Appl. Microbiol. 2011, 110, 387-398.

(82) Stone, W.; Kroukamp, O.; Korber, D. R.; McKelvie, J.; Wolfaardt, G. M. Microbes at Surface-Air Interfaces: The Metabolic Harnessing of Relative Humidity, Surface Hygroscopicity, and Oligotrophy for Resilience. Front. Microbiol. 2016, 7, 1-15.

(83) Ronan, E.; Yeung, C. W.; Hausner, M.; Wolfaardt, G. M. Interspecies Interaction Extends Bacterial Survival at Solid-Air Interfaces. Biofouling 2013, 29, 1087-1096.

(84) Saettone, M. F.; Alderigi, C.; Giannaccini, B.; Anselmi, C.; Rossetti, M. G.; Scotton, M.; Cerini, R. Substantivity of Sunscreens-preparation and Evaluation of Some Quaternary Ammonium Benzophenone Derivatives. Int. J. Cosmet. Sci. 1988, 10, 99-109.

(85) Tiller, J. C.; Liao, C.-J.; Lewis, K.; Klibanov, A. M. Designing Surfaces That Kill 
Bacteria on Contact. Proc. Natl. Acad. Sci. 2001, 98, 5981-5985.

(86) Nečas, D.; Klapetek, P. Gwyddion: An Open-Source Software for SPM Data Analysis. Open Phys. 2012, 10, 181-188.

(87) ISO 22196:2007 - Plastics - Measurement of Antibacterial Activity on Plastics Surfaces. International Organization for Standardization: Geneva, Switzerland 2007, pp 1-16.

(88) JIS Z 2801:2010 - Antibacterial Products - Test for Antibacterial Activity and Efficacy. Japanese Industrial Standards Committee: Tokyo, Japan 2010, pp 1-19.

(89) Porosa, L.; Mocella, A.; Wolfaardt, G.; Foucher, D. UV Cured Benzophenone Terminated Quaternary Ammonium Antimicrobials for Surfaces. WO2014089680 (A1), 2014.

(90) Dhende, V. P.; Samanta, S.; Jones, D. M.; Hardin, I. R.; Locklin, J. One-Step Photochemical Synthesis of Permanent, Nonleaching, Ultrathin Antimicrobial Coatings for Textiles and Plastics. ACS Appl. Mater. Interfaces 2011, 3, 2830-2837.

(91) Locklin, J. Photochemical Cross-Linkable Polymers, Methods of Making Photochemical Cross-Linkable Polymers, and Methods of Making Articles Containing Photochemical Cross-Linkalbe Polymers. USP 2014024286 A1, 2014.

(92) Foucher, D.; Wolfaardt, G.; Caschera, A. G.; Khan, A. U.; Mistry, K.; Ronan, E.; Gilmore, L.; Porosa, L. Preparation of Sulfonamide-Containing Antimicrobials and Substrate Treating Compositions of Sulfonamide-Containing Antimicrobials. WO2017031599 (A1), 2017.

(93) Windler, L.; Height, M.; Nowack, B. Comparative Evaluation of Antimicrobials for Textile Applications. Environ. Int. 2013, 53, 62-73. 
(94) Kugler, R.; Bouloussa, O.; Rondelez, F. Evidence of a Charge-Density Threshold for Optimum Efficiency of Biocidal Cationic Surfaces. Microbiology 2005, 151, 1341-1348.

(95) Shchukarev, A. V.; Korolkov, D. V. XPS Study of Group IA Carbonates. Cent. Eur. J. Chem. 2004, 2, 347-362.

(96) Rignanese, G.; Pasquarello, A.; Charlier, J.; Gonze, X.; Car, R. Nitrogen Incorporation at Si(001)-SiO2 Interfaces : Relation between N 1s Core-Level Shifts and Microscopic Structure. Phys. Rev. Lett. 1997, 79, 5174-5177.

(97) Yang, Y.-F.; Hu, H.-Q.; Li, Y.; Wan, L.-S.; Xu, Z.-K. Membrane Surface with Antibacterial Property by Grafting Polycation. J. Memb. Sci. 2011, 376, 132-141.

(98) Goacher, R. E.; Drajeremic, G.; Master, E. R. Expanding the Library of Secondary Ions That Distinguish Lignin and Polysaccharides in Time-of-Flight Secondary Ion Mass Spectrometry Analysis of Wood. Anal. Chem. 2011, 83, 804-812.

(99) Abràmoff, M. D.; Magalhães, P. J.; Ram, S. J. Image Processing with ImageJ. Biophotonics Int. 2004, 11, 36-41.

(100) Stone, W.; Kroukamp, O.; McKelvie, J.; Korber, D. R.; Wolfaardt, G. M. Microbial Metabolism in Bentonite Clay: Saturation, Desiccation and Relative Humidity. Appl. Clay Sci. 2016, 129, 54-64.

(101) Rose, L. J.; Donlan, R.; Banerjee, S. N.; Arduino, M. J. Survival of Yersinia Pestis on Environmental Surfaces. Appl. Environ. Microbiol. 2003, 69, 2166-2171.

(102) Jawad, A.; Heritage, J.; Snelling, A. M.; Gascoyne-Binzi, D. M.; Hawkey, P. M. Influence of Relative Humidity and Suspending Menstrua on Survival of Acinetobacter Spp. on Dry 
Surfaces. J. Clin. Microbiol. 1996, 34, 2881-2887.

(103) Wendt, C.; Dietze, B.; Dietz, E.; Rüden, H. Survival of Acinetobacter Baumannii on Dry Surfaces. J. Clin. Microbiol. 1997, 35, 1394-1397.

(104) Yazgi, H.; Uyanik, M. H.; Ertek, M.; Aktas, A. E.; İgan, H.; Ayyildiz, A. Survival of Certain Nosocomial Infectious Agents on the Surfaces of Various Covering Materials. Turk J Med Sci 2009, 39, 619-622.

(105) Pettit, F.; Lowbury, E. J. L. Survival of Wound Pathogens under Different Environmental Conditions. J. Hyg. (Lond). 1968, 66, 393-406.

(106) Centers for Disease Control and Prevention. Biosafety in Microbiological and Biomedical Laboratories, 5th ed.; Chosewood, L., Wilson, D., Eds.; U.S. Department of Health and Human Services: Atlanta, 2009.

(107) Tang, J. W.; Li, Y.; Eames, I.; Chan, P. K. S.; Ridgway, G. L. Factors Involved in the Aerosol Transmission of Infection and Control of Ventilation in Healthcare Premises. $J$. Hosp. Infect. 2006, 64, 100-114.

(108) Haldar, J.; Weight, A. K.; Klibanov, A. M. Preparation, Application and Testing of Permanent Antibacterial and Antiviral Coatings. Nat. Protoc. 2007, 2, 2412-2417.

(109) The Prokaryotes; Dworkin, M., Falkow, S., Rosenberg, E., Schleifer, K.-H., Stackebrandt, E., Eds.; Springer New York: New York, NY, 2006.

(110) Briers, Y.; Klumpp, J.; Schuppler, M.; Loessner, M. J. Genome Sequence of Listeria Monocytogenes Scott A, a Clinical Isolate from a Food-Borne Listeriosis Outbreak. $J$. Bacteriol. 2011, 193, 4284-4285. 
(111) Cui, L.; Ma, X.; Sato, K.; Okuma, K.; Tenover, F. C.; Mamizuka, E. M.; Gemmell, C. G.; Kim, M.-N.; Ploy, M.-C.; El-Solh, N.; et al. Cell Wall Thickening Is a Common Feature of Vancomycin Resistance in Staphylococcus Aureus. J. Clin. Microbiol. 2003, 41, 5-14.

(112) Mai-Prochnow, A.; Clauson, M.; Hong, J.; Murphy, A. B. Gram Positive and Gram Negative Bacteria Differ in Their Sensitivity to Cold Plasma. Sci. Rep. 2016, 6, 1-11. 